\title{
1916 rumbo \\ a la Constitución \\ de 1917
}

José Luis SOBERANES FERNÁNDEZ Eduardo Alejandro LÓPEZ SÁNCHEZ

Coordinadores

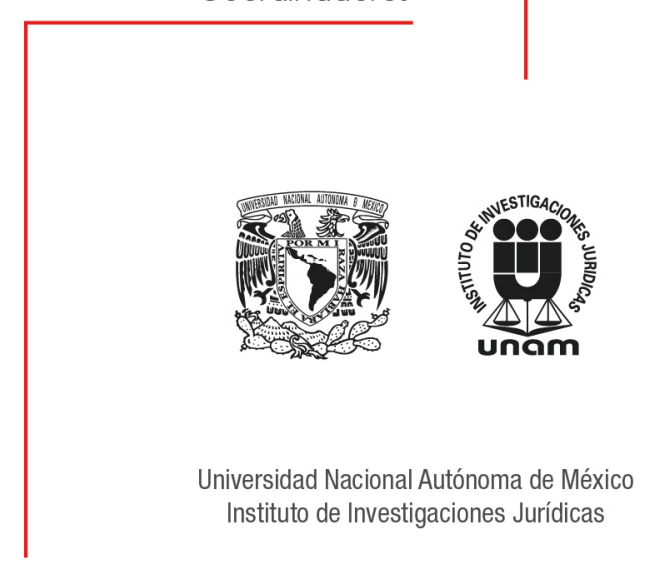


1916 RUMBO A LA CONSTITUCIÓN DE 1917 
INSTITUTO DE INVESTIGACIONES JURÍDICAS

Serie DOCTRINA JURÍDICA, núm. 841

COORDINACIÓN EDITORIAL

Lic. Raúl Márquez Romero

Secretario técnico

Mtra. Wendy Vanesa Rocha Cacho

Fefa del Departamento de Publicaciones

Ricardo Hernández Montes de Oca

Cuidado de la edición y formación en computadora

Mauricio Ortega

Elaboración de portada 


\section{RUMBO \\ A LA CONSTITUCIÓN DE 1917}

EDUARDO ALEJANDRO LÓPEZ SÁNCHEZ

José LuIS SOBERANES FERNÁNDEZ

Coordinadores
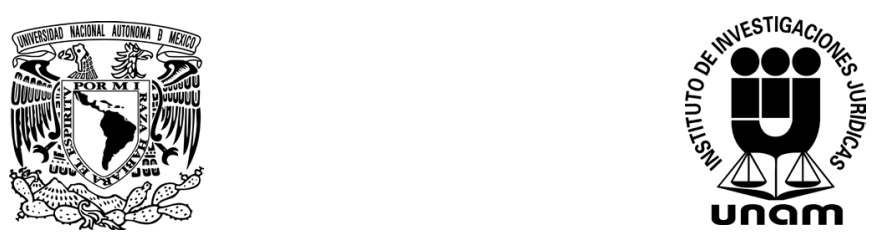

UNIVERSIDAD NACIONAL AUTÓNOMA DE MÉXICO INSTITUTO DE INVESTIGACIONES JURÍDICAS

MÉXICO, 2018 
Primera edición: 14 de noviembre de 2018

DR (C) 2018. Universidad Nacional Autónoma de México

\section{INSTITUTO DE INVESTIGACIONES JURÍDICAS}

Circuito Maestro Mario de la Cueva s/n Ciudad de la Investigación en Humanidades Ciudad Universitaria, 04510 Ciudad de México

Impreso y hecho en México

ISBN: 978-607-30-0867-9 


\section{GONTENIDO}

Presentación............................ VII

Eduardo Alejandro LÓPEz SÁNCHEZ

José Luis Soberanes FernándeZ

La dignidad humana en el Constitucionalismo moderno. Análisis retrospectivo de su evolución: del actual México a la Nueva Es-

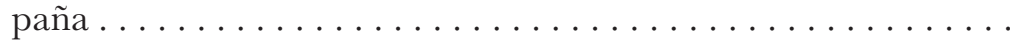

Aniceto MASFERRER

El federalismo y el centralismo como ideologías constructoras del Estado mexicano .......................... José Isidro SAUCEDo GONZÁLEZ

El movimiento constitucionalista y el Congreso Constituyente mexicano: entre la reforma y la revolución: 1913-1916 . . . . . . . . Jaime HERnÁNDEZ DÍAZ

Entre las escuelas nacionales y la Universidad: los Constituyentes de 1917. Un árbol de la vida. . . . . . . . . . . . . . . . . . . . . . . .

Alberto ENRÍQUEZ PEREA

El papel de las mujeres en el Constituyente de 1916 y la apertura a

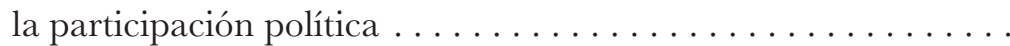

Rosa María DE LA TORRE TORRES

Brenda Yesenia Olalde VÁZQUeZ

El voto directo en los debates y propuestas de los congresos constituyentes de $1856-1857$ y $1916-1917 \ldots \ldots \ldots \ldots \ldots \ldots \ldots$ Juan Carlos SÁNCHez MonTiEL

El nombramiento de los ministros de la Suprema Corte de Justicia de la Nación en el Congreso Constituyente de 1916-1917. . . . . Francisco RAMOs QUIROZ 
Higiene y salud, derechos constitucionales: las enfermedades en la Revolución como problema social (1915-1918) . . . . . . . . . 189 Luis Ángel VARGas REYNOSO

El artículo 3o. constitucional y el proyecto de educación laica: motivaciones de los constituyentes y trayectoria inmediata posterior:

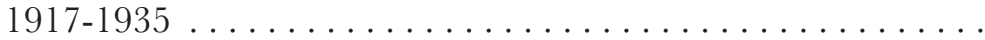

Juan GONZÁLEZ MORFÍN

Francisco J. Múgica, el hombre y el constituyente ........... .

Eduardo Alejandro LóPEz SÁNCHEZ

Daniar CHÁveZ JimÉNEZ

José Natividad Macías: jurista, constituyente y rector . . . . . . . . José Luis SObERANES FERnÁNDEZ

En los albores de la legislación y el derecho urbano moderno y contemporáneo en México: el artículo 27 constitucional. . . . . . . . . 275 Omar Ernesto RoQUE BERNAL

Análisis de la presencia del municipio en el constitucionalismo

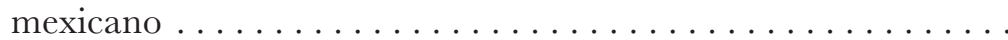

Yadira ORNELAS GARCía

Zacatecas 1916: el año de las elecciones, el año del tifo, el año del hambre............................. José EnCISO GONTRERAS

El juicio de amparo cruza fronteras. Rodolfo Reyes en España .... 361 Eva Elizabeth MARTínez CHÁvez

Los derechos sociales en la Constitución de Querétaro y en la española de la II República. . . . . . . . . . . . . . . . . . . . . . . 383 Mario BEDERA BRAVO

La Revolución mexicana y la Constitución de 1917. Una visión des-

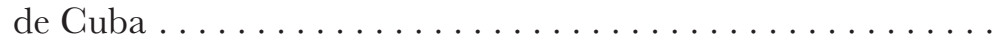

Santiago Antonio BAHAMONDE RodRÍGUEZ 
Este libro forma parte del acervo de la Biblioteca Jurídica Virtual del Instituto de Investigaciones Jurídicas de la UNAM

\section{PRESENTACIÓN}

La Unidad Académica de Estudios Regionales, sede Jiquilpan, Michoacán, de la Coordinación de Humanidades, de la Universidad Nacional Autónoma de México, conjuntamente con el Instituto de Investigaciones Jurídicas de la propia Universidad, con el fin de sumar un esfuerzo más dentro de diversas iniciativas a la conmemoración del centenario de la Constitución mexicana de 1917, que evidentemente fue un parteaguas de nuestra historia constitucional, toda vez que reconoció y respondió a las demandas sociales, económicas y políticas del movimiento armado revolucionario iniciado en 1910 y un ejemplo en el constitucionalismo mundial, han llevado a cabo el presente volumen de estudios en torno al Constituyente queretano de 19161917.

El articulado de la Constitución Política de los Estados Unidos Mexicanos, tanto en su parte orgánica como dogmática, ha sido modificado en incontables ocasiones desde su promulgación a la fecha, con el propósito de adaptarla a los tiempos que se han vivido y como un medio para establecer límites al poder del Estado. Todas las reformas son necesarias e indispensables, siempre y cuando se realicen de manera responsable y pensando en el bien común.

Como es sabido por todos, esta gran reunión para darle vida a la Constitución de 1917, comenzó el 1o. de diciembre de 1916, cuando se instala el Congreso Constituyente en la ciudad de Querétaro y culminó el 5 de febrero de 1917 con su promulgación.

Esta obra, como señalamos antes, tiene como propósito conmemorar este gran acontecimiento y está conformada por diecisiete trabajos, con la visión especializada de juristas, historiadores, filósofos, teólogos, entre otros, nacionales y extranjeros, en la que se analizan acontecimientos relevantes y personajes importantes que contribuyeron en la concepción de nuestra Constitución de 1917.

Los académicos participantes en este libro, provienen de diversas instituciones, a saber: la Universidad Nacional Autónoma de México, la Universidad Michoacana de San Nicolás de Hidalgo, El Colegio de Michoacán, 
Este libro forma parte del acervo de la Biblioteca Jurídica Virtual del Instituto de Investigaciones Jurídicas de la UNAM

la Universidad Panamericana, la Universidad de La Ciénega del Estado de Michoacán de Ocampo, la Universidad Autónoma de Ciudad Juárez, la Universidad Autónoma de Zacatecas, la Universidad de Valencia, y la Universidad de Valladolid, ambas de España, y la Universidad de La Habana, Guba.

En un primer plano encontramos los temas de "La dignidad humana en el constitucionalismo moderno. Análisis retrospectivo de su evolución: del actual México a la Nueva España", por el doctor Aniceto Masferrer, de la Universidad de Valencia; "El federalismo y el centralismo como ideologías constructoras del Estado mexicano" por el doctor José Isidro Saucedo González de la UNAM; "El movimiento constitucionalista y el Congreso Constituyente mexicano: entre la reforma y la revolución: 1913-1916”, por el doctor Jaime Hernández Díaz de la Universidad Michoacana de San Nicolás de Hidalgo, y "Entre las escuelas nacionales y la Universidad: los constituyentes de 1917. Un árbol de la vida" del doctor Alberto Enríquez Perea, de la UNAM.

En un segundo bloque se ubican temáticas sobre "El papel de las mujeres en el constituyente de 1916 y la apertura a la participación política" por la doctora Rosa María de la Torre Torres y la licenciada Brenda Yesenia Olalde Vázquez, ambas de la Universidad Michoacana de San Nicolás de Hidalgo; "El voto directo en los debates y propuestas de los congresos constituyentes de 1856-57 y 1916-1917" a cargo de el doctor Juan Carlos Sánchez Montiel, de la Universidad Autónoma de Ciudad Juárez, y "El nombramiento de los ministros de la Suprema Corte de Justicia de la Nación en el Congreso Constituyente de 1916-1917" por el doctor Francisco Ramos Quiroz, de la Universidad Michoacana de San Nicolás de Hidalgo.

En el tercer bloque, encontramos la "Higiene y salud, derechos constitucionales: las enfermedades en la revolución como problema social (19151918)", por el maestro Luis Ángel Vargas Reynoso de la Universidad de la Ciénega del Estado de Michoacán de Ocampo; "El artículo 3o. constitucional y el proyecto de educación laica: motivaciones de los constituyentes y trayectoria inmediata posterior: 1917-1935" del doctor Juan González Morfín de la Universidad Panamericana, Ciudad de México; "Francisco J. Múgica, el hombre y el constituyente" por los doctores Eduardo Alejandro López Sánchez y Daniar Chávez Jiménez, ambos de la UNAM, y "José Natividad Macías: jurista, constituyente y rector" del doctor José Luis Soberanes Fernández, de la UNAM.

En un cuarto bloque se incluyeron temas como "En los albores de la legislación y el derecho urbano moderno y contemporáneo en México: el 
Este libro forma parte del acervo de la Biblioteca Jurídica Virtual del Instituto de Investigaciones Jurídicas de la UNAM

artículo 27 constitucional" del doctor Omar Ernesto Roque Bernal, de la Universidad de la Ciénega del Estado de Michoacán de Ocampo; "Análisis de la presencia del municipio en el constitucionalismo mexicano" por la licenciada Yadira Ornelas García, de la Universidad Michoacana de San Nicolás de Hidalgo, y "Zacatecas 1916: el año de las elecciones, el año del tifo, el año del hambre" por el doctor José Enciso Contreras, de la Universidad Autónoma de Zacatecas.

El quinto y último bloque, y no por ello menos importante, está integrado con los trabajos sobre "El juicio de amparo cruza fronteras. Rodolfo Reyes en España" a cargo de la doctora Eva Elizabeth Martínez Chávez, de El Colegio de Michoacán; "Los derechos sociales en la Constitución de Querétaro y en la española de la II República" por el doctor Mario Bedera Bravo, de la Universidad de Valladolid, y "La Revolución mexicana y la Constitución de 1917. Una visión desde Cuba" del doctor Santiago Antonio Bahamonde Rodríguez, de la Universidad de La Habana.

Estamos convencidos que debemos honrar a nuestra carta magna, con una mirada interdisciplinaria y vislumbrar, con el aprendizaje de la historia, un futuro en el que, con trabajo y reflexiones responsables, se continúe adaptando nuestro máximo ordenamiento jurídico a los tiempos y situaciones actuales.

Los que tuvimos la fortuna de coordinar la presente obra agradecemos la suma de esfuerzos y voluntades de todos los que participaron en ella, de manera directa e indirecta, colaboración sin la cual no hubiera podido ver la luz este proyecto.

Eduardo Alejandro LÓPEZ SÁNCHEZ José Luis SOBERANEs FernÁNDEZ 
Este libro forma parte del acervo de la Biblioteca Jurídica Virtual del Instituto de Investigaciones Jurídicas de la UNAM

\title{
LA DIGNIDAD HUMANA \\ EN EL CONSTITUCIONALISMO MODERNO. ANÁLISIS RETROSPECTIVO DE SU EVOLUCIÓN: DEL ACTUAL MÉXICO A LA NUEVA ESPAÑA
}

\author{
Aniceto MASFERRER*
}

\begin{abstract}
SUMARIO: I. La dignidad humana en la vigente Constitución mexicana. II. La dignidad humana en el derecho constitucional comparado. III. El origen de la noción jurídica de dignidad humana tras la Segunda Guerra Mundial. IV. Los precedentes históricos de la noción de dignidad humana (del siglo XIX al siglo XVI). V. Consideraciones finales.
\end{abstract}

\section{LA DIGNIDAD HUMANA EN LA VIGENTE CONSTITUGIÓN MEXICANA}

La historia de la dignidad humana en el Constitucionalismo mexicano - no así la de sus derechos fundamentales - es relativamente reciente y breve. ${ }^{1}$

* Universidad de Valencia.

El presente estudio fue el objeto de una conferencia magistral que impartí, con un título casi idéntico, el 29 de noviembre en la Universidad de La Ciénega del Estado de Michoacán de Ocampo, en el marco del Congreso Internacional "1916 Rumbo a la Constitución de 1917”, organizado por varias instituciones académicas mexicanas (UAER, COHU, UNAM, CEAM, COLMICH, UMSNH), y que tuvo lugar en diversas sedes (Jiquilpan, Sahuayo, Zamora y Morelia), del 29 de noviembre al 1o. de diciembre de 2016. Quiero agradecer al doctor José Luis Soberanes Fernández la invitación a participar en ese Congreso, así como sus constantes muestras de hospitalidad a lo largo de mi estancia, como investigador visitante, en el Instituto de Investigaciones Jurídicas de la UNAM. A él, así como a los doctores José Isidro Saucedo González, Javier Saldaña y José Daniel Hidalgo, les agradezco la lectura del manuscrito y sus valiosos comentarios. Este estudio ha sido llevado a cabo en el marco del Proyecto "Las influencias extranjeras en la Codificación penal española: su concreto alcance en la Parte Especial de los Códigos decimonónicos" (ref. DER2016-78388-P), financiado por el Ministerio de Economía y Competitividad.

1 Al respecto, véanse Díaz Romero, Juan, "El principio de la dignidad humana y su repercusión en la Constitución de los Estados Unidos Mexicanos", Conferencia magistral del Primer Congreso Internacional sobre Justicia Constitucional y Quinto Encuentro Iberoamericano de Derecho procesal constitucional, 16 de mayo de 2008 (disponible en la Biblioteca Jurídica Virtual del Instituto de Investigaciones Jurídicas de la UNAM, pp. 189-205; también en: https://wwrw:yumpu.com/es/document/view/14719494/diaz-romero-juan-quotel-principio-de-la-dig 
Este libro forma parte del acervo de la Biblioteca Jurídica Virtual del Instituto de Investigaciones Jurídicas de la UNAM

La primera Constitución mexicana, la de 1824, no recogió este concepto. Tampoco lo hizo la de 1857, ni la de 1917, que este año celebra su centenario. Fue hace setenta años cuando, en el contexto de la segunda reforma del artículo 3o. (educación) del texto constitucional de 1917, publicada el 30 de diciembre de 1946, se dispuso que la educación:

Contribuirá a la mejor convivencia humana, tanto por los elementos que aporte, a fin de robustecer en el educando, junto con el aprecio para la dignidad de la persona y la integridad de la familia, la convicción del interés general de la sociedad, cuanto por el cuidado que ponga en sustentar los ideales de fraternidad e igualdad de derechos de todos los hombres, evitando los privilegios de razas, de sectas, de grupo, de sexo o de individuos. ${ }^{2}$

El presente texto reviste de particular importancia porque confiere a México el honor de ser el primer país de la tradición occidental en haber introducido la expresión "dignidad" en su texto constitucional estatal (o nacional).

Unos años después, aunque este mismo fragmento fue parcialmente modificado en la tercera reforma de este mismo artículo 3o. relativo a la educación, publicada el 28 de enero de 1992, mantuvo la expresión "dignidad":

Contribuirá a la mejor convivencia humana, tanto por los elementos que aporte a fin de robustecer en el educando, junto con el aprecio para la dignidad de la persona y la integridad de la familia, la convicción del interés general de la sociedad, cuanto por el cuidado que ponga en sustentar los ideales de fraternidad e igualdad de derechos de todos los hombres, evitando los privilegios de razas, de religión, de grupos, de sexos o de individuos. ${ }^{3}$

nidad-humana-y-su- (fecha de consulta: 9 de enero de 2017); López Sánchez, Rogelio, "El tardío desarrollo de la dignidad humana y libre desarrollo a la personalidad en el Estado constitucional mexicano", Derecho en Libertad. Revista del Centro de Investigaciones Furídicas de la Facultad Libre de Derecho de Monterrey, año 2, núm. 3, julio-diciembre de 2009, pp. 127-151; Alarcón I., Gonzalo, "La dignidad como valor y como derecho en la perspectiva constitucional", $X V$ Congreso Nacional de Abogados de la Barra Mexicana. A cien años de la Constitución de 1917, Ciudad de México, Themis, noviembre de 2016, pp. 2441-2455.

2 Artículo 3o., inciso I, fracción c, Constitución de México, 1917 (CM 1917), que reforma la del 5 de febrero de 1857; el texto reproducido recoge la reforma publicada el 30 de diciembre de 1946 (disponible en: http://wrere.diputados.gob.mx/bibliot/publica/inveyana/polint/ cua2/evolucion.htm); agradezco al doctor José Luis Soberanes hacerme notar la existencia de esa reforma constitucional de 1946, que en ocasiones ha sido ignorada por los estudiosos de la dignidad humana en el constitucionalismo mexicano; si no se dice lo contrario, la letra cursiva de los textos transcritos es mía.

3 Artículo 3o., inciso I, fracción c, CM 1917; el texto reproducido recoge la reforma publicada el 22 de enero de 1992 (disponible en: http://wrereddiputados.gob.mx/bibliot/publica/ inveyana/polint/cua2/evolucion.htm). 
Este libro forma parte del acervo de la Biblioteca Jurídica Virtual del Instituto de Investigaciones Jurídicas de la UNAM

Este fragmento se reprodujo íntegramente un año después, en la quinta reforma del mismo artículo 3o., publicada el 5 de marzo de $1993 .{ }^{4}$

Unos años más tarde, una reforma constitucional del 14 de agosto de 2001 volvió a incorporar esta expresión en el Constitucionalismo mexicano:

Queda prohibida toda discriminación motivada por origen étnico o nacional, el género, la edad, las capacidades diferentes, la condición social, las condiciones de salud, la religión, las opiniones, las preferencias, el estado civil o cualquier otra que atente contra la dignidad humana y tenga por objeto anular o menoscabar los derechos y libertades de la persona. ${ }^{5}$

Como se desprende del contenido del propio texto, la reforma de la Constitución se limitó a considerarlo como un principio que no cabe contravenir en el sentido discriminatorio. Conectó, pues, los conceptos de dignidad humana y discriminación, ${ }^{6}$ pero nada dijo con respecto a su fundamento, ${ }^{7}$ noción, alcance y extensión.

El 10 de junio de 2011 quedó plasmado un nuevo texto en el artículo 1o., dando plena expresividad a la dignidad humana. Al texto de la mencionada reforma de 2001 ("Queda prohibida toda discriminación motivada por origen étnico o nacional..."), se le incorporaron tres importantes párrafos antecedentes que vinieron a introducir el principio pro persona en el derecho constitucional mexicano ${ }^{8}$ dentro del

4 Artículo 3o., inciso I, fracción $c$, CM 1917; la reforma publicada el 5 de marzo de 1993 recogió el texto de 1992 (véase http://wrere.diputados.gob.mx/bibliot/publica/inveyana/po lint/cua2/evolucion.htm).

5 Artículo 1o., párrafo tercero, CM 1917; dicha reforma fue publicada en el Diario Oficial de la Federación el 14 de Agosto de 2001 (uso la versión del texto constitucional mexicano recogido en http://wrere.diputados.gob.mx/LeyesBiblio/htm/1.htm).

$6 \mathrm{Al}$ respecto, véase Torre Martínez, Carlos de la, El derecho a la no discriminación en México, México, Porrúa-Comisión Nacional de los Derechos Humanos, 2006, pp. 40-53, donde se trata de la dignidad humana como fundamento de la no discriminación.

7 Saldaña Serrano, Javier, "La dignidad de la persona. Fundamento del derecho a no ser discriminado injustamente", Derecho a la no discriminación, México, UNAM-ConapredCDHDF, 2006, pp. 57-80 (disponible en: file:///C:/Users/Direccion/Downloads/8.pdf(fecha de consulta: 24 de enero de 2017).

8 Sobre la introducción del principio pro persona en el derecho constitucional mexicano, véanse Saltalamacchia Ziccardi, Natalia y Covarrubias Velasco, Ana, "La dimensión internacional de la reforma de los derechos humanos: antecedentes históricos", La reforma constitucional de los derechos humanos. Un nuevo paradigma, México, UNAM-Porrúa, 2012, pp. 1-38; Caballero Ochoa, José Luis, "La cláusula de interpretación conforme y el principio pro persona (art. 1o., 2o. párrafo, de la Constitución)", La reforma constitucional de los derechos humanos. Un nuevo paradigma, México, UNAM-Porrúa, 2012, pp. 103-133; Saucedo González, José Isidro, "Implicaciones filosóficas de las resoluciones de la Corte Interamericana de De- 
Este libro forma parte del acervo de la Biblioteca Jurídica Virtual del Instituto de Investigaciones Jurídicas de la UNAM

capítulo I con la rúbrica "De los derechos humanos y sus garantías").9

Poco tiempo después, al reformarse el artículo 3o. relativo a la educación, se introdujo otra referencia expresa a la "dignidad de la persona" al disponer que la educación:

Contribuirá a la mejor convivencia humana, a fin de fortalecer el aprecio y respeto por la diversidad cultural, la dignidad de la persona, la integridad de la familia, la convicción del interés general de la sociedad, los ideales de fraternidad e igualdad de derechos de todos, evitando los privilegios de razas, de religión, de grupos, de sexos o de individuos. ${ }^{10}$

El 5 de junio de 2013, al reformarse el artículo 25 del texto constitucional, se estableció que corresponde al Estado crear una serie de condiciones

rechos Humanos", AAPAUNAM, Academia, Ciencia y Cultura, México, año 5, núm. 4, octubrediciembre de 2013; Galindo Monroy, Jorge Antonio, "Los derechos naturales del hombre. Su disponibilidad y la Tesis por contradicción 293/2011", XV Congreso Nacional de Abogados de la Barra Mexicana. A cien años de la Constitución de 1917, México, Themis, noviembre de 2016, pp. 899-952; Hidalgo Murillo, José Daniel, Problemáticas procesales. Estudio, análisis y soluciones al Código nacional de procedimientos penales. 206 preguntas con sus respuestas, México, Editorial Flores, 2016 , pp. 2 y 3.

9 Artículo 1o., párrafo tercero, CM 1917; Decreto publicado en el DOF de México el 10 de junio de 2011: "Queda prohibida toda discriminación motivada por origen étnico o nacional, el género, la edad, las discapacidades, la condición social, las condiciones de salud, la religión, las opiniones, las preferencias sexuales, el estado civil o cualquier otra que atente contra la dignidad humana y tenga por objeto anular o menoscabar los derechos y libertades de las persona"; la única diferencia de este párrafo con respecto al de 2001 fue la introducción de la expresión "sexuales" (tras el término "preferencias").

El artículo 1o. quedó como sigue:

"En los Estados Unidos Mexicanos todas las personas gozarán de los derechos humanos reconocidos en esta Constitución y en los tratados internacionales de los que el Estado Mexicano sea parte, así como de las garantías para su protección, cuyo ejercicio no podrá restringirse ni suspenderse, salvo en los casos y bajo las condiciones que esta Constitución establece.

Las normas relativas a los derechos humanos se interpretarán de conformidad con esta Constitución y con los tratados internacionales de la materia favoreciendo en todo tiempo a las personas la protección más amplia.

Todas las autoridades, en el ámbito de sus competencias, tienen la obligación de promover, respetar, proteger y garantizar los derechos humanos de conformidad con los principios de universalidad, interdependencia, indivisibilidad y progresividad. En consecuencia, el Estado deberá prevenir, investigar, sancionar y reparar las violaciones a los derechos humanos, en los términos que establezca la ley.

Está prohibida la esclavitud en los Estados Unidos Mexicanos. Los esclavos del extranjero que entren al territorio nacional alcanzarán, por este solo hecho, su libertad y la protección de las leyes.

[seguido del párrafo final recogido al principio de la presente nota]".

10 Artículo 3.B.II.c CM 1917 (inciso reformado, DOF, 9 de febrero de 2012 y 26 de febrero de 2013). 
Este libro forma parte del acervo de la Biblioteca Jurídica Virtual del Instituto de Investigaciones Jurídicas de la UNAM

que permitan "el pleno ejercicio de la libertad y la dignidad de los individuos, grupos y clases sociales". ${ }^{11}$

Más tarde, en otra reforma, el 22 de mayo de 2015, se modificó el artículo 2.A, fracción II, refiriéndose a la "dignidad e integridad de las mujeres". En concreto, el precepto dispone que la ley fundamental mexicana "...reconoce y garantiza el derecho de los pueblos y las comunidades indígenas a la libre determinación y, en consecuencia a la autonomía para:... II. Aplicar sus propios sistemas normativos... sujetándose a los principios generales de esta Constitución, respetando... la dignidad e integridad de las mujeres...". ${ }^{12}$

\title{
II. LA DIGNIDAD HUMANA EN EL DERECHO CONSTITUCIONAL COMPARADO
}

\begin{abstract}
México no introdujo tempranamente la referencia expresa a la dignidad humana en su texto constitucional, en comparación con otros Estados. En efecto, a partir de 1947, varias Constituciones de Europa y América Latina optaron por incluir esta noción en sus cartas magnas. Además, la Constitución mexicana - a diferencia de la española y la alemana - no ha hecho "de la dignidad humana la «piedra angular» de todo el ordenamiento jurídico mexicano". ${ }^{13}$ La mayoría de los países que aprobaron un texto constitucional tras la Segunda Guerra Mundial optaron por hacer una mención expresa a la noción de dignidad humana, tesitura que no se dio en México al contar ya con una Constitución desde 1917, texto reformado de la 1857.
\end{abstract}

11 Artículo 25 CM 1917: "Corresponde al Estado la rectoría del desarrollo nacional para garantizar que éste sea integral y sustentable, que fortalezca la Soberanía de la Nación y su régimen democrático y que, mediante la competitividad, el fomento del crecimiento económico y el empleo y una más justa distribución del ingreso y la riqueza, permita el pleno ejercicio de la libertad y la dignidad de los individuos, grupos y clases sociales, cuya seguridad protege esta Constitución. La competitividad se entenderá como el conjunto de condiciones necesarias para generar un mayor crecimiento económico, promoviendo la inversión y la generación de empleo".

12 Artículo 2.A II: "Aplicar sus propios sistemas normativos en la regulación y solución de sus conflictos internos, sujetándose a los principios generales de esta Constitución, respetando las garantías individuales, los derechos humanos y, de manera relevante, la dignidad e integridad de las mujeres. La ley establecerá los casos y procedimientos de validación por los jueces o tribunales correspondientes".

13 García González, Aristeo, "La dignidad humana: núcleo duro de los derechos humanos", Ius. Revista furídica, núm. 28, 2008, disponible en: http://wrere.unla.mx/iusunla28/ reflexion/La\%20Dignidad\%20Humana.htm (fecha de consulta: 9 de enero de 2017), texto principal entre las notas al pie 68 y 69. 
Este libro forma parte del acervo de la Biblioteca Jurídica Virtual del Instituto de Investigaciones Jurídicas de la UNAM

En 1999 se promulgó la Constitución Federal de la Confederación Suiza. ${ }^{14} \mathrm{Su}$ artículo 7 o., con el título "Dignidad humana", dispone que "La dignidad humana debe ser respetada y protegida".

Este texto constitucional recoge por segunda vez la expresión "dignidad humana" al disponer que "La Confederación elaborará la normativa sobre la utilización del patrimonio genético y embrionario humano; de esta manera velará por asegurar la protección de la dignidad humana, de la personalidad y de la familia" (artículo 119. 2 CFCS 1999).

Dos años antes, la Constitución de la República de Polonia, del 2 de abril de 1997, dispuso expresamente en su artículo 30: "La inherente e inalienable dignidad de la persona deberá constituir una fuente de libertad y derechos de las personas y los ciudadanos. Deberá ser inviolable".

Dos décadas antes, la expresión había sido recogida en la Constitución Española. ${ }^{15}$ La introducción de la dignidad humana en el constitucionalismo español fue tardía. Ningún texto constitucional anterior a la vigente Constitución (1978) lo recogió (1812, 1837, 1845, 1869, 1876, 1931). Pero sí se hizo al aprobar la primera Constitución de la segunda mitad del siglo XX. Y se recogió en el Título I ("De los derechos y deberes fundamentales”), en su artículo 10.1, al señalar lo siguiente:

"La dignidad de la persona, los derechos inviolables que le son inherentes, el libre desarrollo de la personalidad, el respeto a la ley y a los derechos de los demás son fundamento del orden político y de la paz social". ${ }^{16}$

Según el tenor del propio texto, el respeto a los derechos de los demás constituye una exigencia de la misma dignidad humana, que se erige, además, en el fundamento y valor fundamental del ordenamiento jurídico, ${ }^{17}$

14 Constitución Federal de la Confederación Suiza, del 18 de abril de 1999.

15 Constitución Española, 6 de diciembre de 1978; al respecto, véase Fernández, Segado Francisco, "La dignidad de la persona en el ordenamiento constitucional español", Revista Vasca de Administración Pública, núm. 43, 1995, pp. 49-80 (publicado, con el mismo título, en Estudios Constitucionales. Revista Mexicana de Derecho Constitucional, 2004).

16 Artículo 10.1 Constitución española 1978 (CE 1978; disponible en: http://wrere.congreso.es/consti/constitucion/indice/titulos/articulos.jsp?ini $=10 \mathcal{E}^{2} \mathrm{fin}=55 \mathcal{E}^{2}$ tipo $=2$, fecha de consulta: 9 de enero de 2017); seguido del artículo 10.2 que establece: "Las normas relativas a los derechos fundamentales y a las libertades que la Constitución reconoce se interpretarán de conformidad con la Declaración Universal de Derechos Humanos y los tratados y acuerdos internacionales sobre las mismas materias ratificados por España".

$17 \mathrm{Al}$ respecto, véase Fernández Segado, Francisco, "La dignidad de la persona como valor supremo del ordenamiento jurídico", Derecho PUCP 50, Lima, diciembre de 1996, pp. 11-45 (disponible en: http://revistas.pucp.edu.pe/index.php/derechopucp/article/view/5924/5 933, fecha de consulta: 9 de enero de 2017); sobre si la dignidad humana es, además, un derecho fundamental, véase el estudio de Gómez Sánchez, Yolanda, "Dignidad y ordenamien- 
Este libro forma parte del acervo de la Biblioteca Jurídica Virtual del Instituto de Investigaciones Jurídicas de la UNAM

junto con los "valores superiores" recogidos en el artículo 1o. ("la libertad, la justicia, la igualdad y el pluralismo político").

Todos los derechos fundamentales, contenidos en la sección la. del capítulo II ("De los derechos fundamentales y de las libertades públicas"), derivan y encuentran su fundamento en la dignidad humana, como recoge expresamente el mencionado artículo 10.1 ("los derechos inviolables que le son inherentes").

Dos años antes Portugal había promulgado su Constitución (2 de abril de 1976), recogiendo, en su artículo 1o., una mención expresa a la dignidad: "Portugal es una República soberana, basada en la dignidad de la persona humana y en la voluntad popular, y empeñada en la construcción de sociedad libre, justa y solidaria".

El artículo 13.1, al consagrar el principio de igualdad, señala que "Todos los ciudadanos tienen la misma dignidad social y son iguales ante la ley", si bien este precepto no se refiere propiamente a la dignidad natural (de ahí la expresión "dignidad social"); de lo contrario, tal dignidad no podría derivar de la condición de ciudadano de un país.

En el título II ("De los derechos, libertades y garantías"), capítulo I ("De los derechos, libertades y garantías personales"), el artículo 26 del texto portugués recoge dos referencias explícitas a la dignidad humana natural:

"La ley establecería garantías efectivas contra la utilización abusiva, o contraria a la dignidad humana, de informaciones relativas a las personas y a las familias" (artículo 26.2 CP 1976).

"La ley garantizará la dignidad personal y la identidad genética del ser humano, especialmente en la creación, desarrollo, utilización de la tecnología y en la experimentación científica" (artículo 26.3 CP 1976).

El artículo 67, al regular "la familia, como elemento fundamental de la sociedad", dispone que corresponde al Estado "Reglamentar la procreación asistida, en términos que salvaguarden la dignidad de la persona humana" (artículo 67. 5 CP 1976).

Finalmente, el artículo 206 ("De las audiencias de los tribunales") dispone que las audiencias son públicas "salvo cuando el propio Tribunal disponga lo contrario, por auto motivado, para la salvaguarda de la dignidad de las personas y de la moral pública o para garantizar su normal funcionamiento".

Un año antes, la Constitución griega (del 11 de junio de 1975), en su título "Dignidad humana", había dispuesto que "El respeto y la protección

to jurídico", Revista de Derecho Constitucional Europeo (ReDCE), núm. 4, julio-diciembre de 2005, pp. 219-254. 
Este libro forma parte del acervo de la Biblioteca Jurídica Virtual del Instituto de Investigaciones Jurídicas de la UNAM

de la dignidad humana constituye la obligación primaria del Estado" (artículo 2o. CG 1975). ${ }^{18}$

La Constitución griega contiene dos preceptos más con referencias expresas a la dignidad humana: "Se prohíben y serán castigadas con arreglo a lo dispuesto en la ley las torturas, toda sevicia corporal y todo atentado a la salud o presión sicológica, así como cualquier otro atentado a la dignidad humana" (artículo 7.2. GG 1975).

"No está permitido que la iniciativa económica privada se desarrolle en detrimento de la libertad y de la dignidad humana, ni en perjuicio de la economía nacional" (artículo 106. 2 CG 1975).

La primera Constitución nacional - o estatal - que confirió a la dignidad humana un puesto de primer orden, como piedra basilar de todo el edificio constitucional, fue la Ley Fundamental de Bonn. ${ }^{19}$ La consagración del principio de protección de la dignidad humana en el artículo lo. del texto constitucional alemán constituía una respuesta clara y contundente a las violaciones de los derechos humanos llevadas a cabo en el marco del régimen político nacionalsocialista:

Artículo 1

[Protección de la dignidad humana, vinculación de los poderes públicos a los derechos fundamentales]

(1) La dignidad humana es intangible. Respetarla y protegerla es obligación de todo poder público.

(2) El pueblo alemán, por ello, reconoce los derechos humanos inviolables e inalienables como fundamento de toda comunidad humana, de la paz y de la justicia en el mundo.

(3) Los siguientes derechos fundamentales vinculan a los poderes legislativo, ejecutivo y judicial como derecho directamente aplicable.

El texto de Bonn no contiene más referencias a la dignidad humana. Sin embargo, su inserción en el artículo 1o. como dispositivo de apertura

18 Este artículo 2.1 de la Constitución griega fue objeto de reforma el 27 de junio de 2008, quedando como sigue: "El respeto y la protección del valor de la persona humana constituyen la obligación primordial del Estado".

19 El Consejo Parlamentario comprobó, en sesión pública el 23 de mayo de 1949 en Bonn, que la Ley Fundamental para la República Federal de Alemania, acordada el 8 de mayo de 1949 por el Consejo Parlamentario, fue aprobada en la semana del 16 al 22 de mayo de 1949 por las representaciones del pueblo de más de los dos tercios de los Länder alemanes participantes. En virtud de esta comprobación, el Consejo Parlamentario, representado por su presidente, ha sancionado y promulgado la Ley Fundamental (Grundgesetz). Era el tercer texto constitucional de la historia de Alemania, tras los de 1871 y 1919. 
Este libro forma parte del acervo de la Biblioteca Jurídica Virtual del Instituto de Investigaciones Jurídicas de la UNAM

constitucional expresa un rasgo fundamental del nuevo ordenamiento democrático y del Estado de derecho establecido por el texto constitucional. De ahí que el artículo 79.3, regulador de la "Reforma de la Ley Fundamental", impida la posibilidad de reformar este principio constitucional, protegiendo la dignidad de la persona como principio y valor originario de todo ser humano. ${ }^{20}$

La dignidad humana lleva consigo, como reza el mencionado precepto, el reconocimiento de "los derechos humanos inviolables e inalienables como fundamento de toda comunidad humana" (artículo 1o.). De ahí que los artículos 2o. a 19 consagren el reconocimiento de tales derechos, empezando por la "Libertad de acción y de la persona", es decir, el derecho a la vida y a la libertad:

Artículo 2

[Libertad de acción y de la persona]

(1) Toda persona tiene el derecho al libre desarrollo de su personalidad siempre que no viole los derechos de otros ni atente contra el orden constitucional o la ley moral.

(2) Toda persona tiene el derecho a la vida y a la integridad física. La libertad de la persona es inviolable. Estos derechos sólo podrán ser restringidos en virtud de una ley.

Es precisamente la dignidad humana la que exige que la persona pueda actuar autónomamente, ejerciendo su propia libertad ("desarrollo de su personalidad"), aunque no de modo ilimitado ("siempre que no viole los derechos de otros ni atente contra el orden constitucional o la ley moral").

No se trata de desarrollar aquí la noción de dignidad humana en el texto constitucional alemán. ${ }^{21}$ Resulta suficiente para nuestro propósito subrayar que la Ley Fundamental de Bonn fue la primera Constitución estatal en recoger la expresión y noción de dignidad humana, y que constituyó un importante precedente para otros textos constitucionales de Europa y América Latina, que seguirían el ejemplo del texto alemán, aunque de un modo diverso. Conviene advertir que la Ley Fundamental de Bonn no fue, sin embargo, el primer texto jurídico que recogió la dignidad humana. Dicho en otras palabras, la noción jurídica de dignidad humana no nació en Bonn,

20 "No está permitida ninguna modificación de la presente Ley Fundamental que afecte la organización de la Federación en Länder, o el principio de la participación de los Länder en la legislación, o los principios enunciados en los artículos 1 y 20" (artículo 79.3 LFB 1949).

$21 \mathrm{Al}$ respecto, véase Starck, Christian, "Introducción a la dignidad humana en el derecho alemán”, Anuario Iberoamericano de Fusticia Constitucional, Madrid, núm. 9, 2005, pp. 489-497. 
Este libro forma parte del acervo de la Biblioteca Jurídica Virtual del Instituto de Investigaciones Jurídicas de la UNAM

sino en San Francisco dos años antes, no en el marco del derecho constitucional (nacional), sino en la esfera del derecho internacional público.

Pese a todo, conviene recordar - como se vio- que fue México, y no Alemania, el primer país que hizo una referencia expresa a la "dignidad" [humana] en su texto constitucional. ${ }^{22}$

\section{EL ORIGEN DE LA NOGIÓN JURÍDIGA DE DIGNIDAD HUMANA TRAS LA SEGUNDA GUERRA MUNDIAL}

La expresión "dignidad humana" no se recogió - como se verá- en los inicios del constitucionalismo moderno. Se puede afirmar, pues, que la historia de esta expresión en el constitucionalismo es bastante breve, pero al mismo tiempo intensa y exitosa, tanto en el derecho constitucional - Constituciones nacionales - como en el derecho internacional público - declaraciones e instrumentos internacionales - Intensa, por su (omni)presencia, como se ha visto, tras la Segunda Guerra Mundial y, en particular, a partir del 26 de junio de 1945. Exitosa, por haberse convertido en el fundamento de todo el derecho público. La expresión bobbiana de la "época de los derechos", bien podría aplicarse a la dignidad humana, denominando la etapa que se inició en la segunda mitad del siglo XX como "época de la dignidad humana".

De hecho, la historia de los "derechos humanos" y la historia de la "dignidad humana" presentan interesantes paralelismos: i) ambas expresiones son recientes, pese a que su significado y sentido gozan de una dilatada evolución histórica; ii) ambas expresiones triunfan, pero en un momento en el que resulta difícil - por no decir, imposible - ponerse de acuerdo con respecto al fundamento, ${ }^{23}$ significado y alcance de su contenido;24 iii) ambas expresiones son objeto de reivindicación y defensa en teo-

22 Véase la nota al pie 2, así como su correspondiente texto principal.

23 A este respecto, conviene recordar el suceso que aconteció en una de las reuniones preparatorias del texto de la Declaración Universal de los Derechos humanos, narrada por Jacques Maritain, Los derechos del hombre. Estudios y comentarios en torno a la Nueva Declaración de los Derechos del Hombre, México, Fondo de Cultura Económica-UNESCO, 1949, p. 15: “....alguien se quedó asombrado al advertir que personas de tan distintas y antagónicas ideologías se hubieran puesto de acuerdo respecto de la tabla de derechos aprobada. Pero, en realidad, lo que sucedió es que todos manifestaron su acuerdo, siempre y cuando no se les preguntara el porqué y el cómo habían llegado a dicho acuerdo, ya que con el porqué empezaba la disputa".

24 Sobre las diversas concepciones de dignidad humana en la tradición occidental, desde sus orígenes hasta la reforma protestante, véase el estudio de Baker, Herschell, The Dignity of Man, Cambridge, Mass., Harvard University Press, 1947; lógicamente, la noción de digni- 
Este libro forma parte del acervo de la Biblioteca Jurídica Virtual del Instituto de Investigaciones Jurídicas de la UNAM

ría - o en abstracto-, pero en la práctica - o en las circunstancias concretas - su respeto o protección resulta a menudo desigual e insuficiente, y iv) ambas expresiones parecen tener un significado claro - a modo de presupuestos que no requieren de demostración alguna-, pero éste es traicionado o puesto en entredicho por determinadas corrientes de la filosofía de derecho o de la filosofía política. Lo que sucedió con la noción de "derechos fundamentales" en los siglos XVIII y XIX, ha afectado también a la "dignidad humana" y a los "derechos humanos" en los siglos XX y XXI. ¿A qué se debió la "positivización" o "constitucionalización" de la "dignidad humana"? ¿Por qué se optó por emplear esa expresión en los textos jurídicos de derecho internacional y constitucionales tras la Segunda Guerra Mundial? La respuesta es bien conocida: para mostrar el rechazo frente a las horrorosas consecuencias de esa guerra, que segó la vida a 50 millones de civiles y a 20 millones de combatientes. La historia de la humanidad no conocía un episodio que hubiera provocado tantas pérdidas humanas, tanto sufrimiento humano, y tanta destrucción y daños materiales.

Regímenes políticos totalitarios, coadyuvados por determinadas corrientes de pensamiento filosófico, político y jurídico, produjeron un gran daño a toda la humanidad. El primer enemigo a abatir era lógicamente el régimen político nacionalsocialista, que fue el primer responsable de la Guerra y sus dramáticas consecuencias. Sólo así cabía volver a defender la dignidad que en la Guerra había sido degradada, denigrada y pisoteada. Así se expresaba un conocido economista alemán en 1944:

No hay sino un medio para salvar nuestra civilización y para preservar la dignidad del hombre. Es aniquilar el nazismo radicalmente y lastimosamente. Sólo después de la destrucción total del nazismo el mundo podrá reanudar sus esfuerzos para mejorar la organización social y para construir una sociedad mejor. Las alternativas son la humanidad o la bestialidad, pacífica cooperación humana o despotismo totalitario. Todos los planes para una tercera solución son ilusorios. ${ }^{25}$

dad está estrechamente relacionada con la cuestión de qué es el hombre; al respecto, Buber, Martin, ¿Qué es el hombre?, trad. de Eugenio Ímaz, México, Fondo de Cultura Económica, 1979; sobre la condición dialógica del hombre, véase Buber, Martin, Yo y tú, trad. de Horacio Crespo, Buenos Aires, Galatea Nueva Visión, 1956, p. 30: "El hombre se torna en un yo a través del tú"; "Otro ser humano es prójimo no sólo con base en un genérico sentimiento de humanidad, sino primariamente con base en su ser «otro yo»” (Wojtyla, Karol, “¿Participación o alienación?", El hombre y su destino, Madrid, Palabra, 1998).

25 Von Mises, Ludwig, Omnipotent Government: The Rise of the Total State and Total War (1944), p. 267, disponible en: http://oll.libertyfund.org/titles/2399\#Mises_OmnipotentGovt1579_873-874. 
Este libro forma parte del acervo de la Biblioteca Jurídica Virtual del Instituto de Investigaciones Jurídicas de la UNAM

Sin embargo, convenía también reducir aquellas doctrinas filosóficas, políticas y jurídicas que, de un modo u otro, habían defendido o justificado un uso arbitrario y despótico del poder político. ¿Cómo era posible defender la dignidad y los derechos humanos en el marco de corrientes de pensamiento dominadas por el utilitarismo, el instrumentalismo, el consecuencialismo, el positivismo jurídico o las tesis filosófico-políticas de Carl Schmitt? ¿Era posible evitar que se repitiera de nuevo la tragedia de la guerra con tan solo eliminar el nacionalsocialismo como régimen político, pero sin erradicar las doctrinas que sirvieron a esta causa política, proporcionando el sustrato y la justificación necesarios para un ejercicio ilimitado del poder político?

Con la creación de la Organización de Naciones Unidas - y su Carta de San Francisco - en 1945, y la redacción de la Declaración Universal de los Derechos Humanos en 1948, se ponía de manifiesto que la garantía y protección de los derechos fundamentales - que los textos empezaron a denominar "derechos humanos" - no podía depender de los Estados nacionales, porque tales derechos son comunes a todos los hombres; lo son porque todo ser humano posee la misma "dignidad natural". Las expresiones "inherente" o "intrínseca" se refieren precisamente a esta "dignidad natural", común a todo ser humano (distinta de la "dignidad moral", la cual depende de la conducta de cada persona). Esto explica por qué, a menudo, las Declaraciones y textos internacionales recogen las expresiones "inherente" o "intrínseca" al referirse a la dignidad humana, como hicieran los primeros textos constitucionales modernos - en los siglos XVIII y XIX - al referirse a los "derechos naturales" o "derechos fundamentales".

Las consecuencias de la negación y violación de la dignidad humana en la Segunda Guerra Mundial fueron terribles. El resurgimiento del concepto de la dignidad humana a partir de 1945 vino a recordar lo que la humanidad había olvidado y marcó el camino a seguir para la construcción de un mundo - o sociedad global - justa y pacífica. En efecto, tras la Segunda Guerra Mundial, los derechos humanos se convirtieron en la lingua franca de las relaciones internacionales. Tanto las declaraciones - o instrumentos jurídicos - internacionales como las Constituciones nacionales establecieron los derechos humanos como base de los sistemas jurídicos. ${ }^{26} \mathrm{Al}$ hacerlo, los

$26 \mathrm{Al}$ respecto, véase, por ejemplo, el estudio de Soberanes Fernández, José Luis, Sobre el origen de las declaraciones de derechos humanos, México, Comisión Nacional de los Derechos Humanos-UNAM, Instituto de Investigaciones Jurídicas, 2009; véase también Saldaña Serrano, "La dignidad de la persona. Fundamento del derecho a no ser discriminado injustamente", cit., pp. 61-64. 
Este libro forma parte del acervo de la Biblioteca Jurídica Virtual del Instituto de Investigaciones Jurídicas de la UNAM

textos legales citaron explícitamente, por vez primera, la dignidad humana como origen y fundamento de los derechos humanos.

El primer texto de naturaleza jurídica que recogió la noción de dignidad humana fue la Carta de las Naciones Unidas, firmada el 26 de junio de 1945 en San Francisco (por ello denominada también "Carta de San Francisco"), al terminar la Conferencia de las Naciones Unidas sobre Organización Internacional, entrando en vigor el 24 de octubre del mismo año. Así reza su Preámbulo:

\section{NOSOTROS LOS PUEBLOS DE LAS NACIONES UNIDAS RESUELTOS}

- a preservar a las generaciones venideras del flagelo de la guerra que dos veces durante nuestra vida ha infligido a la Humanidad sufrimientos indecibles,

- a reafirmar la fe en los derechos fundamentales del hombre, en la dignidad y el valor de la persona humana, en la igualdad de derechos de hombres y mujeres y de las naciones grandes y pequeñas,

- a crear condiciones bajo las cuales puedan mantenerse la justicia y el respeto a las obligaciones emanadas de los tratados y de otras fuentes del derecho internacional,

- a promover el progreso social y a elevar el nivel de vida dentro de un concepto más amplio de la libertad...

El texto reconoce, además de los derechos fundamentales del hombre, "la dignidad y el valor de la persona humana". La Carta no contiene ya más referencias a la dignidad humana.

Lo hizo tres años más tarde, y de un modo particularmente enfático y elocuente, el texto más emblemático de la recién creada ONU, esto es, su Declaración Universal de los Derechos Humanos (DUDH). ${ }^{27}$ De entrada, el Preámbulo recoge la expresión en dos ocasiones (siendo la segunda una

27 La Declaración Universal de los Derechos Humanos es un documento declarativo que fue adoptado por la Asamblea General de las Naciones Unidas en su Resolución 217 A (III), el 10 de diciembre de 1948 en París; en ésta se recogen en sus 30 artículos los derechos humanos considerados básicos, a partir de la Carta de San Francisco (26 de junio de 1945). Como es sabido, el título originario del texto en versión española fue "Declaración Universal de Derechos del Hombre"; más tarde, la Asamblea General, en su resolución 548 (VI) del 5 de febrero de 1952, decidió modificar todos los documentos de trabajo en español, para emplear la expresión "derechos humanos" en vez de "derechos del hombre", habida cuenta de que el contenido y la finalidad de la Declaración "tienen un amplio significado que no cabe dentro del título en lengua española de «derechos del hombre», teniendo en cuenta además que el cuerpo del instrumento alude a la expresión «derechos humanos» y que distinguidos representantes hispanoamericanos «han expresado su preferencia por la terminología empleada en la Carta»". 
Este libro forma parte del acervo de la Biblioteca Jurídica Virtual del Instituto de Investigaciones Jurídicas de la UNAM

reproducción literal parcial — no completa- del texto de la Carta de San Francisco):

Considerando que la libertad, la justicia y la paz en el mundo tienen por base el reconocimiento de la dignidad intrínseca y de los derechos equitativos e inalienables de todos los miembros de la familia humana...

Considerando que los pueblos de las Naciones Unidas han reafirmado en la Carta su fe en los derechos fundamentales del hombre, en la dignidad y el valor de la persona humana y en la igualdad de derechos de hombres y mujeres, y se han declarado resueltos a promover el progreso social y a elevar el nivel de vida dentro de un concepto más amplio de la libertad...

Tras el Preámbulo, otros tres artículos contienen una referencia expresa a la "dignidad humana". El más relevante es, sin duda, el primero: "Todos los seres humanos nacen libres e iguales en dignidad y derechos y, dotados como están de razón y conciencia, deben comportarse fraternalmente los unos con los otros" (artículo 1o. DUDH).

El artículo recoge una noción de dignidad humana natural ("Todos los seres humanos nacen libres e iguales en dignidad"), pues la dignidad deriva del mero hecho de nacer como ser humano, condición que se caracteriza por estar dotado de "razón y conciencia". ${ }^{28} \mathrm{El}$ precepto presenta una influencia kantiana, pero va más allá, como se verá más adelante. Además, como la nobleza obliga ("Noblesse oblige"), ${ }^{29}$ todos los seres humanos, precisamente por razón de su dignidad como seres dotados de razón y conciencia, "deben comportarse fraternalmente los unos con los otros".

28 Véase, por ejemplo, el estudio de Bloch, Ernst, Derecho natural y dignidad humana, trad. de Felipe González Vicén, Madrid, Dykinson, 2011; distinto es al respecto el parecer de Bobbio, Norberto, "Sobre el fundamento de los derechos del hombre", El tiempo de los derechos, Madrid, Sistema, 1991, pp. 53-62; véase también el estudio de López Guerra, Rodrigo, Afirmar a la persona por si misma. La dignidad como fundamento de los derechos de la persona, México, Comisión Nacional de los Derechos Humanos, 2003.

29 Realidad que fue olvidada en el siglo XX, como pone de manifiesto Julián Marías, El tiempo que no vuelve ni tropieza, Barcelona, EDHASA, 1964, p. 99: "Lo que define al hombre masa es no exigirse. Su moral es la inversa del lema noblesse oblige. Por esto se afirma tal como se encuentra, cree que tiene derecho a todo, que todo le es debido, que no tiene que esforzarse por nada: por ser justo, por ser inteligente, por tener razón. Cuenta con las cosas de que disfruta como si éstas existiesen automáticamente y sin más, como si no fuesen problemáticas y debidas a invención, talento, trabajo y sacrificio. No escucha, no admite que otros puedan tener razón - en rigor, si siquiera admite que pueda propiamente haber otros irreductibles a él一, y por ello pretende imponer violentamente sus puntos de vista o sus apetencias; dicho con más exactitud, pretenden que sean espontáneamente acatados, sin esforzarse siquiera en, de hecho, imponerlos"; véase también Arriola, Juan Federico, La libertad, la autoridad y el poder en el pensamiento filosófico de José Ortega y Gasset, México, UNAM, 2003, p. 31. 
Este libro forma parte del acervo de la Biblioteca Jurídica Virtual del Instituto de Investigaciones Jurídicas de la UNAM

Las otras dos menciones expresas a la dignidad se refieren al derecho que tiene toda persona a "la satisfacción de los derechos económicos, sociales y culturales, indispensables a su dignidad y al libre desarrollo de su personalidad" (artículo 22), ${ }^{30}$ así como "a una remuneración equitativa y satisfactoria, que le asegure, así como a su familia, una existencia conforme a la dignidad humana" (artículo 23). ${ }^{31}$

La DUDH supuso un gran avance en el reconocimiento de la dignidad humana y los derechos fundamentales. ${ }^{32}$ Constituye, además, el primer instrumento internacional con un catálogo integral de derechos y libertades fundamentales de alcance y pretensión universal adoptado por la comunidad internacional a nivel mundial. ${ }^{33}$

Conviene no olvidar que, unos meses antes de la aprobación formal de la Declaración Universal de los Derechos Humanos, la recién creada Organización de los Estados Americanos, había aprobado la Declaración Americana de Derechos y Deberes del Hombre (DADDH), que fue, en realidad, el primer catálogo internacional con pretensión universal, si bien promovida por una organización de ámbito regional. En efecto, la DADDH fue apro-

30 Artículo 22 DUDH: "Toda persona, como miembro de la sociedad, tiene derecho a la seguridad social, y a obtener, mediante el esfuerzo nacional y la cooperación internacional, habida cuenta de la organización y los recursos de cada Estado, la satisfacción de los derechos económicos, sociales y culturales, indispensables a su dignidad y al libre desarrollo de su personalidad".

31 Artículo 23 DUDH:

(1) Toda persona tiene derecho al trabajo, a la libre elección de su trabajo, a condiciones equitativas y satisfactorias de trabajo y a la protección contra el desempleo.

(2) Toda persona tiene derecho, sin discriminación alguna, a igual salario por trabajo igual.

(3) Toda persona que trabaja tiene derecho a una remuneración equitativa y satisfactoria, que le asegure, así como a su familia, una existencia conforme a la dignidad humana y que será completada, en caso necesario, por cualesquiera otros medios de protección social.

(4) Toda persona tiene derecho a fundar sindicatos y a sindicarse para la defensa de sus intereses.

32 A este respecto, véase, por ejemplo, el estudio de Carrillo Salcedo, Juan Antonio, Dignidad frente a barbarie. La Declaración Universal de Derechos Humanos, cincuenta años después, Madrid, Trotta, 1999; o los trabajos de Bobbio, Norberto, "La resistencia a la opresión, hoy", El tiempo de los derechos, Madrid, Sistema, 1991; del mismo autor, "La Declaración Universal de Derechos del Hombre", Teoría general de la política, 3a. ed., Madrid, Trotta, 2009.

33 Sobre los orígenes, el proceso de redacción y contenido de la DUDH, véanse los estudios de Morsink, Johannes, The Universal Declaration of Human Rights. Origins, Drafting and Intent, Philadelphia, University of Pennsylvania Press, 1999; del mismo autor, "The Universal Declaration of Human Rights as a Norm for Societies in Transition", en Horowitz, S. y Schnabel, A., Human Rights and Societies in Transition. Causes, consequences, responses, Tokio-Nueva York-París, United Nations University Press, 2004, pp. 29-51; del mismo autor, Inherent Human Rights. Philosophical Roots of the Universal Declaration, Philadelphia, University of Pennsylvania Press, 2009. 
Este libro forma parte del acervo de la Biblioteca Jurídica Virtual del Instituto de Investigaciones Jurídicas de la UNAM

bada en el marco de la Novena Conferencia Internacional Americana, en Bogotá (Colombia), el 2 de mayo de 1948. ${ }^{34}$

El texto de esta Declaración americana contiene dos referencias expresas a la "dignidad humana". La primera aparece en el Preámbulo y es muy similar - casi literal - a la formulación que más tarde fue aprobada en la ya mencionada DUDH:

Todos los hombres nacen libres e iguales en dignidad y derechos y, dotados como están por naturaleza de razón y conciencia, deben conducirse fraternalmente los unos con los otros.

El cumplimiento del deber de cada uno es exigencia del derecho de todos. Derechos y deberes se integran correlativamente en toda actividad social y política del hombre. Si los derechos exaltan la libertad individual, los deberes expresan la dignidad de esa libertad.

Los deberes de orden jurídico presuponen otros, de orden moral, que los apoyan conceptualmente y los fundamentan.

Las diferencias entre ambos textos son claras. Así, por ejemplo, la $D U D H$ optó por no incluir la referencia expresa a la "naturaleza", tal como había hecho la Declaración americana ("dotados como están por naturaleza de razón y conciencia”). Además, en la DUDH no se encuentra de un modo tan explícito la idea de correlatividad entre derechos y deberes, ${ }^{35}$ ni menos aún la afirmación de que el orden moral constituya el sustrato o fundamento de los deberes del orden jurídico. Es evidente que las doctrinas filosóficas de Hume - para quien del ser no pueden inferirse normas éticas o morales - y Kant - para quien el derecho y la moral deben mantenerse separadas porque aquél pertenece a la esfera de lo contingente y ésta en la de lo necesario, las normas jurídicas son seguidas "coactivamente" y las morales por mero "respeto"-, ejercieron su influjo en la DUDH. ${ }^{36}$

La segunda - y última - referencia a la dignidad humana de la DADDH aparece en su artículo 23, al consagrar el "Derecho a la propiedad" con los siguientes términos: "Toda persona tiene derecho a la propiedad privada

$34 \mathrm{Al}$ respecto, véase el estudio de Gros Espiell, Héctor, "La Declaración Americana. Raíces conceptuales y políticas en la historia, la filosofía y el derecho americano", Derechos humanos y vida internacional, México, UNAM-CNDH, 1995.

$35 \mathrm{Al}$ respecto, véase el estudio de d'Agostino, Francesco, "Los derechos y deberes del hombre", en Saldaña, Javier (coord.), Problemas actuales sobre derechos humanos. Una propuesta filosófica, México, UNAM, 2000, pp. 91-106.

$36 \mathrm{Al}$ respecto, véase, por ejemplo, el estudio de Carpintero, Francisco, "Igualdad y simetría: la selección de los derechos", en Saldaña, Javier (coord.), Problemas actuales sobre derechos humanos..., cit., pp. 76-80. 
Este libro forma parte del acervo de la Biblioteca Jurídica Virtual del Instituto de Investigaciones Jurídicas de la UNAM

correspondiente a las necesidades esenciales de una vida decorosa, que contribuya a mantener la dignidad de la persona y del hogar".

El impacto de estas dos primeras declaraciones de 1948 -DADDH y DUDH - fue grande. Desde entonces, muchos documentos internacionales, Constituciones nacionales y doctrinas filosóficas empezaron a considerar la dignidad humana como "fuente de los derechos humanos" 37 y fundamento del derecho público. ${ }^{38}$ Resulta elocuente constatar cómo los instrumentos internacionales de derechos humanos han hecho hincapié en la estrecha relación existente entre los derechos humanos y la dignidad humana y, más en particular, hasta qué punto han reconocido explícitamente que "los derechos humanos derivan de la dignidad inherente a la persona humana". ${ }^{39}$

Conviene detenerse ahora precisamente en la referencia explícita al carácter "inherente" de la dignidad humana. Mientras la mayoría de los instrumentos internacionales de derechos humanos se refieren a la "dignidad humana", algunos de ellos han optado por añadir la expresión "inherente". La expresión adicional de este adjetivo ("inherente") resulta particularmente significativa. Como es sabido, "inherente" puede definirse como "una característica básica o esencial que da a algo su carácter", ${ }^{40}$ "una parte natural o básica de algo", ${ }_{41}$ "aquello que es permanente, esencial, o un atributo

37 Mieth, Corinna, "The Double Foundation of Human Rights in Human Nature", en Alber, Marion et al. (eds.), Human Rights and Human Nature, Dordrecht-Heidelberg-LondresNueva York, Springer, 2014, p. 11; sobre esta cuestión, véase también James Griffin, On Human Rights, Oxford, Oxford University Press, 2008; Nussbaum, Martha C., Frontiers of Fustice: Disability, Nationality, Species Membership, Cambridge, Mass., Harvard University Press, 2006.

38 A este respecto, léase el Prefacio del volumen 23 de la colección Studies in International Law, Patrick Capps, Human Dignity and the Foundations of International Law, OxfordPortland-Oregon, Hart Publishing, 2009: "Un Estado, a su vez, debe ser entendido como receptor de una legitimidad que proviene en última instancia de la búsqueda de la dignidad humana de la comunidad que éste gobierna, así como la dignidad de aquellos seres humanos y los Estados son afectados por sus acciones en las relaciones internacionales".

39 International Covenants on Civil and Political, and on Economic, Social and Cultural Rights (1966), Preámbulos; al respecto, véase Barak, Aharon, Human Dignity: The Constitutional Value and the Constitutional Right, Cambridge, Cambridge University Press, 2015, cap. 3; véase, también, Alzina de Aguilar José Pablo, "Human Dignity According to International Instruments on Human Rights", Revista Electrónica de Estudios Internacionales, núm. 22, 2011, pp. 1 y ss., disponible en: http://wrere.reei.org/index.php/revista/num22/notas/human-dignity-accordingto-international-instruments-on-human-rights; Andorno, Roberto, "Human Dignity and Human Rights", en Ten Have, Henk A. M. J. y Gordijn, Bert (eds.), Handbook of Global Bioethics, Dordrecht-Heidelberg-Londres-Nueva York, Springer, 2014, pp. 49 y 50.

40 Véase http://wrere.macmillandictionary.com/dictionary/british/inherent (fecha de consulta: 30 de julio de 2015).

41 Véase http://dictionary.cambridge.org/dictionary/british/inherent (fecha de consulta: 30 de julio de 2015). 
Este libro forma parte del acervo de la Biblioteca Jurídica Virtual del Instituto de Investigaciones Jurídicas de la UNAM

característico de algo". ${ }^{42}$ En otras palabras, "una cualidad que es inherente en algo es una parte natural y no puede ser separada de ese algo". ${ }^{43}$ En definitiva, calificar la dignidad humana como "inherente" significa que las personas merecen ser respetadas por lo que son (dignidad natural), no por su comportamiento o por sus capacidades (dignidad moral). La dignidad natural es común a todos los individuos y este es el tipo de dignidad humana que es considerada como fuente de los derechos humanos. ${ }^{44}$

La primera referencia al carácter "inherente" de la dignidad humana en el derecho internacional público se encuentra tras la Segunda Guerra Mundial, en el Preámbulo de la Declaración Universal de los Derechos Humanos (1948): "Considerando que el reconocimiento de la dignidad intrínseca y de los derechos equitativos e inalienables de todos los miembros de la familia humana es el fundamento de la libertad, la justicia y la paz en el mundo...".

Unos años después, en 1966, el Preámbulo del Pacto Internacional de Derechos Civiles y Políticos (ICGP) y el Pacto Internacional de Derechos Económicos, Sociales y Culturales (PIDESG) reconoce el carácter inherente de la dignidad humana: “...El reconocimiento de la dignidad intrínseca y los derechos iguales e inalienables de todos los miembros de la familia humana es el fundamento de la libertad, la justicia y la paz en el mundo".

Además, el artículo 10 del ICCP se refiere a la "dignidad intrínseca de la persona humana", ${ }^{45}$ una expresión idéntica a la empleada en 1984 por el Convenio contra la Tortura y Otros Tratos o Penas Crueles, Inhumanos o Degradantes, en la que se afirma que "los derechos humanos derivan de la dignidad inherente de la persona humana". ${ }^{46}$

Así mismo, el Convenio Internacional sobre la Protección de los Derechos de todos los Trabajadores Migratorios y de sus Familiares (1990) proclamó que "los trabajadores migratorios y miembros de sus familias que estén privados de su libertad deben ser tratados humanamente y con el res-

42 Véase http://wrwre.oxforddictionaries.com/es/definicion/ingles/inherent/fecha de consulta: 30 de julio de 2015).

43 Véase http://wrere.ldoceonline.com/dictionary/inherent (fecha de consulta: 30 de julio de 2015).

44 Véase la nota 14.

45 Artículo 10 del ICCP: "Toda persona privada de libertad será tratada humanamente y con el respeto debido a la dignidad inherente de la persona humana".

46 Dos años después, en 1986, la Asamblea General aprobó otro texto como directriz para los nuevos convenios sobre derechos humanos. El texto afirma que los derechos humanos "derivan de la dignidad inherente y el valor de la persona humana". 
Este libro forma parte del acervo de la Biblioteca Jurídica Virtual del Instituto de Investigaciones Jurídicas de la UNAM

peto debido a la dignidad inherente al ser humano y a su identidad cultural" (artículo 17.1).

La Conferencia Mundial de Derechos Humanos celebrada en Viena (14-25 de junio de 1993) redactó la Declaración y Programa de Acción de Viena (12 de julio de 2003), con el siguiente Preámbulo: "Todos los derechos humanos derivan de la dignidad y el valor inherentes a la persona humana".

El preámbulo del Convenio sobre los Derechos de las Personas con Discapacidad (2007) afirma que toda discriminación contra cualquier persona por motivos de discapacidad violaría "la dignidad y el valor inherentes del ser humano". Además, el artículo 3o. establece el "respeto de la dignidad inherente" como uno de los principios básicos del Convenio.

La UNESCO ha aprobado varias declaraciones relativas a los derechos humanos, también en el ámbito de la bioética, en las que la dignidad humana es considerada como el principio básico. En ese sentido, el artículo 1o. de la Declaración Universal sobre el Genoma Humano y los Derechos Humanos dispone que "[el] genoma humano es la base de la unidad fundamental de todos los miembros de la familia humana y del reconocimiento de su dignidad y diversidad intrínsecas".

Hay también textos regionales que mencionan el carácter inherente de la dignidad humana. En Europa, en el marco de las reformas a la Convención Europea para la Protección de Derechos Humanos y de las Libertades Fundamentales (1950), gracias a las cuales la pena de muerte fue suprimida (1983 y 2002) ${ }^{47}$ el Preámbulo de las reformas declara que la derogación de la pena de muerte es esencial "para el reconocimiento pleno de la dignidad inherente de todos los seres humanos". ${ }^{48}$ En 2009, el Consejo de la Unión Europea emitió las Directrices de los Derechos Humanos y el Derecho Internacional Humanitario, declarando que la

[p]romoción y protección de los derechos del niño es una prioridad de la política de derechos humanos de la UE. La Unión Europea (UE) considera que es de importancia crítica abordar el tema de los niños y los conflictos armados, no sólo porque los niños están sufriendo en la actualidad y conformarán el futuro, sino porque tienen derechos inherentes e inalienables, como se establece en la

47 Protocolo núm. 6 relativo a la abolición de la pena de muerte: 28 de abril de 1983; entrada en vigor: 1o. de marzo de 1985; Protocolo núm. 6 relativo a la abolición de la pena de muerte en cualquier circunstancia: 3 de mayo de 2002; entrada en vigor: 1o. de julio de 2003).

48 Protocolo núm. 13 a la Convención para la Protección de los Derechos Humanos y de las Libertades Fundamentales relativo a la abolición de la pena de muerte en todas las circunstancias (Vilnius, 3 de mayo de 2002), Preámbulo. 
Este libro forma parte del acervo de la Biblioteca Jurídica Virtual del Instituto de Investigaciones Jurídicas de la UNAM

Convención sobre los Derechos del Niño, sus Protocolos Facultativos y demás instrumentos internacionales y regionales de derechos humanos. ${ }^{49}$

En el ámbito americano, el artículo 2o. de la Convención Americana sobre Derechos Humanos (aprobada en 1969 por la Organización de los Estados Americanos - la OEA-, en vigor desde 1978), declara que "[t]oda persona privada de libertad será tratada con el respeto debido a la dignidad inherente al ser humano". El Preámbulo de la Convención Internacional sobre la Prevención, Castigo y Extirpación de Violencia contra Mujeres (1994), establece que toda mujer tiene los "derechos a ser respetada en la dignidad inherente de su persona y protegida su familia".

En África, la Carta Africana sobre los Derechos Humanos y de los Pueblos (1986; redactada por la Organización de la Unidad Africana, OUA), se refiere al carácter inherente de la dignidad humana en dos artículos. El artículo 5o. estipula que "cada individuo tendrá el derecho al respeto de la dignidad inherente en un ser humano y al reconocimiento de su personalidad jurídica". En el artículo 3o. de uno de los protocolos que agregaron derechos a la carta, más concretamente, en uno relativo a los derechos de la mujer en África, afirma que "[t]oda mujer tiene derecho a la dignidad inherente al ser humano y al reconocimiento y a la protección de sus derechos humanos y jurídicos". Tan sólo la Liga Árabe y la Organización de Cooperación Islámica han optado por no emplear el adjetivo "inherente" al referirse a la dignidad humana.

\section{LOS PREGEDENTES HISTÓRICOS DE LA NOGIÓN DE DIGNIDAD HUMANA (DEL SIGLO XIX AL SIGLO XVI)}

\section{La ausencia de la expresión "dignidad humana" en los primeros textos constitucionales modernos}

¿Cuál fue el precedente de la noción jurídica de "dignidad humana" recogida en las diversas declaraciones - sobre todo, las de derechos-y demás textos constitucionales nacionales tras la Segunda Guerra Mundial?

Las primeras declaraciones del constitucionalismo moderno no contenían referencia alguna a la dignidad humana. En efecto, la expresión "dignidad" o "dignidad humana" no se encuentra en la Declaración de Virginia

49 Algunos derechos son inherentes a los individuos porque provienen simple y llanamente de su condición humana, es decir, porque poseen una dignidad humana natural. 
Este libro forma parte del acervo de la Biblioteca Jurídica Virtual del Instituto de Investigaciones Jurídicas de la UNAM

(1776), ni en la Declaración de Independencia norteamericana (1776), ni en la Declaración de Derechos del Hombre y del Ciudadano (1789). Tampoco cabe encontrarla en las diversas constituciones modernas que, aprobadas las primeras - en particular, la francesa y la norteamericana - a finales del siglo XVIII, fueron promulgándose a lo largo del siglo XIX, tanto en la tradición continental (Europa y América Latina) como en la anglosajona (Reino Unido, Estado Unidos, Canadá, Australia, Nueva Zelanda, etcétera).

Para los textos del Constitucionalismo moderno, eran los derechos $-\mathrm{y}$ no la dignidad humana - el elemento fundamental para establecer límites al poder político. De ahí el contenido del artículo 16 de la Declaración de Derechos del Hombre y del Ciudadano (1789): "Una sociedad en la que la garantía de los derechos no está asegurada, ni la separación de poderes determinada, no tiene Constitución".

Actualmente, este precepto resultaría inconcebible sin añadir la dignidad humana ("Una sociedad en la que la dignidad humana no está reconocida, la garantía de los derechos no está asegurada...”). Pero la expresión "dignidad humana" — no la idea - resultaba innecesaria para aquellos que redactaron las primeras declaraciones y textos constitucionales modernos. Se daba, sencillamente, por supuesta. Si los derechos derivaban de la dignidad del ser humano, el reconocimiento y protección de éstos llevaba consigo el respeto a la dignidad humana. Si el reconocimiento de los derechos constituía el más poderoso y genuino modo de limitar el poder del Estado, no hacía falta recurrir a la dignidad de todo ser humano.

En efecto, las Constituciones liberales surgidas en Occidente tras la Declaración de Independencia norteamericana y la Revolución francesa marcaron unos límites claros al poder político tras los abusos propios de los regímenes políticos absolutistas del Antiguo Régimen. ${ }^{50}$ El paso del absolutismo monárquico a un sistema liberal constitucional supuso, precisamente, el reconocimiento de la existencia de unos derechos fundamentales - $\mathrm{O}$ humanos - que correspondían a todo individuo (dignidad natural) y cuya protección, al constituir la razón de ser del poder político, legitimaba la existencia del Estado. Así lo expresó el artículo I de la Declaración de Derechos de Virginia (1776):

50 En esta línea, véase Masferrer, Aniceto y Obarrio, Juan Alfredo, “The State Power and the Limits of the Principle of Sovereignty: An Historical Approach", en Masferrer, A. (ed.), Post $9 / 11$ and the State Of Permanent Legal Emergency, Dordrecht-Heidelberg-Nueva York-Londres, Springer, 2012, pp. 15 y ss.; los mismos autores, "El principio de soberanía: una aproximación histórica a sus límites", Historia y derecho. Estudios dedicados al profesor Santos Coronas, v. II, Universidad de Oviedo-KRK Ediciones, 2014, pp. 965 y ss. 
Este libro forma parte del acervo de la Biblioteca Jurídica Virtual del Instituto de Investigaciones Jurídicas de la UNAM

Que todos los hombres son, por naturaleza, igualmente libres e independientes, y que tienen ciertos derechos inherentes de los que, una vez constituidos en sociedad, no puede en lo sucesivo privarse o desposeerse por ningún pacto; a saber, el goce de la vida y de la libertad, con los medios de adquirir y poseer la propiedad y perseguir y obtener la felicidad y la seguridad.

Como puede apreciarse, el texto no deja lugar a dudas de que tales derechos corresponden a todo ser humano y son, por tanto, "inherentes" al proceder de la misma naturaleza (humana). Tales derechos tenían, en consecuencia, un origen y carácter pre-políticos; de ahí que no pudiera "en lo sucesivo privarse o desposeerse por ningún pacto". Es más, la protección de tales derechos constituía, precisamente, la razón de ser del mismo poder político.

Así lo recogió el texto de la Declaración de Independencia americana (1776). Tras insistir en el carácter inalienable de los derechos, añadió "que para asegurar estos derechos se instituyen los gobiernos entre los hombres, derivando su poder del consentimiento de los gobernados". ${ }^{51}$ Por tanto, es función de los gobiernos, cuyo poder deriva del consentimiento de los gobernados (soberanía del pueblo o nación), el aseguramiento o garantía de tales derechos.

En el contexto francés, la Declaración de los Derechos del Hombre y del Ciudadano (1789) recogía en su mismo Preámbulo su propósito de "exponer, en una declaración solemne, los Derechos naturales, inalienables y sagrados del hombre, con el fin de que esta declaración, presente de manera constante en todos los miembros del cuerpo social, les recuerde permanentemente sus derechos y sus deberes". Tras señalar, en fin, que "los hombres nacen y permanecen libres e iguales en derechos" (artículo 1o.), empleaba una fórmula parecida a las declaraciones norteamericanas de 1776: "El objetivo de toda asociación política es la conservación de los derechos naturales e imprescriptibles del hombre. Estos Derechos son la libertad, la propiedad, la seguridad y la resistencia a la opresión" (artículo 2o.).

El contenido de este precepto es nítido y no da pie a interpretación alguna. No en vano se ha señalado que "el respeto a los derechos naturales se impone objetivamente al pacto social, marcando así sus límites y dándole sentido", habida cuenta de que "la afirmación, la defensa, y la protección de tales derechos... como auténtico prius y fundamento de la sociedad, constituirá el criterio de legitimación de toda convivencia humana, el límite y,

51 Párrafo II del Preámbulo de la Declaración de Independencia de Estados Unidos (4 de julio de 1776). 
Este libro forma parte del acervo de la Biblioteca Jurídica Virtual del Instituto de Investigaciones Jurídicas de la UNAM

al propio tiempo, el sentido del pacto social". ${ }^{52}$ Precisamente porque tales derechos eran declarados naturales e imprescriptibles, la Constitución francesa de 1791, al garantizar varios de los mismos en su Título I, dispuso que "el poder legislativo no podrá hacer leyes que mermen y dificulten el ejercicio de los derechos naturales y civiles consignados en el presente título y garantizados por la Constitución".

En definitiva, los redactores de los primeros textos constitucionales modernos entendieron que, si bien el reconocimiento de la soberanía nacional resultaba un título más que suficiente para la organización del Estado con sus diversos poderes, entendiéndose que éstos habían sido "creados" o constituidos por el pueblo o la nación soberana, no cabía decir lo mismo con respecto a los derechos fundamentales. Éstos no emanaban de la soberanía sino de la naturaleza, por lo que tan solo cabía reconocerlos o declararlos, dejando claro que tales derechos eran naturales, es decir, correspondientes a la naturaleza o inherentes al ser humano y, en cualquier caso, no susceptibles de privación o desposesión merced a pacto alguno.

Las expresiones "derechos naturales" o "derechos inherentes", recogidas en los primeros textos constitucionales modernos, dejan claro el origen y anclaje de los derechos en la naturaleza humana y, en consecuencia, su carácter prepolítico. Para los redactores de estos primeros textos constitucionales así como para los juristas, filósofos o políticos de la época-, introducir una referencia expresa a la "dignidad humana" hubiera resultado vano, superfluo o redundante. De ahí que, aunque no se recogiera la expresión, la noción sí estaba presente - de un modo implícito - como fundamento basilar no visible, al estar, precisamente, soterrado, dando consistencia a todo el edificio constitucional. Este fundamento - la dignidad de todo ser humano-, así como el reconocimiento y protección de sus derechos "naturales" o "inherentes", estaban en la base del constitucionalismo moderno, ${ }^{53}$ confiriendo, al mismo tiempo, la necesaria legitimidad al poder político.

A diferencia del nacionalsocialismo alemán, que entendía que no todo ser humano goza de la misma dignidad ni es merecedor de los mismos derechos, los primeros textos constitucionales modernos partían de la base de

52 Díaz de Tejada, Elías, "Libertad-igualdad en la Declaración de Derechos del Hombre y del Ciudadano de 1789", Filosofia y derecho. Estudios en honor del Profesor Fosé Corts Grau, Valencia, Universidad de Valencia, 1977, t. I, p. 238.

$53 \mathrm{Al}$ respecto, véase Masferrer, Aniceto, "Legislación anti-terrorista, Estado de derecho y derechos fundamentales: una aproximación a los límites del Estado en el constitucionalismo moderno", en Masferrer, A. (ed.), Estado de derecho y derechos fundamentales en la lucha contra el terrorismo. Una aproximación multidisciplinar (histórica, jurídico-comparada, filosófica y económica), Pamplona, Thomson-Aranzadi, 2011, pp. 191 y ss. 
Este libro forma parte del acervo de la Biblioteca Jurídica Virtual del Instituto de Investigaciones Jurídicas de la UNAM

que todo sistema jurídico debe garantizar el respeto de los derechos fundamentales de los individuos, no porque éstos sean inteligentes, estén cualificados o bien dotados, sino por su mera condición humana o, si se prefiere, por su dignidad natural. Desde esta perspectiva, entendieron que si las leyes no reconocieran y respetasen la dignidad natural de todos los individuos en igualdad de condiciones, se produciría un daño grave a las personas, especialmente a las más vulnerables. Las leyes y los Estados perderían toda su legitimidad y las sociedades se derrumbarían.

\section{El resurgimiento e influjo de la doctrina kantiana de dignidad humana}

Se ha visto cómo las declaraciones e instrumentos internacionales recogieron de forma expresa la noción de dignidad humana, cómo ésta pasó a las Constituciones nacionales — siendo la Ley Fundamental de Bonn (1949) la primera-, y a qué se debió el uso de esta expresión tras la Segunda Guerra Mundial. Conviene ahora preguntarse de dónde surgió esa noción de dignidad humana. En otras palabras, ¿cuáles son las raíces históricas y filosóficas de esta noción?

Suele afirmarse que las bases filosóficas de la noción de dignidad humana recogida por los textos jurídicos desde mediados del siglo XX se encuentran en Immanuel Kant. ¿Es cierta esta tesis? ¿Fue Kant el pensador que más influyó en la noción de dignidad humana "constitucionalizada" a partir de 1945? Más en concreto, ¿fue Kant el primero en defender la "dignidad natural" de todo ser humano o en relacionar la dignidad y los derechos con la naturaleza humana?

Mi tesis al respecto podría resumirse como sigue: i) la noción de "dignidad humana" recogida en los textos jurídicos es deudora, en buena medida, de la doctrina kantiana; ii) Kant no fue, sin embargo, el primer pensador que vinculó la dignidad humana y los derechos con la naturaleza humana, sino que recogió el legado de la tradición anterior. De hecho, autores anteriores a Kant emplearon en los siglos XVII y XVIII la expresión "dignidad de la naturaleza humana", y iii) la interpretación que algunos autores hacen de la doctrina kantiana sobre la dignidad humana, presentando la autonomía de la voluntad como ilimitada y la moral como mero ejercicio de la libertad, no hace justicia al pensamiento de este filósofo alemán.

Kant sostuvo, en efecto, que la autonomía era la base de la dignidad humana. Sin embargo, insistió también en la necesidad de "una buena voluntad". No todas las opciones son igualmente buenas, ni reflejan "una buena voluntad". ¿Qué entendía Kant por "buena voluntad”? 
Este libro forma parte del acervo de la Biblioteca Jurídica Virtual del Instituto de Investigaciones Jurídicas de la UNAM

Eso, que ahora conocemos, es una buena voluntad cuya máxima, si llegara a ser universal, no sería repugnante a si misma. Este principio es su ley suprema: "Actuar de acuerdo con esta máxima cuya universalidad, como derecho, puedas al mismo tiempo querer". Esta es la única condición en la que la voluntad nunca puede contradecirse a sí misma; y este imperativo es categórico. Y desde tal voluntad, si se considera como realización de sus máximas, es análogo al uniforme y sistemático orden de sucesos en el sistema físico que llamamos naturaleza, el imperativo categórico puede expresarse así: "Actúa de conformidad con aquellas máximas que puedan ser consideradas como leyes universales de la naturaleza". Éstas son las fórmulas que indican lo que es una buena voluntad absoluta. ${ }^{54}$

Kant reconoció que, junto con "el sistema físico que llamamos naturaleza", existen "leyes universales de la naturaleza" (no físicas). En su opinión, una buena voluntad siempre debería comportarse con arreglo a tales leyes universales de la naturaleza: "Actuar de conformidad con aquellas máximas que puedan ser consideradas como leyes universales de la naturaleza". El conocido principio kantiano según el cual ningún hombre debería ser tratado jamás como medio (sino como fin) hunde sus raíces en la dignidad de la humanidad o naturaleza humana: “...cada ser inteligente, siendo por naturaleza un fin en sí mismo, debería subordinar a este fin las máximas de todos sus fines causales y arbitrarios". 55

La exigencia kantiana de subordinar a este fin - fundado en la naturaleza humana - la máxima de los demás "fines causales y arbitrarios" vino a poner límites a la concepción libertaria o utilitaria de libre albedrío o voluntad autónoma. ${ }^{56}$ No todas las alternativas son buenas. La bondad de los

54 Kant, Immanuel, The Metaphysics of Ethics (1796), Ch. II ('On the a priori spring of the will'), p. 52, disponible en: http://oll.libertyfund.org/titles/1443\#Kant_0332_147. Énfasis añadido.

55 Kant, The Metaphysics of Ethics (1796), Ch. II ('On the a priori spring of the will'), pp. 51 y 52, disponible en: http://oll.libertyfund.org/titles/1443\#Kant_0332_145. Énfasis añadido.

$56 \mathrm{Al}$ respecto, véase Saldaña Serrano, "La dignidad de la persona. Fundamento del derecho a no ser discriminado injustamente", op. cit., pp. 61-64; sobre los aspectos problemáticos de la fundamentación kantiana de dignidad humana, véase Gallego García, Gloria María, "Sobre el concepto y fundamento de la dignidad humana", en Velásquez Velásquez, F. (coord.), Derecho penal liberal y dignidad humana. Libro homenaje al doctor Hernando Londoño Fiménez, Bogotá, Temis, 2005, pp. 245-271, en particular, pp. 253-256; De la Torre Martínez, El derecho a la no discriminación en México, pp. 46-48; para un ejemplo de cómo puede erigirse la voluntad autónoma cuasi-ilimitada en el rasgo característico de la dignidad humana, afirmándose - llevando la tesis kantiana hacia un extremo que el propio Kant difícilmente compartiría - debe reconocerse la dignidad tan sólo a aquellos seres que sean capaces de determinarse a sí mismos, de autolegislarse o proponerse a sí mismos normas de conducta ética, véase Singer, Peter, Practical Ethics, Cambridge, Cambridge University Press, 1993. 
Este libro forma parte del acervo de la Biblioteca Jurídica Virtual del Instituto de Investigaciones Jurídicas de la UNAM

actos morales no proviene simplemente del libre albedrío. ${ }^{57}$ Existen algunas normas que están fundadas en la naturaleza humana, y la autonomía debería moverse dentro de estas "leyes universales de la naturaleza". Así, pues, Kant vinculó autonomía, dignidad humana y naturaleza humana. De este modo, asumió el legado de la filosofía política y del derecho del siglo XVII, que defendía la necesidad de un orden social basado en un orden natural, una nueva sociedad secularizada, sobre la base de un fundamento racional y filosófico (y no teológico o basado en la autoridad del texto bíblico).

Tras la Segunda Guerra Mundial, la doctrina kantiana experimentó un resurgimiento y propició lo que George P. Fletcher denominó como "glorificación de la autonomía". ${ }^{58}$ La autonomía fue empleada para explicar que las personas jamás deberían ser tratadas como medio sino como un fin en sí mismas. Muchas tragedias de la Segunda Guerra Mundial se produjeron por tratar a miles de seres humanos como simples medios y no como fines. Ante este triste episodio de la historia de la humanidad, el pensamiento jurídico kantiano fue empleado para defenderse de la amenaza del utilitarismo que, junto con el instrumentalismo y el consecuencialismo, constituían la base filosófica de una concepción totalmente distinta de la dignidad humana: una dignidad humana relacionada con la autonomía, pero completamente alejada y distante de la naturaleza humana. El utilitarismo y el derecho natural (y los derechos naturales) resultan incompatibles. En esta línea, conviene recordar que mientras Kant mostró un notable respeto por la naturaleza, las leyes de la naturaleza y la ley natural, Jeremy Bentham rechazó por completo estas nociones: “¿Cuáles son estas leyes naturales, que nadie ha hecho, y que todo el mundo supone en su fantasía?". ${ }^{59}$

Mientras Kant relacionó la "naturaleza humana" con un orden moral, basado en las leyes de la naturaleza (no físicas), el utilitarismo de Bentham concebía la "naturaleza humana" desde una perspectiva radicalmente distinta. A diferencia de Kant, Bentham criticó duramente a los estudiosos del

$57 \mathrm{Al}$ respecto, véase el estudio de Starck, Christian, "The Religious and Philosophical Background of Human Dignity and its Place in Modern Constitutions", en Kretzmer, David y Klein, Eckart (eds.), The Concept of Human Dignity in Human Rights Discourse, 2002, p. 181: "Human dignity does not mean unlimited self-determination, but self-determination which is exercised on the basis that everyone - not simply the person claiming the right to selfdetermination - is of value in his or her own right".

58 Expresión tomada de Fletcher, George P., "Human Dignity as a Constitutional Value", 22 U. W. Ontario L. Rev. 171, 1984, p. 171.

59 Bentham, Jeremy, The Works of Feremy Bentham, vol. 3 (Usury, Political Economy, Equity, Parliamentary Reform) [1843], General view of a complete code of laws, Ch. I (disponible en: http://oll.libertyfund.org/titles/1922\#Bentham_0872-03_1307). 
Este libro forma parte del acervo de la Biblioteca Jurídica Virtual del Instituto de Investigaciones Jurídicas de la UNAM

derecho natural - como Grocio y Pufendorf - por fingir ser los legisladores de la raza humana (crítica ciertamente curiosa, pues el mismo Bentham empeñó toda su vida precisamente en este intento). ${ }^{60}$

El resurgimiento de la concepción kantiana de dignidad humana, tras la Segunda Guerra Mundial, perseguía rechazar el enfoque utilitario de los derechos humanos, según el cual la rectitud moral de un acto se mide tan solo por sus consecuencias, o, en otras palabras, que un acto es correcto si va a generar un beneficio en forma de placer o en el bienestar de los afectados. En términos más económicos, cabría decir que un acto es correcto si sus beneficios superan sus costes. Tras la Segunda Guerra Mundial se llegó a la conclusión de que los derechos humanos y la dignidad humana no podían fundarse en meros principios utilitarios, ${ }^{61}$ pese a que algunos autores del siglo XX siguen empeñados en mantener viva esa corriente filosófica. ${ }^{62}$ La tragedia de dos guerras mundiales en apenas medio siglo demostraron el error de Bentham al calificar los derechos naturales como disparates (nonsense upon stilts). ${ }^{63}$

Referirse a los derechos naturales como "sinsentido", o a "los derechos fundamentales" como meras creaciones del Estado que impone sin más legitimidad que la fuerza vinculante de la ley (entendida como simple manda-

60 Bentham, Jeremy, The Works of Jeremy Bentham, vol. 3 (Usury, Political Economy, Equity, Parliamentary Reform) [1843], "Pannomial Fragments", Ch. III: "Expositions", p. 221; disponible en: http://oll.libertyfund.org/titles/1922\#Bentham_0872-03_2411): "Behold the professors of natural law, of which they have dreamed - the legislating Grotii - the legislators of the human race: that which the Alexanders and the Tamerlanes endeavoured to accomplish by traversing a part of the globe, the Grotii and the Puffendorffs would accomplish, each one sitting in his arm chair: that which the conqueror would effect with violence by his sword, the jurisconsult would effect without effort by his pen. Behold the goddess Nature! - the jurisconsult is her priest; his idlest trash is an oracle, and this oracle is a law".

61 Las principales obras de la corriente filosófica utilitarista del siglo XIX pueden encontrarse en Bentham, Jeremy, The Principles of Morals and Legislation (1789); Austin, John, The Province of Jurisprudence Determined (1832); Holmes, Oliver W., The Common Law (Londres, Macmillan \& Co., 1881).

62 La figura más representativa a este respecto es probablemente Richard Posner, Economic Analysis of Law (Boston: Little, Brown and Company, 1972, 1st ed.; 2010, 8th ed.); véase también Iñigo Álvarez Gálvez, Utilitarismo y derechos humanos (Madrid, Plaza y Valdés, 2009).

63 Bentham, Jeremy, "Anarchical Fallacies", in The Works of Jeremy Bentham, vol. 2 (Judicial Procedure, Anarchical Fallacies, works on Taxation) [1843], p. 502, disponible en: http:// oll.libertyfund.org/titles/1921\#Bentham_0872-02_6149: "Natural rights is simple nonsense: natural and imprescriptible rights, rhetorical nonsense,- nonsense upon stilts. But this rhetorical nonsense ends in the old strain of mischievous nonsense: for immediately a list of these pretended natural rights is given, and those are so expressed as to present to view legal rights. And of these rights, whatever they are, there is not, it seems, any one of which any government can, upon any occasion whatever, abrogate the smallest particle". 
Este libro forma parte del acervo de la Biblioteca Jurídica Virtual del Instituto de Investigaciones Jurídicas de la UNAM

to del Estado), parece ser la mejor "legitimación" para conculcar los derechos cuando el Estado los considera como inconvenientes por cualesquiera razones, como muestra la reciente experiencia. ${ }^{64}$

Por el contrario, cuando los derechos fundamentales son reconocidos y protegidos por los Estados y los instrumentos internacionales porque su fuente es pre-política, como son los seres humanos y su dignidad, la amenaza del Estado totalitario disminuye considerablemente. Un fundamento sólido de los derechos humanos no resuelve el peligro de su posible violación, pero ayuda a protegerlos cuando se pretenden conculcar en nombre de un falso "interés público" (como la seguridad nacional) o de unos intereses de índole político o económico. ${ }^{65}$

Kant, en parte consciente de esta necesidad, elaboró su teoría de la dignidad humana. ${ }^{66}$ En efecto, al relacionar la dignidad humana con las leyes de la naturaleza y la naturaleza humana, ${ }^{67}$ recogió el legado de los siglos

64 En la lucha contra el terrorismo, por ejemplo, es evidente que los Estados han ido más allá de lo que cabe suponer como razonable en el marco de una democracia constitucional; al respecto, véase Masferrer, Aniceto (ed.), Post 9/11 and the State of Permanent Legal Emergency: Security and Human Rights in Countering Terrorism (Dordrecht-Heidelberg-LondresNueva York, Springer, 2012; Collection 'Ius Gentium: Comparative Perspectives on Law and Justice'); Masferrer, Aniceto y Walker, Clive (eds.), Counter-Terrorism, Human Rights and the Rule of Law: Crossing Legal Boundaries in Defence of the State, Londres, Edward Elgar Publishing, 2013; Masferrer, Aniceto (ed.), Estado de derecho y derechos fundamentales en la lucha contra el terrorismo. Una aproximación multidisciplinar (histórica, jurídico-comparada, filosófica y económica), Cizur, ThomsonAranzadi, 2011.

65 En este sentido, véase, por ejemplo, Knox, Vicesimus, The Spirit of Despotism (1795), donde el autor describe cómo el despotismo político nacional pueden surgir bajo la excusa de estar luchando en una guerra extranjera.

66 Las principales obras en las que Immanuel Kant desarrolló su concepto de dignidad humana fueron escritas a partir de 1781 (Critique of Pure Reason - Kritik der reinen Vernunft-, 1781, 2a. ed., 1787; Groundwork of the Metaphysics of Morals - Grundlegung zur Metaphysik der Sitten-,1785; Critique of Practical Reason - Kritik der praktischen Vernunft-, 1788; Metaphysics of Morals - Metaphysik der Sitten-, 1797); sin embargo, algunas observaciones sobre la dignidad humana pueden ser encontradas veinte años antes, en sus Observations on the Feeling of the Beautiful and Sublime - Beobachtungen über das Gefühl des Schönen und Erhabenen -, 1764); on Kant's human dignity, véase M. A., Cattaneo, Dignità umana e pena nella filosofia di Kant (Milán, Giuffrè, 1981); Cattaneo,M. A., Dignità unama e pace perpetua: Kant e la critica della politica (Milán, CEDAM, 2002), Shell, S. M., "Kant on Human Dignity", en Kraynak, R. P. y Tinder, G. (eds.), In Defense of Human Dignity, Notre Dame, Indiana, University of Notre Dame Press, 2003.

67 Esto no significa que Kant basara la dignidad humana en la naturaleza humana, como si diera su aprobación a una aproximación escolástica de la dignidad humana. Como se ha dicho - y con razón - "Kant y la noción de derecho natural («natural right») no se basa en una idea de naturaleza humana, sino en la razón y la racionalidad. Que Kant todavía se refiera a ella como «derecho natural» no puede ocultar que es más un derecho de la razón 
Este libro forma parte del acervo de la Biblioteca Jurídica Virtual del Instituto de Investigaciones Jurídicas de la UNAM

XVI y XVII. De hecho, los juristas de este periodo tenían en mente laidea de dignidad humana ${ }^{68}$ pero no llegaron a emplear la expresión "dignidad" de un modo tan asiduo. Fue Kant quien tomó el término de sus precursores, y empezó a utilizarlo frecuentemente. Sin embargo, conviene subrayar que numerosos autores anteriores a Kant ya venían empleando - desde los siglos XVII y XVIII - la expresión "dignidad de la naturaleza humana".

\section{La expresión y noción (pre-kantianas) de "dignidad humana" en los siglos XVII Y XVIII}

Como se ha dicho, las principales obras en las que Immanuel Kant desarrolló su concepto de dignidad humana fueron escritas a partir de 1781.69 Veamos, ahora, qué autores, en qué contexto y en qué sentido emplearon la expresión "dignidad humana" y, más en concreto, la de "dignidad de la naturaleza humana", vinculando "dignidad" y "naturaleza" humanas. Siguiendo el método cronológico retrospectivo, partiremos de algunos autores

que un derecho de la naturaleza. Esta calificación es necesaria. No significa, sin embargo, que aquellas reflexiones sobre la naturaleza humana y la capacidad no tengan ninguna importancia para Kant" (Jörn Reinhardt, "Human Rights, Human Nature, and the Feasibility Issue", en Alber, Marion et al. (eds.), Human Rights and Human Nature, Springer (Ius Gentium: Comparative Perspectives on Law and Justice, vol. 35), 2014, pp. 137-158, p. 145); al respecto, véase también Thornhill, C., "Natural Law, State Formation and the Foundations of Social Theory", fournal of Classical Sociology 13(2), 2013, pp. 197-221; aunque sea verdadero que "con el énfasis sobre los derechos subjetivos, Kant completa un cambio central del derecho subjetivo clásico al moderno, «un cambio de la metafísica del derecho natural a los derechos naturales»" (Haakonsen, K., "German Natural Law", en Goldie, M. y Wokler, R. (eds.), Cambridge History of Eighteenth-Century Political Thought, Cambridge, Cambridge University Press, 2006, p. 280), él no negó las "leyes de la naturaleza" y, de hecho «como se ha dicho», conectó la dignidad humana con las leyes de la naturaleza y la naturaleza humana.

68 A este respecto, véase la obra clásica de Finnis, John, Natural Law and Natural Rights, Oxford, Oxford University Press, 1980; para una perspectiva histórica, véase Gordon Lauren, Paul, "Philosophical Visions: Human Nature, Natural Law, and Natural Rights", The Evolution of International Human Rights: Visions Seen, Philadelphia: University of Pennsylvania Press, 2003; Helmholz, R. H., "Natural Law and Human Rights in English Law: From Bracton to Blackstone", 3 Ave Maria L. Review, 1 2005, pp. 1-22; Tierney, Brian, "Natural Law and Natural Rights", en Witte, J. y Alexander, F. S. (eds.), Christianity and Law: An Introduction, Cambridge, Cambridge University Press, 2008, pp. 89-103; Helmholz, R. H., "Human Rights in the Canon Law", en Witte, J. y Alexander, F. S. (eds.), Christianity and Human Rights: An Introduction, Cambridge, Cambridge University Press, 2010, pp. 99-112.

$69 \mathrm{Al}$ respecto, véase la nota al pie n. 55. 
Este libro forma parte del acervo de la Biblioteca Jurídica Virtual del Instituto de Investigaciones Jurídicas de la UNAM

contemporáneos a Kant, e iremos descendiendo en el tiempo hasta llegar al siglo XVII. ${ }^{70}$

Las fuentes muestran cómo a lo largo del siglo XVIII, y con anterioridad a Kant, numerosos autores (filósofos, políticos, juristas, médicos, etcétera) empleaban tanto la noción como la expresión de dignidad humana.

En Escocia, David Hume (1711-1776) había dedicado un breve ensayo a la dignidad humana ("de la dignidad o la mezquindad de la naturaleza humana"). ${ }^{71} \mathrm{El}$ filósofo escocés sostenía que quienes ofrecen una opinión positiva de la dignidad humana están más cercanos a la verdad que los que defienden la mezquindad de naturaleza humana. ${ }^{72} \mathrm{~A}$ su juicio, pese a que

70 Para una visión más completa de este apartado, pero sin emplear el método retrospectivo que aquí se sigue, véanse mis estudios: "Taking Human Dignity more Humanely: A Historical Contribution to the Ethical Foundations of the Constitutional Democracy", en Masferrer, Aniceto y García-Sánchez, Emilio (eds.), Human Dignity of the Vulnerable in the Age of Rights: Interdisciplinary Perspectives, Dordrecht-Heidelberg-Londres-Nueva York, Springer, 2016, pp. 221-256; “"Dignidad de la naturaleza humana». Los precedentes históricos de la noción jurídica de dignidad humana (siglos XVII-XVIII): un modelo para el presente y el futuro", Pasado, presente y futuro del constitucionalismo mexicano: la Constitución de 1917, tomo VI. Tendencias constitucionales para el siglo XXI, vol. II, Porrúa-Universidad de Anáhuac-Escuela Libre de Derecho, 2017 (en prensa).

71 Hume, David, Essays Moral, Political, Literary (LF ed.) (1777), Essay XI: "Of the Dignity or Meanness of Human Nature", pp. 81-87 (disponible en: http://oll.libertyfund.org/ titles/704\#Hume_0059_199); como señaló Eugene F. Miller en su Prólogo, "la preparación y revisión de sus ensayos ocuparon a Hume durante toda su vida adulta. A los veintimuchos años, después de completar los tres libros del Tratado, Hume comenzó a publicar ensayos sobre temas morales y políticos. Sus Essays, Moral and Political se publicaron a finales de 1741 por Alexander Kincaid, editor principal de Edinburgh". Esta edición incluyó los ensayos siguientes: (1) "De la Delicadeza del Gusto y Pasión"; (2) "De la Libertad de la Prensa"; (3) "De Impudencia y Modestia"; (4) "Qué Políticas pueden ser reducidas a una Ciencia"; (5) "De los Primeros Principios de Gobierno"; (6) "De Amor y Matrimonio"; (7) "Del Estudio de la Historia"; (8) "De la Independencia del Parlamento"; (9) "Si el Gobierno británico se inclina más a la Monarquía Absoluta, o a una República"; (10) "De los Partidos en General"; (11) "De los Partidos de Gran Bretaña"; (12) "De la Superstición y el Entusiasmo"; (13) "De la Avaricia"; (14) "De la Dignidad de Naturaleza Humana"; y (15) "De la libertad y el despotismo". El título del ensayo 14 pasó a titularse "De la dignidad o la mezquindad de la naturaleza humana" en la edición de 1770 de sus Essays and Treatises on Several Subjects (ibidem, nota 5).

72 Hume, Essays Moral, Political, Literary, Essay XI: 'Of the Dignity or Meanness of Human nature', p. 82 (disponible en: http://oll.libertyfund.org/titles/704\#Hume_0059_200): "Sin embargo, soy de la opinión, que los sentimientos de quienes se inclinan a pensar favorablemente sobre humanidad, son más ventajosos para la virtud, que los principios contrarios, que nos dan una opinión mezquina de nuestra naturaleza. Cuando un hombre está predispuesto con un alto concepto de su rango y su carácter en la creación, se esforzará por actuar de forma natural, y despreciará hacer una acción baja o viciosa, que podría hundirlo debajo de aquella figura que él hace en su propia imaginación. En consecuencia encontramos, que 
Este libro forma parte del acervo de la Biblioteca Jurídica Virtual del Instituto de Investigaciones Jurídicas de la UNAM

el hombre en ocasiones "pueda ser conducido a ciegas por el instinto", ${ }^{73} \mathrm{el}$ hombre y los animales tienen naturalezas distintas. Sostenía que quienes "han insistido tanto en el egoísmo del hombre", no han entendido la importancia de la virtud en la vida humana, ${ }^{74}$ al sostener que "la amistad y la virtud no pueden ser desinteresadas", ${ }^{75}$ o que las personas virtuosas persiguen la vanidad, los elogios y "los aplausos de los demás". ${ }^{76}$ Hume llegó a admitir que comportarse de un modo libre y racional es lo más apropiado o "acorde con la dignidad de la naturaleza humana". ${ }^{77}$

Poco antes, el filósofo y político irlandés Edmund Burke (1729-1797) se había referido, en un discurso pronunciado el 22 de marzo de 1775, a "todos los derechos esenciales, y la dignidad intrínseca de la naturaleza humana". ${ }^{78}$

El filósofo inglés John Cartwright (1740-1824), en su obra The Legislative Rights of the Community Vindicated (1777), fundamentó en la "dignidad de la naturaleza humana" la extensión del derecho de sufragio a todos los hombres mayores de edad. Rechazando que la elección de los representantes se hiciera depender del patrimonio o de la propiedad de los individuos, señala que:

...los pobres tienen seguramente tanto interés como los ricos [en ejercer el derecho de sufragio]... Su pobreza es indudablemente la peor de todas las razones que se puedan alegar para despojarles de sus naturales derechos; por el contrario, debemos tratar de reconciliarles con las múltiples durezas de su situación, demostrándoles que ésta no les degrada por debajo del nivel de la naturaleza humana. Ya que no tienen motivos para sentirse orgullosos, que

todos nuestros moralistas corteses y de moda insisten en este asunto, y procuran representar el vicio como indigno del hombre, así como odioso en sí mismo".

73 Hume, Essays Moral, Political, Literary, Essay XI: "Of the Dignity or Meanness of Human nature", p. 83 (disponible en: http://oll.libertyfund.org/titles/704\#Hume_0059_203).

74 Ibidem, p. 86 (disponible en: http://oll.libertyfund.org/titles/704\#Hume_0059_208).

75 Ibidem, pp. 86 y 87 (disponible en: http://oll.libertyfund.org/titles/704\#Hume_0059_208): "En primer lugar, encontraron que cada acto de virtud o amistad iba anejo a un placer secreto; de dónde ellos concluyeron que aquella amistad y virtud no podían ser desinteresadas. Pero el error de esto es obvio. El sentimiento virtuoso o la pasión producen el placer, pero no provienen de él. Siento un placer en hacer el bien a mi amigo, porque lo amo; pero no lo amo por ese placer".

76 Ibidem, p. 89 (disponible en: http://oll.libertyfund.org/titles/704\#Hume_0059_209).

77 Hume, Essays Moral, Political, Literary, Essay XV: "Of the Protestant Succession", p. 509 (disponible en: http://oll.libertyfund.org/titles/704\#Hume_0059_1012).

78 Burke, Edmund, Select Works of Edmund Burke, vol. 1 (Thoughts on the Cause of the Present Discontents; Two Speeches on America) (1770; 2a. ed., 1775), p. 223 (disponible en: http://oll.libertyfund.org/titles/796\#Burke_0005-01_566). 
Este libro forma parte del acervo de la Biblioteca Jurídica Virtual del Instituto de Investigaciones Jurídicas de la UNAM

conserven al menos la dignidad de la naturaleza humana, sabiendo que son libres y que participan en los privilegios que son inseparables de la libertad. ${ }^{79}$

Criticando la postura de John Locke, quien defendía la importancia de la propiedad para poder ejercer el derecho de sufragio, Cartwright afirma que no es la propiedad

...lo que constituye verdaderamente la libertad. No; ésta es sin duda, un don hecho a toda la especie humana por Dios, que añadió la libre voluntad a la racionalidad, con objeto de hacer de los hombres seres responsables de sus actos. Todos son por naturaleza libres e iguales; la libertad implica elección; la igualdad excluye grados de libertad. Por tanto, todos los miembros del Estado Llano tienen igual derecho a votar para elegir a quienes van a ser los guardianes de sus libertades; y nadie puede tener derecho a más de un voto... Mi concepto de la verdad me obliga a creer que la personalidad es el único fundamento del derecho a estar representado; y que la propiedad no tiene, en realidad, nada que hacer con este problema... ${ }^{80}$

El segundo presidente norteamericano, John Adams (1735-1826), había recurrido a la expresión "dignidad de la naturaleza humana" en sus obras. En sus Reflexiones sobre el Gobierno, sostuvo que "la felicidad de la humanidad, así como la verdadera dignidad de naturaleza humana, consiste en la virtud". ${ }^{81}$

79 Cartwright, John, The Legislative Rights of the Community Vindicated, I, 35. (ed. 1777, pp. 28, 30; texto recogido en Carlyle, A. J., La libertad política, México, Fondo de Cultura Económica, 1942, p. 254; de la edición original Political Liberty: A History of the Conception of Middle Ages and Modern Times, Oxford University Press, 1941).

80 Ibidem, secs. 39, 41, 42 (pp. 31-32; recogido en Carlyle, La libertad política, cit., pp. 254 y 255); sobre la condición humana como ser libre y la consiguiente necesidad de ejercitar velis nolis - esa libertad, véase Ortega y Gasset, José, Obras completas, Madrid, Alianza-Revista de Occidente, 1987, t. 4, p. 171; recogido en Arriola, Juan Federico, La libertad, la autoridady el poder en el pensamiento filosófico de José Ortega y Gasset, México, UNAM, 2003, p. 57: "Vivir es sentirse fatalmente forzado a ejercitar la libertad, a decidir lo que vamos a ser en este mundo. Ni un solo instante se deja descansar a nuestra actividad de decisión. Inclusive cuando desesperados nos abandonamos a lo que quiera venir, hemos decidido no decidir. Es, pues, falso decir que en la vida «deciden las circunstancias». Al contrario, las circunstancias son el dilema, siempre nuevo, ante el cual tenemos que decidirnos. Pero el que decide es nuestro carácter".

81 Adams, John, The Works of Fohn Adams, vol. 4, Novanglus, Thoughts on Government, Defence of the Constitution) [1851], p. 205 (disponible en: http://oll.libertyfund.org/titles/2102\# Adams_1431-04_591): "Todos los investigadores moderados que buscan la verdad, antiguos y modernos, teólogos, moralistas y filósofos, han coincidido en que la felicidad de la humanidad, así como la verdadera dignidad de naturaleza humana, consiste en la virtud; si hay una forma de gobierno cuyo principio y fundamento es la virtud, ¿no reconocerá cualquier sabio que es más probable que promueva la felicidad general que cualquier otro?”. 
Este libro forma parte del acervo de la Biblioteca Jurídica Virtual del Instituto de Investigaciones Jurídicas de la UNAM

Adams parecía estar convencido - como escribió en una carta al Senadode qué "Virtudes, dones, talentos y logros, que constituyen la dignidad de la naturaleza humana, y sentó las bases para la prosperidad o duración de los imperios". ${ }^{82}$ También él relacionó la "dignidad de la naturaleza humana" con la afirmación de que los derechos "derivan sólo de la naturaleza y del autor de la naturaleza; que son inherentes, inalienables, e irrevocables por cualesquiera leyes, pactos, contratos, convenciones o estipulaciones, que el hombre pudiera concebir". ${ }^{83}$ También recurrió a la "dignidad de la naturaleza humana" para enaltecer la sabiduría y la humanidad del derecho inglés pocos años antes de la independencia norteamericana. En efecto, en sus Escritos revolucionarios (1763), señaló que el common law de Inglaterra, a diferencia de otras tradiciones jurídicas (como la española y la francesa), se caracterizaba por tener en alta estima "la libertad, el carácter inalienable e imprescriptible de los derechos de los hombres, el honor y la dignidad de la naturaleza humana". ${ }^{84}$ Afirmó, además, que el sistema de gobierno inglés "era más conforme con la dignidad de la naturaleza humana, que cualquiera... en Europa". ${ }^{85}$

Henry Home, Lord Kames (1696-1782), uno de los líderes de la Ilustración escocesa y juez en los tribunales supremos de Escocia, también escribió sobre la dignidad humana con anterioridad a Kant. En sus Elementos de la crítica (1762), capítulo IX ("Dignidad y gracia"), señaló que la expresión "dignidad de la naturaleza humana" poseía diversos significados y existían distintos niveles de "dignidad". ${ }^{86}$ Afirmó que las expresiones "dignidad" y "mezquindad" "deben pertenecer a los seres sensibles, probablemente al hombre solamente". ${ }^{87}$ Además, tras subrayar que "nunca atribuimos dignidad a cualquier acción, sino a lo que es virtuoso" 88 y que "cada acción

82 Adams, John, The Works of Fohn Adams, vol. 9 (Letters and State Papers 1799-1811) (1854), p. 149 (disponible en: http://oll.libertyfund.org/titles/2107\#Adams_1431-09_430).

83 Adams, John, The Works of John Adams, vol. 10 (Letters 1811-1825, Indexes) (1854), pp. 316-317 (disponible en: http://oll.libertyfund.org/titles/2127\#Adams_1431-10_1058).

84 Adams, John, Revolutionary Writings (1763), p. 15 (disponible en: http://oll.libertyfund.org/ titles/592\#Adams_0284_82).

85 Adams, John, Revolutionary Writings (1763), p. 26 (disponible en: http://oll.libertyfund.org/ titles/592\#Adams_0284_103).

86 Henry Home, Lord Kames, Elements of Criticism (1762), vol. 1, Chap. XI: 'Dignity and Grace', p. 246 (disponible en: http://oll.libertyfund.org/titles/1430\#Home_1252-01_641).

87 Lord Kames, Elements of Criticism, vol. 1, Chap. XI, p. 246 (disponible en: http://oll. libertyfund.org/titles/1430\#Home_1252-01_642).

88 Lord Kames, Elements of Criticism, vol. 1, Chap. XI, p. 247 (disponible en: http://oll. libertyfund.org/titles/1430\#Home_1252-01_643). 
Este libro forma parte del acervo de la Biblioteca Jurídica Virtual del Instituto de Investigaciones Jurídicas de la UNAM

de dignidad crea respeto y estima al autor", ${ }^{99}$ sostenía que "la dignidad y la mezquindad se fundan en un principio natural", lo cual significa que "el hombre está dotado con un SENTIDO de la dignidad y la excelencia de su naturale$z a$ : se considera más perfecta que la de los otros seres de su alrededor, y percibe que la perfección de su naturaleza consiste en la virtud, especialmente en las virtudes de más alto rango". ${ }^{90}$ De este modo, este ilustre escocés relacionaba la dignidad humana con la virtud y la naturaleza humana. En su opinión, la perfección del hombre consiste en la virtud. ${ }^{91}$

Thomas Gordon (1692-1750) fue un liberal radical que defendió, a principios del siglo XVIII, el constitucionalismo y la libertad del individuo contra la corrupción política, el imperialismo y el militarismo. Se refirió a la "Dignidad de la naturaleza humana, y la Superioridad que Dios omnipotente otorgó al hombre sobre otros seres", pese a la debilidad e imperfección del hombre, "para hacerle consciente de su mortalidad, hacerle humilde en su orgullo, y excitar su diligencia". ${ }^{92}$ Según este pensador, el hombre debería oponerse a todo lo que fuera "una Afrenta al sentido común, y por debajo de la Dignidad de la Naturaleza Humana" y esto puede hacerse porque nosotros [los seres humanos] gozamos de la Libertad o del Conocimiento". ${ }^{93}$

Unos años antes, el médico holandés Bernard Mandeville (1670-1733), en su obra más famosa, titulada La Fábula de las abejas o Vicios privados, Beneficios Públicos (1714), ${ }^{94}$ se había referido a la "Excelencia de nuestra naturaleza por encima de otros animales", aunque reconoció que la naturaleza humana presenta "fuerzas y debilidades". ${ }^{55} \mathrm{Al}$ tratar de los seres humanos, afirmó

89 Idem.

90 Lord Kames, Elements of Criticism, vol. 1, Chap. XI, p. 247 (disponible en: http://oll. libertyfund.org/titles/1430\#Home_1252-01_644).

91 Y añadía: "Para expresar ese sentido, el termino dignidad es apropiado. Además, comportarse con dignidad, y abstenerse de todas las malas acciones, se considera no sólo una virtud, sino un deber: es un deber que cada hombre se debe a sí mismo. Al actuar de esa manera, él atrae amor y estima: actuando maliciosamente, o por debajo de él, es desaprobado y despreciado" (idem).

92 Gordon, Thomas, The Independent Whig (1720; 7a. ed. 1743), vol. 2, pp. 210 y 211 (disponible en: http://oll.libertyfund.org/titles/2382\#Gordon_1563-02_299).

93 Ibidem, vol. 1, pp. 280 y 281 (disponible en: http://oll.libertyfund.org/titles/2380\#Gord on_1563-01_655).

94 Mandeville, Bernard, The Fable of the Bees or Private Vices, Publick Benefits, 2 vols., 1732; disponible en: http://oll.libertyfund.org/titles/mandeville-the-fable-of-the-bees-or-private-vices-publickbenefits-2-vols); esta obra fue editada en más de media docena de veces y se convirtió en una de las más polémicas obras del siglo XVIII por sus afirmaciones acerca de los fundamentos morales de la sociedad comercial moderna.

95 Mandeville, Bernard, The Fable of the Bees or Private Vices, Publick Benefits, vol. 1, pp. 43 y 44 (disponible en: http://oll.libertyfund.org/titles/846\#Mandeville_0014-01_340). 
Este libro forma parte del acervo de la Biblioteca Jurídica Virtual del Instituto de Investigaciones Jurídicas de la UNAM

"cómo era impropia de la dignidad de estas criaturas sublimes ser solícitos en la gratificación de los apetitos que tienen en común con las bestias". ${ }^{96}$ Más adelante, señaló que el hombre, a diferencia de las bestias,

estableciendo su verdadero valor sobre ellos, no tomó ningún placer, sino en adornar aquella Parte en la cual consistía su Excelencia; como menospreciando lo que tuvieran en común con las criaturas irracionales, se opuso con la Ayuda de la Razón a sus más violentas inclinaciones; y haciendo una continua Guerra con ellos mismos para promover la Paz para los demás, procurando nada menos que el bienestar público y la conquista de su pasión. ${ }^{97}$

Tampoco estos autores del siglo XVIII, anteriores a Kant, fueron los primeros en utilizar tanto la noción como la expresión de "dignidad humana". Como es sabido, los juristas del siglo anterior ejercieron un notable influjo sobre la filosofía jurídica y la doctrina jurídica del XVIII. Las nociones de "derechos naturales" (o derechos del hombre) y "naturaleza humana" ocuparon un lugar central en el pensamiento jurídico del siglo XVII. Junto con Hugo Grocio y Pufendorf, pensadores como Thomasius ${ }^{98}$ y Wolff, ${ }^{99}$ entre otros, relacionaron las nociones de "derechos naturales" y "naturaleza humana", y éstos con la idea de "dignidad humana". En este sentido, la expresión "dignidad de la naturaleza humana" aparece con frecuencia en las fuentes doctrinales del siglo XVII. De ahí que no pocos pensadores del siglo XVIII utilizaron, como se ha visto, la expresión "dignidad de la naturaleza

96 Ibidem, p. 44.

97 Ibidem, pp. 43 y 44 (disponible en: http://oll.libertyfund.org/titles/846\#Mandeville_001401_341): "Para introducir, además, una emulación entre los hombres, que divide toda la especie en dos clases, muy diferentes una de la otra: Uno consistía en la más abyecta, gente de miras cortas, que siempre van tras el goce inmediato, eran totalmente incapaces para la abnegación, y sin tener en cuenta el bien de los demás, no tenía más objetivo que su ventaja privada; como esclavizados por las voluptuosidades, rendidos sin resistencia a cada deseo bruto, y no haciendo uso de sus facultades racionales, sino para aumentar el placer sensual. Estos viles serviles desgraciados, dijeron, fueron las escorias de su tipo, y teniendo [44] sólo la forma de hombres, no difieren de las bestias en nada más que en su figura externa. Pero la otra clase se compone de nobles criaturas de alto espíritu, que libres de egoísmo sórdido, apreciaron las mejoras de la mente como sus posesiones más justas; y poniendo un valor verdadero sobre sí mismos, no tomó ningún placer más que el de embellecer la parte en la que su Excelencia consistió; como menospreciando lo que tuvieran en común con las criaturas irracionales, oponiéndose con la ayuda de la razón a sus inclinaciones más violentas; y haciendo una guerra constante con ellos para promover la paz de otros, enfocados en nada menos que el bienestar público y la conquista de su propia pasión".

98 Thomasius, Christian, Fundamenta juris naturae et gentium (1705); véanse también sus Institutiones iurisprudentiae divinae (1688).

99 Wolff, Christian, Fus naturae and Fus Gentium (1740-1749). 
Este libro forma parte del acervo de la Biblioteca Jurídica Virtual del Instituto de Investigaciones Jurídicas de la UNAM

humana", sin recoger una definición ni una explicación del término, como si éste se diera por supuesto. Como se acaba de ver, los autores utilizaron la expresión de un modo positivo, salvo raras excepciones. ${ }^{100}$ Algunos enaltecieron tanto la naturaleza divina como la humana. ${ }^{101}$ Sin embargo, la mayoría de autores relacionaron la "dignidad de la naturaleza humana" con la dignidad moral de los seres humanos, es decir, con la virtud, no para sostener tan solo la dignidad de las personas virtuosas, sino para subrayar que la práctica de la virtud era el comportamiento más acorde con la "dignidad de la naturaleza humana", vista como fuente de exigencia (o del deber moral), obligando a actuar en consecuencia y de llevar una vida virtuosa. En otras palabras, "la dignidad natural de la naturaleza humana" constituía una llamada a la excelencia moral, ${ }^{102}$ y constituía la fuente de los "derechos y privilegios inalienables comunes de la humanidad". ${ }^{103}$ Sin embargo, a los autores no se les escapaba que, pese a esa "dignidad de la naturaleza humana", el hombre podía denigrar su razón, ${ }^{104}$ y degradarse a sí mismo con la búsqueda de placeres sensuales o haciendo caso omiso de los dictados de su propia conciencia. ${ }^{105}$

Los juristas del siglo XVII ya utilizaron la expresión "dignidad", aunque con menor asiduidad que en el siglo XVIII. Samuel Pufendorf fue el único que usó la expresión "dignidad humana" con mayor frecuencia, si-

100 John Trenchard (England, 1662-1723) sería una de estas excepciones. Además de afirmar que muchos autores utilizan la expresión sin comprenderla, dio una visión bastante negativa respecto a la 'dignidad' de la naturaleza humana; Trenchard, John, Cato's Letters, vol. 2 June 24, 1721 to March 3, 1722 (LF ed.) (1724), Letter n. 40, Saturday, August 5, 1721 : Considerations on the restless and selfish Spirit of Man, Gordon; disponible en: http://oll.libertyfund.org/ titles/1238\#Trenchard_0226-02_115-116).

101 Véase, por ejemplo, Ashley Cooper, Anthony, Earl of Shaftesbury (England, 16711713), Characteristics of Men, Manners, Opinions, Times, vol. 2 (1737), Part III, section I, p. 195 (disponible en: http://oll.libertyfund.org/titles/812\#Shaftesbury_6666_573).

102 Turnbull, George (Scotland, 1699-1748), The Principles of Moral and Christian Philosophy, vol. 1: The Principles of Moral Philosophy (1740), pp. 13 y 14 (disponible en: http://oll.libertyfund.org/titles/1342\#Turnbull_0968-01_102).

103 Turnbull, The Principles of Moral and Christian Philosophy, vol. 2: The Principles of Moral Philosophy (1740), p. 700 (disponible en: http://oll.libertyfund.org/titles/1822\#Turnbull_096802_590).

104 Ibidem, p. 611 (disponible en: http://oll.libertyfund.org/titles/1822\#Turnbull_096802_469).

105 Ibidem, p. 705 (disponible en: http://oll.libertyfund.org/titles/1822\#Turnbull_0968-02_ 592); véase también George Turnbull, Observations upon Liberal Education, in All its Branches (1742), p. 108 (disponible en: http://oll.libertyfund.org/titles/892\#Turnbull_0478_343). 
Este libro forma parte del acervo de la Biblioteca Jurídica Virtual del Instituto de Investigaciones Jurídicas de la UNAM

tuando esta noción en el centro de la doctrina iusnaturalista. ${ }^{106}$ Sin embargo, tampoco fue él el primero, como se verá.

Samuel von Pufendorf (1632-1694) utilizó la expresión "dignidad", "dignidad del hombre" o - como Grocio, unos años antes - "dignidad de la naturaleza humana" con mayor frecuencia. ${ }^{107} \mathrm{Al}$ analizar - en su Elementorum jurisprudentiae universalis libri duo (1660)—108 el principio según el cual un hombre está destinado por naturaleza a vivir en sociedad, Pufendorf sostuvo que no hay seres vivientes que tengan mayor necesidad de la sociedad que los seres humanos. Tras afirmar que "[n]ada es más sombrío para un hombre que la soledad perpetua", el jurista alemán describió los distintos modos por los cuales los hombres y los animales logran el necesario alimento para sí mismos, si bien reconocía que "la capacidad de obtener el alimento para el estómago es sólo una parte muy pequeña [o de escaso valor] en el merecimiento de la dignidad del llamado hombre". ${ }^{109}$

Según el parecer de Pufendorf, la razón dicta que un hombre debe cuidar de sí mismo, de modo que la sociedad humana no se vea abocada al desorden. ${ }^{110}$ Es ese dictado de la razón lo que permite llegar al conocimiento de la ley de la naturaleza, ${ }^{111}$ y de ahí surge la obligación de comportarse en conformidad con él. ${ }^{112}$ Tras fundar la obligación de seguir las leyes de la naturaleza - o el dictado de la razón - en la autoridad (o voluntad) del Creador ("voluntarismo"), ${ }^{113}$ sostenía que las leyes fundamentales de la na-

106 Welzel, H., Introducción a la filosofia del derecho, trad. de F. González Vicén, Madrid, Aguilar, 1971, p. 146, nota 113.

$107 \mathrm{Al}$ respecto, véase el estudio de Saastamoinen, K., "Pufendorf on Natural Equality, Human Dignity and Self-Esteeem”, Fournal of the History of Ideas, núm. 71, 2010, pp. 39 y ss.

108 Utilizamos una edición inglesa: Pufendorf, Samuel, Two Books of the Elements of Universal Furisprudence, trad. de William Abbott Oldfather, 1931 (revisado por Thomas Behme; editado con una introducción de Thomas Behme) (Oxford, Clarendon Press; Londres, H. Milford, 1931; disponible en: http://oll.libertyfund.org/titles/pufendorf-two-books-of-the-elements-ofuniversal-jurisprudence).

109 Pufendorf, Two Books of the Elements of Universal Furisprudence, Observation III: "A man is destined by nature to lead a social life with men", p. 235 (disponible en: http://oll.libertyfund. org/titles/2220\#lf1495_label_837). Énfasis añadido.

110 Pufendorf, Two Books of the Elements of Universal Furisprudence, Observation IV: "La razón dicta que un hombre debe cuidar de sí mismo, de tal manera que la sociedad humana no sea llevada al desorden", pp. 240 y ss.

111 Pufendorf, Two Books of the Elements of Universal furisprudence, Observation IV, pp. 240241 (disponible en: http://oll.libertyfund.org/titles/2220\#lf1495_label_854).

112 Ibidem, pp. 241 y 242 (disponible en: http://oll.libertyfund.org/titles/2220\#lf1495_label_855).

113 Ibidem, pp. 242 y 243 (disponible en: http://oll.libertyfund.org/titles/2220\#lf1495_label_856). 
Este libro forma parte del acervo de la Biblioteca Jurídica Virtual del Instituto de Investigaciones Jurídicas de la UNAM

turaleza, así como las demás que de éstas emanan, se reducen a dos: la autopreservación y no molestar a la sociedad humana. ${ }^{114}$

En este contexto, Pufendorf hizo una referencia explícita a la "dignidad de la naturaleza humana" al analizar la primera ley de la naturaleza, en relación con la autopreservación. A su juicio, una de las consecuencias era que "cada uno debe omitir todo aquello que pueda debilitar tanto el uso de la razón como dañar o perjudicar el cuerpo". ${ }^{115}$ Defendió que la ley natural "ordena a los miembros de la sociedad la protección de sí mismos, procurar no ser una carga para ellos mismos ni para la sociedad". ${ }^{116}$ En definitiva, "a partir de esa ley emanan los preceptos de la ley de la naturaleza respecto a cómo lidiar con las emociones y ponerlas bajo el mando [imperio] de la razón, ya que éstas nos impiden formar un juicio correcto sobre las cosas, y con frecuencia nos conducen a lo que resulta dañino, tanto a nosotros como a los demás". 117 Uno de los ámbitos que, según Pufendorf, debería estar regulado por las leyes positivas es el pudor (o sentimiento de vergüenza) con respecto a los actos del matrimonio. Era, a su juicio, una exigencia de "la dignidad del hombre":

Por lo demás, aunque fue una exigencia de la dignidad del hombre no ser procreado como los animales mediante relaciones sexuales no reguladas, el decoro del orden en los estados contribuye notablemente al fortalecimiento de la cohabitación de hombres y mujeres, con la escrupulosa observancia de un pacto; aun así parece ciertamente extraño, que, entre las naciones más civilizadas, al menos, el pudor más sensible considera tanto a los miembros destinados a la procreación, como a los actos de procreación en sí mismos, si bien el pudor no parece surgir de deformidad natural alguna de los miembros o de una forma absurda; y el acto es en sí mismo conforme a la naturaleza, y totalmente necesario para la preservación de la especie humana, y adecuado para la generación de un ser de tal dignidad. ${ }^{118}$

114 Ibidem, p. 243 (disponible en: http://oll.libertyfund.org/titles/2220\#lf1495_label_857): (1) Que cualquiera debe proteger su propia vida y extremidades, lo más posible y salvarse a sí mismo y lo que es suyo. (2) Que no debería molestar a la sociedad humana, o, en otras palabras, que no debería hacer nada que pueda hacer la sociedad entre los hombres menos tranquila. Estas leyes deberían conspirar, y por así decirlo, entrelazarse una con la otra, como fundirse, por así decirlo, en una ley, a saber: Que cada uno debia ser celoso para preservarse a sí mismo, que la sociedad entre los hombres no sea perturbada".

115 Pufendorf, Two Books of the Elements of Universal furisprudence, Observation IV, pp. $247-$ 248 (disponible en: http://oll.libertyfund.org/titles/2220\#lf1495_label_861).

116 Ibidem, p. 247.

117 Idem.

118 Pufendorf, Two books of the Elements of Universal Furisprudence, Observation V, 5: 'Of [the feeling of] shame regarding the acts of matrimony', p. 279 (disponible en: http://oll. liberty fund.org/titles/2220\#Pufendorf_1495_465). 
Este libro forma parte del acervo de la Biblioteca Jurídica Virtual del Instituto de Investigaciones Jurídicas de la UNAM

Nuestro jurista sajón tenía pleno convencimiento de que las leyes de la naturaleza debían seguirse con el fin de lograr el necesario orden social, un orden social conforme a un orden natural que podía ser captado por la recta razón. De ahí que concediera tanta importancia a las leyes de la naturaleza. Defendió que las leyes positivas eran necesarias para garantizar el respeto a las leyes de la naturaleza. E incluso el derecho positivo, proveniente de la libre decisión del soberano (o legislador), debía conformarse "con un definido status [o condición] de los hombres". ${ }^{119}$ En resumen, debían respetar y estar conformes con la naturaleza humana o - empleando la expresión de Pufendorf - con la "dignidad de la naturaleza humana".

Algunos años después desarrolló - en su De iure naturae et gentium (1672) - ${ }^{120}$ su noción de dignidad humana. ${ }^{121}$ Su enfoque voluntarista de la moral y la ética le llevó a destacar el papel de la libertad, tanto en la naturaleza humana como en la dignidad humana. Distinguió entre los seres físicos (entia physica) y los seres morales (entia moralia). Respecto a estos últimos, siguió a Aristóteles al afirmar que todas las realidades del universo tienen sus propias características y principios esenciales, provenientes del Creador. Cada uno de ellos presenta propiedades que emanan de su sustancia y sus capacidades (o virtudes). ${ }^{122}$ Sostenía que el hombre, a diferencia de otros seres vivos, era el único cuya conducta/operación depende de su libre voluntad, en vez de estar sometidos al yugo de la naturaleza. Subrayó la importancia de la razón - como excelente luz que permite conocer las cosas, juzgar, tomar decisiones, etcétera - y de la voluntad. Ambas — razón y voluntad - distinguen al hombre de las bestias. De ahí que los hombres - a diferencia de las bestias (o animales irracionales) - no quedaron sometidos a comportamientos uniformes y automatizados. Los hombres eran - a diferencia de las bestias - seres morales (entia moralia).

Tras comparar la superioridad física del hombre sobre los animales, $\mathrm{Pu}$ fendorf destacó un rasgo característico de los seres humanos, a saber, el perfecto orden interior que refleja la unidad de la razón y de la voluntad. La razón era la luz sin la cual la voluntad no podría llevar a cabo su cometido. ${ }^{123}$

119 Idem.

120 Utilizo aquí una versión francesa: Pufendorf, Samuel von, Le droit de la nature et des gens (transl. by J. Barbeyrac; ed. by J. R. Thourneisen) (Bâle, 1732; reed. by the Centre de philosophie politique et juridique de l'Université de Caen: "Bibliothèque de philosophie politique et juridique", Caen, 1987).

121 Para una panorámica exhaustiva a este respecto, véase el estudio de Pelé, Filosofía e historia en el fundamento de la dignidad humana, pp. 839 y ss.

122 Pufendorf, Le droit de la nature et des gens, Préliminaires, § II, p. 2.

123 Ibidem, L. I, Chap. III, § I \& III, pp. 38 y 39. 
Este libro forma parte del acervo de la Biblioteca Jurídica Virtual del Instituto de Investigaciones Jurídicas de la UNAM

El libre albedrío también jugaba un papel importante porque gracias a él los hombres tenían la capacidad de desarrollar su primitiva naturaleza (biológica). De este modo, los hombres podían ser protagonistas de su plena realización como seres humanos. ${ }^{124}$ La naturaleza humana empuja permanentemente al hombre hacia su perfección, ${ }^{125}$ tendencia que no se produce de un modo automático - como los entia physica - sino por el impulso - guiado por la razón - del libre albedrío. En este sentido, Pufendorf exaltó la libertad porque empodera a los hombres, concediéndoles la facultad de ejercer un efectivo control sobre su propia conducta e incluso sobre sí mismos.

Pufendorf sostenía que lo que distingue la libertad humana de la de los animales es la moralidad. Fue precisamente en este contexto cuando empleó la expresión "la dignidad y excelencia del hombre". ${ }^{126}$ Podría decirse que la libertad humana constituye, según su parecer, el fundamento de la dignidad moral del hombre. Esto no significa que negara la dignidad humana de quienes actuaran de modo inmoral o prefirieran vivir en la inmoralidad. Según el jurista y filósofo alemán, todos los hombres poseen una dignidad innata por la libertad moral que a todos - como seres humanosles fue concedida, con independencia de la conducta particular que luego el sujeto desplegara en su concreto vivir moral.

Del principio según el cual todos los seres humanos son iguales por naturaleza - incluso cuando sus elecciones particulares fueran ilícitas o inmorales - ${ }^{127}$ provenía la obligación — que a todos incumbe - de respetar y tratar a los demás como iguales, cuestión a la que Pufendorf dedicó todo un capítulo. ${ }^{128}$ A este respecto, afirmó que la expresión "hombre" contiene en sí la idea de dignidad. También fue ese el argumento más fuerte que esgrimió al afrontar insultos y maltratos, recordando a sus autores que, "a pesar de todo, no soy un perro; Soy un hombre como usted". ${ }^{129}$ No hay duda de que estaba defendiendo la idea de la dignidad humana natural (o intrínseca).

Esa idea de dignidad exigía la igualdad, la cual no casaba con la esclavitud. De ahí que rechazara que algunos hombres pudieran tener la consideración natural de esclavos. La esclavitud constituye una violación de la

124 Ibidem, L. I., Chap. I, § IV \& VI, pp. 5 y 6.

125 Ibidem, Préliminaires, $\S$ III, p. 4.

126 Ibidem, L. II, Chap. I, § V, pp. 145 y 146.

127 Ibidem, L. III, Chap. II, § I, p. 308, donde se recurrió a la idea de que Dios escribió la ley en el corazón del hombre.

128 Ibidem, L. III, Chap. II.

129 Ibidem, L. III, Chap. II, § I, p. 309; según el parecer de J. Barbeyrac, Pufendorf inspiró aquí en la poesía de Estacio, Tebaida, Lib. XII, v. 556 ss. 
Este libro forma parte del acervo de la Biblioteca Jurídica Virtual del Instituto de Investigaciones Jurídicas de la UNAM

igualdad natural de todos los hombres. ${ }^{130}$ Permitir la esclavitud suponía negar tanto la igualdad natural como la libertad natural de todos los hombres. Por lo tanto, ningún hombre debía estar sometido a la voluntad de los otros sin su libre consentimiento. ${ }^{131} \mathrm{Si}$ todos los hombres son iguales y poseen una libertad natural común, los hombres que hubieran sido investidos con otras cualidades o facultades carecían del derecho a someter a los demás. ${ }^{132}$ Como afirma nuestro autor, las desigualdades civiles jamás podían ser empleadas para legitimar o justificar la violación o destrucción de la igualdad natural de todos los hombres. ${ }^{133}$

Antes de Pufendorf, Hugo Grocio (1583-1645) ya había empleado la expresión de "dignidad del hombre" o "dignidad de la naturaleza humana". En efecto, al analizar la costumbre común de dar sepultura a los muertos y desentrañar los motivos de la misma, concluyó señalando que "la explicación más obvia debe ser encontrada en la dignidad del hombre". ${ }^{134}$ Según este ilustre jurista holandés, el derecho a ser sepultado provenía de la "dignidad de la naturaleza humana", ${ }^{135} \mathrm{y}$ tal deber podía ser solicitado por cualquiera, incluso por parte de enemigos mortales. ${ }^{136}$ En pocas palabras, tanto el derecho de sepultura como el deber de realizar este servicio no se fundaba en razones de índole religiosa, sino que se debía al justo reconocimiento de la "dignidad de la naturaleza humana".

Como ha podido observarse, en los siglos XVII y XVIII la filosofía jurídica mantuvo la idea de excelencia moral y dignidad natural de los seres hu-

130 Ibidem, L. III, Chap. II, § VIII, p. 316.

131 Ibidem, L. III, Chap. II, § VIII, p. 317.

132 Ibidem, L. III, Chap. II, § VIII, p. 317.

133 Ibidem, L.III, Chap. II, § VIII, p. 319.

134 Hugo Grotius, The Rights of War and Peace (1901 ed.) (1625), Book II, Ch. XIX: 'On the Right of Burial', II, p. 216 (disponible en: http://oll.libertyfund.org/titles/553\#Groti us_0138_583-585): "Pero la explicación más obvia debe ser encontrada en la dignidad de hombre, para quién sobrepasando a otras criaturas, esto sería una vergüenza, si es un acto de compasión entonces, dijo Quintiliano, conservar los cuerpos de los hombres de los estragos de pájaros y bestias. Para ser rasgado por bestias salvajes, como Cicerón observa en su primer libro On Invention, debe ser privado de aquellos honores, en la muerte, debido a nuestra naturaleza común...”.

135 Grotius, The Rights of War and Peace, II, XIX, II, 4.

136 Grotius, The Rights of War and Peace, II, XIX, II, 5; esta idea se puede encontrar en Seneca, L. A., "Carta LXXXVIII", Cartas Morales a Lucilio, trad. de J. Bofill y Ferro, Barcelona, Planeta, 1989, pp. 270 y ss.; sobre este tema, véase también Griffin, M., Seneca. A philosopher in Politics, Oxford, Oxford University Press, 1991; Pelé, Antonio, Filosofia e historia en el fundamento de la dignidad humana, $\mathrm{PhD}$ unpublished, Getafe, Instituto de Derechos Humanos "Bartolomé de las Casas", 2006, pp. 366 y ss., disponible en: http://e-archivo.uc3m.es/bitstream/ handle/10016/3052/Tesis_Pele.pdf? sequence $=7$. 
Este libro forma parte del acervo de la Biblioteca Jurídica Virtual del Instituto de Investigaciones Jurídicas de la UNAM

manos, pese a que luego las conductas individuales pudieran no reflejar de un modo nítido esa dignidad humana natural. La expresión "dignidad de la naturaleza humana", de origen ciceroniano y recogida con tanta frecuencia en las fuentes de los siglos XVII y XVIII, ${ }^{137}$ muestra la notable atención que los autores prestaron a la naturaleza humana y a su dignidad. Su doctrina podría sintetizarse en los siguientes principios: 1) la dignidad natural deriva de la naturaleza humana; 2) esta dignidad natural implica la obligación de actuar en consecuencia, forjándose así una dignidad moral cuyo grado depende de la práctica de las virtudes, y 3) la dignidad natural, que proviene de la naturaleza humana, debe ser reconocida siempre, incluso cuando la conducta de alguien pudiera parecer mezquina o viciosa. Veamos brevemente cada uno de ellos.

1) Según la mayoría de los filósofos del derecho de los siglos XVII y XVIII, la dignidad natural emana de la naturaleza humana. Según estos pensadores, la dignidad natural proviene del simple hecho de ser humano. No hace falta nada más. Además, los derechos naturales se basan en la dignidad natural, con independencia de que el individuo sea o no capaz de ejercitarlos o gozar de ellos. La incapacidad no afectaría a la dignidad natural que a todos corresponde por el solo hecho de ser humano, es decir, de poseer la naturaleza humana. Los filósofos de estos siglos relacionaron la naturaleza humana y la condición de ser humano con la dignidad natural y los derechos naturales. Mientras en el siglo XVI los pensadores (juristas, filósofos y teólogos) establecieron la conexión entre naturaleza humana y derechos naturales (Francisco Suárez, Francisco de Vitoria, Domingo de Soto, etcétera), a partir del siglo XVII los autores comenzaron a utilizar la expresión 'dignidad' para subrayar la idea de respeto y consideración que todo individuo merece por el solo hecho de ser humano, o, si se prefiere, por poseer la naturaleza humana. Al empezar a utilizar la expresión "dignidad de la naturaleza humana" se buscaba precisamente mostrar de un modo claro la consideración y el respeto que merece la humanidad en general y cualquier individuo singular en particular. En este sentido - como se ha visto - algunos autores del siglo XVII declararon que los derechos naturales emanaban de la "dignidad de la naturaleza humana", mientras que otros siguieron afirmando - en consonancia con la doctrina de la Escuela de Salamanca - que los derechos naturales hundían sus raíces en la

137 En efecto, Cicerón, en Sobre los deberes, trad. de J. de Guillén Cabañero, Madrid, Tecnos, 1999, p. 55, recoge de un modo explícito esa expresión al sostener la conveniencia de que la propia conducta estuviera acorde con "la excelencia y la dignidad de la naturaleza humana". 
Este libro forma parte del acervo de la Biblioteca Jurídica Virtual del Instituto de Investigaciones Jurídicas de la UNAM

naturaleza humana. Eran dos modos de expresar la misma idea, es decir, que los derechos naturales pertenecen a los seres humanos (o a aquellos que comparten la naturaleza humana), cuya dignidad natural provenía del solo hecho de ser humano.

2) Los autores de los siglos XVII y XVIII consideraron la dignidad natural no sólo como el origen de los derechos naturales, cuya protección constituía la raison d'être de cualquier poder político. La dignidad natural era, además, fuente de deberes y obligaciones. En este sentido, la naturaleza humana confiere una dignidad natural de la que emanaban derechos para el individuo, pero también la obligación de llevar una vida acorde con su dignidad. "La nobleza obliga", dice el refrán. La dignidad natural implica el deber de llevar una vida virtuosa. En efecto, con la práctica de la virtud se da un gradual aumento de la dignidad moral de cada individuo. Desde esta perspectiva, se entiende por libertad o voluntad autónoma la facultad humana que permite a una persona conducirse de un modo acorde con su dignidad natural, aumentando así progresivamente su dignidad moral (o la estima entre sus iguales). Libertad y autonomía eran vistas como la principal facultad humana sin la cual el hombre no podía honrar su dignidad natural persiguiendo libremente aquello que resulta acorde o "adecuado a la dignidad de la naturaleza humana" ${ }^{138}$ Cuanto más practique un hombre la virtud, más honra su dignidad humana, y más feliz será, porque la felicidad no puede ser perseguida ni alcanzada al margen de aquello que es acorde con la dignidad de la naturaleza humana.

3) La dignidad natural, que proviene de la naturaleza humana, no debe ser confundida con la dignidad moral o la estima pública que produce una vida virtuosa a los ojos de los demás. La dignidad natural obliga a actuar en consecuencia. La mala conducta, o llevar una vida mezquina, podría empañar, ensombrecer o incluso destruir casi por completo la dignidad moral de un individuo, pero jamás disminuir lo más mínimo su dignidad natural, ya que éste no puede dejar de ser humano (incluso pese a que con su conducta no honrara ni reflejara la "dignidad de la naturaleza humana"). ${ }^{139}$

138 Véase la nota al pie n. 65.

139 Algunos autores distinguen entre la "dignidad intrínseca" (la que todos poseen por el simple hecho de ser humanos, y no la reservada al virtuoso) y "dignidad extrínseca" (que depende de la mentalidad y el comportamiento de las personas); al respecto, véase Stetson, "Human dignity: Rhetoric versus Reality", pp. 15-18; Roberto Andorno distingue entre "dignidad intrínseca" y "dignidad ética" (Bioética y dignidad de la persona, p. 73), basando el concepto de dignidad humana en la primera. 
Este libro forma parte del acervo de la Biblioteca Jurídica Virtual del Instituto de Investigaciones Jurídicas de la UNAM

\section{La noción de dignidad humana en el siglo XVI}

Que fuera a partir del siglo XVII cuando los autores empezaron a utilizar asiduamente la expresión "dignidad humana", "dignidad del hombre" o "dignidad de la naturaleza humana", no significa que la historia de esa noción — ni de la expresión misma, probablemente - comience en ese siglo. ${ }^{140}$

Como es bien sabido, los juristas, filósofos y teólogos del siglo XVI, al relacionar la naturaleza humana y derechos naturales, defendieron que la dignidad del hombre emanaba precisamente de la naturaleza humana. El concepto de naturaleza humana venía de la Antigüedad, pero fue objeto de particular desarrollo en el siglo XVI, en el contexto de la colonización española de América (Francisco Suárez, Francisco de Vitoria, Domingo de Soto, etcétera). ${ }^{141}$ Carecería de sentido hacer depender la historia de la noción de dignidad humana de la de su expresión, máxime cuando esa noción puede ser defendida sin hacer uso del término "dignidad". En este sentido, resulta paradigmático el famoso sermón que pronunció fray Antonio Montesinos el 21 de diciembre de 1511, en el cuarto domingo de adviento, criticando las prácticas del sistema colonial de encomienda, así como "la crueldad y tiranía" con que algunos trataban a los nativos:

Esta voz (dixo él) os dice que todos estáis en pecado mortal y en él vivís y morís por la crueldad y tiranía que usáis con estas inocentes gentes. Decid, ¿con qué derecho y con qué justicia tenéis en tan cruel y horrible servidumbre aquestos indios? ¿Con qué auctoridad habéis hecho tan detestables guerras a estas gentes que estaban en sus tierras mansas y pacíficas, donde tan infinitas dellas, con muerte y estragos nunca oídos habéis consumido? ¿Cómo los tenéis tan opresos y fatigados, sin dalles de comer ni curallos en sus enfermedades en que, de los excesivos trabajos que les dais, incurren y se os mueren y, por mejor decir, los matáis por sacar y adquirir oro cada día? ¿Y qué cuidado tenéis de quien los doctrine y cognozcan a su Dios y criador, sean baptizados, oigan misa, guarden las fiestas y domingos? ¿Éstos, no son hombres? ¿No tienen áni-

140 Según el parecer de Martín Alonso (Diccionario medieval español. Desde las Glossas emilianenses y Silenses (s. X) hasta el siglo XV, Salamanca, Universidad Pontificia de Salamanca, 1986, t. II, p. 956), las expresiones "dignidad" y "dignitat", entendidas como "calidad de digno" o "merecedor de dignidad", provienen de finales del siglo XV (1495); agradezco a la doctora María del Refugio González Domínguez, quien me sugirió indagar este punto y con quien consulté este Diccionario en su mismo despacho de trabajo.

$141 \mathrm{Al}$ respecto, véase el estudio de Isabel Sánchez de Movellán Torent, "La dignidad humana como base de los derechos humanos fundamentales: de los escritos de los teólogosjuristas del s. XVI a la Carta de Derechos Fundamentales de la Unión Europea", La eficacia de los derechos fundamentales de la UE. Cuestiones avanzadas, Pamplona, Aranzadi-Thomson Reuters, 2014, pp. 593-611. 
Este libro forma parte del acervo de la Biblioteca Jurídica Virtual del Instituto de Investigaciones Jurídicas de la UNAM

mas racionales? ¿No sois obligados a amallos como a vosotros mismos? ¿Esto no entendéis? ¿Esto no sentís? ¿Cómo estáis en tanta profundidad de sueño tan letárgico dormidos? Tened por cierto, que en el estado que estáis no os podéis más salvar que los moros o turcos que carecen y no quieren la fe de Jesucristo. ${ }^{142}$

En efecto, el texto del sermón no recoge la expresión "dignidad", pero resulta innegable que esa noción estaba en el centro del mensaje de Montesinos, al igual que estuvo bien presente en los pensadores de la segunda escolástica española, con independencia de que la expresión "dignidad" [humana] pudiera no recogerse de un modo expreso en sus obras. Con ello no se está afirmando que ningún autor del siglo XVI recogió esa expresión. Sí puede encontrarse en algunos textos, pero no con la asiduidad que se ha podido constatar en las fuentes de los siglos XVII y XVIII. Pese a ello, esto es, aunque las fuentes del siglo XVI no recogieran la expresión "dignidad de la naturaleza humana", el concepto y su significado, estuvieron bien presentes a lo largo de ese siglo.

Defender que la dignidad humana de los indígenas provenía de la naturaleza, y no de la gracia, supuso un avance notable en el desarrollo de la expresión "dignidad de la naturaleza humana" que los autores emplearían en los siglos XVII y XVIII. En efecto, aunque Tomás de Aquino trazó la distinción entre naturaleza y gracia, ${ }^{143}$ fue "mérito de Vitoria el haber visto en su propio tiempo sus implicaciones políticas". ${ }^{144}$

La distinción tomista entre naturaleza y gracia llevó a Vitoria a defender que la naturaleza de los indios también podía ser:

142 Manejo el texto disponible en: http://wrerr.dominicos.org/kit_upload/file/especial-montesi no/Montesino-gustavo-gutierrez.pdf.

143 Tomás de Aquino, In III Sententiarum, d. 29, q. 1, a. 7: la gracia no modifica la naturaleza, sino que la realiza plenamente; Vitoria tomó de Tomás de Aquino algunas ideas al aplicar a los indios los siguientes tres principios: "1) Cada hombre, en cuanto imago Dei, tiene una personal dignidad y por eso es sujeto de derechos fundamentales con independencia de si comparte o no la fe cristiana, a la que es libre de adherirse, como es libre también para la elección del gobierno político; 2) Las formas del poder y dominio se introdujeron con el derecho humano, el cual no está anulado por el derecho divino; 3) La Iglesia no tiene poder sobre los pueblos infieles que no le están sometidos de iure et de facto, o que no ocupen tierras de reyes cristianos. Por eso ella no puede forzarlos a elegir o cambiar de régimen político. Lo cual no excluye una intervención indirecta de la misma Iglesia, apelando a sus finalidades espirituales" (Savignano, Armando, "Diálogo intercultural y derechos humanos. El debate entre Sepúlveda, Vitoria y Las Casas", en Cruz Cruz, Juan (ed.), Razón práctica y derecho. Cuestiones filosófico-jurídicas en el Siglo de Oro español, Pamplona, EUNSA, 2011, p. 107).

144 Justenhoven, Heinz-Gerhard, "Las raíces teológicas del Derecho internacional según Francisco de Vitoria”, en Cruz Cruz, Juan (ed.), Razón práctica y derecho..., cit., pp. 87-98, en particular, p. 89; al respecto, véase también Matz, U., "Vitoria", Klassiker des politischen Denkens, I, München, Beck, 1968, p. 277. 
Este libro forma parte del acervo de la Biblioteca Jurídica Virtual del Instituto de Investigaciones Jurídicas de la UNAM

Plenamente realizada por la gracia de Dios: la dignidad y el valor de la naturaleza del indio están apoyados en la disposición de dicha naturaleza en cada ser humano, disposición que puede cumplirse plenamente por la gracia de Dios. En otras palabas, el hecho de que los indios puedan convertirse al cristianismo, muestra que Dios les ha dado una naturaleza que está abierta a la gracia divina. Los indios, entonces, deben tener la misma naturaleza creada que los europeos, dado que están dotados con razón suficiente para entender el sentido del evangelio. El fundamento de la dignidad humana y de los derechos de los indios se halla en el hecho de que tienen una naturaleza que está obviamente dotada con una razón suficiente para entender el evangelio, y por tanto son imágenes de Dios. ${ }^{145}$

La defensa de los indios llevada a cabo por Francisco de Vitoria y fray Bartolomé de las Casas, frente a la postura de Sepúlveda, constituyó una defensa de la dignidad humana natural, ${ }^{146}$ y de sus consecuencias. Así, por ejemplo, Vitoria sostenía que "el deber de evangelizar llevaba consigo el respeto a la libertad de adhesión a la fe; puesto que el acto de fe, para ser tal, ha de ser esencialmente libre". ${ }^{147}$ Por otra parte, esa dignidad natural no era compatible con la esclavitud. En este sentido, al defender la dignidad de las personas, distinguió entre la esclavitud natural y la esclavitud civil o legal, afirmando - en contra del parecer de Aristóteles - que nadie podía ser esclavo por naturaleza, no admitiendo tampoco la esclavitud legal ni para aquellos indios que, por falta de educación, pudieran parecer estúpidos o idiotas. ${ }^{148}$

145 Ibidem, p. 90; véase también Justenhoven, H. G., Francisco de Vitoria zu Krieg und Frieden, Köln, Bachem, 1991, pp. 60 y ss.

$146 \mathrm{Al}$ respecto, véase el estudio de Savignano, "Diálogo intercultural y derechos humanos. El debate entre Sepúlveda, Vitoria y Las Casas", ya citado; véanse también los trabajos de Hanke, L., Aristotle and the American Indian. A Study of Race Prejudice in the Modern World, Bloomington-Londres, University of Indiana Press, 1970; Brufau Prats, J., "Juan Ginés de Sepúlvera y su controversia con Bartolomé de las Casas", en Fartos Martínez, M. (coord.), La filosofia española en Castilla y León: de los orígenes al Siglo de Oro, t. 1, Valladolid, Universidad de Valladolid, 1997, pp. 207-217.

147 Savignano, "Diálogo intercultural y derechos humanos. El debate entre Sepúlveda, Vitoria y Las Casas", pp. 105-106; y añade: "La defensa de los derechos de los indios parece evidente cuando pone la cuestión del principio, en los tres capítulos fundamentales (de su Relectio de indis, 1539, L. Pereña y M. Pérez Prendes (eds.), Madrid, CSIC, 1967): los que se refieren al reconocimiento de la 'dignidad humana' de los indios, al derecho de aquellos pueblos a la defensa de su soberanía (dominium), y al derecho del orbe a colaborar constructivamente en la solidaridad entre los pueblos"; al respecto, véase también el estudio de Pereda, L., La idea de justicia en la conquista de América, Madrid, Mapfre, 1992.

148 Savignano, "Diálogo intercultural y derechos humanos. El debate entre Sepúlveda, Vitoria y Las Casas", cit., pp. 108 y 109; al respecto, véase Francisco de Vitoria, Relectio de indis, pp. 30 y 31 ). 
Este libro forma parte del acervo de la Biblioteca Jurídica Virtual del Instituto de Investigaciones Jurídicas de la UNAM

También Bartolomé de las Casas defendió la dignidad natural de los indios, ${ }^{149}$ rechazando "con contundencia el recurso a la irracionalidad y a la coerción para que el otro se inserte a una comunidad de comunicación, en la que hay que avanzar con el método racional y con el diálogo, desde el presupuesto básico de reconocimiento de la igual dignidad y de iguales derechos". ${ }^{150}$ En efecto, De las Casas hizo una defensa de la libertad y dignidad humanas que impedía forzar la conversión de los indígenas:

Pero la criatura racional tiene una aptitud natural para que se lleve, dirija o atraiga de una manera blanda, dulce, delicada y suave, en virtud de su libre albedrío, para que voluntariamente escuche, voluntariamente obedezca y voluntariamente preste su adhesión y su obsequio a lo que se oye. Luego el modo de mover, dirigir, atraer o encaminar a la criatura racional al bien, a la verdad, a la virtud, a la justicia, a la fe pura y a la verdadera religión, ha de ser un modo que esté de acuerdo con el modo, la naturaleza y condición de la misma criatura racional, es decir, un modo dulce, blande delicado y suave, de manera que de su propio motivo, con voluntad de libre albedrío y con disposición y facultad naturales, escuche todo lo que se le proponga y notifique acerca de la fe, de la verdadera religión, de la verdad, de la virtud y de las demás cosas que se refieren a la fe y a la religión. ${ }^{151}$

La idea de que la evangelización debía llevarse a cabo respetando la libertad, con razones y modos persuasivos, propios de seres racionales y con libre albedrío, aparece constantemente en el pensamiento lascasiano: “...es único, solo y el mismo, el modo que la divina Providencia estableció para notificar su verdad y para atraer e invitar a los hombres a la verdadera religión en todo tiempo; a saber, un modo persuasivo por medio de razones en cuanto al entendimiento, y suavemente atractivo en relación con la voluntad". ${ }^{152}$

$149 \mathrm{Al}$ respecto, véase Beuchot, Mauricio, "El fundamento de los derechos humanos en Bartolomé de las Casas", Revista Portuguesa de Filosofia, 52 (1/4), 1996, pp. 87-95; del mismo autor, Filosofia y política en Bartolomé de las Casas, México, San Esteban, 2013.

150 Savignano, "Diálogo intercultural y derechos humanos. El debate entre Sepúlveda, Vitoria y Las Casas", p. 113, donde se recoge, en nota al pie, la obra de B. de las Casas, Del único modo de atraer a todos los pueblos a la verdadera religión [1536], México, Fondo de Cultura Económica, 1975, p. 343.

151 Fray Bartolomé de las Casas, Del único modo de atraer a todos los pueblos a la verdadera religión [1536], México, Fondo de Cultura Económica, 1942, § II, p. 15.

152 Casas, Del único modo de atraer a todos los pueblos a la verdadera religión, cit., § XIII, p. 339; a este respecto, véanse en particular los $\S \S$ XV-XVI, p. 373-393; véanse también pp. 17-23, 35, 39, 45, 51, 63, 79-81, 87-89, 111-115, 203, 211, 309, 327, 335, 343, 349, 357-359, 363, 367); al respecto, véase el estudio de Castañeda, Paulino, "Las doctrinas sobre la coacción y 
Este libro forma parte del acervo de la Biblioteca Jurídica Virtual del Instituto de Investigaciones Jurídicas de la UNAM

En su Apologética historia sumaria (1539), Bartolomé de las Casas defendió que los derechos naturales y los derechos humanos derivan de una naturaleza "predicable de todos los individuos marcados por una igual dignidad. Cada hombre está definido como animal racional que tiene inteligencia, voluntad y libre albedrío". ${ }^{153}$ Esa igual dignidad le llevó - como a Francisco de Vitoria - a rechazar la esclavitud. ${ }^{154}$

Tras insistir en que lo que define al hombre es su racionalidad, ${ }^{155}$ "que todos tienen entendimiento y su voluntad y libre albedrío como sean formados a imagen y semejanza de Dios", 156 "que todo linaje de los hombres es uno, y todos los hombres cuanto a su creación y a las cosas naturales son semejantes y nadie nace enseñado", ${ }^{157}$ que "todas las naciones del mundo tienen entendimiento y voluntad, y lo que de ambas a dos estas potencias en el hombre resulta que es el libre albedrío", ${ }^{158}$ De las Casas fue más allá. No se limitó a defender la dignidad natural de todos los seres humanos, sino que llegó incluso a emplear la expresión "dignidad” con esa acepción: “...las creaturas racionales, como sean formadas a la imagen y semejanza de Dios, su dignidad y excelencia sobre las otras criaturas...". ${ }^{159}$

Aunque se requeriría un análisis más exhaustivo de las fuentes, que aquí y ahora rebasaría por completo los límites del presente estudio, ${ }^{160}$ parece

el «idearium» de Las Casas", Fray Bartolomé de Las Casa, Obras Completas, 2. De único vocationis modo, Madrid, Alianza Editorial, 1990, pp. XVII-XLII.

153 Savignano, "Diálogo intercultural y derechos humanos. El debate entre Sepúlveda, Vitoria y Las Casas", p. 114, recogiendo en nota 58 la obra de Las Casas, Apologética historia sumaria, 1539, edición de E. O’Gorman, México, UNAM, 1967, t. III, c. 48.

154 Savignano, "Diálogo intercultural y derechos humanos. El debate entre Sepúlveda, Vitoria y Las Casas", p. 114, nota al pie 60, donde se recoge otra obra de De las Casas, Algunos principios que deben servir de punto de partida en la controversia destinada a poner de manifiesto y defender la justicia de los indios, en Tratados, pp. 1249 y 1250, poniendo de manifiesto que todos los hombres, iguales por naturaleza, son libres, rechazándose la esclavitud; véase también Bartolomé de las Casas, Tratado comprobatorio del imperio soberano, 1522, en Tratados, México, Fondo de Cultura Económica, 1965, t. II, pp. 1069-1071.

$155 \mathrm{Al}$ respecto, véase el estudio de Beuchot, Mauricio, "Bartolomé de las Casas, el humanismo indígena y los derechos humanos", Anuario Mexicano de Historia del Derecho, núm. 6, 1994, pp. 37-48, en particular pp. 45-47.

156 Fray Bartolomé de las Casas, Apologética historia sumaria, cit., libro III, cap. 48, pp. 257-258.

157 Ibidem, p. 258.

158 Idem.

159 Ibidem, p. 259.

$160 \mathrm{Al}$ respecto, véanse, por ejemplo, los estudios de Beuchot, Mauricio, Derechos humanos, historia y filosofia, México, Fontamara, 1999; Derechos humanos y naturaleza humana, México, UNAM, 2000 (en coautoría con Javier Saldaña); Derechos humanos, iuspositivismo y iusnaturalismo, México, UNAM, 1995; Filosofia y derechos humanos, México, Siglo XXI, 2004. 
Este libro forma parte del acervo de la Biblioteca Jurídica Virtual del Instituto de Investigaciones Jurídicas de la UNAM

claro que los autores del siglo XVI hicieron una defensa de la dignidad humana natural, como derivada de la propia naturaleza humana, empleando la expresión "dignidad" en menor medida que los autores de los siglos XVII y XVIII.

Lo mismo cabría decir con respecto al desarrollo de esta noción con anterioridad al siglo XVI. Es bien conocido el Discurso sobre la dignidad del hombre (1486), de Giovanni Pico della Mirandola. ${ }^{161}$ Una lectura atenta al texto resulta suficiente para constatar que, pese a la bella apología del autor a la "dignidad del hombre" - como refleja el mismo título de la obra-, no estimó oportuno ni necesario emplear la expresión "dignidad" a lo largo de la obra. Al distinguir, con prosa clara y elegante, entre la condición humana y la del animal, agradece a Dios que haya conferido al ser humano la libertad y la autonomía (" ¡suma y admirable suerte del hombre al cual le ha sido concedido obtener lo que desee, ser lo que quiera!"), ${ }^{162}$ pero no usó la expresión "dignidad". Al referirse al deber de comportarse con arreglo a la propia dignidad [humana], tampoco mencionó ese término. ${ }^{163}$

161 Pico della Mirandola, Giovanni, Discurso sobre la dignidad del hombre (1486), Ensayos para Pensar, Medellín, Editorial r, 2006 (disponible en: http://editorialpi.net/ensayos/discurso sobreladignidaddelhombre.pdf).

162 "Estableció por lo tanto el óptimo artífice que aquel a quien no podía dotar de nada propio le fuese común todo cuanto le había sido dado separadamente a los otros. Tomó por consiguiente al hombre así construido, obra de naturaleza indefinida, y habiéndolo puesto en el centro del mundo, le habló de esta manera:

Oh Adán, no te he dado ni un lugar determinado, ni un aspecto propio, ni una prerrogativa peculiar con el fin de que poseas el lugar, el aspecto y la prerrogativa que conscientemente elijas y que de acuerdo con tu intención obtengas y conserves. La naturaleza definida de los otros seres está constreñida por las precisas leyes por mi prescritas. Tú, en cambio, no constreñido por estrechez alguna te la determinarás según el arbitrio a cuyo poder te he consignado. Te he puesto en el centro del mundo para que más cómodamente observes cuanto en él existe. No te he hecho ni celeste ni terreno, ni mortal ni inmortal, con el fin de que tú, como árbitro y soberano artífice de ti mismo, te informases y plasmases en la obra que prefirieses. Podrás degenerar en los seres inferiores que son las bestias, podrás regenerarte, según tu ánimo, en las realidades superiores que son divinas.

¡Oh suma libertad de Dios padre, oh suma y admirable suerte del hombre al cual le ha sido concedido obtener lo que desee, ser lo que quiera! Las bestias en el momento mismo en que nacen, sacan consigo del vientre materno, como dice Lucilio, todo lo que tendrán después. Los espíritus superiores desde un principio, o poco después, fueron lo que serán eternamente. $\mathrm{Al}$ hombre, desde su nacimiento, el Padre le confirió gérmenes de toda especie y gérmenes de toda vida y, según como cada hombre los haya cultivado, madurarán en él y le darán sus frutos" (Ibidem, pp. 5 y 6).

163 "Pero ¿para qué destacar todo esto? Pues para que comprendamos, ya que hemos nacido en la condición de ser lo que queramos, que nuestro deber es cuidar de todo esto: que no se diga de nosotros que, siendo en grado tan alto, no nos hemos dado cuenta de habernos vuelto semejantes a los brutos y a las estúpidas bestias de labor" (ibidem, pp. 7 y 8). 
Este libro forma parte del acervo de la Biblioteca Jurídica Virtual del Instituto de Investigaciones Jurídicas de la UNAM

Que los autores medievales pudieran no emplear la expresión "dignidad" para expresar la dignidad humana natural, ${ }^{164}$ no significa que desconocieran esa noción, ni mucho menos que carecieran de ella, porque como afirmaron los autores de los siglos aquí estudiados - cada ser humano es portador de unos derechos "inherentes" que debían ser objeto de respeto y protección en la esfera jurídica. ${ }^{165}$

\section{CONSIDERACIONES FINALES}

Una aproximación a los orígenes y evolución histórica de la dignidad humana en general, ${ }^{166}$ y a su noción entre los siglos XVI y XVIII en particular, ${ }^{167}$ revela cómo la mayoría de los filósofos y juristas de ese periodo, incluyendo a Immanuel Kant (1724-1804), defendían la existencia de una dignidad natural o intrínseca - que deriva de la misma naturaleza o condición humana-, distinta de la dignidad moral - forjada con la propia conducta-.

164 Michael Rosen, en su obra Dignity: Its History and Meaning, Cambridge, Harvard University Press, 2012, muestra cómo Tomás de Aquino, por ejemplo, emplea esa expresión; según el Aquinate, "Dignidad significa algo que es bueno por sí mismo"; Beuchot, Derechos humanos, historia y filosofia, donde trata de la dignidad humana y de los derechos humanos en Tomás de Aquino (pp. 49-60), Francisco de Vitoria (pp. 61-69), Fray Bartolomé de las Casas, (pp. 70-79), Fray Alonso de la Vera Cruz (pp. 80-89), Jacques Maritain (pp. 90-98), en la doctrina social de la Iglesia (pp. 99-110); al respecto, véase también Gonzalo Alarcón, "La dignidad como valor y como derecho en la perspectiva constitucional", p. 2446.

165 El carácter "inherente" de los derechos humanos constituye otro motivo que aconseja historiar la evolución de tales derechos, como afirma Escudero, José Antonio, "Sobre los derechos humanos", en Hermida, C. y Santos, J. A. (coords.), Una filosofía del derecho en acción. Homenaje al profesor Andrés Ollero, Madrid, Congreso de los Diputados-Universidad Rey Juan Carlos, 2015, pp. 1045-1050: "Y si los derechos humanos son los inherentes a la persona, y el hombre de la gleba o el remero de galeras era portador en su tribulación de tan egregio depósito moral, no parece razonable la ligereza de echar al desván los diecisiete siglos anteriores al XVIII (con sus Declaraciones) o los dieciocho anteriores (con sus Constituciones). Los derechos humanos han sido reconocidos o negados históricamente de muchas maneras y no sólo sub specie de Declaraciones y Constituciones. Por ello reclamo, yo que no soy medievalista, una mayor atención a lo medieval y al mundo antiguo, tal como lo hizo un sector bastante poco conocido de la historiografía alemana de los años treinta" (pp. 1046 y 1047).

$166 \mathrm{Al}$ respecto, véase Antonio Pelé, Filosofia e historia en el fundamento de la dignidad humana, tesis doctoral inédita, Getafe, Instituto de Derechos Humanos "Bartolomé de las Casas", 2006, disponible en: http://e-archivo.uc3m.es/bitstream/handle/10016/3052/Tesis_Pele.pdf?'se quence $=7$ (fecha de consulta: 1o. de octubre de 2016); Sánchez de Movellán Torent, "La dignidad humana como base de los derechos humanos fundamentales: de los escritos de los teólogos-juristas del s. XVI a la Carta de Derechos Fundamentales de la Unión Europea”, ya citado.

$167 \mathrm{Al}$ respecto, véanse mis estudios, ya citados en la nota al pie n. 58. 
Este libro forma parte del acervo de la Biblioteca Jurídica Virtual del Instituto de Investigaciones Jurídicas de la UNAM

La expresión "dignidad inherente" o "dignidad intrínseca" de muchas declaraciones e instrumentos internacionales tras la Segunda Guerra Mundial al referirse a la dignidad humana, entronca, en realidad, con la noción de dignidad humana natural de los autores de los siglos XVII y XVIII, quienes, como se ha podido constatar, emplearon con frecuencia la expresión "dignidad de la naturaleza humana".

Las expresiones "inherentes", "inviolables", "naturales" o "imprescriptibles", recogidas por las primeras Constituciones modernas al referirse a los derechos fundamentales, llevaban implícito el concepto de dignidad humana, pese a que ninguno de estos primeros textos constitucionales modernos recogiera la expresión "dignidad" (humana).

Si la noción de dignidad humana ha estado presente de un modo implícito en buena parte de la tradición cultural occidental, en particular a partir del siglo XVI, y de un explícito a partir de los siglos XVII y XVIII, cabe hacerse las siguientes dos preguntas:

1) ¿Por qué los "derechos naturales" no sirvieron para respetar y proteger la dignidad de las personas hasta el siglo XVIII? La respuesta tiene que ver con la existencia de un sistema político, de corte absolutista, en el que el poder político carecía, en la práctica - y, según algunos autores, incluso en la teoría- de límites.

2) Más tarde, tras el advenimiento del régimen liberal, y con el reconocimiento de los "derechos fundamentales", ¿por qué tales derechos, concebidos en teoría por el Constitucionalismo moderno como límites al poder político, no impidieron los horrores de la Segunda Guerra Mundial? A mi juicio, ello se debió a la fragilidad de unos "derechos fundamentales" que quedaron notablemente relegados tras identificar el derecho con la ley, entendiendo ésta como mera "expresión de la voluntad general". ${ }^{168}$

Cabría afirmar que, en el siglo XIX, las corrientes utilitaristas e iuspositivistas se impusieron frente a la iusnaturalista, desembocando en una concepción voluntarista del derecho. Conviene no perder de vista que la concepción racionalista del derecho, que suponía entender el derecho como expresión de la razón, tuvo que enfrentarse con otra radicalmente opuesta, esto es, la que consideraba el derecho como expresión de la voluntad. Ambas concep-

168 Véase la bibliografía recogida en la nota al pie n. 41. 
Este libro forma parte del acervo de la Biblioteca Jurídica Virtual del Instituto de Investigaciones Jurídicas de la UNAM

ciones confluyeron en los orígenes del constitucionalismo moderno. ${ }^{169} \mathrm{La}$ historia muestra cómo, con el paso del tiempo, la concepción voluntarista del derecho se impuso a la racionalista. De hecho, el positivismo jurídico, las tesis filosófico-políticas de Carl Schmitt y el nacional socialismo alemán (que provocó la Segunda Guerra Mundial) constituyen concretas manifestaciones de esta concepción del derecho, entendido como mera "expresión de la voluntad popular" (Rousseau) o mero "mandato del Estado" (John Austin). Si el derecho es mero procedimiento, ${ }^{170}$ formalidad o continente, carente de exigencia material o sustantiva alguna, y los individuos carecen de una dignidad o derechos de naturaleza prepolítica - previos al poder político-, el Estado deja de ser "garante" de una realidad previa a su misma existencia, y se convierte en "fundante", en "creadora" de la dignidad humana y sus derechos, cuyo contenido puede cambiar de modo radical si determinadas "razones de Estado", de "seguridad nacional" o de "coyuntura cultural" así lo exigen.

Esto es precisamente lo que permite explicar, en buena medida, por qué, tras la Segunda Guerra Mundial, y pese al reconocimiento teórico y la consagración expresa de la dignidad humana en los instrumentos internacionales y constituciones nacionales, tal dignidad resulta a menudo, en la práctica, tan escasamente protegida.

A mi juicio, el triunfo de la concepción voluntarista del derecho no sólo explica la fragilidad - y el consiguiente fracaso - de los derechos fundamentales como límite al poder político en los inicios del constitucionalismo moderno, a pesar de que los propios textos constitucionales consagraran el carácter prepolítico de los derechos - con las expresiones "natural", "inherente" o "intrínseco"- L La expresión "dignidad humana" en estos textos no se recogía expresamente, dándose por supuesta, porque tales derechos de índole prepolítico sólo podían tener anclaje en la naturaleza humana y en su dignidad.

Tras la Segunda Guerra Mundial, se optó por recurrir a la expresión "dignidad humana" con la idea de reforzar el respeto y protección de los

$169 \mathrm{Al}$ respecto, véase Masferrer, Aniceto, "La antinomia «Derechos fundamentales»«soberanía nacional» en los orígenes del Constitucionalismo moderno", GLOSSAE. European Journal of Legal History, núm. 10, 2013, pp. 277 y ss.; véase también Masferrer, Aniceto y Taitslin, Anna, "The ill-fated Union: Constitutional Entrenchment of Rights and the Will Theory from Rousseau to Waldron", en Hickey, James E. y Silkenat, James R. (eds.), The Legal Doctrines of the Rule of Law and the Legal State (Rechtsstaat), Dordrecht-Heidelberg-LondresNueva York, Springer, 2014, pp. 105-128.

170 Sobre la "procedimentalización" del derecho como falsa alternativa, véase Ollero, Andrés, Derechos humanos. Entre la moral y el derecho, México, UNAM, 2007, pp. 347 y 348. 
Este libro forma parte del acervo de la Biblioteca Jurídica Virtual del Instituto de Investigaciones Jurídicas de la UNAM

“derechos humanos" (expresión que venía a subrayar su carácter universal, supranacional o global, distinguiéndose así de los "derechos fundamentales", más propios hasta entonces de las Constituciones nacionales). El problema está en que los derechos de los individuos no son objeto de efectivo respeto y protección por el mero empleo - más o menos afortunado- de expresiones, categorías o etiquetas, sino más bien cuando se remueven aquellos obstáculos que impiden entender el verdadero sentido y significado de las nociones o conceptos. En otras palabras, aquellas corrientes utilitaristas y positivistas, defensoras de una concepción voluntarista del derecho, han desembocado en una cultura posmodernista que, a mi juicio, resulta incompatible con una noción más humana de la dignidad humana. No es humano rechazar la universalidad de la dignidad humana, ni negar a los más vulnerables su dignidad como seres humanos.

Si la naturaleza humana es negada, resulta difícil — si no, imposibledefender la dignidad natural o inherente de todo ser humano. Para quienes defienden esta postura, "el hombre simplemente es lo que hace..., no hay ninguna naturaleza humana en absoluto, sólo comportamiento humano". ${ }^{171}$ La dignidad humana es, según esta concepción, una mera construcción histórica y cultural. Si no hay igualdad natural alguna entre los individuos, la dignidad igualitaria debe ser construida por el poder político, es decir, por el Estado mediante leyes. No existen leyes ni derechos de origen prepolítico. Las consecuencias de esta línea de pensamiento es que el poder político sólo tiene los límites que quiera imponerse a sí mismo, y los derechos de los individuos no son reconocidos ni garantizados, sino totalmente diseñados y creados por el Estado. ${ }^{172}$

171 Mitchell, John J., "Why Study Human Nature", en Mitchell, John J. (ed.), Human Nature: Theories, Conjectures, and Descriptions, Metuchen, The Scarecrow Press, 1972, pp. 23 y 24: "Hay, por supuesto, conclusiones no universalmente aceptadas sobre la naturaleza humana. Muchos estudiosos, especialmente desde John Locke, tienen la impresión de que el término «naturaleza humana» es una verdadera ironía y, de hecho, no existe tal realidad. Como otras invenciones ficticias, la «naturaleza humana» no es sino una reivindicación, que no corresponde con la realidad en el mundo material... Una teoría más moderna sugiere que el hombre es simplemente lo que hace. Algunos están domesticados, otros salvajes. Algunos comparten, otros acumulan; algunos monógamos, otros polígamos... Como se ve, sigue razonando, no hay naturaleza humana en absoluto, sólo el comportamiento humano. Las posibilidades son infinitas, en cuanto al comportamiento que una determinada persona o sociedad determinada pueden emprender. Este punto de vista, que denomino como «hombre como concepto neutro de la naturaleza humana» («man-as-neutral concept of human nature»), es probablemente la postura más ampliamente aceptada sobre la naturaleza humana en la comunidad científica del siglo XX".

172 Sobre esta cuestión, véase Masferrer, Aniceto, "The Fragility of Fundamental Rights in the Origins of Modern Constitutionalism: its Negative Impact in Protecting Human 
Este libro forma parte del acervo de la Biblioteca Jurídica Virtual del Instituto de Investigaciones Jurídicas de la UNAM

El problema es que la promulgación de leyes al margen de la realidad de la condición humana - con sus necesidades básicas, fragilidades y vulnerabilidades - hace a las personas más frágiles y vulnerables. Como señala Heyd, "si no tenemos un concepto de naturaleza humana, ¿podemos hablar de derechos del hombre o de derechos humanos que descansan sobre la naturaleza humana?". ${ }^{173}$ Como afirmó Griffin, una vez que el contexto metafísico y epistemológico que los derechos naturales comporta "es abandonado, como lo fue en el curso de la Ilustración, ¿qué queda? ¿Es suficiente lo que queda?". ${ }^{174}$

Negar la trascendencia del ser humano y su dignidad - como realidad previa al orden político y jurídico-positivo-, no sólo dificulta encontrar un fundamento sólido a los derechos humanos y una definición rigurosa de dignidad humana, sino que plantea además serios problemas a la hora de establecer límites al poder del Estado. El posmodernismo empezó declarando la muerte de Dios a fin de liberar a las personas de la moral y demás limitaciones religiosas e irracionales, ${ }^{175} \mathrm{y}$ terminó anunciando la muerte del hombre. ${ }^{176}$ Como se ha señalado de un modo acertado:

Rights in the «War on Terror» Era”, en Masferrer, A. y Walker, C. (eds.), Counter-Terrorism, Human Rights and the Rule of Law, Londres, Edward Elgar Publishing, 2013, pp. 37 y ss., defendiendo que los derechos fundamentales tienen un carácter pre-político, en el sentido de que su reconocimiento y protección es lo que justifica la existencia del propio orden político.

173 Heyd, David, "Human Nature: An Oxymoron", fournal of Medicine and Philosophy, núm. 28 (2), 2003, p. 168.

174 Griffin, James, On Human Rights, Oxford, Oxford University Press, 2008, p. 14: "El derecho natural comenzó como parte de una metafísica teleológica capaz de soportar fuertes interpretaciones de cómo la moralidad está arraigada en la naturaleza, y que terminó al cierre del siglo XVIII en algo parecido a la vacuidad. No es que la fuerte, concepción no vacua del derecho natural, no tenga sus propios problemas considerables. Aún así, muchas concepciones escolásticas de la ley natural nos dieron por lo menos algo para decidir qué derechos naturales existen. Una vez que el fondo metafísico y epistemológico que brindaron es abandonado, como lo fue en el curso de la Ilustración, ¿qué queda? ¿queda suficiente?”.

175 Nietzsche, Friedrich, Die fröhliche Wissenschaft (1882), Section 125 (utilizo la versión inglesa: The Gay Science: With a Prelude in Rhymes and an Appendix of Songs by Friedrich Nietzsche; translated, with commentary, by Walter Kaufmann, Vintage Books, March 1974): "Dios está muerto. Dios permanece muerto. Y nosotros le hemos matado. ¿Cómo podríamos reconfortarnos, los asesinos de todos los asesinos? Lo que era más santo y el más poderoso de todo lo que el mundo aún ha poseído ha sangrado hasta la muerte bajo nuestros cuchillos: ¿quién limpiará esta sangre nuestra? ¿Qué agua está ahí para poder limpiarnos? ¿Qué festivales de expiación, qué juegos sagrados tendremos que inventar? ¿No es la grandeza de este acto demasiado grande para nosotros? ¿Debemos nosotros mismos no ser dioses simplemente para aparecer dignos de él?".

176 Foucault, Michel, The Order of Things. An Archaeology of the Human Sciences, Nueva York, Vintage Books, 1994, pp. 341 y 342. 
Este libro forma parte del acervo de la Biblioteca Jurídica Virtual del Instituto de Investigaciones Jurídicas de la UNAM

Foucault anuncia la muerte del hombre durante la década de 1960, y no ve otro camino que destruir el cuadrilátero "antropológico" en su fundamento mismo..., Foucault habla de la muerte del hombre como un resultado necesario de la muerte de Dios. Hombre y Dios pertenecen el uno al otro, la muerte del segundo es sinónimo de la desaparición de la primero. ${ }^{177}$

Pienso que no es necesario llevar las cosas tan lejos, hasta el punto de pronosticar la muerte del hombre o la destrucción de la humanidad, pero es innegable que existe una relación entre la negación de la dignidad inherente o natural del ser humano, así como de sus derechos, y la difícil tarea de establecer límites - tanto en teoría como en la práctica - al poder político. Resulta necesario el reconocimiento expreso de la dignidad humana natural, si se quiere construir una sociedad global justa y pacífica, cuyo derecho respete y proteja a todas las personas, y especialmente a las más vulnerables. Para ello es necesario cambiar el modelo actual, que, "con su énfasis en el éxito y la autosuficiencia, no parece propiciar una inversión en esfuerzos encaminados a ayudar a que los lentos, los débiles o los menos dotados encuentren también oportunidades en sus vidas". ${ }^{178}$

Si las democracias constitucionales reconocen y protegen los derechos fundamentales en los términos recogidos por los instrumentos internacionales, conscientes de que su origen (o fundamento) es prepolítico, como lo es todo ser humano y su dignidad, la amenaza del Estado totalitario disminuye considerablemente. Entendemos que el reconocimiento del carácter prepolítico de la dignidad humana y sus derechos fundamentales no resuelve el peligro de su posible violación, pero contribuye notablemente a su debida protección y salvaguarda, máxime cuando se pretenden conculcar en nombre de un falso "interés público" (como la seguridad nacional) o de otros intereses de índole político o económico. ${ }^{179}$

177 Tepe, Harun, "Rethinking Human Nature as a Basis for Human Rights", en Alber, Marion et al. (eds.), Human Rights and Human Nature, Springer (Ius Gentium: Comparative Perspectives on Law and Justice, vol. 35, 2014, pp. 57-77, en particular p. 64.

178 Papa Francisco, Exhort. Ap. Evangelii gaudium (24 de noviembre de 2013), n. 209.

179 En este sentido, véase, por ejemplo, Knox, Vicesimus, The Spirit of Despotism (1795), donde el autor describe cómo el despotismo político de un Estado puede pretender justificarse por estar en guerra (empleamos versión editada en Londres, William Hone, 1821; disponible en: http://oll.libertyfund.org/titles/knox-the-spirit-of-despotism); referirse a los "derechos naturales" como "sinsentido", o a "los derechos fundamentales" como meras creaciones del Estado que impone sin más legitimidad que la fuerza vinculante de la ley (entendida como simple mandato del Estado), parece ser la mejor "legitimación" para conculcar los derechos cuando el Estado los considera como inconvenientes por cualesquiera razones, como muestra la reciente experiencia; en la lucha contra el terrorismo, por ejemplo, es evidente que los 
Este libro forma parte del acervo de la Biblioteca Jurídica Virtual del Instituto de Investigaciones Jurídicas de la UNAM

Toda vida humana posee una dignidad natural y merece un respeto incondicional. Este es, en buena medida, el legado de la noción de dignidad humana de los siglos XVI, XVII y XVIII, de cuya fidelidad depende la dignidad de la misma humanidad y el respeto a la dignidad de todos y cada uno de los seres humanos que la conforman. ${ }^{180}$

Estados han ido más allá de lo que cabe suponer como razonable en el marco de una democracia constitucional; al respecto, véase la bibliografía citada en la nota al pie 57.

180 Algunos ejemplos de cómo la dignidad humana ha sido aplicada en la jurisprudencia alemana y francesa de los últimos años pueden verse en Alarcón, Gonzalo, "La dignidad como valor y como derecho en la perspectiva constitucional", cit., pp. 2449-2453. 
Este libro forma parte del acervo de la Biblioteca Jurídica Virtual del Instituto de Investigaciones Jurídicas de la UNAM

\title{
EL FEDERALISMO Y EL GENTRALISMO COMO IDEOLOGÍAS CONSTRUCTORAS DEL ESTADO MEXICANO
}

\author{
José Isidro SAUCEDo GONZÁLEZ*
}

\begin{abstract}
SUMARIO: I. Introducción. II. Los primeros constituyentes mexicanos: federalistas. III. Las legislaturas del Congreso. IV. Congreso Constituyente de 1835-1836: centralista. V. Las Bases Orgánicas de la República Mexicana de 1843: centralismo e intolerancia. VI. El Proyecto de Constitución: federalista. VII. La Constitución Política de la República Mexicana (Constitución de 1857): federalismo. VIII. La Constitución de 1917: federalista y presidencialista. IX. Conclusiones. X. Bibliografia.
\end{abstract}

\section{INTRODUCGIÓN}

Este documento es el primero en torno a una revisión sistemática sobre la historia de los constituyentes mexicanos para apreciar la forma en que sus decisiones, con reconocida carga ideológica, han impactado a favor o en contra de nuestro proceso revolucionario. En tal sentido vemos que la historia constitucional mexicana tiene bandos ideológicos como los motores del avance, el retroceso y el estancamiento político de nuestro país. Los responsables directos han sido los constituyentes que propusieron y votaron texto a texto las formas legales para regular una forma general de la sociedad mexicana emergida desde la Revolución de Independencia.

La pregunta metodológica que nos hicimos fue la siguiente: ¿cómo es que las ideologías de los individuos impactan la toma de decisión en favor o en contra de los procesos revolucionarios a tal grado que han llegado a con-

* Doctor en filosofía por la UNAM, profesor en la División de Estudios de Posgrado de la Facultad de Derecho de la UNAM y editor en el Instituto de Investigaciones Jurídicas de la UNAM. Investigador Nacional nivel 1 del Conacyt; isidro_saucedo@hotmail.com. Agradezco las aportaciones críticas de Enrique Sánchez y Ricardo Hernández que me permitieron lograr las precisiones referenciales de las obras citadas. 
Este libro forma parte del acervo de la Biblioteca Jurídica Virtual del Instituto de Investigaciones Jurídicas de la UNAM

figurar bandos ideológicos como impulsores de un proceso histórico? Este cuestionamiento contiene la expectativa de que tales ideologías están presentes en nuestros documentos fundamentales, como el Decreto Constitucional para la Libertad de la América Mexicana y las subsecuentes Constituciones.

Pero también contiene una segunda pregunta, y es qué entendemos por ideología. ${ }^{1}$ Luis Villoro encuentra que se trata de un pensamiento filosófico que se transforma en acción política. La reflexión filosófica tiene como función esclarecer y, a su vez, dotar a la acción de un propósito normativo "El pensamiento clarifica la práctica, la práctica cumple el pensamiento... Es la liga entre teoría y práctica, la significación de las ideas varía con la función que desempeñan". ${ }^{2}$ Así, las ideas son el vehículo en movimiento, y este acontecer es lo ideológico, de donde el mismo autor nos informa que "El pensamiento ideológico no permanece estático", ${ }^{3}$ es decir, se encuentra en constante movimiento. Son las ideologías las que han orientado los destinos históricos de este país.

En primer lugar, considero que la deuda con España aún no ha sido cubierta del todo. La Constitución de Cádiz rigió nominalmente en el territorio de la Nueva España, pero su inaplicación fue tan real como los brotes insurreccionales que detonaron en esa época el espíritu rebelde, insurgente, antirrealista e independentista; pero perviven en nuestros textos constitucionales algunas de sus formas jurídicas, como el juramento o protesta.

En segundo lugar, nuestro Decreto Constitucional para la Libertad de la América Mexicana - como primer documento fundamental- exclama

1 Luis Villoro propuso una interpretación del término ideologías en su libro La Revolución de Independencia (México, UNAM, 1952); fue el primer título que empleó para referir el proceso transformador que permitió la separación política de México con respecto a España. La segunda edición llevaría por nombre El proceso ideológico de la Revolución de Independencia (México, SEP-UNAM, 1981). Es notorio el añadido al primer título del mismo nombre: "El proceso ideológico"; ¿por qué Villoro querría precisar un aspecto de la Revolución de Independencia? La respuesta creemos encontrarla en un ensayo que publicó en 1963 y que se denominó "Las corrientes ideológicas de la época de la independencia" en el libro Estudios de historia de la filosofía en México (México, UNAM, 1963); dicho ensayo, años después tuvo cierta aparición justificativa en el "Prólogo" a la segunda edición mencionada: fueron "retoques de interpretación" que respondían "mejor al contenido real del libro" (op. cit., pp. 7 y 8). El cambio de título y el ensayo entre ambas ediciones fueron las motivaciones que me hicieron reflexionar en la necesidad de repensar la presencia de las ideologías de los hombres que empezaron las transformaciones históricas de nuestro país. Esa es la razón histórica, pues también tenemos la razón o motivación política y ésta se refiere a las formas de suma facilidad con que algunos políticos mexicanos cambian de organización partidaria, como si su raigambre ideológica no fuera sólida.

2 Villoro, Luis, "Las corrientes ideológicas de la época de la independencia", en varios autores, Estudios de historia de la filosofia en México, México, UNAM, 1963, p. 170.

3 Idem. 
Este libro forma parte del acervo de la Biblioteca Jurídica Virtual del Instituto de Investigaciones Jurídicas de la UNAM

toda la fuerza revolucionaria de un pueblo en armas. Se trata del texto fundador del espíritu separatista, liberador y concreto de las aspiraciones criollas y de las castas que habitaban la Nueva España, o sea México desde ese momento de 1814 en adelante.

En tercer lugar, conviene acercarse a quienes han mostrado un panorama constitucional desde que México inició su independencia, como Emilio Rabasa, político porfirista, quien traza el devenir constitucionalista en un libro que conviene releer ahora que se celebra el centenario de nuestra Constitución de 1917, misma que fue producto tanto de un propósito reformador de la Constitución de 1857 como de un movimiento armado que cristalizaría en la expulsión del dictador Porfirio Díaz y en la instalación de una figura de gobierno formal que fue la República, pero con un predominio personal de quien ostentaría la banda presidencial: el presidencialismo.

Las viejas fórmulas de lucha entre realistas e insurgentes, así como entre conservadores y liberales, se transformaron entre revolucionarios y reaccionarios; pero de ambos emergió la sociedad política con que hoy contamos, por eso es imprescindible un análisis que no excluya a ninguno de los participantes en la disputa por los destinos nacionales.

Hoy iniciamos el estudio de nuestros constituyentes y sus Constituciones con el aporte de Emilio Rabasa y con dos de sus críticos: Daniel Cosío Villegas y Diego Valadés, quienes nos permiten valorar las aportaciones del constitucionalista que vivió de 1856 a 1930.

\section{LOS PRIMEROS CONSTITUYENTES MEXICANOS: FEDERALISTAS}

El 24 de febrero de 1822 se congregó el primer constituyente de México y se disolvió por decreto de Agustín de Iturbide el 31 de octubre de ese mismo año. Ocho meses vivió nuestro primer ejercicio parlamentario.

Desde ese Congreso, Rabasa es demoledor, pues con la responsabilidad de constituir a México en una monarquía moderada a cuyo frente iba a estar un príncipe español, el populacho proclamó emperador a Iturbide y el Congreso aceptó la imposición; pero cuando éste pretendió recobrar su libertad perdida, Iturbide lo disuelve. Para Rabasa - a juicio de Daniel Cosío Villegas - ése resultó un antecedente fatal, pues "la idea democrática fue así destruida en su germen; la fe en los principios que la alimentan vaciló desde entonces". ${ }^{4}$

4 Cosío Villegas, Daniel, La Constitución de 1857 y sus críticos, México, Fondo de Cultura Económica-El Colegio Nacional-Clío, 2007, p. 76. 
Este libro forma parte del acervo de la Biblioteca Jurídica Virtual del Instituto de Investigaciones Jurídicas de la UNAM

El segundo Congreso se reunió al año siguiente. El 7 de noviembre de 1823 quedó instalado y el 31 de enero de 1824 aprobó el Acta Constitutiva de la Federación Mexicana. ${ }^{5}$

Emilio O. Rabasa anota que el Acta Constitutiva de la Federación Mexicana y la Constitución Federal de los Estados Unidos Mexicanos aprobadas el mismo año, aunque en diferentes meses (el Acta en enero y la Constitución en octubre), constituyen un "todo orgánico-constitucional". ${ }^{6}$

A la distancia histórica, los primeros constituyentes fueron preponderantemente federalistas, pero también estaban marcados algunos por el enfoque centralista de la monarquía española. No obstante, el federalismo fue el que predominó en nuestra primera Constitución y los primeros constituyentes que se encargaron de adoptarlo fueron los 98 siguientes:

(1) Lorenzo de Zavala, (2) Manuel Crescensio Rejón, (3) José María Sánchez, (4) Fernando Valle, (5) Pedro Tarrazo y (6) Joaquín Casares y Armas (Yucatán); (7) Florentino Martínez y (8) José Ignacio Gutiérrez (Chihuahua); (9) Miguel Ramos Arizpe y (10) Erasmo Seguín (Coahuila y Texas); (11) Francisco Antonio Elorriaga y (12) Pedro Ahumada (Durango); (13) Juan Ignacio Godoy, (14) Víctor Márquez, (15)José Felipe Vázquez, (16)José María Anaya, (17) Juan Bautista Morales, (18) José María Uribe y (19) José Miguel Llorente (Guanajuato); (20)Juan Rodríguez, (21) Juan Manuel Assorrey, (22) José Francisco de Barreda, (23) José Basilio Guerra, (24) Carlos María Bustamante, (25) Ignacio de Mora y Villamil, (26) José Ignacio González Caralmuro, (27) José Hernández Chicho Condarco, (28) José Ignacio Espinosa, (29) Luciano Castorena, (30) Luis de Cortázar, (31) José Agustín Paz, (32) José María de Bustamante, (33) Francisco María Lombardo, (34) Felipe Sierra, (35) José Cirilo Gómez y Anaya y (36) Francisco Patiño y Domínguez (Estado de México); (37) José María de Izazaga, (38) Manuel Solórzano, (39) José María de Cabrera, (40) Ignacio Rayón y (41) Tomás Arriaga (Michoacán); (42) Servando Teresa de Mier (Nuevo León); (43) Nicolás Fernández del Campo, (44) Víctor de Manero, (45) Demetrio del Castillo, (46) Joaquín de Miura y Bustamante, (47) Vicente Manero Embides, (48) Manuel José Robles, (49) Francisco de Larrazábal y Torre, (50) Francisco Estévez y (51) José Vicente Rodríguez (Oaxaca); (52) Mariano Barbosa, (53) José María de la Llave, (54) José de Sanmartín, (55) Rafael Mangino, (56) José María Jiménez, (57) José Mariano Marín, (58) José Vicente de Robles, (59) José Rafael Berruecos, (60) José Mariano Castillero, (61) José María Pérez Dunslaguer, (62) Alejandro Carpio, (63) Mariano Tirado Gutiérrez, (64) Ignacio Zaldívar, (65) Juan de Dios Moreno, (66) Juan Manuel Irrizarri, (67) Miguel Wenceslao Gasca y (68) Bernardo Cop-

5 Rabasa, Emilio O., Historia de las Constituciones mexicanas, 3a. ed., México, UNAM, Instituto de Investigaciones Jurídicas, 2008, p. 16.

6 Idem. 
Este libro forma parte del acervo de la Biblioteca Jurídica Virtual del Instituto de Investigaciones Jurídicas de la UNAM

co (Puebla); (69) Félix Osores y (70) Joaquín Guerra (Querétaro); (71) Tomás Vargas, (72) Luis Gonzaga Gordoa y (73) José Guadalupe de los Reyes (San Luis Potosí); (74) Manuel Fernández Rojo, (75) Manuel Ambrosio Martínez de Vea, (76) José Santiago Escobosa y (77) Juan Bautista Escalante y Peralta (Sonora y Sinaloa); (78) Pedro Paredes (Tamaulipas); (79) José Miguel Guridi y Alcocer (Tlaxcala); (80) Manuel Argüelles y (81) José María Becerra (Veracruz); (82) José María Covarrubias, (83) José de Jesús Huerta, (84) Juan de Dios Cañedo, (85) Rafael Aldrete y (86)Juan Cayetano Portugal (Jalisco); (87) Valentín Gómez Farías, (88) Santos Vélez, (89) Francisco García y (90)José Miguel Gordoa (Zacatecas); (91) Manuel Ortiz de la Torre (territorio de Baja California); (92) José María Jerónimo Arzac (territorio de Colima); (93) Rafael Alarid, (94) Manuel de Vega y Cosío (territorio de Nuevo México); (95) Epigmenio de la Piedra (Veracruz); (96) José María Castro (México); y (97) José María Castro y (98) Juan José Romero (Jalisco). ${ }^{7}$

\section{LAS LEGISLATURAS DEL CONGRESO}

Al Congreso mexicano también hay que identificarlo a través de sus legislaturas. Por ejemplo, comenzó en la V Legislatura, en 1834, y fue de corte liberal. También en junio de ese mismo año se dio una confrontación entre el presidente (Antonio López de Santa Anna) y el Congreso, impidiendo a aquél excederse en el ejercicio de sus atribuciones, pues pretendía derogar algunas leyes anticlericales.

Santa Anna hizo circular una disposición en la que instruía suspender las leyes anticlericales. La VI Legislatura, reunida en enero de 1835, prosiguió el conservadurismo clerical y cesó a Valentín Gómez Farías como vicepresidente; redujo la milicia en los estados, el Distrito Federal y los territorios federales; Zacatecas se opuso con argumentos de la Constitución de 1824, pero Santa Anna expidió una ley el 2 de mayo de 1835 bajo el argumento de que el Congreso tenía facultades extraconstitucionales para alterar su contenido.

Ese cambio fue la forma de gobierno. Y la VI Legislatura prepararía el terreno para la reforma constitucional que haría centralista a la república.

\section{Congreso Constituyente De 1835-1836: CEnTralista}

El Consejo de Gobierno señalado en la Constitución de 1824 convocó a sesión extraordinaria del Congreso General con base en el artículo 116, frac-

7 Rabasa, Emilio O., Historia de las constituciones mexicanas, cit., pp. 25 y 26. 
Este libro forma parte del acervo de la Biblioteca Jurídica Virtual del Instituto de Investigaciones Jurídicas de la UNAM

ción III. Hubo una Junta Preparatoria el 16 de julio de 1835, y se acordó entrar en sesión tres días después con un punto de la orden del día contrario a la Constitución: reformar la forma de gobierno de la nación mexicana (en oposición al artículo 171).

El 22 de septiembre de 1835 se expidió una ley mediante la cual el Congreso asumía las funciones conferidas a las cámaras de Diputados y Senadores, "quedando suspendidos los artículos del Acta Constitutiva, de la Constitución General, así como del Reglamento Interior de Congreso". ${ }^{8}$

En los distintos estados reinaba la confusión, pues las legislaturas locales carecían de autoridad por no haberse reunido en tiempo y forma para entenderse de asuntos como el cambio del sistema federal por el centralista en tanto forma de gobierno.

Hubo necesidad de proponer una Comisión formada por los centralistas Sánchez de Tagle, Antonio Pacheco Leal, José María Cuevas, José Ignacio de Anzorena y Miguel Valentín; el resultado de las sesiones fue un proyecto obviamente centralista publicado el 3 de octubre de 1835. Uno de sus puntos ofrecía la posibilidad legislativa de otorgar a los órganos de gobierno provisionales capacidad de dictar medidas preventivas contra el federalismo. Otros puntos eran conservar en sus funciones a los gobernados aun cuando por ley ya habían cumplido su mandato, pero siempre y cuando asumieran el mandato del Supremo Gobierno de la Nación y no de sus legislaturas. Obligaron a las legislaturas locales a su disolución previo nombramiento de Juntas Departamentales; asimismo, los jueces y tribunales permanecerían en sus funciones hasta en tanto no hubiera la legislación correspondiente a esa rama del poder.

Así, como dice Rabasa, en 1835 se inaugura el centralismo como forma de gobierno para México; sus ideólogos formados en comisión veían un país con "gobernados insolentes" y "gobernantes tímidos", "leyes sospechadas de insubsistencia y... sin vigor", legislaturas sin prestigio ni fuerza moral. ${ }^{9}$ En otras palabras, México demandaba cambios, por eso propusieron a esos hombres con perfil centralizador para un gobierno que reuniera el poder en un Supremo Poder Conservador.

De ahí se entiende por qué el segundo proyecto de la Comisión publicaría veinte días después las Bases para la nueva Constitución (23 de octubre de 1835). De este documento emergieron las Siete Leyes Constitucionales. La primera Ley Constitucional se promulgó el 15 de diciembre de 1835; tuvo 15 artículos, entre los cuales se obligaba a profesar a los mexicanos la

\footnotetext{
8 Ibidem, p. 34.

9 Ibidem, p. 36.
} 
Este libro forma parte del acervo de la Biblioteca Jurídica Virtual del Instituto de Investigaciones Jurídicas de la UNAM

religión católica y cooperar con los gastos del Estado y defender a la patria; en contraparte, tenían derecho a no ser privados de sus propiedades y que no procedería el cateo de casas y papeles; asimismo, se proclamaba la libertad de tránsito y de imprenta.

La segunda de las Siete Leyes Constitucionales constaba de 23 artículos y contemplaba "la creación de un exótico 'Supremo Poder Conservador', compuesto por cinco miembros que podrían ser reelectos". ${ }^{10}$ Entre sus funciones estaba declarar nulas leyes o decretos, actas del Ejecutivo y de la Suprema Corte de Justicia, "declarar la incapacidad física o moral del presidente de la República, suspender a la Suprema Corte de Justicia [y] calificar las elecciones de los senadores... Se decretó que el Supremo Poder sólo era responsable ante Dios y la opinión pública... y sus individuos... no podían ser juzgados ni reconvenidos por sus opiniones". ${ }^{11}$

La más importante de las Siete Leyes, para nuestros fines, la constituye la tercera, pues en ella se establece con claridad en dónde residiría el Poder Legislativo, que no es otro que el Congreso General de la Nación, compuesto por dos cámaras, una de diputados y otra de senadores. A esta última correspondía aprobar o desaprobar los proyectos presentados por los diputados, el Ejecutivo o la Suprema Corte sin hacerle modificaciones.

La Cuarta Ley establecía la organización del Poder Ejecutivo, depositado en un "supremo magistrado" y duraría ocho años en el cargo con posibilidades de reelección. Asimismo, esta Ley establecía la conformación de cuatro ministros: interior, relaciones exteriores, hacienda y guerra y marina.

La Quinta Ley organizaba al Poder Judicial, que descansaba en la Suprema Corte de Justicia, los tribunales superiores de los departamentos, los de Hacienda y juzgados de primera instancia.

La Sexta Ley dividió al territorio de la República Mexicana y fijó su forma de gobierno. De la división hecha resultaron los departamentos; de éstos, los distritos y de éstos, a su vez, los partidos. Los gobernadores de los departamentos eran nombrados por el Ejecutivo y duraban ocho años en el puesto, con posibilidad de ser reelectos. Cada departamento contaba con una Junta que, entre otras facultades, iniciaba leyes de impuestos, educación pública, industria, comercio y administración municipal.

La última Ley constitucional impedía hacer modificaciones a la Constitución en los siguientes seis años de promulgada. Se ha dado fecha de culminación de la Constitución el 6 de diciembre de 1836. Pero con ella no

\footnotetext{
10 Ibidem, p. 37.

11 Idem.
} 
Este libro forma parte del acervo de la Biblioteca Jurídica Virtual del Instituto de Investigaciones Jurídicas de la UNAM

terminaron los problemas, ya que Texas se independizó, Yucatán amenazaba con hacerlo y se acrecentaba la intención de una invasión extranjera.

Francia reclamaría indemnizaciones a sus conciudadanos por la devaluación de la moneda de cobre decretada el 8 de marzo de 1837. Al año siguiente, México se declaró en guerra con Francia y en 1839 se firmaría un Tratado de Paz. En cuanto a las intenciones separatistas de Yucatán, se resolvió en diciembre de 1843 mediante un convenio en el que se reconocía al gobierno provisional y a las Bases de Tacubaya.

Las contrariedades políticas de Texas, Yucatán y Francia, se verían incrementadas por las intenciones reformistas de los ideólogos federalistas encabezados por Valentín Gómez Farías en 1840. Ya para ese entonces se había autorizado por el Supremo Poder Conservador para que el Congreso asumiera funciones de Constituyente, contraviniendo el plazo de seis años establecido por la Constitución de 1836.

Sería en 1840 cuando un grupo de constituyentes presentó un proyecto de reformas, entre las cuales figuraba por vez primera el control de constitucionalidad a cargo de la Suprema Corte de Justicia.

El presidente de la República Mexicana en 1841 era Anastasio Bustamante y en su discurso de apertura admitió la situación complicada entre el Congreso y el Ejecutivo; lo mismo diría el presidente del Congreso, Pedro Barajas, al contestarle en ese día 1o. de enero.

Dadas las circunstancias políticas, los generales Mariano Paredes Arrillaga, Gabriel Valencia y Antonio López de Santa Anna propusieron planes reformistas. Fue tal la anarquía, que al cabo de varios meses lograron integrar un Plan de Bases en Tacubaya, y en septiembre de 1841 lo firmaron —además de los mencionados- José Ignacio Gutiérrez, Julián Juvera y José María Tornel.

$\mathrm{Al}$ año siguiente, el 10 de abril de 1842, se realizaron elecciones para diputados; tres meses después se efectuaría la apertura del Congreso General. Se presentaron en él dos proyectos, uno adoptaba el sistema representativo, popular y federal, mientras que el segundo "sostenía el sistema republicano, popular y representativo". ${ }^{12}$

Fue entonces que los habitantes de Huejotzingo, Puebla, desconocieron al Congreso; era el 11 de diciembre de 1842, y para el 6 de enero de 1843 el Gobierno decidió nombrar, con base en la fracción séptima de las Bases de Tacubaya, una Junta Nacional Legislativa.

Los nombres de los 75 (23 menos que el Congreso de 1824) diputados al Congreso Constituyente de 1836 fueron:

12 Ibidem, p. 44. 
Este libro forma parte del acervo de la Biblioteca Jurídica Virtual del Instituto de Investigaciones Jurídicas de la UNAM

(1) Atenógenes Castillero, (2) Rafael Adorno, (3) José Rafael Berruecos, (4) José González y Ojeda, (5) Manuel M. Gorozpe, (6) Antonio Montoya, (7) José María Santelices y (8) Miguel Valentín (Puebla); (9) Tirso Vejo, (10) Mariano Esparza, (11) Antonio Eduardo Valdés y (12) Mariano Medina y Madrid (San Luis Potosí); (13) José Antonio Carrillo y (14) José Mariano Monterde (Baja California); (15) Ignacio Loperena y (16) Manuel Larraínzar (Chiapas); (17)José Antonio Arce (Chihuahua); (18) Víctor Blanco (Coahuila y Texas); (19) Pedro Ahumada y (20) Guadalupe Victoria (Durango); (21) Mariano Chico, (22) Manuel de Cortázar, (23) José Francisco Nájera, (24) Luis de Portugal y (25) Ángel María Salgado (Guanajuato); (26) Basilio Arrillaga, (27) Ángel Besares, (28) Juan Manuel de Elizalde, (29) José María Guerrero, (30) José Francisco Monter y Otamendi, (31) José Ignacio Ormaechea, (32) Francisco Patiño y Domínguez, (33) Agustín Pérez de Lebrija, (34) Gerónimo Villamil y (35) Rafael de Irazábal (Estado de México); (36) José Ignacio de Anzorema, (37) Antonio Cumplido, (38) Isidro Huarte, (39) José R. Malo, (40) Teodoro Mendoza, (41) Luis Gonzaga Movellán y (42) Francisco Manuel Sánchez de Tagle (Michoacán); (43) Carlos María de Bustamante, (43) Demetrio del Castillo, (44) Manuel Miranda, (45) Luis Morales e Ibáñez de Corbera, (46) Manuel Regules y (47) José Francisco Irigoyen (Oaxaca); (48) Mariano Oyarzábal, (49) Ángel García Quintanar y (50) Felipe Sierra (Querétaro); (51) Francisco G. Conde (Sonora); (52) José Palao (Sinaloa); (53) Juan de Dios Salazar (Tabasco); (54) José Antonio Quintero y (55) Juan Martín de la Garza y Flores (Tamaulipas); (56) José María Becerra y (57) José Manuel Moreno Cora (Veracruz); (58) Pedro Barajas, (59) José María Bravo, (60) José María Echaurri, (61) Antonio Pacheco Leal, (62) José Cirilo Gómez y Anaya, (63) José Miguel Pacheco y (64) Joaquín Párres (Jalisco); 65) Wenceslao Alpuche, (66) Néstor Escudero, (67) Gerónimo López de Llergo, (68) Rafael de Montalvo y (69) Tomás Requena (Yucatán); (70)José María del Castillo, (71) Casiano G. Veyna, (72) Pedro María Ramírez, (73)Julián Rivero y (74) José C. Romo (Zacatecas); (75) Bernardo Guimbarda (Nuevo León).

\section{LAS Bases ORgánicas de la RepúbliCa MeXiCANa de 1843: CENTRALISMO E INTOLERANCIA}

Las Bases Orgánicas de 1843 se consideran una nueva Constitución de la República Mexicana, aunque no llevan en sí la nomenclatura de Constitución. Lo relevante de estas bases son sus reiteraciones a la independencia, a la intolerancia de otra religión que no fuera la católica y a que se suprimiera el Supremo Poder Conservador pero dejando al centralismo como forma política de gobierno. 
Este libro forma parte del acervo de la Biblioteca Jurídica Virtual del Instituto de Investigaciones Jurídicas de la UNAM

En cuanto al Congreso, señaló que tenía dos periodos ordinarios; el Ejecutivo podía iniciar leyes, lo mismo que los diputados, las asambleas de los departamentos (congresos locales) y la Suprema Corte. Constituyó cuatro ministerios: 1. Relaciones exteriores, gobernación y policía; 2. Justicia y negocios eclesiásticos, instrucción pública e industria; 3. Hacienda, y 4. Guerra y Marina.

Al Poder Judicial lo integraban la Suprema Corte y los tribunales superiores de los departamentos, los juzgados de primera instancia y los de Hacienda.

Con las Bases Orgánicas de 1843 se inauguró la existencia de una Corte Marcial integrada por generales y letrados; asimismo, se creó un tribunal especial con senadores y diputados para juzgar a los ministros de la Corte.

Se practicó la democracia indirecta al permitir la elección de un elector primario por cada 500 habitantes; electores que a su vez nombraban a un elector secundario, de los que resultaba un Colegio Electoral, el cual nominaba a diputados al Congreso General y vocales a las asambleas locales.

Estas Bases de 1843 establecieron la pena de muerte, se crearon tribunales sin sujeción a derecho y se restringió severamente la libertad de imprenta.

No obstante el fortalecimiento del Poder Ejecutivo con la supresión del Supremo Poder Conservador, la estabilidad del país no era posible; al contrario, tres años después, en 1846, el gobierno estadounidense inició la invasión a México luego de la anexión de Texas en 1845. Ante ello, Mariano Salas convocó desde la Ciudadela a un Congreso, el cual inició sus sesiones el 6 de diciembre de 1846. Entre sus asistentes figuraban: Mariano Otero, Crescencio Rejón, Valentín Gómez Farías y Benito Juárez.

Los miembros de la Junta Nacional Legislativa que emitieron las Bases Orgánicas en 1843 fueron 67, y son los siguientes:

(1) Manuel Baranda, (2) Cayetano Ibarra, (3) José María Aguirre, (4) Ignacio Alas, (5) Basilio Arrillaga, (6) José Arteaga, (7) Pedro Agustín Ballesteros, (8) Pánfilo Barasorda, (9) José Ignacio Basadre, (10) Manuel Diez de Bonilla, (11) José de Caballero, (12) Sebastián de Camacho, (13) Tiburcio Cañas, (14) Martín Barrera, (15) Crispiano del Castillo, (16) José Fernández de Orlis, (17) Luis G. Chávarri, (18) José Florentino Conejo, (19) José Gómez de la Cortina, (20) Mariano Domínguez, (21) Pedro Escobedo, (22) Rafael Espinosa, (23) Pedro García Conde, (24) Simón de la Garza, (25) Juan de Goríbar, (26) José Miguel Garibay, (27) Antonio de Icaza, (28) Juan Manuel Arzobispo de Cearea, (29) José María Iturralde, (30) Juan Icaza, (31) Manuel Larraínzar, (32) Joaquín Lebrija, (33) Francisco Lombardo, (34) Diego Moreno y Jove, (35) José Francisco Nájera, (36) Juan Gómez de Navarrete, (37) Francisco Or- 
Este libro forma parte del acervo de la Biblioteca Jurídica Virtual del Instituto de Investigaciones Jurídicas de la UNAM

tega, (38) Juan de Orbegoso, (39) Antonio Pacheco Leal, (40) Manuel Payno Bustamante, (41) Manuel de la Peña y Peña, (42) Tomás López Pimentel, (43) Manuel Arzobispo de México, (44) Andrés Pizarro, (45) José María Puchet, (46) Andrés Quintana Roo, (47) Santiago Rodríguez, (48) Romualdo Ruano, (49) Juan Rodríguez de San Miguel, (50) Gabriel Sagaseta, (51) Vicente Sánchez Vergara, (52) Vicente Segura, (53) Gabriel de Torres, (54) Gabriel Valencia, (55)José Mariano Vizcarra, (56) Hermenegildo de Viya y Castro, (57) José Manuel Zozaya, (58) Luis Zuloaga, (59) Miguel Cervantes, (60) Manuel Dublán, (61) Mariano Pérez Tagle, (62) Urbano Fonseca, (63) Manuel Rincón, (64) Juan José Quiñones, (65) Juan Martín de la Garza y Flores, (66) José Lázaro Villamil y (67) José María Cora.

\section{El Proyecto de CONSTituGión: FEDERALista}

El 6 de diciembre de 1846, el Congreso mexicano con facultades de Constituyente, nombró una comisión con el encargo de elaborar un Proyecto de Constitución. Estuvo integrada por J. J. Espinosa de los Monteros, Manuel Crescencio Rejón, Mariano Otero, Joaquín Cardoso y Zubieta.

No emergió otra Constitución sino un Acta de Reformas, donde quedó establecido el sistema federal como forma de gobierno, la edad de 25 años para poder ser elector y la incorporación en el artículo 25 de la figura del amparo constitucional. Fue firmada el 18 de mayo de 1847; sus congresistas fueron 81 (14 más que en el Congreso anterior):

(1) José Joaquín de Herrera; (2) Clemente Castillejo y (3) Pedro José Lanuza (Chiapas); (4) José María Urquide, (5) Manuel Muñoz y (6) José Agustín Escudero (Chihuahua); (7) Eugenio María de Aguirre (Coahuila); (8) José de la Bárcena (Durango); (9) Octaviano Muñoz Ledo, (10) Pascasio Echeverría, (11) Juan José Bermúdez, (12) Jacinto Rubio, (13) Juan B. Sañudo y (14) Ramón Reynoso (Guanajuato); (15) Juan José Espinosa de los Monteros, (16) Manuel Robredo, (17) Joaquín Navarro, (18) José María de Lacunza, (19) Mariano Riva Palacio, (20) José B. Alcalde, (21) Manuel Terreros, (22) José A. Galindo, (23) Manuel M. Medina, (24) Ramón Gamboa, (25) J. Noriega, (26) Pascual González Fuentes, (27) José Trinidad Gómez, (28) José María Benítez, (29) Francisco Herrera Campos, (30) Agustín Buenrostro y (31) Francisco S. Iriarte (Estado de México); (32) Juan B. Cevallos, (33) E. Barandiarán, (34) Luis Gutiérrez Correa, (35) Miguel Zincúnegui, (36) Ignacio Aguilar, (37) José Ignacio Álvarez, (38) Teófilo G. Carrasquero y (39) Manuel Castro (Michoacán); (40) Benito Juárez, (41) Guillermo Valle, (42) B. Carbajal, (43) M. Iturribarría, (44) Tiburcio Cañas, (45) Francisco Banuet, (46) Manuel M. de Villada y (47) M. Ortiz de Zárate (Oaxaca); (48) José 
Este libro forma parte del acervo de la Biblioteca Jurídica Virtual del Instituto de Investigaciones Jurídicas de la UNAM

María Lafragua, (49) Ignacio Comonfort, (50) Joaquín Cardoso, (51) Joaquín Ramírez de España, (52) Manuel Zetina Abad, (53) J. Ambrosio Moreno, (54) Juan N. De la Parra, (55) José M. Espino, (56) Mariano Talavera, (57) Juan de Dios Zapata y (58) Fernando M. Ortega (Puebla); (59) José Ignacio Yáñez y (60) Miguel Lazo de la Vega (Querétaro); (61) Lugardo Lechon, (62) Juan Othón y (63) Domingo Arriola (San Luis Potosí); (64) Pomposo Verdugo (Sinaloa); (65) Ricardo Palacio y (66) Ramón Morales (Sonora); (67) Manuel Zapata (Tabasco); (68) Ignacio Muñoz Campuzano (Tamaulipas); (69) A. M. Salonio, (70) José Mariano Jáuregui y (71) Miguel Bringas (Veracruz); (72) Mariano Otero, (73) Bernardo Flores, (74) Cosme Torres, (75) Magdaleno Salcedo y (76) José Ramón Pacheco (Jalisco); (77) Manuel Buenrostro, (78) José María del Río y (79) Joaquín Vargas (Distrito Federal); (80) Antonio Rivera López, y (81) José M. Berriel (Tlaxcala).

\section{La Constitución Política de la República Mexicana (CONSTITUCiÓn DE 1857): FEDERALISMO}

Sobresale el perfil ideológico de las tres corrientes que conformarían el Congreso Constituyente: los liberales, los conservadores y los moderados. Esta Constitución Política de la República Mexicana entró en vigor el 16 de septiembre de 1857.

No obstante con esas situaciones como contexto en el proceso independentista, Rabasa "achaca muchos de los defectos técnicos y de fondo a las situaciones equívocas que creó la mezcla de liberales moderados y puros... el Congreso [Constituyente] fue concebido, en suma, como un freno al poder dictatorial que por necesidad tendría el caudillo de una revolución triunfante". Y la "Constitución — concluye Rabasa - fue así el resultado necesario de una serie de transacciones y concesiones, lejos de ser la expresión de un credo político uniforme". ${ }^{13}$

En forma relacionada, el Constituyente del 56 (el productor) y la Constitución del 57 (su producto), fueron resultado de los "signos nefastos" emanados de la presencia del partido moderado, "pues produjo la natural confusión de quien se planta en el centro de una contienda para obsequiar los deseos de todos como medio de acabar con ella". ${ }^{14}$

Autores como Enrique Olavarría y Ferrari consideran la circunstancia constitucional como "verdadera fecha [1857] de la independencia y soberanía nacional". ${ }^{15}$

13 Cosío Villegas, Daniel, La Constitución de 1857 y sus críticos, cit., p. 79.

14 Ibidem, p. 79.

15 Arias, Juan de Dios y Olavarría y Ferrari, Enrique, "México Independiente (1821- 
Este libro forma parte del acervo de la Biblioteca Jurídica Virtual del Instituto de Investigaciones Jurídicas de la UNAM

Ignacio Comonfort era el líder de los moderados (Vidaurri, Comonfort, Ocampo, Álvarez). Benito Juárez sería de los liberales, mientras que Antonio López de Santa Anna lo sería de los conservadores. La moderación de Comonfort estaba en gran medida influida por su conciencia religiosa, propio de la época, sobre todo debido a la cercanía de su madre, quien le había inculcado un fuerte sentimiento clerical.

"Rabasa en su tiempo y nosotros - dice Cosío Villegas - en el nuestro, sabemos que los moderados dominaron en el Constituyente de 56 y que por eso resultó moderada la Constitución que hicieron". ${ }^{16}$ Opinión que es matizada por Anselmo de la Portilla, quien fue testigo de esa época y escribió que:

Al Constituyente fueron "las personas más exaltadas del partido liberal" y que "en el Congreso prevalecieron las más avanzadas teorías de la escuela revolucionaria". Comonfort, el liberal moderado por antonomasia, creyó recoger el sentimiento nacional cuando dijo que el país quería "reparar todos los infortunios pasados, conciliar todos los intereses presentes y proteger todas las esperanzas futuras". ${ }^{17}$

Rabasa menciona a un conjunto de Constituyentes, que impregnaron su sello ideológico a la Constitución de 1857. Es - dice - "el más ilustrado de nuestra historia política. Sobrepasó al de 1824 que había contado con el acervo cultural de, entre otros, Miguel Ramos Arizpe y Servando Teresa de Mier" ${ }^{18}$ Ahí se recordó al primero por su separatismo en Nuevo León y Coahuila; al segundo no se le recordó, pero sí a Manuel Crescencio Rejón, "liberal distinguido" y José María Luis Mora por su oposición a la retroactividad de las leyes.

Como liberales puros, Rabasa coloca a Francisco Zarco, León Guzmán, Ignacio Ramírez, Guillermo Prieto, Joaquín Ruiz, Santos Degollado e Isidoro Olvera. "Varias de las aportaciones de Degollado y de Olvera fueron importantes; Olvera, por ejemplo, a más de su famoso voto particular sobre la propiedad, presentó otro sobre la Constitución en general y proyecto de ley sobre libertad de imprenta y sobre facultades extraordinarias del Ejecutivo en épocas de necesidad, medida que hubiera ahorrado a la República muchos dolores de cabeza en los 20 años siguientes". ${ }^{19}$

1855)", en Riva Palacio, Vicente (coord.), México a través de los siglos, México, Ballescá-Espasa, 1880, t. IV, p. 825.

16 Cosío Villegas, Daniel, La Constitución de 1857 y sus críticos, cit., p. 80.

17 Idem.

18 Rabasa, Emilio O., Historia de las constituciones mexicanas, cit., p. 63.

19 Cosío Villegas, Daniel, La Constitución de 1857 y sus críticos, cit., p. 71. 
Este libro forma parte del acervo de la Biblioteca Jurídica Virtual del Instituto de Investigaciones Jurídicas de la UNAM

Cosío Villegas critica a Rabasa por el abandono reflexivo hacia otros constituyentes:

Rabasa no estudió a fondo... las aportaciones de las 20 primeras figuras del Constituyente; por eso habrá varias sorpresas cuando se estudien. Ignacio Mariscal, por ejemplo, una figura aparentemente menor, fue el autor del dictamen sobre ratificación de la ley Juárez del 23 de noviembre de 55; Mata, que pasa por simple segunda voz de Arriaga, llevó el peso de la Comisión de Constitución en el debate más prolongado, el de la libertad de cultos; Vallarta, también figura secundaria, tuvo tres intervenciones largas y notables, una sobre libertad industrial y otras dos para oponerse al juicio por jurados y al restablecimiento de la Compañía de Jesús; Ocampo condujo la defensa de la comisión en el delicadísimo debate sobre la suspensión de las garantías individuales; de Santos Degollado es el proyecto de ley orgánica electoral... ${ }^{20}$

Aunque reconoce los comentarios de elogio que le merecieron los constituyentes de esa generación al decir que:

De ningún Congreso mexicano salió un grupo de hombres tan famosos como del Constituyente del 56. Ocurre pensar, sin embargo, que de él estuvieron ausentes varios que hicieron la historia inmediata del país, u hombres que ya para entonces tenían un nombre hecho. Entre los primeros están Miguel y Sebastián Lerdo de Tejada, Ignacio Zaragoza y Porfirio Díaz; entre los segundos, Manuel Doblado, Santiago Vidaurri, José María Iglesias, Manuel María de Zamacona, Manuel Payno...21

La convocatoria al Congreso Constituyente indicaba que se nombraría un diputado por cada 50,000 almas y podría representar a varios estados. Un ejemplo de esto fue Ponciano Arriaga, quien fue electo por San Luis Potosí, Guerrero, Jalisco, México, Michoacán, Puebla, Zacatecas y Distrito Federal, o sea ocho estados, con lo cual se aseguraba un sesgo liberal de $25 \%$ sobre cualquier votación, al haber 32 representaciones. Asimismo, fue electo presidente del Congreso. Al cabo de 141 sesiones, el Congreso culminó con una nueva Constitución dividida.

Ya desde el proyecto de Constitución emerge un concepto paradigmático en el texto: los derechos del hombre, así como otro gran tema trascendental en la forma de gobierno de los mexicanos: el federalismo. La de 1857 recuperó el espíritu ideal de la república, así como el de la soberanía residente en el pueblo.

$20 \quad$ Ibidem, pp. 71 y 72.

21 Ibidem, p. 73. 
Este libro forma parte del acervo de la Biblioteca Jurídica Virtual del Instituto de Investigaciones Jurídicas de la UNAM

También quedaron como propuesta la supresión del Senado y sólo serían los diputados quienes serían el Poder Legislativo; el amparo en sentido ampliado pues esta vez se formulaba para resolver controversias "por leyes o actos de cualquier autoridad que violaren las garantías individuales o de la Federación". ${ }^{22}$

Se estableció el juicio político mediante un jurado dual: el de acusación y el de sentencia.

La Constitución de 1857 tuvo ciertas características políticas que considero rescatables. La primera la ofrece Rabasa cuando anota la división de los redactores del Proyecto presentado el 16 de junio de 1856, ya que una fracción de ella, "se había separado desde el principio de los trabajos" y había acudido a pocas de las "laboriosas y debatidas conferencias". ${ }^{23} \mathrm{La}$ segunda se refiere a la forma de gobierno, pues la disputa entre centralistas y federalistas quedaba registrada en la discusión del artículo 4o. (libertad de oficios), el cual finalmente fue aprobado por el Congreso General el 9 de septiembre de 1856 por 84 diputados presentes.

Una tercera característica del Proyecto de Constitución es la relativa a los derechos del hombre en su título I, como "la base y el objeto de las instituciones sociales". ${ }^{24}$ Dos características que pueden expresarse, la primera de corte proteccionista, el amparo, y la segunda de corte punitivo, el juicio político con dos jurados, uno de acusación y otro de sentencia.

La soberanía nacional se redimensionó al agregarse el término "originariamente", pues en la de 1824 se anotaba que sólo esencialmente correspondía al pueblo.

Por último, se suprimió al Senado y quedó en Congreso unicameral cuyo Poder Legislativo se había ampliado en número debido a la reducción de representatividad: 30,000 por diputado.

Del número de artículos originalmente presentado por la comisión en el Proyecto de Constitución, se le agregaron dos, pues de 126 aumentó a 128 ya en el texto constitucional.

Conviene apuntar el perfil ideológico de algunos constituyentes de 1857. Por el lado conservador o reaccionario estaban, entre otros, Marcelino Castañeda, que intentaba restaurar la Constitución de 1824, Santos Degollado, Joaquín García Granados, Mariano Arizcorreta (presidente del Congreso) y Juan Antonio de la Fuente. A su vez, los liberales estaban identificados en

22 Rabasa, Emilio O., Historia de las constituciones mexicanas, cit., p. 67.

23 Ibidem, p. 66.

24 Ibidem, p. 67. 
Este libro forma parte del acervo de la Biblioteca Jurídica Virtual del Instituto de Investigaciones Jurídicas de la UNAM

Filomeno Mata, Ponciano Arriaga y Francisco Zarco. En el medio estaban los moderados como Juan Álvarez e Ignacio Comonfort.

En la sesión del 4 de septiembre de 1856, fue votado el Proyecto de Restaurar la Constitución de 1824, y ganó por 54 votos contra 51 de los liberales. En un acto de rebeldía, los liberales protestaron y el presidente del Congreso ordenó enviar el Proyecto a la comisión respectiva, lo cual significaba darle el documento a los liberales. De modo que meses después, el 16 de febrero de 1857, firmada y jurada la nueva Constitución, el proyecto de la Comisión fue archivado.

La libertad religiosa fue otro de los aspectos que resaltaron en el Proyecto de Constitución y en la Constitución misma. Liberales y conservadores la tomaban como bandera política; para los primeros, como Ponciano Arriaga y Francisco Zarco, "ninguna autoridad tenía el derecho a prohibir la libertad de conciencia"; 25 había que declarar la independencia entre el Estado y la Iglesia; la exclusividad religiosa contrariaba los principios republicanos y democráticos.

Cosío Villegas anota lo relevante del tema religioso en la Constitución de 1857: la libertad de cultos fue crucial.

El ministro Luis de la Rosa llevó la voz del gobierno al discutirse en lo general el proyecto de Constitución... José María Lafragua, otro de los ministros, expresó la misma oposición... y todavía otro ministro, Ezequiel Montes, volvió a criticarlo asegurando que la tolerancia religiosa "conmovería a la sociedad hasta sus cimientos y sería contraria a la voluntad de la mayoría absoluta de la nación". 26

En opinión de Valadés en cuanto a la libertad de cultos, nos dice que ésta tiene un factor de carácter social precisamente en el hecho de que la maduración política respecto a la religiosidad en México, emergen desde la Constitución de 1824, aun cuando su contenido sea de intolerancia de credo; pero ya en 1833 se abre la posibilidad de generar espacios de tolerancia y será en 1857 "cuando, a pesar de no haberse declarado expresamente, se establece la tolerancia de cultos como consecuencia ineludible de la libertad de conciencia". ${ }^{27}$

No obstante lo anterior, la participación directa de la Iglesia católica había sido factor de desestabilidad militar y de gobierno, ya que había or-

25 Rabasa, Emilio O., Historia de las constituciones mexicanas, cit., p. 70.

26 Cosío Villegas, Daniel, La Constitución de 1857 y sus críticos, cit., p. 81.

27 Valadés, Diego, "Prólogo", en Rabasa, Emilio, La evolución histórica de México, México, Miguel Ángel Porrúa-UNAM, Coordinación de Humanidades, 1986, p. XLII. 
Este libro forma parte del acervo de la Biblioteca Jurídica Virtual del Instituto de Investigaciones Jurídicas de la UNAM

ganizado y financiado la primera sublevación armada contra el gobierno de Comonfort. Con todo, los rebeldes fueron sometidos pero

Guillermo Prieto, un liberal bien puro, pidió... clemencia para los vencidos... El gobierno había ordenado el cierre del convento de San Francisco... poco tiempo después, un grupo numeroso de personas redactó un escrito pidiendo el levantamiento del castigo. En él se ven las firmas de muchos liberales moderados, pero también las de puros muy conspicuos, como Francisco Zarco y Guillermo Prieto, José María Castillo Velasco, Benito Gómez Farías y Pedro Baranda...28

Los efectos de tal influencia en el texto constitucional se reflejarían en el contenido del famoso artículo 15 del proyecto, que quedó como una adición al artículo 123 de la Constitución de 1857: "Corresponde exclusivamente a los poderes federales ejercer, en materia de culto religioso y disciplina externa, la intervención que designen las leyes". ${ }^{29}$

Así, la Constitución aprobada el 5 de febrero de 1857 quedó compuesta por 128 artículos en ocho títulos y un transitorio. Era una Constitución liberal, con el federalismo como forma de gobierno, la intolerancia religiosa quedó suprimida, los derechos del hombre fueron formulados claramente en 29 artículos; la libertad tuvo apellidos: de enseñanza, de trabajo, de expresión, de imprenta, de petición, de asociación, de portación de armas y de tránsito.

La Constitución de 1857 también prohibió los monopolios y la retroactividad de las leyes; la soberanía nacional la hizo residir esencial y "originariamente" en el pueblo. El Poder Legislativo se convirtió en unicameral, ya que se suprimió la Cámara de Senadores.

Asimismo, quedó configurado el amparo en los artículos 101 y 102; el control judicial ocupó la parte que tenía el control político para conocer de las violaciones de las garantías individuales.

Cosío Villegas en el punto de la designación de ministros a la Corte, anota el acierto de Rabasa:

La elección popular es un malísimo sistema para designar a los magistrados de la Corte; es gravísimo hacer del presidente el vicepresidente de la Repú-

28 Cosío Villegas, Daniel, La Constitución de 1857 y sus críticos, cit., p. 81.

29 Rabasa, Emilio O., Historia de las constituciones mexicanas, cit., p. 71. Con respecto a la participación de la Iglesia católica en ese periodo, es oscura, pues "los archivos eclesiásticos siguen siendo hasta el día de hoy [1957] inaccesibles para el investigador laico", Cosío Villegas, Daniel, La Constitución de 1857 y sus críticos, cit., p. 82. 
Este libro forma parte del acervo de la Biblioteca Jurídica Virtual del Instituto de Investigaciones Jurídicas de la UNAM

blica, porque lo lanza, y con él puede lanzar a la Corte toda, al torbellino de la política; y ciertamente el pueblo puede no resultar el mejor juez para determinar si una persona es tan buen jurista que merezca su exaltación al más alto tribunal de la República. ${ }^{30}$

A su vez, la responsabilidad de los funcionarios públicos establecida en los artículos 103 al 108, configuró los delitos comunes y oficiales: los primeros eran procedentes a juicio del Congreso de la Unión y se turnaban a los tribunales comunes, en tanto que los segundos, el jurado de acusación lo conformaba el Congreso de la Unión, pero la sentencia la hacía la Suprema Corte de justicia.

La Constitución de 1857 fue promulgada por Ignacio Comonfort el 12 de febrero de ese año y publicada el 11 de marzo; el transitorio instruía su vigencia a partir del 16 de septiembre, con excepción de las elecciones de los supremos poderes federales y estatales. En opinión de Diego Valadés, "Al convertirse la Constitución de 1857 en lo que Rabasa denomina «promesa, programa y bandera», se inicia la era constitucional mexicana; era que culmina cuando la misma Constitución es también utilizada como promesa, programa y bandera por Venustiano Carranza". ${ }^{31}$

Los constituyentes de 1857 fueron 94 (número muy cercano al Constituyente de 1824), a saber:

(1) Manuel Buenrostro (Aguascalientes); (2) Francisco Robles y (3) Matías Castellanos (Chiapas); (4) José Eligio Muñoz, (5) Pedro Ignacio Irigoyen (Chihuahua); (6) Simón de la Garza y Melo (Coahuila); (7) Marcelino Castañeda y (8) Francisco Zarco (Durango); (9) Francisco de Paula Cendejas, (10) José María del Río, (11) Ponciano Arriaga, (12) J. M. del Castillo Velasco y (13) Manuel Morales Puente (Distrito Federal); (14) Antonio Escudero, (15) José L. Revilla, (16) Julián Estrada, (17) I. de la Peña y Barragán, (18) Esteban Páez, (19) Rafael María Villagrán, (20) Francisco Fernández de Alfaro, (21) Justino Fernández, (22) Eulogio Barrera, (23) Manuel Romero Rubio, (24) Manuel de la Peña y Ramírez, (25) Manuel Fernando Soto, (26) Isidoro Olvera y (27) León Guzmán (Estado de México); (28) Ignacio Sierra, (29) Antonio Lemus, (30) José de la Luz Rosas, (31) Juan Morales, (32) Antonio Aguado, (33) Francisco P. Montañez, (34) José María Cortés y Esparza, (35) Francisco Guerrero y (36) Blas Balcárcel (Guanajuato); (37) Francisco Ibarra (Guerrero); (38) Espiridión Moreno, (39) Mariano Torres Aranda, (40) Jesús Anaya y Hermosillo, (41) Albino Aranda, (42) Ignacio Luis Vallarta, (43) Beni-

30 Cosío Villegas, Daniel, La Constitución de 1857 y sus críticos, cit., p. 93.

31 Valadés, Diego, "Prólogo", en Rabasa, Emilio, La evolución histórica de México, México, Miguel Ángel Porrúa-UNAM, Coordinación de Humanidades, 1986, p. LXV. 
Este libro forma parte del acervo de la Biblioteca Jurídica Virtual del Instituto de Investigaciones Jurídicas de la UNAM

to Gómez Farías, (44)Jesús D. Rojas, (45) Ignacio Ochoa Sánchez, (46) Guillermo Langlois, (47) Joaquín M. Degollado y (48) Valentín Gómez Farías (Jalisco); (49) Santos Degollado, (50) Sabás Iturbide, (51) Francisco G. Anaya, (52) Ramón I. Alcaraz, (53) Francisco Díaz Barriga, (54) Luis Gutiérrez Correa, (55) Mariano Ramírez y (56) Mateo Echaiz (Michoacán); (57) Manuel P. de Llano (Nuevo León); (58) Mariano Zavala, (59) G. Larrazábal, (60) Ignacio Mariscal, (61) Juan Nepomuceno Cerqueda, (62)J. A. Gamboa, (63) Félix Romero y (64) Manuel E. Goytia (Oaxaca); (64) Miguel María Arrioja, (65) Fernando María Ortega, (66) Guillermo Prieto, (67) J. Mariano Viadas, (68) Francisco Banuet, (69) Manuel M. Vargas, (70) Francisco Lazo Estrada, (71) Juan de Dios Arias, (72) Juan N. Ibarra y (73)Juan N. de la Parra (Puebla); (74) Ignacio Reyes (Querétaro); (75) Francisco J. Villalobos y (76) Pablo Téllez (San Luis Potosí); (77) Ignacio Ramírez (Sinaloa); (78) Benito Quintana (Sonora); (79) Gregorio Payró (Tabasco); (80) Luis García de Arellano (Tamaulipas); (81) José Mariano Sánchez (Tlaxcala); (82) José de Empáram, (83) José María Mata, (84) Rafael González Pérez y (85) Mariano Vega (Veracruz); (86) Benito Quijano, (87) Francisco Iniestra, (88) Pedro de Baranda y (89) Pedro Contreras Elizalde (Yucatán); (90) Joaquín García Granados (Territorio de Tehuantepec); (91) Mateo Ramírez (Territorio de la Baja California); (92) Miguel Auza, (93) Agustín López de Nava y (94) Basilio Pérez Gallardo (Zacatecas). ${ }^{32}$

\section{LA CONSTITUCIÓN DE 1917: FEDERALISTA Y PRESIDENCIALISTA}

Entre 1857 y 1917 distan 60 años. Pero en ese lapso también se encuentran varios sucesos relevantes, como la Guerra de los Tres Años (1857-1861), la invasión francesa (1862-1867), la República Restaurada (1867-1876), la dictadura de Porfirio Díaz (1877-1911) y la Revolución de 1910. Sin embargo, el factor más desestabilizador fue la cuestión religiosa.

En cuanto a reformas constitucionales, el mayor número fue durante los regímenes porfirianos. No obstante, debe considerarse que hubo siete presidentes que en su conjunto reformaron 83 artículos constitucionales.

Formalmente, la Constitución de 1917 es producto de una reforma, según su título original: "Constitución Política de los Estados Unidos Mexicanos que reforma la del 5 de febrero de 1857 " ${ }^{33}$ Asimismo, los diputados que protestaron "guardar y hacer guardar" la Constitución el 31 de enero de 1917, lo hicieron bajo los términos "que reforma la del 5 de febrero de

32 Véase también Memoria politica de México, en wrerc.memoriapoliticademexico.org/Textos/3 Reforma/ 1857CFM.html (consultada el 25 de julio de 2015).

33 Rabasa, Emilio O., Historia de las constituciones mexicanas, cit., p. 79, nota 137. 
Este libro forma parte del acervo de la Biblioteca Jurídica Virtual del Instituto de Investigaciones Jurídicas de la UNAM

1857”, y así se promulgó el 5 de febrero de 1917, sólo que con cambios importantes en sus artículos 3o., 8o., 27, 123, 130 y 131.

La era porfiriana duró poco más de 30 años; en 1877, al asumir la presidencia, se inicia el largo tiempo de Porfirio Díaz en el poder, su salida sería el 25 de mayo de 1911 con su renuncia. Francisco I. Madero asumiría la presidencia de México el 6 de noviembre de 1911, y moriría el 22 de febrero de 1913, al cabo de un levantamiento armado llamado la "Decena trágica", encabezado por Victoriano Huerta, violando el orden constitucional.

Como porfirista, Rabasa hablaría bien del hombre y del político que gobernó a México poco más de 30 años de "honradez acrisolada y firmeza en los principios". Otro elemento moral de Díaz según Rabasa era la tolerancia que, sumado a la disciplina, "lo convirtió en un notable administrador, como lo había hecho antes un buen soldado". ${ }^{34}$ El proyecto reformador de Díaz en su plan de mantenerse en el poder no era transformar el sistema autoritario porfirista en democrático, sino "la mera transformación de la autocracia a la oligarquía". ${ }^{35}$

Con todo, Rabasa - dice Valadés - afirma que el llamado "pueblo bajo" encontraba en el derecho a votar un enigma sin valor:

Hay que admitir, en este punto, cómo los liberales mexicanos se vieron enfrascados en largas y duras luchas para construir la sociedad civil, emancipándolas de las prerrogativas castrenses y eclesiásticas, sin parar mientes en la conveniencia de fortalecer instituciones democráticas cifradas en el apoyo popular, que hicieron viables y duraderas las conquistas constitucionales. ${ }^{36}$

Mi opinión hasta aquí con relación a la actitud de Rabasa hacia las clases populares, fueran indígenas o urbanas, es que muestra una volubilidad perceptiva y crítica, pues, como resalta Valadés,

No puede escapar al lector la palmaria contradicción que existe en el texto de Rabasa [La evolución de México] cuando afirma, en el capítulo quinto, que «la nobleza y generosidad de la raza conquistadora... sirvieron para hacer lo que la colonia tuvo de unidad, a pesar de las dos razas y las dos civilizaciones distanciadas», frente a la tesis externada en el capítulo décimo tercero de que «tres millones de indios... sin una idea ni un sentimiento común que los ligara

34 Valadés, Diego, "Prólogo", en Rabasa, Emilio, La evolución histórica de México, México, Miguel Ángel Porrúa-UNAM, Coordinación de Humanidades, 1986, pp. XIX y XX.

35 Ibidem, p. XLIV.

36 Ibidem, p. LX. 
Este libro forma parte del acervo de la Biblioteca Jurídica Virtual del Instituto de Investigaciones Jurídicas de la UNAM

con la parte consciente de la población, fueron el legado que la nación nueva recibió de la muerta colonia». ${ }^{37}$

Serían Venustiano Carranza, Francisco Villa y Emiliano Zapata quienes encabezarían el movimiento armado que intentaba restablecer el orden constitucional. Mediante el Plan de Guadalupe, en Coahuila, del 27 de marzo de 1913, se desconocía a Victoriano Huerta y se designaba a Venustiano Carranza como jefe del Ejército Constitucionalista para convocar a elecciones.

En 1915, Carranza expidió leyes como la Agraria (6 de enero); reformas al Código Civil (29 de enero) y la de Abolición de Tiendas de Raya (22 de junio). Un año antes había expedido la del Municipio Libre y la de Divorcio (25 de diciembre).

Rabasa anota un criterio fundamental del derecho: "Debe normar la existencia real de los hombres", es decir, debe percatarse de la inoperancia de ciertas leyes y dar cauce a las que requieren las nuevas circunstancias, o sea, la vida real.

Asimismo, Carranza expidió el 14 de diciembre de 1916 el decreto que reformaba los artículos 4o., 5o. y 6o. del decreto del 12 de diciembre de 1914, para anunciar la convocatoria del Constituyente.

Los representantes al Congreso serían un diputado propietario y un suplente por cada 60,000 habitantes o fracción que pase de 20,000; instalado el Constituyente, el Primer Jefe del Ejército Constitucionalista le presentaría el proyecto de Constitución reformada y tendría dos meses para "desempeñar su cometido"; concluido el plazo, expediría la Constitución y el Congreso se disolvería.

Fue el 19 de septiembre de 1916 cuando Carranza convocó al Congreso y el 1o. de diciembre de ese año presentó el proyecto de Constitución.

Las posiciones ideológicas que estuvieron representadas en el Congreso Constituyente de 1916-1917, Rabasa las describe así:

Los carrancistas, Pastor Rouaix, Cándido Aguilar, Luis Manuel Rojas, José Natividad Macías, Alfonso Cravioto y Félix Palavicini, también designados algunos como "renovadores"; los "progresistas o radicales" como Heriberto Jara, Francisco J. Mújica, Luis G. Monzón, Esteban B. Calderón, Rafael Martínez de Escobar y otros; y también, los que se consideraban ajenos a corriente ideológica determinada. ${ }^{38}$

37 Ibidem, pp. LXI y LXII.

38 Véase Romero Flores, Jesús, Historia del Congreso Constituyente 1916-1917, México, UNAM-INEHRM, 2014. En ese libro hay un pasaje que recupera Rabasa y que describe 
Este libro forma parte del acervo de la Biblioteca Jurídica Virtual del Instituto de Investigaciones Jurídicas de la UNAM

Los primeros trabajos fueron para acreditar a los diputados elegidos, pues había gente adicta a personas non gratas, como Félix Díaz, hermano del dictador. Fernando González Roa fue rechazado como diputado suplente por Guanajuato por su amistad con el hermano de Porfirio Díaz.

$\mathrm{El}$ acto inaugural fue el 1o. de diciembre de 1916 a las 15:50 horas con un quórum de 151 diputados. El mismo Jesús Romero Flores, constituyente de esa época, describe la composición social del Congreso:

Había generales, ex ministros, jurisconsultos, periodistas, literatos, historiadores, poetas, obreros de las fábricas, trabajadores de las minas, campesinos, maestros de escuela y hasta artistas de teatro. En el ramo de las profesiones todos estaban representados: ingenieros, arquitectos, agrónomos, abogados, médicos, profesores normalistas. ${ }^{39}$

Agregaba con plena convicción revolucionaria: "No había un solo tema que podía debatirse en el que no hubiera una persona capaz de dar su opinión con plena conciencia profesional y con absoluta honradez". ${ }^{40}$

Carranza expuso las deficiencias de la Constitución de 1857 y en seguida propuso sus reformas al artículo 16 (detención con orden de aprehensión); al artículo 27 (expropiación con monto de autoridad judicial); al artículo 72 (conferir al Poder Legislativo la facultad de expedir leyes sobre el trabajo); se suprimía la figura de la vicepresidencia; independencia completa del Poder Judicial... La sesión inaugural concluyó con la respuesta del presidente del Congreso, Luis Manuel Rojas, a las 18:00 horas.

En dos meses, lapso establecido en el decreto del 14 de diciembre de 1916, el Congreso Constituyente desempeñó su cometido: una Constitución que reformaba la de 1857. Rabasa identificaba dos partes meridianas: una liberal y otra social. La liberal es la guía carrancista en cuanto imperio de la ley; y la social en el contenido de los artículos 3o. (educación laica y gratuita); 5o. y 123 (trabajo); 27 (agrario); 28 (antimonopolios) y 24 y 130 (separación Estado-iglesias, religión).

El 31 de enero de 1917, los constituyentes de Querétaro juraron guardar y hacer guardar la Constitución; el primer jefe del Ejército Constitu-

las tonalidades regionales de los soldados que custodiaban la ciudad de Querétaro, lugar donde se desarrollaban los trabajos de discusión de la nueva Constitución: "los yaquis de Sonora, los juchitecos de Oaxaca, los tamaulipecos con sus cueros, los norteños tocados con sus grandes sombreros texanos y muchos generales... con sus trajes mitad charros, mitad militares" (Romero Flores, Jesús, Historia del Congreso Constituyente 1916-1917, cit., p. 18, citado por Rabasa, Emilio O., Historia de las constituciones mexicanas, cit., p. 90).

39 Rabasa, Emilio O., Historia de las constituciones mexicanas, cit., p. 92.

40 Idem. 
Este libro forma parte del acervo de la Biblioteca Jurídica Virtual del Instituto de Investigaciones Jurídicas de la UNAM

cionalista también lo hizo; la Constitución jurada fue promulgada el 5 de febrero de 1917. Fue, al decir de Rabasa, la primera Constitución liberalsocial del siglo XX en el mundo.

Si en esta Constitución de 1917 se resolvió a favor del federalismo, también se permitió la figura fuerte del Ejecutivo, con lo que se estableció a partir de ahí nuestro presidencialismo mexicano. ${ }^{41}$

Los diputados al Congreso Constituyente de 1917 fueron 218 (más del doble de los congresistas originales, que fueron 98), cuyos nombres son los siguientes:

(1) Daniel Cervantes y (2) Aurelio L. González (Aguascalientes); (3) Ignacio Roel (territorio de Baja California); (4) Manuel Aguirre Berlanga, (5) Manuel Cepeda Medrano, (6) Ernesto Meade Fierro, (7) José Rodríguez González, (8) José María Rodríguez y (9) Jorge E. Von Versen (Coahuila); (10) Francisco Ramírez Villarreal (Colima); (11) Cristóbal L. Castillo, (12) Lisandro López, (13) J. Amílcar Vidal, (14) Enrique Suárez y (15) Daniel A. Zepeda (Chiapas); (16) Manuel M. Prieto (Chihuahua); (17) Ciro B. Ceballos, (18) Carlos Duplan, (19) Francisco Espinosa, (20) Alfonso Herrera, (21) Lauro López Guerra, (22) Amador Lozano, (23) Rafael Martínez, (24) Antonio Norzagaray, (25) Félix F. Palavicini, (26) Ignacio L. Pesqueira, (27) Rafael de los Ríos, (28) Román Rosas y Reyes, (29) Arnulfo Silva y (30) Gerzayn Ugarte (Distrito Federal); (31) Fernando Castaños, (32) Silvestre Dorador, (33) Rafael Espeleta, (34) Fernando Gómez Palacio, (35) Antonio Gutiérrez, (36) Alberto Terrones Benítez y (37) Jesús de la Torre (Durango); (38) Luis M. Alcocer, (39) Manuel C. Aranda, (40) Nicolás Cano, (41) Enrique Colunga, (42) Ramón Frausto, (43) Vicente M. Valtierra, (44) José Natividad Macías, (45) Jesús López Lira, (46) David Peñaflor, (47)José Villaseñor Lomelí, (48) Antonio Madrazo, (49) Santiago Manrique, (50) Hilario Medina, (51) Ignacio López, (52) Francisco Díaz Barriga, (53) Fernando Lizardi, (54) Gilberto M. Navarro, (55) Luis Fernández Martínez y (56) Carlos Ramírez Llaca (Guanajuato); (57) Fidel Jiménez, (58) Fidel R. Guillén y (59) Francisco Figueroa (Guerrero); (60) Antonio Guerrero, (61) Leopoldo Ruiz, (62) Alberto M. González, (63) Rafael Vega Sánchez, (64) Alfonso Cravioto, (65) Matías Rodríguez, (66) Crisóforo Aguirre, (67) Ismael Pintado Sánchez, (68) Refugio M. Mercado y (69) Alfonso Mayorga (Hidalgo); (69) Luis Manuel Rojas, (70) Marcelino Dávalos, (71) Federico E. Ibarra, (72) Manuel Dávalos Ornelas, (73) Francisco Martín del Campo, (74) Bruno Moreno, (75) Gaspar Bolaños V., (76) Ramón Castañeda y Castañeda, (77) Juan de Dios Robledo, (78) Jorge Villaseñor, (79) Amado Aguirre, (80) José L. Solórzano, (81) Ignacio Ramos Praslow, (82) Francisco Labastida Izquierdo, (83) José Manzano, (84) Joaquín Aguirre Berlanga, (85) Esteban B. Calderón,

41 Carpizo, Jorge, El presidencialismo mexicano, México, Siglo Veintiuno Editores, 1994. 
Este libro forma parte del acervo de la Biblioteca Jurídica Virtual del Instituto de Investigaciones Jurídicas de la UNAM

(86) Paulino Machorro y Narváez, (87) Sebastián Allende, (88) Carlos Villaseñor y (89) Rafael Ochoa (Jalisco); (90) Aldegundo Villaseñor, (91) Fernando Moreno, (92) Enrique Ofarril, (93) Guillermo Ordorica, (94) José J. Reynoso, (95) Antonio Aguilar, (96) Juan Manuel Giffaro, (97)José E. Franco, (98) Manuel A. Hernández, (99) Enrique A. Enríquez, (100) Donato Bravo Izquierdo y (101) Rubén Martí (Estado de México); (102) José P. Ruiz, (103) Alberto Peralta, (104) Cayetano Andrade, (105) Uriel Avilés, (106) Gabriel R. Cervera, (107) Onésimo López Couto, (108) Salvador Alcaraz (109) Romero, (110) Manuel Martínez Solórzano, (111) Martín Castrejón, (112) Alberto Alvarado, (113) José Álvarez, (114) José Silva Herrera, (115) Rafael Márquez, (116) Amadeo Betancourt, (117) Francisco J. Mújica y (118) Jesús Romero Flores (Michoacán); (119) Antonio Garza Zambrano, (120) José L. Gómez y (121) Álvaro L. Alcázar (Morelos); (122) Manuel Amaya, (123) Nicéforo Zambrano, (124) Lorenzo Sepúlveda, (125) Luis Ilizaliturri, (126) Ramón Gámez, (127) Reynaldo Garza, (128) Agustín Garza González y (129) Plutarco González (Nuevo León); (130) Salvador González Torres, (131) Juan Sánchez, (132) Leopoldo Payán, (133) Luis Espinosa, (134) Manuel Herrera, (135) Porfirio Sosa, (136) Celestino Pérez, (137) Crisóforo Rivera Carrera y (138) José Gómez (Oaxaca); (139) Salvador R. Guzmán, (140) Rafael P. Canete, (141) Miguel Rosales, (142) Gabriel Rojano, (143) David Pastrana Jaimes, (144) Froylán G. Manjarrez, (145) Antonio de la Barrera, (146) José Rivera, (147) Epigmenio A. Martínez, (148) Pastor Rouaix, (149) Luis T. Navarro, (150) Porfirio del Castillo, (151) Federico Dinorín, (152) Gabino Bandera y Mata, (153) Leopoldo Vázquez Mellado, (154) Gilberto de la Fuente, (155) Alfonso Cabrera y (156) José Veráztegui (Puebla); (157) Juan N. Frías, (158) Ernesto Perusquía y (159) José María Truchuelo (Querétaro); (160) Samuel de los Santos, (161) Arturo Méndez, (162) Rafael Martínez Mendoza, (163) Rafael Nieto, (164) Cosme Dávila, (165) Dionisio Zavala, (166) Gregorio A. Tello y (167) Rafael Curiel (San Luis Potosí); (168) Pedro R. Zavala, (169) Andrés Magallón, (170) Carlos M. Ezquerro, (171) Cándido Avilés y (172) Emiliano C. García (Sinaloa); (173) Luis G. Monzón, (174) Flavio A. Bojórquez, (175) Ramón Ross y (176)Juan de Dios Bojórquez (Sonora); (177) Rafael Martínez de Escobar, (178) Santiago Ocampo y (179) Carmen Sánchez Magallanes (Tabasco); (180) Pedro A. Chapa, (181) Zeferino Fajardo, (182) Emiliano P. Nafarrete y (183) Fortunato de Leija (Tamaulipas); (184) Cristóbal Limón, (185) Marcelino Cedano y (186) Juan Espinosa Bávara (Tepic); (187) Antonio Hidalgo, (188) Modesto González Galindo y (189) Ascención Tepatl (Tlaxcala); (190) Saúl Rodiles, (191) Enrique Meza, (192) Benito Ramírez G., (193) Eliseo L. Céspedes, (194) Adolfo C. García, (195) Josafat F. Márquez, (196) Alfredo Solares, (197) Alberto Román, (198) Silvestre Aguilar, (199) Ángel Juarico S., (200) Heriberto Jara, (201) Victorio E. Góngora, (202) Cándido Aguilar, (203) Carlos L. Gracidas, (204) Marcelo Torres, (205) Galdino H. Casados, (206) Juan de Dios Palma y (207) Fernando A. Pereyra (Veracruz); 
Este libro forma parte del acervo de la Biblioteca Jurídica Virtual del Instituto de Investigaciones Jurídicas de la UNAM

(208) Antonio Ancona Albertos, (209) Enrique Recio, (210) Héctor Victoria y (211) Miguel Alonso Romero (Yucatán); (212) Adolfo Villaseñor, (213) Julián Adame, (214) Jairo D. Dyer, (215) Samuel Castañón, (216) Andrés L. Arteaga, (217) Antonio Cervantes y (218) Juan Aguirre Escobar (Zacatecas).

Documentos constitucionales y representantes electos 1824-1917

\begin{tabular}{|c|c|c|c|c|}
\hline Órgano y fecha & Documento expedido & Ideología & Diputados & Diferencia \\
\hline $\begin{array}{c}\text { Congreso de } \\
1824\end{array}$ & $\begin{array}{c}\text { Acta Constitutiva } \\
\text { de la Federación } \\
\text { Mexicana }\end{array}$ & Federalista & 98 & \\
\hline $\begin{array}{c}\text { Congreso } \\
\text { Constituyente } \\
\text { de 1835-1836 }\end{array}$ & $\begin{array}{c}\text { Siete Leyes } \\
\text { Constitucionales }\end{array}$ & Centralista & 75 & $\begin{array}{c}23 \text { menos que } \\
\text { el Congreso de } \\
1824\end{array}$ \\
\hline $\begin{array}{c}\text { Junta Nacional } \\
\text { Legislativa de } \\
1843\end{array}$ & $\begin{array}{c}\text { Bases Orgánicas } \\
\text { de la República } \\
\text { Mexicana }\end{array}$ & Centralista & 67 & $\begin{array}{l}8 \text { menos que } \\
\text { el Congreso de } \\
1835-1836 \text { y } 31 \\
\text { que el de } 1824\end{array}$ \\
\hline $\begin{array}{c}\text { Congreso } \\
\text { Constituyente } \\
\text { de } 1846\end{array}$ & Acta de Reformas & Federalista & 81 & $\begin{array}{l}14 \text { más que la } \\
\text { Junta Legisla- } \\
\text { tiva de } 1843, \\
\text { pero } 17 \text { menos } \\
\text { que el Congreso } \\
\text { de } 1824\end{array}$ \\
\hline $\begin{array}{c}\text { Congreso } \\
\text { Constituyente } \\
\text { de } 1857\end{array}$ & $\begin{array}{l}\text { Constitución } \\
\text { Política de } \\
\text { la República } \\
\text { Mexicana }\end{array}$ & Federalista & 94 & $\begin{array}{l}\text { Sólo cuatro } \\
\text { menos que el } \\
\text { Constituyente } \\
\text { de } 1824\end{array}$ \\
\hline $\begin{array}{c}\text { Congreso } \\
\text { Constituyente } \\
\text { de } 1917\end{array}$ & $\begin{array}{c}\text { Constitución } \\
\text { Política de los } \\
\text { Estados Unidos } \\
\text { Mexicanos }\end{array}$ & $\begin{array}{l}\text { Federalista } \\
\text { y presiden- } \\
\text { cialista }\end{array}$ & 218 & $\begin{array}{l}120 \text { más que el } \\
\text { Constituyente } \\
\text { de } 1824\end{array}$ \\
\hline
\end{tabular}

FUENTE: elaboración propia. 
Este libro forma parte del acervo de la Biblioteca Jurídica Virtual del Instituto de Investigaciones Jurídicas de la UNAM

\section{GONCLUSIONES}

La ruta dual que ha seguido nuestra historia constitucional en cuanto a su forma de gobierno, centralista y federalista, ha sido manifiesta en cada uno de los documentos constitucionales. No obstante, tanto uno como otro tipo han sido respaldados por los hombres que los han aprobado tras singulares debates.

En esos largos, encontrados y acalorados debates se encuentran las motivaciones y aspiraciones de la nación mexicana desde su independencia a principios del siglo XIX.

El repaso que hace Emilio O. Rabasa de nuestras Constituciones y las opiniones de Daniel Cosío Villegas y Diego Valadés en torno a algunas valoraciones de su ascendiente Emilio Rabasa, nos dan una oportunidad de reflexionar sobre el centenario de nuestra Constitución del 5 de febrero de 1917.

\section{BibliografíA}

Arias, Juan de Dios y Olavarría y Ferrari, Enrique, "México Independiente (1821-1855)", en Riva PALACIO, Vicente (coord.), México a través de los siglos, México, Ballescá y Espasa, 1880, t. IV.

CARPIZO, Jorge, El presidencialismo mexicano, México, Siglo Veintiuno Editores, 1994.

Cosío Villegas, Daniel, La Constitución de 1857 y sus críticos, México, Fondo de Cultura Económica-El Colegio Nacional-Clío, 2007.

López SÁnchez, Eduardo Alejandro y Soberanes Fernández, José Luis (coords.), La Constitución de Cádiz de 1812 y su impacto en el occidente novohispano, México, UNAM, 2015.

Memoria política de México, en wrere.memoriapoliticademexico.org/Textos/3Reforma/ 1857CFM.html (fecha de consulta: 25 de julio de 2015).

MIRANDA, José, Las ideas e instituciones politicas mexicanas; primera parte: 15211820, México, UNAM, Instituto de Derecho Comparado, 1952.

RABASA, Emilio, Historia de las Constituciones mexicanas, 3a. ed., México, UNAM, Instituto de Investigaciones Jurídicas, 2008.

Romero Flores, Jesús, Historia del Congreso Constituyente 1916-1917, México,UNAM-INEHRM, 2014.

VALADÉs, Diego, "Prólogo", en RABasa, Emilio, La evolución histórica de Mé- 
Este libro forma parte del acervo de la Biblioteca Jurídica Virtual del Instituto de Investigaciones Jurídicas de la UNAM

xico, México, Miguel Ángel Porrúa-UNAM, Coordinación de Humanidades, 1986.

VILLORO, Luis, "Las corrientes ideológicas de la Revolución de Independencia", en Estudios de historia de la filosofia en México, México, UNAM, 1963. 
Este libro forma parte del acervo de la Biblioteca Jurídica Virtual del Instituto de Investigaciones Jurídicas de la UNAM

\author{
EL MOVIMIENTO CONSTITUCIONALISTA \\ Y EL CONGRESO CONSTITUYENTE MEXICANO: \\ ENTRE LA REFORMA \\ Y LA REVOLUCIÓN: 1913-1916
}

Jaime HERNÁNDEZ DÍAZ*

SUMARIO: I. Introducción. II. La reforma constitucional, algunos aspectos teóricos. III. El movimiento constitucionalista mexicano 1913-1916: entre la reforma y la revolución. IV. La revolución constitucional. V. Reflexión final. VI. Bibliografia.

\title{
I. INTRODUCGIÓN
}

Una recurrencia sistemática de la vida política mexicana durante el siglo XIX, fue acompañar a todo movimiento político de una propuesta de Constitución o de respeto a la misma, además en nuestro país, todas las Constituciones que han tenido una vigencia significativa han derivado de congresos constituyentes resultado de una revolución, 1824, 1857, y 1917 no fue la excepción. En nuestro país, la relación revolución-Constitución es pues una constante y, sin embargo, escasos trabajos se han dedicado a reflexionar desde la óptica de lo jurídico esta tendencia de la vida política constitucional mexicana.

En el marco de este Congreso, dedico mi reflexión en torno a este tema, con la variante de que en el caso que nos ocupa del movimiento constitucionalista de 1913-1916, este proceso se caracteriza por el tránsito entre un proyecto de carácter reformista y una revolución en el sentido más amplio del concepto. Se articula pues entre 1913-1916 la reforma a la Constitución con una nueva Constitución en medio de una revolución.

* Profesor-investigador en la Facultad de Derecho y Ciencias Sociales y en la Facultad de Historia de la Universidad Michoacana de San Nicolás de Hidalgo. 
Este libro forma parte del acervo de la Biblioteca Jurídica Virtual del Instituto de Investigaciones Jurídicas de la UNAM

\section{LA REFORMA GONSTITUCIONAL, ALGUNOS ASPECTOS TEÓRICOS}

En los inicios del movimiento constitucional acompañó la idea de que los constituyentes elaboraban un texto jurídico para una larga vida, prácticamente perene, y se pensaba que los documentos constitucionales no deberían sufrir alteraciones o modificaciones sustanciales; por ello, desde el campo de la teoría constitucional se pensaba que el texto o ley fundamental ideal sería aquél en el que todo desarrollo futuro de la comunidad en los diversos aspectos políticos, económicos o culturales, pudieran ser previstos, y en consecuencia no sería necesaria una modificación de estas normas jurídicas. ${ }^{1}$

Por lo anterior, se pensaba que el poder constituyente expresaba su voluntad a través del texto constitucional, de manera fija, afirma en ese sentido Gustavo Zagrebelsky:

...el poder constituyente es fijación, es absolutización de valores políticos, es puro deber ser, es comienzo ex novo, es elisión del pasado y reducción de todo futuro al presente, es inicialmente aceleración histórica inesperada y sucesivamente detención del movimiento, es expresión de un solo proyecto político, individualización e incondicionado y por ello soberano, es predeterminación de los problemas y planificación de las soluciones. ${ }^{2}$

Esta idea de "fijar la materia constitucional" con la intención de impedir que se sujetara a las acciones corrosivas del tiempo era una idea que en general se compartía por los ilustrados de fines del siglo XVIII y aunque tomará diversas direcciones los revolucionarios de la época asociaban este pensamiento a "los principios inmortales" que hacían sustraer la Constitución a la necesidad histórica, que a su vez los convertían en principios de carácter universal, transformando en la práctica la historia constitucional de un país en una simple historia de las Constituciones. ${ }^{3}$

En la elaboración de las primeras Constituciones modernas se pensó en la posibilidad de prohibir cualquier modificación a las mismas, porque se entendía que cualquier cambio representaba una modificación a la voluntad constituyente, y el poder constituyente actúa al elaborar una Constitución con la convicción de redactar un texto jurídico que esté acorde o en consonancia con la naturaleza, y por consecuencia busca la eternidad de su obra y tiende a dejar plasmada la absoluta fijeza constitucional, como

1 Loewenstein, Karl, Teoría de la Constitución, Madrid, Ariel, 1979, pp. 163 y 164.

2 Zagrebelsky, Gustavo, Historia y Constitución, Madrid, Trotta, 2005, pp. 36 y 37.

3 Ibidem, pp. 33-35. 
Este libro forma parte del acervo de la Biblioteca Jurídica Virtual del Instituto de Investigaciones Jurídicas de la UNAM

lo aprecia Zagrebelsky, "como en todo lo que es manifestación de un espíritu puramente abstracto, en la constitución así concebida no puede haber cambio. Por el contrario, el cambio es visto como un atentado a la propia constitución y la pura y simple propuesta de cambiar puede constituir por si sola un delito capital". ${ }^{4}$

Esta idea de contar con una Constitución aprobada para todo tiempo y resistente al cambio se localiza, de acuerdo con Zagrebelsky, en el pensamiento iusnaturalista de la Constitución escrita, en el que se aprecian dos condiciones: una de tipo objetivo que aprecia a la Constitución como un acto de reconocimiento o una declaración, y otra que considera a la Constitución como un acto de imposición. ${ }^{5}$

A pesar de esa aspiración de prever situaciones futuras completas en una Constitución, esta se encuentra sujeta a una política cambiante, ya que en realidad las instituciones reflejan el estado de cosas que existen en el momento de su nacimiento y no pueden prever el futuro; es probable que si se encuentra inteligentemente redactada puede intentar tener en cuenta situaciones futuras por medio de apartados cuidadosamente redactados, con el riesgo de incorporar formulaciones muy elásticas que pondrían en peligro la seguridad jurídica. ${ }^{6}$

En la medida que evolucionó la experiencia y la teoría constitucional, se entendió mejor el papel de la Constitución en la sociedad y el significado de sus cambios. Así se llegó a comprender que toda Constitución es producto de un momento histórico determinado y en ella se refleja el equilibrio alcanzado, así sea temporalmente, por las fuerzas sociales que participan en su elaboración; Karl Loewenstein sostiene que los actores que participan en la creación constitucional se esfuerzan en alcanzar el equilibrio reconocido por todos, con la idea de buscar un máximo acercamiento entre la Constitución real y legal, siguiendo el análisis formulado por Lasalle desde 1862, al considerar que la esencia de la Constitución muestra una concordancia entre la estructura social y legal. ${ }^{7}$

En el pensamiento iusnaturalista e ilustrado del siglo XVIII, atendiendo a la naturalidad de la Constitución, se localiza una idea favorable al necesario cambio de las leyes y la Constitución. Uno de los mejores exponentes de este pensamiento fue sin duda alguna Thomas Jefferson, autor que consideraba que las leyes y la Constitución deberían ser mantenidas con vida sólo

\footnotetext{
4 Ibidem, pp. 37 y 38.

5 Ibidem, pp. 40 y 41.

6 Loewenstein, Karl, op. cit., p. 164.

7 Ibidem, pp. 163 y 164.
} 
Este libro forma parte del acervo de la Biblioteca Jurídica Virtual del Instituto de Investigaciones Jurídicas de la UNAM

durante la generación que las había hecho, ya que si tuvieran que durar más se convertirían en acto de fuerza, no de derecho, traduciéndose en que la generación precedente oprimiría a la sucesiva idea que encontró una acogida satisfactoria en las primeras Constituciones francesas. ${ }^{8}$ En efecto, el primer constitucionalismo francés recogió el pensamiento de Jefferson en el plan de Constitución presentado por los Girondinos a la Convención Nacional el 15 y 16 de febrero de 1791, el artículo 33 de la Declaración de los Derechos afirmaba que "un pueblo tiene siempre derecho a revisar, reformar y cambiar su constitución. Una generación no tiene derecho a someter a sus leyes a las generaciones futuras, y toda herencia de las funciones es absurda y tiránica". ${ }^{9}$ En este mismo sentido, el artículo 28 de la Declaration del 24 de junio de 1793, premisa de la Constitución jacobina, incorporaba prácticamente de manera literal el derecho de toda generación de no someterse a la voluntad de sus progenitores, y para ello "recomenzar del todo" cuando lo hubiere querido. ${ }^{10}$

Con la misma orientación de reconocer a las Constituciones como resultado de un momento histórico, otro destacado pensador alemán, Jellinek, reconocía que "las leyes fundamentales se establecen, como las demás, en cuanto necesidad inevitable reconózcase o no, en el curso de los acontecimientos históricos", ${ }^{11}$ por ello consideraba que a pesar de que tenía cierta fuerza la idea de las leyes fundamentales como productos especiales en los que se basa toda la estructura del Estado, y a pesar del aparente estado es inconmovible, difícil de cambiar del que tenían las Constituciones, como resultado de la vida práctica; la estabilidad de las Constituciones en realidad no es mayor que la que tienen otras leyes, digamos de menor jerarquía, razón por la cual se ha yuxtapuesto la elaboración de muchas Constituciones y su modificación en muchos Estados, lo que ha derivado en un debilitamiento muy evidente en la fe depositada en la sabiduría de las asambleas constituyentes como en la sabiduría del legislador. ${ }^{12}$

De tal forma, la experiencia histórica y la teoría constitucional han demostrado la necesidad inevitable de adecuar las leyes fundamentales a la realidad, por ello Jellinek reconocía lo interesante que resulta plantearse el problema acerca de las vías seguidas para reformar las Constituciones escri-

8 Zagrebelsky, op. cit., pp. 41 y 42.

9 Ibidem, pp. 42 y 43.

10 Idem.

11 Jellinek, G., Reforma y mutación de la Constitución, Madrid, Centro de Estudios Constitucionales, 1991, pp 5-7.

12 Ibidem, pp. 5 y 6. 
Este libro forma parte del acervo de la Biblioteca Jurídica Virtual del Instituto de Investigaciones Jurídicas de la UNAM

tas, y piensa además que resultan muy interesantes las formas de operar los procesos de reforma constitucional, fenómeno que para su tiempo sólo se había examinado con motivo de investigaciones generales de las fuentes del derecho, y nunca con todas sus particularidades. ${ }^{13}$

En realidad el tema de la reforma constitucional se convirtió en uno de los relevantes del derecho constitucional y en torno a él se entremezclan consideraciones de carácter filosófico-ideológico, y aún de carácter histórico y sociológicas, que colocan el tema en una delicada y por momentos difusa situación, a que las Constituciones no obstante que son producto de un poder de naturaleza extraordinaria, cuya actuación se limita a un momento histórico determinado, en realidad “...como las constituciones no son más que una obra humana como cualquier otra (aunque más cargadas de simbolismos y solemnidades que otras normas jurídicas, pero productos humanos al fin), debe crearse un mecanismo para llevar a cabo los cambios necesarios de sus preceptos". ${ }^{14}$

George Jellinek, al estudiar los mecanismos de cambio de las Constituciones, entiende o destaca dos formas fundamentales: la reforma y la mutación.

Por reforma de la constitución entiendo la modificación de los textos constitucionales producida por acciones voluntarias e intencionadas. Y por mutación de la constitución entiendo las modificaciones que deja indemne su texto sin cambiarlo formalmente que se produce por hechos que tienen que ir acompañados por la intención o consciencia de tal mutación. ${ }^{15}$

Uno de los aspectos más interesantes en el análisis que hace Jellinek sobre el tema consiste en que además de reconocer la participación de los órganos del Estado en el proceso de reforma constitucional en un procedimiento normal, digámoslo así, incorpora en su estudio los procedimientos que no ajustan a derecho y sin embargo representan una reforma constitucional, como ocurre cuando se realiza una revolución, sostiene así que:

La teoría atribuye al Estado Soberano un poder de decisión ilimitado. Por consiguiente, también puede modificar a discreción su constitución, abrogarla o sustituirla. Y no sólo ajustándose al Derecho. La Constitución de un Estado puede sufrir mediante el poder una subversión total. Toda revolución

13 Ibidem, pp. 6 y 7.

14 Carbonell, Miguel, Constitución, reforma constitucional y fuentes del derecho, México, UNAM, 1998, pp. 233-235.

15 Jellinek, G., op. cit., pp. 6 y 7. 
Este libro forma parte del acervo de la Biblioteca Jurídica Virtual del Instituto de Investigaciones Jurídicas de la UNAM

abre el camino a una reforma de la constitución. En efecto, no hay ningún poder alguno por encima del Estado que pueda impedir lo hecho por tales revoluciones, vengan de arriba o de abajo, así cada revolución triunfante crea un Derecho nuevo. ${ }^{16}$

\section{Karl Loewenstein considera que:}

El concepto de reforma constitucional tiene un significado formal y material. En sentido formal se entiende bajo dicha denominación la técnica por medio de la cual se modifica el texto, tal como existe en el momento de realizar el cambio de la constitución. En este sentido es - o, por lo menos debe serlo cada vez - modificación del texto constitucional. En la mayor parte de las constituciones, las disposiciones a este respecto se encuentran al final del documento. La reforma constitucional en sentido material, por otra parte, es el resultado del procedimiento de enmienda constitucional, esto es, el objeto al que dicho procedimiento se refiere o se ha referido. En el proceso de reforma constitucional participan de una forma determinada los detentadores del poder previstos por la constitución misma para este caso. ${ }^{17}$

En relación con la reforma constitucional, Loewenstein piensa que lo primero que es necesario preguntarse es bajo qué circunstancias es necesaria o motivada una reforma de esta naturaleza, y al respecto considera que no es posible establecer criterios o reglas generales, aunque considera que habría que buscar en las relaciones económicas, políticas y sociales las causas que obligan a una reforma y adecuar las normas a esa realidad, piensa así que son:

Las modificaciones que experimentan las relaciones sociales, económicas o políticas son las responsables de que una norma constitucional que parecía razonable y suficiente en el momento de crear la constitución, haya perdido su capacidad funcional y tenga que ser, por tanto, completada, eliminada o acoplada de alguna otra manera a las nuevas exigencias en interés de un desarrollo sin fricciones del proceso político. ${ }^{18}$

Esta idea de la correspondencia entre la realidad sociopolítica con la norma como base de la reforma constitucional en buena medida deriva de la idea sustentada por este autor de la Constitución, para él un texto fundamental es el producto de un compromiso de las fuerzas políticas y resultado

\footnotetext{
16 Ibidem, p. 9.

17 Karl Loewenstein, Teoría de la Constitución, Madrid, Ariel, 1979, pp. 164 y 165

18 Ibidem, p. 170.
} 
Este libro forma parte del acervo de la Biblioteca Jurídica Virtual del Instituto de Investigaciones Jurídicas de la UNAM

de este equilibrio así sea temporal entre las fuerzas sociales que participan en el nacimiento de la Constitución, tal como están representadas en ese acto o momento, afirma de tal manera que:

...los grupos que participan en el acto de creación constitucional se esfuerzan a través de una mutua acomodación de sus intereses, por conseguir un equilibrio aceptable para todos ellos y que pretende el máximo acercamiento entre la constitución real y legal, tal como fue formulado por Lasalle en su famosa conferencia de 1862 sobre la esencia de la constitución, o como se podría decir, que muestre una concordancia entre la estructura social y legal. ${ }^{19}$

Loewenstein considera que el criterio general aceptado en nuestro tiempo acerca de una reforma constitucional es aquel en el que participan fundamentalmente los órganos de carácter legislativo y por ende se realiza por la vía legislativa. En este sentido la regla reconocida es que el procedimiento para diferenciarse de la vía ordinaria se someta a requisitos determinados que dificulten su realización. En la realización o diseño del procedimiento de reforma constitucional desde el siglo XVIII, existe el dilema para el legislador constitucional, por una parte cuando los requisitos que se exigen se pueden cumplir con relativa facilidad, esto permite que la reforma constitucional se pueda efectuar en cualquier momento, sin mayor impedimento esencial, generando que esta situación incite a la mayoría parlamentaria que ocupa el poder a moldear la Constitución de acuerdo con sus intereses particulares. Por la otra, si las exigencias para celebrar una reforma constitucional son de un difícil cumplimiento, de tal forma que solamente pueda efectuarse en ocasiones de lograr un consenso de manera extraordinaria, se pone en peligro alguna reforma que se considera necesaria y no puede llevarse a cabo o se realiza con un serio retraso en caso de una posible realización en esos términos. ${ }^{20}$

Cuando el legislador establece exigencias difíciles de poder cumplir, el riesgo que se genera consiste en que los actores del proceso político tienden a buscar soluciones por vías propiamente extraconstitucionales, las que con demasiada facilidad pueden desembocar en la ilegalidad en diversas modalidades como el desacato y la violación de la Constitución, de ahí que Loewenstein concluya en este apartado de la reforma constitucional señalando "la tarea, pues del poder constituyente es teniendo en cuenta tanto las experiencias generales como la situación nacional concreta, conducir su

\footnotetext{
19 Ibidem, pp. 163 y 164.

20 Ibidem, pp. 176 y 177.
} 
Este libro forma parte del acervo de la Biblioteca Jurídica Virtual del Instituto de Investigaciones Jurídicas de la UNAM

barco constitucional evitando caer en el peligro de procedimientos de reforma excesivamente difíciles o excesivamente fáciles". ${ }^{21}$

Aceptando pues la necesidad de establecer un procedimiento equilibrado de la reforma constitucional, Loewenstein, pasa a examinar lo que denomina límites de la reforma, para lo cual propone diversos criterios, el primero de ellos tiene que ver con los tiempos o plazos de espera para poder realizar una reforma constitucional, considera de tal manera que "el legislador constitucional puede ordenar que su obra no sea sometida a ninguna enmienda durante un determinado periodo de tiempo con el fin de dar posibilidad a la constitución de aclimatarse, y a la nación de familiarizarse con ella". ${ }^{22}$ Estos plazos se pueden establecer para poder reformar determinadas disposiciones constitucionales sobre todo aquellas que en su formulación hayan generado un compromiso alcanzado con gran dificultad.

El siguiente criterio para establecer límites en la formulación de reformas constitucionales, tiene que ver de acuerdo con Loewenstein con ciertas disposiciones dentro de la Constitución, denominadas por él intangibles, mismas que "tienen como fin librar radicalmente de cualquier modificación a determinadas normas constitucionales". ${ }^{23}$ Estas disposiciones intangibles se pueden presentar en dos situaciones diferentes: por una parte se localizan disposiciones para proteger instituciones constitucionales concretas, denominada en este caso intangibilidad articulada, y por otra parte se ubican disposiciones que están orientadas para garantizar determinados valores fundamentales de la Constitución, que rigen como valores implícitos o inherentes al texto constitucional,

en el primer caso determinadas normas constitucionales se sustraen a cualquier enmienda por medio de una prohibición jurídico-constitucional y en el segundo caso la prohibición de reforma se produce a partir del "espíritu" ó "telos" de la constitución sin una proclamación expresa en una proposición jurídico-constitucional. ${ }^{24}$

Carl Schmitt, en su estudio sobre la Constitución, también se refirió a los límites que debe tener la reforma a la Constitución, su análisis parte de la idea de que la reforma a la Constitución tiene como punto de partida el carácter de la competencia que tiene el Estado para la realización, esta no puede ubicarse en una actividad como las que de manera ordinaria realiza

\footnotetext{
21 Idem.

22 Ibidem, p. 188.

23 Idem.

24 Idem.
} 
Este libro forma parte del acervo de la Biblioteca Jurídica Virtual del Instituto de Investigaciones Jurídicas de la UNAM

el Estado, sino más bien sería una actividad verdaderamente excepcional o extraordinaria, así afirma que "la competencia para reformar la constitución no es una competencia normal en el sentido de un circuito de actividades regulado y delimitado. Reformar las leyes constitucionales no es una función normal del Estado, como dar leyes, resolver procesos, realizar actos administrativos, etc. Es una facultad extraordinaria". ${ }^{25}$

No obstante que Smitt reconoce el acto de reforma a la Constitución con un carácter extraordinario, éste no puede ser una facultad legal constitucional de forma ilimitada, por el contrario, se encuentra sujeta a ciertos límites y el fundamento más importante de estos límites lo localiza en la necesidad de garantizar la identidad y la continuidad de la Constitución. Afirma de manera contundente:

Los límites de la facultad de reformar la constitución resultan del bien entendido concepto de reforma constitucional. Una facultad de "reformar la constitución" atribuida por una normación legal-constitucional, significa que una o varias regulaciones legal-constitucionales pueden ser sustituidas por otras regulaciones legal-constitucionales, pero sólo bajo el supuesto de que queden garantizadas la identidad y continuidad de la constitución considerada como un todo. La facultad de reformar la constitución contiene, pues, tan sólo la facultad de practicar, en las prescripciones legal-constitucionales, reformas, adiciones, refundaciones, etc; pero manteniendo la constitución. ${ }^{26}$

\section{EL MOVIMIENTO CONSTITUCIONALISTA MEXICANO 1913-1916: ENTRE LA REFORMA Y LA REVOLUCIÓN}

A los fines de nuestro trabajo resulta útil el planteamiento de Ulises Schmill, quien propone la necesaria elaboración de una teoría jurídica de las revoluciones, afirma:

Las explicaciones que se han construido para explicar jurídicamente las revoluciones se refieren a una revolución triunfante y poco o nada se dice en relación con el movimiento revolucionario antes de su triunfo o fracaso... ¿cuál es la dimensión jurídica del movimiento revolucionario, mientras dura, antes de que pueda considerar que ha triunfado o fracasado. Ya no nos preguntamos sobre el orden jurídico creado con la revolución triunfante o por el orden jurí-

25 Schmitt, Carl, Teoría de la Constitución, Madrid, Alianza Universidad, 2006, p. 118.

26 Ibidem, pp. 118 y 119. 
Este libro forma parte del acervo de la Biblioteca Jurídica Virtual del Instituto de Investigaciones Jurídicas de la UNAM

dico anterior derogado por el nuevo, sino por el carácter jurídico de los actos integrantes del movimiento revolucionario, antes de que triunfe o fracase. ${ }^{27}$

En el plan firmado en la hacienda de Guadalupe, en Coahuila, el 26 de marzo de 1913, se desconoce al general Victoriano Huerta como presidente de la República, a los poderes Legislativo y Judicial y a los gobiernos de los estados que reconocieran al gobierno usurpador, el movimiento se autodenominaba "constitucionalista" y se designaba en calidad de primer jefe del Ejército al gobernador de Coahuila, Venustiano Carranza, preveía que al llegar a la Ciudad de México, ocuparía el cargo de interino y se convocaría a elecciones generales, "tan luego como se haya consolidado la paz". ${ }^{28}$

La aspiración reformista de los seguidores de Carranza quedó expresada desde el momento de la elaboración del Plan de Guadalupe en 1913, en la pretensión sin éxito en ese momento de que se incorporaran algunas reformas, bajo el argumento del primer jefe de que no era el momento de impulsarlas y que habría que concentrarse en el triunfo político y la derrota de Victoriano Huerta. Se trataba de restablecer el orden constitucional luego del asesinato del presidente Francisco I. Madero.

Tiene importancia mencionar que en esa ocasión un grupo de oficiales jóvenes intentaron incorporar en el Plan un conjunto de propuestas de reformas sociales con la oposición de Carranza. El testimonio de Múgica es elocuente:

...se habló mucho y largo entre la juventud que rodeaba al gobernador coahuilense, de formular un plan revolucionario en que se proclamaran como razones de la lucha los principios sociales, que más tarde debían de ser la invencible bandera de la Revolución... pero don Venustiano, con aquella prudencia y aquella solemnidad que caracterizó toda su vida de caudillo rebelde, replicaba a la impaciente juventud que lo seguía, con una prudente dilatoria que hiciera cristalizar antes que todo en la conciencia del país y en el juicio del exterior el fundamento legal de la lucha. Pensaba, con la entereza de hombre cuerdo, que la ley ultrajada era el argumento menos discutible para justificar la lucha sangrienta iniciada por él e iba, así emplazando nuestra fogosidad y nuestra impaciencia sin negarnos la razón en la amplitud de nuestro ideal. ${ }^{29}$

27 Schmill, Ulises, Las revoluciones. Teoría jurídica y consideraciones sociológicas, Madrid, Trotta, 2009, pp. 17 y 18.

28 Plan de Guadalupe, en Fuentes para la historia de la Revolución mexicana. Planes políticos y otros documentos, México, Fondo de Cultura Económica, 1974, t. I, pp. 137-144.

29 Bórquez, Djed, Crónica del Constituyente 1916-1917, México, Miguel Ángel Porrúa, 2017. 
Este libro forma parte del acervo de la Biblioteca Jurídica Virtual del Instituto de Investigaciones Jurídicas de la UNAM

El Plan fue adicionado en Veracruz el 12 de diciembre de 1914, en los considerandos explica las circunstancias que impidieron la realización de las elecciones, derivado de la división de las fuerzas revolucionarias y se dibuja ahora sí un plan de reformas sociales. Sería en las adiciones al Plan de Guadalupe en Veracruz en diciembre de 1914, cuando se logra tal aspiración reformista, tanto en la exposición de motivos como en el artículo 2 o. que consignó:

El Primer Jefe de la Revolución y Encargado del Poder Ejecutivo, expedirá y pondrá en vigor, durante la lucha, todos las leyes, disposiciones y medidas encaminadas a dar satisfacción a las necesidades económicas, sociales y políticas del país, efectuando las reformas que la opinión pública exige como indispensables para restablecer un régimen que garantice la igualdad de los mexicanos entre sí: leyes agrarias que favorezcan la formación de la pequeña propiedad, disolviendo los latifundios y restituyendo a los pueblos las tierras de que fueron injustamente privados; leyes fiscales encaminadas a obtener un sistema equitativo de impuestos a la propiedad raíz; legislación para mejorar la condición del peón rural, del obrero, del minero, y en general de las clases proletarias; establecimiento de la libertad municipal como institución constitucional; bases para un nuevo sistema de organización del Poder Judicial Independiente, tanto en la Federación como en los Estados; revisión de las leyes relativas al matrimonio y al estado civil de las personas; disposiciones que garanticen el estricto cumplimiento de las leyes de Reforma; revisión de los códigos Civil, Penal y de Comercio; reformas del procedimiento judicial, con el propósito de hacer expedita y efectiva la administración de justicia; revisión de las leyes relativas a la explotación de minas, petróleo, aguas, bosques y demás recursos naturales del país, y evitar que se formen otros en lo futuro; reformas políticas que garanticen la verdadera aplicación de la Constitución de la República, y en general todas las demás leyes que se estimen necesarias para asegurar a todos los habitantes del país la efectividad y el pleno goce de sus derechos y la igualdad ante la ley. ${ }^{30}$

Es bastante conocida la elaboración de las leyes dadas a conocer en Veracruz, la Ley Agraria del 6 de enero de 1915 y el programa reformista impulsado por Carranza; sin embargo, es menos conocido o se olvida el conjunto de modificaciones legislativas adoptadas por los gobernadores constitucionalistas, sin ser una legislación completa. En el estado de Jalisco, Manuel M. Dieguez, expidió el 2 de septiembre de 1914, un decreto sobre el trabajo, el 4 de octubre del mismo año, el gobernador de Veracruz, Ma-

30 Adiciones al Plan de Guadalupe, en Fuentes para la historia de la Revolución mexicana..., cit., pp. 158-164. 
Este libro forma parte del acervo de la Biblioteca Jurídica Virtual del Instituto de Investigaciones Jurídicas de la UNAM

nuel Pérez Romero, lanzaba otro, estableciendo el descanso semanal obligatorio para las empresas. El 7 de octubre de 1914, nuevamente en Jalisco, el gobernador Manuel Aguirre Berlanga, estableció un salario mínimo, ministraciones adicionales al salario, normas sobre trabajo a destajo o precio alzado, descanso obligatorio, horas de trabajo, prohibición de las tiendas de raya, inembargabilidad de los salarios, prescripción de las deudas de los jornaleros, desarraigo del obrero en juicios civiles, estableciendo que los derechos de los proletarios no serían renunciables. La ley del 19 de octubre de 1914, promulgada por el gobernador Cándido Aguilar en Veracruz. En esa dirección ya en el año de 1915, en Yucatán, el general Salvador Alvarado, promulgó una ley que creaba el Consejo de Conciliación y el Tribunal de Arbitraje, a la cual siguió la ley del trabajo de ese estado, reconoció la creación de las asociaciones profesionales; el derecho de huelga (no sin advertir que debería ejercitarse sólo en último extremo); limitó la jornada de trabajo; implantó el salario mínimo; reglamentó el trabajo de las mujeres y de los niños; sentó la responsabilidad del patrono por los accidentes ocurridos a sus operarios con motivo y en el ejercicio de su profesión y trabajo, a menos que el accidente se debiera a fuerza mayor, extraña al trabajador en que se produjera, y señaló la necesidad de que el Estado creara una sociedad mutualista en beneficio de los trabajadores.

Hace algunos años en el seno del movimiento socialista, se debatió con intensidad los conceptos de reforma y revolución, siempre se identificaba a la reforma como un proceso mucho más limitado que el sentido profundo y radical que caracteriza a una revolución. La Revolución mexicana se discutía en torno a sus alcances y en relación con el movimiento constitucionalista se pretendió comparar este movimiento con respecto al pensamiento zapatista o villista, en cuanto a la profundidad de su programa de transformaciones sociales y económicas, sin embargo, en las características de su proyecto de reformas algunos autores ubican el triunfo no sólo armado, sino ideológico del constitucionalismo.

El movimiento constitucionalista reformista estaba convencido de la necesidad de restablecer el orden constitucional una vez que se derrocara a Huerta y más tarde después de obtener el triunfo sobre Villa. Su idea era actualizar la Constitución de 1857, y no se incorporaban las reformas sociales. La postura de Palavicini nos ilustra al respecto:

...Es necesario acabar con la poesía de la Constitución y poner en ella principios fundamentales, precisos; prácticos que sepamos y podamos respetar, cumplir y hacer cumplir. El deber de los constitucionalistas es gobernar con una Constitución. Que sea la ley de 1857; pero que a ésta se le hagan las re- 
Este libro forma parte del acervo de la Biblioteca Jurídica Virtual del Instituto de Investigaciones Jurídicas de la UNAM

formas necesarias, el urgente perfeccionamiento que ha menester, para que responda a las aspiraciones nacionales...

Una vez derrotado Huerta, surgió la división del movimiento revolucionario y Carranza y los constitucionalistas se ocuparon de manera prioritaria en obtener la victoria militar sobre Villa y Zapata, no obstante, y una vez que se perfilaba el triunfo, Carranza emprendió la realización de un conjunto de reformas jurídicas de gran calado relacionadas con temas agrarios y sociales, medidas adoptadas con mayor intensidad durante la estancia del gobierno constitucionalista en Veracruz.

Todo parece indicar que en la medida que evolucionaban los acontecimientos político militares, se fue abriendo paso la idea de convocar a un Congreso Constituyente con la intención de incorporar estas reformas jurídicas y como un paso para iniciar la estabilidad política del país. Carranza se apoyó para definir y elaborar estas reformas en un grupo de profesionistas. En la Secretaría de Instrucción Pública, se integró una sección de Legislación Social, responsable de elaborar los proyectos de reforma, integrada por Félix Palavicini, José Natividad Macías, Luis Manuel Rojas y Alfonso Cravioto, y desde luego colaboraron otros destacados miembros del gobierno de Carranza, como Luis Cabrera, Rafael Nieto y Rafael Zubarán. ${ }^{31}$

En 1915, todo parece indicar que prevalecía la idea en Carranza de que la lucha armada estaba concluida y era la hora de empezar el restablecimiento del orden legal, los titubeos del primer jefe parecen más obedecer al alcance del Congreso Constituyente, al seno del movimiento constitucionalista estaban ya definidas dos facciones claras, una de corte liberal, partidaria de modificar la Constitución, conservando su espíritu liberal y la otra mucho más radical con la firme convicción de incorporar en la Constitución reformas que se venían impulsando. Carranza el 14 de septiembre señaló que las reformas instituidas durante el periodo de la Revolución serían incorporadas en la Constitución, no obstante debido al clima de inseguridad que se vivía aún y la presencia de diversos bandos y con el propósito de evitar cualquier excusa para atacar al gobierno establecido y que se alterara la paz, era necesario convocar a una asamblea constituyente elegida con el único fin de escribir una nueva Constitución. Así Carranza se comprometió a presentar a la Asamblea un proyecto que los diputados iban a discutir,

31 Marván Laborde, Ignacio, "El Constituyente de 1917: rupturas y continuidades", en Noriega Elio, Cecilia y Salmerón, Alicia (coords.), México un siglo de historia constitucional (1808-1917). Estudios y perspectivas, México, Instituto Mora-Poder Judicial de la Federación, 2010, p. 310 . 
Este libro forma parte del acervo de la Biblioteca Jurídica Virtual del Instituto de Investigaciones Jurídicas de la UNAM

aprobar o modificar y en el cual serían incorporadas todas las reformas instituidas por decreto.

De manera fundamental, se estableció en las adiciones al Plan de Guadalupe, el 12 de diciembre de 1914, el compromiso del primer jefe de expedir y poner en vigor durante la lucha, disposiciones y medidas encaminadas a dar satisfacción a las necesidades económicas, políticas y sociales del país y definió que al terminar la lucha, se convocaría a elecciones municipales y a un Congreso, ante el cual el primer jefe presentaría un proyecto de reformas para que se elevaran a rango constitucional.

Palavicini, encargado del Ministerio de Instrucción Pública, fue el encargado de preparar el terreno para la realización del nuevo Congreso, se ocupó de desprestigiar a la Constitución de 1857, por "conservadora" y de proponer la elaboración de una nueva en la que se inscribieran las demandas de la sociedad o el pueblo mismas que recogía el movimiento constitucionalista. ${ }^{32}$

Carranza estableció controles para la integración del Congreso a través de la Convocatoria, fundamentalmente se restringiría la participación a los simpatizantes constitucionalistas, quedarían vetados de participar por una parte los que hubiesen colaborado con el gobierno Huertista en calidad de funcionarios y por la otra, los villistas y zapatistas. Sería pues el Congreso de los vencedores. A pesar del clima de intranquilidad que prevalecía en el país, se realizaron las elecciones como estaban previstas, primero las municipales y después las correspondientes al Congreso que debería instalarse el 1o. de diciembre de 1916 en la ciudad de Querétaro. ${ }^{33}$

La base o fundamento jurídico del Congreso Constituyente se encuentra en las adiciones al Plan de Guadalupe, si bien es cierto era sumamente escueto, señalaba que una vez establecido el Congreso el primer jefe sometería a la consideración del mismo las reformas expedidas para que se elevaran a preceptos constitucionales las que deberían tener ese carácter, antes de regresar al orden constitucional.

La Convocatoria al Congreso Constituyente se ubicaba en un contexto manifiestamente reformista, pues se mencionaba que la nación entera exprese de manera indubitable su soberana voluntad; pues de este modo a la vez se discutirán y resolverán en forma y vía más adecuadas todas las cuestiones que hace tiempo están reclamando solución que satisfaga am-

32 Córdova, Arnaldo, La nación y la Constitución. La lucha por la democracia en México, México, Era, 1989, p. 18.

33 Cumberland, Charles C., La Revolución mexicana. Los años constitucionalistas, México, Fondo de Cultura Económica, 1975, p. 297. 
Este libro forma parte del acervo de la Biblioteca Jurídica Virtual del Instituto de Investigaciones Jurídicas de la UNAM

pliamente las necesidades públicas y también se prometía que se respetaría escrupulosamente el espíritu liberal de dicha Constitución a la cual sólo se quiere purgar de los defectos que tiene, ya por la contradicción u obscuridad de algunos de los preceptos ya por los huecos que hay en ella o por las reformas que con el deliberado propósito de desnaturalizar su espíritu democrático se le hicieron durante las dictaduras pasadas.

\section{LA REVOLUGIÓN GONSTITUGIONAL}

Por ello, como bien apunta Germán List Arzubide:

La misma convocatoria anunciaba ya una pugna entre lo que se pretendía hacer con la nueva Constitución y los hechos que ocurrían en los Estados donde el constitucionalismo iba dominando con la fuerza de sus armas; pues mientras se prometía respetar el espíritu liberal de la vieja Carta, nuevas leyes de tipo francamente socialista abrían el surco hacía una Constitución de tipo económico-social. ${ }^{34}$

Las corrientes políticas que actuaron en el Congreso Constituyente, se formaron en el seno del movimiento encabezado por Carranza. Se integró una tendencia representada por jóvenes oficiales partidarios de impulsar cambios en la estructura agraria, que permitiera una mejor distribución de la riqueza, las relaciones laborales, que crearan condiciones de trabajo más dignas para jornaleros y trabajadores. Esa corriente materializó esas ideas en el conjunto de innovaciones incorporadas en las reformas al Plan de Guadalupe en Veracruz, mismas que dieron origen al conjunto de disposiciones jurídicas promulgadas por Carranza, como la ley del 6 de enero de 1915 y las medidas sociales que promulgaron los gobernadores militares constitucionalistas en sus estados de Veracruz, Jalisco, Michoacán, Zacatecas, Coahuila, Yucatán, a las que el primer jefe se comprometió a incorporar en la Constitución.

Esta corriente arribó al Congreso Constituyente y una vez conocido el proyecto presentado por Carranza fue la que consideró necesario ajustar, modificar y adicionar para incorporar en el documento constitucional a las anheladas reformas sociales. Esta corriente se enfrentó a los llamados renovadores que se habían convertido en el principal grupo de apoyo de Carranza, probablemente por su mejor formación intelectual y experiencia

34 List Arzubide, Germán, La rebelión constituyente de 1917, México, UNAM, 1967. 
Este libro forma parte del acervo de la Biblioteca Jurídica Virtual del Instituto de Investigaciones Jurídicas de la UNAM

política y en buena medida fueron los autores del proyecto que presentó éste ante el Congreso. ${ }^{35}$

No es mi propósito realizar un estudio minucioso acerca del constituyente de 1916-1917, como tampoco de los debates más importantes que se dieron al seno de éste, para ello hay trabajos que lo hacen como los ya citados, únicamente aspiro a presentar las características más generales para situar al lector en el tipo de obra que tiene en sus manos. El Congreso Constituyente de Querétaro de 1916-1917, representa en la historia mexicana el inicio de un conjunto de cambios políticos, la elaboración de la Constitución hizo necesaria una serie de ajustes de las fuerzas políticas, fortaleció el Poder Ejecutivo y abrió un periodo de profundos cambios en la estructura agraria, las relaciones de trabajo, la educación, se conformó un nuevo Estado.

El Congreso Constituyente de 1916-1917, se apartó de algunas de las características que habían asumido las anteriores asambleas mexicanas de esta naturaleza, si bien coincidían en que fueron la reunión de los triunfadores de la contienda, son el producto de movimientos políticos revolucionarios. Entre el 20 y el 30 de noviembre de 1916 se celebraron las sesiones preliminares dedicadas a revisar si las credenciales de los diputados electos reunían los requisitos establecidos en la convocatoria, es decir, si eran de filiación constitucionalista y no hubiesen colaborado con el régimen usurpador. Se dio en esos días la primera confrontación de tendencias ante el intento de los obregonistas de no dejar pasar al Congreso a los diputados llamados renovadores.

Los radicales se enfrentaron desde las primeras sesiones dedicadas a la autorización de las credenciales y a lo largo del debate a los llamados "renovadores, que habían formado parte de la XXVI legislatura, eran los diputados más fieles a Carranza en esos momentos, de tendencia liberal, maderistas, preparados intelectualmente, se opusieron a los cambios al proyecto presentado en buena medida por razones de técnica jurídica, eran partidarios del fortalecimiento de la figura del Ejecutivo y simplemente querían

35 Respecto a los estudios referidos al Congreso destacaría a manera de ejemplo, los siguientes trabajos: Ferrer Mendiola, Gabriel, Historia del Congreso Constituyente de 1916-1917, México, Instituto Nacional de Estudios Históricos de la Revolución Mexicana, 1957; List Arzubide, Germán, La rebelión Constituyente de 1917, cit.; Smith, Peter H., "La política dentro de la Revolución: el Congreso Constituyente de 1916-1917”, Historia Mexicana, vol. 22, núm. 3, 1973; Córdova, Arnaldo, La nación y la Constitución. La lucha por la democracia en México, México, Era, 1989; Marván Laborde, Ignacio, "El Constituyente de 1917: rupturas y continuidades”, México un siglo de historia constitucional, (1808-1917). Estudios y perspectivas, cit., todos ellos de carácter académico e interpretativo. 
Este libro forma parte del acervo de la Biblioteca Jurídica Virtual del Instituto de Investigaciones Jurídicas de la UNAM

actualizar la Constitución de 1857, representaron una minoría de alrededor de 23 diputados.

El 1o. de diciembre, el Congreso inició sus sesiones con la asistencia de 193 diputados, de los cuales 66 provenían de las fuerzas militares, fenómeno que no había ocurrido en los congresos constituyentes anteriores y se explica por el carácter que asumió la revolución armada, había igualmente abogados, ingenieros, médicos, profesores, periodistas, obreros, lo que refleja la nueva composición de los actores políticos mexicanos.

$\mathrm{El}$ inicio de los trabajos del Congreso, igualmente marcan una diferencia sustancial, en la sesión del lo. de diciembre, el primer jefe del Ejército Constitucionalista, que tenía bajo su responsabilidad el Ejecutivo, presentó un proyecto de reforma constitucional, que sería la base de los trabajos, sin embargo, la pretensión de que fuese aprobado tal como fue presentado, fue cuestionada por la tendencia más progresista de los constituyentes que discreparon no sólo en cuanto a que no incorporaba las reformas sociales, sino en relación con las facultades de los estados y la federación.

En el análisis del Congreso una cuestión importante de resaltar consiste en que al interior del mismo se conformaron diversas tendencias ideológicas como no podía esperarse de otra manera. Lejos estuvo de ser un bloque único, monolítico, era evidente el grupo llamado de los renovadores, el más cercano en esos momentos al primer jefe, sus miembros habían formado parte del Congreso que conoció de los sucesos relacionados con la renuncia de Madero y la llegada al poder de Victoriano Huerta, ellos habían preparado el documento que Carranza presentó el primero de diciembre de 1916.

El grupo obregonista, cuestionó duramente la llegada de los "renovadores" al Congreso, cuestionaron las credenciales de Palavicini y Ezquero, de este último cuyo dictamen desfavorable tanto se empeñó en defender el grupo de los renovadores, desde ese momento, señala nuestro cronista, "se vio que los incondicionales del Sr. Carranza estaban en el Congreso en reducida minoría. El resultado final fue de 39 votos contra 117\%. A lo largo del trabajo nos da cuenta de las votaciones, por ejemplo, acerca del cambio de nombre del Estado mexicano que perdieron los renovadores 57 votos a favor del dictamen y 108 en contra. En la discusión acerca de la libertad de reunión 127 votos contra 26.

La historiografía ha interpretado que Bojórquez sostuvo que la Constitución había sido elaborada por una minoría de radicales jacobinos, izquierdistas, sin embargo, consideró que no existe en su obra una afirmación de esa naturaleza, eso sí, sostiene que fue impulsada por esta corriente, pero 
Este libro forma parte del acervo de la Biblioteca Jurídica Virtual del Instituto de Investigaciones Jurídicas de la UNAM

alcanzando amplias mayorías en el Congreso, por ello, siguiendo el diario de los debates da cuenta de las votaciones alcanzadas mismas que reflejan una amplia mayoría del Congreso. Eso significa que lograron convencer al extendido segmento del pantano. Demuestra en su crónica cómo fueron derrotadas las propuestas sustentadas principalmente por los renovadores que no lograron convencer a la mayoría.

Una de las tesis fundamentales de Bojórquez, consiste en sostener que el primer jefe y su grupo fueron derrotados, pone como ejemplo el artículo 3o., en un párrafo de la Crónica ejemplifica esta opinión, así afirma:

La votación del artículo tercero puso de relieve que el grupo radical de la Cámara estaba formado por dos terceras partes del número total de constituyentes. En capítulos posteriores veremos que los "jacobinos" llegaron a ganar votaciones con las cuatro quintas partes de la Cámara. Los señores renovadores, o sea los en ese momento amigos incondicionales del señor Carranza, nunca han querido confesar la forma en que perdieron en Querétaro. Pero más elocuente que todo lo que pudiéramos decir a este respecto, son los resultados de los escrutinios. Cada vez que el Diario de los Debates nos da las cifras finales de una votación, haremos hincapié en ellas, para que los lectores sigan viendo en que el C. Primer Jefe y su grupo fueron derrotados en el Constituyente. ${ }^{36}$

En efecto, la Constitución, no fue obra de una minoría, fuera de pocos artículos en que se polarizaron las fuerzas, y se alcanzaron votaciones de amplios consensos.

En el Congreso el movimiento que había asumido una posición reformista se transformó en una verdadera revolución jurídica que trastocó el pensamiento liberal constitucional para crear el pensamiento social en la Constitución.

\section{REFLEXIÓN FINAL}

Las Constituciones políticas mexicanas más representativas (1824, 1857, 1917) fueron el resultado de movimientos revolucionarios, esta circunstancia debería estimular la reflexión teórica acerca de la relación existente entre la revolución y la Constitución desde un punto de vista jurídico. En la doctrina constitucional que se refiere al estudio de la reforma constitucional se encuentran elementos de posible utilización, como el planteamiento de

36 Bórquez, Djed, Crónica del Constituyente 1916-1917, México, Miguel Ángel Porrúa, 2017. 
Este libro forma parte del acervo de la Biblioteca Jurídica Virtual del Instituto de Investigaciones Jurídicas de la UNAM

Jellinek que encuentra en la revolución una manera legítima de plantearse cambios constitucionales. El movimiento constitucionalista mexicano de 1913-1916 es un ejemplo de un tránsito entre una propuesta de restablecimiento del orden constitucional, una reforma a la Constitución transformada en una verdadera revolución y una modificación profunda en el orden constitucional.

\section{BIBLIOGRAFÍA}

BórQuez, Djed, Crónica del Constituyente 1916-1917, México, Miguel Ángel Porrúa, 2017.

CARbONELL, Miguel, Constitución, reforma constitucional y fuentes del derecho, México, UNAM, 1998.

CóRdova, Arnaldo, La nación y la Constitución. La lucha por la democracia en México, México, Era, 1989.

Cumberland, Charles C., La revolución mexicana. Los años constitucionalistas, México, Fondo de Cultura Económica, 1975.

Fuentes para la historia de la Revolución mexicana. Planes políticos y otros documentos, t. I, prólogo de Manuel González Ramírez, México, Fondo de Cultura Económica, 1974.

JellineK, G., Reforma y mutación de la Constitución, Madrid, Centro de Estudios Constitucionales, 1991.

LisT ARZuBIDE, Germán, La rebelión Constituyente de 1917, México, UNAM, 1967.

Loewenstein, Karl, Teoría de la Constitución, Madrid, Ariel, 1979.

MARVÁN LABORDE, Ignacio, "El Constituyente de 1917: rupturas y continuidades", en Noriega Elio, Gecilia y SAlmerón, Alicia (coords.), México un siglo de historia constitucional (1808-1917). Estudios y perspectivas, México, Instituto Mora-Poder Judicial de la Federación, 2010.

SCHMILL, Ulises, Las revoluciones. Teoría jurídica y consideraciones sociológicas, Madrid, Trotta, 2009.

Schmitt, Carl, Teoría de la Constitución, Madrid, Alianza-Universidad, 2006.

Smith, Peter H., "La política dentro de la Revolución: el Congreso Constituyente de 1916-1917”, Historia Mexicana, vol. 22, núm. 3, 1973.

Zagrebelsky, Gustavo, Historia y Constitución, Madrid, Trotta, 2005. 
Este libro forma parte del acervo de la Biblioteca Jurídica Virtual del Instituto de Investigaciones Jurídicas de la UNAM

\title{
ENTRE LAS ESGUELAS NAGIONALES Y LA UNIVERSIDAD: LOS GONSTITUYENTES DE 1917. UN ÁRBOL DE LA VIDA
}

\author{
Alberto ENRÍQUEZ PEREA*
}

\author{
Sumario: I. Raíces. II. Fundación y diseño. III. Conclusión. IV. Anexos. \\ V. Fuentes.
}

\section{RAÍCES}

El triunfo de la República sobre la Monarquía en 1867 fue el hecho histórico más importante ocurrido en México desde el día que logró su independencia nacional. ${ }^{1}$ Con la República triunfante se podía iniciar la anhelada reorganización política teniendo como base indiscutible la Constitución de 1857. México, sin duda alguna, se fortaleció con este triunfo y logró respeto y admiración de países en uno y otro lado del mar océano. La decisión de ser una República laica, liberal, democrática, federal quedó definitivamente arraigada en la conciencia nacional. Triunfaba la República, no se restauraba. Triunfaba sobre una Monarquía que no tenía legalidad ni mucho menos legitimidad; fue impuesta por las armas extranjeras y no deseada por la in-

* Facultad de Ciencias Políticas y Sociales de la UNAM.

1 Doña Clementina Díaz de Ovando, con gran alegría por ese triunfo de nuestra República liberal, escribió una página admirable sobre la llegada de don Benito Juárez a la Ciudad de México. Nos dice que eran las nueve y media de la mañana, del 15 de julio de 1867, y después de "una ausencia de cuatro años y 45 días" del gobierno republicano, entraba triunfalmente a la capital de la República. "Justo premio, sin duda, a su tenacidad y patriotismo". Y recordaba la distinguida maestra universitaria, los "alumnos del Colegio de San Ildefonso, muchos de los cuales en los días del Imperio se habían declarado republicanos, y con buen humor estudiantil se habían reído del general Miguel Miramón, no podían dejar de celebrar entusiastamente la liberación de la patria. Feliz acontecimiento que aunaron a la instalación de la asociación alonsiaca". Díaz y de Ovando, Clementina, "La Escuela Nacional Preparatoria", en Villegas Moreno, Gloria (coord.), La UNAM en la historia de México. De la fundación de la Escuela Nacional Preparatoria a la promulgación de la Ley Constitutiva de la Universidad Nacional (1867-1910), México, UNAM, 2011, pp. 65 y 66. 
Este libro forma parte del acervo de la Biblioteca Jurídica Virtual del Instituto de Investigaciones Jurídicas de la UNAM

mensa mayoría de los mexicanos. A partir de este triunfo, el gobierno de la República encabezado por don Benito Juárez envió al Congreso unicameral iniciativas de ley y emitió diversos decretos para consolidar las estructuras del Estado mexicano.

Entre los decretos expedidos pocos meses después del triunfo de la República se encuentra el del 30 de noviembre de 1867 que, después de varios intentos de establecerla, por fin llegaba el día de crear la Biblioteca Nacional. ${ }^{2}$ Vicente Quirarte señalaba que esta epopeya liberal era de positivas consecuencias para la cultura nacional: "La historia de la planeación de la Biblioteca Nacional es la historia de la evolución del liberalismo, liberalismo que se da en la acción, como subraya ya Jesús Reyes Heroles en su obra ya clásica", El liberalismo mexicano. ${ }^{3}$

Y el del 2 diciembre de 1867, en el único "Considerando" de esta ley decembrina, obra de Antonio Martínez de Castro, señala: "Que difundir la ilustración en el pueblo es el medio más seguro y eficaz de moralizarlo y de

2 Iguínez asegura que, al triunfo de la República, "el gobierno acordó el restablecimiento de la Biblioteca Nacional", porque "el presidente Comonfort dio un decreto con fecha 14 de septiembre de 1857 suprimiendo la Universidad y destinado su edificio, sus bienes y su librería a la formación de la Biblioteca Nacional" (Iguínez, Juan B., "La Biblioteca Nacional", Revista de Historia de América, núm. 8, abril de 1940, pp. 58 y 59). Hay un antecedente que se debe tomar en cuenta, el esfuerzo que se hizo en 1833. Cfr. los interesantes estudios de Carmen Vázquez Mantecón, Carlos Herrero, Alfonso Flamenco, La Biblioteca Nacional de México. 1810-1910. Las bibliotecas mexicanas en el siglo XIX, México, Universidad Autónoma Metropolitana-Iztapalapa, 2007.

3 Quirarte, Vicente, "Hija del pensamiento liberal", La Biblioteca Nacional. Triunfo de la República, México, UNAM, 2006, p. 13. En la presentación que hizo Quirarte a La Biblioteca Nacional de México, dijo: "El primer decreto para el establecimiento de la Biblioteca Nacional data de 1833. Posteriormente, en 1867, el presidente Benito Juárez la estableció definitivamente en el antiguo convento de san Agustín. Hija de la Reforma y del pensamiento liberal, la Biblioteca Nacional de México, al igual que las nacidas en otros países a partir de sus movimientos de independencia, se nutrió de fondos de las corporaciones religiosas y de donaciones particulares. Como otras bibliotecas nacionales del mundo, tiene como objetivos concentrar, custodiar y hacer accesibles los materiales impresos, o registrados en otros soportes, que integran la memoria histórica del país" (Quirarte, Vicente, "Presentación", en Ruiz Castañeda, María del Carmen et al. (comp. y ed.), La Biblioteca Nacional de México. Testimonios y documentos para su historia, México, UNAM, Instituto de Investigaciones Bibliográficas, 2004, pp. 17 y 18). Olivera López, por su parte, escribió que nuestra Biblioteca Nacional es una "institución liberal de la cultura, surgida para enriquecerla, y crear más conocimiento". Y para que no se nos olvide jamás, recalca, esta es una "Institución laica, en donde la figura de la República adquiere su función integradora, al cohesionar a la nación desde el punto de vista del respeto a la tolerancia del conocimiento dado en sus múltiples tipos de fuentes". Así pues, nuestra Biblioteca Nacional "debe su razón histórica al triunfo de la República, cuya fundamentación liberal quedó plasmada por creación gubernamental en 1867”, y su primer director fue José María Lafragua (Olivera López, Luis, "La folletería, triunfo del liberalismo republicano", La Biblioteca Nacional. Triunfo de la República, cit., p. 126). 
Este libro forma parte del acervo de la Biblioteca Jurídica Virtual del Instituto de Investigaciones Jurídicas de la UNAM

establecer de una manera sólida la libertad y el respeto a la Constitución y a las leyes". ${ }^{4}$ Por lo tanto, se establecieron las escuelas: Preparatoria, Ingenieros, Medicina, Jurisprudencia, entre otras muy importantes, recogiendo cada una de ellas sus antecedentes, su historia, su herencia. ${ }^{5}$ Como toda creación institucional, el tiempo es el mejor juez para rectificar y afianzar las obras creadas. Así pasó con las obras de la República liberal, siempre el entusiasmo por delante, pero con los sentidos en alerta.

Sin embargo, como bien lo dijo el doctor Lamoine, el "paso más audaz" de estas reformas republicanas y liberales fue que la Escuela Nacional Preparatoria se convirtió en la "columna vertebral" de la citada ley del 2 de diciembre de 1867, y el genio de don Gabino Barreda iluminó el viejo edificio de San Ildefonso. Al mismo tiempo,

significó, por ello mismo, el obstáculo mayor que hubo que vencer para que la revolucionaria medida se trasladara del papel que estaba escrita a la realidad, de las oficinas de Palacio a las aulas en espera de una juventud ávida de aprender la tarea, difícil, complicada y llena de trampas, demandaba la pericia de un diestro y enérgico timonel, y Juárez, con esa sagacidad que mostró casi siempre en la elección de sus colaboradores, designó, como primer director de la preparatoria, el 17 de diciembre [de 1867], al doctor Gabino Barreda. ${ }^{6}$

En los 30 años que restaban del siglo XIX se fueron reformando las instituciones educativas (el 15 de mayo de 1869 se tuvo nueva Ley Orgánica de Instrucción Pública, y en octubre de 1872 se escucharon voces que pedían la "introducción de las humanidades en la enseñanza superior"), ${ }^{7}$ adecuándolas al tiempo político y a las necesidades de México. Del periodo juarista se pasó al lerdista, iglesista, y como oasis en el tiempo, el gonzalista, para dar paso a toda una época, al porfirismo. En cada uno de estos periodos gubernamentales las instituciones educativas resistieron los vendavales de la política y se adecuaron planes de estudios y creación de nuevas carreras a las necesidades nacionales. Por ejemplo, "la formación de ingenieros civiles

4 Ley Orgánica de la Instrucción Pública en el Distrito Federal, Diario de la Federación, 2 de diciembre de 1867, disponible en: wrwrsep.gob.mx/work/models/sep1/Resource/3f9a47ccefd9.../ley_02121867.pdf (fecha de consulta: 6 de octubre de 2016).

5 Cfr. el siguiente importante estudio para ver antecedentes de las escuelas nacionales como la de Jurisprudencia, Medicina e Ingenieros, García Verástegui, Lía, Del proyecto nacional para una Universidad en México. 1867-1910, México, UNAM, 1984.

6 Lemoine, Ernesto, La Escuela Nacional Preparatoria en el periodo de Gabino Barreda. 18671978, México, UNAM, 1970, p. 15.

7 García Verástegui, Lía, Del proyecto nacional para una Universidad en México. 1867-1910, cit., p. 45 . 
Este libro forma parte del acervo de la Biblioteca Jurídica Virtual del Instituto de Investigaciones Jurídicas de la UNAM

se constituyó en una prioridad durante el Porfiriato", señala Domínguez Martínez. Y rememora que el ingeniero Luis Suárez fue autor del proyecto del Gran Canal de Desagüe del Valle de México", que el ingeniero Roberto Gayol diseñó el sistema de alcantarillado de la Ciudad de México y "participó en la dotación de agua potable". ${ }^{8}$

Jorge L. Tamayo, en su Breve reseña de la Escuela Nacional de Ingeniería, ofrece estos datos: el 28 de noviembre de 1881 esta Escuela pasó a depender de la Secretaría de Fomento, hasta 1891, y de esta fecha en adelante a la Secretaría de Justicia e Instrucción Pública. El ingeniero Mariano Villamil creó en 1889 la carrera de Ingeniero electricista y dos años antes se abandonaba la "francesa designación de la carrera de Ingenieros de Caminos Puentes y Canales" por la de Ingeniería civil. ${ }^{9}$

El maestro Francisco de Paula Herrasti, uno de los grandes humanistas mexicanos, estudioso de Virgilio, que obtuvo su título de abogado el 21 de marzo de $1903,{ }^{10}$ al dar a conocer sus "Recuerdos de la Escuela N[acional]. de Jurisprudencia”, señaló que, así como pasaba un siglo a otro, el XIX al $\mathrm{XX}$, ocurría lo mismo con los profesores. Los nuevos educadores desplazaban a los viejos, y "con ellos sus ideas y métodos, y aún sus libros y miras". Además,

el gobierno de don Porfirio, refundiendo meritísimamente, y para bien y con aplauso de todos, la caótica legislación heredada, nos venía dando uno tras otro, los libros que la codificaban, el Código Civil, el de Comercio, los de Procedimientos Civiles y Penales del Distrito, y aún el de Procedimientos Civiles Federales. ${ }^{11}$

8 Domínguez Martínez, Raúl, "Contribución de los ingenieros al México moderno", en Villegas Moreno, Gloria (coord.), La UNAM en la historia de México..., cit., p. 199.

9 Tamayo, Jorge L., Breve reseña sobre la Escuela Nacional de Ingeniería, edición y prólogo de Armando Escanero Muñoz, México, Imprenta La Espera, 1958, pp. 48 y 53.

10 López de Lara, Guillermo, "Don Francisco de Paula Herrasti: un humanista mexicano", Revista de Derecho Notarial Mexicano, México, núm. 64, 1976, p. 29, disponible en: wrere. historico.juridicas.unam.mx/publica/librev/rev/dernotmex/cont/64/cnt/cnt2.pdf (fecha de consulta: 17 de diciembre de 2016).

11 Don Francisco recordaba ese paso de autores: De Bentham a "Le Bon y a Lauret; y la de Bluntschli a Fiore, y a Funck Brentano; y luego, a Calvo, y a Bonfilms; la de don Guillermo Prieto, a Beauregard, y a Leroy Beaulieu; la de señor Castillo Velasco, a Vallarta, y a Story, y a Kent, y aun a Coronado, y a la propia del mismo don Eduardo Ruiz, profesor entonces de la cátedra de Derecho Constitucional; y en Derecho Administrativo, a la de don Luis Labastida. La obra del señor Lozano había dejado su puesto en Derecho Penal a la muy estimada de Ortolan, sostenida, suavitir in modo, fortiter in re, por don Miguel Macedo, y en fin, ya había don José Algara escrito e impreso elegantemente su abstrusa obra de Derecho internacional privado; ya el maestro Pallares había escrito sus interesantes monografías de Legislación 
Este libro forma parte del acervo de la Biblioteca Jurídica Virtual del Instituto de Investigaciones Jurídicas de la UNAM

Lo mismo ocurrió en la Escuela Nacional de Medicina que no podía ni debía ser ajena a las necesidades del país, y atenta, como otras disciplinas, a las nuevas corrientes del pensamiento, con ilustres maestros y cuerpo de directivos que siempre han dado un perfil humano a la institución. Don Carlos Viesca, en su "Prólogo" al libro de la estudiosa de esta institución, Martha Eugenia Rodríguez, señala:

La escuela dejó de tener casa en varios momentos, pero las casas de los profesores y, sobre todo, los hospitales continuaron siendo sedes de enseñanza que no fue interrumpida. Sus médicos participaron al unísono en la formación de brigadas frente a la invasión norteamericana y se dividieron [en] el efímero imperio de Maximiliano, pero siempre continuaron velando porque su escuela permaneciera activa y formando nuevos médicos y, fueran liberales o conservadores, imperialistas o republicanos, siguieron profesando cátedra y guiando a sus alumnos en el camino del saber. ${ }^{12}$

Justamente formados en la última década del siglo XIX salieron los primeros siete profesionistas que se presentaron al Congreso Constituyente de 1916 y 1917, el abogado Guillermo Ordorica Manjarrez, que presentó su examen profesional en 1891; el médico Arturo Méndez, que lo presentó en 1893; el abogado, Alberto M. Méndez, en 1894; dos médicos, Jairo Dyer Castañeda y José María Rodríguez, en 1895; un ingeniero, Pastor Rouaix Méndez, en 1896, y un médico más, Alberto Román, en 1898. ${ }^{13}$

El título de la tesis del abogado Ordorica, Problemas de la propiedad, es ya un anuncio de lo que estaba aconteciendo en México, y que recuerda lo que a inicios de ese siglo XIX decían tanto liberales como conservadores, la concentración de la propiedad es causa de las revoluciones. El médico Román presentó Responsabilidad legal en las personas afectadas de histeria, y cita profusamente a los representantes de la Escuela de París, que no sería novedad, pues era la Escuela que se seguía, sino a dos de sus integrantes: a Sigmund Freud y a Joseph Brauer, que en realidad era Bertha Pappenheim, cuando apenas unos años antes había editado, en coautoría, Estudios sobre la histeria (1895).

Complementaria del Derecho Civil, y su tomo de Derecho Mercantil (Herrasti, Francisco de P., "Recuerdos de la Escuela Nacional de Jurisprudencia", Revista de Ciencias Sociales, t. II, núm. 1, agosto de 1925, p. 7.

12 Rodríguez, Martha Eugenia, La Escuela Nacional de Medicina. 1833-1910, prólogo de Carlos Viesca T., México, UNAM, Facultad de Medicina-Departamento de Historia y Filosofía de la Medicina, pp. 10 y 11.

13 Véase los cuadros que se encuentran más adelante, por Escuela, con otros datos, como los expedientes de alumnos que se encuentran en el Archivo Histórico de la UNAM. 
Este libro forma parte del acervo de la Biblioteca Jurídica Virtual del Instituto de Investigaciones Jurídicas de la UNAM

En la primera década del siglo XX, presentaron sus exámenes de grado nueve, y también fueron al constituyente queretano dos abogados, Antonio Aguilar y Refugio M. Mercado Fuentes, en 1900; en 1902, ingeniero, Pascual Ortiz Rubio, que inició sus estudios en Michoacán, pero por sus ideas antireeleccionistas, terminó sus formación en la Escuela Nacional de Minería; en 1905, dos médicos, Amadeo Betancourt Villaseñor y Fernando Gómez Palacio; en 1906, igualmente dos, un ingeniero, Julián Adame Alatorre, y un abogado, Fernando Lizardi; en 1909, un abogado más, Juan Manuel Giffard, y en mayo de 1910, un médico, Marcelo Torres. ${ }^{14}$

El siglo XX mexicano nació antirreleccionista. Y los egresados de las escuelas nacionales abrazaban unos más que otros, esos ideales. En sus respectivas comunidades se les encuentra políticamente activos. El hartazgo, que no sólo ellos lo manifestaban, sino que la población lo expresaba a través de manifestaciones públicas, movimientos políticos y huelguísticos. El sector estudiantil era uno de los más sensible porque expresaba como ningún otro grupo el estado de la cuestión política y social y la respuesta que daba el Estado a sus demandas. Entre 1906 y 1907 hubo descontento porque la educación laica no se respetaba, el régimen porfirista había hecho concesiones a la Iglesia sin importarle nada, y por ciertas modificaciones que don Justo Sierra quería introducir en la Escuela Nacional Preparatoria.

Por esos años se llevaron a cabo las huelgas de Cananea y Río Blanco, respectivamente; en 1908 se fundó la Sociedad de Alumnos de la Escuela Nacional de Ingenieros y al año siguiente, 1909, en la Capilla del Palacio de Minería se reunió el Primer Congreso Nacional Estudiantil; en ese mismo año apareció el libro más importante del siglo XX en materia democrática, La sucesión presidencial en 1910, de don Francisco I. Madero, que propuso que, a través del sufragio efectivo y la no reelección, se construyera definitivamente en México un Estado de derecho y democrático. Estas manifestaciones, en su conjunto, eran señales de las claudicaciones que estaba haciendo el régimen porfirista y de las exigencias de la sociedad mexicana.

14 Hay que advertir que estos médicos, abogados e ingenieros son de los que se tiene evidencia de su paso por las Escuelas Nacionales de Medicina, Ingeniería y Jurisprudencia. Hay otros que sólo están sus nombres en sus expedientes de alumnos y no hay documento alguno que avale su paso, como es el caso de Alfonso Cravioto, un personaje importante desde los albores del siglo XX, pues también fue antirreeleccionista, sufrió cárcel, fundó la revista Savia Moderna que abrió las grandes alamedas al arte, a la literatura, a la crítica. Asimismo existe el testimonio del constituyente Jesús Romero Flores de que también estudiaron en la Escuela Nacional de Jurisprudencia Fidel Jiménez; Fortunato de Leyja, por ejemplo; que estudiaron medicina en la Ciudad de México, Gilberto de la Fuente; José Franco Espinosa y Gabino Bandera y Mata. Cfr. Romero Flores, Jesús, Historia del Congreso Constituyente 1916-1917, con la reseña gráfica, México, Talleres de la Editorial Gupy, 1985. 
Este libro forma parte del acervo de la Biblioteca Jurídica Virtual del Instituto de Investigaciones Jurídicas de la UNAM

Todas estas manifestaciones las pasaba por alto el régimen porfirista. $\mathrm{Ni}$ siquiera las expresiones políticas del reyismo, que llegaron a ser multitudinarias, y sobre todo del movimiento maderista, que se convirtió en la primera manifestación pública de masas organizadas haciendo política y teniendo en sus manos un proyecto político, que no hicieron cambiar de opinión al régimen. Sólo un hombre, desde su mirador que era la Secretaría de Instrucción Pública, veía desde hace años que México ya no era el mismo que le heredaron sus padres y mucho menos el de sus abuelos. Desde hacía tiempo también propuso la creación de la Universidad y ahora, acaso más que nunca, se necesitaba fundarla. Se acercaba una fecha importante en el calendario cívico, el primer centenario del inicio de nuestra Independencia nacional, y mejor momento político no había que pasarlo por alto.

\section{FUNDACIÓN Y DISEÑO}

El 7 de abril de 1910 se dio el primer paso en la reorganización del sistema de lo que hoy llamamos educación superior. Se expidió ese día la Ley Constitutiva de la Escuela Nacional de Altos Estudios, y en el artículo 2o., están los objetivos por la que fue creada:

1o. Perfeccionar, especializándolos y subiéndolos a un nivel superior, estudios que en grados menos altos se hagan en las Escuelas Nacionales Preparatoria, de Jurisprudencia, de Medicina, de Ingenieros y de Bellas Artes, o que estén en conexión con ellos; 2o. Proporcionar a sus alumnos y a sus profesores los medios de llevar a cabo metódicamente investigaciones científicas que sirvan para enriquecer los conocimientos humanos, y 3o. Formar profesores de las escuelas secundarias y profesionales.

Y el artículo 3o. indica las secciones que debería tener:

La primera, de Humanidades, comprenderá: las lenguas clásicas y las lenguas vivas, las literaturas, la filología, la pedagogía, la lógica, la psicología, la ética, la estética, la filosofía y la historia de las doctrinas filosóficas. -La segunda sección de Ciencias Exactas, Físicas y Naturales, abrazará la matemática en sus formas superiores y las ciencias físicas, químicas y biológicas. -La tercera sección será la de Ciencias Sociales, Políticas y Jurídicas, y comprenderá todas las que tienen por base o por objeto fenómenos sociales. ${ }^{15}$

15 La Universidad de México. 1910, 2a. ed. facsimilar, México, UNAM, Coordinación de Humanidades-Centro de Estudios sobre la Universidad, 1990, pp. 9 y 10. 
Este libro forma parte del acervo de la Biblioteca Jurídica Virtual del Instituto de Investigaciones Jurídicas de la UNAM

Semanas más tarde, el 26 de mayo de 1910, don Justo Sierra, señalaba que el presidente Porfirio Díaz hacía saber que con fecha 24 del mismo mes, el Congreso de la Unión tuvo a bien dirigirle el siguiente decreto: "El Congreso de los Estados Unidos decreta: Ley Constitutiva de la Universidad Nacional de México", que en su artículo 1o., señala: "Se instituye con el nombre de «Universidad Nacional de México» un cuerpo docente cuyo objeto primordial será realizar en sus elementos superiores la obra de la educación nacional"; en el 2o., se establece que la

Universidad quedará constituida por la reunión de las Escuelas Nacionales Preparatoria, de Jurisprudencia, de Medicina, de Ingenieros, de Bellas Artes (en lo concerniente a la enseñanza de la arquitectura) y de Altos Estudios.- El Gobierno Federal podrá poner bajo la dependencia de la Universidad otros institutos superiores, y dependerán también de la misma los que ésta funde con sus recursos propios, previa aprobación del Ejecutivo, o aquellos cuya incorporación acepte, mediante los requisitos especificados en los reglamentos.

Importante también es el siguiente artículo 3o., que dice: "El Ministro de Instrucción Pública y Bellas Artes será el Jefe de la Universidad; el gobierno de ésta quedará, además, a cargo de un Rector y un Consejo Universitario". ${ }^{16}$

El 22 de septiembre de 1910, a las 10 de la mañana, en el Anfiteatro de la Escuela Nacional Preparatoria, se dieron cita para inaugurar solemnemente la Universidad Nacional de México. Don Genaro García, quien hizo la crónica de este magno acontecimiento escribió que esta tuvo:

16 La Universidad Nacional de México. 1910, cit., pp. 35 y 36. Conviene reproducir una parte del dictamen de las Comisiones Unidas 1a. y 2a. de Instrucción de la Cámara de Diputados, sobre el Proyecto de Ley constitutiva de la Universidad Nacional de México, que dice: "Hoy por hoy, y conforme al proyecto sometido a la consideración de Vuestra Señoría, la Universidad nacional mexicana será de hecho y de derecho una Universidad de Estado, como lo es la Universidad francesa; un poco más tarde, cuando su desenvolvimiento interior se marque, podrá ser como las Universidades Alemanas, una Universidad libre de hecho, aunque no lo sea de derecho, y acaso no diste mucho el día en que suficientemente desarrollada, pueda ser, como las grandes Universidades americana autónoma de hecho y de derecho.- El proyecto de Universidad Nacional, sometido al dictamen de las Comisiones que suscriben, no será sin duda una obra perfecta, si se da a este vocablo un sentido absoluto; pero es sin duda un proyecto viable adecuado a nuestras peculiares condiciones y exigencias, y las Comisiones dictaminadoras no creen engañarse al afirmar que su realización producirá grandes ventajas en los importantes y delicados dominios de la educación nacional" ("Dictamen presentado a la H. Cámara de Diputados proponiendo el proyecto de ley constitutiva de la Universidad Nacional de México", Cuadernos del Archivo Histórico de la UNAM, México, UNAM, Centro de Estudios sobre la Universidad, núm. 1, enero-abril de 1982, p. 13). 
Este libro forma parte del acervo de la Biblioteca Jurídica Virtual del Instituto de Investigaciones Jurídicas de la UNAM

Caracteres relevantes por su severa grandeza y la alta significación moral; y la institución recientemente creada que, entre otros fines, tiene a procurar la uniformidad y la independencia de la instrucción superior, nació, así, con toda pompa en el mes glorioso de la patria, como si se quisiera darle un augurio de desarrollo y engrandecimiento. ${ }^{17}$

La Universidad Nacional de México nacía querida, deseada, anhelada si se quiere; modestamente en recursos y ambiciosa en afanes y proyectos, como han nacido todas las instituciones nacionales; con los elementos necesarios apenas para sobrevivir, pero con la fuerza necesaria para enfrentar y encarar el futuro y salir adelante; se tenía fe en sus destinos y, sobre todo, de la alta misión que le encomendaba la nación mexicana.

El discurso de don Justo Sierra que pronunció el día 22 de septiembre fue una gran pieza oratoria; un discurso político por excelencia; unos de esos discursos que en los anales de la historia antigua y moderna sólo fueron escritos para grandes momentos, como nos recuerda Tucídides en su Historia de la guerra del Peloponeso. Discurso de tesis, como también decía frecuentemente el embajador Gilberto Bosques Saldívar, que era necesario pronunciar porque en ellos se encontraban las bases de la acción inmediata, de la construcción y edificación de la obra perenne que se quería dejar para las presentes y futuras generaciones. Eso era el discurso de don Justo Sierra. Pieza bien escrita, bien hecha, bien pulida, en una prosa sin igual.

Don Justo se imaginaba que:

Un grupo de estudiantes de todas las edades sumadas en una sola, la edad de la plena aptitud intelectual, formando una personalidad real a fuerza de solidaridad y de conciencia de su misión y que, recurriendo a toda fuente de cultura, brote de donde brotara, con tal que la linfa sea pura y diáfana, se propusiera adquirir los medios de nacionalizar la ciencia, de mexicanizar el saber. ${ }^{18}$

Nacionalizar la ciencia, mexicanizar el saber, ¿no es acaso un anhelo nacional hasta el día de hoy y que nuestra Universidad Nacional hoy Autónoma y que sigue siendo de México, ha puesto todo su empeño, su sabiduría, su inteligencia para lograr el día que se imaginaba don Justo Sierra?

El maestro Sierra continuó leyendo su hermoso discurso, lleno de imágenes, donde pululan las alegorías:

17 "Crónica de la fiesta de inauguración de la Universidad Nacional de México", Cuadernos del Archivo Histórico de la UNAM, México, UNAM, Centro de Estudios sobre la Universidad, núm. 1, enero-abril de 1982, p. 20.

18 La Universidad Nacional de México. 1910, cit., p. 113. 
Este libro forma parte del acervo de la Biblioteca Jurídica Virtual del Instituto de Investigaciones Jurídicas de la UNAM

El telescopio, al cielo nuestro, sumario de asterismos prodigiosos en cuyo negror hecho de misterio infinito, fulguran a un tiempo el Septentrión inscribiendo eternamente el surco ártico de derredor de la estrella virginal del Polo, y los diamantes siderales que clavan en el firmamento la Cruz austral; el microscopio, a los gérmenes que bullen invisibles en la retorta del mundo orgánico, que en el ciclo de sus transformaciones incesantes hacen de toda existencia un medio en que efectuar sus evoluciones; que se emboscan en nuestra fauna, en nuestra flora, en la atmósfera en que estamos sumergidos, en la corriente de agua que se desliza por el suelo, en la corriente de sangre que circula en nuestras venas, y que conspiran, con tanto acierto como si fueran seres conscientes, para descomponer toda vida y extraer de la muerte nuevas formas de vida. ${ }^{19}$

En otra parte de su discurso explicaba por qué a esta Universidad se le había dado el carácter de nacional:

Realizando [la Universidad] esta obra inmensa de cultura y de atracción de todas las energías de la República, aptas para la labor científica, es como nuestra institución universitaria merecerá el epíteto de nacional que el legislador le ha dado; a ella toca demostrar que nuestra personalidad tiene raíces indestructibles en nuestra naturaleza y en nuestra historia; que, participando de los elementos de otros pueblos americanos, nuestras modalidades son tales que constituyen una entidad perfectamente distinta entre las otras y que en el tantum sui simile gentem de Tácito puede aplicarse con justicia al pueblo mexicano.

Y a continuación agregó este sin igual pensamiento:

Para que sea no sólo mexicana, sino humana esta labor, en que no debemos desperdiciar un solo día del siglo en que llegará a realizarse, la Universidad no podrá olvidar, a riesgo de consumir sin renovarlo el aceite de su lámpara, que le será necesario vivir en íntima conexión con el movimiento de la cultura general; que sus métodos, que sus investigaciones, que sus conclusiones, no podrán adquirir valor definitivo mientras no hayan sido probados en la piedra de toque de la investigación científica que realiza nuestra época, principalmente por medio de las Universidades. La ciencia avanza, proyectando hacia adelante su luz que es el método, como una teoría inmaculada de verdades que van en busca de la verdad; debemos y queremos tomar nuestro lugar en esa divina procesión de antorchas. ${ }^{20}$

\footnotetext{
19 Idem.

20 Ibidem, p. 116.
} 
Este libro forma parte del acervo de la Biblioteca Jurídica Virtual del Instituto de Investigaciones Jurídicas de la UNAM

El poeta, sin embargo, era un gran historiador y un perspicaz político. No descendencia de su pedestal sino lo elevaba, como sus altas miras al hacer historia y escribir una página en la historia de México. Pero no era cualquier página, sino una página fundacional, que no se escribe en cualquier momento ni en cualquier día. El maestro de historia y autor de obras históricas, en su momento, se preguntó: “¿Tenemos una historia?”. Y se respondió con un rotundo "no", e inmediatamente, disertaba:

La Universidad mexicana que nace hoy no tiene árbol genealógico; tiene raíces, sí, las tiene en una imperiosa tendencia a organizarse que revela en todas sus manifestaciones la mentalidad nacional y por eso apenas brota del suelo el vástago, cuando el primer beso del sol de la Patria se cubre de renuevos y yemas, nuncios de frondas, de flores, de frutos. Ya es fuerte, lo sentimos: fará da se. Si no tiene antecesores, si no tiene abuelos, nuestra Universidad tiene precursores: el gremio y el claustro de la Real y Pontificia Universidad de México no es para nosotros el antepasado, es el pasado. Y sin embargo, la recordamos con cierta involuntaria filialidad; involuntaria, pero no destituida de emoción ni interés. Nació con la Colonia, nació con la sociedad engendrada por la conquista cuando no tenía más elementos que aquellos que los mismos conquistadores proporcionaban o toleraban; hija del pensamiento del primer virrey, el magnánimo don Antonio de Mendoza, y del amor infrangible por el país nuevo del santo padre Las Casas, no pudo venir a la luz sino cuando fueron oídos los votos del Ayuntamiento de México, ardientemente secundados por otro gran virrey que mereció de sus coetáneos el sobre nombre de Padre de la Patria. ${ }^{21}$

La Universidad inició sus labores resistiendo y enfrentando duras pruebas. Unos días antes de su inauguración, y por 12 días (6-18 de septiembre) se llevó a cabo el Primer Congreso Nacional de Estudiantes, y Alfonso Cabrera, alumno que inició sus estudios en el Colegio del Estado de Puebla, antirreeleccionista, y que los estaba terminando en la Escuela Nacional de Medicina, fue alma y conciencia de este hecho singular. Y dos meses después de esas fechas tan importantes para la vida universitaria, ${ }^{22}$ el 20 de

21 La Universidad Nacional de México. 1910, cit., pp. 118 y 119. Para García Verástegui, Justo Sierra "crea un concepto de universidad moderna, en México, al pretender aglutinar a todos los institutos de educación superior a la manera de universidades norteamericanas existentes entonces" (García Verástegui, Lía, Del proyecto nacional para una Universidad en México. 1867-1910, cit., p. 54).

22 Cfr. importante trabajo sobre el Primer Congreso Nacional de Estudiantes, Velázquez Albo, María de Lourdes, "La propuesta estudiantil de reforma en 1910. Primer Congreso Nacional de Estudiantes", en Alvarado, Lourdes (coord.), Tradición y reforma en la Universidad de México, México, CESU-Miguel Ángel Porrúa, 1994. 
Este libro forma parte del acervo de la Biblioteca Jurídica Virtual del Instituto de Investigaciones Jurídicas de la UNAM

noviembre de 1910, iniciaba la revolución maderista que enarbolaba las ideas del sufragio efectivo y no reelección que hicieron cimbrar al régimen del presidente Porfirio Díaz, en principio, y poco tiempo después los revolucionarios lograban su renuncia y salida del país y se dejaba libre paso a un nuevo régimen democrático, bajo el imperio de la Constitución de 1857.

Entre 1911 y 1913 México vivió los vaivenes y tensiones propias de un tránsito entre el viejo y nuevo régimen. No fue posible encontrar un acuerdo a pesar de los esfuerzos pacificadores y mediadores del presidente Madero y en 1913 se dio el cuartelazo, los asesinatos del presidente constitucional y del vicepresidente don José María Pino Suárez. La respuesta a ese atentado vino del Norte. Don Venustiano Carranza con su Plan de Guadalupe lucha política y militarmente contra ese régimen y en 1914 triunfa. Pero hay nuevos retos que superar en las filas mismas de los revolucionarios. Nuevamente fueron las armas y no la conciliación ni acuerdos ni pactos los que obligaron a definir a través de las armas el rumbo a seguir. Entre 1915 y 1916 el campo se ha deslindado, aunque quedan tensiones políticas que se resolverán al paso de cuatro años. Mientras tanto, las fuerzas constitucionalistas encabezadas por Carranza triunfaban y convocaban a un nuevo Congreso Constituyente, que el 5 de febrero de 1917, dio una nueva carta constitucional. Promulgada la carta queretana, previas elecciones, don Venustiano Carranza, se convirtió en el primer presidente constitucional emanado de la Revolución mexicana inaugurando una nueva etapa histórica que ya es centenaria.

Y en estos años que corren de 1910 a 1917, ¿qué pasó en la Universidad Nacional de México? Para mejor apreciar este periodo hay que dividirlo en dos, el que va de 1910 a 1914; y de 1914 a 1917. En estos dos periodos hubo varios hechos significativos que explican la vida universitaria. Se seguían graduando alumnos que pronto estarían en el Teatro de la República, en Querétaro: en 1911 se graduó el médico, Alfonso Cabrera Lobato; en 1912, el abogado, Rafael Martínez de Escobar y Jesús López Lira, egresado de la Escuela Nacional de Enseñanza Dental, y en 1913, también de abogado, Hilario Medina Gaona. Asimismo, en pleno régimen maderista, Luis Cabrera llegó a la dirección de la Escuela Nacional de Jurisprudencia y empezó a dictar acuerdos y hacer declaraciones que no les gustaron a los alumnos de Jurisprudencia. En respuesta, éstos protestaron y se fueron a una huelga. $\mathrm{Al}$ mismo tiempo renunció un viejo maestro, opositor al presidente de la República, Jorge Vera Estañol.

En los documentos que Jaime del Arenal publicó sobre la "Fundación de la Escuela Libre de Derecho", nos encontramos una serie de expresiones de uno y otro lado que dan cuenta de las tensiones que se vivieron en junio de ese mismo año. De los dos lados hubo intolerancia, falta de diálogo, 
Este libro forma parte del acervo de la Biblioteca Jurídica Virtual del Instituto de Investigaciones Jurídicas de la UNAM

de acuerdos, visiones del mundo encontradas con un sistema político que estaba a pique y uno que apenas daba señales de vida. Y lo que más llama la atención, a pesar de todo lo difícil de la situación, es que los puentes de entendimiento se tendían y no se rompían entre los maestros de la Escuela Nacional de Jurisprudencia y la que pronto va a nacer, la Escuela Libre de Derecho. Destaco un nombre por el papel que jugaría en los próximos meses, el del licenciado don José Natividad Macías, que en 1913 dio el Segundo Gurso de Procedimientos Civiles, en la Libre de Derecho. ${ }^{23}$

En el Informe que rindió el doctor Joaquín Eguía Lis, "Rector de la Universidad Nacional, sobre las labores de la institución, durante el periodo de septiembre de 1910 a septiembre de 1912, pronunciado el 5 de diciembre de 1912", se encuentran estas palabras que, como la de todos los rectores de nuestra Máxima Casa de Estudios, son de prudencia, serenidad, lúcida reflexión.

De este movimiento, a todas luces de indisciplina, como la que había tomado su origen en el propósito de no cumplir con una disposición expresa de la ley, surgió, en cambio, más tarde, la Escuela Libre de Derecho, que cuenta con un cuerpo de dirección y profesores, en su mayor parte, muy distinguidos y muy dignos, entre ellos, cinco que son a la vez profesores en la Escuela oficial de Jurisprudencia. Como en realidad, la huelga, por una parte, y por otra, la fundación de la Escuela Libre obedecen a tendencias distintas, pues si de la huelga nació la Escuela, esta se debió solamente a la necesidad en que los alumnos huelguistas quedaron colocados de continuar sus estudios fuera de la Escuela oficial, esta Rectoría tiene que declarar que le parece muy reprobable la huelga por injustificada y los motivos que la produjeron, por la indisciplina que revelan; pero debo manifestar también que juzga la fundación de la Escuela Libre de Derecho como un acto de alta significación y probablemente de grandes y benéficas consecuencias para el porvenir de la institución en México. Esa Escuela, por lo que tiene de libre, se concierta con los fines de la Universidad. ${ }^{24}$

El segundo y último periodo fue fundamental y decisivo para la Universidad Nacional, por las decisiones que tomó don Venustiano Carranza. El Instituto Médico Nacional que tanto había dado al país, Carranza lo su-

23 Arenal Fenochio, Jaime del, "La fundación de la Escuela Libre de Derecho. Documentos", Revista de Investigaciones Furídicas, México, núm. 11, 1987, p. 761. Cfr. Garciadiego, Javier, "Los orígenes de la Escuela Libre de Derecho", Revista de Investigaciones furídicas, México, núm. 21, 1993.

24 Arenal Fenochio, Jaime del, "La fundación de la Escuela Libre de Derecho. Documentos", cit., p. 708. 
Este libro forma parte del acervo de la Biblioteca Jurídica Virtual del Instituto de Investigaciones Jurídicas de la UNAM

primió, quizá mal asesorado, dice Hernández del Castillo. ${ }^{25}$ El 15 de mayo de 1914, la Biblioteca Nacional formó parte de la Universidad, y el 3 de septiembre de ese mismo año Luis Manuel Rojas fue su director, por tres meses; volvió a asumir esa función del 23 de agosto de 1916 al 21 de abril de 1917. El médico José María Rodríguez, fue nombrado presidente del Consejo Superior de Salubridad de la Ciudad de México. ${ }^{26}$ Mención especial merece el ingeniero Pastor Rouaix que fue autor de la primera ley agraria expedida en el país, enero de 1915, y primer jefe y fundador de la Comisión Nacional Agraria. ${ }^{27}$ En 1916, Alfonso Cabrera Lobato asumió la dirección del Hospital General. En la Escuela Nacional de Jurisprudencia también hubo importantes movimientos. Don José Natividad Macías fue nombrado, primero, director de esa Escuela, y poco tiempo después, rector de la Universidad Nacional. Don Venustiano lo comisionó para hacer el proyecto de una nueva Constitución.

En la Escuela Nacional de Medicina, su director, don Ángel Hidalgo, que apenas duró tres meses en su cargo (marzo-junio de 1915), compró, "por 100,000 pesos, la casa número 35 de la 4a. calle de Santo Domingo, inmediata al antiguo edificio de la Inquisición, y que posteriormente ocupó la facultad Odontológica. Efectuó también una renovación del profesorado, hizo una revisión de métodos y programas de estudio, mejoró el trabajo en laboratorios y clínicas". ${ }^{28}$

En 1916 Jorge Prieto Laurens, apoyado por el rector Macías, organizó el Congreso Local Estudiantil y se celebró el Día del Estudiante, con la presencia del Varón de Cuatro Ciénegas. De aquí en adelante pues, se fue preparando el terreno para lo que vendría a ser el más grande suceso político del país, el Congreso Constituyente de 1916-1917. Y he aquí que de los 218 diputados constituyentes algunos pasaron por las aulas de la Escuela Nacional Preparatoria, continuaron sus estudios en la Escuela Nacional de Jurisprudencia, de la de Medicina y de Ingeniería, que a partir de 1910 formaron parte de la Universidad Autónoma de México, como quedó dicho.

Como se observará, no era necesario llegar a los años veinte para reconstruir a México. La reorganización de México se estaba dando desde 1913, se anduvo más rápido cuando se logró la derrota de Huerta y los

25 Hernández del Castillo, Francisco, Historia de la Academia Nacional de Medicina de México, México, Fournier, 1956, p. 120.

26 Bustamante, Miguel E., Cinco personajes de la salud en México, México, Miguel Ángel Porrúa, 1986, pp. 63-96.

27 Tamayo, Jorge L., Breve reseña sobre la Escuela Nacional de Ingeniería, cit., p. 62.

28 Graue Wiechers, Enrique et al., Presencia médica en la vida universitaria, México, UNAM, Facultad de Medicina, 2011 , p. 86. 
Este libro forma parte del acervo de la Biblioteca Jurídica Virtual del Instituto de Investigaciones Jurídicas de la UNAM

huertistas, y sin tantos contratiempos a partir de 1916, que fue un año fundacional para México: el 1o. de diciembre de 1916, en la ciudad de Querétaro, iniciaba el periodo de sesiones único, del Congreso Constituyente. Esta es la gran fecha fundacional de México. Ya no sólo para reconstruir sino para crear el Estado de la Revolución mexicana.

A esta cita histórica fue un contingente universitario que se formó en las Escuelas Nacionales, pilares de la Universidad Nacional de México: 11 abogados, 10 médicos, 1 dentista y 5 ingenieros. Del total, 27 obtuvieron su grado; algunos no terminaron su carrera o no obtuvieron el grado. Además, desde 1914 la Universidad tuvo en su seno tres académicos que participaron en el Constituyente, y dos más se incorporaron después de promulgada la carta queretana. La suma, entonces, se enriquece. En total: 32. Es posible que pronto se tengan datos de otros distinguidos constituyentes que sus contemporáneos aseguran que estudiaron en las Escuelas Nacional / Universidad Nacional, o que laboraron, pero hasta este momento, no se tiene completa seguridad. ${ }^{29}$ Empero, lo que se puede afirmar es que la Universidad no sólo forma y genera recursos humanos, cuadros altamente calificados y comprometidos con el porvenir de la nación sino también sus propios cuadros para formar nuevos profesionales.

El contingente universitario en el Congreso Constituyente de 1916, por su número, fue mayoritario: 32. El estado que mayor número de diputados constituyentes tuvo fue Jalisco, 20; le siguió Veracruz, con 19; Puebla y Guanajuato, con 18. Es de suma importancia manifestar que, de las 30 Diputaciones que conformaron ese Constituyente, en 14 hubo más de un universitario. Un dato más, el diputado constituyente, propietario, ingeniero Pascual Ortiz Rubio, fue el primero de estas nuevas generaciones que se estaban formando en lo que es hoy la Universidad Nacional Autónoma de México, que llegó por el voto popular, a ocupar el cargo de presidente de la República. Y si bien es cierto que don Venustiano Carranza no fue al Congreso Constituyente, empero, fue gracias a su tenacidad, y sobre todo a su visión política, es hijo de la Escuela Nacional Preparatoria (1874-1877), ${ }^{30}$ que presentó el 1o. de diciembre de 1916, el proyecto de Constitución.

De las XXX diputaciones que conformaron el Congreso Constituyente, hay por lo menos un diputado como mínimo y cuatro como máximo, en 14, casi la mitad, del contingente universitario: Coahuila, Distrito Federal, Durango, Guanajuato, Guerrero, Hidalgo, Jalisco, México, Michoacán, Puebla, San Luis Potosí, Tabasco, Veracruz y Zacatecas. Y abrieron y cerraron

\footnotetext{
29 Cfr. los anexos que se encuentran al final del artículo.

30 Taracena, Alfonso, Venustiano Carranza, México, Jus, 1963, pp. 6-8.
} 
Este libro forma parte del acervo de la Biblioteca Jurídica Virtual del Instituto de Investigaciones Jurídicas de la UNAM

las sesiones del Congreso Constituyente, dos universitarios. Luis Manuel Rojas, director de la Biblioteca Nacional (1914-1915 y 1917), e Hilario Medina, que hizo sus estudios en la Escuela Nacional Preparatoria y en la Escuela Nacional de Jurisprudencia.

En las comisiones que tuvo el Congreso, también hubo univeritarios: Primera Revisora. Sección 2a., Luis T. Navarro; Segunda Revisora, José María Rodríguez; Primera de Constitución, Alberto Román; Segunda de Constitución, Hilario Medina y Arturo Méndez. También estuvo Paulino Machorro Narváez, que después del Constituyente fue un destacadísimo profesor en la Universidad Nacional. De Estilo, Ciro B. Ceballos; De Peticiones, Fernando Lizardi, Del "Diario de los Debates", Fernando Lizardi. ${ }^{31}$

En la respuesta que dio el presidente del Congreso Constituyente, Luis Manuel Rojas, el 1o. de diciembre de 1916, a Venustiano Carranza, al entregar su Informe de labores y hacer entrega del proyecto de Constitución, dijo:

Vos sois, señor, quizá el hombre que durante varios años ha reunido en sus manos los poderes más absolutos y enérgicos de este país; y cuando el ejercicio de esta enorme suma de facultades ha dado ocasión a nuestros enemigos, tanto en el interior como en el extranjero, para presagiar que no resignaríais fácilmente esos poderes, venís hoy a declarar, de la manera más franca y sincera, a la vez que más espontánea, que el principio fundamental sobre el cual debe asentarse la nueva Constitución de la República, es el respeto más amplio a la libertad humana, proclamando muy alto, además, el derecho del pueblo a gobernarse por sí mismo, precisamente cuando os halláis en la más elevada cima del poder y de la gloria, donde las tentaciones de la ambición y las sugestiones del egoísmo ejercen de ordinario una influencia tan perniciosa como difícil de eludir.

Mas con mucha razón proclamáis, de una manera principal, que no debe ser exclusivamente la obra de la voluntad de la nación, y que sólo a este título y con este apoyo puede ser fuerte para imponer el orden interior y para alcanzar también consideración y respeto en el extranjero. ${ }^{32}$

En los 50 discursos doctrinarios en el Congreso Constituyente de la Revolución Mexicana, que presentó Raúl Noriega, y que Jesús Castañón y Alberto Morales Jiménez, acompañan con notas bibliográficas y efemérides, destacan,

31 Diario de los Debates. Congreso Constituyente de Querétaro. 1916-1917, t. II, edición facsimilar, México, Cámara de Diputados, LXIII Legislatura-Dirección General de Recursos Materiales y Servicios-Talleres Gráficos, 2016, p. LI.

32 Diario de los Debates. Congreso Constituyente de Querétaro. 1916-1917, t. I, edición facsimilar, México, Cámara de Diputados, LXIII Legislatura-Dirección General de Recursos Materiales y Servicios-Talleres Gráficos, 2016, p. 270. 
Este libro forma parte del acervo de la Biblioteca Jurídica Virtual del Instituto de Investigaciones Jurídicas de la UNAM

"Alcances del amparo", los de "La libertad de conciencia en los artículos 24 y 130", los pronunciados por Fernando Lizardi; sobre "La cuestión del fuero militar", por Hilario Medina; "Alcance y efectividad de las garantías individuales", "Nacionalidad mexicana", "El Ministerio Público", por José Natividad Macías; "La federalización de la salubridad", por José María Rodríguez; "La pena de muerte", por Rafael L. de los Ríos; "El equilibrio de los poderes de la Unión", por Rafael Martínez de Escobar; "Trascendencia de la función del Senado", por Paulino Machorro Narváez; "Las reivindicaciones sociales y nacionales en el artículo 27", por Luis T. Navarro. ${ }^{33}$

Y el 31 de enero, por la tarde, con una asistencia de 184 ciudadanos diputados, el diputado Luis Manuel Rojas al hacer la entrega de la nueva carta magna al primer jefe, expresó:

Si en algunos puntos se ha ido un poco más allá de lo que vuestra sabiduría había indicado como un término medio, justo y prudente de las encontradas tendencias nacionales, el calor de la juventud, que ha seguido la gloriosa bandera enarbolada por usted en Guadalupe, su entusiasmo revolucionario después de la lucha, y su natural afán de romper los viejos moldes sociales, reaccionando así contra inveterados vicios del pasado, explican suficientemente los verdaderos motivos habidos en el seno de esta asamblea, para apartarse en algo de la senda serena y perfectamente justificada que usted nos había trazado, no obstante que por otra parte, en la gran mayoría de los señores diputados al Constituyente de Querétaro, hay y ha habido siempre el sentimiento de su comunidad de ideas y aspiraciones en favor del pueblo mexicano, ideas y aspiraciones de que usted es justamente la más alta personificación, como el jefe supremo de la revolución constitucionalista. ${ }^{34}$

\section{Y continuó:}

De cualquier manera que se piense, es claro que la obra legislativa que surge de este congreso, como el fruto admirable de la gran revolución constitucionalista, había de caracterizarse por su tendencia a buscar nuevos horizontes y a desentenderse de los conceptos consagrados de antaño, en bien de las clases populares que forman la mayoría de la población mexicana, que han sido tradicionalmente desheredadas y oprimidas. ${ }^{35}$

3350 discursos doctrinales en el Congreso Constituyente de la Revolución Mexicana. 1916-1917, presentación Raúl Noriega, notas biográficas y efemérides de Jesús Castañón y Alberto Jiménez Morales, México, Talleres Gráficos de la Nación, 1967.

34 Diario de los Debates. Congreso Constituyente de Querétaro. 1916-1917, t. II, cit., p. 346.

35 Idem. 
Este libro forma parte del acervo de la Biblioteca Jurídica Virtual del Instituto de Investigaciones Jurídicas de la UNAM

Una vez que el primer jefe pronunció su discurso y rindió su protesta de guardar y hacer guardar la Constitución Política de los Estados Unidos Mexicanos, expedida este día, que reforma la del 5 de febrero de 1857, Hilario Medina pronunció uno de los discursos más memorables del constituyente. En una parte de esa alocución, con seguridad, afirmó:

[En] La Constitución Política que se acaba de protestar hay, como los grandes basamentos, como las macizas columnas en donde está el edificio constitucional, cuatro cosas principales: el artículo 3o., que se refiere a la cuestión de la enseñanza; el artículo 5o., que ha resuelto el problema del trabajo; el artículo 24, que se refiere al llamado problema religioso, y el artículo 129, que ha dado una organización a esa clase social que se llama Clero. De esas cuatro cosas, señores diputados, que son, como lo he dicho, las columnas del edificio, hay dos que corresponden, o mejor dicho, todas ellas corresponden a lo que nosotros podemos llamar la reforma social, y todas las demás que hacen nuestra Constitución, son precisamente las que hacen la reforma democrática o política, y si es cierto que en esta Cámara, en un principio hubo alguna diferencia de tendencias, yo creo, si es cierto que existen, que ellas serán solamente en la apreciación de los límites de las reformas; por una parte la reforma política, que se refiere a la organización del Gobierno, y por otra parte la reforma social, que ha puesto los fundamentos de la reforma social. ${ }^{36}$

Una vez concluidas las sesiones del Congreso Constituyente, cada uno de sus integrantes volvieron a sus trabajos. Don José Natividad Macías, a la rectoría de la Universidad Nacional de México, don Fernando Lizardi, llegó a la dirección de la Escuela Nacional de Jurisprudencia; don Ciro B. Ceballos, a la Biblioteca Nacional, y, con el tiempo se sumaron don Hilario Medina, don Paulino Machorro Narváez y don Jesús López Lira, como profesores. Todos ellos continuaron entregando lo mejor de su vida a la casa magna de la nación mexicana.

\section{CONCLUSIÓN}

Labor magna la de nuestras instituciones educativas a pesar de tiempos dificiles que han vivido. Y nuestra Máxima Casa de Estudios, como bien lo dijo don Justo Sierra, tiene raíces profundas, robustas, y en su juventud y madurez ha dado ejemplo de fortaleza institucional, prudencia política, visión en la formación de cuadros que el país ha necesitado. De este grupo de universi-

36 Ibidem, p. 848 . 
Este libro forma parte del acervo de la Biblioteca Jurídica Virtual del Instituto de Investigaciones Jurídicas de la UNAM

tarios que asistieron al Constituyente de 1917 hay muchas cosas más que se pueden estudiar. Pero este ejercicio mínimo que sólo sea para recordar una odisea más de la Universidad en un momento único en la vida de México, en su Congreso Constituyente de 1916-1917. Por eso y como bien lo decimos los universitarios, digo: Como no te voy a querer..

\section{ANEXos}

\section{Anexo 1. Escuela Nacional de Furisprudencia}

1) Guillermo Ordorica Manjarrez (1874). Presentó su examen profesional el 7 de septiembre de 1891.37 Diputado al Congreso Constituyente por el 4o., distrito electoral, Tenancingo, México. Propietario.

2) Antonio Aguilar (1873). Hidalgo. El 16 de junio de 1900 presentó su examen profesional. ${ }^{38}$ Diputado al Congreso Constituyente por el 1 1o., distrito electoral, Tlanepantla, México. Propietario.

3) Refugio M. Mercado Fuentes (1876). El 4 de julio 1900 hizo su examen de grado. Tuvo como jurado a Francisco de P. Segura, José Algara, Luis G. Labastida, Víctor M. Castillo, dr. Román Ramírez y como suplente a Tomás R. Retana. Tesis: Doctrinas consagradas por nuestra legislación en la adquisición, conservación y pérdida de la nacionalización mexicana. ${ }^{39}$ Diputado al Congreso Constituyente por el 10o., distrito electoral, Zacualtipán, Hidalgo. Propietario.

4) Alberto M. González (1879). Presentó su examen profesional en 1894..$^{40}$ Diputado al Congreso Constituyente por el 3o. distrito electoral. Atotonilco. Hidalgo. Propietario.

5) Fernando Lizardi (1883). Hizo sus estudios preparatorianos y profesionales en el Colegio del Estado de Guanajuato y en la Escuela Nacional de Jurisprudencia, entre 1899 y 1904 (revalidados y cursados). Presentó su examen profesional el 11 de septiembre de $1906 .{ }^{41}$ Diputado al Congreso Constituyente de 1917 por el 13o., distrito electoral, Acámbaro, Guanajuato. Propietario.

37 Archivo Histórico de la Universidad Nacional Autónoma de México. En adelante. AHUNAM. Sección alumno. Expediente.

38 AHUNAM. Sección alumno. Expediente 16583.

39 AHUNAM. Sección alumno. Expediente 2128.

40 AHUNAM. Sección alumno. Expediente1916.

41 AHUNAM. Sección alumno. Expediente 46507. 
Este libro forma parte del acervo de la Biblioteca Jurídica Virtual del Instituto de Investigaciones Jurídicas de la UNAM

6) Juan Manuel Giffard (1885). Hizo sus estudios en la Escuela Nacional Preparatoria. Su examen profesional fue el 7 de diciembre de 1909. ${ }^{42}$ Diputado al Congreso Constituyente por el 12o. distrito electoral, Cuautitlán, México. Propietario.

7) Rafael Martínez de Escobar Urgell (1888). Presentó su examen profesional el 19 de junio de 1912, con el Caso propuesto por el ciudadano profesor licenciado Victoriano Pimentel y aprobado por la dirección de la Escuela Nacional de Furisprudencia para el examen profesional de abogado del alumno Rafael M. Escobar. ${ }^{43}$ Diputado al Congreso Constituyente de 1917, por el 1o. distrito electoral, Villahermosa, Tabasco. Propietario.

8) Ismael Pintado y Sánchez (1889). Estudió en la Escuela Nacional de Jurisprudencia de 1910 a 1912. ${ }^{44}$ Diputado al Congreso Constituyente por el 9o. distrito electoral, Tulancingo, Hidalgo. Propietario.

9) Rafael L. de los Ríos (1890). Estudió en la Escuela Nacional Preparatoria. ${ }^{45}$ Diputado al Congreso Constituyente de 1917, por el 70. distrito electoral, Giudad de México, Distrito Federal. Propietario.

10) Román Rosas y Reyes (1890). Hizo sus estudios en la Escuela Nacional Preparatoria. ${ }^{46}$ Según Romero Flores llegó hasta cuarto año de la carrera de Abogado.

11) Hilario Medina Gaona (1891). Hizo sus estudios en la Escuela Nacional Preparatoria y aquí dio clases de Historia universal, para costear sus estudios en Jurisprudencia (1909-1912). El 6 de septiembre de 1913 sustentó su examen profesional, y la tesis que presentó se llama Estudio sobre la jurisprudencia en México. ${ }^{47}$ Fue diputado al Congreso Constituyente por el 8o. distrito electoral, León, Guanajuato. Propietario.

\section{Anexo 2. Escuela Nacional de Medicina}

1) Arturo Méndez (1868). Presentó su examen en 1893. Tesis: 150 casos de involución uterina. ${ }^{48}$ Diputado al Congreso Constituyente por el 20. distrito electoral, San Luis, San Luis Potosí. Propietario.

\footnotetext{
42 AHUNAM. Sección alumno. Expediente 2633.

43 AHUNAM. Sección alumno. Expediente 2823.

44 AHUNAM. Sección alumno. Expediente 2075.

45 AHUNAM. Sección alumno. Expediente 39794.

46 AHUNAM. Sección alumno. Expediente 24460.

47 AHUNAM. Sección alumno. Expediente 2872.

48 AHUNAM. Sección alumno. Expediente 11699.
} 
Este libro forma parte del acervo de la Biblioteca Jurídica Virtual del Instituto de Investigaciones Jurídicas de la UNAM

2) Jairo Dyer Castañeda (1869). Hizo examen de grado el 4 de agosto de 1895. Tesis: La conjuntivitis blenorrágica. Tesis inaugural que para el examen general de medicina, cirugía y obstetricia. ${ }^{49}$ Diputado al Congreso Constituyente por el 3er. distrito electoral, Sombrerete, Zacatecas. Propietario.

3) José María Rodríguez (1870). En 1895 obtuvo su título de médico. ${ }^{50}$ Diputado al Congreso Constituyente por el 3er. distrito electoral, Torreón, Coahuila. Propietario.

4) Alberto Román (1872). El 18 y 19 de julio presentó su examen profesional en la Sala de Actos de la Escuela Nacional de Medicina y la del Hospital de San Andrés. Tesis: Responsabilidad legal en las personas afectadas de histeria. ${ }^{51}$ Diputado al Congreso Constituyente por el 10o. distrito electoral, Huatusco, Veracruz. Propietario.

5) Amadeo Betancourt Villaseñor (1876). Estudió en la Escuela Nacional Preparatoria. Presentó su examen profesional en la Sala de Actos de la Escuela Nacional de Medicina y en la de Juntas del Hospital General, los días 16 y 17 de mayo de 1905. Aprobado por unanimidad. Se le expidió su título de Médico Cirujano el 29 de mayo de 1905. Su tesis se intitula: De la trepanación de la apófisis mastoide. Tesis inaugural que para el examen general de medicina, cirugía y obstetricia. ${ }^{52}$ Diputado al Congreso Constituyente por el 14o. distrito electoral, Jiquilpan, Michoacán. Propietario.

6) Marcelo Torres (1876). Estudió en la Escuela Nacional Preparatoria. Hizo prácticas en el Hospital de la Luz. Realizó su examen profesional el 14 de mayo de 1910.53 Diputado al Congreso Constituyente por el 16o. distrito electoral, Zongolica, Veracruz. Propietario.

7) Alfonso Cabrera Lobato (1881). Hizo sus estudios en el Colegio del Estado, Puebla, Pue., y en la Escuela Nacional de Medicina (Revalidados y cursados) (1906-1911). Presentó examen profesional el 1o. de agosto de 1911 y se le expidió su título de Médico Cirujano, el 12 de agosto de 1911. Tesis: Cistotomía suprapública. ${ }^{54}$ Diputado al Congreso Constituyente por el 17o. distrito electoral, Zacatlán, Puebla. Propietario.

49 AHUNAM. Sección alumno. Expediente 11848.

50 AHUNAM. Sección alumno. Expediente 11833.

51 AHUNAM. Sección alumno. Expediente 12112.

52 AHUNAM. Sección alumno. Expediente 46336.

53 AHUNAM. Sección alumno. Expediente 46903.

54 AHUNAM. Sección alumno. Expediente 30383. 
Este libro forma parte del acervo de la Biblioteca Jurídica Virtual del Instituto de Investigaciones Jurídicas de la UNAM

8) Salvador R. Guzmán Esparza (1888). Hizo sus estudios de Preparatoria en el Colegio del Estado de Puebla (1903-1908), y que fueron revalidados por la Escuela Nacional Preparatoria (26 de septiembre de 1910).55 Diputado al Congreso Constituyente por el ler. distrito electoral, Puebla, Puebla. Suplente.

9) Fidel R. Guillén (1890). El 17 de junio de 1919, a las seis de la tarde, comenzó su examen profesional; se continuó al día siguiente, a la misma hora y se citó a las nueve de la mañana del 19 de agosto, en el Hospital General, para concluirlo. Tesis: Raquianalgesia por el clorhidrato de urea y quinina. ${ }^{56}$ Diputado al Congreso Constituyente por el 2o. distrito electoral, Guerrero. Propietario.

10) Fernando Gómez Palacio (1881). Presentó su examen el 8 y 9 de junio de 1905. ${ }^{57}$ Diputado al Congreso Constituyente por el 5o. distrito electoral, Durango. Propietario.

Anexo 3. Escuela Nacional de Enseñanza Dental

1) Jesús López Lira (1888). Estudió en la Escuela Nacional Preparatoria. Pasante de cirugía dental. Concluyó sus estudios el 15 de febrero de 1912.58 Diputado al Congreso Constituyente de 1917, por el 4o. distrito electoral, Salamanca, Guanajuato. Propietario.

\section{Anexo 4. Escuela Nacional de Ingeniería}

1) Pastor Rouaix Méndez (1874). Estudió en la Escuela Nacional Preparatoria. Presentó su examen profesional para obtener el grado de Ingeniero Topógrafo e Hidrógrafo, el 20 de agosto de 1896 y en este mismo año obtuvo su título. ${ }^{59}$ Diputado al Congreso Constituyente por el 10o. distrito electoral, Tehuacán, Puebla. Propietario.

2) Pascual Ortiz Rubio (1877). Presentó su examen profesional el 2 de septiembre de 1902. ${ }^{60}$ Diputado al Congreso Constituyente de 1917,

55 AHUNAM. Sección alumno. Expediente 31258.

56 AHUNAM. Sección alumno. Expediente 5531.

57 AHUNAM. Sección alumno. Expediente 46415.

58 AHUNAM. Sección alumno. Expediente 5769, y Archivo Histórico de la DGPA.

59 AHUNAM. Sección alumno. Expediente 4499.

60 AHUNAM. Sección alumno. Expediente 44984. 
Este libro forma parte del acervo de la Biblioteca Jurídica Virtual del Instituto de Investigaciones Jurídicas de la UNAM

por el 8o. distrito electoral, Tacámbaro, Michoacán. Propietario. [No asistió al Constituyente. Su lugar lo ocupó su suplente, Manuel Martínez Solórzano].

3) Julián Adame Alatorre (1882). Estudio en la Escuela Nacional Preparatoria y en la Escuela Nacional de Ingenieros estudió Topografía e Hidrografia. Su examen profesional fue el 9 de mayo de 1906. ${ }^{61}$ El título se le expidió el 5 de mayo de 1906. Diputado al Congreso Constituyente por el 2o. distrito electoral, Ojocaliente, Zacatecas. Propietario.

4) Luis T. Navarro Garza (1884). Escuela Nacional Preparatoria/Colegio Civil de Nuevo León. Presento su examen profesional el 5 de abril de 1919.62 Diputado al Congreso Constituyente de 1917, por el 11o. distrito electoral, Tecamachalco, Puebla. Propietario.

5) Adolfo Villaseñor Román (1888). En 1910 pidió su certificado de estudios. ${ }^{63}$ Diputado al Congreso Constituyente por el 1er. distrito electoral, Zacatecas, Zacatecas. Propietario.

\section{Anexo 5. Académicos}

1) José Natividad Macías (1857). Guanajuato. "Hizo sus estudios de primaria en Silao, los preparatorianos en León y los de abogado en el Colegio del Estado" (Moreno, 77: 180) de Guanajuato. "Presentó su examen profesional el 24 de noviembre de 1883" (Moreno, 77: 180). Profesor de derecho público en la Escuela Nacional de Jurisprudencia. Director de la Escuela Nacional de Jurisprudencia (28 de agosto al 19 de noviembre de 1914). Rector de la UNM (19141920). Miembro de la Comisión de Legislación Social en el Puerto de Veracruz, 1914-1915. Autor del proyecto de Constitución. Diputado al Congreso Constituyente de 1917 por el 3er. distrito, Silao, Guanajuato. Propietario.

2) Luis Manuel Rojas (1871). ${ }^{64}$ Jalisco. Estudió en la Escuela Nacional de Jurisprudencia y obtuvo su título en 1897. Director de la Biblioteca Nacional (7 de septiembre-7 de diciembre de 1914 y 23 de agosto

61 AHUNAM. Sección alumno. Expediente 30184.

62 AHUNAM. Sección alumno. Expediente 30584.

63 AHUNAM. Sección alumno. Expediente 45379.

64 Iguínez da como fecha de nacimiento de Rojas el 21 de septiembre de 1870 (Iguínez, Juan B., "La Biblioteca Nacional de México", Historia de América, núm. 8, abril de 1940, p. 61. 
Este libro forma parte del acervo de la Biblioteca Jurídica Virtual del Instituto de Investigaciones Jurídicas de la UNAM

de 1915-21 de abril de 1917). Presidente del Congreso Constituyente 1916-1917. Diputado al Congreso Constituyente de 1917 por el 1 er, distrito electoral, Guadalajara, Jalisco. Propietario.

3) Paulino Machorro Narváez (1877). Durango. Profesor en la Escuela Nacional de Jurisprudencia de 1925-28. Profesor de Derecho Constitucional y Penal, de 1939 en adelante, en la Facultad de Derecho de la Universidad Nacional Autónoma de México. Diputado al Congreso Constituyente de 1917 por el 18o. distrito electoral, San Gabriel, Jalisco. Propietario.

4) Ciro B. Ceballos (1873). Ciudad de México. Director de la Biblioteca Nacional de México (22 de abril de 1917-30 de noviembre de 1918). Diputado al Congreso Constituyente de 1917 por el 11 o. distrito electoral, Coyoacán, Distrito Federal. Propietario.

5) Ignacio Ramos Praslow (1885). Sinaloa. Estudio en Guadalajara donde obtuvo su grado de abogado. Profesor de la Escuela Nacional de Jurisprudencia. 1915-1916. Diputado al Congreso Constituyente por el 13o. distrito electoral, Autlán, Jalisco. Propietario.

\section{FUENTES}

50 discursos doctrinales en el Congreso Constituyente de la Revolución Mexicana. 1916 1917, presentación del Lic. Raúl Noriega, notas biográficas y efemérides, Lics. Jesús Castañón y Alberto Morales Jiménez, México, Talleres Gráficos de la Nación, 1917.

Archivo Histórico de la Universidad Nacional Autónoma de México. Estudiantes.

Arenal FenOCHIO, Jaime del "La fundación de la Escuela Libre de Derecho. Documentos", Revista de Investigaciones furídicas, Escuela Libre de Derecho, México, núm. 11, 1987.

"Crónica de la fiesta de inauguración de la Universidad Nacional de México", Cuadernos del Archivo Histórico de la UNAM, México, UNAM, Centro de Estudios sobre la Universidad, núm. 1, enero-abril de 1982,

DÁvalos, Marcelino, Así pasan..., prólogo de José Rojas Garciadueñas, México, UNAM, 1945.

Diario de los Debates. Congreso Constituyente de Querétaro. 1916-1917, dos tomos, edición facsimilar, México, Cámara de Diputados, LXIII Legislatura, 2016.

DíAZ Y DE Ovando, Glementina, "La Escuela Nacional Preparatoria", en VIllegas Moreno, Gloria (coord.), La UNAM en la historia de México. De la 
Este libro forma parte del acervo de la Biblioteca Jurídica Virtual del Instituto de Investigaciones Jurídicas de la UNAM

fundación de la Escuela Nacional Preparatoria a la promulgación de la Ley Constitutiva de la Universidad Nacional (1867-1910), México, UNAM, 2011.

"Dictamen presentado a la H. Cámara de Diputados proponiendo el proyecto de ley constitutiva de la Universidad Nacional de México", Cuadernos del Archivo Histórico de la UNAM, México, UNAM, Centro de Estudios sobre la Universidad, núm. 1, enero-abril de 1982.

García Verástegui, Lía, Del proyecto nacional para una Universidad en México. 1867-1910, México, UNAM, 1984.

GARGIADIEGO, Javier, "Los orígenes de la Escuela Libre de Derecho", Revista de Investigaciones furídicas, México, núm. 21, 1993.

Herrasti, Francisco de P., "Recuerdos de la Escuela Nacional de Jurisprudencia", Revista de Ciencias Sociales, t. II, núm. 1, agosto de 1925.

Iguínez, Juan B., "La Biblioteca Nacional de México", Historia de América, abril de 1940.

La Universidad de México. 1910, 2a. ed. facsimilar, México, UNAM, Coordinación de Humanidades-Centro de Estudios sobre la Universidad, 1990.

Ley Orgánica de la Instrucción Pública en el Distrito Federal, Diario de la Federación, 2 de diciembre de 1867, disponible en: www.sep.gob.mx/work/ models/sep1/Resource/3f9a47cc-efd9.../ley_02121867.pdf (fecha de consulta: 6 de octubre de 2016).

LEMOINE, Ernesto, La Escuela Nacional Preparatoria en el periodo de Gabino Barreda. 1867-1878, México, UNAM, 1970.

Martínez Domínguez, Raúl, "Contribución de los ingenieros al México moderno", en VILLEGAS MORENO, Gloria (coord.), La UNAM en la historia de México. De la fundación de la Escuela Nacional Preparatoria a la promulgación de la ley constitutiva de la Universidad Nacional. (1867-1910), México, UNAM, 2011.

Merino, Manuel M., Historia de la revolución en Guanajuato, México, Talleres Gráficos de la Nación, 1977.

Merino, Manuel M., "En la conmoción formativa", en AlmanzA RoA, Edmundo et al., El recinto legislativo de Guanajuato. Una semblanza histórica del pueblo de Guanajuato a través de su representación popular, México, Universidad de Guanajuato-Asesoría Gráfica-Proculta, 1995.

Olivera López, Luis, "La folletería, triunfo del liberalismo republicano", La Biblioteca Nacional. Triunfo de la República, México, UNAM, 2006.

Pasquel, Leonardo, Veracruzanos en la Revolución, México, Talleres Gráficos de la Nación, 1985. 
Este libro forma parte del acervo de la Biblioteca Jurídica Virtual del Instituto de Investigaciones Jurídicas de la UNAM

QUIRARTE, Vicente, "Hija del pensamiento liberal”, La Biblioteca Nacional. Triunfo de la República, México, UNAM, 2006.

Romero Flores, Jesús, Historia del Congreso Constituyente 1916-1917. Con la reseña gráfica. Constitución Política de los Estados Unidos Mexicanos. 1917, México, edición del autor, 1985.

TAMAYO, Jorge L., Breve reseña sobre la Escuela Nacional de Ingeniería, edición y prólogo de Armando Escanero Muñoz, México, Imprenta La Espera, 1958. 
Este libro forma parte del acervo de la Biblioteca Jurídica Virtual del Instituto de Investigaciones Jurídicas de la UNAM

\title{
EL PAPEL DE LAS MUJERES EN EL CONSTITUYENTE DE 1916 Y LA APERTURA A LA PARTICIPACIÓN POLÍTICA
}

\author{
Rosa María DE LA TORRE TORRES* \\ Brenda Yesenia OLALDE VÁZQUEZ**
}

Sumario: I. Nota introductoria. II. Primer Congreso Feminista, 1916. III. Hermila Galindo. El paradigma del empoderamiento femenino de 1916. IV. Participación politica de la mujer actual. V. Comentarios finales.

VI. Fuentes de consulta.

\section{NOTA INTRODUCTORIA}

El empoderamiento de las mujeres, término que se refiere al aumento progresivo de la participación de las mujeres en los procesos que implican la toma de decisiones, así como el acceso al poder y ejercicio de derechos político electorales, es relativamente nuevo, sin embargo la lucha por el reconocimiento de los derechos de las mujeres tiene más de 200 años; siendo uno de los antecedente más antiguo la publicación de la Declaración de los Derechos de la Mujer y de la Ciudadana en 1791, escrita por de Olympe de Gouges, considerando que la ignorancia, el olvido o el desprecio de los derechos de la mujer son las únicas causas de los males públicos y de la corrupción de los gobiernos, ${ }^{1}$ exigió para las mujeres los mismos derechos y libertades re-

* Doctora en derecho constitucional. Investigadora en la División de Estudios de Posgrado de la Facultad de Derecho y Ciencias Sociales de la UMSNH. Miembro del Sistema Nacional de Investigadores. E-mail: rosdelatorre@gmail.com.

* Licenciada en derecho por la Universidad Michoacana de San Nicolás de Hidalgo. Auxiliar de Investigación en la División de Estudios de Posgrado de la Facultad de Derecho y Ciencias Sociales. E-mail: iuslitis@gmail.com.

1 Gouges, Olympe, Declaración de los derechos de la mujer y de la ciudadana. Para ser decretada por la Asamblea Nacional Francesa (1791), disponible en: http://clio.rediris.es/n31/derechosmu jer.pdf(fecha de consulta: septiembre de 2016). 
Este libro forma parte del acervo de la Biblioteca Jurídica Virtual del Instituto de Investigaciones Jurídicas de la UNAM

conocidos a los hombres en la Declaración de Derechos del Hombre y del Ciudadano de 1789.

El funcionamiento de un sistema social, político y cultural, durante siglos ha estado bajo el ejercicio de una subordinación femenina, donde la superioridad masculina es imperante, tal sistema es denominado como patriarcado. ${ }^{2}$ Las mujeres durante muchos siglos, han fungido un papel minimizado en relación con los hombres, en la antigüedad romana, por ejemplo, las mujeres no tenían existencia legal, el único con poder reconocido era el del pater familias. ${ }^{3}$ Así mismo, la sociedad griega, consideraba que la mujer y el hombre al ser tan distintos, estaban destinados a cumplir tareas diversas. El papel de la mujer por su naturaleza y considerada como frágil, su único espacio para desarrollarse era el del hogar. ${ }^{4}$

Y así en la medida que avanzó el tiempo, es decir, durante el medievo, la edad moderna y contemporánea, la religión católica conservó un modelo patriarcal en la sociedad, lo que mantuvo el rol de las mujeres bajo una subordinación ante los hombres.

La situación de las mujeres en la historia de nuestro país, no fue distinta a la de otros países, toda vez que también fue de subordinación ante los hombres. Sin embargo, han siempre existido mujeres que se han distinguido, por no quedarse calladas y alzar la voz en movimientos tan importantes como en el movimiento de Independencia de 1810, tal es el caso de Josefa Ortiz de Domínguez o Leona Vicario, mismas que en solidaridad con el movimiento apoyaron mediante información a los insurgentes durante el levantamiento en contra de la Corona española.

Durante el Porfiriato, la mujer luchó por lograr un lugar privilegiado en la sociedad, pero la mayoría se mantuvo bajo los estrictos lineamientos de los roles femeninos (mujer de casa, bajo el mandato del hombre). La vida de la mujer en general giraba según la religión (católica) y apegada al hogar. La situación era diferente según la posición económica-social; la mujer de clase alta era obligada a dedicarse sólo a cosas banales y superficiales; la mujer de clase media tenía que buscar un lugar en la sociedad, creando con ello diferentes esferas para la superación y el desenvolvimiento de lo femenino; mientras que la mujer de clase menos favorable, era la más desprotegida. ${ }^{5}$

2 Cid López, Rosa María (coord.), Mujeres en la historia, Instituto Asturiano de la MujerGobierno del Principado de Asturias-Consejería de Presidencia, Justicia e Igualdad-Instituto Asturiano de la Mujer-Ámbitu.

3 Pernoud, Régine, "La mujer en la historia", Humanitas, núm. 6, disponible en: http:// humanitas.cl/html/biblioteca/articulos/d0159. html (fecha de consulta: agosto de 2016).

4 Cid López, Rosa María (coord.), Mujeres en la historia, cit.

5 Rojas G., Ingrid y Sotelo P., Jocelyn Regina, La mujer mexicana a través de los años. Reper- 
Este libro forma parte del acervo de la Biblioteca Jurídica Virtual del Instituto de Investigaciones Jurídicas de la UNAM

En 1901, Juana Belén Gutiérrez de Mendoza fundó en Guanajuato un periódico opositor al régimen de Porfirio Díaz, en el que atacó al clero y criticó la situación política en México. Años más tarde, Dolores Correa Zapata y Columba Rivera fundaron la revista Mujer Mexicana, en la que buscaban que las mujeres fueran más participativas en todos los ámbitos sociales y que hubiera una misma moral para ambos sexos; hasta este momento, el movimiento feminista era impulsado por mujeres educadas que demandaban educación para las mujeres, así como oportunidades de trabajo, salarios y reformas al Código Civil de 1884; toda vez que este código mantenía a las mujeres subordinadas al yugo masculino. ${ }^{6}$

Durante la Revolución mexicana, la participación femenina fue crucial en esta época; en los frentes de la lucha las mujeres, participaron como soldados u oficiales (coronelas y capitanas), haciendo funciones de inteligencia. Denunciaron la situación de miseria en que vive el campesino, la opulencia de los hacendados y de la clase política de la época.

La importancia de la Constitución Política de los Estados Unidos Mexicanos, publicada en el Diario Oficial de la Federación el 5 de febrero de 1917, promulgada en la ciudad de Querétaro, y la cual tomó como base la Constitución de 1857, no tiene sólo como punto característico su amplio espectro social, en su momento fue considerada como una Constitución de vanguardia, ya que introdujo entre sus disposiciones, temas de carácter social, tales como el derecho agrario, derecho de los trabajadores e incluso señalaba la educación como obligatoria y gratuita.

El devenir constitucional es producto del reconocimiento de las prerrogativas y/o reivindicaciones legítimas de la sociedad civil, dirigidas a su consagración por la misma carta magna. Estos cambios de trascendencia constitucional surgen a partir de los esfuerzos de grupos vulnerables, cuyas luchas han servido como paradigma del reconocimiento jurídico de sus derechos.

Recordar como modelo la participación de las mujeres en actividades políticas durante la etapa revolucionaria, ante la lucha de la igualdad, sirvió como precedente para buscar la posibilidad de acceder en igualdad de circunstancias a la vida política del país.

De este tiempo, podemos señalar a María Teresa Arteaga (esposa de Ricardo Flores Magón), quien colaboró en el sostenimiento del periódico

cusiones históricas y laborales como factores de empuje en la migración internacional, tesis licenciatura, Relaciones Internacionales. Departamento de Relaciones Internacionales e Historia, Escuela de Ciencias Sociales, Universidad de las Américas Puebla, 2003.

6 Macías, Anna, Contra viento y marea. El movimiento feminista en México hasta 1940, México, UNAM, Programa Universitario de Estudios de Género, 2002. 
Este libro forma parte del acervo de la Biblioteca Jurídica Virtual del Instituto de Investigaciones Jurídicas de la UNAM

Regeneración, formó parte de la junta organizadora del Partido Liberal Mexicano y organizó comités internacionales en defensa de Flores Magón, sufrió persecuciones y el destierro. ${ }^{7}$

Otro importante hecho es el Primer Congreso Feminista, desarrollado en la Ciudad de Mérida en enero de 1916, mismo en el que, entre otras cosas, se propuso el derecho a votar de las mujeres. Sobre este congreso se hablará más adelante.

Finalmente, la participación de las mujeres estuvo presente en el Congreso Constituyente de Querétaro, representada por Hermila Galindo, quien con sólo 20 años de edad, solicitó el voto femenino, el 16 de enero de 1917.

Aunque las muestras de lucha por el reconocimiento de los derechos de las mujeres no eran muchos, no significa que no eran sobresaliente, todo lo contrario, toda vez que sirvieron de brecha para alcanzar tales reconocimientos y aunque los efectos no eran inmediatos, sí se reflejaban impactando la opinión pública.

\section{Primer Gongreso Feminista, 1916}

...Se convoca a todas las mujeres honradas de Yucatán y foráneas, que posean cuando menos conocimientos de educación primaria, al Primer Congreso Feminista de Yucatán, el cual tendrá verificativo el 13 de enero de 1916, en el teatro Peón Contreras de la Ciudad de Mérida...

Del 13 al 16 de enero de 1916, se efectuó en Yucatán el Primer Congreso Feminista apoyado por el gobernador Salvador Alvarado. Al evento asistieron 617 mujeres de diversas clases sociales y de varias entidades del país. ${ }^{8}$

Realizado en Yucatán, participaron 620 delegadas. Fue el Primer Congreso Feminista en México y el segundo de América Latina. ${ }^{9}$ La junta organizadora del congreso estuvo constituida por Consuelo Zavala, Dominga Canto, Adolfina Valencia de Ávila, María Luisa Flota, Beatriz Peniche,

7 Tovar, Aurora, Mil quinientas mujeres, en nuestra conciencia, México, Premios DemacUNAM, 1996, p. 662.

8 Valles Ruiz, Rosa María, Hermila Galindo: ideas y acción de una feminista ilustrada, Ciencia Universitaria.

9 El primero se realizó en la Ciudad de Buenos Aires, Argentina, en mayo de 1810. 
Este libro forma parte del acervo de la Biblioteca Jurídica Virtual del Instituto de Investigaciones Jurídicas de la UNAM

Amalia Gómez, Piedad Carrillo Gil, Isolina Pérez Castillo, Elena Osorio, Fidelia González, Candelaria Villanueva, Lucrecia y Adriana Vadillo, Rosina Magaña y Consuelo Andrade.

Los preparativos para la realización del Congreso Feminista empezaron en 1915, con la formación de un comité organizador integrado por siete mujeres. ${ }^{10}$

El objetivo del congreso era dar respuesta a los siguientes ejes temáticos: ${ }^{11}$

- ¿Cuáles son los medios sociales que deben emplearse para manumitir a la mujer del yugo de las tradiciones?

- ¿Cuál es el papel que corresponde a la escuela primaria en la reivindicación femenina, ya que aquella tiene por finalidad preparar para la vida?

- ¿Cuáles son las artes y ocupaciones que debe fomentar y sostener el Estado, y cuya tendencia sea preparar a la mujer para la vida intensa del progreso?

- ¿Cuáles son las funciones públicas que puede y debe desempeñar la mujer a fin de que no solamente sea elemento dirigido sino también dirigente de la sociedad?

Los resultados de este Congreso mejoraron la condición de las mujeres, propusieron su derecho a votar y ser votada y formular leyes que garantizaran estas resoluciones. Se destaca el concepto de igualdad jurídica de las mujeres a los hombres o de la emancipación de las mujeres a los 21 años de edad. ${ }^{12}$

La importancia del Congreso Feminista radica en las peticiones de otorgar el voto a la mujer, el derecho de las mujeres mayores de 21 años a votar en las elecciones municipales y el acceso a desempeñar cargos municipales; así como exigir al gobierno del estado las reformas a la Constitución de la República. ${ }^{13}$

10 Jiménez Álvarez, Ana Victoria y Reyes Castellanos, Francisca, Sembradoras de Futuro (2000), Memoria de la Unión Nacional de Mujeres Mexicanas, Unión Nacional de Mujeres Mexicanas.

11 Cortina G. Quijano, Aurora, Los congresos feministas de Tucatán en 1916 y su influencia en la legislación local y federal, disponible en: http://historico.juridicas.unam.mx/publica/librev/rev/hisder/ cont/10/cnt/cnt9.pdf (fecha de consulta: octubre de 2016).

12 Disponible en: http://wrerr.gob.mx/sre/articulos/cien-anos-del-primer-congreso-feminista-enmexico (fecha de consulta: septiembre de 2016).

13 Cortina G. Quijano, Aurora, Los congresos feministas de Tucatán..., cit., p. 6. 
Este libro forma parte del acervo de la Biblioteca Jurídica Virtual del Instituto de Investigaciones Jurídicas de la UNAM

\section{HERMila GaLINDO. \\ EL PARADIGMA DEL EMPODERAMIENTO FEMENINO DE 1916}

Ante el recuerdo del Constituyente de Yucatán, es digno de mención los nombres de las mujeres que a través de la historia del país lucharon por incluir los derechos de las mujeres en la carta magna.

Una de ellas es Hermila Galindo, pionera del movimiento feminista en México, luchadora social, maestra y periodista que durante su vida encontró en la defensa de los derechos de las mujeres el aliciente que condujo su vida y su trayectoria política. Considerada como la primera feminista en México, que aunque no asistió al Congreso feminista personalmente, envió ponencias que crearon controversia. ${ }^{14}$

Como periodista, fundó el diario feminista La Mujer Moderna, publicación que promovió el desarrollo de las mujeres al ubicarlas en el sitio que les correspondía en la sociedad. Desde este medio, afirmaba que la igualdad política debía extenderse a la educación, al trabajo y a las relaciones personales. ${ }^{15}$

Defendió la educación laica, reclamó la educación sexual y el derecho de las mujeres a ejercer libremente su sexualidad, sosteniendo que las mujeres, al igual que los hombres, tienen los mismos deseos sexuales, tesis que le acarreó fuertes críticas de sectores feministas conservadores y el rechazo social.

Para Hermila Galindo, las obligaciones de las mujeres, como integrantes de la sociedad, les daba el derecho de ejercer sus derechos políticos, en especial el derecho al sufragio. ${ }^{16}$

\section{Actividad politica de Hermila Galindo}

Trabajó como secretaria para el régimen maderista. Combatió en oposición al gobierno contrarrevolucionario de Victoriano Huerta y participó de forma activa en la Revolución constitucionalista. Organizó varios clubes revolucionarios en Veracruz, Tabasco, Campeche y Yucatán.

Se incorporó al movimiento constitucionalista, en 1914, convirtiéndose en la secretaria particular de Venustiano Carranza, primer gobernante de

14 Morton, Ward M., Women suffrage in Mexico, Gainesville, Florida, University of Florida Press, 1962, p. 3.

15 Cruz Jaimes, Guadalupe, Hermila Galindo, una feminista en la Constituyente de 1917, disponible en: http://werere.cimacnoticias.com.mx/node/56354 (fecha de consulta: octubre de 2016).

16 Valle Ruiz, Rosa María, Hermila Galindo: Ideas y acción de una feminista ilustrada, Ciencia Universitaria, disponible en: https://goo.gl/wEj26w (fecha de consulta: noviembre de 2016). 
Este libro forma parte del acervo de la Biblioteca Jurídica Virtual del Instituto de Investigaciones Jurídicas de la UNAM

la Revolución triunfante. Carranza la nombró su representante en Cuba y Colombia, donde Galindo se hizo cargo de difundir la doctrina internacional del gobierno, haciendo gala de su excelente oratoria.

En el primer Congreso Feminista en Mérida, Yucatán, en 1916, demandó los derechos políticos y sexuales de las mujeres, donde exigió la ciudadanía de las mujeres, que aunque no se presentó, envió sus ponencias las cuales generaron escándalo en la época.

Hermila Galindo, tuvo la oportunidad de presentar una propuesta para que la nueva carta magna incluyera los derechos políticos de las mujeres. No obstante, la apertura al voto femenino no estuvo en la agenda de los constituyentes, lo que fue la primera decepción que sufrió Hermila Galindo confiada en que la Revolución garantizaría los derechos políticos de las mujeres.

Hermila decidió postularse como candidata a diputada por el 5o. distrito electoral de la Ciudad de México, suceso histórico en nuestro país, que convirtió a Galindo en la primera mujer que contendió por un cargo de elección electoral.

Según la historiadora Gabriela Cano, Hermila obtuvo la mayoría de los votos que la hubieran conducido hasta la Cámara de Diputados, pero el Colegio Electoral rechazó el resultado.

Su participación política fue ejemplo seguido por otras mujeres del país, en los años de 1920 y 1930. En 1952 fue nombrada la primera mujer congresista. Galindo logró ver concluida la lucha por el voto de las mujeres mexicanas en la Constitución, en 1953. Con sus logros en el ámbito de la política, la feminista consiguió mostrar de manera pública que las mujeres podían y debían ser elegidas para ocupar puestos públicos.

La trascendencia de esta mujer radica en la apertura de espacios que se creían exclusivamente masculinos para las siguientes generaciones de mujeres mexicanas comprometidas con la lucha por los derechos políticos de las mujeres y la inclusión de estos en la Constitución Política mexicana.

Desde mediados del siglo pasado, la mayor parte de los países ha reconocido el derecho de las mujeres al voto, lo que ha aumentado su influencia en la toma de decisiones y, con ello, la posibilidad de impulsar sus derechos políticos, económicos, sociales y culturales.

A partir de que dejó de existir impedimento legal para que las mujeres tuvieran participación en la política, el empoderamiento femenino ha ido creciendo entre las mujeres del país; sin embargo, seguimos enfrentando obstáculos en la participación política, los cuales giran en torno a prejuicios formados por ignorancia de los derechos de las mujeres y la discriminación hacia ellas. 
Este libro forma parte del acervo de la Biblioteca Jurídica Virtual del Instituto de Investigaciones Jurídicas de la UNAM

\section{PARTICIPACIÓN POLÍTICA DE LA MUJER AGTUAL}

La participación política de la mujer se fundamenta en los artículos constitucionales 1o.:

En los Estados Unidos Mexicanos todas las personas gozarán de los derechos humanos reconocidos en esta Constitución y en los tratados internacionales de los que el Estado Mexicano sea parte, así como de las garantías para su protección, cuyo ejercicio no podrá restringirse ni suspenderse, salvo en los casos y bajo las condiciones que esta Constitución establece...

4o.: "El varón y la mujer son iguales ante la ley...", y 35: derecho a votar y ser votado. ${ }^{17}$

El derecho de las mujeres a participar en el ámbito de la política es reconocido como un derecho humano fundamental, requisito para lograr la igualdad entre mujeres y hombres, el respeto pleno a la ciudadanía y el fortalecimiento de la democracia.

El Pacto Internacional de Derechos Civiles y Políticos es un instrumento importante porque reconoce y garantiza el disfrute de todos los derechos civiles y políticos de igual manera para las mujeres y los hombres, como se señala en su artículo 3o., que establece que: “...los Estados Partes en el presente Pacto se comprometen a garantizar a hombres y mujeres la igualdad en el goce de todos los derechos civiles y políticos enunciados en el presente Pacto". ${ }^{18}$

En la actualidad las mujeres mexicanas ejercen el derecho a votar en mayor proporción que los hombres:

- Para 2012, las mujeres constituyeron 51.6\% del padrón electoral; en la lista nominal el porcentaje fue de 51.8.

- Del total de votantes, en las elecciones federales de 2009, 55.7\% se conformó por mujeres. El abstencionismo, no obstante, fue alto: votó $47.4 \%$ de las mujeres registradas en la lista nominal, y $40.5 \%$ de los votantes registrados.

- En instancias de vigilancia del voto, las mujeres componen $55.8 \%$ del funcionariado de casilla y $50.3 \%$ de los observadores registrados.

17 Constitución Política de los Estados Unidos Mexicanos, disponible en: http://wrere. diputados.gob.mx/LeyesBiblio/htm/1.htm (fecha de consulta: octubre de 2016).

18 Pacto Internacional de Derechos Civiles y Políticos, disponible en: http://wrere.ohchr. org/SP/ProfessionalInterest/Pages/CCPR.aspx (fecha de consulta: septiembre de 2016). 
Este libro forma parte del acervo de la Biblioteca Jurídica Virtual del Instituto de Investigaciones Jurídicas de la UNAM

La alta participación de las mujeres como votantes, de acuerdo con la Encuesta Nacional sobre Discriminación en México 2010, el 7.7\% de las mujeres encuestadas pide permiso para votar. ${ }^{19}$

Los artículos 2o. al 4o. de la CEDAW exhortan a los Estados parte a buscar activamente la eliminación de la discriminación en la participación política de las mujeres a través de medidas legales y temporales especiales y de acciones afirmativas.

$\mathrm{El}$ artículo 7o. de la CEDAW instruye a los Estados parte a tomar todas las medidas apropiadas para eliminar la discriminación contra la mujer en la vida politica y pública del pais.

Lo que garantiza a las mujeres a vivir en igualdad de condiciones con los hombres, así como el derecho a:

- Votar en todas las elecciones y referéndums públicos y ser elegibles para todos los organismos cuyos miembros sean objeto de elecciones públicas.

- Participar en la formulación de las políticas gubernamentales y en la ejecución de éstas y ocupar cargos públicos y ejercer todas las funciones públicas en todos los planos gubernamentales.

- Participar en organizaciones y en asociaciones no gubernamentales que se ocupen de la vida pública y política del país.

En México, la necesidad de fortalecer el liderazgo político de las mujeres ha empezado a ser reconocido, por ello habría que destacar la importancia de la reforma más reciente al Código Federal de Instituciones y Procedimientos Electorales (Cofipe), particularmente, lo referido en sus artículos 25, 38 y 78.

Según la Ley General de Partidos Políticos, en sus numerales 3, 4 y 5, señala como obligación de los partidos políticos promover y garantizar la paridad entre los géneros para integrar el Congreso de la Unión, congresos estatales y la Asamblea del Distrito Federal. Así como promover la cultura democrática entre las niñas, niños y adolescentes, buscando la participación de ambos géneros en la integración de los órganos y postulación de las candidaturas.

Por su parte el artículo 37 de la LGPP, indica la obligación de promover la participación política en igualdad de oportunidades y equidad entre mujeres y hombres.

19 Conapred-Inmujeres, Encuesta Nacional sobre Discriminación en México (ENADIS 2010) Resultados sobre mujeres, México, 2012, p. 48. 
Este libro forma parte del acervo de la Biblioteca Jurídica Virtual del Instituto de Investigaciones Jurídicas de la UNAM

Las cuotas de género son una medida concreta en el ámbito internacional que busca dar respuesta al actual desequilibrio de género en los órganos de toma de decisiones. Existen tres tipos de cuotas, las adoptadas por la vía constitucional, vía legislativa y las aplicadas por los partidos políticos.

\section{Estadísticas concretas}

PROPORCIÓN DE VOTANTES EN LAS ELECGIONES FEDERALES DE 200920
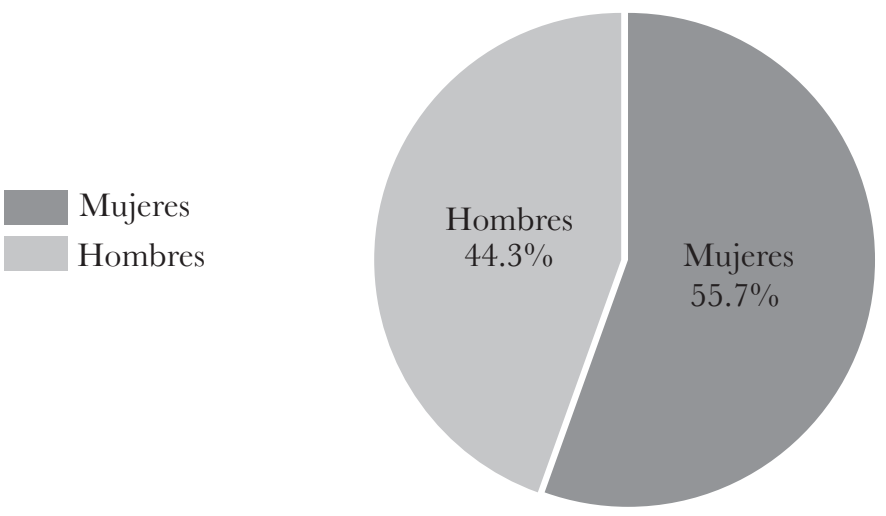

\section{ESTADÍSTICA ELECTORAL POR SEXO EN MÉXICO²1}
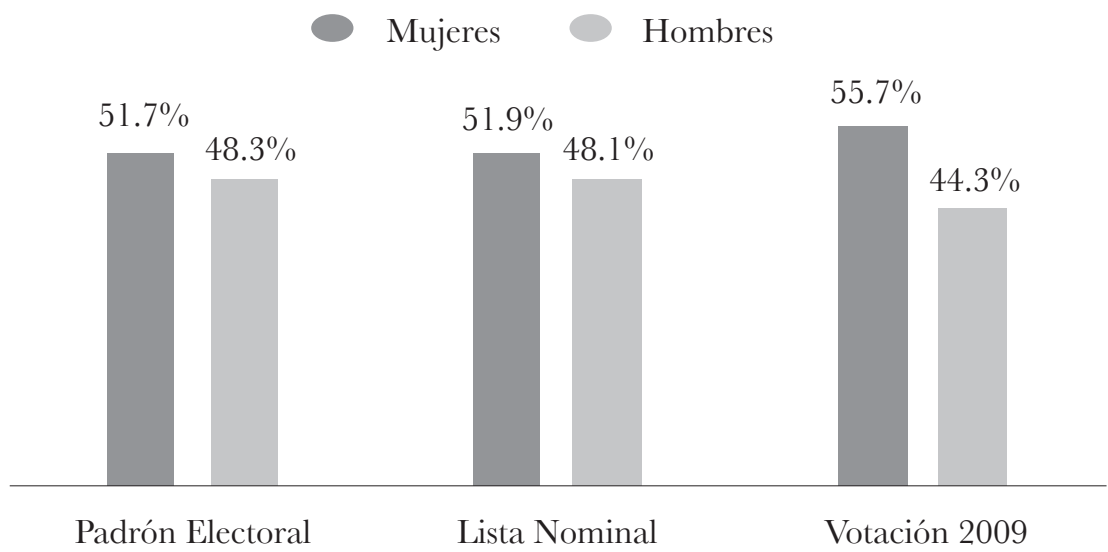

20 IFE, Estudio muestra de la participación ciudadana en las elecciones federales 2009, México, 2010 .

21 Disponible en: http://genero.ife.org.mx/docs/docs_mat-PNUD-1_10jul2012.pdf (fecha de consulta: mayo de 2016). 
Este libro forma parte del acervo de la Biblioteca Jurídica Virtual del Instituto de Investigaciones Jurídicas de la UNAM

\section{SENADO DE LA REPÚBLICA ${ }^{22}$}

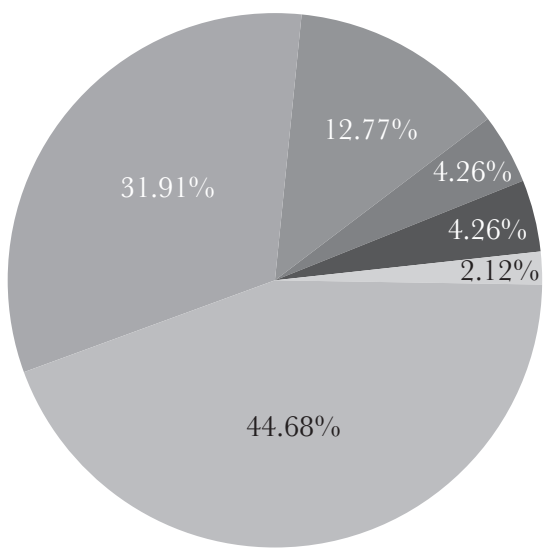

Grupo Parlamentario del Partido Revolucionario

Grupo Parlamentario Institucional del Partido Acción Nacional

垱年 Grupo Parlamentario del Partido de la Revolución Democrática

Grupo Parlamentario del Partido Verde

Última fecha de actualización: 29 de abril de 2016

\section{EVOLUGIÓn PORGENTAJE DE SENADORAS EN MÉXICO 1964-2012²3}

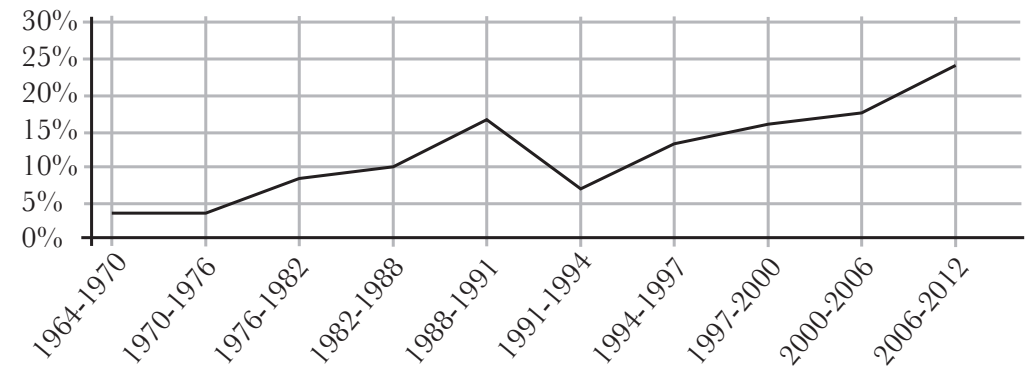

Fuente: Datos de 1964-2006 PRONAM y actualización propia.

22 Disponible en: http://wrwe.senado.gob. $m x /$ index.php?ver $=i n t \& m n=4 \mathcal{E}^{2} s m=2$ \&str $=M$ (fecha de consulta: mayo de 2016).

23 Datos de 1964-2006 Pronam. 
Este libro forma parte del acervo de la Biblioteca Jurídica Virtual del Instituto de Investigaciones Jurídicas de la UNAM

LXIII Legislatura de diputados ${ }^{24}$

\begin{tabular}{cccccccc}
\hline $\begin{array}{c}\text { Grupo } \\
\text { Parlamentario }\end{array}$ & Hombres & $\%$ & Mujeres & $\%$ & Total & $\%$ \\
\hline PRI & 119 & 57.2 & 89 & 42.8 & 208 & 100.0 \\
PAN & 62 & 56.9 & 47 & 43.1 & 109 & 100.0 \\
PRD & 38 & 63.3 & 22 & 36.7 & 60 & 100.0 \\
PVEM & 25 & 59.5 & 17 & 40.5 & 42 & 100.0 \\
MORENA & 17 & 47.2 & 19 & 52.8 & 36 & 100.0 \\
MC & 14 & 58.3 & 10 & 41.7 & 24 & 100.0 \\
NA & 6 & 54.5 & 5 & 45.5 & 11 & 100.0 \\
PES & 5 & 55.6 & 4 & 44.4 & 9 & 100.0 \\
INDEPENDIENTE & 1 & 100.0 & 0 & 0.0 & 1 & 100.0 \\
\hline TOTAL & 287 & 57.4 & 213 & 42.6 & 500 & 100.0
\end{tabular}

Las primeras se consagran en el ámbito de la ley fundamental de cada país, preferentemente la Constitución. Las legislativas son establecidas generalmente en las leyes electorales. Mientras que por vía de partidos políticos, se utilizan voluntariamente el sistema de cuotas de género en sus procedimientos de selección de cargos internos. ${ }^{25}$

\section{A. Ejecutivo local}

A nivel local, los avances también han sido graduales. Seis entidades federativas de 32 que conforman el país han sido gobernadas por mujeres: Colima, por Griselda Álvarez; Tlaxcala, por Beatriz Paredes; Yucatán, por Dulce María Sauri e Ivonne Ortega (actual gobernadora); Ciudad de México, por Rosario Robles, y Zacatecas, por Amalia García. ${ }^{26}$

\section{B. Ámbito municipal}

El escenario más adverso de la participación política de las mujeres en México se encuentra en el ámbito municipal. De los 2440 municipios y 16

24 Disponible en: http://sitl.diputados.gob.mx/LXIII_leg/album_foto_tc.pdf (fecha de consulta: mayo de 2016).

25 Huerta, M. y Magar, E. (eds.), Mujeres legisladoras en México, Avances, obstáculos, consecuencias y propuestas, México, Inmujeres-Conacyt-ITAM-Fundación Friedrich Ebert, 2006.

26 Disponible en: http://genero.ife.org.mx/docs/docs_mat-PNUD-1_10jul2012.pdf (fecha de consulta: mayo de 2016). 
Este libro forma parte del acervo de la Biblioteca Jurídica Virtual del Instituto de Investigaciones Jurídicas de la UNAM

delegaciones que existen en el país, únicamente 156 están presididos por una mujer, esto representa el 6.8\%. Siendo el municipio la base de la relación entre ciudadanía y gobierno, la mayor presencia de mujeres al frente de los mismos se presenta como uno de los mayores retos a nivel país. ${ }^{27}$

La paridad se presenta como una medida que busca que mujeres y hombres participen en igualdad de condiciones y oportunidades en todas las esferas sociales, especialmente en cargos públicos.

La paridad implica que ningún género tenga más de $40 \%$ de los cargos o, en su versión más radical, establece una distribución de $50 \%$ a $50 \%$. Es decir, constituye el proyecto de una sociedad inclusiva equitativa entre mujeres y hombres en todos los órganos de decisión y representación pública.

Es necesario señalar entonces que uno de los factores que impide la plena participación de la mujer en las actividades relacionadas a la toma de decisiones se encuentra originada por esa mal considerada posición social de la mujer, influenciada por la ignorancia y la discriminación que gira en torno a los roles de género, reflejado en prejuicios y estereotipos.

Para avanzar en el ejercicio del derecho de las mujeres al sufragio se recomienda:

- Generar información regular sobre el ejercicio del derecho al voto, en particular de votantes, desagregada por sexo y otras categorías (zona geográfica, condición indígena, afrodescendiente, etcétera). ${ }^{28}$

- Garantizar la autonomía en el ejercicio del voto para todas las mujeres.

- Incrementar tanto el porcentaje de mujeres como de hombres que votan.

La participación de las mujeres en la actividad política, permite contribuir al desarrollo de la legitimidad democrática, del buen gobierno y del desarrollo sostenible, generando efectos positivos para eliminar los estereotipos sexistas.

27 Sistema Nacional de Información Municipal del Inafed, marzo de 2012. No se dispone de información sobre 176 ayuntamientos, por lo que el porcentaje considera 2,280 municipios.

28 Disponible en: http://wrere.equidad.org.mx/capacitacion/documentos/9\%20Participacio\%CC $\% 81$ \% $\% 20$ Poli\%CC\%81tica\%20de\%20las\%20Mujeres\%20en\%20Me\%CC\%81xico._.\%2060\% 20 an\%CC\%83os\%20del\%20reconocimiento\%20del\%20derecho\%20al\%20voto\%20femenino.pdf (fecha de consulta: octubre de 2016). 
Este libro forma parte del acervo de la Biblioteca Jurídica Virtual del Instituto de Investigaciones Jurídicas de la UNAM

\section{COMENTARIOS FINALES}

La Constitución ante la misma evolución social, sirve como paradigma a la apertura política, social, cultural y económica, dando paso a la armonía y unión entre hombres y mujeres, valores base del respeto de la dignidad y los derechos humanos, valores necesarios en toda sociedad caracterizada por el pluralismo, la justicia, la solidaridad y la igualdad entre hombres y mujeres.

No se trata de compensar la desventajosa situación a la que las mujeres han estado sujetas, se trata de reconocer en igualdad de derechos y oportunidades a las mujeres; por tal razón, es necesario destacar la importancia de la Constitución, la cual sirve en pro del empoderamiento femenino, fomentando la apertura no sólo política sino la apertura a la equidad sustantiva constitucional.

La participación política no sólo favorece a las mujeres, sino también al sistema democrático, toda vez que no se puede hablar de un Estado democrático, en donde las demandas de la mayoría no son escuchadas o representadas en las estructuras del poder.

La agenda de las mujeres ha posicionado temas como el reconocimiento de las desigualdades y las propuestas para modificar esas situaciones, reconocimiento de derechos a la diversidad, respeto por el medio ambiente, licencias de paternidad y maternidad, condiciones laborales equitativas, entre otros muchos.

Desde mediados del siglo pasado, la mayor parte de los países ha reconocido el derecho de las mujeres al voto, lo que ha aumentado su influencia en la toma de decisiones y, con ello, la posibilidad de impulsar sus derechos políticos, económicos, sociales y culturales.

El derecho a la participación política de las mujeres abarca el derecho al acceso y plena participación en la vida política, el ejercicio efectivo del poder político y procesos de toma de decisiones en todas las esferas de la vida pública, en igualdad con los hombres y sin discriminación de ningún tipo.

Es momento en el que los prejuicios originados por el desconocimiento y sobre todo la discriminación hacia las mujeres dejen de limitar el pleno ejercicio de los derechos de las mujeres. La necesidad de reducir y eliminar los factores que impide la plena participación de la mujer en las actividades relacionadas a la toma de decisiones es un reto del derecho actual.

El trabajo y la participación de las mujeres en los temas públicos, ha legitimado su participación en la vida política, pues cada que las mujeres hacen presencia en la política se generan cambios positivos. Cambios, que han beneficiado a todos por igual, ya que la agenda de las mujeres al iden- 
Este libro forma parte del acervo de la Biblioteca Jurídica Virtual del Instituto de Investigaciones Jurídicas de la UNAM

tificar y denunciar las desigualdades, permea a todos los sectores y formas de organización; donde haya injusticias y desigualdad en las oportunidades entre una y otra persona, habrá mujeres luchando y pronunciándose para transformar la realidad.

La participación política de las mujeres debe contribuir a la legitimidad democrática, del buen gobierno y del desarrollo sostenible, generando efectos positivos para eliminar los estereotipos sexistas.

\section{FUENTES DE CONSULTA}

CID LóPEz, Rosa María (coord.), Mujeres en la historia, Instituto Asturiano de la Mujer-Gobierno del Principado de Asturias-Consejería de Presidencia, Justicia e Igualdad-Instituto Asturiano de la Mujer- Ámbitu.

Conapred \& Inmujeres, Encuesta Nacional sobre Discriminación en México (ENADIS 2010) Resultados sobre mujeres, México, 2012.

Constitución Política de los Estados Unidos Mexicanos, disponible en: http:// wrere.diputados.gob.mx/LeyesBiblio/htm/1.htm (fecha de consulta: octubre de 2016).

Cortina, G. y QUijano, Aurora, Los congresos feministas de Tucatán en 1916 y su influencia en la legislación local y federal, disponible en: http://historico.juridicas. unam.mx/publica/librev/rev/hisder/cont/10/cnt/cnt9.pdf (fecha de consulta: octubre de 2016).

Gruz JaImes, Guadalupe, "Hermila Galindo, una feminista en la Constituyente de 1917", disponible en: http://wrere.cimacnoticias.com.mx/node/56354 (fecha de consulta: octubre de 2016).

Datos de 1964-2006 PRONAM:

Disponible en: http://genero.ife.org.mx/docs/docs_mat-PNUD-1_10jul2012.pdf (fecha de consulta: mayo de 2016).

Disponible en: http://sitl.diputados.gob.mx/LXIII_leg/album_foto_tc.pdf(fecha de consulta: mayo de 2016).

Disponible en: http://wrerr.gob.mx/sre/articulos/cien-anos-del-primer-congreso-femi nista-enmexico (fecha de consulta: septiembre de 2016).

Disponible en: http://wrere.senado.gob.mx/index.php? ?ver $=$ int $\mathcal{E}^{2} m n=4 \mathcal{E}^{2} \mathrm{sm}=2 \mathrm{E} s t r$ $=M$ (fecha de consulta: mayo de 2016).

Gouges, Olympe, Declaración de los derechos de la mujer y de la ciudadana. Para ser decretada por la Asamblea Nacional Francesa (1791), disponible en: http://clio. rediris.es/n31/derechosmujer.pdf (fecha de consulta: septiembre de 2016). 
Este libro forma parte del acervo de la Biblioteca Jurídica Virtual del Instituto de Investigaciones Jurídicas de la UNAM

Huerta, M. y Magar, E. (eds.), Mujeres legisladoras en México, avances, obstáculos, consecuencias y propuestas, México, Inmujeres-Conacyt-ITAM-Fundación Friedrich Ebert, 2006.

IFE, Estudio muestra de la participación ciudadana en las elecciones federales 2009, México, 2010.

Jiménez Álvarez, Ana Victoria y Reyes Castellanos, Francisca, Sembradoras de Futuro, Memoria de la Unión Nacional de Mujeres Mexicanas, Unión Nacional de Mujeres Mexicanas, 2000.

MACíAS, Anna, Contra viento y marea. El movimiento feminista en México hasta 1940, México, UNAM, Programa Universitarios sobre Estudios de Género, 2002.

Morton, Ward M., Women Suffrage in Mexico, Gainesville, Florida, University of Florida Press, 1962.

Pacto Internacional de Derechos Civiles y Políticos, disponible en: http:// wrew.ohchr.org/SP/ProfessionalInterest/Pages/CCPR.aspx (fecha de consulta: septiembre de 2016).

PERNOUD, Régine, "La mujer en la historia", Humanitas, núm. 6, disponible en: http://humanitas.cl/html/biblioteca/articulos/d0159.html (fecha de consulta: agosto de 2016).

ROJAS G., Ingrid et al., La mujer mexicana a través de los años. Repercusiones históricas y laborales como factores de empuje en la migración internacional, tesis de licenciatura. Relaciones Internacionales. Departamento de Relaciones Internacionales e Historia, Escuela de Ciencias Sociales, Universidad de las Américas Puebla, 2003.

Sistema Nacional de Información Municipal del INAFED, marzo de 2012.

Tovar, Aurora, Mil quinientas mujeres, en nuestra conciencia, México, Premios Demac-UNAM, 1996, p. 662

VAlLES RuIz, Rosa María, Hermila Galindo: ideas y acción de una feminista ilustra$d a$, Ciencia Universitaria. 
Este libro forma parte del acervo de la Biblioteca Jurídica Virtual del Instituto de Investigaciones Jurídicas de la UNAM

\title{
EL VOTO DIREGTO EN LOS DEBATES Y PROPUESTAS DE LOS CONGRESOS CONSTITUYENTES DE 1856-1857 Y 1916-1917
}

\author{
Juan Carlos SÁnchez MonTiEL*
}

\begin{abstract}
SUMARIO: I. Introducción. II. Soberanía popular, representación y elecciones en el Constituyente de 1856-57. III. Voto indirecto vs. voto directo. IV. El debate acerca del voto directo en el Constituyente de 1856. V. El maderismo y la búsqueda del sufragio efectivo. VI. El debate sobre el voto directo en la era maderista. VII. La discusión acerca del voto directo en el Constituyente de 1916. VIII. Conclusiones. IX. Fuentes primarias.
\end{abstract}

\section{INTRODUCGIÓN}

El voto directo en los debates de los congresos constituyentes mexicanos de 1856 y 1916, se presentó como uno de los principios en que debía fundarse todo régimen de representación política basado en el dogma de la soberanía popular; sin embargo, como ideales democráticos, para sus opositores se consideraban aspiraciones utópicas, impracticables en un pueblo poco ilustrado sin una conciencia y cultura política capaz de generar el interés de los ciudadanos en la conformación del gobierno.

En el Constituyente de 1856 la propuesta para establecer el voto directo fracasó frente a dos imperativos, el convencimiento de que el pueblo mexicano aún no estaba preparado para ejercer tal responsabilidad, por ser inculto y aún no emancipado del todo, y que el voto indirecto ofrecía más expectativas de control político-electoral a las elites y los grupos de poder político.

El voto indirecto permitía mantener el dogma de la representación popular, y al mismo tiempo, mediante sucesivas escalas de representación del pueblo, ejercer una tutela sobre éste, que dejaba en manos de las elites polí-

\footnotetext{
* Universidad Autónoma de Ciudad Juárez.
} 
Este libro forma parte del acervo de la Biblioteca Jurídica Virtual del Instituto de Investigaciones Jurídicas de la UNAM

ticas la regulación de la disputa por el acceso al poder político. En cambio, el voto directo, aún con restricciones al acceso a la ciudadanía, admitía una mayor cantidad de electores que podían decidir sobre la formación del gobierno, lo que introduciría nuevos espacios de negociación y de acción política, que no estaban seguros de controlar.

Para 1916, el contexto político había cambiado trascendentalmente, la crisis política generada por la reelección de Porfirio Díaz, y la campaña política de Madero, amparada en los principios democráticos de la no reelección y el voto efectivo, crearon las condiciones favorables a la posibilidad del voto directo. Se mantenía la idea de un pueblo no capacitado para el ejercicio de la vida democrática, pero, presionados por las demandas de cambio político que apuntaban hacia una participación más efectiva del pueblo en la formación del gobierno, los legisladores de la XXV Legislatura y del Constituyente de 1916, dieron su voto de confianza al voto directo y a otras reformas electorales, como la creación de los partidos políticos, confiando en que tendrían un efecto transformador de la conciencia, la cultura y los hábitos políticos de la población que tendría derecho al voto, pero también establecieron procedimientos que ofrecían nuevas posibilidades de control político electoral, sobre todo a partir de las competencias que se otorgaron a los municipios en la organización de las elecciones, que se sumarían a las inercias de una cultura democrática incipiente y el peso de las prácticas y conductas electorales informales que tradicionalmente se habían puesto en marcha ante la disputa político electoral, y que el nuevo régimen electoral, pese a sus buenos propósitos, no lograría eliminar.

\section{SOBERANÍA POPULAR, REPRESENTACIÓN Y ELEGGIONES EN EL CONSTITUYENTE DE 1856-57}

El significado del Constituyente y la Constitución de 1857 era materializar un nuevo pacto institucional y político, a partir del cual se crearía un nuevo marco de legalidad, bajo un régimen representativo y republicano, que sería validado por un nuevo régimen electoral que regularía la manera en que los ciudadanos y electores participarían en la formación del gobierno. ${ }^{1}$

Los constituyentes habían adoptado el precepto liberal de la representación como expresión de la voluntad general, ${ }^{2}$ de ella debía emanar la legitimidad de los poderes nacionales y las instituciones de gobierno; una

1 Malamud, "La efimera", 2000, p. 105.

2 Capellan, "Representación", en Fernández Sebastián, Javier, Diccionario político y social del siglo XIX español, Madrid, Alianza, 2002, pp. 612-614. 
Este libro forma parte del acervo de la Biblioteca Jurídica Virtual del Instituto de Investigaciones Jurídicas de la UNAM

forma de constituir esa representación era mediante la participación de los ciudadanos en las elecciones, lo cual estaría sujeto a las pautas de organización y acceso a la participación político electoral que estableciera el nuevo régimen político.

La soberanía popular resultaba ser el fundamento de toda representación política, lo cual presuponía la existencia de un sujeto, el pueblo, que se convertía en un ente impersonal, abstracto, materializado a través de representaciones que podían tomar formas distintas, dependiendo de cómo se concibiera la manera de construir esas representaciones, y expresarlas a través de instituciones. ${ }^{3}$

Carmagnani considera que el liberalismo de medio siglo había cambiado con respecto al de las primeras décadas de vida independiente, la experiencia del uso de medios violentos para resolver disputas políticas, pesaba sobre el imaginario político de los contemporáneos, de tal forma que esta generación se había propuesto conciliar el otorgamiento de las libertades más amplias con el mantenimiento del orden. ${ }^{4}$ Dicha máxima marcaría en buena medida los debates en torno a si se adoptaba el voto directo o se mantenía el voto indirecto en el Constituyente de 1856, pero también las contradicciones que llevaba implícitas, dado lo ocurrido en el pasado inmediato y la realidad social y política del momento.

La gran disyuntiva entre los constituyentes de 1856 en cuanto al régimen de sufragio que se debía adoptar era, aceptado el dogma de la soberanía popular, cómo se traduciría en materia electoral, es decir, cómo quedaría regulada la participación del pueblo, representado por los ciudadanos-electores, en las elecciones. La forma de constituir esa representación popular a través del voto directo o indirecto, tenía implicaciones sobre el papel que desempeñaría el pueblo y específicamente el ciudadano en la conformación del poder, y los mecanismos de organización y legitimación de la elección de las autoridades a las que se les conferiría dicha representación popular; materia que también ocupó a los constituyentes locales, y que produjo algunas variantes en el régimen electoral y de sufragio que adoptaron algunos estados, como fue el caso de Chihuahua, donde se optó por instaurar el voto directo para la elección de todos los poderes del estado, incluidos los gobiernos municipales, moción que no había logrado cuajar en el Constituyente nacional de 1856.

3 Rosanvallon, Pierre, Por una historia conceptual de lo político, México, Fondo de Cultura Económica, 2003, pp. 23 y 24.

4 Carmagnani, "La tensión entre libertad y poder en el constitucionalismo de 1850", en Noriega, Cecilia y Salmerón, Alicia, México: un siglo de historia constitucional (1808-1917), México, Instituto Mora-Poder Judicial de la Federación, 2009, pp. 288 y 289. 
Este libro forma parte del acervo de la Biblioteca Jurídica Virtual del Instituto de Investigaciones Jurídicas de la UNAM

\section{VOTO INDIRECTO VS. VOTO DIRECTO}

El primer antecedente de la implementación del voto indirecto fue la Constitución de Cádiz, que marcó el inicio de la transición de una representación política corporativa, basada en el reconocimiento de privilegios de tipo asociativo, a una representación fundada en individuos que integraban la nación y participaban en la formación del gobierno mediante el ejercicio de sus derechos de ciudadanía, entre los que el sufragio desempeñaba un papel trascendental, debido a que bajo la cultura política liberal era la única fuente de legitimidad para las autoridades públicas, porque era el artilugio mediante el cual el pueblo tomaba parte en el gobierno, a través de la elección de representantes, en quienes delegaba la soberanía.

Una de las innovaciones introducidas por la Constitución de Cádiz y que luego acabaría prevaleciendo a lo largo del siglo XIX, fue el precepto de que sólo a través del sufragio de los ciudadanos se podía legitimar a las autoridades que conformaban un gobierno. El poder político se podía conquistar de muchas formas, pero una condición que se hizo necesaria para retenerlo y para mantener la gobernabilidad fue la celebración de elecciones, ${ }^{5}$ y la autorización de la voluntad general del pueblo expresada a través del voto.

Esto hizo que los debates y las propuestas entre las facciones y grupos políticos que en distintos momentos disertaron acerca de la forma de constituir a las autoridades que integrarían el gobierno en México, se centraran en buena medida en torno a la definición de la ciudadanía, los derechos políticos que esta calidad confería a los individuos, su acceso y participación en las elecciones, y la regulación de las prácticas que rodeaban la realización de las elecciones, donde el tema de la representación era el telón de fondo que ocupaba a todos estos actores políticos.

Pese a que la representación popular exigía legitimarse a través de la participación del pueblo en el gobierno, se tenía recelo hacia la democracia, pues se consideraba que tenía la imposibilidad práctica de abrir la participación política a las masas, tumultuosas, incultas, violentas, dominadas por la pasión y carentes de razón, por lo que era necesario poner algunos candados a su intervención inmediata. ${ }^{6}$

5 Gantús y Salmerón (coords.), Prensa y elecciones. Formas de hacer política en el México del siglo XIX, México, Instituto de Investigaciones Dr. José María Luis Mora-Conacyt-Instituto Federal Electoral, 2014, p. 16.

6 Capellán, "Representación”, en Fernández Sebastián, Javier, Diccionario político y social del siglo XIX español, Madrid, Alianza Editorial, 2002, pp. 612-614. 
Este libro forma parte del acervo de la Biblioteca Jurídica Virtual del Instituto de Investigaciones Jurídicas de la UNAM

En México la participación del pueblo en los movimientos políticos con frecuencia había desatado la violencia social, el llamado al pueblo para resolver conflictos electorales había demostrado su efectividad en casos como el motín del Parían en 1828, pero también había puesto de manifiesto a los ojos de las elites el poder de los sectores sociales bajos, quienes debido a su falta de luces, podían convertirse en una fuerza destructora del orden. ${ }^{7}$

Estos temores afianzaron aún más la idea de que el voto directo era la mejor forma de conciliar la exigencia liberal de constituir una representación de tipo popular, con la necesidad de dejar sólo en manos de los hombres de mayores luces la decisión de elegir a las autoridades y poderes de la nación; pero también, plantearon la necesidad de restringir más el acceso al sufragio, de ahí los requisitos de alfabetización y de ingreso para tener derecho al voto, que se establecieron durante la etapa centralista. ${ }^{8}$

El voto indirecto era una respuesta a la complicación que suponía para el régimen representativo abrir demasiado el acceso a la participación de las masas. Para quienes consideraban un peligro la intervención inmediata de los ciudadanos-electores, el voto indirecto ofrecía la posibilidad de establecer mecanismos de exclusión que iban cerrando paulatinamente el acceso a la participación política, para tener mayor control sobre la etapa concluyente y decisiva de la elección, sin que la representación dejara de ser "popular".

La modernidad política presuponía la existencia de un pueblo, que sólo existía a través de las representaciones que se hacían de él, y admitía representaciones sucesivas, ${ }^{9}$ de ahí que el voto indirecto, pese a que jerarquizaba la participación de los ciudadanos en la decisión para elegir a sus autoridades, no dejaba de ser una representación de carácter popular, constituida a partir de representaciones sucesivas del pueblo, partiendo del ciudadano que tenía participación en el primer grado de la elección, hasta llegar a los electores que tomaban parte en los siguientes grados de la elección, y que mantenían la investidura de representantes del pueblo.

El rechazo a las consecuencias negativas que podría tener una intervención directa de las masas en la formación del gobierno, llevaría a considerar que el voto indirecto era la única posibilidad para países donde se tenía un pueblo poco ilustrado, y se corría el riesgo de que la ampliación masiva de la

7 Arrom, Silvia M., "Protesta popular en la Ciudad de México: el motín del Parián en 1828”, en Arrom, Silvia y Ortoll, Servando (coords.), Revuelta en las ciudades. Políticas populares en América Latina, México, Universidad Autónoma Metropolitana-El Colegio de SonoraMiguel Ángel Porrúa, 2004, pp. 114 y 115.

8 Ibidem, p. 114.

9 Rosanvallon, Pierre, Por una historia conceptual de lo político, México, Fondo de Cultura Económica, 2003, p. 23. 
Este libro forma parte del acervo de la Biblioteca Jurídica Virtual del Instituto de Investigaciones Jurídicas de la UNAM

participación política en la fase decisiva de las elecciones propiciara el voto irreflexivo, dominado por la pasión, la intriga y la emotividad, lo que conduciría irremediablemente a la demagogia, como era el caso de Bolivia, ${ }^{10}$ pero que bien podía aplicarse al caso mexicano.

Sin embargo, para algunos el voto indirecto era incompatible con la idea de establecer una representación e instituciones de carácter popular, pues favorecía el dominio de los intereses de las minorías sobre el de las mayorías, y facilitaba los artilugios y las intrigas en las elecciones al reducirse el número de electores sobre los que recaía la responsabilidad final de elegir a las autoridades, por lo que con frecuencia podían salir electos sujetos que resultaban antipáticos a las masas, y por ende se negaban a reconocerlos como sus representantes. Así lo había expresado Manuel Crescencio Rejón en el Constituyente de 1846-1847, con el apoyo de Mariano Otero y otros diputados que apoyaban el cambio del voto indirecto al directo, propuestas que finalmente no se consumaron en este Constituyente. ${ }^{11}$

El voto directo tenía varias implicaciones en las formas de acceder al poder, en la manera en que participaría la ciudadanía en las elecciones y su papel en la decisión de los cargos de elección, donde el objetivo era que la ciudadanía tuviera un mayor poder de decisión y cercanía en la política y la conformación del gobierno, a través del voto popular, ${ }^{12}$ lo cual podría poner límites a las negociaciones que se generaban en el momento deliberativo de las elecciones a que daba lugar el voto indirecto, de las que el ciudadano común quedaba excluido.

\section{EL DEBATE AGERGA DEL VOTO DIREGTO EN EL CONSTITUYENTE DE 1856}

La renovación generacional entre la elite política y el replanteamiento del liberalismo mexicano de mediados de siglo, nuevamente puso en la discusión el tema acerca del papel que debería tener el pueblo en la constitución de la

10 Marta Irurozqui, "Sobre leyes y transgresiones: reformas electorales en Bolivia, 18261952", en Malamud, Carlos (coord.), Legitimidad, representación y alternancia en España y América Latina: las reformas electorales (1880-1930), México, Fondo de Cultura Económica-El Colegio de México, 2000, p. 283.

11 Ochoa Campos, Moisés, Los debates sobre la adopción del sufragio universal y el voto directo, México, Cámara de Diputados, 1971, pp. 25-27.

12 Tapia, Regina, "Competencia electoral, honor y prensa. México en 1857”, en Gantús, Fausta y Salmerón, Alicia (coords.), Prensa y elecciones. Formas de hacer política en el México del siglo XIX, México, 2014, p. 70. 
Este libro forma parte del acervo de la Biblioteca Jurídica Virtual del Instituto de Investigaciones Jurídicas de la UNAM

representación política, lo cual llevaría al cuestionamiento del significado de la soberanía popular y, bajo este supuesto, qué tipo de participación debía tener el pueblo en la formación del gobierno.

En el Constituyente de 1856, la búsqueda de otorgar mayores libertades y de lograr instituir algunos principios democráticos, a partir de la constitución de un gobierno e instituciones que de manera más genuina representaran la voluntad del pueblo, llevaría a la revisión del régimen electoral que había funcionado hasta ese momento en México, basado en el voto indirecto, y al análisis y discusión acerca de las posibilidades que tendría para un país como México, la adopción de un sistema electoral basado en el voto directo.

Aunque los llamados liberales puros o radicales, entre quienes se puede señalar a Francisco Zarco, Ponciano Arriaga, Guillermo Prieto e Isidoro Olvera, compartían muchas ideas en común, como la ampliación de libertades en materia de cultos y de conciencia, la secularización, y el cometido de proponer un sistema federal perfeccionado, en algunos temas, las posiciones que fijaron algunos de ellos generó divisiones, ${ }^{13}$ la discusión de la propuesta para establecer el voto directo en México fue uno de esos casos.

El debate perfilaría claramente dos posturas, la encabezada por Francisco Zarco, que consideró que ese era el momento para lograr consolidar un régimen político fundado en una más fidedigna representación del pueblo, y la que podríamos definir como "histórica", en el sentido de mantenerse fiel al voto indirecto, siguiendo la tradición iniciada a partir de la Constitución de Cádiz, sobre la que pesaba más el trauma que hasta ese momento del recorrido histórico del país habían dejado los estallidos sociales y la intervención de las masas en los momentos álgidos de la disputa política, y que decía ser más congruente con la realidad histórica de México, que correspondía a la de un país con un pueblo poco ilustrado, no emancipado por completo, carente de conciencia política, y por tanto, incapaz de asumir del todo los principios de la teoría democrática.

En el grupo opositor al voto directo destacan figuras como Ponciano Arriaga e Isidoro Olvera, que pese a considerar que el voto directo era un ideal deseable bajo el dogma de la soberanía popular, consideraban que la falta de ilustración del pueblo real, de las masas populares, sería un impedimento para poner en práctica dicho sistema electoral.

Para Francisco Zarco el voto indirecto no era el mejor medio de expresar la voluntad del pueblo, y era una contradicción a las teorías democrá-

13 Reyes Heroles, Jesús, El liberalismo mexicano, 1994, México, Fondo de Cultura Económica, t. II, p. 444. 
Este libro forma parte del acervo de la Biblioteca Jurídica Virtual del Instituto de Investigaciones Jurídicas de la UNAM

ticas que se habían adoptado. Zarco consideraba que el voto indirecto era una forma de engañar al pueblo, pues en los distintos grados de la elección se separaba más de los intereses del pueblo, y finalmente era el voto de una aristocracia la que se quedaba con el control de la decisión electoral. ${ }^{14}$

La defensa de Zarco del voto directo, se debe a que él consideró que era una posibilidad para hacer efectiva la idea de soberanía, sustentada en la prefiguración de un pueblo integrado por individuos que tienen capacidad para cooperar en la toma de decisiones de la nación. ${ }^{15}$ Así apelaba al pueblo en la sesión del 18 de septiembre de 1856, en oposición al horror al pueblo que habían manifestado diputados como Ponciano Arriaga: “... Pero ya que su señoría quiere que de las últimas clases del pueblo salgan los representantes, comience por el principio, recurra a la fuente más pura, al pueblo y sólo al pueblo, y haga que sea verdad que todo ciudadano es elector". ${ }^{16}$

Además, el voto directo permitiría la ampliación de la base electoral y de la capacidad de representación política, lo cual se traduciría en la expansión de la base social del régimen y una mayor legitimidad de los poderes e instituciones constituidos a partir del voto ciudadano. A este respecto Zarco señaló: "Si es verdad la soberanía popular, de las masas por ignorantes que sean, deben derivarse los poderes públicos". ${ }^{17}$

La propuesta hecha por Francisco Zarco partía de la idea de establecer un sistema de sufragio que al permitir una participación más inmediata de los ciudadanos en el momento decisivo de la elección, que sólo podía ser a través del voto directo, acarrearía una mayor representación popular en la conformación de los poderes de gobierno, lo cual también se lograría desvinculando la ciudadanía política del atributo local que representaba la vecindad. ${ }^{18}$

Zarco y el resto de los liberales del constituyente que debatieron acerca del voto directo, se manifestaron como convencidos de la democracia, la fractura en sus opiniones estaba en la realización práctica de tales teorías, para quienes se oponían era un ideal tan elevado la materialización de la democracia a través del voto directo, que era irrealizable en las condiciones sociales que imperaban en ese momento. En contraste, Zarco era un con-

14 Zarco, Historia del Congreso Constituyente de 1857, Secretaría de Gobernación-INEHRM, 2009, p. 502-553.

15 Carmaganani, op. cit., p. 292.

16 Zarco, Historia del Congreso Constituyente de 1857, cit., p. 503.

17 Ibidem, p. 517.

18 Carmagnani y Hernández, op. cit., 2003, p. 384. 
Este libro forma parte del acervo de la Biblioteca Jurídica Virtual del Instituto de Investigaciones Jurídicas de la UNAM

vencido de que ese era el momento de alcanzar los ideales de la democracia traducidos en una real representación popular, no había que esperar a la transformación social y de la cultura política del pueblo, esta se daría en la práctica a través del ejercicio del voto directo, pues esto tendría un efecto pedagógico.

Otorgar al pueblo la libertad de decidir la forma de constituir su gobierno y una verdadera representación nacional, debía ser uno de los fundamentos del nuevo régimen que se estaba constituyendo. Zarco incluso estaba dispuesto a respetar un congreso contrario al partido liberal, si a través del voto directo el pueblo decidía instaurarlo:

...(Zarco) Si en último caso, apelando al pueblo, y sólo al pueblo, hemos de perder las elecciones, los congresos no serán liberales: pero serán verdadera representación nacional. Entonces sabremos que el pueblo no quiere lo que queremos, que le parecen irrealizables nuestras teorías; entonces sabremos la verdad, y fieles a nuestros principios acataremos su voluntad soberana. ${ }^{19}$

Arriaga acusó a Zarco de tener una fe ciega en el pueblo, que le impedía ver los efectos perniciosos que tendría para los destinos de la nación el dejar en las masas, carentes de costumbres políticas, la decisión de constituir el gobierno; ${ }^{20}$ sin embargo, el apoyo de Zarco al voto directo se fundaba en la creencia de que un régimen de mayores libertades políticas, que incluyera al pueblo en la toma de decisiones, fomentaría el interés y la conciencia política, lo cual coadyuvaría a la transformación de la cultura política de las masas.

En el discurso de quienes sostuvieron el debate en torno al voto directo, hay una vinculación de esta forma de sufragio con el concepto de democracia, en la que subyace la contradicción entre el principio que consagra al sujeto colectivo, el pueblo, como el fundamento del poder político, frente al imperativo de constituir un poder racional a través del sufragio, que exponía una tensión entre el derecho que debían tener los ciudadanos a decidir a través de su participación electoral sobre quienes querían que los representaran, y la deficiente capacidad que se les imputaba para asumir esta responsabilidad de manera racional. ${ }^{21}$

19 Zarco, Historia del Congreso Constituyente de 1857, cit., sesión del 18 de septiembre de 1856, p. 506.

20 Ibidem, p. 504.

21 Rosanvallon, Pierre, Por una historia conceptual de lo político, México, Fondo de Cultura Económica, 2003, pp. 23 y 35. 
Este libro forma parte del acervo de la Biblioteca Jurídica Virtual del Instituto de Investigaciones Jurídicas de la UNAM

Tanto los diputados que apoyaron el voto directo, como quienes querían mantener el sufragio indirecto, tenían la convicción de comulgar con los ideales de la democracia, sólo que los primeros estaban convencidos de que las reformas políticas y sociales que se estaban generando en el constituyente emanciparían al pueblo y lo dotarían de las libertades necesarias para transformarlo, despertar su interés por la vida política de su país y ser un agente político activo tanto a través de la práctica del sufragio, como en el fortalecimiento de la opinión pública.

Para quienes rechazaban el voto directo, el nuevo orden jurídico institucional propiciaría algunos cambios que fomentarían el cambio social, pero aún no era el momento, pues tales cambios serían paulatinos, por lo que el otorgar plenamente al pueblo la posibilidad de ejercer su poder social a través del sufragio, sin que estuviera preparado para hacerlo, traería grandes consecuencias; en este sentido, el diputado Espiridión Moreno señaló: "El pueblo necesita ser guiado por hombres probos e instruidos, necesita que haya quien los conduzca como a un rebaño por el sendero del bien, y la reforma debe ser lenta y gradual para que sea provechosa". ${ }^{22}$

Tanto Arriaga como Zarco reconocieron que el pueblo mexicano carecía de la cultura política necesaria para involucrarse de una manera más consciente en los asuntos de la vida política, a través del fortalecimiento de la opinión pública; sin embargo, mientras para Arriaga esto era un impedimento para la ampliación de los derechos políticos y de participación del pueblo en la vida pública, para Zarco, el deber de la asamblea constituyente era reformar esas costumbres para lograr la emancipación del pueblo, y el voto directo sería el medio adecuado para hacerlo, porque despertaría el interés de todos los ciudadanos en las elecciones al saber que de ellos dependían los resultados de la elección de sus autoridades, con lo que se lograría un despertar de la conciencia política de las masas. ${ }^{23}$

La crítica de Isidoro Olvera a la propuesta de Zarco, respaldaba el rechazo de Arriaga a la idea de establecer el voto directo, fundamentalmente el problema seguía siendo la imposibilidad de una democracia pura, y los peligros de la demagogia y la anarquía que esto traería ante la incompatibilidad de su aplicación en el contexto mexicano. Él reconoció el predicamento en el que se colocaba, pues, reconociéndose como demócrata, debía sostener la idea de que, dadas las circunstancias peculiares del pueblo mexicano, no podía apoyar la moción del voto directo. ${ }^{24}$

\footnotetext{
22 Zarco, Historia del Congreso Constituyente de 1857, cit., p. 512.

23 Ibidem, pp. 504 y 505.

24 Monitor Republicano, "Crónica parlamentaria", 19 de septiembre de 1856, p. 4.
} 
Este libro forma parte del acervo de la Biblioteca Jurídica Virtual del Instituto de Investigaciones Jurídicas de la UNAM

$\mathrm{Al}$ igual que otros liberales de su época, Olvera tuvo que enfrentar el conflicto que generaba la adopción ideológica del dogma de la soberanía popular, como fundamento del sistema político que se deseaba constituir, con el hecho real de contar con un pueblo integrado por individuos que se hallaban mal organizados, que en algunos casos aún no se hallaban emancipados de las corporaciones a las que pertenecían o de la dependencia que mantenían por sus relaciones laborales, como era el caso de los jornaleros, y además, que tenía muy bajos niveles de instrucción. ${ }^{25}$

El problema de fondo era la ausencia de una reforma social, que pese a las medidas que se habían implementado para establecer la igualdad jurídica entre los individuos, para emanciparlos de la sujeción a las corporaciones, y las libertades que se habían implementado, no se consideraban suficientes para transformar al pueblo y hacerlo un ente interesado en la vida política de su país y consciente de las decisiones que se tomaran en esta materia, de ahí los recelos hacia su conducta política.

En respuesta a Olvera, Zarco retomó la idea de que la función del constituyente era precisamente la de organizar al pueblo, y que ese proyecto político que se estaba desarrollando ya había tomado cartas en el asunto en algunos de sus artículos para emancipar al pueblo de un modo tan franco y liberal, que no tendría que desconfiarse ni temerse de él. ${ }^{26}$

Los diputados Gamboa e Ignacio Ramírez, también apoyaron la instauración del voto directo, y se pronunciaron a favor de la elección por candidaturas, un elemento que junto con la definición de los electores y de los procedimientos de la elección, constituye una de las grandes vertientes del hecho electoral, ${ }^{27}$ que no había sido contemplado hasta entonces en los regímenes electorales que habían operado en el país, en los que se excluía la posibilidad de que existieran candidaturas oficialmente reconocidas, bajo la consigna de eliminar todo aquello que pudiera fomentar la creación de vínculos entre electores y elegidos, y que afectara los lazos que debían conectar a los individuos con quienes conformarían su representación colectiva. ${ }^{28}$

25 Idem.

26 Idem.

27 Peña Guerrero, María Antonia, "Mais cette souveraineté qu' est-elle devenue? La influencia del orleanismo en la legislación electoral de la España liberal”, en Caballero López, José Antonio et al. (eds.), El debate constitucional en el siglo XIX. Ideología, oratoria y opinión pública, Madrid, Fundación Práxedes Mateo-Sagasta-Marcial Pons, 2015, p. 109.

28 Gueniffey, Patrice, La Revolución francesa y las elecciones. Democracia y representación a finales del siglo XVIII, México, Instituto Federal Electoral-Fondo de Cultura Económica, 2001, pp. 39 y 40 . 
Este libro forma parte del acervo de la Biblioteca Jurídica Virtual del Instituto de Investigaciones Jurídicas de la UNAM

Para Ramírez, la elección por candidaturas ofrecía la posibilidad de que el candidato se diera a conocer mediante un programa propuesto por él mismo, a cuyo cumplimiento debía comprometerse, y de no cumplir sus promesas perdería el voto de los ciudadanos. La ausencia de candidaturas hasta entonces había dejado únicamente a aspirantes que intrigaban para lograr ganar los cargos de elección sin comprometerse a nada. ${ }^{29}$ Este era un elemento importante de las democracias liberales, que será retomado al adoptarse el voto directo en 1912.

El principal aporte que Gamboa hizo a la discusión en defensa del voto directo, fue el destacar el efecto que el voto directo y la elección por candidaturas tendrían sobre el interés de los ciudadanos en las elecciones, sobre todo porque hizo alusión a la acción que debían tener bajo este régimen de elección los partidos políticos. Señaló que los candidatos y los partidos que los postularan se encargarían de publicar sus programas y de exponer sus intenciones, con lo cual otorgaba a los partidos un papel destacado en la competencia electoral y en la movilización del electorado. ${ }^{30}$

En su intervención en defensa del voto directo, Ramírez tocó un punto que consideró nodal en la negativa de aprobar tal régimen de sufragio, y que era fundamental en la evaluación que las elites políticas de la época debían hacer acerca de cualquier propuesta de régimen electoral. Para él la preocupación por la falta de ilustración del pueblo para entender una responsabilidad tan grande como era la de elegir a sus representantes, era una forma de justificar el ejercicio permanente de una tutela por parte del gobierno y de la autoridad que ostentaba, sobre el derecho legítimo del pueblo a elegir a sus gobernantes, lo cual ofrecía garantías de control político a las elites y posibilidades de intervención del gobierno en las elecciones. ${ }^{31}$

Desde luego el voto directo también podía ofrecer posibilidades de control político-electoral al gobierno y a las autoridades, sobre todo a partir de la definición de los procedimientos electorales, pero en ese momento el grupo encabezado por Arriga consideró que ese control se ponía en menor riesgo a través del voto indirecto, que era un sacrificio que se hacía por el bienestar de la nación, a pesar de aceptar que contrariaba sus convicciones democráticas.

El grupo opositor al voto directo veía en el voto indirecto un estadio provisional, en lo que se lograba el perfeccionamiento de la sociedad para

29 Monitor Republicano, 19 de septiembre de 1856, p. 4.

30 Zarco, Historia del Congreso Constituyente de 1857, cit., sesión del 25 de septiembre de 1856, pp. 511.

31 Ibidem, p. 509. 
Este libro forma parte del acervo de la Biblioteca Jurídica Virtual del Instituto de Investigaciones Jurídicas de la UNAM

que algún día el sufragio efectivamente fuera una expresión del poder social en la formación del gobierno, como un esencial principio democrático. ${ }^{32}$

El resultado final de la discusión sobre el régimen electoral para la elección de diputados, fue que se rechazó la moción de Francisco Zarco para establecer el voto directo, no por rechazar doctrinariamente el ideal de constituir la representación popular a partir de una participación directa de los ciudadanos en la elección de sus autoridades, sino por el convencimiento de que el pueblo real, representado por los ciudadanos-electores, carecía de la instrucción necesaria para practicar el sistema democrático. ${ }^{33}$

La Constitución de 1857 abunda poco en materia electoral, debido a que sería en la Ley Orgánica Electoral del 12 de febrero de 1857, donde se especificarían los procedimientos y la normativa electoral instituida por el nuevo régimen; ${ }^{34}$ sin embargo, ya en el texto constitucional se anunciaban de manera sustancial algunos cambios importantes, como el paso de un régimen de elección doblemente indirecto, a uno indirecto simple, al eliminar a los electores secundarios en la elección para diputados al Congreso federal, para presidente de la República y ministros de la Suprema Corte de Justicia. Además, establecía como una de las prerrogativas de los ciudadanos mexicanos el votar y ser votados en las elecciones populares; definía la ciudadanía a partir de la vecindad y la organización de las elecciones con base en distritos de hasta cuarenta mil habitantes. ${ }^{35}$

\section{EL MADERISMO Y LA BÚSQUEDA DEL SUFRAGIO EFECTIVO}

El compromiso político adquirido por Francisco I. Madero desde el inicio de su campaña de oposición al régimen porfirista era la realización de un reformismo político-electoral, basado en los ideales democráticos de la no reelección y el sufragio universal, que sin hacer grandes promesas en cuanto a reivindicaciones sociales, se convirtió en una corriente política abierta a todos los sectores sociales que habían sido excluidos de la participación política, ${ }^{36}$ y que debían incluirse de alguna forma en el nuevo ordenamiento político

32 Olvera, Isidoro, "Crónica parlamentaria", Monitor Republicano, 19 de septiembre de 1856, p. 4.

33 Monitor Republicano, 19 de septiembre de 1856, p. 4.

34 Dublan y Lozano, Legislación, v. VIII, 1876, p. 409.

35 Carmagnani y Hernández, "La ciudadanía", cit., p. 383.

36 Guerra Francois Xavier, México: del antiguo régimen a la Revolución, 2a. ed., México, Fondo de Cultura Económica, 1991, p. 135. 
Este libro forma parte del acervo de la Biblioteca Jurídica Virtual del Instituto de Investigaciones Jurídicas de la UNAM

que él estaba proponiendo constituir, bajo la observancia de los principios democráticos.

El proyecto de oposición de Madero se valió de la realización de giras de campaña por distintos lugares del país, en las que llevó el mensaje de que la democratización del país a partir de elecciones libres y justas, que lograran despertar el interés de los ciudadanos, y convencerlos de que su decisión expresada en las urnas sería respetada, sería la fórmula para transformar el país. ${ }^{37}$

Una vez que se precipitó el derrocamiento de Porfirio Díaz, no de la forma que había planeado Madero, sino mediante el estallido de la violencia, debía reinstaurarse el orden institucional, y en primer plano para lograrlo debían estar las promesas de reforma electoral hechas durante su campaña, porque serían las que le darían legitimidad al nuevo gobierno y justificarían el derrocamiento del dictador.

Sin embargo, la salida de Díaz, reelecto mediante una elecciones consideradas fraudulentas, no implicó la nulidad de todas las elecciones, como quizá correspondía en la lógica de restablecer el régimen de legalidad mediante elecciones libres, que era el principal cuestionamiento que había provocado el estallido revolucionario en noviembre de 1910. Los convenios de Ciudad Juárez sólo contemplaron la renuncia del presidente y vicepresidente, pero se mantuvo el Congreso y el Senado, que como resabio del régimen porfirista, serían un actor crítico y de contrapeso importante al gobierno de Madero.

Pese a su filial porfirista, la XXV Legislatura, tuvo que atender las demandas de reforma en el sistema electoral y dar el tiro de gracia al régimen electoral porfirista, para construir una nueva legitimidad basada en la confianza en los procedimientos electorales como expresión del voto libre y la voluntad popular, de ahí la necesidad de aprobar nuevas medidas para ahuyentar el fraude y hacer efectivo el sufragio; pero en este incipiente proceso de recomposición política se adoptaron también medidas de mayor trascendencia, como fueron la instauración del voto directo para la elección de diputados y senadores, y la participación de los partidos políticos en las elecciones, con plena personalidad jurídica, ${ }^{38}$ lo cual significaba un cambio notable en las reglas de la competencia política, que demandaban una

37 Knight, Alan, La Revolución mexicana, México, Fondo de Cultura Económica, 2010, p. 533.

38 Medina Peña, Luis, "El maderismo: la oportunidad perdida", en Medina Peña, Luis (coord.), El siglo del sufragio, México, Fondo de Cultura Económica-Consejo Nacional Para La Cultura y Las Artes-Instituto Federal Electoral-Consejo Nacional de Ciencia y Tecnología, 2010, p. 47. 
Este libro forma parte del acervo de la Biblioteca Jurídica Virtual del Instituto de Investigaciones Jurídicas de la UNAM

mayor inclusión de los ciudadanos en las decisiones político-electorales y el robustecimiento de la opinión pública a partir de la acción de los partidos políticos y los candidatos por dar a conocer sus programas. Estos nuevos elementos fomentarían el cambio en la cultura política de los actores populares y despertaría su conciencia política.

\section{EL DEBATE SOBRE EL VOTO DIREGTO EN LA ERA MADERISTA}

La impronta de la insurrección generada por la reelección de Porfirio Díaz en medio de acusaciones de fraude electoral, y su salida de la presidencia, apuró el debate acerca de las reformas al sistema electoral. La iniciativa presentada el 9 de octubre de 1911 al Senado por Emilio Rabasa y Miguel Macedo, expone las circunstancias en las que el último congreso porfirista trató de asumir y dar respuesta a las reformas electorales, entonces sí consideradas necesarias, pese a que se dudaba que hubiera las condiciones en el país para realizarlas.

La propuesta hecha por Rabasa y Macedo para que la elección de senadores y diputados fuera a través del voto popular directo, no deseaban darle el mérito al gobierno de Madero de ser el origen de las iniciativas para poner en práctica la democracia, e hicieron una apología de los intentos que ya antes se habían hecho por efectuar algunas reformas, aunque algunas de ellas no lograron concretarse. De lo que se manifestaron convencidos fue de la oportunidad para el movimiento de acción efectiva a favor de las libertades que ofrecía el momento de cambio político que se acababa de gestar.

La realización libre y efectiva del derecho al sufragio no sería la panacea que sanaría la ineptitud demostrada hasta entonces para el régimen constitucional, pero también reconocieron que el sufragio libre era sin duda el fundamento real de todas las libertades, y que un gobierno emanado de la voluntad de la mayoría sería más legítimo y siempre sería respetado.

En la iniciativa de Rabasa y Macedo emergió el viejo dilema entre la adopción del dogma de la soberanía del pueblo y los recelos hacia el pueblo real, considerado no apto para el ejercicio de las prácticas democráticas. Ellos señalaron la necesidad de que las reformas para alcanzar el sistema democrático promovieran cambios en el pueblo, caracterizado por su heterogeneidad y desnivelado culturalmente, por lo que como punto de partida dichas reformas debían limitarse a los avances que en materia democrática permitían las condiciones sociales que imperaban en ese momento. 
Este libro forma parte del acervo de la Biblioteca Jurídica Virtual del Instituto de Investigaciones Jurídicas de la UNAM

En este contexto, la instauración del voto directo era la primer medida para lograr el cumplimiento del voto efectivo, pero la iniciativa debía quedarse hasta ahí, sin precipitarse antes de que se cumplieran las condiciones para dar los siguientes pasos, había que esperar que se disipara el ilimitado populismo que había traído consigo la Revolución.

Los partidos políticos no habían logrado convertirse en las agrupaciones homogéneas fundadas en principios y propósitos que definieran su filiación, debido a la falta de educación del pueblo, pero el voto directo junto con la acción de los partidos para ganar adeptos a partir de un programa definido, favorecería las condiciones para la realización del sufragio efectivo y consciente, los ciudadanos que a pesar de las nuevas libertades y principios democráticos mantuvieran su ignorancia y apatía frente a las elecciones, quedarían simplemente como un elemento perturbador de la democracia.

$\mathrm{Al}$ igual que Zarco y quienes apoyaron la moción para instaurar el voto directo en el Constituyente de 1856, la iniciativa de Rabasa y Macedo consideró que el voto directo tendría un efecto pedagógico, capaz de modificar los hábitos y la cultura política del pueblo de manera paulatina, reduciría la incidencia del fraude y las prácticas electorales irregulares, y despertaría su interés en participar en las elecciones.

Para 1912 las elecciones para la renovación del Congreso provocaron nuevos debates en torno a las elecciones, el sufragio efectivo y el voto directo, materias sobre las que ya se habían llevado a cabo algunas reformas, pero que habían expuesto también sus primeros tropiezos. Esto había puesto en entredicho hasta dónde las reformas electorales implementadas podían sobreponerse a las viejas prácticas en los procedimientos electorales, que antes como ahora, perseguían el asegurar un resultado electoral favorable, aprovechando el amplio margen de acción que el sistema electoral dejaba en las autoridades gubernamentales para intervenir en las elecciones, y cumplir los ideales democráticos de voto efectivo como expresión de la voluntad del pueblo, puesta de manifiesto a través del voto directo.

La prensa de oposición a Madero, como era el caso del periódico El Imparcial, se esforzó por exponer el abismo que había entre los ideales democráticos fundados en el sufragio efectivo y el voto directo, y las circunstancias políticas del momento, que ponían al gobierno de Madero ante la disyuntiva de apegarse a los principios democráticos que él había promovido, o recurrir a las viejas prácticas de control electoral para asegurar un resultado que le ayudara a consolidar su gobierno, sin tener un congreso molesto.

En su editorial del 3 de junio de 1912, con motivo de la renovación de la Cámara, El Imparcial, se interrogaba, ante las aspiraciones del ejecutivo 
Este libro forma parte del acervo de la Biblioteca Jurídica Virtual del Instituto de Investigaciones Jurídicas de la UNAM

de contar en el Congreso con los elementos afines e incondicionales a sus intereses, ¿cuál sería la actitud del gobierno frente a las próximas elecciones? Su respuesta a esta interrogante era que el gobierno de Madero tendría que sustituir las unidades disolventes por otras sanas y cooperativas, y que tendría que hacerlo a toda costa, lo cual quería decir que se vería obligado a fraguar sus elecciones del mismo modo en que esto se practicaba en el pasado régimen..$^{39}$

Las primeras experiencias electorales después de las reformas al sistema electoral, pese a proponerse hacer efectivo el voto y lograr erradicar la apatía del pueblo con base en el voto directo y la creación de los partidos políticos, no provocaron una politización popular extendida, la falta de interés en las elecciones llevó en algunos momentos a altos niveles de abstencionismo, al parecer, la nueva política electoral no lograba convencer a muchas comunidades. Pero, tampoco logró ausentar del escenario electoral la manipulación, la coacción y el fraude. ${ }^{40}$

Frente a la posibilidad de tener que lidiar con una cámara enemiga, que se agregaría a los elementos de desintegración y de oposición ya existentes, y a los enormes riesgos que implicaba la realización de elecciones libres en medio del clima de agitación poseída por el vértigo revolucionario, que enviaría a las cámaras un contingente de jacobinismo y demagogia, $E l$ Imparcial sentenciaba que Madero se vería forzado a abandonar los sueños utópicos y el entusiasmo democrático, para lograr fortalecer su gobierno y lograr implementar su programa político. ${ }^{41}$ Para esas alturas la promesa de sufragio efectivo se consideraba letra muerta.

La democracia no se alcanzaría jamás por medio de la anarquía, el desorden ni la agitación revolucionaria, había que cambiar la composición social y acrecentar las aptitudes políticas, y eso no se daría de la noche a la mañana, por lo que El Imparcial estaba convencido de que "el gobierno, disfrazado de Club Político se encargaría de hacer las elecciones, práctica que ya se había usado para imponer al candidato a la vicepresidencia". ${ }^{42}$

Esta postura asumía que fuera del hemisferio teórico y del ordenamiento político-electoral formal, fundado en los ideales democráticos, la intervención del gobierno en los procedimientos electorales, bajo prácticas comunes y aceptadas, pero no formalmente instituidas, seguía siendo un elemento fundamental para la formación de un gobierno más armónico,

39 El Imparcial, 3 de junio de 1912, p. 3.

40 Knight, Alan, La Revolución mexicana, cit., pp. 560 y 561.

41 El Imparcial, 3 de junio de 1912, p. 3.

42 El Imparcial, 6 de julio de 1912. 
Este libro forma parte del acervo de la Biblioteca Jurídica Virtual del Instituto de Investigaciones Jurídicas de la UNAM

heterogéneo, donde los elementos de oposición se mantuvieran dominados por las fuerzas políticas favorables al gobierno.

\section{LA DISGUSIÓN AGERCA DEL VOTO DIRECTO EN EL Constituyente De 1916}

La discusión del voto directo en el Constituyente de 1916, llegó con la carga de lo que ya se había debatido en el Constituyente de 1856, pero también de los debates en torno al sufragio efectivo y las reformas electorales para hacer que las elecciones fueran una expresión más genuina de la voluntad popular y de la vida democrática. Además, para cuando inició sesiones, ya habían pasado algunos años de las reformas electorales de la era maderista, y se habían puesto a prueba su efectividad y su capacidad transformadora para cambiar la cultura y los hábitos políticos tanto de las masas populares que, representadas por los ciudadanos-electores, intervendrían de una manera más directa en las elecciones, como de los grupos de poder que a través de los partidos políticos intentarían hacerse del poder bajo la observancia de los cambios al juego político que habían supuesto las reformas maderistas.

Aunque se considera que fueron diversas las fuentes que pudieron influir en los constituyentes de 1916, es difícil identificarlas a todas, debido a que no fueron mencionadas en los debates. ${ }^{43}$ En materia electoral, desde luego el antecedente inmediato fueron las reformas realizadas por la XXV Legislatura durante el mandato de Madero; sin embargo, con respecto a los antecedentes del voto directo, cómo ya se trató en este trabajo, en el Constituyente de 1857, se hicieron propuestas para instaurarlo, críticas a los efectos del voto indirecto, y suscitó acalorados debates entre el grupo liderado por Francisco Zarco, y el que encabezaba Ponciano Arriaga.

En algunos estados sí logró cristalizar la idea de otorgar el voto directo a los ciudadanos, a mediados del siglo XIX, aunque sólo para algunas instancias de gobierno, tal fue el caso de entidades como San Luis Potosí, donde su Constitución de 1861 estableció el voto directo para la elección de alcaldes municipales. Una mención aparte en esta revisión merece Chihuahua, donde el voto directo se estableció para todos los ámbitos de gobierno en la Constitución de 1858. Aunque no contempló la formación de partidos políticos, se tomaron medidas en los procedimientos electorales para garantizar

43 Marván Laborde, Ignacio, "El constitucionalismo de 1917: rupturas y continuidades", en Noriega, Cecilia y Salmerón, Alicia (coords.), México: un siglo de historia constitucional (1808-1917), cit., p. 369. 
Este libro forma parte del acervo de la Biblioteca Jurídica Virtual del Instituto de Investigaciones Jurídicas de la UNAM

un sufragio libre, directo, confiable a partir de la elaboración de padrones muy detallados, que otorgó a los alcaldes de los ayuntamientos y jefes políticos una participación importante en la organización de los procesos electorales, y trató de corregir las prácticas de inducción, cohecho y fraude, que tradicionalmente habían acompañado las elecciones. ${ }^{44}$

Es posible que estas experiencias y las codificaciones que se realizaron para instaurar el voto directo, hayan sido un referente para los diputados del Constituyente de 1916, porque se trataba de experiencias prácticas en el contexto nacional, de la instauración de esta forma de sufragio.

Para algunos diputados, como Félix Palavicini, el Constituyente tendría como propósito legitimar las reformas que se habían logrado a través de la vía revolucionaria, pero también la de revisar otras cuestiones constitucionales, una de ellas era la cuestión del sufragio y las elecciones, que ya habían sido atendidas por la XXV Legislatura durante el gobierno de Madero, pero que tras su muerte y el reacomodo de las fuerzas políticas del país, ameritaban discutirse nuevamente.

En su declaratoria ante el Congreso Constituyente del 1o. de diciembre de 1916, el presidente Venustiano Carranza expuso que para que el ejercicio del derecho al sufragio fuera una positiva y verdadera manifestación de la soberanía nacional, era indispensable que fuera general, igual para todos libre y directa, condiciones todas necesarias para hacer valer la voluntad clara y manifiesta del pueblo. Sin embargo, también advirtió que apegándose a la teoría política el derecho electoral sólo debía otorgarse a quienes tuvieran plena conciencia política, y negarse a las masas ignorantes.

Para entonces el voto directo ya había sido otorgado, desde el gobierno de Madero, y en opinión de Carranza, dado el papel tan destacado que habían tenido las clases ignorantes en la revolución contra la dictadura, y por haber sufrido más directamente la crueldad del despotismo, no podía negárseles el derecho al sufragio. Bajo este discurso el voto directo y universal otorgado al pueblo era un caso de excepción, una concesión ineludible para no contrariar la revolución popular, que hubiera exigido racionalmente, bajo otro escenario, que los ciudadanos tuvieran la instrucción necesaria para conocer la importancia de la función electoral.

Este ánimo de recelo hacia los efectos que tendría la participación de las masas populares en las elecciones sobre las dinámicas políticas del país, estuvo también presente en la discusión del artículo 35, que establecía las

44 Constitución del Estado de Chihuahua, 1858, en Nueva colección de Leyes del estado de Chihuahua, en virtud del decreto de 19 de enero de 1880. Revisada y aprobada por el H. Congreso del mismo estado, y decretada con fecha de 31 de de julio del citado año, pp. 5-24. 
Este libro forma parte del acervo de la Biblioteca Jurídica Virtual del Instituto de Investigaciones Jurídicas de la UNAM

prerrogativas del ciudadano de votar y ser votado. El dilema fundamental expuesto por el diputado Esteban Calderón, era si valía la pena poner en riesgo los intereses de la nación y el afianzamiento del poder, logrado no por el sufragio efectivo ni el voto directo, sino por la homogeneidad lograda en el gobierno y el Congreso mismo a partir del sometimiento de la reacción por la fuerza de las armas, por mantener el principio del sufragio ilimitado.

Para Calderón, era claro que de acuerdo al plano teórico, el pueblo mexicano, por su alto nivel de analfabetismo, no estaba preparado para asumir el voto universal. El sufragio efectivo, universal y directo, era un logro conquistado por los sectores sociales bajos que habían hecho triunfar la revolución, pero con el tiempo la reacción se volvería a organizar, y entonces, volvería a atacar abiertamente a los verdaderos hombres de la revolución. Esto forzaría al partido liberal a recurrir al fraude electoral para afianzar el poder, y esto llevaría a la dictadura militar.

\section{CONCLUSIONES}

En el discurso de los diputados constituyentes de 1857 el concepto de democracia aparecía asociado al de liberalismo, en la invocación que hacían de la soberanía popular como fundamento del nuevo régimen que se estaba constituyendo; sin embargo, la mayoría decidió adoptar sólo algunos principios democráticos, que garantizaran la utilización del pueblo como elemento legitimador de la representación popular, sin otorgarle un verdadero poder de decisión político-electoral. Esto garantizó el mantenimiento de los mecanismos de control político electoral que habían operado hasta entonces bajo el sistema del voto indirecto.

El rechazo al voto directo no tenía un fundamento nuevo, simplemente era la aplicación del sentido práctico, el precepto teórico de la soberanía del pueblo expresada a partir del sufragio directo, era impracticable para la realidad del país. Sin embargo, también debe considerarse que a casi medio siglo de funcionar el voto indirecto en México, se había vuelto en parte de la cultura política del país, que entrañaba prácticas de negociación política y de regulación del acceso al poder, entre minorías que constituían una elite del poder político, social, económico e intelectual, que implicaba la exclusión de los sectores populares de la disputa por el poder, y que habían encontrado en el voto indirecto una fórmula para conciliar de alguna forma el dogma liberal de la representación del pueblo, con el interés de mantener bajo su esfera de acción el control del acceso al poder político. Poner la deci- 
Este libro forma parte del acervo de la Biblioteca Jurídica Virtual del Instituto de Investigaciones Jurídicas de la UNAM

sión de cómo se constituiría el gobierno en manos de las masas, implicaba un cambio en el juego político que venía a complicar el escenario de la disputa política, riesgo que decidieron no tomar.

El voto directo aparecía como algo ya resuelto en el constituyente de 1916, debido a que había sido uno de los logros de la impronta revolucionaria y el triunfo del proyecto de reforma político-electoral propuesta por Madero, aunque se mantenían posturas que aún consideraban que no había una cultura política propicia para otorgar a la ciudadanía una participación directa en la elección de sus autoridades.

\section{FUENTES PRIMARIAS}

Arrom, Silvia M., "Protesta popular en la Ciudad de México: el motín del Parián en 1828", en ARROM, Silvia y ORTOLL, Servando (coords.), Revuelta en las ciudades. Políticas populares en América Latina, México, Universidad Autónoma Metropolitana-El Colegio de Sonora-Miguel Ángel Porrúa, 2004.

CAPELlán, "Representación", 2002, en FERnÁNDEZ SEBASTián, Javier, Diccionario político y social del siglo XIX español, Madrid, Alianza Editorial, 2002.

Carmagnani, Marcelo, "La tensión entre libertad y poder en el constitucionalismo de 1850", en Noriega, Cecilia y Salmerón, Alicia, México: Un siglo de Historia Constitucional (1808-1917), México, Instituto Mora-Poder Judicial de la Federación, 2009.

Carmagnani, Marcelo y Hernández, Alicia, "La ciudadanía orgánica mexicana, 1850-1910", en SABATO, Hilda (coord.), Ciudadanía politica y formación de las naciones, México, Fondo de Cultura Económica-El Colegio de México, 2003.

Constitución del estado de Chihuahua, 1858, en: Nueva colección de Leyes del estado de Chihuahua, en virtud del decreto de 19 de enero de 1880. Revisada y aprobada por el H. Congreso del mismo estado, y decretada con fecha de 31 de de julio del citado año.

Constitución Política del Estado de San Luis Potosí. Año de 1861, sección X de las municipalidades, en Cañedo Gamboa, Sergio, Cien años de vida legislativa, el Congreso del estado de San Luis Potosí, 1824-1924, México, El Colegio de San Luis, 2000.

Diario de los Debates de la Cámara de Senadores del Congreso de los Estados Unidos Mexicanos, 1911-1912, disponible en: http://wrere.trife.gob.mx/sites/default/fi les/Parte38.pdf(fecha de consulta: 8 de septiembre de 2016).

Diario de los Debates del Congreso Constituyente de 1916-1917, t. I, México, Ediciones de la Comisión Nacional para la Celebración del Sesquicentenario 
Este libro forma parte del acervo de la Biblioteca Jurídica Virtual del Instituto de Investigaciones Jurídicas de la UNAM

de la Proclamación de la Independencia Nacional y del Centenario de la Revolución Mexicana, 1960.

El Imparcial, 6 de julio de 1912.

El Imparcial, 3 de junio de 1912.

Gantús y SALMERÓn (coords.), Prensa y elecciones. Formas de hacer política en el México del siglo XIX, México, Instituto de Investigaciones Dr. José María Luis Mora-Conacyt-Instituto Federal Electoral, 2014.

Gueniffey, Patrice, La Revolución francesa y las elecciones. Democracia y representación a finales del siglo XVIII, México, Instituto Federal Electoral-Fondo de Cultura Económica, 2001.

GuerRA, François Xavier, México: del antiguo régimen a la Revolución, 2a. ed., México, Fondo de Gultura Económica, 1991.

IRUROZQUI, Marta, "Sobre leyes y transgresiones: reformas electorales en Bolivia, 1826-1952, en MALAMUD, Carlos (coord.), Legitimidad, representación y alternancia en España y América Latina: las reformas electorales (1880-1930), México, Fondo de Cultura Económica-El Colegio de México, 2000.

KNIGHT, Alan, La Revolución mexicana, México, Fondo de Cultura Económica, 2010.

Luna ARGudín, María, El Congreso y la política mexicana (1857-1911), México, Fondo de Cultura Económica-El Colegio de México, 2006.

MARVÁN LABORDE, Ignacio, "El Constitucionalismo de 1917: rupturas y continuidades", en Noriega, Cecilia y SALmerón, Alicia (coords.), México: un siglo de historia constitucional (1808-1917), 2010.

MEDina PEÑA, Luis, "El maderismo: la oportunidad perdida", en MEDINA PeÑA, Luis (coord.), El siglo del sufragio, México, Fondo de Cultura Económica-Consejo Nacional para La Cultura y las Artes-Instituto Federal Electoral-Consejo Nacional de Ciencia y Tecnología, 2010.

Monitor Republicano, "Crónica parlamentaria”, 19 de septiembre de 1856, p. 4.

OchOA CAMPOS, Moisés, Los debates sobre la adopción del sufragio universaly el voto directo, México, Cámara de Diputados, 1971.

PeÑa Guerrero, María Antonia, “Mais cette souveraineté qu' est-elle devenue? La influencia del orleanismo en la legislación electoral de la España liberal", en CABALLERO LÓPEZ, José Antonio et al. (eds.), El debate constitucional en el siglo XIX. Ideología, oratoria y opinión pública, Madrid, Fundación Práxedes Mateo-Sagasta-Marcial Pons, 2015.

Reyes Heroles, Jesús, El liberalismo mexicano, México, Fondo de Cultura Económica, t. II, 1994. 
Este libro forma parte del acervo de la Biblioteca Jurídica Virtual del Instituto de Investigaciones Jurídicas de la UNAM

Rosanvallon, Pierre, Por una historia conceptual de lo politico, México, Fondo de Cultura Económica, 2003.

TAPIA, Regina, "Competencia electoral, honor y prensa. México en 1857", en Gantús, Fausta y SAlmerón, Alicia (coords.), Prensa y elecciones. Formas de hacer política en el México del siglo XIX, México, 2014.

Zarco, Francisco, Historia del Congreso Constituyente de 1857, México, Secretaría de Gobernación-INEHRM, 2009. 
Este libro forma parte del acervo de la Biblioteca Jurídica Virtual del Instituto de Investigaciones Jurídicas de la UNAM

\title{
EL NOMBRAMIENTO DE LOS MINISTROS DE LA SUPREMA CORTE DE JUSTICIA DE LA NAGIÓN EN EL CONGRESO CONSTITUYENTE DE 1916-1917
}

\section{Francisco RAMOS QUIROZ*}

\begin{abstract}
Sumario: I. Presentación. II. Antecedentes de la necesidad de reformar el Poder Fudicial. III. El nombramiento de los ministros de la Suprema Corte de Justicia de la Nación en el Constituyente de 1916-1917. IV. Conclusiones. V. Fuentes.
\end{abstract}

\section{PRESENTACión}

La justicia ha sido un tema de suma importancia en cualquier sociedad, desde la antigüedad hasta nuestros días. El propio San Agustín desde el siglo V d. C. se refirió a la misma en La ciudad de Dios asentando de manera contundente: "Sin la virtud de la justicia, ¿qué son los reinos sino unos execrables latrocinios?". ${ }^{1}$ En la actualidad y bajo la idea de división de poderes, la cuestión relacionada con la forma de nombrar a los integrantes de los órganos encargados de llevar a la práctica la justicia sigue siendo un tema polémico y en constante evolución.

Para nuestra participación en 1916 Rumbo a la Constitución de 1917, hemos decidido referirnos a un tema relacionado con el órgano encargado de impartir justicia en el ámbito federal, concretamente en el momento del Congreso Constituyente de 1916-1917, por lo que en este trabajo se analizará la forma en que fue abordado el tema del nombramiento de los minis-

* Doctor en derecho por la Universidad Autónoma de Aguascalientes. Doctor en ciencias sociales y jurídicas por la Universidad de Cádiz. Miembro del Sistema Nacional de Investigadores nivel I. Profesor en la Facultad de Derecho y Ciencias Sociales de la Universidad Michoacana de San Nicolás de Hidalgo.

1 San Agustín, La ciudad de Dios, introducción de Francisco Montes de Oca, 19a. ed., México, Porrúa, 2008, p. 97. 
Este libro forma parte del acervo de la Biblioteca Jurídica Virtual del Instituto de Investigaciones Jurídicas de la UNAM

tros de la Suprema Corte de Justicia de la Nación en aquel difícil momento en donde la independencia de la judicatura era fuertemente cuestionada.

Este trabajo se divide en dos partes, una primera destinada a la revisión de algunos antecedentes sobre la necesidad de reformar el Poder Judicial de la Federación, previo al establecimiento del Congreso Constituyente, y la segunda parte encaminada a la reflexión sobre la forma en que los diputados constituyentes abordaron el asunto relativo a la organización de la Suprema Corte de Justicia de Nación, especialmente respecto de la forma de elección de los ministros y el establecimiento de la inamovilidad judicial.

\section{ANTEGEDENTES DE LA NEGESIDAD DE REFORMAR EL PODER JUDICIAL}

Durante el Porfiriato el texto constitucional vigente fue la Constitución Federal de 1857, que tuvo aplicación hasta principios del siglo XX. En términos generales este documento constitucional respetó los postulados de la división de poderes, estableciendo la fórmula clásica de Legislativo, Ejecutivo y Judicial que había estado vigente desde las experiencias anteriores del siglo XIX, además incorpora un interesante catálogo de derechos del hombre.

En materia del Poder Judicial de la Federación, y concretamente respecto de su cabeza, como es la Suprema Corte de Justicia, la Constitución de 1857 estableció una novedad, pues por primera vez se previó un mecanismo de nombramiento de los ministros de la Corte a través de una elección indirecta en primer grado, al señalar el artículo 92: "Cada uno de los individuos de la Suprema Corte de Justicia durará en su encargo seis años, y su elección será indirecta en primer grado, en los términos que disponga la ley".

Los constituyentes de 1856-1857 mostraron confianza en la elección que se haría por parte del pueblo a través de la elección indirecta en primer grado, pues como refiere Francisco Zarco, al respecto se mencionó en el Congreso Constituyente:

No hay que temer que, aprobado el artículo, la Corte sea invadida por leguleyos y charlatanes y queden excluidos los jurisconsultos. No, el pueblo elegirá entre los abogados más dignos y más honrados, entre los hombres íntegros, que son la gloria de nuestro foro por su rectitud y su fama inmaculada. No hay que desconfiar tanto del pueblo. No hay que creer que mandará a la Corte curanderos y parteras y, si alguna vez se equivoca mandando un imbécil a la Corte, como suele mandarlos a otras partes, el mal es eterno, porque los magistrados van a ser amovibles aunque esta reforma será también combatida, sosteniéndose que el que una vez es magistrado, magistrado ha de ser toda 
Este libro forma parte del acervo de la Biblioteca Jurídica Virtual del Instituto de Investigaciones Jurídicas de la UNAM

su vida para poder ser independiente y justiciero. La elección y la renovación son excelentes garantías: los buenos serán reelectos, los malos no se perpetuarán en la magistratura y habrá así un estímulo a la probidad, sabiendo que todos están vigilados por la opinión pública y sujetos a su fallo. ${ }^{2}$

A pesar de la confianza del Congreso Constituyente, este importante cambio en la forma de realizar el nombramiento de los ministros de la Suprema Corte de Justicia que resultó toda una novedad, luego de haber sido probado recibió severas críticas por parte de intelectuales, entre las que podemos citar a Emilio Rabasa, quien se refirió a la forma de nombrar ministros mediante sufragio de la siguiente forma:

La teoría la reprueba, porque la elección popular no es para hacer buenos nombramientos, sino para llevar a los poderes públicos funcionarios que representen la voluntad de las mayorías, y los magistrados no pueden, sin prostituir la justicia, ser representantes de nadie, ni expresar ni seguir voluntad ajena ni propia. ${ }^{3}$

Aunque las críticas no se limitaron solamente a los teóricos del derecho, pues era amplio el sector que compartía esa desconfianza natural hacia la nueva forma de nombrar a los ministros de la Corte, de modo que no era un tema ajeno para algunos miembros del constituyente revolucionario de 1916-1917, que vieron en ese momento la posibilidad de realizar cambios. Un ejemplo de lo anterior es Félix Fulgencio Palavicini, quien años después del Congreso Constituyente dejó ver su postura crítica respecto de la elección popular de los miembros de la Suprema Corte al señalar:

Todos sabemos que la elección de magistrados a la Corte Suprema de Justicia hecha por el pueblo desde la Baja California hasta Quintana Roo, es absurda. Aparte de que los magistrados no debieran pertenecer a partido político alguno, para no crear otros intereses ni tener más compromisos que el interés de la justicia y la obligación de aplicarla rectamente, no pueden ser electos por toda la nación. Los magistrados siempre han sido el resultado de una elección fraudulenta, de un mejurge electoral confeccionado por el Ejecutivo en la Secretaría de Gobernación, y no podía ser de otra manera en un país de tan escasas vías de comunicación, de tan reducidos elementos de publicidad. ${ }^{4}$

2 Zarco, Francisco, Crónica del congreso extraordinario constituyente 1856-1857, estudio preliminar, texto y notas de Catalina Sierra Casasús, México, El Colegio de México, 1957, p. 713.

3 Rabasa, Emilio, La Constitución y la dictadura, estudio sobre la organización política de México, 10a. ed., México, Porrúa, 2006, p. 196.

4 Palavicini, Félix F., Historia de la Constitución de 1917, México, INEHRM-UNAM, Instituto de Investigaciones Jurídicas, 2014, t. I, p. 25. 
Este libro forma parte del acervo de la Biblioteca Jurídica Virtual del Instituto de Investigaciones Jurídicas de la UNAM

El texto del artículo 92 de la Constitución de 1857 no sufrió reformas, por lo que estuvo vigente durante todo el Porfiriato, hasta que el sistema cambió con la nueva Constitución en el siglo XX como resultado de la Revolución mexicana, iniciada en 1910 por Francisco I. Madero mediante el Plan de San Luis. En dicho plan Madero hace una crítica severa contra los tres poderes, incluido el Judicial, del cual refiere:

Tanto el poder Legislativo como el Judicial, están completamente supeditados al Ejecutivo; la división de poderes, la soberanía de los Estados, la libertad de los Ayuntamientos, y los derechos del ciudadano, sólo existen escritos en nuestra Carta Magna... la justicia, en vez de impartir su protección al débil, sólo sirve para legalizar los despojos que comete el fuerte; los jueces, en vez de ser los representantes de la justicia, son agentes del Ejecutivo, cuyos intereses sirven fielmente. ${ }^{5}$

Lo anterior llama la atención si tomamos en cuenta que durante los movimientos del siglo XIX era normal que el Poder Judicial fuera respetado, pues regularmente los conflictos eran contra los poderes Legislativo y Ejecutivo, pero en esta ocasión se incluyó a la judicatura, respecto de la cual había un descontento en varios sectores de la sociedad, pues se le consideraba una institución al servicio del presidente de la República.

Durante el desarrollo de la Revolución mexicana el propio Venustiano Carranza se pronunció a favor de un Poder Judicial independiente, inclusive esta idea había sido parte de su programa desde sus primeras experiencias políticas en Coahuila, ${ }^{6}$ pero ya durante el movimiento revolucionario llegó a referirse a la necesidad de lograr una verdadera independencia del Poder Judicial, tanto federal como en los estados, por lo que en las "Adiciones al Plan de Guadalupe", de finales de 1914, en el artículo 2o. hizo referencia a la necesidad de sentar las: "...bases para un nuevo sistema de organización del Poder Judicial independiente, tanto en la Federación como en los estados...". ${ }^{7}$ De modo que la problemática no había sido ajena al movimiento.

5 Plan de San Luis Potosí, en Tena Ramírez, Felipe, Leyes fundamentales de México 18082005, 24a. ed., México, Porrúa, 2005, pp. 732 y 733.

6 Krauze, Enrique, Puente entre siglos, Venustiano Carranza, México, Fondo de Cultura Económica, 1987, p. 16.

7 Artículo 2o. de las Adiciones al Plan de Guadalupe presentadas en Veracruz el 12 de diciembre de 1914, disponible en: http://wrwre.constitucion1917.gob.mx/work/models/Constitucion 1917/Resource/494/1/images/rev_const-47.pdf. 
Este libro forma parte del acervo de la Biblioteca Jurídica Virtual del Instituto de Investigaciones Jurídicas de la UNAM

\section{El NOMBRAMIENTO DE LOS MiNiSTROS DE LA SUPREMA CORTE DE Justiaia de LA NAGión EN EL Constituyente DE 1916-1917}

Cuando por fin el movimiento revolucionario constitucionalista había logrado avances importantes, Venustiano Carranza convocó a un nuevo Congreso Constituyente, mismo que se reunió a finales de 1916. En esta nueva etapa había retos importantes, mismos que tuvieron que ser atendidos por el Constituyente de 1916-1917, entre los cuales figuró el de establecer un Poder Judicial de la Federación con un alto grado de independencia respecto del Poder Ejecutivo, pues todavía pesaba en la memoria de los constituyentes la experiencia del Porfiriato y la idea de una sujeción absoluta de la judicatura a los intereses del presidente de la República.

El Congreso Constituyente se reunió en Querétaro y comenzó sus labores el 21 de noviembre de 1916. Venustiano Carranza entregó al Congreso el 1o. de diciembre su proyecto de Constitución, mismo que debería ser estudiado por éste en los meses siguientes. Dicho proyecto propuso que la Constitución de 1857 fuera reformada. Por lo que respecta al Poder Judicial se estableció en el proyecto presentado por el primer jefe del Ejército Constitucionalista que la Suprema Corte de Justicia se integraría por nueve ministros, que durarían cuatro años en el cargo siendo nombrados por el Congreso de la Unión en funciones de colegio electoral. ${ }^{8}$ Estos son los ejes sobre los cuales tendría que desarrollarse la discusión respecto del Poder Judicial.

$\mathrm{Al}$ interior del Congreso Constituyente se formó la Segunda Comisión de Constitución integrada por los diputados Paulino Machorro y Narváez, Heriberto Jara, Agustín Garza González, Arturo Méndez e Hilario Medina, ${ }^{9}$ A esta comisión que presentaba equilibrio entre moderados y jacobinos, ${ }^{10}$ le correspondía realizar, entre otros temas, el proyecto relativo al Poder Judicial, por lo que dio a conocer su propuesta sobre el asunto el 17 de enero de 1917.

Entre los cambios que operaron en el proyecto de la Segunda Comisión, respecto del texto presentado por Venustiano Carranza pueden señalarse los siguientes: se aumentó el número de ministros, de nueve a once, siendo

8 Proyecto de Constitución presentado por el primer jefe al Congreso Constituyente, en Tena Ramírez, Felipe, op. cit., pp. 789 y 790.

9 Diario de los Debates del Congreso Constituyente 1916-1917, 4a. reproducción facsimiliar de la edición de 1960, México, INEHRM-SEP-UNAM, Instituto de Investigaciones Jurídicas, 2014, t. I, p. 915.

10 Hernández Martínez, María del Pilar, El poder judicial federal en México. Dimensión histórica e institucional en los debates de 1917, México, Poder Judicial de la Federación, 2016, p. 8. 
Este libro forma parte del acervo de la Biblioteca Jurídica Virtual del Instituto de Investigaciones Jurídicas de la UNAM

la razón expresada por la Segunda Comisión la siguiente: "El número de ministros de la Corte se fijó en once, por parecer este número el más conveniente para conciliar las necesidades de la resolución por un número de magistrados que no sea exiguo, con las consideraciones de economía y de expedición en el despacho...". ${ }^{11}$ Por otra parte, a diferencia de los cuatro años de duración en el cargo de ministro de la Suprema Corte de Justicia que propuso Carranza, en el nuevo proyecto de la Segunda Comisión se incorporó el principio de inamovilidad del Poder Judicial, según el cual a partir de 1921 los ministros de la Suprema Corte, magistrados de circuito y los jueces de distrito no podrían ser removidos mientras observaran buena conducta, y solamente en caso contrario debería llevarse a cabo el juicio de responsabilidad respectivo a fin de poder destituirlos. ${ }^{12}$ Con este nuevo principio de inamovilidad judicial se buscaba integrar un órgano judicial más fuerte e independiente, pues a partir de su creación durarían cuatro años, es decir de 1917 a 1921, y a partir de esta fecha serían inamovibles. Las razones que argumentó la Comisión fueron las siguientes:

La Comisión ha adoptado el principio de inamovilidad del Poder Judicial, para garantizar la independencia más completa de los funcionarios respectivos y la buena administración de justicia. Este gran paso en el desarrollo de las instituciones, se dará de un modo definitivo en el año de 1920, porque los próximos cuatro años serán como un periodo de prueba para el personal que en ella funcione y se vea a las personas que es más conveniente entren en 1920 a formar el Poder Judicial completamente inamovible. ${ }^{13}$

Durante la 52a. sesión ordinaria del Congreso Constituyente, que tuvo lugar la tarde del sábado 20 de enero de 1917, inició el debate respecto de los artículos sobre el Poder Judicial establecidos en el proyecto presentado por la 2a. Comisión de Constitución. Como refiere el constituyente Juan de Dios Bojórquez: "En esta jornada dedicada al Poder Judicial, son principalmente los abogados quienes intervienen y a ellos atañe, más que a otros diputados, el asunto a debate". ${ }^{14}$

11 Diario de los Debates del Congreso Constituyente 1916-1917, cit., t. II, p. 570.

12 En ese sentido, el juicio de responsabilidad se llevaría a cabo tratándose de delitos comunes u oficiales, en el caso de los primeros la Cámara de Diputados fungiría como Gran Jurado y determinaría mediante votación si ha o no lugar a proceder contra el funcionario. Por su parte, cuando se tratara de delitos oficiales el Senado funcionaría como Gran Jurado, previa acusación de la Cámara de Diputados.

13 Diario de los Debates del Congreso Constituyente 1916-1917, cit., t. II, p. 570.

14 Bojórquez, Juan de Dios, Crónica del constituyente 1916-1917, cit., p. 340. 
Este libro forma parte del acervo de la Biblioteca Jurídica Virtual del Instituto de Investigaciones Jurídicas de la UNAM

En un primer momento el diputado por el Distrito Federal Rafael L. de los Ríos pidió la palabra para hacer una interpelación en el sentido de solicitar a la comisión autora del proyecto que explicara las razones que tuvo para establecer la inamovilidad de los ministros de la Corte, la cual calificó como un disparate..$^{15}$ Dicha interpelación no fue respondida en ese momento, pues como refirió el diputado Hilario Medina, eso era justo la materia del debate, por lo que la comisión respondería posteriormente. ${ }^{16}$ En tanto que el diputado queretano José María Truchuelo se sumó a la discusión y manifestó su postura crítica respecto del proyecto, del cual refirió que seguramente estaba inspirado en las ideas de Emilio Rabasa, pues señaló:

No me explico, repito, cómo la Comisión nos quiere hacer retroceder siglos y siglos para venir a sostener como principios de ese dictamen teorías que han sido ya cubiertas con el polvo del olvido y del desprecio jurídico. Si examinamos cuáles pueden haber sido esos motivos no encuentro otros, señores, sino la lectura de un libro reaccionario en muchos puntos: "La Constitución y la dictadura", de Emilio Rabasa. ${ }^{17}$

El diputado Truchuelo se refería a dos cosas, por una parte, a la idea de Rabasa de que el Poder Judicial no es un poder sino un departamento, ${ }^{18} \mathrm{y}$ por la otra, lo relativo a la inamovilidad del Poder Judicial. Sobre esta última se refirió de manera contundente al cuestionar:

¿Cómo puede establecerse en México la inamovilidad judicial cuando no tenemos ni siquiera un colegio de abogados que nos indique cuales son los verdaderos jurisconsultos; cuando no tenemos ni jurisprudencia establecida, cuando no hay absolutamente ninguna carrera judicial, cuando la jurisprudencia de Querétaro es distinta a la jurisprudencia de Guadalajara y a la de cualquier otro estado de la República, cuando no hay ni siquiera uniformidad? 19

15 Diario de los Debates del Congreso Constituyente 1916-1917, cit., p. 701.

16 Idem.

17 Idem.

$18 \mathrm{Al}$ respecto señala Rabasa: "El departamento judicial nunca es un poder, porque nunca la Administración de Justicia es dependiente de la voluntad de la nación; porque en sus resoluciones no se toman en cuenta ni el deseo ni el bien públicos, y el derecho individual es superior al interés común; porque los tribunales no resuelven lo que quieren en nombre del pueblo, sino lo que deben en nombre de la ley, y porque la voluntad libre, que es la esencia del órgano poder, sería la degeneración y la corrupción del órgano de la justicia”. Rabasa, Emilio, op. cit., p. 188.

19 Diario de los Debates del Congreso Constituyente 1916-1917, cit., pp. 705 y 706. 
Este libro forma parte del acervo de la Biblioteca Jurídica Virtual del Instituto de Investigaciones Jurídicas de la UNAM

Para apoyar la postura anterior y evidenciar los peligros de la inamovilidad judicial en una nación carente de una administración de justicia organizada y probada, el diputado Truchuelo se refirió a un teórico del derecho, el rumano Christodul J. Suliotis, del cual traía la obra y sobre la misma expresó citándolo:

Para que exista el principio de inamovilidad se necesita que antes esté perfectamente organizada la administración de justicia; que se hayan dado pruebas inequívocas de que se tiene comprobado por una experiencia secular, completa madurez de criterio jurídico; de que existen magistrados que gocen de fama intachable, cuyas ideas estén perfectamente orientadas y que no puedan variar su opinión, porque su prestigio les impide tener ligas y estar dependiendo de algún otro Poder; pero en los países jóvenes, textualmente lo dice, en aquellos países en donde todavía está todo por hacerse, en aquellos países que están ensayando diversos sistemas y en donde la magistratura no puede presentar un carácter de madurez, sería el absurdo mayor establecer el principio de la inamovilidad judicial. ${ }^{20}$

Por lo anterior, en lugar de la inamovilidad judicial, el diputado Truchuelo propuso aumentar la duración de los ministros de la Corte de cuatro a ocho años. Respecto de la designación de los ministros establecida en el proyecto, Truchuelo se manifestó en el sentido de que ésta en vez de ser llevada a cabo por las cámaras de diputados y senadores, fuera por voto popular y que el número de magistrados fuera de uno por cada entidad federativa.

El diputado por Guanajuato Fernando Lizardi se unió al debate para responder al licenciado Truchuelo, argumentando que al ser un número tan grande de ministros la Corte sería una asamblea política, y los tribunales, en cambio, deben ser poco numerosos para perder el carácter político, por lo que refirió:

Pero quiero suponer por un momento que hubiera necesidad de ampliar más el número de magistrados de la Corte, como nos propone el licenciado Truchuelo, a 31; esto tendría un inconveniente gravísimo: las asambleas demasiado numerosas toman, por regla general, un carácter político, y los tribunales precisamente deben ser poco numerosos para hacerles perder su carácter político, para que cumplan debidamente con su misión, que es la de administrar justicia y no la de hacer política. ${ }^{21}$

\footnotetext{
20 Ibidem, p. 706.

21 Ibidem, pp. 707 y 708.
} 
Este libro forma parte del acervo de la Biblioteca Jurídica Virtual del Instituto de Investigaciones Jurídicas de la UNAM

El diputado Alberto L. González, representante del estado de Hidalgo, se unió a las filas de los que estaban a favor de la elección popular, misma que en su opinión debería basarse en una ley electoral bien elaborada. Su negativa guardaba relación con la siguiente idea que expresó: "Los congresos, al nombrar a los magistrados, al elegirlos y al verificar todos los actos que esta ley les dice, siempre tendrán en cuenta al partido político y nunca los méritos de los abogados o de las personas conocedoras de la ciencia que deban ir a ocupar la magistratura". ${ }^{22}$ De igual forma apoyó al diputado Truchuelo en la idea de elegir a un ministro por cada estado.

El tabasqueño Rafael Martínez de Escobar, por su parte, resaltó la importancia del Poder Judicial, refutando a Rabasa. En su opinión, a pesar de que la función de la Corte es eminentemente política, el origen de ésta no debía serlo, por lo que con una postura muy crítica y radical se manifestó en contra de la elección popular y de la intervención del Ejecutivo en el nombramiento. Propuso imitar en ese sentido a otras naciones como Bolivia, en donde los ministros se nombraban por parte de la Cámara de Diputados, a partir de una terna del Senado. De manera enfática manifestó su inconformidad por la participación del ejecutivo en el nombramiento de los ministros de la Corte al señalar:

Debemos, pues, pensar la forma más conveniente de elegir a los magistrados, pero de ninguna manera le demos intervención al poder Ejecutivo. Si nosotros establecemos que el poder Ejecutivo tenga intervención en el nombramiento de los magistrados de la Suprema Corte, sepamos de una vez por todas, o declaremos honradamente que no hemos venido aquí a hacer una labor sana, independiente y eficaz de gobierno, de gobierno democrático; en cambio; si podría decirse que la haremos de gobierno perfectamente dictatorial, de gobierno autocrático; pero si en vuestros cerebros palpita el democratismo, si existe en vosotros la idea de que se vaya difundiendo el pensamiento libertario y de que la Suprema Corte de Justicia cumpla con su elevada función, con su misión noble, no dejemos intervención al Poder Ejecutivo al integrarla, porque el Poder Ejecutivo solamente designará como magistrados a aquellos que desee que vayan a hacer lo que él quiera en las delicadas cuestiones de interés particular y general de que tenga que conocer aquella suprema institución. ${ }^{23}$

La participación sobre el Poder Judicial era nutrida, pues como apunta Bojórquez:

\footnotetext{
22 Ibidem, p. 710.

23 Ibidem, pp. 720 y 721.
} 
Este libro forma parte del acervo de la Biblioteca Jurídica Virtual del Instituto de Investigaciones Jurídicas de la UNAM

Los abogados del Congreso se creen todos con la obligación de hablar. Ha llegado el momento en que deberán sacar a relucir sus conocimientos en Derecho. La oportunidad es única y así, cuando el debate parecía agotado, fueron surgiendo nuevos oradores porque todos los jurisconsultos querían "alumbrar" con sus luces la organización revolucionaria del Poder Judicial. ${ }^{24}$

Por ello, no resultaban raras las frecuentes referencias directas de autores de la época, tanto para apoyar sus comentarios como para criticar a los contrarios.

Las discusiones siguieron en la 53a. sesión ordinaria celebrada el mismo 20 de enero por la noche. En esa ocasión el diputado veracruzano Silvestre Aguilar se sumó a las críticas al proyecto y abogó por el establecimiento de la elección popular de los ministros de la Suprema Corte de Justicia. Después de haber escuchado todos los comentarios en contra del proyecto, por fin hizo su aparición el presidente de la Segunda Comisión de Constitución, el jalisciense Paulino Machorro y Narváez, quien naturalmente salió en defensa del proyecto y señaló que la función del magistrado es diversa de la del diputado o senador en virtud de que el magistrado no representa a nadie, pues únicamente se elige a quien se considera poseedor de ciertas cualidades para ejercer el cargo. Sobre la elección popular de los ministros de la Suprema Corte señaló:

Los electores, encontrándose sin conocimientos directos de las personas, tendrán que acudir al consejo, a la dirección de alguno otro que tenga más conocimientos, y ¿quién tiene mayores conocimientos en materia de Derecho en las poblaciones pequeñas que son las que dan mayoría de votos? Los tinterillos. Pues a los magistrados de la Corte los elegirían los tinterillos. Este es el resultado que vendría a dar la elección popular. ${ }^{25}$

Sin duda el punto más crítico era justamente la participación del Ejecutivo en el nombramiento de los ministros, al respecto señaló que con ello se favorecía la búsqueda del equilibrio de un poder con otro, además de que podría ser útil que el Ejecutivo presentara alguna candidatura, sin que el Congreso estuviera obligado a votarla, pues estableció:

En cuanto a la intervención del Poder Ejecutivo, la Comisión la ha aceptado, porque se tuvo en cuenta, no solamente el equilibrio de un Poder con otro, sino también que prácticamente puede ser útil que el Ejecutivo presente una

24 Bojórquez, Juan de Dios, op. cit., p. 344.

25 Diario de los Debates del Congreso Constituyente 1916-1917, cit., p. 728. 
Este libro forma parte del acervo de la Biblioteca Jurídica Virtual del Instituto de Investigaciones Jurídicas de la UNAM

candidatura sin obligación, por supuesto, para el Congreso, de votar aquella. El Congreso queda en libertad de no aceptarla; es simplemente una orientación que puede recibir, con el fin de que aquellas personas que en la magistratura y que en grados inferiores se han distinguido puedan tener acceso a la Suprema Corte de Justicia, así como a los demás empleos de la judicatura. ${ }^{26}$

El representante por Puebla, David Pastrana Jaimes, se agregó al debate con una proposición diferente, una elección indirecta a cargo de los ayuntamientos, con la finalidad de evitar la intervención del Ejecutivo y que al mismo tiempo favoreciera la participación de los abogados de las provincias y disminuyera la concentración de abogados del Distrito Federal. ${ }^{27}$ Esta propuesta, aunque original, no tuvo eco en los congresistas.

Ante la negativa de los diputados en contra del proyecto, nuevamente un miembro de la Segunda Comisión de Constitución se unió al debate a favor del proyecto, en este caso el diputado guanajuatense Hilario Medina. Además de manifestarse a favor de la inamovilidad, explicó que la participación del Ejecutivo sería únicamente para proponer, si lo consideraba necesario, algún candidato o candidatos, siendo el Congreso el que decidiría finalmente, de esa forma se respetaría la voluntad popular a través de la elección indirecta.

Resulta claro que en la discusión sobre el Poder Judicial uno de los temas más importantes fue la forma de nombramiento de los ministros de la Suprema Corte de Justicia. Al respecto, las dos posturas principales manifestadas por los diputados del constituyente fueron, por una parte, a favor de la elección popular de los ministros de la Corte y, por la otra, aquellos que se mostraban a favor de una elección a través del Congreso de la Unión, como lo establecía el proyecto de la Segunda Comisión de Constitución o inclusive mediante la participación de los ayuntamientos.

Otro tema álgido fue el relativo a la inamovilidad de los miembros de la Suprema Corte de Justicia, es decir, el carácter vitalicio del cargo. También fue arduamente discutida la participación del Ejecutivo en la elección de los miembros de la Corte. Sobre esto último debemos tomar en cuenta que aún pesaba en los constituyentes la idea de un presidente omnipotente y dictador, producto de perpetuación en el poder por parte de Porfirio Díaz y aquella percepción de una Suprema Corte de Justicia subordinada totalmente a éste.

$\mathrm{Al}$ calor de los intensos debates y durante la 54a. sesión ordinaria celebrada la tarde del domingo 21 de enero de 1917, la Segunda Comisión

\footnotetext{
26 Ibidem, pp. 728 y 729.

27 Ibidem, p. 733.
} 
Este libro forma parte del acervo de la Biblioteca Jurídica Virtual del Instituto de Investigaciones Jurídicas de la UNAM

de Constitución decidió retirar el proyecto para reelaborarlo tomando en cuenta las opiniones, principalmente sobre los puntos referidos anteriormente, pero dejando en claro cuáles serían las modificaciones para evitar mayores complicaciones. Por lo que el diputado Paulino Machorro y Narváez asentó de manera contundente:

Señores diputados: habiéndose acercado los firmantes de la iniciativa sobre la adopción de un nuevo sistema electoral del Poder Judicial de la Federación, la comisión ha hablado con ellos y se ha llegado al siguiente acuerdo, que sometemos a la deliberación de la Cámara, con el fin de conocer su opinión antes de redactar el dictamen y no tener que presentarlo y volver a retirarlo. Los puntos son los siguientes: el número de magistrados será el de once. Sistema electoral: las legislaturas de los estados proponen un candidato y el congreso elige dentro de esos candidatos los que deban ser; no interviene el Ejecutivo. Tercero: el periodo de prueba para llegar a la inamovilidad y ver si conviene, es de seis años hasta 1923; de manera que en estos seis años se verá si conviene o no este sistema, el que también en este lapso de tiempo podrá discutirse en libros, en la prensa y por otros medios análogos. ${ }^{28}$

De modo que en esta intervención se sentaban las bases de lo que sería presentado en el proyecto corregido por la Segunda Comisión de Constitución y que finalmente permitiría arribar a un consenso. Todavía en este punto el diputado michoacano Francisco J. Mújica sugirió que el periodo de seis años para probar a los ministros antes de nombrarlos vitalicios, se dividiera en dos periodos, uno primero de cuatro y otro posterior de dos años, ${ }^{29}$ lo cual parece haber tenido eco en los redactores del proyecto quienes efectivamente dividieron el periodo en dos, pero a la inversa de lo propuesto por Mújica, pues en la versión final quedó un periodo de dos años al inicio, esto es, de 1917 a 1919, y otro de cuatro años, de 1919 a 1923.

El proyecto se retiró para ser corregido y se presentó durante la misma sesión, pues mientras estaba listo los diputados aprovecharon para discutir el artículo 30 de la Constitución. Así, una vez concluido se presentó en los términos señalados y finalmente se llevó a cabo la votación sobre los artículos discutidos que guardaban relación con el Poder Judicial, los cuales fueron aprobados la noche del domingo 21 de enero de 1917 por una mayoría casi absoluta de los participantes, pues en lo general los artículos relativos al Poder Judicial se aprobaron por los 150 diputados presentes, y solamente el artículo 94 tuvo dos votos en contra, los de José M. Truchuelo y Rafael L.

\footnotetext{
28 Ibidem, p. 755.

29 Idem.
} 
Este libro forma parte del acervo de la Biblioteca Jurídica Virtual del Instituto de Investigaciones Jurídicas de la UNAM

de los Ríos; en tanto que el artículo 96 solamente tuvo un voto en contra, el del diputado Truchuelo.

De esta forma se abordó por parte del Congreso Constituyente la cuestión relacionada con la Suprema Corte de Justicia de la Nación, lo cual no llevó más de cinco días en total, aunque no debemos perder de vista que el propio decreto expedido por Carranza el 14 de septiembre de 1916, que reformaba el de 12 de diciembre de 1914, señalaba en su artículo 6o. que el Congreso Constituyente debía dedicarse a su objetivo sin poder exceder el término de dos meses, lo cual resultaba por demás complicado, pues elaborar una Constitución no es tarea simple, y menos aún en un contexto como el que se vivía en donde los diferentes actores no se ponían de acuerdo. Bien cabe aquí la cita de José C. Valadés, para quien: "No fueron extrañas las prisas al Congreso Constituyente. No todas las condiciones del país quedaron debidamente examinadas. No se dio la medida legislativa necesaria para poder determinar los efectos de la ley. Las realidades continuaron en poder de la intuición. Lo popular sustituyó a lo clásico. Olvidáronse u omitiéronse los articulados de la Constitución de 1857...". ${ }^{30}$ Sin duda que en materia del Poder Judicial efectivamente se olvidaron y omitieron los artículos de la Constitución de 1857, pues hubo una ruptura importante en el tema al ser modificado de manera sustancial todo lo relativo a los ministros de la Corte por parte del Constituyente.

Los trabajos del Congreso Constituyente continuaron y finalmente el 5 de febrero de 1917 fue promulgada la Constitución Política de los Estados Unidos Mexicanos, iniciando con ello una nueva etapa en nuestra historia constitucional. Sobre la organización del Poder Judicial el nuevo texto estableció:

Art. 94.- Se deposita el ejercicio del Poder Judicial de la Federación en una Suprema Corte de Justicia y en Tribunales de Circuito y de Distrito cuyo número y atribuciones fijará la ley. La Suprema Corte de Justicia de la Nación se compondrá de once ministros y funcionará siempre en tribunal pleno, siendo sus audiencias públicas...

Cada uno de los ministros de la Suprema Corte designados para integrar ese poder en las próximas elecciones, durará en su encargo dos años; los que fueren electos al terminar este primer periodo durarán cuatro años y, a partir del año de 1923, los ministros de la Corte, los magistrados de Circuito y los

30 Valadés, José C., Historia general de la Revolución mexicana, México, Miguel Ángel PorrúaH. Cámara de Diputados LXII Legislatura, 2013, t. III, p. 347. 
Este libro forma parte del acervo de la Biblioteca Jurídica Virtual del Instituto de Investigaciones Jurídicas de la UNAM

jueces de Distrito sólo podrán ser removidos cuando observen mala conducta y previo el juicio de responsabilidad respectivo... ${ }^{31}$

Mediante este artículo se organizó la Suprema Corte integrada por once ministros, con la característica de que funcionaría siempre en pleno, lo cual se mantuvo hasta que se llevó a cabo una reforma posterior en $1928 .{ }^{32}$ El otro aspecto importante sobre la Corte referido en este artículo fue el establecimiento de la inamovilidad judicial, misma que consistía en que a partir de 1923 los miembros de la Corte no podrían ser removidos de su cargo, salvo que observaran mala conducta y mediante juicio. En este sentido, los ministros electos a partir de 1917 durarían dos años en el cargo, es decir, hasta 1919, posteriormente los que resultaran electos para el periodo siguiente durarían cuatro años, esto era hasta 1923 y a partir de esa fecha los nuevos ministros designados serían inamovibles.

El artículo 96 de la Constitución Política de los Estados Unidos Mexicanos establecía lo siguiente:

Los miembros de la Suprema Corte de Justicia de la Nación serán electos por el Congreso de la Unión en funciones de Colegio Electoral, siendo indispensable que concurran, cuando menos, las dos terceras partes del número total de diputados y senadores. La elección se hará en escrutinio secreto y por mayoría absoluta de votos. Los candidatos serán previamente propuestos, uno por cada Legislatura de los Estados, en la forma que disponga la ley local respectiva. ${ }^{33}$

Conforme al artículo anterior se optó por una elección indirecta a cargo del Congreso de la Unión, con lo cual quedó en el pasado el sistema de elección indirecta en primer grado a cargo de los electores. La otra cuestión importante en este artículo es que se eliminó totalmente la intervención del Ejecutivo, pues como pudo observarse en los debates del Congreso Constituyente, la mayoría de diputados se mostraban reacios a la participación del presidente de la República en el nombramiento de los miembros del alto tribunal. De esta forma, el nuevo orden constitucional estableció una Suprema Corte electa por el Congreso de la Unión a propuesta de las legislaturas de los estados, sin participación alguna del Ejecutivo.

31 Constitución Política de los Estados Unidos Mexicanos, que reforma la del 5 de febrero de 1857, Diario Oficial de la Federación, t. V, 5 de febrero de 1917, 4a. época, núm. 30, p. 156.

32 Sobre esta reforma puede verse el texto: Zaraus López, Héctor L., Álvaro Obregón y la reforma a la Suprema Corte de fusticia de la Nación en el año de 1928, México, Suprema Corte de Justicia de la Nación, 2016.

33 Constitución Política de los Estados Unidos Mexicanos, cit., p. 156. 
Este libro forma parte del acervo de la Biblioteca Jurídica Virtual del Instituto de Investigaciones Jurídicas de la UNAM

Los primeros ministros de la Suprema Corte de Justicia de la Nación nombrados para el periodo de 1917 a 1919 fueron los licenciados: Enrique M. de los Ríos, Enrique Colunga, Victoriano Pimentel, Agustín del Valle, Enrique García Parra, Manuel E. de la Cruz, Enrique Moreno, Santiago Martínez Alomía, José M. Truchuelo, Alberto M. González y Agustín Urdapilleta. ${ }^{34}$ Resulta curioso que justamente el diputado José M. Truchuelo fue nombrado ministro, a pesar de que fue el único constituyente que votó en contra de los artículos 94 y 96 que establecen la forma de nombramiento de los integrantes de la Corte, aunque dicho sea de paso, su nombramiento fue solamente para los dos primeros años, pues en el siguiente periodo ya no fue considerado.

Los ministros de la Suprema Corte Justicia de la Nación nombrados con carácter vitalicio el 26 de julio de 1923 fueron los licenciados: Salvador Urbina, Ricardo B. Castro, Victoriano Pimentel, Francisco Modesto Ramírez, Francisco Díaz Lombardo, Gustavo A. Vicencio, Ernesto Garza Pérez, Leopoldo Estrada, Sabino M. Olea, Jesús Guzmán Baca y Manuel Padilla. ${ }^{35}$

\section{GOnClusiones}

La Constitución Federal de 1857 estuvo vigente hasta principios del siglo XX, periodo durante el cual los ministros de la Suprema Corte de Justicia se nombraron por medio de una elección indirecta en primer grado, lo cual generó severas críticas por parte de diversos sectores que inclusive ponían en tela de juicio el papel del alto tribunal. Lo anterior se ve reflejado inclusive en el Plan de San Luis, en el que Madero arremetió contra el Poder Judicial, al cual consideraba como un órgano al servicio del presidente de la República.

Durante la Revolución mexicana el propio Venustiano Carranza se había pronunciado sobre la necesidad de establecer un Poder Judicial independiente, por lo que el Congreso Constituyente convocado por el primer jefe del Ejército Constitucionalista parecía la oportunidad perfecta para realizar cambios en la materia. De esta forma, el proyecto presentado por Carranza al Constituyente de Querétaro el 1o. de diciembre de 1916 establecía modificaciones importantes respecto de la Constitución de 1857, siendo el más importante lo relacionado con la forma de nombramiento de

34 Decreto relativo a la designación de los ministros que deben integrar la Suprema Corte de Justicia de la Nación de 29 de mayo de 1917, La Suprema Corte de fusticia sus leyes y sus hombres, México, 1985, p. 607.

35 Poder Judicial de la Federación, La Suprema Corte de Fusticia en el periodo del presidente Obregón (1920-1924), México, SCJN, 1996, p. 467. 
Este libro forma parte del acervo de la Biblioteca Jurídica Virtual del Instituto de Investigaciones Jurídicas de la UNAM

los ministros de la Corte, que ahora en vez de ser realizados por elección indirecta en primer grado a cargo de los electores, se proponía una elección realizada por el Congreso de la Unión.

Pero el Congreso Constituyente fue mucho más allá de lo que había propuesto el caudillo y la Segunda Comisión de Constitución presentó el 17 de enero su propuesta que modificaba el proyecto de Carranza en algunos puntos, entre ellos aumentó el número de ministros de 9 a 11. También se modificó la duración en el cargo, pues Carranza había propuesto cuatro años y la Comisión estableció en su proyecto que los ministros fueran inamovibles a partir de 1923. Con estas modificaciones la Comisión buscaba establecer un Poder Judicial más fuerte e independiente.

Los debates sobre el Poder Judicial iniciaron la tarde del sábado 20 de enero y continuaron la noche del mismo día, con una participación importante por parte de los abogados que integraban el Constituyente, participando en los mismos Rafael L. de los Ríos, José María Truchuelo, Fernando Lizardi, Alberto L. González, Rafael Martínez Escobar, Silvestre Aguilar, Paulino Machorro, David Pastrana e Hilario Medina. Los temas más importantes que se abordaron en las discusiones versaban sobre la forma de nombrar a los ministros de la Suprema Corte de Justicia, en donde hubo dos posturas principales, una a favor de la elección popular de los ministros de la Corte, y otra a favor de una elección a través del Congreso de la Unión como lo establecía el proyecto de la Segunda Comisión de Constitución. Hubo otras propuestas que no tuvieron eco en el Congreso, como aquella de realizar la elección mediante la participación de los ayuntamientos.

Otro tema que cobró relevancia en las discusiones fue el relacionado con la inamovilidad de los miembros de la Suprema Corte de Justicia, esto es, el carácter vitalicio del cargo. Y sin duda la discusión mayor guardó relación con la participación del Ejecutivo en la designación de los miembros de la Corte, lo cual resulta fácil de entender si recordamos que todavía pesaba en la memoria de los constituyentes aquella idea del presidente omnipotente con un Poder Judicial completamente subordinado.

Los debates se prolongaron a la sesión del domingo 21 de enero y en esa fecha se decidió retirar el proyecto por parte de la Segunda Comisión de Constitución para su reelaboración con base en las opiniones vertidas, principalmente sobre los puntos ya referidos. El mismo día pero durante la noche se presentó la nueva versión del proyecto de la Segunda Comisión de Constitución, misma que se sometió a votación y fue aprobada por una mayoría casi absoluta de votos. 
Este libro forma parte del acervo de la Biblioteca Jurídica Virtual del Instituto de Investigaciones Jurídicas de la UNAM

Finalmente la Constitución Política de los Estados Unidos Mexicanos fue promulgada el 5 de febrero de 1917, estableciendo una Suprema Corte de Justicia de la Nación bastante fortalecida y libre de cualquier injerencia del Ejecutivo, pues quedó integrada por 11 ministros que funcionaban siempre en Pleno. Los ministros nombrados a partir de 1923 serían inamovibles y su nombramiento se realizaría por el Congreso de la Unión en funciones de colegio electoral, sin participación alguna del presidente de la República, lo cual se mantuvo hasta la reforma constitucional de 1928 que promovió Álvaro Obregón y que terminó por subordinar completamente la Corte al Ejecutivo, pero esa es otra historia.

\section{FUENTES}

Bojórquez, Juan de Dios, Crónica del Constituyente 1916-1917, México, Universidad Michoacana de San Nicolás de Hidalgo-Miguel Ángel Porrúa, 2016.

Diario de los Debates del Congreso Constituyente 1916-1917, 4a. reproducción facsimiliar de la edición de 1960, México, INEHRM-SEP-UNAM, Instituto de Investigaciones Jurídicas, 2014, ts. I y II.

Diario Oficial de la Federación, t. V, 5 de febrero de 1917, 4a. época, núm. 30.

Hernández Martínez, María del Pilar, El poder judicial federal en México. Dimensión histórica e institucional en los debates de 1917, México, Poder Judicial de la Federación, 2016.

Krauze, Enrique, Puente entre siglos: Venustiano Carranza, México, Fondo de Cultura Económica, 1987.

PaLaVicini, Félix F., Historia de la constitución de 1917, t. I, México, INEHRMUNAM, Instituto de Investigaciones Jurídicas, 2014.

Poder Judicial de la Federación, La Suprema Corte de Justicia sus leyes y sus hombres, México, SCJN, 1985.

Poder Judicial de la Federación, La Suprema Corte de Justicia en el periodo del presidente Obregón (1920-1924), México, SGJN, 1996.

RABASA, Emilio, La Constitución y la dictadura, estudio sobre la organización política de México, 10a. ed., México, Porrúa, 2006.

Tena Ramírez, Felipe, Leyes fundamentales de México 1808-2005, 24a. ed., México, Porrúa, 2005.

VAladés, José C., Historia general de la Revolución Mexicana, t. III, México, Miguel Ángel Porrúa-H. Cámara de Diputados LXII Legislatura, 2013. 
Este libro forma parte del acervo de la Biblioteca Jurídica Virtual del Instituto de Investigaciones Jurídicas de la UNAM

Zaraus LóPEz, Héctor L., Álvaro Obregón y la reforma a la Suprema Corte de fusticia de la Nación en el año de 1928, México, Suprema Corte de Justicia de la Nación, 2016.

ZARCO, Francisco, Crónica del congreso extraordinario constituyente 1856-1857, estudio preliminar, texto y notas de Catalina Sierra Casasús, México, El Colegio de México, 1957. 
Este libro forma parte del acervo de la Biblioteca Jurídica Virtual del Instituto de Investigaciones Jurídicas de la UNAM

\title{
HIGIENE Y SALUD, DEREGHOS CONSTITUCIONALES: LAS ENFERMEDADES EN LA REVOLUGIÓN COMO PROBLEMA SOCIAL (1915-1918)
}

\author{
Luis Ángel VARGas REYNOSO*
}

SumARIO: I. El hambre, contexto de las enfermedades. II. De la falta de higiene a la salud como derecho en la Constitución de 1917. III. A manera de conclusión. IV. Fuentes.

Uno de los artículos más importantes de la Constitución de 1917 es el 123, el cual hace referencia a los derechos y obligaciones en el aspecto laboral; dentro de sus múltiples incisos, llama la atención el XII, XIV y XV, los cuales apuntan hacia aspectos de higiene y salud.

Existieron varias causas que conllevaron a tomar en cuenta condiciones higiénicas para prevenir enfermedades dentro de las fábricas y la vida cotidiana en torno a ellas: apariciones de padecimientos estomacales, infecciones en las vías respiratorias, hacinamiento de personas, extenuantes jornadas laborales... y, sobre todo, el desconocimiento de las posibles causas de las mismas. Otras razones pudieron haber sido la epidemia de tifoidea y la gripe española, que se dieron entre los años 1916-1918.

El objetivo de esta ponencia es analizar las enfermedades ocurridas en las regiones de la Ciénega de Chapala, específicamente en Jiquilpan y Sahuayo, y los Altos de Jalisco, particularmente en Lagos de Moreno, a fin de relacionar una posible causa que llevó a tomar medidas sobre una educación en higiene dirigida a la sociedad. Por ello, se plantean dos preguntas: ¿Cómo se vivió el proceso de las enfermedades en las regiones de la Ciénega y los Altos de Jalisco? La decisión de abordar mejores condiciones higiénicas

* Licenciado en historia y maestro en historia de México por la Universidad de Guadalajara. Profesor-investigador en la Universidad de la Ciénega del Estado de Michoacán de Ocampo. 
Este libro forma parte del acervo de la Biblioteca Jurídica Virtual del Instituto de Investigaciones Jurídicas de la UNAM

para plasmarlas en la Constitución de 1917, ¿fue debido, en parte, a tales padecimientos?

\section{EL HAMBRE, GONTEXTO DE LAS ENFERMEDADES}

Uno de los objetivos a analizar como antecedente a la Constitución de 1917, es el periodo de 1915-1917, donde el hambre azotó a la sociedad como consecuencia de los constantes conflictos venidos desde 1910. Sin embargo, para entender las causas que provocaron el hambre y, por ende, posteriores enfermedades, debemos analizar el contexto de la crisis económica que atravesó el país.

Habían pasado cuatro años de luchas, tanto militares como políticas, desde que Francisco I. Madero se pronunció en contra de Porfirio Díaz en 1910. A partir de 1914, las consecuencias de estos enfrentamientos fueron apareciendo de manera paulatina. Entonces, "los ritmos económicos eran diferentes, más lentos que los políticos y militares: sólo a fines de 1913 y a principios de 1914, los efectos acumulados del conflicto político empezaron a minar la vigorosa economía mexicana". ${ }^{1}$

La caída de Victoriano Huerta y el triunfo de los revolucionarios no significaron que los problemas habían terminado. La falta de una soberanía, es decir, un gobierno estable que fomentara cierto grado de seguridad en lo económico y político en la sociedad mexicana, comenzó a cobrar cuota con el desabasto de productos básicos, su carestía y acaparamiento; la exigencia de préstamos para contribuir a la guerra, la división entre Villa y Carranza, así como la puesta en circulación de billetes de emisión forzosa. Uno de los resultados de esta crisis fue la creciente aparición de bandas o gavillas, que se dedicaban a robar haciendas, ranchos y hasta poblaciones, causando estragos entre los habitantes de estos lugares, quienes se vieron reducidos aún más en la pobreza debido al despojo de sus bienes por parte de estos grupos delictuosos.

Otro de los problemas graves que resultaron por la convergencia de los factores antes mencionados fue el hambre. Trabajar el campo no era garantía de que se pudiera extraer mucho de la tierra, devastada, y mellada por la falta de alimentos. ${ }^{2}$

1 Knight, Alan, La Revolución mexicana. Del Porfiriato al nuevo régimen constitucional, México, Fondo de Cultura Económica, 2010, p. 1176.

2 Ibidem, p. 1188. 
Este libro forma parte del acervo de la Biblioteca Jurídica Virtual del Instituto de Investigaciones Jurídicas de la UNAM

Todo ello conllevó a que entre 1914 y 1918 se viviera una crisis económica que repercutió en robos, motines en contra de comerciantes, se perdieran bienes, cosechas e, incluso, que se llegara al grado de recurrir al trueque, con el objetivo de obtener lo necesario para vivir. México estaba sumergido en un estado lamentable, donde la miseria crecía constantemente. Un comerciante de la ciudad de Guadalajara manifestó lo siguiente:

...se comprende que la clase menesterosa ba [sic] ha tener que llegar a estremo de morir una que otra familia de ambre, pues a estas fechas ya se comienza a notar una miseria espantosa entre la clase media o sea la gente artesana, pues infinidad de talleres están totalmente paralisados por falta de empresa ó movimiento de los señores capitalistas. ${ }^{3}$

Al no existir una autoridad sólida que proporcionara seguridad a la sociedad, las consecuencias se reflejaban en una débil economía que no podía soportar el peso de las carestías, resultados de la falta de trabajo en el campo, los robos a pueblos y haciendas productoras, así como a la interrupción del flujo comercial. Las zonas más urbanizadas, en ese entonces, eran las que más se veían perjudicadas en la escasez de alimentos y con la circulación de billetes de emisión forzosa. A finales de julio de 1917, un diario llamado Flagelo describió en su columna editorial el panorama que, una vez más, se vivía en Guadalajara:

La ciudad encuéntrase literalmente plagada de pordioseros, de diversas edades que por todos sitios salen al encuentro de los transeúntes implorando la caridad pública.

La situación económica de nuestro pueblo es desesperante, y si el Gobierno no soluciona el conflicto, presenciaremos cuadros de miseria y desolación. ${ }^{4}$

De esta forma, el hambre se fue haciendo presente en la población. Es natural pensar que ante el debilitamiento del cuerpo por falta de comida, así como la casi nula cultura de higiene, comenzaron a brotar las enfermedades. Además, en cuanto a la ausencia de alimentos, la preocupación cen-

3 Archivo Histórico de Jalisco (AHJ). El señor Federico Castañeda, opina que el préstamo de 5 millones impuesto para gastos de guerra a varios ricos de Guadalajara, perjudicará a la clase proletaria. Guadalajara, septiembre 7 de 1914. Ramo: Gobernación. Asunto: no clasificado. Año: 1914.

4 Archivo de la Casa de Cultura Jurídica de Jalisco (ACGJJ). Fondo Jalisco. S. 1o. J. Penal. Serie: Amparo. SJ. PN. Año: 1917. Legajo 2. Expediente 67. Flagelo. Bisemanario Liberal Independiente, redactor en jefe: Manuel E. Acosta. t. I. Guadalajara, Jal., y 26 de julio de 1917, núm. I, p. 1. 
Este libro forma parte del acervo de la Biblioteca Jurídica Virtual del Instituto de Investigaciones Jurídicas de la UNAM

tral no era que la muerte sobreviniera del hambre misma, de forma directa, sino del transcurso angustioso que la inanición provocaba para llegar a la defunción. Es decir, las personas que vivieron los años del hambre durante la Revolución mexicana, sobre todo en 1916, estuvieron expuestas a las consecuencias fisiológicas provocadas por la falta de una alimentación adecuada. Como lo dice Gloria Franco, "el verdadero problema radica en que estaban subalimentados, lo que les hacía especialmente vulnerables a las enfermedades, al deterioro psicológico y a la muerte". ${ }^{5}$ La noción o idea de morir surge; sale libre del encierro represivo a la que las personas normalmente la someten. La muerte no se manifiesta sólo en el acto literal de dar el último aliento; la despedida comienza desde antes, cuando una persona ya no ve la seguridad de una ingesta de alimentos constante, por ejemplo. El hambre, visto desde esta perspectiva, es el generador de enfermedades que de pronto amenaza con reducir o cortar de tajo, la existencia de un humano. "El quebrantamiento de la salud suele separar ya a [algunos] del resto de los mortales". 6

Ahora, cabe interrogarse, ¿qué factores provocaron el hambre en los años de 1915-1917? Las constantes luchas durante el transcurso de la revolución, las muertes ocurridas por la misma guerra, las carestías, como resultado de una economía debilitada por las interrupciones del comercio y las actividades en el campo, los robos, además de enfermedades que asolaron, no sólo a México, sino a diversos países en el mundo (como el tifo), convergieron para encrudecer el hambre. Se trata de la pérdida de seguridad y "la pacificación interna de la sociedad, la protección del individuo frente a todo hecho violento no sancionado por el Estado, así como frente a la muerte por inanición".7

A raíz de la falta de alimentos necesarios, las personas recurrían a la súplica para ser ayudados, migraban, o bien, se unían a las filas revolucionarias o a las gavillas. Reiterando, no era la muerte por inanición el temor central, sino la deficiencia alimenticia; se trata de una exclamación implícita hacia la noción de verse encaminados a morir, de forma lenta, debido a la falta de comida. Aquí es cuando se pierde "la firme creencia en la inmortalidad personal — otros mueren, pero yo no-" ${ }^{8}$ Las intervenciones de

5 Franco Rubio, Gloria A., "El espectro del hambre", Cultura y mentalidad en la Edad Moderna, Sevilla, Mergablum Edición y Comunicación, 1999, p. 17.

6 Elias, Norbert, La soledad de los moribundos, México, Fondo de Cultura Económica, 1989, p. 8.

7 Ibidem, p. 14.

8 Ibidem, p. 7. 
Este libro forma parte del acervo de la Biblioteca Jurídica Virtual del Instituto de Investigaciones Jurídicas de la UNAM

haciendas y las sequías por las que atravesaron varias regiones, provocaron una escasez de semillas y ganado que se reflejó en la carestía y su acaparamiento, por parte de los comerciantes. En la zona Altos de Jalisco, no había maíz en San Julián; en Ojuelos, en marzo de 1915, era vendido el poco que quedaba a San Luis Potosí, a costa de los más pobres, lo que provocó altercados intermunicipales entre la facción villista. Las autoridades de San Diego de Alejandría rogaron al presidente municipal de Lagos de Moreno que les vendieran parte del maíz que acababa de llegar en tren. El hambre se vislumbró, además, en la aparición de una enfermedad llamada enteritis, para el caso particular de Lagos de Moreno. En la región Ciénega, los ataques de bandidos provocaron también problemas similares, como lo narraron algunos pobladores de Jiquilpan, Michoacán.

La carta de un sacerdote, Guadalupe Garibay, del 8 de noviembre de 1916, describió la difícil situación que se atravesaba: "Todo [es] muy caro, no hay que comer porque no quieren vender, hay una miseria aplastante". ${ }^{9} \mathrm{Ga}$ ribay afirmó que, de continuar así, no le quedaría más remedio que "pedir limosna para vivir". Sin comida, "una población mal alimentada está más expuesta al impacto de las enfermedades por su incapacidad para generar las defensas necesarias". ${ }^{10}$ María Barragán Martínez, originaria de Jiquilpan, en una entrevista afirmó que había muchos padecimientos, “...el tifo, la viruela, y luego pegó muy fuerte la gripe española; mucha gente que murió, mucha gente...". ${ }^{11}$ Este panorama tan delicado se vivió de alguna forma en gran parte del país. "La situación era difícil todavía en 1919; la producción de maíz fue inferior a la de 1906-1910, que había sido también baja". ${ }^{12}$ De acuerdo a Alan Knight, hubo numerosos informes sobre los constantes aumentos del precio del maíz, su escasez y acaparamiento a partir de 1915; siendo 1916 el año más crítico. Por ejemplo, en Aguascalientes, el precio del maíz, de costar 40 centavos en 1915 , aumentó a $\$ 2.50$ para septiembre de $1916 . .^{13}$

El mismo autor afirma que esos años sorprenden con su "impresionismo" en cuanto a la descripción que se hace sobre el hambre en la documentación. Y los casos particulares, que se verán a continuación, no saltan esa

9 Archivo Histórico de la Arquidiócesis de Guadalajara (AHAG). Carta de Guadalupe Garibay, donde describe la miseria que se vive en Lagos de Moreno. Sección: Gobierno. Serie: Parroquias/Lagos. Años 1911-1933. Las cursivas son mías.

10 Franco Rubio, Gloria A., op. cit., pp. 21 y 22.

11 Unidad Académica de Estudios Regionales (UAER), Archivo de Historia Oral (AHO).

Entrevista transcrita a María Barragán Martínez, Núm. 9, Sin Código, p. 29.

12 Kinght, Alan, op. cit., p. 1185.

13 Idem. 
Este libro forma parte del acervo de la Biblioteca Jurídica Virtual del Instituto de Investigaciones Jurídicas de la UNAM

regla. En octubre de 1917, el párroco de la Asunción en Lagos de Moreno, dijo que la situación del campo era lamentable:

Las fincas del campo estuvieron intervenidas y quedaron desmanteladas por la intervención, y después de recibirlas los dueños en estado lamentable, lejos de tener ventajas de ellas, por la falta de lluvias y por el hielo, han perdido las cosechas de dos años y se ven en la necesidad de vender el poco ganado que les dejaron para el pago de la grandes contribuciones. ${ }^{14}$

En el lapso de noviembre de 1914 a junio de 1915, varias haciendas fueron intervenidas por el gobierno villista. Mucha producción de cereales y ganado, provenientes de tales haciendas, fue destinado a las tropas que pasaban por Lagos, así como enviados a las que combatían a las fuerzas constitucionalistas, tanto en el centro como en el sur de Jalisco. Las consecuencias de dichas intervenciones son descritas arriba por Luis Macías, quien, además, hace mención de la falta de lluvias y heladas, como factores importantes para la pérdida de cosechas.

Pero incluso, desde mediados de 1915, el factor humano, en el aspecto del abandono del campo y la guerra, así como el clima, ya habían convergido para acarrear problemas en la falta de alimentos. Para muestra, tenemos un caso en Veracruz, donde el cónsul brasileño informó al secretario de estado, en Washington, sobre una alarmante escasez de comida, así como las inconveniencias causadas por las desesperadas luchas de los convencionistas para expulsar a los carrancistas. "No hay más maíz y gran escasez de artículos de primera necesidad en la ciudad; esto ha causado gran sufrimiento entre todas las clases y disturbios populares contra esta Delegación por falsos reportes de tener comida en abundancia en el depósito". ${ }^{15}$

Incluso, en Guadalajara, el cónsul Will B. Davis dijo en su informe del 27 de julio de 1915, que "las circunstancias de comida están creciendo más embarazosamente a diario". ${ }^{16} \mathrm{El}$ mismo Davis envió una copia del periódico Acción con la misma fecha, donde se informaba al público que la masa de maíz se vendería a mitad de precio; pero "el público debe convencerse de que el trigo es más nutritivo que el maíz". ${ }^{17}$ Esta última oración es un

14 AHAG. Carta de Luis Macías donde informa del estado lamentable de las fincas que fueron intervenidas en 1915 por el villismo. Sección: Gobierno. Serie: Parroquias/Lagos. Años: 1911-1933.

15 National Archive Washington (NAW). Carta del cónsul Brasileño Cardoso de Oliveira. 30 de junio de 1915.

16 NAW. Carta del cónsul Americano Will B. Davis. 27 de julio de 1915.

17 NAW. Acción. Diario de la tarde, Guadalajara, época II, año I, t. I, núm. 32, 27 de julio de 1915. 
Este libro forma parte del acervo de la Biblioteca Jurídica Virtual del Instituto de Investigaciones Jurídicas de la UNAM

signo de las dificiles circunstancias por las que se atravesaba en la población tapatía; así como una señal de debilitamiento por parte del gobierno, pues intentaban convencer a la población de una especie de efecto placebo. Pero también refleja, implícitamente, los síntomas de una sociedad desesperada, la cual no aceptaba el hecho de no poder conseguir cereal indispensable en la canasta básica.

Volviendo a los Altos de Jalisco, a finales del mismo año de 1915, el presidente municipal constitucionalista de Lagos de Moreno escribió:

Acatando el contexto de su Circular núm. 5 de 4 del corriente, recibida ayer, tengo el honor de informar á esa Superioridad, que en esta región las cosechas de cereales conceptuadas como artículos de primera necesidad, se perdieron en su totalidad, en virtud de falta de oportunidad en las llubias (sic). Por lo que toca a existencias anteriores con que pudiera subvenirse las necesidades del pueblo, debo manifestar, que desaparecieron por el bandidaje que en grande escala se ha desarrollado en el municipio, y que continua desarrollandose por la falta de elementos para destruirlo.

Protesto a Ud. mi respetuosa consideración.

Constitución y Reformas

Lagos de Moreno, diciembre 15 de 1915.

E. P. M. I.

Darío F. Cortés. ${ }^{18}$

El mal clima, aunado a la falta de mano de obra para trabajar el campo, también incidió en la escasez de alimentos, sobre todo de maíz. "Después de 1914, a la acción humana se sumó el clima para que la producción disminuyera todavía más". ${ }^{19}$ Además, el bandidaje, como resultado de la falta de trabajo y las condiciones de miseria que empezaban a vislumbrarse, fue otro elemento presente en la zona, dado que robaban las existencias que estaban destinadas a alimentar al pueblo.

Se podría pensar que a partir de 1916, luego de que las fuerzas de Villa fueron replegadas al norte y los constitucionalistas obtuvieron la victoria, la situación general en el país mejoraría. Pero no fue así, "la recuperación parcial de 1916 dio lugar a la tendencia descendente y la escasez de 1917". ${ }^{20}$ Por lo que es erróneo pensar que luego de la depresión en las cosechas de 1915, siguieron años de recuperación.

18 AHJ. "Carta de Darío F. Cortés al Gobernador del Estado de Jalisco". ES-2-915, Caja 202, Exp. 4742. Las cursivas son mías.

19 Knight, Alan, op. cit., p. 1186.

20 Ibidem, p. 1187. 
Este libro forma parte del acervo de la Biblioteca Jurídica Virtual del Instituto de Investigaciones Jurídicas de la UNAM

Entre 1915 y 1918, el hambre se presentó de una forma más inquietante. Recordemos que "el hambre era ubicua; llegó incluso a los pueblos mineros de Sonora... llegó también al Morelos zapatista". ${ }^{21}$ Los precios de los víveres básicos ya eran demasiado altos. La angustia comenzaba a hacer presa a varios sectores de la sociedad. En San Juan de los Lagos, Román Ochoa escribió a Manuel Alvarado, para expresarle su preocupación acerca de los sueldos de él y otros sacerdotes, que no eran suficientes; ni "para ayudarme a los crecidos gastos que se están haciendo, por la exorbitante carestía de lo muy indispensable para vivir". ${ }^{22}$ Era finales de abril de 1916. Ochoa manifestó que el dinero no le alcanzaba ni para ocho días, "he tenido necesidad para comer, pedir prestado", pues el precio del maíz en esa población, oscilaba entonces a $\$ 3.80$ el almud, es decir, cuatro litros. ${ }^{23}$

Mientras que en San Miguel el Alto, en junio de 1916, los únicos tres sacerdotes que aún quedaban no podían obtener alimentos, dado que las misas y otros sacramentos les eran pagados en papel moneda, y los comerciantes locales sólo aceptaban dinero en metálico; por lo tanto, "la situación es sumamente grave". ${ }^{24}$ De vuelta en Lagos, en agosto del mismo año, el presbítero Francisco Ramírez suplicaba a la sagrada mitra, que si podía nombrarlo ministro de alguna parroquia, con la finalidad de que su sueldo alcanzara para sostenerse. Dado que sólo ganaba entre 15 y 20 centavos diarios, lo cual no bastaba, porque se encontraba "excesivamente escaso de recursos", aunado a la "escasez de víveres y recursos pecuniarios". ${ }^{25}$

Sin embargo, la situación era cada vez más preocupante. A mediados de agosto, el hospital de San Juan de los Lagos también estaba sufriendo por la escasez de maíz, así como la desmedida alza en su precio. El Ayuntamiento otorgaba a dicho hospital 15 pesos diarios en papel moneda blanco. Para el presbítero Silverio Hernández, esto era una burla, puesto que había muchos enfermos que atender y alimentar. Debemos recordar que 15 pesos en papel moneda no valía literalmente los quince pesos. Cada peso en papel moneda era recibido por los comerciantes a tan sólo 8 centavos; haciendo

21 Ibidem, p. 1188.

22 AHAG. Carta de Román Ochoa, donde detalla la carestía y el alto precio del maíz. Sección: Gobierno. Serie: Parroquias/San Juan de los Lagos. Años: 1903-1919. Caja núm. 9, s/f.

23 Idem.

24 AHAG. Informe de Joaquín Briseño Robles sobre la circulación de moneda en papel y metálico en San Miguel el Alto. Sección: Gobierno. Serie: Parroquias/San Miguel el Alto. Años: 1909-1974. Caja 3.

25 AHAG. El presbítero Francisco Ramírez pide que lo nombren ministro de alguna parroquia. Gobierno. Serie: Parroquias/Lagos. Años: 1911-1933. 
Este libro forma parte del acervo de la Biblioteca Jurídica Virtual del Instituto de Investigaciones Jurídicas de la UNAM

cálculo, quince pesos en papel moneda a ocho centavos, equivalían a un total de tan sólo $\$ 1.20$. Si en abril del mismo año el precio de un almud de maíz era de $\$ 3.20$, entonces para agosto, que seguramente ya había subido un poco más, con $\$ 1.20$ no era posible comprar siquiera un almud de maíz para alimentar a los enfermos del hospital. La desesperación de Hernández se refleja en su carta, al respecto dice: "Anteriormente con 25 centavos se compraba la misma cantidad [un almud de maíz] en último análisis, ii25 centavos diarios cuando hay muchos enfermos!!”. ${ }^{26}$

Por otro lado, en la población de Manalisco, perteneciente a Yahualica, sus habitantes expresaban la pobreza a la que se vieron reducidos, debido a la revolución. "Conocida como lo es de esa Superioridad, la pobreza de este vecindario, y agregado a esto, la situación en que nos encontramos, debido a las circunstancias anormales por las que atravesamos, [y] la falta casi absoluta de fondos". ${ }^{27}$ Este caso es interesante. Pese a que los vecinos de Manalisco estaban conscientes de la difícil situación, la petición de ellos no se redujo a adquirir fondos para comprar alimentos, sino para pagar al capellán. Ellos estaban empeñados en que las obras del templo, además, fueran terminadas. Por ello, manifestaron que "las pocas limosnas que dan los fieles, se dediquen únicamente a las obras materiales del templo". ${ }^{28}$

Se puede suponer que el hambre no estuvo presente en esta población; sin embargo, quizás los vecinos de Manalisco sí estaban atravesando por una situación de escasez alimenticia. Pero la forma de evitar, para ellos, morir de inanición era a través de las plegarias. Es decir, los habitantes de Manalisco tal vez creían que si terminaban el templo y mantenían con ellos a su capellán, sus rezos y alguna intervención divina podrían ayudar a detener la escasez, así como reducir la pobreza por la que estaban a travesando. Casos similares se dieron en Oaxaca, en las comunidades de San Pablo y San Pedro Tequixtepec, y en Magdalena Tequisistlán, lugares donde sus habitantes oraban para que la intervención divina detuviera los robos, saqueos, guerras y asesinatos provocados por la Revolución mexicana. "En todo México, los curas y los fieles crearon y recrearon la iconografía, los rituales y las creencias locales y religiosas para entender y buscar tregua de un

26 AHAG. El padre Silverio Hernández explica de forma detallada al valor y circulación de papel moneda forzosa. Gobierno. Serie: Parroquias/San Juan de los Lagos. Años: 19031919. Caja núm. 9, s/f.

27 AHAG. Petición de los vecinos de Manalisco, a Manuel Alvarado, para que el capellán que los atiende sea pagado con fondos de la Parroquia de Yahaulica, debido a su precaria situación. Sección: Gobierno. Serie: Parroquias/Yahualica. Años: 1870-1920. Caja núm. 2.

28 Idem. 
Este libro forma parte del acervo de la Biblioteca Jurídica Virtual del Instituto de Investigaciones Jurídicas de la UNAM

mundo cambiante y amenazador" ${ }^{29} \mathrm{Y}$, contrario al panorama descrito en la región de los Altos de Jalisco, en la Ciénega de Chapala, en Jiquilpan, una sobreviviente de la época revolucionaria manifestó lo siguiente con respecto a los alimentos: "Pues el pueblo [Jiquilpan] era demasiado sano, yo creo que la alimentación era demasiado buena, poca gente, digo poca aglomeración, mucho oxígeno porque las calles tenían muchos árboles...". ${ }^{30}$ Con esto podemos darnos una idea de las diversas variables que existieron para dentro del marco de la Revolución y las enfermedades. Aunque el testimonio citado antes debe tomarse con reserva, a falta de una búsqueda más exhaustiva de fuentes que nos hablen de la situación, específicamente de los alimentos, en la región Ciénega de Chapala.

Pero no todos aguardaban a que la intervención divina llegara, para sacarlos de la compleja situación de hambre en la que se veían. A finales de 1916, María del Refugio Morán, viuda de Velázquez, escribió también a la sagrada mitra, a cargo de Manuel Alvarado, desde Lagos de Moreno, desesperada, pidiendo ayuda por la miseria que comenzaba a rodearla.

Hace como dos meses le escribí a su Señoría manifestándole de nuestra situación por la que atravesamos mis hijitos y yo, de la cual no he tenido ninguna contestación.

Espero que su Señoría se digne a contestar a mi ocurso, dada a las circunstancias que son verdaderamente muy aflictivas.

Ya comprendo la escasez de recursos que tendrá la Sda. Mitra pero yo le suplico, a S. S., remedie mi horrible situación pues ya se imaginará cuál es. ${ }^{31}$

La carta de la señora Morán refleja angustia en sus palabras. Incluso, hasta de manera literal ella describe "la horrible situación" que invita a imaginar la desesperación que la está consumiendo. Y si la súplica no había sido atendida por la sagrada mitra, bien se podía deber a que ese órgano de la iglesia tuviera otros problemas más, por los cuales no ponía atención a una de sus feligreses. Haya sido por atender otras suplicas manifestadas en sus sacerdotes, quienes advertían de la escasez y pedían aumentos; o bien, por las dificultades que atravesaban con los constitucionalistas, debido a los

29 Smith, Benjamin, "El Señor del Perdón y los matacristos de Oaxaca: la Revolución mexicana desde el punto de vista de los católicos", Desacatos. Historias a contraluz. Revista de Antropología Social, México, septiembre-diciembre de 2010, p. 62.

30 UAER, AHOCLC-E: 7-28. Entrevista a E. V. G., en Jiquilpan, Michoacán.

31 AHAG. Carta de María del Refugio Morán, Vda. De Velázquez, donde pide ayuda a la Sagrada Mitra por su precaria situación. Sección: Gobierno. Serie: Parroquias/Lagos. Años: 1911-1933. 
Este libro forma parte del acervo de la Biblioteca Jurídica Virtual del Instituto de Investigaciones Jurídicas de la UNAM

ideales anticlericales de estos últimos. El hambre se manifiesta con metáforas en esta carta; salen a relucir los "hijitos" de la señora Morán, como representativos de la fragilidad de la familia ante los embates de la escasez. El punto es que la señora Morán es un claro ejemplo de la situación que se estaba viviendo no sólo en Lagos, sino también en muchas otras partes del país.

En mayo de 1917, el panorama aún no era bueno. Luis Macías describió la pobreza y el hambre que varios habitantes de Lagos de Moreno experimentaron. Según él, los hacendados sólo pagaban a sus sirvientes entre 2 o 3 litros de maíz y unos 6 o 10 centavos. Por ende, "las pobres mujeres andan cortando nopales y raspando magueyes para ajustar la comida" ${ }^{32} \mathrm{En}$ algunas rancherías, incluso, el vestuario no alcanzaba para todos, "unos se confiesan y comulgan y se van a prestarles la ropa a los otros, para que puedan ir también a confesarse y comulgar". ${ }^{33}$ Esta situación llevó a Macías a reducir el número de capellanes en la parroquia de Lagos, pues los ingresos no alcanzaban para pagarles.

Sin embargo, hay que notar el detalle de que la gente, pese a todo, intentaba cumplir con sus obligaciones espirituales. Las personas creían que pudiera existir una intervención divina para ayudarles en su situación. $\mathrm{O}$ bien, sólo buscaban algo de consuelo ante la cruda realidad que se estaba viviendo. "A pesar del diluvio de miserias que azota a tantos pobres, han estado muy dóciles para el cumplimiento, se les ve muy fervorosos y cantadores". ${ }^{34}$ Debemos recordar que en cierta medida el factor climático repercutió en la escasez de alimentos en Lagos de Moreno y poblaciones vecinas. Pero, desde 1915, las intervenciones de haciendas por el villismo, es decir, el factor humano, también tuvieron un papel importante en las posteriores carestías que provocaron hambruna.

\section{DE LA FALTA DE HIGIENE A LA SALUD GOMO DEREGHO EN LA CONSTITUGIÓN DE 1917}

En el artículo 123 de la Constitución de 1917, se plasmaron los puntos que modificaron las jornadas laborales (8 horas y descanso dominical), el derecho a huelga y un salario mínimo; pero también se mencionan algunos aspectos

32 AHAG. Carta de Luis Macías, donde expresa los motivos por los cuales la sociedad laguense sufre pobreza. Sección: Gobierno. Serie: Parroquias/Lagos. Años: 1911-1933.

33 Idem.

34 Idem. 
Este libro forma parte del acervo de la Biblioteca Jurídica Virtual del Instituto de Investigaciones Jurídicas de la UNAM

que, de una u otra forma, hacían alusión al contexto que nos interesa en este trabajo: la salud.

Como se vio en el apartado anterior, la guerra, crisis económica junto al alza en precios de la canasta básica, el hambre y las consecuentes enfermedades, diezmaron a la sociedad que vivía (en mayor medida) los efectos de una conflagración prolongada. Sin embargo, hay que reiterar los puntos establecidos, e innovadores, en el artículo 123 de la Constitución: “obligaba al gobierno federal y estatal a presentar una legislación laboral, incluía leyes sobre salario mínimo, establecía jornadas máximas de ocho horas... estipulaba una serie de medidas para asegurar condiciones de trabajo higiénicas y seguras...". ${ }^{35}$ Esta será la primera mención a lo que se refiere a la salud de los mexicanos, tema que será retomado y trabajado en posteriores reformas. ${ }^{36}$

El tema de la salud invariablemente nos lleva al de la higiene, un tópico que está implícito en el apartado de arriba, referente al hambre. La higiene toma su lugar en un contexto donde se reafirma su importancia para evitar enfermedades; a nivel global hubo una campaña que promovía el aseo personal. Dicha promoción era el resultado de una ideología de elite, la cual había descubierto una especie de carta presentación, al mostrarse como ejemplo a seguir, ante sus semejantes menos favorecidos (las clases bajas).

Tal ideología higienista promovida por las clases altas se fue construyendo a lo largo de los siglos XVIII y XIX, cuando las epidemias comenzaron a ser asociadas con el hacinamiento y la suciedad. Una de las primeras formas de detectar tales problemas, aunque parezca irónico, no fue a la vista, sino a través del olfato. "Se sabía que las inmundicias eran causas importantes y se tomaban medidas de limpieza en los arroyos y en las calles, pero... eran preocupaciones aisladas", hasta que "en medio del discurso racional del siglo XVIII... el olfato adquirió preeminencia, se convirtió en un detector de peligros que ocultaba la atmósfera". ${ }^{37}$ Ante tales descubrimientos y asociaciones sobre enfermedades y mala higiene, comienzan a surgir las figuras de los higienistas; tales personajes emprenden las campañas que intentaron evitar las prácticas cotidianas que producían los problemas de salud, pero también debe mencionarse que en "el seno de las elites [de

35 Knigth, Alan, op. cit., p. 1263. Énfasis añadido.

36 Para un vistazo amplio a las reformas que se han efectuado en la Constitución de 1917 hasta la fecha, véase: http://wrwre.diputados.gob.mx/LeyesBiblio/ref/cpeum_crono.htm (fecha de consulta: 2 de octubre de 2016).

37 Martínez Delgado, Gerardo, "La higiene pública: el gran regenerador y la verdadera panacea", Cambio y proyecto urbano. Aguascalientes, 1880-1914. México, Fomento Cultural Banamex-H. Ayuntamiento de Aguascalientes 2008-2010-Pontificia Universidad Javeriana Bogotá-Universidad Autónoma de Aguascalientes, 2009, p. 101. 
Este libro forma parte del acervo de la Biblioteca Jurídica Virtual del Instituto de Investigaciones Jurídicas de la UNAM

donde provenías los higienistas], promotoras y receptoras de la nueva sensibilidad [olfativa], se formó... toda una revolución social que aumentó la segregación entre ricos y pobres". ${ }^{38}$

Y es que debemos tomar en cuenta que entre la vida cotidiana de los sectores privilegiados y la de los menos favorecidos hay diferencias obvias. Los sectores populares se caracterizaban por el hacinamiento, en habitaciones pequeñas sin ventilación; las personas tenían la costumbre de arrojar todo desecho a las calles, lavar trastos y ropa en fuentes, ríos y otros sitios de abastecimientos acuíferos al cual acudían gran parte de los habitantes. Además, como bien sabemos, la higiene personal tampoco era algo de relevancia. Para la época porfiriana, meses antes de la Revolución, "se creía que los miasmas y su hedor fecal estaba relacionados con la enfermedad [tifo]. Por ello, los más prominentes higienistas mexicanos recomendaban ventilación, lavar vestimentas, el drenado de los lagos y de las aguas estancadas, así como la pulcritud en el hogar y la ropa de cama". ${ }^{39}$

Aunado a lo anterior, "en temporada de lluvias, las calles se convertían en enormes lodazales, los que se «amalgamaban» con estercoleros y muladares llenos de basura esparcidos por doquier... La calidad del agua era deficiente y... las autoridades sanitarias realizaban análisis bacteriológicos". ${ }^{40}$ Las recomendaciones de sanear los sitios donde se desarrollaba la vida cotidiana era una idea que no parecía tener eco dentro de una cultura que, pese a ciertos avances en la ciencia médica, no asociaba la falta de higiene con las enfermedades. Con esto no se trata de emitir un juicio de valor que tergiverse la idea sobre la higiene, más bien es intentar comprender la situación en una sociedad que tenía un estilo de vida que no sería cambiado de manera tan sencilla. Como ejemplo podemos citar un fragmento del Informe General, del doctor Enrique Sahagun Cortés, médico de Sahuayo que dio detalles del panorama higiénico y geográfico, pero en 1939:

Muchos enfermos no se curan ni aunque se les asuste y ni manera de hacer que lo hagan a la fuerza; otros se ponen una caja de inyecciones se mejoran y se abandonan; otros se cansan de llevar un tratamiento largo, y por fin a al-

38 Ibidem, pp. 101 y 102.

39 Tenorio-Trillo, Mauricio, "De piojos, ratas y mexicanos", Istor, núm. 41, verano de 2010 , p. 9.

40 Cuenya, Miguel Ángel, "La salubridad urbana", Revolución y tifo en la ciudad de Puebla 1915-1916, México, Benemérita Universidad de Puebla, 2008, p. 25. 
Este libro forma parte del acervo de la Biblioteca Jurídica Virtual del Instituto de Investigaciones Jurídicas de la UNAM

gunos les es imposible por la pobreza en que viven, hay de todo menos gente que se atienda como es debido, salvo raros casos de gente culta y consciente. ${ }^{41}$

Con la descripción anterior, podemos dar cuenta que los procesos de cambios en la sociedad, en este caso de hábitos de cuidados personales e higiene, llegan a ser de mediano a largo plazo; si bien la política higienista viene desde mediados del siglo XIX, ésta no hizo su aparición en poblaciones como Sahuayo hasta entrado el siglo XX, dadas las condiciones particulares, geográficas y sociales.

"Pos, decían que el tifo venía del desaseo, de las personas sí. Porque mucha gente pues, pos antes era muy distinto todo...". ${ }^{42}$ Esta afirmación, de María de Jesús Álvarez, quien vivió la época convulsa de la Revolución, reafirma lo descrito por el doctor Sahagun en su informe. Además, Álvarez misma afirma que las enfermedades hoy en día nada tienen que ver con las que padeció junto a sus contemporáneos: “...fiebres biliosas que por la revolución que mucha gente se biliaba, se enfermaban el hígado y eso era de lo que moría la gente...". ${ }^{43}$ Apoyándonos en el contexto que se ha visto, las fiebres biliosas provocadas por la Revolución se relacionan debido a la escasez de alimentos y a la falta de higiene en las aguas que se utilizaban en la vida diaria. En el caso que se cita, Álvarez era originaria de Jiquilpan, en la región Ciénega de Chapala, y para esos tiempos, el pueblo se encontraba muy cerca del vaso lacustre del mar chapálico.

Ante tales condiciones, tanto geográficas como sociales, las fiebres biliales se hacían presentes por las picaduras de mosquitos, presentes por la presencia de agua en la zona. Hoy se sabe que las fiebres biliares son una variante la malaria. Por otro lado, como bien lo dice la misma María Álvarez, la presencia de la fiebre de tifo se debía a la falta de higiene, y no sólo personal, sino también en los hogares, "la higiene privada, la del interior de las casas, estaba lejos de ser óptima... pues los desechos se arrojaban al exterior, y las acequias muchas veces iban recogiendo a su camino toda la basura de las viviendas y de las calles". ${ }^{44}$ Hubo otros casos donde la pobreza, aumentada por las carestías y falta de alimentos en la época, acentuó las situaciones de mal aseo personal; por ejemplo, el presbítero Luis Macías,

41 Sahagun Cortés, Enrique, Informe general que sobre exploración sanitaria de Sahuayo, Michoacán y lugares circunvecinos, México, UNAM, Facultad de Medicina, Informe de Examen Profesional de Médico Cirujano, 1939, p. 19.

42 UAER, AHOCLC-31-3:87, entrevista a María de Jesús Álvarez Vda. de S., Jiquilpan, Michoacán el 26 de junio de 1983.

43 Idem. Énfasis añadido.

44 Martínez Delgado, Gerardo, op. cit., p. 99. 
Este libro forma parte del acervo de la Biblioteca Jurídica Virtual del Instituto de Investigaciones Jurídicas de la UNAM

párroco del pueblo de Lagos de Moreno, informó en junio de 1917, que los pobres que asistían a las misas lo hacían de manera intermitente, dado que no tenían ni siquiera qué vestir, por lo que optaban por prestarse las ropas una vez que salían de la iglesia, para que el siguiente pudiera entrar. ${ }^{45}$

Pero la tifo y fiebres biliares no eran las únicas enfermedades de las que debían preocuparse las personas de aquél entonces. Al tiempo que el tifo asolaba la región de los Altos de Jalisco, en Jiquilpan, Michoacán, la gripe española hacía acto de presencia. Esta enfermedad tiene antecedentes antiguos, pues en 1357 hizo su aparición en una población italiana, en Florencia, para después pasar a Sevilla, España, en 1405. Con la llegada de los europeos a nuevas tierras, incluyendo nuestro continente, la gripe española también formó parte de las nuevas enfermedades que se sufrieron en las colonias. ${ }^{46}$ Hoy sabemos que tal enfermedad es causada por el virus A (H1N1), pero entre 1917 y 1918, Lourdes Márquez Morfín y América Molina del Villar, refieren que la gripe española también era conocida como la muerte púrpura o peste roja. En su trabajo, estas investigadoras analizan el impacto demográfico ocasionado por tal enfermedad, y citan datos de un periódico del año 1918, El Demócrata, para dar un vistazo general al número de muertes en cada estado de la República Mexicana. Para el caso de Michoacán, en octubre de 1918, las muertes diarias se estimaban en 80 personas.

Los testimonios dados por sobrevivientes de aquella época, nos permiten vislumbrar el dolor y temor causados por la gripe: “...esa gripe española era, era arrojar sangre por boca y nariz, pero no creas que poquita, medias bacinicas, charcos en el suelo, a mí me dio, a mí me dio esa gripe española". ${ }^{47}$ Es claro que ante estas enfermedades, varias personas no estaban seguras de lo que ocurría. Los síntomas de la gripe española incluyen fiebre de más de 40 grados, dolor agudo en la cuenca de los ojos, dolor en los oídos y la zona lumbar; por supuesto, otros síntomas son las dificultades respiratorias y hemorragias nasales violentas, marcas rojas en los ojos y

45 AHAG. Informe de Luis Macías, donde detalla los efectos de la revolución y le epidemia de tifo en la feligresía de Lagos de Moreno. Sección: Gobierno. Serie: Parroquias. Años 1916-1918. Caja núm. 10, s/f.

46 Para una mejor comprensión sobre los antecedentes de la gripe española, e impacto demográfico en la Revolución mexicana, véase Márquez Morfín, Lourdes y Molina del Villar, América, "El otoño de 1918: las repercusiones de la pandemia de gripe en la ciudad de México", Desacatos, México, núm. 32, enero-abril de 2010, disponible en: http://wwre.scielo. org. $m x /$ scielo.php.script=sci_arttext\&pid=S1405-92742010000100010 (fecha de consulta: 5 de octubre de 2016).

47 UAER, AHOCLC-Z1-E: 84/66 PP., entrevista a la señora Irene Aguilera Ordaz, realizada por Griselda Villegas, Jiquilpan, Michoacán. 
Este libro forma parte del acervo de la Biblioteca Jurídica Virtual del Instituto de Investigaciones Jurídicas de la UNAM

manchas púrpuras en el rostro. Como bien lo dice otro testimonio, "Cuando estuvo aquí, hubo la fiebre esa que ya era el... Que da en el cerebro, que hubo mortandad aquí..."; 48 las fiebres que "dan en el cerebro" son una clara descripción de los síntomas mencionados antes. Algunas poblaciones sufrieron decesos considerables, por lo cual, los habitantes se cuestionaban si debían seguir sus vidas en tales condiciones, u optar por arriesgarse a salir y buscar otros sitios dónde vivir:

Fue el año '18 la gripe cayó en Tamazula ya no enterraban en hombros ya no se llevaban los muertos en hombros pues carretones... y los juntaban y había algunos que dicían era imposible ya estar en Tamazula y onde quiera oyíamos que dicían... que... los muertos... le[s] echaban paladas de tierra... y otro día otra y le tapaban ahí, sabrá Dios que cantidad morirían en Tamazula. ${ }^{49}$

El impacto causado en la población, por estas enfermedades, todavía queda pendiente de estudio. Por ahora, los testimonios dan pie a reconstruir los hechos, partiendo de algunas inferencias que salen al comparar las fuentes de Jiquilpan y Lagos de Moreno.

La mención del posible despoblamiento de Tamazula, es tan solo un ejemplo de reacciones sociales ante los embates del hambre y las enfermedades. En Lagos de Moreno, se informó que debido a la epidemia de tifo, muchas rancherías quedaron desiertas y una gran miseria se notaba en los pobladores sobrevivientes. Aunado a lo anterior, los párrocos que intentaban llegar con sus feligreses para dar los santos óleos, aparte de arriesgarse a sucumbir ante los embates de la tifo, de pronto se enfermaban de derrames biliosos, otro padecimiento del que se habló antes. ${ }^{50}$

Ante este panorama, regresemos a lo estipulado en el artículo 123 de la Constitución de 1917, sobre todo en lo referente al cuidado de la salud e higiene de los obreros. Recordemos que, en la teoría, la Constitución fue innovadora en muchos aspectos, estableciendo leyes y derechos que con anterioridad no se habían plasmado. Pero, ¿esto respondía de verdad a las necesidades de una sociedad que estaba sumergida en diversas crisis, desde lo social, económico y hasta político? Sí, la salud como derecho se estipu-

48 UAER, AHO, entrevista a Altagracia Vargas Amezcua, realizada por Griselda Villegas. Jiquilpan, Michoacán. Las cursivas son mías.

49 UAER, AHOCLC-Z1-E: 99/73 PP., entrevista a Socorro Sánchez Ruan. Jiquilpan, Michoacán, 5 de abril de 1984.

50 AHAG. Carta de Luis Macías al Presbítero José Trinidad Santiago, donde señala las malas condiciones que sufren tanto su feligresía, como sus compañeros eclesiásticos. Sección: Gobierno. Serie: Parroquias. Lagos, Años 1916-1918. Caja núm. 10, s/f. 
Este libro forma parte del acervo de la Biblioteca Jurídica Virtual del Instituto de Investigaciones Jurídicas de la UNAM

ló, pero haciendo referencia a un sector de la población: los obreros. ¿Qué ocurría con el resto de los mexicanos? Algunas de las respuestas no se tienen todavía a la mano; se necesita una investigación más profunda que rebasa los propósitos establecidos en la introducción de este trabajo. Pero detengámonos un poco en lo que respecta a las necesidades y la realidad social, frente a lo establecido en la Constitución.

De acuerdo con Alan Knight, las medidas tomadas para la promulgación de la Constitución de 1917, fueron poniéndose a la práctica de una manera lenta, y si queremos "rescatar algo de la importancia real... que la Constitución tuvo en su época, es necesario tener en cuenta las circunstancias en que nació, la naturaleza de sus progenitores y cómo fue el alumbramiento". ${ }^{51}$ Si nos limitamos a los escenarios en los que nació la Constitución, veremos que el contexto, el cual hemos estado explicando durante el desarrollo del presente trabajo, no era un panorama alentador. En la búsqueda de un equilibrio social, la Constitución de 1917 surge como una forma de controlar las dificultades que se atravesaban, no como una planificación nacional que tomara una seria solución ante los embates de la revolución.

Lo anterior se refleja en el propio artículo 123, el cual fue un logro en materia laboral y donde se exigen mejores condiciones sanitarias en las zonas de trabajo, teóricamente hablando. Pero en la práctica, tales disposiciones fueron tomando forma de manera lenta en las siguientes décadas. Se insiste, este tópico da para una reflexión y análisis aparte, pero podemos cerrar citando lo siguiente: "Mientras [los constituyentes] discutían, en Guanajuato la gente moría de hambre". ${ }^{52}$

\section{A MANERA DE GONCLUSIÓN}

Este trabajo, inicialmente, fue considerado sólo para estudiar una epidemia que afectó en la región de los Altos de Jalisco, el tifo. Sin embargo, el espectro se amplía con una nueva búsqueda de fuentes en la región Ciénega de Chapala, y la hipótesis inicial de la investigación, sobre que el tifo afectó a gran parte del país, se viene abajo. Por ello, se ha optado por realizar un primer acercamiento no a una enfermedad, sino a varios padecimientos que la sociedad mexicana sufrió a causa de la Revolución. Por supuesto, analizar si tales consecuencias fueron consideradas en la Constitución de 1917, ofrece una

\footnotetext{
51 Knight, Alan, op. cit., p. 1263.

52 Idem.
} 
Este libro forma parte del acervo de la Biblioteca Jurídica Virtual del Instituto de Investigaciones Jurídicas de la UNAM

oportunidad para lograr un trabajo interdisciplinario entre temas de salud, política e historia.

Considerando las interrogantes planteadas al inicio del trabajo, podemos ver que hubo diferentes variables que conllevaron a sufrir enfermedades, en mayor medida, durante los años de 1915-1918. La crisis económica que provocó una devaluación monetaria, carestía en los precios de la canasta básica, así como el dominio de la regiones por diferentes facciones, las cuales no aceptaban un tipo de billete emitido por el bando contrario, o en el mejor de los casos, los resellaban para que tuviera un valor mucho menor que el inicial. A eso sumemos el factor climático: sequías y heladas que impidieron tener cosechas en ciertas zonas.

El encarecimiento de alimentos y la escasez de los mismos tuvieron sus obvias repercusiones en el hambre. Se padeció en diferentes niveles, pero al final la subalimentación tuvo consecuencias en el organismo de los actores históricos de la época: debilitamiento del sistema inmune y su posterior caída ante el tifo, gripe española, fiebres biliares, etcétera. Lo anterior aunado a entornos poco saludables, debido a la casi nula cultura de higiene. Hacinamiento, acumulación de desechos, drenajes inexistentes y contaminación del agua son tan sólo algunos aspectos que consideraron para entender el desarrollo de las enfermedades.

No se respondió del todo si hay una conexión argumentada entre las epidemias vistas en este trabajo, y lo establecido en el artículo 123 de la Constitución de 1917; a lo sumo, podemos tener algunas inferencias, pero harán falta más fuentes que den pie a un mejor análisis y, por ende, a una propuesta mejor trabajada. Lo que sí queda claro es que la consideración de tener mejores condiciones higiénicas en las zonas de trabajo, fue un primer paso que desembocaría en posteriores reformas que dieran a los mexicanos el derecho a la salud.

\section{FUENTES}

Archivo de la Casa de Cultura Jurídica de Jalisco (ACGIJ).

Archivo Histórico de la Arquidiócesis de Guadalajara (AHAG).

Archivo Histórico de Jalisco (AHJ).

Guenya, Miguel Ángel, Revolución y tifo en la ciudad de Puebla 1915-1916, México, Benemérita Universidad de Puebla, 2008.

Elias, Norbert, La soledad de los moribundos, México, Fondo de Cultura Económica, 1989. 
Este libro forma parte del acervo de la Biblioteca Jurídica Virtual del Instituto de Investigaciones Jurídicas de la UNAM

Franco Rubio, Gloria A., Cultura y mentalidad en la Edad Moderna, Sevilla, Mergablum Edición y Comunicación, 1999.

http://wrerr.diputados.gob.mx/LeyesBiblio/ref/cpeum_crono.htm.

http://werere.scielo.org.mx/scielo.php?script=sci_arttextEpid=S1405-927420100001 00010.

KNIGHT, Alan, La Revolución mexicana. Del Porfiriato al nuevo régimen constitucional, México, Fondo de Cultura Económica, 2010.

MarTínez Delgado, Gerardo, Cambio y proyecto urbano. Aguascalientes, 18801914, México, Fomento Cultural Banamex-H. Ayuntamiento de Aguascalientes 2008-2010-Pontificia Universidad Javeriana Bogotá-Universidad Autónoma de Aguascalientes, 2009.

National Archive Washington (NAW).

SAHAGUN CORTÉS, Enrique, Informe general que sobre exploración sanitaria de Sahuayo, Michoacán y lugares circunvecinos, México, UNAM, Facultad de Medicina, Informe de Examen Profesional de Médico Cirujano, 1939.

SMITH, Benjamin, "El Señor del Perdón y los matacristos de Oaxaca: la Revolución Mexicana desde el punto de vista de los católicos", Desacatos. Historias a contraluz. Revista de Antropología Social, México, revista cuatrimestral, septiembre-diciembre de 2010, CIESAS, 2010.

TenOrio-TRillo, Mauricio, "De piojos, ratas y mexicanos", Istor, núm. 41, verano de 2010.

Unidad Académica de Estudios Regionales (UAER), Archivo de Historia Oral (AHO). 
Este libro forma parte del acervo de la Biblioteca Jurídica Virtual del Instituto de Investigaciones Jurídicas de la UNAM

\author{
EL ARTÍGULO 3o. CONSTITUGIONAL \\ Y EL PROYEGTO DE EDUCACIÓN LAICA: \\ MOTIVACIONES DE LOS CONSTITUYENTES \\ Y TRAYECTORIA INMEDIATA POSTERIOR: 1917-1935
}

\title{
Juan GONZÁLEZ MORFÍN*
}

\begin{abstract}
SUMARIO: I. Introducción. II. Antecedentes del artículo 3o. en la etapa constitucionalista. III. Los debates sobre el artículo 30. y su redacción definitiva. IV. Entre protestas, rectificaciones e intentos de aplicación. V. De laica a racional y de racional a socialista. VI. A modo de conclusión. VII. Fuentes utilizadas.
\end{abstract}

\section{INTRODUCGIÓN}

A partir de su independencia, una cierta libertad que existía para impartir educación de una manera indiscriminada comenzó a pasar por un previsible proceso de institucionalización. Por ejemplo, por una explicable necesidad de que la enseñanza impartida tuviera un sustrato común en todo el país, el gobierno central terminaría arrogándose la obligación de impartirla y supervisarla desplazando así a las ciudades y municipios. Esto no necesariamente conllevó que se impartiera una mejor educación o que se alcanzara un grado mayor de penetración en la mayoría de la población, pues consta que en algunas regiones la alfabetización era mucho mayor cuando las ciudades y municipios tenían este encargo. ${ }^{1}$ Sin embargo, el cambio más significativo que se habría de tener en el siglo XIX en ese terreno, fue el de la introducción del concepto "libertad de enseñanza", es decir, la apertura de la enseñanza

* Universidad Panamericana.

1 Cfr. Guerra, Francisco Xavier, México: del antiguo régimen a la Revolución, vol. 1, México, Fondo de Cultura Económica, 1988, p. 266. 
Este libro forma parte del acervo de la Biblioteca Jurídica Virtual del Instituto de Investigaciones Jurídicas de la UNAM

a cualquier credo religioso. ${ }^{2}$ Este principio, establecido por primera vez en el artículo 4o. de la ley del 23 de octubre de 1833, fue elevado a rango constitucional en 1857. ${ }^{3}$ Posteriormente, la ley del 15 de abril de 1861 habría de ratificar la libertad de enseñanza y haría gratuita la educación oficial. Más tarde, durante el mandato de Sebastián Lerdo de Tejada, con la Ley Orgánica de 1874 se suprimió la enseñanza religiosa en las escuelas; sin embargo, ésta prácticamente no llegó a hacerse valer a causa de las circunstancias turbulentas por las que atravesaba el país, además de que caería absolutamente en desuso a partir del ascenso al poder de Porfirio Díaz.

Todos estos cambios no habrían de afectar mayormente la intervención de la Iglesia católica en la impartición de enseñanza en los diferentes niveles, especialmente la primaria, pues siguieron funcionando todo tipo de escuelas, incluidas las de artes y oficios, en donde además de la instrucción específica se proporcionaba la religiosa. ${ }^{4}$ Pero la educación impartida por el Estado, que siguiendo el precepto constitucional era laica, superaba ampliamente a la religiosa en número de personas a las que se llegaba. ${ }^{5}$

Por otra parte, aunque no tan extendida como la católica, también hay que considerar la escuela protestante que, a principios del siglo XX ya tenía alguna presencia. ${ }^{6}$ Además, era precisamente a través de la escuela como más adeptos ganaban:

2 Recuérdese que por la Constitución de 1824 y, ya antes durante el breve Imperio de Iturbide, México fue un Estado oficialmente católico.

3 Sobre sus efectos, véase Lloyd Mecham, James, Church and State in Latin America, Chapel Hill, The University of North Carolina Press, 1966, p. 351.

4 Cfr. Olmos Velázquez, Evaristo, "La educación salesiana en la Escuela de Artes y Oficios del Espíritu Santo-Colegio Salesiano, 1906-1922”, Boletín Eclesiástico X (2016/5), pp. 307-329.

5 Una de las razones aducidas por el grupo reformador para no establecer prohibiciones a los particulares que pertenecían a alguna agrupación religiosa para impartir educación primaria y secundaria, era precisamente su penetración poco significativa en este terreno, así lo explicaba el diputado Alfonso Cravioto: "Las escuelas religiosas no son en la república ni tan peligrosas ni tantas como se cree. Tenemos para la república, en 1907, los datos siguientes: escuelas oficiales sostenidas por el gobierno federal, por los gobiernos de los estados y por los municipios, incluyendo las de párvulos y de enseñanza primaria elemental y superior, 9,620. Escuelas de igual carácter sostenidas por el clero, 586" (Diario de los Debates del Congreso Constituyente 1916-1917, vol. I, México, SEP-INEHRM-UNAM, Instituto de Investigaciones Jurídicas, 2014, pp. 660 y 661).

6 En 1909, los metodistas tenían en su sistema de escuelas 4,529 alumnos ( $c f r$. Bastian, Jean-Pierre, Protestantismo y sociedad en México, México, CUPSA, 1983, p. 93) y, en 1911, existían en el país 163 escuelas protestantes, que atendían a 11,862 alumnos ( $c f r$ r. Bastian, JeanPierre, Los disidentes, México, Fondo de Cultura Económica, 1989, p. 148). 
Este libro forma parte del acervo de la Biblioteca Jurídica Virtual del Instituto de Investigaciones Jurídicas de la UNAM

Las sectas protestantes que penetraron en México a la sombra del poder liberal, no tuvieron su éxito por su poder espiritual, o por el mero apoyo político que recibieron, sino más bien por los servicios sociales que ofrecieron. La escuela y el hospital fueron los dos puntos de lanza de la conquista pacífica de estas iglesias. Sin embargo la escuela fue el eje principal de la difusión de las ideas religiosas y del pensamiento político social del protestantismo norteamericano. Los Metodistas, los Presbiterianos, los Bautistas y los Congregacionales construyeron la escuela rural o urbana al lado de sus templos. En la mayoría de los casos el pastor evangélico era también el maestro de la escuela. ${ }^{7}$

Por estos años, el medio más efectivo para difundir, atacar y defender ideas, era la prensa. Y es significativo que "para la prensa católica, el enemigo principal de la religiosidad y la fuente de la degeneración moral era la educación laica, responsable de todos los males: vicios como el alcohol, el juego y la prostitución, así como de la pornografía y los suicidios", ${ }^{8}$ según se desprendía de los diarios católicos con mayor difusión, a saber, La Voz de México, El Tiempo y El Pais.

Ya en 1916, el proyecto original del artículo 3o. constitucional presentado al Constituyente por Carranza, tenía sólo esta aspiración heredada del pensamiento liberal del siglo XIX: que la educación que impartía el Estado siguiera siendo laica, es decir neutra, sin que por eso se excluyera la posibilidad de que en otras instituciones particulares, existiera la posibilidad de que se impartiera algún tipo de enseñanza religiosa.

Como en otros artículos, la redacción final no sería la propuesta por el primer jefe, sino la postulada por el grupo llamado radical o jacobino, quien ya desde antes de que siquiera fuera convocado el Constituyente, había venido pugnando porque se retirara a las corporaciones religiosas la posibilidad de trabajar en la enseñanza primaria, secundaria y normal. Esta aspiración, en algunos de los diputados, rebasaba incluso ese límite y buscaba que la enseñanza más que laica fuera antirreligiosa. Lo que posteriormente llevó a los partidarios de esta postura a insistir en sucesivas modificaciones al artículo 3o. En este artículo se buscará ilustrar cuál fue el entorno y las discusiones que se dieron hasta llegar a la redacción del artículo 3o. como quedó en la Constitución de 1917, así como la trayectoria que siguió en los primeros años después de que esta fue promulgada.

7 Bastian, Jean-Pierre, Protestantismo..., cit., p. 157.

8 Pérez Rayón, Norma, "El anticlericalismo en México durante el Porfiriato. Modalidades, temas y manifestaciones", en Pacheco, María Marta (coord.), Religión y sociedad en México durante el siglo XX, México, INEHRM, 2007, p. 80. 
Este libro forma parte del acervo de la Biblioteca Jurídica Virtual del Instituto de Investigaciones Jurídicas de la UNAM

\section{ANTEGEDENTES DEL ARTÍCULO 3O. EN LA ETAPA CONSTITUCIONALISTA}

A partir de 1914 que comenzó a tomar fuerza el movimiento armado en contra del usurpador Huerta, conforme avanzaban las tropas constitucionalistas hacia la capital, junto con otras represalias contra la Iglesia católica, a la que acusaban de colaboración con el régimen golpista, una que se vivió frecuentemente fue el cierre y confiscación de colegios y establecimientos educativos religiosos. ${ }^{9}$ Además, muy pronto se corrió la noticia que una de las medidas que habría de tomar el grupo revolucionario en cuanto se hiciera del poder, sería precisamente la de prohibir la educación religiosa, así como la participación de los religiosos en el terreno educativo. Así lo explicaba al papa el arzobispo de México en carta de 1916 en la que anticipaba que una de las medidas que se sabía habría de implementar el gobierno revolucionario sería la de no tolerar escuelas dependientes de asociaciones religiosas. ${ }^{10}$

En ausencia del arzobispo Mora y del Río, gobernaba la arquidiócesis de México un personaje singular, Antonio de Jesús Paredes, quien se había significado por llevar una buena relación con el régimen revolucionario y, más concretamente, con el presidente Carranza. ${ }^{11}$ De él sería publicada en la primera plana de El Universal una entrevista en la que se aborda el tema de las restricciones que el artículo 3o. de la Constitución, por promulgarse en esos días, traería a las asociaciones religiosas. El título del reportaje, que abarcaba tres columnas, era "Opinión del vicario sr. Paredes sobre el art. 3o. constitucional", y estaba acompañado del siguiente subtítulo: "Los católicos respetarán ese precepto".

En la introducción, el entrevistador hacía notar que el objetivo de la conversación había sido "conocer la opinión del jefe accidental de la Iglesia en México, para ilustrar el criterio de nuestros lectores sobre la acogida que ha tenido la labor del Congreso Constituyente sobre el asunto que nos ocupa", esto puesto que "las reformas en cuestión se refieren de manera directa a los ministros de cultos religiosos en materia de enseñanza". ${ }^{12}$

9 Cfr. Palomera, Esteban J., La obra educativa de los jesuitas en Guadalajara, 1586-1986, Guadalajara, Instituto de Ciencias-ITESO-UIA, 1986, pp. 244-249.

10 Cfr. Mora y del Río, José, Carta a Benedicto XV, 5 de agosto de 1916, en Archivo de la Arquidiócesis de Guadalajara, sección gobierno, serie obispos: Francisco Orozco y Jiménez, años 1912-1918, sin número de folio.

11 Véase "Antonio de J. Paredes y el régimen carrancista: entre el colaboracionismo y el cisma", Anuario de Historia de la Iglesia 24 (2015), pp. 359-381.

12 "Opinión del Vicario Sr. Paredes Sobre el Art. 3o. Constitucional”, El Universal, 29 de enero de 1917 , p. 1. 
Este libro forma parte del acervo de la Biblioteca Jurídica Virtual del Instituto de Investigaciones Jurídicas de la UNAM

A diferencia de lo que se podía haber esperado de un jerarca a cuya iglesia se le va a retirar la posibilidad de intervenir desde las aulas en la educación religiosa de la niñez y de la juventud, Paredes presenta una argumentación más bien débil, si no es que incluso condescendiente con la medida adoptada por el Constituyente:

Yo creo que frente a la escuela católica debe establecerse la escuela positivista, la protestante, etc., de tal manera que la lucha sea de ideas, de credo contra credo, de doctrina contra doctrina, de escuela contra escuela; pero no que se dicte una ley que, evitando esa lucha intelectual y benéfica, venga a restringir la libertad de conciencia y de pensamiento. ${ }^{13}$

Incluso, en otro lugar de la entrevista, parece intentar convencer a los diputados de que el criterio adoptado para suprimir la enseñanza religiosa en los planteles iba en contra de la ideología del Constituyente:

La libertad de enseñanza debe estar dentro del criterio liberal que proclama la libre emisión del pensamiento, sin más restricciones, a mi juicio, que el respeto a la moral y a la paz pública. Por tanto, no se concibe que la legislación de un país libre se oponga a la libertad de enseñanza... Lo que ha acordado el Congreso Constituyente no es consecuente con el criterio que lo creó, desde el momento en que su labor en este asunto no está de acuerdo con las ideas liberales del gobierno actual, partidario de todos los derechos del hombre y dispuesto a garantizarlos para todos. ${ }^{14}$

Esas afirmaciones causarían desconcierto dentro y fuera del país: $;^{15} \sin$ embargo, en ese momento fueron un espaldarazo a la redacción aprobada del artículo 3o., es decir, aquella que fue impulsada por el ala radical y, por carta posterior del entrevistado, se pueden encuadrar en toda una estrategia para conseguir que, al menos inmediatamente, dentro del país no hubiera mayores protestas. Efectivamente, Paredes hacía ver a su obispo, Mora y del Río, que "desde el principio les manifesté que yo no iba a hablar según los principios católicos, sino colocándome bajo el punto de vista liberal” y que

13 Idem.

14 Idem.

15 La Santa Sede fue una de las más desconcertadas; de hecho, en el Archivo Secreto Vaticano se pueden ver varias reminiscencias de la preocupación causada por este artículo, como la existencia del mismo (Archivio Segreto Vaticano [ASV], Archivio della Delegazione Apostolica in Messico, fasc. 109, f. 39) y una carta del arzobispo de México deslindándose de las declaraciones del vicario (José Mora y del Río, Carta a Giovanni Bonzano, 24 de julio de 1917, en ASV, Archivio della Delegazione Apostolica in Messico, fasc. 109, f. 56r). 
Este libro forma parte del acervo de la Biblioteca Jurídica Virtual del Instituto de Investigaciones Jurídicas de la UNAM

algunas de las afirmaciones que se le atribuían no eran suyas. ${ }^{16}$ En cualquier caso, estas declaraciones del "jefe accidental de la Iglesia en México", como se le llamó en la entrevista, contribuyeron a que, al menos en los albores de su promulgación, el artículo 3o. no fuera severamente cuestionado por los católicos.

\section{LOS DEBATES SOBRE EL ARTÍGULO 3O. Y SU REDAGGIÓN DEFINITIVA}

La propuesta original, del presidente Carranza, decía: "Habrá plena libertad de enseñanza; pero será laica la que se dé en los establecimientos oficiales de educación, y gratuita la enseñanza primaria superior y elemental, que se imparta en los mismos establecimientos"; además, continuaba apoyando la libertad de enseñanza que se había vivido desde la Constitución de 1857 y agregaba que sería gratuita y laica la que se impartiera en establecimientos oficiales. Con ello no excluía de manera alguna que las asociaciones religiosas pudieran intervenir en todos los niveles. Sin embargo, el grupo radical no lo aceptó en esos términos y, junto con varias modificaciones, propuso adicionarlo con la cláusula: "Ninguna corporación religiosa, ministro de algún culto o persona perteneciente a alguna asociación semejante, podrá establecer o dirigir escuelas de instrucción primaria, ni impartir enseñanza personalmente en ningún colegio". Esta adición, a la postre, sería la más discutida entre los dos grupos que se habían formado en el seno del Constituyente.

Los radicales fundaban su pretensión de modificar la redacción propuesta por el primer jefe argumentando que la neutralidad que se había vivido en el siglo XIX había tolerado que el clero continuara su labor de adoctrinamiento a través de la educación, así, por ejemplo, lo sostenía el voto particular del diputado Luis G. Monzón:

La soberanía de un pueblo que ha luchado por su dignificación y engrandecimiento, nos ha confiado la tarea de que quebrantemos los hierros del siglo XIX en beneficio de la posteridad, y nuestro principal deber es destruir las hipócritas doctrinas de la escuela laica, de la escuela de las condescendencias y las tolerancias inmorales. ${ }^{17}$

16 Paredes, Antonio J., Carta a fosé Mora y del Rí, 12 de marzo de 1917, en AHAM, fondo episcopal: José Mora y del Río (1917), caja 145, expediente 66.

17 Diario de los Debates del Congreso..., cit., p. 641. En el mismo sentido que Monzón hablaría más tarde el diputado Álvarez, argumentando que la palabra laica era neutral, por lo que proponía que se estableciera que la educación debería ser liberal o racional. 
Este libro forma parte del acervo de la Biblioteca Jurídica Virtual del Instituto de Investigaciones Jurídicas de la UNAM

En ese voto particular, explicado por él mismo, reclamaba incluso sustituir la palabra laica, por otra que le diera más peso a la idea de no permitir ningún tipo de educación religiosa, como podía ser la palabra racional.

Por su parte, y sin necesidad de hacer cambio alguno de palabras, el general Francisco J. Múgica quien se destacó por su no disimulada postura anticlerical, consideraba antipatriótica la actitud de quienes no aprovecharan el momento que se estaba viviendo para retirar al clero del terreno de la enseñanza:

Sí, señores, si dejamos la libertad de enseñanza absoluta para que tome participación en ella el clero con sus ideas rancias y retrospectivas, no formaremos generaciones nuevas de hombres intelectuales y sensatos, sino que nuestros pósteros recibirán de nosotros la herencia del fanatismo, de principios insanos, y surgirán más tarde otras contiendas que ensangrentarán de nuevo a la patria, que la arruinarán y que quizá la llevarán a la pérdida total de su nacionalidad. ${ }^{18}$

Con distintas palabras y a través de las sesiones en las que se discutió el artículo en cuestión, los argumentos a favor del dictamen que modificaba la propuesta original se centraron en defender la conciencia de la niñez y de la juventud de la influencia de doctrinas clericales. Así, por ejemplo, el congresista Román Rosas y Reyes insistía en aprovechar la oportunidad histórica para dar un paso trascendente en este sentido:

Con el clamor de un deber a vuestra conciencia, os digo, señores: estamos legislando para el porvenir, nosotros tal vez no recibamos el fruto de nuestra labor; pero si queremos ver a nuestra patria feliz y fuerte, si queremos que esa amada matrona que tanto ha llorado por la muerte de tantos de sus hijos, enjugue su llanto y viva feliz, sin temores por el porvenir, hagamos en estos momentos solemnes, en este gran día para ella, una labor reivindicadora, hagamos la labor de un hábil cirujano que extirpe de una vez para siempre la gangrena que la corroe; si queremos nosotros, señores, que nuestras razas futuras llenen las aspiraciones que anhelamos nosotros, si queremos que lleven la savia vigorosa de la verdad en su mente y por ella rijan siempre sus menores actos, ayudadme a destruir esas escuelas católicas, que no son otra cosa que fábricas de frailes, en donde se acapara de una vez para siempre el pequeño espíritu, la conciencia, la razón, en donde desde pequeño, se enseña al hombre a ser hipócrita, a ser egoísta, a ser falaz, a ser mentiroso: ayudadme a destruir esas escuelas católicas, en donde se sentencia desde temprano

\footnotetext{
18 Ibidem, p. 643.
} 
Este libro forma parte del acervo de la Biblioteca Jurídica Virtual del Instituto de Investigaciones Jurídicas de la UNAM

a la niñez a llevar una vida de degradación, de dudas, de obscurantismo, de miseria moral. ${ }^{19}$

De poco sirvieron los argumentos a favor de la libertad de enseñanza como uno de los pilares del pensamiento liberal, o bien, del poco impacto que, al final de cuentas, tenían los planteles católicos, o el hecho constatable de que en esas escuelas los que realmente enseñaban pocas veces eran clérigos, ninguno de estos argumentos hacía modificar siquiera un poco la postura radical. Se invocó también el patriotismo y la indudable visión liberal del primer jefe, que era quien incluso con su presencia en una de las sesiones intentó que no se estableciera dicha prohibición. El diputado Luis Manuel Rojas en una larguísima perorata buscó convencerlos que no era en el artículo 3o., puesto que se encontraba éste en el apartado de garantías individuales, donde convenía establecer un límite a la libertad de enseñanza. Todo fue en vano.

Se buscaron caminos diversos, como la denuncia de que la postura defendida por los radicales había sido impuesta desde fuera por Obregón y por su operador Aguirre Berlanga: tampoco funcionó.

Finalmente, se apeló a la sensatez de los constituyentes recordándoles que se estaba legislando para todos y que el pueblo mexicano era mayoritariamente católico, como incluso el ideólogo Luis Cabrera lo había reconocido, pero continuamente salía a relucir que el problema de mayor trascendencia que había que solucionar era el político y que "a este propósito nadie disiente de que las escuelas católicas han sido simplemente un medio para preparar a las generaciones venideras contra el credo liberal". De modo que, visto esto, “¿por qué no tenemos el valor en nuestras leyes, igualmente, de afirmar un acto de aniquilamiento para el enemigo, como se hizo, por ejemplo, cuando se proclamaron las Leyes de Reforma?". ${ }^{20}$

Alfonso Cravioto apelaba a la necesidad de que todos participaran en la gran tarea de la educación, pues “decía Dantón que el progreso consiste en audacia, en audacia y más audacia. Digamos nosotros que para México el progreso consiste en escuelas, en escuelas y en escuelas". Por lo que no había que poner dique alguno a esta fundamental obra constructiva: "Difundamos la cultura. Esparzamos la instrucción, pero sin hollar libertades respetables. La de enseñanza no os asuste. La verdad siempre se abre su camino y triunfa. Llegamos de gran cruzada contra la reacción y hemos vencido; vayamos ahora en una gran cruzada contra la ignorancia y vence-

19 Ibidem, p. 687.

20 Palabras del diputado Alberto Román en Diario de los Debates del Congreso..., cit., p. 657. 
Este libro forma parte del acervo de la Biblioteca Jurídica Virtual del Instituto de Investigaciones Jurídicas de la UNAM

remos". Y concluía: "La revolución se ha hecho no sólo en beneficio de los revolucionarios sino en beneficio y bienestar de todo el pueblo mexicano. Hay que subordinar a este grande interés colectivo, nuestros mezquinos intereses parciales". ${ }^{21}$

Luis Rojas anticipaba la posibilidad de una nueva guerra civil si no se atendía a todos los reclamos:

Se juzga por muchas personas reflexivas, quienes no han perdido la serenidad en estos momentos, que de los postulados de la nueva ley puede salir la paz o la guerra, y que algún error grave del Congreso Constituyente volverá a encender quizá una nueva conflagración en el país, cuando todavía no se apagan las llamas de la pasada contienda. ${ }^{22}$

José Natividad Macías aludía al liberalismo indiscutible de Obregón que, sin embargo, no le había impedido contraer matrimonio religioso:

Hay otros jacobinos enteramente iguales y por eso, señores, yo no critico al general Obregón en su matrimonio religioso; yo soy liberal y respeto a la conciencia humana; pero lo que pasa es que en el fondo de todo mexicano existe el sentimiento católico. De los catorce millones de habitantes que tiene la república, yo aseguro a usted, señor protestante (dirigiéndose a un ciudadano diputado), que no hay mil liberales verdaderos. Si me pongo a contarlos no hay ninguno. ${ }^{23}$

El último argumento para frenar el dictamen de la comisión, presentado por Palavicini expresamente, y tácitamente por otros, se centraba en que dicha aprobación constituiría una bofetada política para el primer jefe, pero también este fue magistralmente superado en palabras del diputado Espinosa:

Quiero que conste de una vez por todas, que los liberales radicales que nos encontramos en el seno de esta asamblea nunca hemos ni siquiera pensado en hacer política contra el Primer Jefe; al contrario, nuestra actitud es la prueba más elocuente de mis palabras. Lo que nosotros queremos no es únicamente por nosotros, sino por la responsabilidad que tendremos mañana en la historia; es, ciudadanos diputados, antes que todo y sobre todo, por la patria y por el pueblo; es después por el engrandecimiento aun mayor, de esa figura preclara, excelsa, que nos ha llevado hasta la conquista de nuestros ideales

21 Ibidem, pp. 664 y 665.

22 Ibidem, p. 643.

23 Ibidem, p. 681. 
Este libro forma parte del acervo de la Biblioteca Jurídica Virtual del Instituto de Investigaciones Jurídicas de la UNAM

que están cristalizándose ahora; es por el Primer Jefe y su prestigio personal, como un premio a su magna labor de patriota inmaculado, y es también por nosotros mismos. La aprobación del artículo $3^{\circ}$ que nos presenta la comisión dictaminadora, es la aspiración suprema, el anhelo más grande del pueblo mexicano. ${ }^{24}$

A final de cuentas, al llegar el momento de la votación, se aprobaría la propuesta contraria a la redacción del grupo de Carranza por una mayoría nada despreciable: 99 contra 58 votos, ${ }^{25}$ lo que permitía sobre todo ver qué grupo era el que habría de dominar en las sucesivas votaciones, independientemente de los debates. A partir de aquí comenzaría otro debate ya anticipado por algunos de los constituyentes: el de la implementación de un artículo cuyo contenido era opuesto al sentir de la mayoría de los mexicanos.

\section{ENTRE PROTESTAS, RECTIFICACIONES E INTENTOS DE APLICACIÓN}

La Constitución promulgada en Querétaro el 5 de febrero de 1917 no sólo contenía disposiciones de corte anticlerical en el artículo 3o., sino también en el 5o., 24, 27 y 130, lo que ocasionó que los obispos mexicanos radicados en los Estados Unidos, alejados de sus diócesis desde 1914, suscribieran un documento intitulado "Protesta que hacen los Prelados Mexicanos con ocasión de la Constitución Política de los Estados Unidos Mexicanos Publicada en Querétaro el día cinco de febrero de 1917", en el que reclaman que en la nueva carta magna no se reconociera "al fin la libertad religiosa, como los revolucionarios lo habían ofrecido solemnemente a la nación mexicana y a los gobernantes extranjeros", sino "antes bien la Constitución dictada en Querétaro el 5 de febrero último, eleva a estado [permanente] la persecución religiosa sancionándola definitivamente". ${ }^{26}$

Y en relación con el artículo 3o. la protesta señalaba:

Por una parte se restringe la libertad de enseñanza, toda vez que se prohíbe la instrucción religiosa en las escuelas privadas; por otra, se coarta en los sacerdotes la que todo hombre tiene de enseñar, y por último, se ataca el derecho de los padres de familia a educar a sus hijos según su conciencia y su religión,

24 Ibidem, p. 769

25 Cfr. Diario de los Debates del Congreso..., cit., p. 774.

26 Protesta que hacen los Prelados Mexicanos con ocasión de la Constitución Politica de los Estados Unidos Mexicanos Publicada en Querétaro el día cinco de febrero de 1917, en AHAM, fondo episcopal: Pascual Díaz (1917), sección secretaría arzobispal, serie folletos, caja 46, expediente 8. 
Este libro forma parte del acervo de la Biblioteca Jurídica Virtual del Instituto de Investigaciones Jurídicas de la UNAM

puesto que se les obliga a que estos reciban enseñanza laica, es decir, positivamente irreligiosa, como lo expresó la Comisión dictaminadora. ${ }^{27}$

Esta protesta causó malestar en la clase dirigente y ocasionó que el destierro de los obispos se prolongara casi dos años más; sin embargo, también consiguió despertar la sensibilidad de algunos gobernantes como Carranza, que en el tiempo que estuvo gobernando al país después de haber entrado en vigor la nueva Constitución, a la manera de Porfirio Díaz ignoró los puntos álgidos e incluso buscó expresamente una enmienda constitucional para corregir la redacción del artículo 3o., ${ }^{28}$ pero los diputados que conformaban la XXVII legislatura más que pensar en suavizar las disposiciones antirreligiosas, debatían cómo hacerlas más radicales, ${ }^{29}$ por lo que la iniciativa del primer jefe no se llevó a cabo.

A la muerte de Carranza, durante los meses que gobernó Adolfo de la Huerta y luego durante todo el cuadrienio en que Álvaro Obregón estuvo al frente del ejecutivo, no hubo siquiera intentos de aplicar el artículo 3o. a nivel nacional, si bien a nivel local en algunos estados, como en Veracruz, gobernado en esos momentos por Adalberto Tejeda, sirvió como escudo para el cierre de algunas escuelas. ${ }^{30}$

El presidente Calles asumió el poder el 1o. de diciembre de 1924. Su pasado anticlerical como gobernador de Sonora, en donde expulsó del estado a todos los sacerdotes, y algunas situaciones toleradas en sus primeros meses de gobierno, como el apoyo inicialmente dado a una iglesia católica cismática, ocasionaron en el episcopado una actitud defensiva que, a la postre, habría de precipitar los acontecimientos. En noviembre, fueron enviados a Roma dos prelados, el arzobispo de Durango, José María González y Valencia, y el obispo de San Luis Potosí, Miguel de la Mora. El 12 de noviembre tuvieron una audiencia con Pío XI. Su estancia en Europa se prolongó hasta enero, y a su regreso, un diario de la capital dio cuenta de que se llevaría a cabo una nueva asamblea del episcopado para determinar la forma de llevar a cabo una "defensa de los intereses católicos... conforme a las instrucciones del Vaticano, de que son portadores los señores De la Mora y González". ${ }^{31}$ En ese mismo artículo se hablaba de que los prelados promoverían "una campaña dentro de la ley contra determinados preceptos

27 Idem.

28 Cfr. Diario Oficial de la Federación, 21 de septiembre de 1918, p. 1.

29 Cfr. Diario de los Debates de la Cámara de Diputados de los Estados Unidos Mexicanos, periodo extraordinario, XXVII Legislatura, Diario 19, 18 de junio de 1918.

30 Cfr. Archivo Plutarco Elías Calles, expediente 26, inventario 5558, legajo 1/15, f. 43.

31 El Universal, 27 de enero de 1926, p. 1. 
Este libro forma parte del acervo de la Biblioteca Jurídica Virtual del Instituto de Investigaciones Jurídicas de la UNAM

constitucionales"32 y que uno de estos sería el que establece que "ninguna corporación, ni ministro de ningún culto, podrá establecer ni dirigir escuelas de instrucción primaria", es decir, el artículo 3o.

Pocos días después, el mismo diario, publicaría una entrevista con el arzobispo de México, José Mora y del Río en la que supuestamente había afirmado que "la información que publicó El Universal de fecha 27 de enero, en el sentido de que se emprenderá una campaña contra las leyes injustas y contrarias al Derecho Natural, es perfectamente cierta". Y agregaba: "El Episcopado, clero y católicos no reconocemos y combatiremos los artículos 3o., 5o., 27 y 130 de la Constitución vigente. Este criterio no podemos por ningún motivo variarlo sin hacer traición a nuestra Fe y a nuestra Religión". ${ }^{33}$ Independientemente de si estas declaraciones fueron realmente hechas por el prelado, cosa que él negó a los pocos días, ${ }^{34}$ lo cierto es que fueron el detonador para que las implicaciones del artículo 3o. comenzaran a vivirse con todas sus consecuencias, y aún antes de que el gobierno de Calles comenzara a cerrar escuelas, una "Asociación de Constituyentes" publicaba una respuesta "a los ataques dirigidos contra los artículos 3o., 5o., 27 y 130", ${ }^{35}$ suscrita por 63 antiguos diputados del Constituyente de Querétaro. En ella, además de volver a insistir en que no se puede dejar en manos del clero la educación de las conciencias infantiles, se afirmaba:

No es pues el empeño de educar a la niñez lo que mueve las reclamaciones del Clero contra el artículo 3o. de la Constitución, sino la reconquista de aquella arma política, pues esas escuelas deficientes y todo, les servían para sostener la posición de su rebeldía ante la autoridad civil, sintiéndose un Poder ante otro Poder. ${ }^{36}$

Ante la opinión pública mundial, el presidente Calles habría de explicar el cierre de escuelas como una consecuencia de la aplicación del artículo 3o. constitucional, independientemente de las declaraciones del arzobispo Mora. ${ }^{37}$ A partir de aquí, aunque con algunos periodos de tolerancia, la

32 Idem.

33 El Universal, 4 de febrero de 1926, p. 1.

34 Cfr. González Morfín, Juan, Murieron por sus creencias. La guerra de los cristeros hitos y mitos, México, Panorama, 2012, pp. 9-36.

35 Copia mecanografiada del documento, en 5 folios, se encuentra en AHAM, fondo episcopal: José Mora y del Río (1926), caja 148, expediente 24.

36 Ibidem.

37 Cfr. New Tork Herald-Tribune, 23 de febrero de 1926, p. 1; Hammond Murray, Robert, Mexico before the World. Public Documents and Addresses of Plutarco Elias Calles, Nueva York, The 
Este libro forma parte del acervo de la Biblioteca Jurídica Virtual del Instituto de Investigaciones Jurídicas de la UNAM

prohibición de la enseñanza religiosa y de la participación de religiosos en la enseñanza primaria, secundaria y normal, comenzó a exigirse durante el periodo conocido como el Maximato; sin embargo, no faltaban quienes seguían considerando que la educación laica seguía siendo una falta de audacia, por lo menos, de parte de los gobiernos revolucionarios, si querían ir más a fondo en el proceso de desfanatización.

\section{DE LAICA A RACIONAL Y DE RACIONAL A SOCIALISTA}

Ya en 1929 Narciso Bassols, uno de los intelectuales ligados a Calles, abogaba por dar un paso más radical en el terreno de la educación antes de que llegaran a los educadores "espíritus que fuera de la escuela han sido deformados o aniquilados ya", ${ }^{38}$ para lo cual la reforma que se tenía que dar era sobre todo ideológica.

Otro ideólogo que, como Bassols, había sido secretario de educación pública, el doctor José Manuel Puig y Casauranc, escribía a Calles en abril de 1932 contándole que en la revista Fortune habían aparecido una serie de reportajes sobre la Rusia soviética con ideas muy interesantes de considerar para el proceso de transformación en México:

La actitud antirreligiosa del Estado es importante porque no ataca la libertad de creencias sino las creencias en sí. Del mismo modo que se usa la propaganda comercial en los Estados Unidos para vender cigarros o para vender llantas de automóvil, se usa en Rusia para persuadir al pueblo que desprecie a Cristo, a Buddha y a Mohammed. Se ataca a la religión en periódicos, en teatros, en carteles, por radio y, sobre todo y preferentemente, por la educación. El ateísmo es parte importante de todo programa educativo desde la escuela primaria en adelante. Es indiscutible que la generación próxima de modo natural va a considerar la religión hasta como un pecado, aunque los ya mayores no sean influidos por la propaganda y conserve su fe que les sirvió de ilusión. ${ }^{39}$

De conseguirse esto, a través de la educación sobrevendrían de manera natural, como consecuencia obligada, algunas de las características del

Academy Press, 1927, pp. 103-105; Elías Calles, Plutarco, Pensamiento político y social, Antología (1913-1936), México, Fondo de Cultura Económica, 1991, p. 181.

38 Fernando Paz Sánchez, Narciso Bassols, México, Nuestro Tiempo, 1986, p. 199.

39 APEC, José Manuel Puig Casauranc, inventario 4364, expediente 109, legajo 4, f. 233. 
Este libro forma parte del acervo de la Biblioteca Jurídica Virtual del Instituto de Investigaciones Jurídicas de la UNAM

México moderno buscado por los revolucionarios, y esto sin necesidad de imponerlo violentamente:

El cierre de las iglesias, en teoría, es voluntario, no compulsivo. Se entiende que la gente que vive en una ciudad, o en determinado barrio de una ciudad en donde haya un templo, tiene el derecho de decidir si la iglesia debe permanecer abierta o si, por ejemplo, deberá transformarse en un club de trabajadores. Los jóvenes muestran una tendencia creciente a votar en favor de clubs y derrotan frecuentemente a los mayores. ${ }^{40}$

Esto sin duda fue nutriendo de ideas a Calles y a algunos de los que ya habían abogado por una redacción que llevara al artículo 3o. a ir más allá de la enseñanza laica, hasta conseguir una educación realmente antirreligiosa que modelara desde la niñez un nuevo tipo de conciencias. ${ }^{41}$ Por esta época también se ensayó en el estado sureño de Tabasco la educación racionalista, que ya había tenido antecedentes precisamente con Plutarco Elías Calles como gobernador de Sonora, y que tenía un matiz marcadamente antirreligioso. ${ }^{42}$

Los debates en la Cámara de Diputados para que se impulsara una reforma al artículo 3o. constitucional en ese sentido venían ocurriendo desde al menos un par de años atrás. Así, por ejemplo, en octubre de 1932, el diputado Alberto Bremauntz, uno de los impulsores de la educación socialista, abogaba para que se pasara de las palabras a los hechos:

40 Idem.

41 En su discurso del 20 de julio de 1934, el general Calles dio una señal en este sentido que, a la postre, se conocería como el grito de Guadalajara: "Es necesario que entremos en un nuevo periodo revolucionario, que yo llamaría el periodo de la revolución psicológica. Debemos entrar y apoderarnos de las conciencias; de la conciencia de los niños, de la conciencia de la juventud, porque la juventud y la niñez ¡deben pertenecer a la revolución! ¡Es absolutamente necesario sacar al enemigo de las trinchera; asaltarlo con decisión en esa trinchera donde están los conservadores; ¡me refiero a la educación en la escuela! Sería una torpeza grave y delictuosa para los hombres de la revolución, que no arrancáramos a la juventud de las garras de la clerecía, de las garras de los conservadores" "Palabras de Calles al pueblo de Jalisco", El Informador, 21 de julio de 1934, p. 2).

42 Cfr. Arce Gurza, "En busca de una educación revolucionaria", en Hamui Sutton, Mery, Antología de lecturas sobre la historia de la educación básica en México, México, UAM Azcapotzalco, 1996, pp. 151-153. Sobre la educación racionalista, véase también Martínez Assad, Carlos, Los lunes rojos. La educación racionalista en México, México, SEP-El Caballito, 1986, pp. 122-141; Giuseppe, Massimo de, "El Tabasco racionalista frente a lo indígena: entre laboratorio social y experimentación cultural (1922-1934)", Historia Mexicana LXI (2011), pp. 643-706. 
Este libro forma parte del acervo de la Biblioteca Jurídica Virtual del Instituto de Investigaciones Jurídicas de la UNAM

No vengo a producir un discurso, porque entiendo que la Asamblea está ya fatigada de oír el tema; de oír el tema, no de tratar el tema. Estamos cansados de oír, en los mítines políticos y en todas las asambleas que con motivo de las campañas electorales se celebraron en los distintos pueblos de la República. Y el clero no se asusta con esto; el clero no se asusta porque ya se ha dicho hace unos momentos, que cuando se le ataca con discursos, se queda sonriendo y burlando de los revolucionarios... Deseo que el Partido Nacional Revolucionario y la Cámara de Diputados se avoquen a modificar el artículo 3o. de la Constitución; pero que se modifique cuanto antes, que no quede este deseo únicamente en buenas intenciones, ni se diga que se va a hacer una acción revolucionaria en contra del clero. La mejor manera de arrasar a la clerigada no es otra que quitar de sus manos a la niñez, quitar la enseñanza de sus manos y afianzar por la Revolución a la juventud que hasta ahora ha estado saliendo desorientada completamente de las escuelas oficiales primarias. ${ }^{43}$

Y después de aducir que esa era la intención de los constituyentes del 17, mencionaba que la educación laica había resultado insuficiente para que se realizara:

El laicismo no ha dado ningún resultado; hay que confesarlo con franqueza. Bajo el amparo del laicismo, el clero ha difundido escuelas particulares, ha propagado sus doctrinas y está formando una nueva generación que, tarde o temprano, vendrá a provocar otra revolución en la República. Yo pido, pues, que el artículo $3^{\circ}$ constitucional sea reformado cuanto antes, en el sentido de la teoría racionalista o de la socialista. ${ }^{44}$

El mismo Lázaro Cárdenas, durante su campaña presidencial, sostenía en uno de sus discursos: "La Revolución no puede tolerar que el clero siga aprovechando a la niñez y a la juventud como instrumentos de división en la familia mexicana, como elementos retardatarios para el progreso del país, y menos aún que convierta a la nueva generación en enemiga de la clase trabajadora". 45

De esta manera, sería bajo la premisa de que la lucha histórica del clero por apoderarse de las conciencias "impone la necesidad de dar a la enseñanza socialista que se imparta la característica combativa de los prejuicios

43 Diario de los Debates de la Cámara de Diputados del Congreso de los Estados Unidos Mexicanos, 3 de octubre de 1932.

44 Idem.

45 Bremauntz, Alberto, La educación socialista en México. Antecedentes y fundamentos de la Reforma de 1934, México, s. i., 1943, p. 64. Durante su campaña presidencial hizo otras declaraciones parecidas ( $c f r$. El Informador, 23 de junio de 1934, p. 1). 
Este libro forma parte del acervo de la Biblioteca Jurídica Virtual del Instituto de Investigaciones Jurídicas de la UNAM

y dogmas religiosos", ${ }^{46}$ que sobrevino en 1934 una reforma sustancial al texto del artículo 3o. que estableció lo siguiente: "La educación que imparta el Estado será socialista y además de excluir toda doctrina religiosa combatirá el fanatismo y los prejuicios para lo cual la escuela organizará sus enseñanzas y actividades en forma que permita crear en la juventud un concepto racional y exacto del universo y de la vida social". ${ }^{47}$ Con esto se sustituía el concepto "educación laica" por el de "educación socialista" a la que se añadía, como algunos habían venido pidiendo, el componente de "racional". Y, aunque no explicaba exactamente en qué iba a consistir este tipo de educación, sí dejaba prever que iría más allá de "excluir toda doctrina religiosa" para combatir "el fanatismo y los prejuicios". Por otro lado, dicho artículo se adicionaba con cuatro normas y varias fracciones que antes no existían y que garantizaban al Estado la posibilidad de hacer cumplir el mandato primordial, es decir, el institucionalizar la educación socialista, pues aun cuando se preveía la posibilidad de conceder autorizaciones a los particulares para impartir educación primaria, secundaria y normal, estas concesiones tenían que sujetarse a las siguientes normas:

I.- Las actividades y enseñanzas de los planteles particulares deberán ajustarse, sin excepción alguna, a lo preceptuado en el párrafo inicial de este artículo, y estarán a cargo de personas que en concepto del Estado tengan suficiente preparación profesional, conveniente moralidad e ideología acorde con este precepto. En tal virtud, las corporaciones religiosas, los ministros de los cultos, las sociedades por acciones que exclusiva o preferentemente realicen actividades educativas y las asociaciones ligadas directa o indirectamente con la propaganda de un credo religioso, no intervendrán en forma alguna en escuelas primarias, secundarias o normales, ni podrán apoyarlas económicamente.

II.- La formación de los planes, programas y métodos de enseñanza corresponden en todo caso al Estado.

III.- No podrán funcionar los planteles particulares sin haber obtenido previamente, en cada caso, la autorización expresa del poder público.

IV.- El Estado podrá revocar, en cualquier tiempo, las autorizaciones concedidas. Contra la revocación no procederá recurso o juicio alguno. ${ }^{48}$

En el ambiente eclesiástico hubo bastante agitación a causa de la introducción de este tipo de enseñanza. Ya en abril de 1934 el arzobispo Pascual

46 Guevara Niebla, Gilberto, La educación socialista en México (1934-1945), México, SEP, 1985, p. 51.

47 Diario Oficial de la Federación, 13 de diciembre de 1934, p. 1.

48 Ibidem, p. 2. 
Este libro forma parte del acervo de la Biblioteca Jurídica Virtual del Instituto de Investigaciones Jurídicas de la UNAM

Díaz había escrito y hecho repartir entre la feligresía una Instrucción en la que recordaba que el socialismo era una herejía y que no se podía cooperar con él de ninguna manera. Por su parte, el delegado apostólico en el exilio, Leopoldo Ruiz y Flores, escribió dos documentos en diciembre de 1934, apenas se dio la publicación de la reforma al artículo 3o. en el Diario Oficial; en ambos recordaba que se prohibía a los católicos, so pena de incurrir en las censuras establecidas por el derecho canónico, aprender, enseñar o cooperar eficazmente a que se aprenda o enseñe lo que se ha llamado en México "educación socialista", a saber: que el niño pertenece al Estado y no a la familia, que en la instrucción de la niñez debe procurarse por todos los medios arrancar del alma de los niños toda idea religiosa, hasta la existencia de Dios, y que deben inculcárseles las ideas que destruyen la propiedad privada y el derecho a ella. ${ }^{49}$ Ambos documentos permitían ver qué era lo que los jerarcas católicos temían de la educación socialista.

En los primeros meses de 1935, prosiguió el embate de la jerarquía católica contra una educación de la que, en la práctica, no se sabía en qué iba a consistir, pero de la que se preveían grandes males. Así, en enero de ese año, el arzobispo Díaz escribió a su clero una circular en la que mencionaba seis normas a cumplir que se sintetizan de la siguiente manera: I. Hacer suyas todas las indicaciones de la Instrucción de Ruiz y Flores del 12 de diciembre pasado. II. Se prohíbe a los católicos abrir o sostener escuelas con enseñanza socialista, y a los papás enviar a sus hijos a estas escuelas. III. Esta prohibición no se extiende a universidades, preparatorias y escuelas técnicas, en las que no se imparte la educación socialista. IV. Si consta que no se imparte la enseñanza socialista en estas últimas, los padres sí pueden inscribir ahí a sus hijos. V. Los alumnos sui iuris tienen las mismas obligaciones. VI. Los maestros católicos no pueden enseñar ni comprometerse a enseñar el socialismo. ${ }^{50}$

Entre las filas de los católicos hubo todo tipo de protestas para buscar primero evitar y luego modificar la redacción del artículo promulgada en diciembre de 1934. Así, al mismo tiempo que se organizaban las "escuelas hogar" para evitar enviar a los niños a planteles oficiales, surgía una amplia resistencia a este tipo de enseñanza. ${ }^{51}$ De un lado, algunas organizaciones como la Unión de Damas Católicas, la Unión Nacional de Padres de Fami-

49 AHAM, fondo episcopal: Pascual Díaz (1934), caja 85, expediente 1.

50 AHAM, fondo episcopal: Pascual Díaz (1935), caja 56, expediente 102.

51 Cfr. Torres Septién, Valentina, "La educación socialista en la Ciudad de México", en Savarino, Franco et al. (coords.), Política y religión en la Ciudad de México, Siglos XIX y XX, México, IMDOSOC, 2014, p. 257. 
Este libro forma parte del acervo de la Biblioteca Jurídica Virtual del Instituto de Investigaciones Jurídicas de la UNAM

lia, y otras asociaciones de seglares, buscaron agotar los medios legales para conseguir la revocación de la ley; ${ }^{52}$ por otra parte, no faltaron católicos que por medios violentos quisieron desalentar a los profesores oficiales de cumplir con su cometido y llegaron a cometer verdaderos crímenes en contra del profesorado. ${ }^{53}$

El mismo presidente Cárdenas se vio obligado a intervenir en uno de estos casos apersonándose en la iglesia de Cd. González, distrito de San Felipe Torres Mochas, Guanajuato, después de un zafarrancho entre profesores y católicos que se trenzaron a balazos con una brigada que había venido a impartir educación socialista. Las consecuencias inmediatas fueron la muerte 16 personas, además de 25 heridos. ${ }^{54}$ En su discurso dijo:

Nadie ataca la libertad de conciencia, pero que sepan estos señores [el presidente se dirige a los sacerdotes de la iglesia parroquial ahí presentes] que ellos también tienen deberes que cumplir y normas legales a las que sujetarse. Es un engaño lo que han propalado en contra de la Escuela Socialista. Son mentiras las que escribieron en dos hojas sueltas que se distribuyeron profusamente en toda la ciudad. Y ya que excitaron a las multitudes provocando el choque sangriento de ayer, exhorto aquí a estos señores a que abandonen la población en el término de 24 horas. Si las mujeres tienen sus creencias, para ello cuentan con su iglesia y con su casa. ${ }^{55}$

La reacción de Lázaro Cárdenas, si bien fue rápida, no fue ciertamente desproporcionada ni acompañada de represalias, fuera de la expulsión de los sacerdotes probablemente inmiscuidos en incitar la revuelta. El suceso no pasó de ser un hecho lamentable en el que la energía del presidente evitó que este tipo de eventos se multiplicaran, no así otro tipo de agresiones contra docentes acusados de socialistas; aunque, en realidad, fue la ausencia de una gran cantidad del alumnado, que se dejó sentir en los planteles en los que constaba que se impartía enseñanza socialista, la principal respuesta de los católicos a este tipo de educación.

En 1937, el delegado apostólico con cinco años en el exilio, Leopoldo Ruiz y Flores, después de muchas vacilaciones fue sustituido por el recién

52 Cffr. García Alcaraz, María Guadalupe, "El Centro Jalisco de la Unión de Padres de Familia (UNPF) 1917-1965", Revista Mexicana de Investigación Educativa 1, 1996/2, pp. 439-460.

53 Cfr. La Prensa, 5 de diciembre de 1935, p. 1; El Informador, 5 de diciembre de 1935, p. 1.

54 Cfr. Cárdenas, Lázaro, Escuela socialista y religión, México, Talleres Gráficos de la Nación, 1936, p. 3.

55 Ibidem, p. 8. Sobre los hechos ocurridos se puede ver El Informador, 31 de marzo de 1936, p. 1. 
Este libro forma parte del acervo de la Biblioteca Jurídica Virtual del Instituto de Investigaciones Jurídicas de la UNAM

nombrado arzobispo de México Luis María Martínez, ${ }^{56}$ quien por su carácter conciliador jugó un papel importante en la distensión, primero, con Lázaro Cárdenas, y en la reforma constitucional del artículo 3o., un poco más tarde, con Manuel Ávila Camacho.

Esta última tardaría un poco en llegar. En efecto, aunque impulsada por Ávila Camacho en los últimos meses de su gobierno, no sería sino hasta el 30 de diciembre de 1946 que, bajo la presidencia de Miguel Alemán, sería ratificada. Justo un año antes, el obispo Luis María Martínez ya había dado su opinión sobre el proyecto del presidente Ávila Camacho en estos términos:

El proyecto de ley enviado por el Señor Presidente de la República al Congreso de la Unión para reformar el artículo $3^{\circ}$ de la Constitución General de la República, aunque conserva las cortapisas a la libertad de enseñanza establecidas por la Constitución de 1917, constituye sin embargo un paso importante hacia la libertad porque aclara conceptos y remueve los obstáculos que con motivo de la reforma de dicho artículo hecha en 1934 turbaron la tranquilidad espiritual. La orientación que da a la enseñanza tiende a procurar la estabilidad de la familia, tan importante en las sociedades. ${ }^{57}$

En efecto, en dicha reforma se mantenía la prohibición de que las corporaciones religiosas y los ministros de culto intervinieran "en forma alguna en los planteles en que se imparta educación primaria, secundaria y normal" pero, por otro lado, se revivía la opción de que "los particulares podrán impartir educación en todos sus tipos y grados", aunque deberían obtener en cada caso la autorización expresa del poder público, con lo que se dejaba abierta una puerta a que, como ya lo habían hecho antes de Calles, los religiosos, y no sólo católicos sino también de otras religiones, pudieran con la discreción conveniente participar en la educación. Así, aunque también se conservaba la disposición de que el Estado podría "retirar discrecionalmente, en cualquier tiempo, el reconocimiento de validez oficial a los estudios hechos en planteles particulares", cesaba de golpe la obligación, al menos en la letra, de que toda la enseñanza que se impartiera en primaria, secundaria y normal fuera positivamente antirreligiosa, con lo que se daba por terminado el conflicto que se agudizó con la reforma de 1934.

56 Sobre las perplejidades para nombrar delegado a Martínez, véase Solis, Yves, "Un triángulo peligroso: la Santa Sede, Estados Unidos y México en la resolución del conflicto religioso mexicano durante los años 30", en Meyer, Jean (comp.), Las naciones frente al conflicto religioso en México, México, Tusquets, 2010, pp. 341-360.

57 AHAM, fondo episcopal: Luis María Martínez, caja 77, expediente 12. 
Este libro forma parte del acervo de la Biblioteca Jurídica Virtual del Instituto de Investigaciones Jurídicas de la UNAM

\section{A MODO DE CONCLUSIÓN}

En los debates del Constituyente de Querétaro en torno a la redacción del artículo 3o., confluyeron diferentes posturas sobre la actitud del Estado en relación con la enseñanza religiosa. Prevaleció la de los radicales que buscaban excluir todo tipo de elementos religiosos en la educación que se impartiera en las primarias, secundarias y escuelas normales, sin embargo, permaneció latente la de algunos otros, más radicales, que pretendían que ésta debería ser no solamente laica, en el sentido de ajena a cualquier orientación religiosa, sino directamente antirreligiosa. Esta idea no era la dominante ni siquiera en el grupo de los jacobinos, que se limitó a establecer algunos candados para garantizar la ausencia de corporaciones religiosas en esos niveles de educación, pues no se entendía cómo, precisamente en la sección de garantías individuales, se pudieran introducir mandatos legales que fueran claramente violatorios de esas mismas garantías. Sin embargo, ese deseo minoritario incluso entre los radicales, continuó en la mente de algunos y dio lugar a que, años después, se reanudara el debate y a que, en algunas legislaturas estatales, como Tabasco y Sonora, ya en los años treinta, se estableciera una educación no sólo laica, en el sentido de neutra, sino marcadamente antirreligiosa. Los esfuerzos de los partidarios de que esta debería de ser la que prevaleciera en todo el país, habrían de cristalizar en una reforma constitucional, impulsada desde antes, pero promulgada por el general Cárdenas, que establecía que la educación fuera socialista, entendida esta característica, al menos por sus promotores, como francamente antirreligiosa.

Esta decisión de impugnar desde el aula la religión en un país en el que más del 98\%,58 según el censo de 1930, mantenía su adhesión a alguna corriente religiosa, ocasionó grandes trastornos y desasosiego entre la población, incluyendo la decisión de muchos padres de familia de no enviar a sus hijos a la escuela.

Una decena de años después, la Constitución nuevamente habría de ser reformada en un sentido que, por lo menos, no condujera al Estado a convertirse en el árbitro de las decisiones personales sobre lo que cada individuo puede libremente creer y enseñar a sus hijos en materia religiosa. Fueron años de tensión e incluso de enfrentamientos, pero la accidentada duración de la enseñanza socialista como una imposición legal de un estilo de vida ajeno a la religión, permitió reconocer a los gobernantes y legisla-

58 Instituto Nacional de Estudios de Estadística, Geografía e Informática, Estados Unidos Mexicanos. Cien años de censos de población, Aguascalientes, INEGI, 1996, p. 114. 
Este libro forma parte del acervo de la Biblioteca Jurídica Virtual del Instituto de Investigaciones Jurídicas de la UNAM

dores que el Estado no puede arbitrariamente decidir o no sobre el camino religioso o no que elijan sus ciudadanos.

\section{FUENTES UTILIZADAS}

ARCE GuRZA, Francisco, "En busca de una educación revolucionaria", en Hamui Sutton, Mery, Antología de lecturas sobre la Historia de la Educación Básica en México, México, UAM Azcapotzalco, 1996.

Bastian, Jean-Pierre, Protestantismo y sociedad en México, México, CUPSA, 1983.

Bastian, Jean-Pierre, Los disidentes, México, Fondo de Cultura Económica, 1989.

Bremauntz, Alberto, La educación socialista en México. Antecedentes y fundamentos de la Reforma de 1934, México, s. i., 1943.

CÁRDEnAS, Lázaro, Escuela socialista y religión, México, Talleres Gráficos de la Nación, 1936.

Diario de los Debates del Congreso Constituyente 1916-1917, vol. I, México, SEPINEHRM-UNAM, Instituto de Investigaciones Jurídicas, 2014.

Diario de los Debates de la Cámara de Diputados del Congreso de los Estados Unidos Mexicanos, años 1918 y 1932.

Diario Oficial de la Federación, año 1934.

El Informador, años 1934-1936.

El Universal, años 1917 y 1926.

Elías Calles, Plutarco, Pensamiento político y social, Antología (1913-1936), México, Fondo de Gultura Económica, 1991.

García AlGaraz, María Guadalupe, "El Centro Jalisco de la Unión de Padres de Familia (UNPF) 1917-1965", Revista Mexicana de Investigación Educativa $1(1996 / 2)$.

GIUSEPPE, Massimo de, "El Tabasco racionalista frente a lo indígena: entre laboratorio social y experimentación cultural (1922-1934)", Historia Mexicana, LXI, 2011.

GONZÁLEZ MORFÍn, Juan, Murieron por sus creencias. La guerra de los cristeros, hitos $y$ mitos, México, Panorama, 2012.

Guerra, Francisco Xavier, México: del Antiguo Régimen a la Revolución, vol. 1, México, Fondo de Cultura Económica, 1988.

Guevara Niebla, Gilberto, La educación socialista en México (1934-1945), México, SEP, 1985. 
Este libro forma parte del acervo de la Biblioteca Jurídica Virtual del Instituto de Investigaciones Jurídicas de la UNAM

Hammond Murray, Robert, Mexico before the World. Public Documents and Addresses of Plutarco Elias Calles, Nueva York, The Academy Press, 1927.

Instituto Nacional de Estudios de Estadística, Geografía e Informática, Estados Unidos Mexicanos. Cien años de censos de población, Aguascalientes, Inegi, 1996.

La Prensa, año 1935.

Lloyd Mecham, James, Church and State in Latin America, Chapel Hill, The University of North Carolina Press, 1966.

MARTÍnez ASSAD, Carlos, Los lunes rojos. La educación racionalista en México, México, SEP-El Caballito, 1986.

New York Herald-Tribune, año 1926.

Olmos VelÁzQuez, Evaristo, "La educación salesiana en la Escuela de Artes y Oficios del Espíritu Santo-Colegio Salesiano, 1906-1922", Boletín Eclesiástico X (2016/5).

PALOMERA, Esteban J., La obra educativa de los jesuitas en Guadalajara, 15861986, Guadalajara, Instituto de Ciencias-ITESO-UIA, 1986.

Paz SÁnchez, Fernando, Narciso Bassols, México, Nuestro Tiempo, 1986.

PÉREz RAYÓn, Norma, "El anticlericalismo en México durante el Porfiriato. Modalidades, temas y manifestaciones", en PACHECO, María Marta (coord.), Religión y sociedad en México durante el siglo $X X$, México, INEHRM, 2007.

Solis, Yves, "Un triángulo peligroso: la Santa Sede, Estados Unidos y México en la resolución del conflicto religioso mexicano durante los años 30", en MEYER, Jean (comp.), Las naciones frente al conflicto religioso en México, México, Tusquets, 2010.

TORRES SEPtién, Valentina, "La educación socialista en la Ciudad de México", en Savarino, Franco et al. (coords.), Política y religión en la Ciudad de México. Siglos XIX y XX, México, IMDOSOC, 2014.

\section{Archivos consultados}

Archivio Segreto Vaticano, Archivio della Delegazione Apostolica in Messico. Archivo Histórico de la Arquidiócesis de México, fondo episcopal: José Mora y del Río y Pascual Díaz Barreto, Ciudad de México.

Archivo Plutarco Elías Calles del Fideicomiso Archivos Plutarco Elías CallesFernando Torreblanca. 
Este libro forma parte del acervo de la Biblioteca Jurídica Virtual del Instituto de Investigaciones Jurídicas de la UNAM

\title{
FRANCISCO J. MÚGICA, EL HOMBRE Y EL CONSTITUYENTE
}

\author{
Eduardo Alejandro LÓPEZ SÁNCHEZ* \\ Daniar CHÁvez JimÉNEZ*
}

\begin{abstract}
Sumario: I. Origen. II. Estudios en el seminario. III. Los inicios laborales. IV. Con Venustiano Carranza. V. Como administrador de aduanas. VI. El constituyente. VII. Participación en el artículo 30. VIII. Participación en el artículo 27. IX. Participación en el artículo 123. X. Bibliografia.
\end{abstract}

\section{ORIGEN}

Nace en el año de 1884, en Tingüindín, municipio de Michoacán, fue hijo del profesor Francisco J. Múgica y de la señora Agapita Velázquez Espinoza. El profesor Múgica Pérez, liberal de abolengo, ejerció su magisterio accidentalmente en Tingüindín. El abuelo materno también maestro de escuela, y anticlerical. El bisabuelo paterno, de raza indígena pura, fue esclavo, liberto más tarde, y según costumbre adoptó el apellido de su antiguo amo: Múgica, ${ }^{1}$ con el paso de los años los Múgica ejercieron la profesión de artesanos y curtidores. El general Múgica pasó su niñez e hizo sus estudios primarios y superiores en diversos municipios de Michoacán, debido a la profesión de su padre, en 1898 el profesor Múgica consiguió empleo como administrador de rentas en la ciudad de Zamora, motivo que permitió que la familia se estableciera en dicha población.

* Investigadores adscritos a la Unidad Académica de Estudios Regionales de la Coordinación de Humanidades, UNAM.

Se agradece la colaboración a María Guadalupe Ceja Herrera, María de la Luz Rubio Ocaranza y Denisse Moreno Zuno.

1 María y Campos, Armando de y Mondragón, Magdalena, Dos aproximaciones a la figura de Francisco f. Múgica, México, INEHRM, 2004, p. 12. 
Este libro forma parte del acervo de la Biblioteca Jurídica Virtual del Instituto de Investigaciones Jurídicas de la UNAM

\section{ESTUDIOS EN EL SEMINARIO}

En 1898 ingresa junto con su hermano Carlos al Seminario Diocesano de Zamora para estudiar la preparatoria, se mantenía en constante rebeldía contra las enseñanzas dogmáticas, habiéndose negado en forma rotunda a estudiar teología. Su rebeldía causó que fuera expulsado por el profesor de esa materia y aún amenazado de expulsión definitiva del Seminario.

...Se negó terminantemente a aceptar la explicación teológica, declarándose en una especie de huelga en este curso, pues invariablemente decía no saber la lección. Fue necesaria la intervención del Obispo de Zamora, para que con licencia especial de él Múgica dejara de asistir a la clase de Teología y pudiera continuar cursando las demás materias basadas en un fundamento y en una investigación científica. La rebeldía del joven Múgica hubiera trastornado toda la disciplina del Seminario, si el avisado Obispo no transige mediante una medida política. ${ }^{2}$

En 1904 culminó sus estudios en el Seminario; por otro lado, tomó cursos especiales de latín, que lo llevó a traducir las obras poéticas de Ovidio y Horacio. ${ }^{3}$ Uno de sus deseos era estudiar Medicina en la ciudad de Morelia, Michoacán, sueño que fue truncado por carencias económicas.

\section{LOS INICIOS LABORALES}

En 1906, a la edad de 22 años, obtiene un nombramiento de receptor de rentas en Chavinda. Empieza a tomar contacto con las clases populares, y se da cuenta de cómo, en los tiempos del ministro Dublán, se despoja, se roba cínica y cruelmente a los indios, arrancándoles a mísero precio sus tierras, porque hasta en el más modesto funcionario encuentran un cómplice los políticos del estado o del centro. ${ }^{4}$

Está en pleno apogeo la bárbara costumbre de las cuerdas o reemplazos, según la omnímoda voluntad del Prefecto Político que las forma, primero con delincuentes, con borrachitos después, y en seguida con el clásico y pintoresco

\section{Ibidem p. 13.}

3 "FranciscoJ. Múgica, el renovador social", recuperado el 9 de octubre de 2016, disponible en: http://eprints.uanl.mx/10894/1/Francisco\%207.\%20M\%C3\%BAgica\%20renovador\%20so cial.pdf, pp. 24 y 25.

4 María y Campos, Armando de, Múgica, crónica biográfica, México, Compañía de Ediciones Populares, 1939, p. 13. 
Este libro forma parte del acervo de la Biblioteca Jurídica Virtual del Instituto de Investigaciones Jurídicas de la UNAM

tipo del retobado, humilde ciudadano inconforme y rebelde en potencia, que muchas veces prefiere irse al cerro, de coyote, antes de ingresar a filas, tantas veces víctima de los apetitos que su hermana, su esposa o su hija, despertaban en el caciquelo en turno. Así fue como la Revolución, al llegar a Michoacán, encontró un hijo en cada "retobado", en cada "coyote"...5

\section{Anna Ribera Carbó señala que el General Múgica:}

...Se convirtió en un ávido lector de la prensa revolucionaria: el histórico $E l$ Hijo del Ahuizote, El Diario del Hogar, de Filomeno Mata y fundamentalmente, de Regeneración. De este último, manifestaba: "lo leí con avidez... y desde ese instante estuve en el futuro Partido Liberal Mexicano... Guardé el periódico en el interior de la camisa y lo volví a leer en casa. ${ }^{6}$

Así fue como decidió hacerse periodista, escribió un artículo y lo envió a San Luis, Missouri, a Regeneración, cuando recibió el siguiente número pudo ver sus palabras impresas en la primera plana; lo que lo llevó a ser nombrado corresponsal de la publicación en Michoacán. Publicó su primer periódico, El Rayo, semanario de seis páginas, con un tiraje de 800 ejemplares. Guando éste desapareció, le siguieron El Faro, La Voz, La Luz, La Prensa Libre y El Demócrata Zamorano. En el año 1907, con compañeros de sus años de estudiante, inició una campaña contra el gobernador de Michoacán, Aristeo Mercado, desde las páginas de El Ideal, el cual se imprimía en Guadalajara, ya que en Zamora se negaban por la fama de radical que tenía Múgica.

De la actividad periodística pasó a la labor política. En Zamora se pronunció por Bernardo Reyes para la Vicepresidencia de la República, e impidió la realización de un mitin a favor de Ramón Corral, el cual se llevaría a cabo en el Hotel García. Al considerar como detonador su oratoria, fue encarcelado. Desde la prisión siguió escribiendo para El Ideal, asimismo, le tocó vivir la reelección de Porfirio Díaz desde ahí. ${ }^{7}$

Múgica consideraba que las elecciones eran el camino para acabar con la dictadura de Porfirio Díaz, por lo que dijo:

Mas ese silencio, esa paz que humilla, ese reposo que envilece, debe sustituirse por la lucha legal, no por el motín que produce trastornos y perturba hondamente a las sociedades, sino por esa emulación honrada, ese combate

5 Ibidem pp. 13 y 14.

6 Ribera Carbó, Anna, La patria ha podido ser flor. Francisco 7. Múgica, una biografia política, México, INAH, 1999, pp. 20 y 21.

7 Ibidem, p. 21. 
Este libro forma parte del acervo de la Biblioteca Jurídica Virtual del Instituto de Investigaciones Jurídicas de la UNAM

digno en que todos procuran sobrepujar en patriotismo, poniendo en relieve grandes virtudes cívicas.

Sí, esa lucha del civismo dentro de la ley debe provocarse constantemente en los pueblos, porque es la vida de la democracia, la muerte del despotismo y el antídoto del abuso.

En medio de la paz que imponen los tiranos, se producen los más grandes crímenes.

¡Luchemos para que surja el civismo en la República!

¡Luchemos para que nuestra democracia viva y los derechos del hombre sean respetados!

Nunca olvides que los votos se cuentan por números y que la mayoría siempre gana.

Tú eres, ¡oh pueblo!, el mayor número en todas las democracias. Manifiesta tu fuerza dentro del derecho que reconoce la Ley. ${ }^{8}$

Al salir de prisión, fundó el último periódico que publicó en Michoacán, el cual llevaba por nombre 1910, un ejemplar costaba 2 centavos y se editaba en la imprenta "La Suiza" de Zamora. ${ }^{9}$

\section{Gon Venustiano Garranza}

En 1911 Venustiano Carranza tomó posesión de su candidatura para gobernador constitucional del estado de Coahuila y empezó a rodearse de ameritados auténticos revolucionarios; por lo que Múgica salió rumbo a Saltillo para ofrecerle sus servicios al nuevo gobernador de Coahuila. ${ }^{10}$

En 1912 era ya capitán de las fuerzas irregulares, desempeñándose así como ayudante de Carranza. Cuando éste se enteró de los acontecimientos de la Ciudad de México, que desembocaron en el golpe de Estado de Huerta y los asesinatos de Madero y Pino Suárez, envió al capitán Múgica, la noche del 10 de febrero de 1913 a la capital del país, para que una persona de su absoluta confianza hablará con el señor presidente, con la finalidad de informarle desde México sobre la verdadera situación. ${ }^{11}$

8 Múgica, Francisco J., "Luchar es vivir", Hechos, no palabras, México, INEHRM, 1985, pp. 33 y 34 .

9 Ribera Carbó, Anna, op. cit., p. 22.

10 María y Campos, Armando de y Mondragón, Magdalena, Dos aproximaciones a la figura de Francisco 7. Múgica, cit., p. 48.

11 Partido Revolucionario Institucional; Secretaría de Divulgación Ideológica, Francisco 7. Múgica. Serie: semblanzas y perfiles ideológicos de los hombres de la Revolución mexicana, México, núm. 9, 1985, p. 10. 
Este libro forma parte del acervo de la Biblioteca Jurídica Virtual del Instituto de Investigaciones Jurídicas de la UNAM

Múgica quien en días pasados había contraído matrimonio con Ángela Alcaraz, originaria de Zamora, Michoacán, ${ }^{12}$ no dudo en viajar a la Ciudad de México, a fin de cumplir con la encomienda que Venustiano Carranza le había hecho; sin embargo, al llegar a la capital le fue imposible hablar con el presidente Madero, por lo que se entrevistó con algunos miembros de su gabinete, informándole a Carranza por medio de telegramas noticias que iban afirmando el ánimo del gobernante de Coahuila, la gravedad de los sucesos que se desarrollaban en la capital de la República, ${ }^{13}$ cumpliendo con lealtad y valentía la comisión encomendada.

Días después de que Múgica regresara a Saltillo, Venustiano Carranza como gobernador constitucional de Coahuila de Zaragoza, primer Jefe del Ejército Constitucionalista, nombró a Múgica capitán primero ayudante de su estado mayor, "en atención a su civismo y por ser cabo primero de los rurales en depósito, en premio de sus servicios prestados a la Revolución de 1910 a $1911^{\prime \prime} .{ }^{14}$

El capitán Múgica fue de los primeros en seguir a don Venustiano Carranza en su decisión en defensa de la legalidad rota la usurpación de Huerta. Fue, entre los jóvenes oficiales que firmaron el Plan de Guadalupe (26 de marzo de 1913), un destacado propugnador por introducir los considerandos del mencionado Plan, y porque éste hiciera referencia a "lineamientos agrarios, garantías obreras, reivindicaciones y fraccionamientos de latifundios, absolución de deudas y abolición de tiendas de raya"... Permaneció al Estado Mayor de las fuerzas del Teniente Coronel del Primer Regimiento, Libres del Norte, Lucio Blanco. Cuando este Jefe, ya con el grado de General, operaba en el norte de Tamaulipas y luego de la toma de Matamoros, se llevó a cabo un acto agrario: "la repartición de una parte de la hacienda de Las Borregas conocida con el nombre de San Vicente de Chiquihuite y La Canasta”. Esto sucedió el 30 de agosto y el $1^{\circ}$ de septiembre de 1913 y, en dicho acontecimiento revolucionario, Múgica tuvo una decidida e influyente participación. El general Lucio Blanco otorgó al mayor Múgica amplias facultades para ordenar y conducir los servicios públicos y administrativos... ${ }^{15}$

En Matamoros Tamaulipas, ponen en práctica sus ideas sobre reivindicación de la tierra, convenciendo a Lucio Blanco de realizar la repartición

12 María y Campos, Armando de y Mondragón, Magdalena, Dos aproximaciones a la figura de Francisco 7. Múgica, cit., p. 49.

13 Ibidem, p. 51.

14 Ibidem, p. 52.

15 Partido Revolucionario Institucional; Secretaría de Divulgación Ideológica, Francisco 7. Múgica Serie: semblanzas y perfiles ideológicos de los hombres de la Revolución mexicana, cit., p. 10. 
Este libro forma parte del acervo de la Biblioteca Jurídica Virtual del Instituto de Investigaciones Jurídicas de la UNAM

de la hacienda de Félix Díaz denominada "los Borregos", entre los campesinos de Matamoros y los soldados constitucionalistas, acontecimiento que se llevó a cabo el 29 de agosto de $1913 .{ }^{16}$ Este reparto de tierras marca un precedente para la reforma agraria de la Revolución.

\section{GOMO ADMINISTRADOR DE ADUANAS}

En abril de 1914 es nombrado administrador de la Aduana del Puerto de Veracruz, posteriormente fue jefe del puerto de Tampico y en la Aduana de Matamoros. En la aduanas manejaban los fondos para que la lucha armada pudiese continuar. Se hacía la Revolución con la honradez y el patriotismo. En Veracruz suspendió a todos los empleados huertistas, en Tampico aprehendió y desarmó a la gendarmería montada "yanqui"; organizó el correo, la aduana, la oficina federal del timbre, un impuesto llamado "de barra"; hizo obras públicas; prohibió los juegos de azar, el tabaco y hasta el café. Asimismo, conoció muy de cerca las actividades de las compañías petroleras y los problemas obreros y con el "Gremio Unido de los Alijadores" se comprometió a la lucha laboral. ${ }^{17}$

\section{EL CONSTITUYENTE}

Venustiano Carranza, primer jefe del ejército constitucionalista y encargado del Poder Ejecutivo de la República, en uso de las facultades que le otorgaba el artículo 4o. reformado, de las adiciones al Plan de Guadalupe expedido en la H. Veracruz el 12 de diciembre de 1914, decreta lo siguiente:

Artículo 1o.- Se convoca al pueblo mexicano a elecciones de diputados al Congreso Constituyente, el que deberá reunirse en la ciudad de Querétaro, y quedar instalado el primero de diciembre del corriente año.

Artículo 2o.- La elección para diputados al Congreso Constituyente, será directa y se verificará el domingo 22 del próximo octubre, en los términos que establece la ley electoral, que se expide por separado, con la misma fecha... ${ }^{18}$

16 María y Campos, Armando de y Mondragón, Magdalena, Dos aproximaciones a la figura de Francisco F. Múgica, cit., p. 65.

17 Rodríguez Vilchis de Múgica, Cristina, "Múgica constituyente", VII fornadas de Occidente Francisco 7. Múgica, Jiquilpan, Centro de Estudios de la Revolución Mexicana "Lázaro Cárdenas", 1985, p. 90.

18 Bórquez, Djed, Crónica del Constituyente, México, INEHRM-UNAM, 2014, pp. 77 y 78. 
Este libro forma parte del acervo de la Biblioteca Jurídica Virtual del Instituto de Investigaciones Jurídicas de la UNAM

Francisco J. Múgica a sus 32 años formó parte del Congreso Constituyente de 1916-1917 representando al distrito 15 (Zamora) de Michoacán como diputado propietario; quien fungía como diputado suplente era Antonio Navarrete. Es importante mencionar que en dicho Congreso también se tenía la participación del distrito 14 de Jiquilpan, representado por Amadeo Betancourt como diputado propietario, además de éstos dos distritos, el Estado de Michoacán tenía otras representaciones en quince distritos más. ${ }^{19}$

El Congreso Constituyente se instaló en la ciudad de Querétaro, “... los presuntos diputados, quienes, conforme a la convocatoria del C. Primer Jefe del Ejército Constitucionalista, deberían reformar nuestra Constitución Política, de acuerdo con las necesidades del pueblo mexicano y los ideales de la Revolución que tocaba a su fin". ${ }^{20}$ Para Víctor Niemeyer "El Congreso Constituyente de 1916-1917 fue el acontecimiento más importante de la Revolución de 1910 y la Constitución que se redactó es la base legal de todo lo ocurrido en México desde 1917”..21

Para Cristina Rodríguez Vilchis de Múgica ${ }^{22}$ el general Múgica “...tendría una misión histórica: hacer valer plenamente la soberanía del Congreso Constituyente y proclamar la independencia del Congreso de Carranza, sin desconocer el ámbito de autoridad que la Revolución le había dado".

El general Múgica en el Congreso Constituyente pronunció la frase: “¡Delenda est Cartago!” seguido del mensaje siguiente:

Éstas palabras resonaron allá en la ciudad Eterna, en la capital del mundo antiguo, durante toda la época en que un gran hombre, el soberbio Catón, alentó a sus conciudadanos para luchar por la preponderancia de su patria. Estas palabras quiero yo, señores, que os recuerden que estamos en plena revolución triunfante; en momentos solemnes y para nosotros muy gloriosos, porque son el principio de la reconstrucción nacional, o, mejor dicho, el triunfo definitivo de la revolución, supuesto que del criterio que tengáis como legítimos representantes del pueblo mexicano depende la consumación de todos los ideales de esta augusta conmoción patria y el logro de todas las con-

19 Moreno, Daniel, El Congreso Constituyente de 1916-1917, México, UNAM, 1967, p. 73.

20 Hiriart Urdanivia, Humberto (coord.), Francisco 7. Múgica compromiso histórico con la revolución mexicana, México, Gobierno del Estado de Michoacán-INEHRM, 1985, p. 84.

21 Niemeyer Everhard, Víctor, "Reflexiones de los constituyentes: la Constitución de 1917 como resultado de la Revolución de 1910", Congreso Internacional sobre el 75 Aniversario de la Promulgación de la Constitución Política de los Estados Unidos Mexicanos, México, UNAMINEHRM-Instituto de Estudios Constitucionales de Querétaro, 1993, p. 146.

22 Rodríguez Vilchis de Múgica, Cristina, op. cit., p. 93. 
Este libro forma parte del acervo de la Biblioteca Jurídica Virtual del Instituto de Investigaciones Jurídicas de la UNAM

quistas que hemos soñado, y por las cuales muchas veces nos hemos batido en el campo de batalla, renunciando a la suprema aspiración de vivir... ${ }^{23}$

De acuerdo con lo que señala Djed Bórquez, Francisco J. Múgica fue "líder de las mayorías y conductor de la primera comisión de reformas... la figura más conspicua del Congreso". ${ }^{24}$

Armando de María y Campos ${ }^{25}$ manifiesta que la Primera Comisión de Puntos Constitucionales, que se nombró en la sesión del 6 de diciembre, quedó integrada por el general Múgica como presidente, además de Enrique Colunga, Luis G. Monzón, Enrique Recio y Alberto Romano, la cual debía de encargarse de analizar ese proyecto, artículo por artículo y presentar dictámenes a la Asamblea.

Los artículos de la Constitución de 1917 en cuya formulación intervino decisivamente el general Francisco J. Múgica, fueron los artículos 1o., 3o., 5o., 9o., 13, 27, 28, 115, 123 y 130.

Sin embargo, para efectos de este trabajo únicamente nos referiremos a tres importantes artículos constitucionales.

\section{PARTICIPACIÓN EN EL ARTÍCULO 30.}

Ortiz Escamilla menciona que:

Múgica logró plasmar sus ideas: propuso que la educación fuera laica e impartida por el Estado (artículo 3o.), se manifestó vigorosamente a favor del reparto agrario y en contra del acaparamiento de tierras por el clero y extranjeros (artículo 27), defendió inclaudicablemente el derecho de huelga de la clase obrera y las 8 horas como jornada máxima de trabajo (Art. 123). ${ }^{26}$

Melgar Adalid comenta que "el debate sobre la educación es uno de los primeros que se dan en el Congreso Constituyente y muestra las posiciones ideológicas de los constituyentes...".27

23 Hiriart Urdanivia, Humberto (coord.), op. cit., pp. 84 y 85.

24 Bórquez, Djed, op. cit., p. 506.

25 Dos aproximaciones a la figura del general Francisco 7. Múgica. Crónica biográfica, México, INERMH, 2004, p.113.

26 Ortiz Escamilla y Torres Aburto, Alfonso, "General Francisco J. Múgica. Un esquema biográfico", Nuevos ensayos sobre Francisco 7. Múgica, México, INEHRM, 2004, p. 20.

27 Melgar Adalid, Mario, "Comentario del artículo 3o.", en Cámara de Diputados del H. Congreso de la Unión, LV Legislatura, Derechos del pueblo mexicano. México través de sus Constituciones, 4a. ed., México, Porrúa, 1994, t. I, p. 115. 
Este libro forma parte del acervo de la Biblioteca Jurídica Virtual del Instituto de Investigaciones Jurídicas de la UNAM

De acuerdo con Ramírez Reynoso es célebre la intervención inicial que tuvo Múgica "al apoyar el dictamen de la comisión que presidia sobre el artículo 30. Estima, con razón, que se trata del momento más solemne y trascendente de la Revolución...”..28

Múgica da un mensaje a los diputados:

...estamos en el momento más solemne de la revolución... El momento en el que el Congreso Constituyente, aquí reunido, trata de discutir el artículo $3^{\circ}$ de la Constitución de los Estados Unidos Mexicanos... se trata nada menos que del porvenir de la patria, del porvenir de nuestra juventud, del porvenir de nuestra niñez, del porvenir de nuestra alma mater, que debe engendrarse en los principios netamente nacionales y en los netamente progresistas, y evidentemente, señores, la ciencia pedagógica ha hablado ya mucho sobre la influencia que la enseñanza religiosa, que la enseñanza de las ideas absurdas, ejerce sobre los individuos, para degenerarlos, no sólo en lo moral, sino también en lo físico. Yo soy profano en esas cosas, pero hay aquí en esta Asamblea muchos profesores eminentes que puedan hablar más claro que yo sobre este capítulo y a ellos dejo la palabra... ${ }^{29}$

En lo que respecta a este artículo 3o., se considera como el debate más entusiasta, de acuerdo con Camacho Guerrero:

Durante los debates del constituyente se produjeron estudios y discusiones profundos, apasionados y sinceros, en relación con varios artículos de la nueva Constitución, pero sin duda alguna, de todos ellos el debate más entusiasta, enardecido, furioso, aguerrido... versó en torno al artículo tercero y fue motivo y razón para que se dibujaran con pinceladas de énfasis, dos frentes parlamentarios: Representantes populares de vanguardia y diputados de espíritu tradicionalista... ${ }^{30}$

El proyecto del artículo 3o. que formuló la Comisión de Puntos Constitucionales, donde el general Múgica, presidía dicha Comisión, decía:

Artículo 3o. La enseñanza es libre; pero será laica la que se dé en los establecimientos oficiales de educación, lo mismo que la enseñanza primaria, elemental y superior que se imparte en los establecimientos particulares.

28 Ramírez Reynoso, Braulio, "Múgica: vértice y paradigma", en La Constitución mexicana de 1917. Ideólogos, el núcleo fundador y otros constituyentes, México, UNAM, 1990, p. 429.

29 Cámara de Diputados del H. Congreso de la Unión, LV Legislatura, Derechos del pueblo mexicano. México a través de sus Constituciones, t. I, 4a. ed., México, Porrúa, 1994, pp. 176 y 177.

30 Camacho Guerrero, Abel, Francisco f. Múgica en el Constituyente, México, Hersa, 1994, p. 59. 
Este libro forma parte del acervo de la Biblioteca Jurídica Virtual del Instituto de Investigaciones Jurídicas de la UNAM

Ninguna corporación religiosa, ni ministro de ningún culto podrá establecer o dirigir escuelas de instrucción primaria.

Las escuelas primarias particulares sólo podrán establecerse sujetándose a la vigilancia oficial.

En los establecimientos oficiales se impartirá gratuitamente la enseñanza primaria. $^{31}$

Camacho Guerrero ${ }^{32}$ menciona que "el resultado de la votación de este artículo fue de noventa y nueve votos en pro y cincuenta y ocho en contra. Así quedó y queda para la historia el precepto constitucional controvertido tan intensamente en el Constituyente de 1917'”.

Sin duda Múgica se consideraba enemigo del clero, toda vez que lo consideraba como "el más funesto y el más perverso enemigo de la patria". ${ }^{33}$ En este sentido, el general Múgica, ya abierto el debate, declara su anticlericalismo, Ramírez Reynoso señala que Múgica tenía la preocupación de "alejar a las escuelas del patronato de las instituciones religiosas y a los miembros de ella de la impartición directa de la enseñanza". ${ }^{34}$

De igual forma que “...la Comisión entendía por laica - he ahí la mano de Múgica - la enseñanza ajena a toda creencia religiosa, la enseñanza que trasmite la verdad y desengaña del error inspirándose en un criterio rigurosamente científico". ${ }^{35}$

\section{PARTICIPACIÓN EN EL ARTÍ́CULO 27}

Múgica también tuvo una participación importante en el artículo 27, donde en el primer párrafo de ese artículo, de acuerdo con Valdés Abascal, ${ }^{36}$ "se establece la propiedad originaria de la nación y el derecho que ésta tiene de transmitir a los particulares el dominio de las tierras y aguas comprendidas dentro del territorio nacional, constituyendo así la propiedad privada...".

En lo que respecta al congreso constituyente de 1916, en la 61a. sesión ordinaria, celebrada el 25 de enero de 1917, donde se presentó lo referente

\footnotetext{
31 Ibidem, pp. 115 y 116.

32 Idem.

33 Cámara de Diputados del H. Congreso de la Unión, LV Legislatura, Derechos del pueblo mexicano. México a través de sus Constituciones, cit., t. I, p. 177.

34 Ramírez Reynoso, Braulio, op. cit., p. 431.

35 Ibidem, p. 430.

36 Valdés Abascal, Rubén, "Comentario del artículo 27", en Cámara de Diputados del H. Congreso de la Unión, LV Legislatura, Derechos del pueblo mexicano. México a través de sus Constituciones, cit., t. IV, p. 244.
} 
Este libro forma parte del acervo de la Biblioteca Jurídica Virtual del Instituto de Investigaciones Jurídicas de la UNAM

a la propiedad en la República Mexicana y a palabras del presidente del Congreso: ${ }^{37}$

El artículo 27 tendrá que ser el más importante de todos cuantos contenga la Constitución que el H. Congreso viene elaborando. En este artículo tienen por fuerza que sentarse los fundamentos sobre los cuales deberá descansar todo el sistema de los derechos que pueden tenerse a la propiedad raíz comprendida dentro del territorio nacional...

La Comisión presidida por el general Múgica, tuvo en cuenta los siguientes elementos para proponer ante la Asamblea el artículo 27:

1. Debe considerarse la propiedad como derecho natural.

2. Cosa esencial es determinar la extensión de este derecho.

3. Se debe precisar a quien debe reconocerse capacidad para adquirir bienes raíces.

4. ¿Qué bases generales pueden plantearse siquiera como preliminares para la resolución del problema agrario?38

Por otro lado, en cuanto al tema de la iglesia para la adquisición y administración de bienes, como se manifiesta en la fracción II de este artículo 27, el general Múgica manifestó:

A nombre de la Comisión me permito informar a esta honorable asamblea acerca de los motivos que hubo para poner esta limitación; primero, porque hay muchos lugares de oración ocultos en las casas particulares, que son oratorios, capillas, y hasta allá no quiso llegar la Comisión; y segundo, porque como puede informar a ustedes el ministro de Fomento, una colonia de judíos rusos trata de avecindarse en México y ha solicitado el correspondiente permiso del gobierno para venir a colonizar una región del país, habiendo gestionado desde luego que se le permita construir sus templos y que se le den las suficientes garantías para consagrarse al culto de su religión. Esas han sido las razones que tuvo en cuenta la Comisión, pero una vez que la asamblea ha resuelto la reposición del párrafo que pide el C. Medina, la Comisión no tiene inconveniente en hacerlo. ${ }^{39}$

37 Ibidem, p. 483.

38 Camacho Guerrero Abel, op. cit., p. 201.

39 Cámara de Diputados del H. Congreso de la Unión, LV Legislatura, Derechos del pueblo mexicano. México a través de sus Constituciones, cit., t. IV, p. 518. 
Este libro forma parte del acervo de la Biblioteca Jurídica Virtual del Instituto de Investigaciones Jurídicas de la UNAM

En este artículo 27, Múgica defendió los intereses nacionales. Como manifiesta Ramírez Reynoso se propuso la limitación de los derechos de los extranjeros para adquirir propiedades en territorio mexicano:

...al abogar por la vida y la tierra comunales; al hacer aclaraciones sobre la ley agraria de 6 de enero de 1915 ("Ley de Luis Cabrera"); al pronunciarse por la devolución de tierras usurpadas a su legítimos propietarios... al reforzar, en fin, las argumentaciones de quienes perseguían el cumplimiento de la función social de la propiedad. ${ }^{40}$

En este mismo artículo Múgica responde al diputado Espinosa, quien manifestó que en la fracción VI pareciera que hay contradicción, a lo que le responde de la siguiente manera:

...se trata de las comunidades que comprenden tierras, bosques, y aguas, y que cuando se dicte la ley de fraccionamiento de esas comunidades sólo se repartirán las tierras; de tal manera que las aguas y los bosques siempre se disfrutarán en común, no pudiendo en ningún caso dividirse. Ésa es la mente de la fracción según puede verse. ${ }^{41}$

Más adelante se abordan otras cuestiones referentes a este artículo, en el cual Francisco J. Múgica expresa a los diputados:

El caso que pone el C. Cepeda Medrano no es precisamente el caso de la ley. Se trata de propiedades que fueron usurpadas por medio de la fuerza; así claramente lo dice el Proyecto: que esas propiedades serán devueltas a sus dueños sin ningún requisito, por el solo hecho de establecerlo así la Constitución. Además, la ley de 6 de enero cuando trató precisamente de dotar a las comunidades o a los pueblos, de terrenos de que ahora carecen, cuando no tenían tierras que reclamar y reivindicar, que son de los que trata el señor Cepeda Medrano, no tendrían sus actuales poseedores ninguna justicia para hacer reclamaciones, no habiendo tampoco lugar a indemnización ninguna. Entonces, digo, la misma ley de 6 de enero establece que cuando algún individuo sea despojado de algún terreno para ser entregado a una comunidad o a un pueblo, el interesado puede ocurrir a los tribunales del orden común a deducir los derechos que tenga. Si los tiene, es claro que se dictará un fallo a su favor el que no le da más derecho que a la indemnización que expresamente dice la ley que dará el gobierno. Éste sabrá con qué clase de dinero paga al

40 Ramírez Reynoso, Braulio, op. cit., pp. 431 y 432.

41 Cámara de Diputados del H. Congreso de la Unión, LV Legislatura, Derechos del pueblo mexicano. México a través de sus Constituciones, cit., t. IV, p. 526. 
Este libro forma parte del acervo de la Biblioteca Jurídica Virtual del Instituto de Investigaciones Jurídicas de la UNAM

propietario; es cuestión secundaria que a nosotros no nos corresponde tocar (Voces: ¡A votar!). ${ }^{42}$

\section{PARTICIPACiÓN EN EL ARTíCULO 123}

El artículo 123 de la Constitución de 1917 fue otro de los artículos donde Múgica intervino, el cual tiene como antecedente el artículo 5o., en lo que respecta al título VI del trabajo y de la previsión social, en el artículo 123 se establece que:

El Congreso de la Unión y las legislaturas de los estados deberían expedir leyes sobre el trabajo, fundadas en las necesidades de cada región, sin contravenir a las bases siguientes, las cuales regirán el trabajo de los obreros, jornaleros, empleados, domésticos y artesanos y, de una manera general, todo contrato de trabajo... ${ }^{43}$

\section{$\mathrm{Al}$ respecto señala Camacho Guerrero ${ }^{44}$ que:}

Durante las discusiones originadas en torno al artículo 5o., Múgica planteó su concepción de lo que debería hacer la ley obrera en favor de los trabajadores, pues leyendo detenidamente sus exposiciones relacionadas con los dictámenes relativos a la materia, se viene al conocimiento de que concibió lo que más tarde sería el contenido del artículo 123, es decir, el fundamento de la ley laboral de la Revolución Mexicana.

Múgica hace una intervención para poner de manifiesto a los obreros presentes en la asamblea lo siguiente:

...la diferencia que establece la comisión entre la redacción que presenta al debate y la redacción correspondiente al proyecto de la comisión. Desde este punto de vista en que nos hemos colocado, desde luego debe considerarse que no debemos llegar, como acaba de decir el señor diputado De la Barrera, al libertinaje. Creíamos nosotros que la fracción XVIII les ponía más trabas o que más bien podía dar lugar a que hubiera más motivos para que se verificara una huelga, y por esta razón la comisión aceptó mejor la redacción que le ha dado el proyecto. Uno y otro dicen así. Dice el proyecto: "las huelgas

42 Ibidem, pp. 530 y 531.

43 Cámara de Diputados del H. Congreso de la Unión, LV Legislatura, Derechos del pueblo mexicano. México a través de sus Constituciones, cit., t. XII, p. 484.

44 Camacho Guerrero, Abel, op. cit., p. 156. 
Este libro forma parte del acervo de la Biblioteca Jurídica Virtual del Instituto de Investigaciones Jurídicas de la UNAM

serán licitas cuando, empleando medios pacíficos, lleven por objeto conseguir el equilibrio entre los factores capital y trabajo, para realizar la justa distribución de los beneficios". ${ }^{45}$

Lo que se puso a consideración se definía así: "Las huelgas serán licitas cuando tengan por objeto conseguir el equilibrio entre los diversos factores de la producción armonizando los derechos del trabajo con los del capital". ${ }^{46}$ Con ello esta parte se modificaba, Múgica refiriéndose en particular a los ferrocarrileros quienes promovían huelgas cuando sus servicios eran más necesarios, respondiendo al diputado Zavala refiriéndose que "...la huelga había tenido lugar en los momentos en que el gobierno necesitaba más de los ferrocarrileros, y esto es la verdad". ${ }^{47}$

Posteriormente, el C. Gracidas frente a tribuna expresa que "El diputado Múgica asegura que si se hiciera valer los contratos por medio de ese artículo transitorio, sería hacer valer una ley retroactiva...", ${ }^{48}$ a lo que Múgica manifestó que:

La comisión considera que no debe tener en cuenta la adición que propone el señor diputado Gracidas, porque de la misma manera que pudiera favorecerse algún contrato favorable al obrero, también pudiera favorecer algún contrato que le fuera perjudicial o que no estuviera sujeto a las bases que previene esta ley. Por otro parte, por un principio de justica, creemos que desde el momento en que estén en vigor todas estas bases que nosotros hemos dado para la protección de la clase trabajadora, así como la garantía del capital, deben sujetarse los contratos a esas bases. Por lo mismo debe considerarse esta adición. ${ }^{49}$

Es importante destacar que durante la discusión del artículo 9o. el derecho de la gente a expresar libremente su pensamiento, así como del ciudadano de asociarse para tomar parte en los asuntos políticos del país, surge lo relacionado con las huelgas. ${ }^{50}$

El general Múgica:

45 Cámara de Diputados del H. Congreso de la Unión, LV Legislatura, Derechos del pueblo mexicano. México a través de sus Constituciones, t. XII, cit., p. 501.

46 Idem.

47 Ibidem, p. 503.

48 Ibidem, p. 506.

49 Ibidem, p. 507.

50 Rodríguez Vilchis de Múgica, Cristina, op. cit., p. 100. 
Este libro forma parte del acervo de la Biblioteca Jurídica Virtual del Instituto de Investigaciones Jurídicas de la UNAM

Fue irreductible y coherente con sus principios. En lo que le interesaba influir era en la mayoría del Congreso y ante esa mayoría fue conveniente en el momento y se preocupó de ser bien visto en su conducta pues jamás respondió con injurias a los ataques injuriosos... Intervino cuantas veces lo consideró con la inteligencia y el tono adecuado... ${ }^{51}$

El 4 de febrero de 1954, el general Francisco J. Múgica ya enfermo, dicta su último discurso a favor de la Constitución de $1917 .{ }^{52}$

En 1984 se lleva a cabo la inscripción de su nombre en letras de oro en el recinto del Congreso de la Unión a iniciativa de los poderes de los estados de Michoacán, Tabasco y Baja California Sur. ${ }^{53}$

\section{BibliografíA}

BórQuez, Djed, Crónica del Constituyente, México, INEHRM-UNAM, Instituto de Investigaciones Jurídicas, 2014.

Camacho Guerrero, Abel, Francisco 7. Múgica en el Constituyente, México, Hersa, 1994.

Cámara de Diputados del H. Congreso de la Unión, LV Legislatura, Derechos del pueblo mexicano, México a través de sus constituciones, 4a. ed., México, Porrúa, 1994, ts. I, IV Y XII.

Hiriart Urdanivia, Humberto (coord.), Francisco 7. Múgica compromiso histórico con la Revolución mexicana, México, Gobierno del Estado de MichoacánINEHRM, 1985.

MARÍA Y CAMPOS, Armando de, Dos aproximaciones a la figura del general Francisco 7. Múgica. Crónica biográfica, México, INERMH, 2004.

María y Campos, Armando de y Mondragón, Magdalena, Dos aproximaciones a la figura de Francisco 7. Múgica, INEHRM, México 2004.

María y Campos, Armando de, Múgica, crónica biográfica, México, Compañía de Ediciones Populares, 1939.

Melgar Adalid, Mario, "Comentario del artículo 3o.", Derechos del pueblo mexicano, México través de sus Constituciones, 4a. ed, México, Cámara de Diputados del H. Congreso de la Unión, LV Legislatura-Porrúa, 1994, t. I.

51 Ibidem, p. 111

52 Moctezuma Barragán, Javier, Francisco f. Múgica, un romántico rebelde, México, Fondo de Cultura Económica, 2001, p. 678.

53 Idem. 
Este libro forma parte del acervo de la Biblioteca Jurídica Virtual del Instituto de Investigaciones Jurídicas de la UNAM

Moctezuma Barragán, Javier, Francisco 7. Múgica, un romántico rebelde, México, Fondo de Cultura Económica, 2001.

Moreno, Daniel, El Congreso Constituyente de 1916-1917, México, UNAM, 1967.

MúgicA, Francisco J., "Luchar es vivir", Hechos, no palabras, México, INEHRM, 1985.

NiEmeyer Everhard, Víctor, "Reflexiones de los constituyentes: la Constitución de 1917 como resultado de la Revolución de 1910", Congreso Internacional sobre el 75 Aniversario de la Promulgación de la Constitución Política de los Estados Unidos Mexicanos, México, UNAM- INEHRM-Instituto de Estudios Constitucionales de Querétaro, 1993.

Ortiz Escamilla y TORREs AbURTo, Alfonso, "General Francisco J. Múgica. Un esquema biográfico", Nuevos ensayos sobre Francisco f. Múgica, México, INEHRM, 2004.

Partido Revolucionario Institucional, Serie: Semblanzas y perfiles ideológicos de los Hombres de la revolución Mexicana, No. 09, Francisco 7. Múgica, México, 1985.

Ramírez Reynoso, Braulio, "Múgica: vértice y paradigma", La Constitución mexicana de 1917. Ideólogos, el núcleo fundador y otros constituyentes, México, UNAM, 1990.

Ribera Carbó, Anna, La patria ha podido ser flor. Francisco 7. Múgica, una biografia política, México, INAH, 1999.

RodríGuez VILCHIS DE MúGICA, Cristina, "Múgica constituyente", en VII fornadas de Occidente Francisco 7. Múgica, Jiquilpan, Centro de Estudios de la Revolución Mexicana "Lázaro Cárdenas", 1985.

VALDÉS ABASGal, Rubén, "Comentario del artículo 27", Derechos del pueblo mexicano. México a través de sus Constituciones, t. IV, México Cámara de Diputados del H. Congreso de la Unión, LV Legislatura-Porrúa, 1994. 
Este libro forma parte del acervo de la Biblioteca Jurídica Virtual del Instituto de Investigaciones Jurídicas de la UNAM

\title{
JOSÉ NATIVIDAD MACÍAS: JURISTA, CONSTITUYENTE Y RECTOR
}

\author{
José Luis Soberanes FernándeZ*
}

\author{
Sumario: I. Datos biográficos. II. Macías como constituyente. III. Macías \\ y el Proyecto.
}

\section{DATOS BIOGRÁFICOS}

En nuestra modesta opinión, el licenciado don José Natividad Macías fue la figura más importante en el Congreso Constituyente, celebrado en la ciudad de Querétaro entre diciembre de 1916 y enero de 1917, el noveno de nuestra historia. Infortunadamente, la historiografía jurídica mexicana no le ha hecho justicia a tan egregio personaje.

En efecto, Macías, junto con Luis Manuel Rojas, fueron los redactores del proyecto del primer jefe del Ejército Constitucionalista, encargado del Poder Ejecutivo Federal, Venustiano Carranza, mismo que sirvió como base a las discusiones del citado Constituyente, ${ }^{1}$ a pesar de que la Secretaría de Justicia elaboró otro Proyecto, Carranza prefirió presentar el de Macías y Rojas. Macías fue uno de los más lúcidos oradores (aunque un poco majagranzas), uno de los más importantes escritores de los artículos 27 y 123 de nuestra ley suprema, además, encabezó el grupo de diputados carrancistas, el de los llamados renovadores en esa magna asamblea. Entonces, ¿por qué motivo la historiografía no le ha hecho justicia? En primer lugar, reconozcamos que la historia es una disciplina caprichosa, que ama, odia o desprecia a quien quiere, no a quien debe, si no, hay que echarle una mirada al panteón de la patria de los héroes de nuestra independencia (o sea, las calles

\footnotetext{
* Investigador en el Instituto de Investigaciones jurídicas de la UNAM.
}

1 Fernando Lizardi dice que en la redacción de ese Proyecto participaron, además, Félix F. Palavicini, Alfonso Cravioto y algunos otros más. Cfr. el discurso del 26 de febrero de 1955 que más adelante citamos. 
Este libro forma parte del acervo de la Biblioteca Jurídica Virtual del Instituto de Investigaciones Jurídicas de la UNAM

céntricas de nuestros pueblos y ciudades) en donde ni son todos los que están ni están todos los que son.

Independientemente de esta consideración general, pensamos que son dos las causas que han originado esa "mala suerte histórica" de don José Natividad: en primer lugar, porque fue diputado federal entre 1906 y 1910 , en las últimas legislaturas porfirianas, la XXIII y la XXIV, en donde hizo amistad con el senador coahuilense Venustiano Carranza, y, luego, postulado por el Partido Antirreleccionista, fue integrante de la XXVI (1912-1913) coincidente con el gobierno de Francisco I. Madero. En esta última circunstancia se ha querido ver una mancha en la vida pública del licenciado, pues aprobó las renuncias del presidente y del vicepresidente, Madero y Pino Suárez, aunque el 9 de octubre de 1913, el usurpador Victoriano Huerta lo encarceló junto con otros diputados, ${ }^{2}$ después de disolver la XXVI legislatura. Sobre este particular, tenemos que destacar que fue el propio Álvaro Obregón, quien, el 22 de diciembre de 1916, hizo tal imputación; particularmente nos referimos a la carta que el 20 de diciembre de 1916 dirigió el propio Obregón al Constituyente y fuera leída en el seno de éste dos días después, en ella se decía:

Al dirigirme a esa honorable asamblea, como lo hago, no me impulsa otro móvil que el hacer algunas declaraciones que, en mi concepto, son necesarias para que el grupo de diputados ex-renovadores que figura en ese Congreso, grupo dirigido por J. Natividad Macías, Felix F. Palavicini y Luis Manuel Rojas, no continúe lanzando cargos más o menos aventurados en la investigación que pretende hacer sobre quién o quiénes son las personas que trataron de encauzar los criterios de los CG. diputados revolucionarios radicales para rechazar las credenciales de aquéllos a fin de que no formaran parte del Congreso Constituyente.

\section{Y más adelante señaló:}

Con mi carácter de revolucionario y de ciudadano, declaro: Que no hemos sido el señor licenciado Acuña, ni el señor licenciado Estrada, ni el señor Licenciado Aguirre Berlanga, ni yo, sino la conciencia nacional, la que ha exigido y sigue exigiendo al grupo de diputados revolucionarios radicales el cumplimiento del deber, esa misma conciencia nacional que sancionó el fallo del C. Venustiano Carranza. Primer Jefe del ejército constitucionalista, cuando éste, por medio del Plan de Guadalupe, condenó la conducta de los diputados

2 Marta Morineau hace una descripción bastante completa de estos avatares de don José Natividad. Cfrr. "José Natividad Macías", La Constitución mexicana de 1917: ideólogos, el núcleo fundador y otros constituyentes, México, UNAM, 2016, pp. 266-268. 
Este libro forma parte del acervo de la Biblioteca Jurídica Virtual del Instituto de Investigaciones Jurídicas de la UNAM

renovadores que invistieron al usurpador Huerta, de una criminal apariencia de legalidad.

\section{Para concluir posteriormente:}

EL C. Primer Jefe ha declarado, que los diputados renovadores que continuaron al lado de Huerta lo hicieron así por virtud de instrucciones suyas (del C. Primer Jefe); pero como tales instrucciones no pudieron ser dadas con anterioridad al decreto condenatorio, porque de esta manera hubiera resultado falso el decreto [dado en Durango el 7 de agosto de 1913], se deduce:

1o. - Que los repetidos diputados renovadores colaboraron con Huerta y de hecho sancionaron sus actos criminales por espacio de medio año.

2o. - Que, si posteriormente hicieron alguna labor en contra de Huerta, son merecedores, en concepto mío, a un nuevo cargo que antes de ahora no se había hecho pesar sobre ellos; esto es: haber traicionado a Huerta.

Y esto viene precisamente a robustecer los cargos que yo he tenido siempre para ellos, pues tal hecho demuestra que esos personajes son ventajosamente utilizables como elementos de traición; dándonos todos esos antecedentes el derecho de suponer que, con instrucciones del señor Carranza traicionaron después a Huerta; sin ser remoto — y allá van encaminados los temores de los revolucionarios de verdad - que ahora simulen estar colaborando al lado del señor Carranza, con instrucciones del arzobispo Mora y del Río o de Emiliano Zapata.

Ningún hombre, aun con la intriga más hábilmente manejada, podría demostrar que los renovadores habían permanecido en el Congreso después de los asesinatos cometidos por Huerta y después de la sentencia en contra de ellos pronunciada por el C. Primer Jefe, si no fuera este un hecho que está en la conciencia misma de los que ahora quieren aparecer calumniados; como no habrá intriga que intente demostrar que el senador Belisario Domínguez y los diputados renovadores Gustavo Garmendia, ingeniero Alfredo Robles Domínguez, Roberto V. Pesqueira, Rafael Zubaran Capmany y otros, hayan faltado al cumplimiento de su deber; el primero lanzado su viríl acusación en contra del usurpador en pleno Senado, y los últimos aprovechando la primera oportunidad para salir huyendo de la complicidad a incorporarse a la revolución.

En efecto, como relata Juan de Dios Bojórquez, ${ }^{3}$ desde que se discutió la credencial del diputado Ezquerro se vislumbró que el Congreso Constituyente de 1916-1917 estaba dividido en dos facciones, ${ }^{4}$ una llamada de Los

3 Cfr. Crónica del Constituyente, 4a. ed., México, INEHRM-UNAM, Instituto de Investigaciones Jurídicas, 2014, pp. 117-120.

4 Confirmado por el diputado Pastor Rouaix; cfr. Génesis de los artículos 27 y 123 de la 
Este libro forma parte del acervo de la Biblioteca Jurídica Virtual del Instituto de Investigaciones Jurídicas de la UNAM

Renovadores, "que se quedaron en México en 1913 y 1914, sancionando los actos o dando fuerza legal al usurpador, habían rodeado en Veracruz a don Venustiano y se hacían pasar por sus amigos más íntimos", a los cuales definió Luis Manuel Rojas (él mismo pertenecía al grupo) como "las personas que tienen, por circunstancias especiales, el propósito de sostener en este congreso el proyecto del C. Primer Jefe tal como fue presentado... forman lo que, a mi juicio, debe llamarse el grupo liberal carrancista"; mientras que, por otro lado, estaban los radicales también llamados jacobinos-obregonistas que, según los definió el propio Rojas, "se han caracterizado porque representan el criterio francés de la política”, de los cuales Palavicini ${ }^{5}$ aseguró "estaba integrada por elementos liberales, casi todos masones, que como afines a la revolución fueron apoyados por el grupo triunfante".

Sobre este mismo particular, el también constituyente guanajuatense, amigo personal de Macías, Fernando Lizardi, como veremos más adelante, señala en el discurso de 1955:

Y aún cuando algunos diputados renovadores fueron inmediatamente a ponerse a las órdenes del Primer Jefe del Ejército Constitucionalista, el mismo señor Carranza se dio cuenta de que si todos los miembros de ese Congreso se separaban de él y lo abandonaban para ir a ponerse francamente al lado de la Revolución, Victoriano Huerta fácilmente podría improbar un Congreso de burlas que diera cierto aspecto de legalidad a su Gobierno. Por este motivo, el señor Carranza, por conducto de don Eliseo Arredondo, mandó decir a muchos diputados renovadores que permanecieran en sus puestos, a fin de obstruccionar al llamado gobierno de Huerta, lo cual se hizo, dando por resultado la disolución del Congreso y la prisión de muchos diputados, entre los cuales se encontraba el señor Licenciado don José Natividad Macías.

En el fondo, estamos en presencia de la controversia entre diputados carrancistas y diputados obregonistas, cuyo diferendo se vio claramente en la discusión del artículo tercero constitucional; ${ }^{6}$ diferencia que se resolvió a favor de los seguidores de Obregón - los radicales - por una simple razón aritmética: eran más. Como don José Natividad era de los de Carranza - los renovadores — que, como eran menos, resultaron perdedores y en el resto del Constituyente ya no se volvieron a confrontar como tales (eviden-

Constitución Política de 1917; edición original: Puebla, Gobierno del estado de Puebla, 1945. Nosotros hemos manejado el recopilado en: El pensamiento mexicano sobre la Constitución de 1917, Antología, México, Gobierno del Estado de Querétaro-INEHRM, 1987, pp. 261-264.

5 Cfr. Palavicini, Félix F., Historia de la Constitución de 1917 [ed. facsimilar tomada de la del Gobierno del estado de Tabasco, 1980], México, INEHRM-UNAM, 2014, t. I, p. 63.

6 Cfr. Nuestro libro: Y la Revolución se hizo Constitución, México, Porrúa, 2016, pp. 109 y ss. 
Este libro forma parte del acervo de la Biblioteca Jurídica Virtual del Instituto de Investigaciones Jurídicas de la UNAM

temente hasta Tlaxcalantongo, en donde perdieron en definitiva). Esa fue la segunda razón de la "mala suerte histórica" a la que nos referíamos antes.

El licenciado Macías nació en Pavileros, municipio de Silao, estado de Guanajuato, el 8 de septiembre de 1857, hijo de Pedro Macías y María Cleofas Castorena de Macías. Realizó sus estudios primarios en Silao, los preparatorios en el Seminario diocesano de León (aunque no le fueron revalidados por la institución oficial del estado, por ello tuvo que acreditar las correspondientes asignaturas en exámenes a título de suficiencia) $)^{7}$ y los profesionales de derecho en el Colegio del Estado, ${ }^{8}$ en donde obtuvo su título el 24 de noviembre de 1883, y se dedicó al ejercicio de su profesión, primero como pasante y luego como abogado en el bufete de quien era rector del mismo Colegio, licenciado Manuel Lizardi, con quien trabó una gran amistad, lo mismo que con su hijo, el también constituyente Fernando Lizardi; incluso, cuando don Manuel tuvo que retirarse del ejercicio profesional por motivos de salud, Macías encabezó el despacho.

A principio de siglo se trasladó a la Ciudad de México a continuar con el ejercicio del derecho, obligado porque a la muerte del gobernador González, Joaquín Obregón González asumió la gubernatura interina de Guanajuato dedicándose a perseguir, entre otros, al licenciado Macías.

Aquí llegamos a un punto nada claro en la vida de don José Natividad: su paso por el Congreso de la Unión. Manuel González Oropeza, ${ }^{9}$ indica que fue diputado suplente por Tlaxcala durante las XIX (1898-1900) y XXII (1904-1906) legislaturas, y diputado propietario por Guanajuato en la XXIII (1906-1908), y dos veces por Michoacán en las legislaturas XXIV (1908-1910) y XXV (1910-1912).

Dicen, como apuntamos antes, que se trasladó de su natal Guanajuato a la Ciudad de México a principios del siglo XX, para ejercer su profesión de abogado, dentro de la cual derrotó al propio presidente de la República, general Porfirio Díaz, en un juicio civil patrocinando al hacendado queretano, don Manuel Urquiza, lo que motivó a don Porfirio a invitar al licenciado Macías a ser diputado en esas legislaturas.

7 No obstante haber manifestado su deseo de no continuar la carrera eclesiástica, el obispo José María Díez de Sollano permitió que continuase en la preparatoria de la Iglesia, dado su talento, y después lo contrató como profesor de latín para que con lo que le pagase pudiera sostener sus estudios de derecho.

8 No es cierto, como han afirmado algunos, que haya estudiado en la Escuela Nacional Preparatoria ni en la Escuela Nacional de Jurisprudencia, sino en su Guanajuato, como apuntamos antes.

9 Cfr. Los diputados de la nación, México, Cámara de Diputados del Congreso de la UniónSecretaría de Gobernación, 1994, p. 159. 
Este libro forma parte del acervo de la Biblioteca Jurídica Virtual del Instituto de Investigaciones Jurídicas de la UNAM

El constituyente Fernando Lizardi, hijo de don Manuel, como vimos antes, quien se refería a don José Natividad como su "jefe, maestro y amigo" (en 1901 se invirtió lo que había sucedido con su padre, ya que se incorporó como pasante del despacho de Macías en la Ciudad de México) en un discurso pronunciado en la ciudad de Silao, el 26 de febrero de 1955, al cual nos referimos antes, con ocasión de la inauguración de una escuela que llevaría el nombre de José Natividad Macías, relató una historia diferente.

Nos cuenta Lizardi que Macías patrocinó jurídicamente al estado de Tlaxcala en un asunto muy importante, que ganó; cuando el gobernador, coronel Próspero Cahuantzi quiso cubrir sus honorarios profesionales, don José Natividad se negó a ello aduciendo que servir a un estado en estos menesteres es servir a toda la República, además de la amistad personal con el secretario particular del gobernador, Gerzain Ugarte, con quien coincidió en la XXVI Legislatura federal y en el Congreso Constituyente.

Sigue relatando Lizardi que el gobernador Cahuantzi quiso recompensar al licenciado Macías con una diputación federal, pero el presidente Porfirio Díaz, dada su amistad con el hostil gobernador guanajuatense Obregón González, se negó a ello y dijo, con socarronería, que más le correspondería una senaduría pues había servido a todo el estado, pero, como ya se la había ofrecido al ingeniero Manuel María Contreras, con quien tenía compromisos previos, hicieran a Macías senador suplente de este último, como así sucedió; pero, ¡sorpresas tiene la vida! y poco tiempo después de la elección falleció Contreras en 1902 y el escaño lo ocupó nuestro epónimo.

Independientemente de lo afirmado por González Oropeza, Macías fue diputado federal representando a Guanajuato a la XXVI Legislatura (19121913, inconclusa porque la disolvió Victoriano Huerta, como dijimos antes), correspondiente a la administración de don Francisco I. Madero, postulado igualmente por el Partido Antireelecionista, como señalamos antes.

De acuerdo con lo anteriormente descrito, el cambio radical de legislador porfirista a diputado revolucionario en la XXVI legislatura, junto con su amistad con don Venustiano Carranza, salvaron el "pellejo" (político) a nuestro biografiado. Mismo que, posteriormente, se incorporó al movimiento constitucionalista.

En otro orden de ideas, fue profesor de derecho civil y director de la Escuela Nacional de Jurisprudencia del 28 de agosto 1914 al 19 de noviembre del mismo año, ${ }^{10}$ por designación del primer jefe Venustiano Carranza.

Más adelante, acompañando al propio señor Carranza en su retiro de Veracruz, durante lo más álgido de la confrontación de la facciones revolu-

10 Cfr. Mendieta y Núñez, Lucio, Apuntes para la historia de la Facultad de Derecho, México, UNAM, 2002, p. 47. 
Este libro forma parte del acervo de la Biblioteca Jurídica Virtual del Instituto de Investigaciones Jurídicas de la UNAM

cionarias a finales de 1914 y principios de 1915, cuando se daba a la tarea de expedir la legislación preconstitucional, el propio Carranza lo nombró, junto con Cravioto, miembro de la Sección de Legislación Social de la Secretaría de Instrucción Pública, la que redactó la Ley Agraria de 1915 y el Proyecto de Ley del Trabajo en el mencionado puerto de Veracruz, para lo cual, por indicaciones del mismo don Venustiano, se trasladó a los Estados Unidos para enterarse de los avances en esta materia.

No podemos dejar de mencionar que, como informa Diego Valadés, ${ }^{11}$ a fines de 1914, junto con el mismo Alfonso Cravioto, elaboraron un proyecto de ley que establecía la autonomía de la Universidad Nacional, y más adelante señala el mismo Valadés:

En una entrevista de prensa publicada por El Universal el 11 de julio de 1917, el Rector de la Universidad José Natividad Macías, conforme a la posición que ya había sostenido tres años antes, se declaró partidario de la autonomía de la Universidad, independizándola por completo de la política. Para este efecto, dijo, en el Congreso Constituyente de Querétaro se trabajó por la supresión de la Secretaría de Instrucción Pública a efecto de que correspondiera a la Universidad la responsabilidad directa de atender las funciones de enseñanza superior y para ponerla al margen de las inquietudes políticas que resultaban del manejo del Ministerio. Fue por esto que Venustiano Carranza apoyó la creación del Departamento Universitario.

En el proyecto que José Natividad Macías presentó al Presidente Venustiano Carranza en 1917 se establecía que el Rector de la Universidad sería "jefe nato" de la institución. Con eso se quería significar que el Rector no tendría ningún superior jerárquico. No obstante, su nombramiento correspondería al Presidente de la República, a propuesta del Consejo Universitario.

$\mathrm{Al}$ regreso a la Ciudad de México, Carranza lo nombró, el 1o. de julio de 1915, rector de la Universidad Nacional, cargo que ocupó hasta el 22 de noviembre de 1916, y retomó después de celebrado el Constituyente, como apuntaremos más adelante.

Fue diputado constituyente por Silao, Guanajuato, y redactó, ya lo señalamos, junto con Luis Manuel Rojas, el Proyecto de Constitución. Al terminar el Constituyente regresó como rector del 3 de mayo de 1917 hasta el 7 de mayo de 1920; también fue jefe del Departamento Autónomo Universitario y de Bellas Artes. Lizardi nos informa, en el multicitado discurso del 26 de febrero de 1955, que don José Natividad participó en la redacción tanto de la Ley de Amparo de 1919 como en la Ley de Relaciones Familiares de abril de 1917.

11 Cfr. El derecho académico en México, México, UNAM, 1987, pp. 115-118. 
Este libro forma parte del acervo de la Biblioteca Jurídica Virtual del Instituto de Investigaciones Jurídicas de la UNAM

En 1920, con motivo del "Aguaprietazo" acompañó a Carranza en su peregrinaje hacia Veracruz, separándose en la comunidad de Aljibes, en donde el convoy carrancista fue atacado por las fuerzas obregonistas. Macías fue hecho prisionero y encarcelado de nuevo en Lecumberri. Después de meses de cautiverio, fue puesto en libertad a condición de que abandonara el país. Viajó por Europa y, posteriormente, se asentó en San Antonio, Texas, para dedicarse al periodismo. Pudo regresar al país en 1921, se retiró a la vida privada y al ejercicio de su profesión. Falleció en la Ciudad de México, el 19 de octubre de 1948. Fue sepultado en el Panteón Español de la propia capital de la República.

\section{MACíAS COMO GONSTITUYENTE}

Como lo señala Marta Morineau, ${ }^{12}$ hay 225 referencias al diputado Macías en el Diario de Debates del Constituyente de Querétaro, lo cual nos resulta lógico, dado que él fue uno de los redactores del Proyecto y, obviamente, lo conocía como nadie. Como señalamos antes, se trataba de un jurista muy destacado, con experiencia parlamentaria y cabeza visible del grupo Renovador, es decir, carrancista.

Realmente, fueron cuatro las intervenciones fundamentales de nuestro personaje: las relativas al artículo tercero, relacionado con la educación, al 18 , tocante al cumplimiento de las sentencias penales, el 27, por lo que respecta a la reforma agraria, y el 123, referido a la cuestión laboral.

\section{Sobre el artículo primero}

Antes de referirnos brevemente a estos cuatro rubros, permítaseme abordar el tema del artículo primero. Como se recordará, en la Constitución Federal de 1857, se señalaba: "El pueblo mexicano reconoce, que los derechos del hombre son la base y el objeto de las instituciones sociales. En consecuencia declara, que todas las leyes y todas las autoridades del país, deben respetar y sostener las garantías que otorga la presente Constitución".

Evidentemente, ello representaba que dicha ley fundamental asumía en ese particular una postura iusnaturalista. Por otro lado, la carta magna de 1917 cambiaba la orientación en el tenor siguiente: "Artículo 1.- En los Estados Unidos Mexicanos todo individuo gozará de las garantías que otorga

12 Op. cit., p. 261. 
Este libro forma parte del acervo de la Biblioteca Jurídica Virtual del Instituto de Investigaciones Jurídicas de la UNAM

esta Constitución, las cuales no podrán restringirse ni suspenderse, sino en los casos y con las condiciones que ella misma establece".

De tal suerte que se cambiaba la orientación iusnaturalista por una iuspositivista, sin embargo, de la explicación que diera Macías en la 11 a. sesión ordinaria del Constituyente del 13 de diciembre de 1916, aunque don José Natividad, hijo de su tiempo, era positivista, ${ }^{13}$ parece que no fue tanto esa idea, sino más bien amarrar una redacción en la ley suprema que no diera lugar a interpretaciones (como había sucedido con el artículo 14 de la Constitución Federal de 1857 y el amparo judicial). ${ }^{14}$ En efecto, al momento de discutirse tal numeral, nuestro diputado dijo:

Tiene este (se refiere a la redacción del 57) otro inconveniente gravísimo; que como la constitución no hace la enumeración de los derechos naturales, todo el mundo creyó ver en esto, que no había derecho que no estuviera aprobado por la Constitución; de manera que no solamente se creyó que estaban aprobados los derechos propiamente fundamentales; sino estaban comprendidos todos los derechos secundarios y políticos, y de ese error surgieron multitudes de dificultades.

\section{Para continuar más adelante:}

La conclusión a que se ha llegado, es que el hombre tiene un derecho fundamental, que es el derecho a la vida, y en este derecho está comprendido el derecho a la libertad, el cual se traduce por el derecho a todas las necesidades naturales del individuo. Hay que rehuir cuidadosamente todas estas discusiones filosóficas que no sirven más que para hacer confusión de las ideas e inducir a errores que siempre son perjudiciales para los pueblos, y venir a una cosa práctica y positiva. Las constituciones no necesitan declarar cuáles son los derechos; necesitan garantizar de la manera más completa y más absoluta de todas las manifestaciones de la libertad. Por eso deben otorgarse las garantías individuales, y esto es lo que se ha hecho en el artículo que está a discusión.

De tal manera, concluyó esa idea con lo siguiente:

En el fondo están reconocidos los derechos naturales del individuo, sea que estos derechos sean de este, o de aquel, o de cualquier otro, sea que fueran de ocho, diez, veinte o cincuenta; todos están reconocidos allí porque las garantías que otorga la sección primera son para respetar las diversas manifestaciones de la libertad humana.

13 Cfr. nuestro libro Y la Revolución se hizo Constitución, cit., pp. 1-16.

$14 C f$ r. el libro que escribimos junto con el profesor Faustino José Martínez Martínez, Apuntes para la historia del juicio de amparo, México, 2010, pp. 309-335. 
Este libro forma parte del acervo de la Biblioteca Jurídica Virtual del Instituto de Investigaciones Jurídicas de la UNAM

\section{Sobre la educación}

Independientemente de la importancia que de por sí guarda la educación pública, la discusión del artículo tercero representó el primer gran debate en el seno del Constituyente sobre la cuestión religiosa, en donde se confrontaron jacobinos y renovadores. Los primeros fueron, como señalamos antes, los triunfadores por una razón aritmética: eran numéricamente mayoría, lo cual marcó, en estos temas religiosos, el sentido de la carta fundamental de Querétaro y, por ello mismo, realmente no se produjeron más debates de fondo en esa temática, sino que siguió el criterio marcado por dichos jacobinos u obregonistas.

El artículo tercero del Proyecto del Primer Jefe señalaba: "Habrá plena libertad de enseñanza; pero será laica la que se dé en los establecimientos oficiales de educación, y gratuita la enseñanza primaria superior y elemental, que se imparta en los mismos establecimientos". Respecto a la Constitución de 1857 se agregaba la laicidad y gratuidad de la educación oficial. El dictamen de la Comisión proponía importantes innovaciones:

Habrá libertad de enseñanza; pero será laica la que se dé en los establecimientos oficiales de educación, lo mismo que la enseñanza primaria elemental y superior que se imparta en los establecimientos particulares. Ninguna corporación religiosa, ministro de algún culto o persona perteneciente a alguna asociación semejante, podrá establecer o dirigir escuelas de instrucción primaria, ni impartir enseñanza personalmente en ningún colegio. Las escuelas primarias particulares sólo podrán establecerse sujetándose a la vigilancia del Gobierno. La enseñanza primaria será obligatoria para todos los mexicanos y en los establecimientos oficiales será impartida gratuitamente.

Para esto, el diputado Luis G. Monzón quería ir más lejos y en la misma reunión del lunes 11 de diciembre por la mañana, dio lectura a su voto particular en el que proponía que en lugar del adjetivo calificativo "laica" se usara el de "racional", pues el primero implicaba que se ignorase a la religión, mientras que el segundo, según él, obligaba a combatirla.

La propuesta de la Comisión decía:

Art. 3o.- Habrá libertad de enseñanza; pero será laica la que se dé en los establecimientos oficiales de educación, lo mismo que la enseñanza primaria elemental y superior que se imparta en los establecimientos particulares.

Ninguna corporación religiosa, ministro de algún culto o persona perteneciente a alguna asociación semejante, podrá establecer o dirigir escuelas de instrucción primaria, ni impartir enseñanza personalmente en ningún colegio. 
Este libro forma parte del acervo de la Biblioteca Jurídica Virtual del Instituto de Investigaciones Jurídicas de la UNAM

Las escuelas primarias particulares, sólo podrán establecerse sujetándose a la vigilancia del gobierno. La enseñanza primaria será obligatoria para todos los mexicanos y en los establecimientos oficiales será impartida gratuitamente.

Como es obvio, al ser ésta, además, la primera cuestión que en materia religiosa resolvió el Constituyente de Querétaro, era una temática muy importante, tan era así que el propio Carranza quiso asistir a la duodécima sesión celebrada la tarde del miércoles 13 de diciembre, sesión en la que se empezó a debatir tan ardua cuestión. La discusión se continuó en la sesión siguiente, en la que la Comisión retiró su dictamen para presentarse uno nuevo en la decimoquinta, llevada a cabo la tarde del sábado 16. Pero ¿qué pasó?

En la mencionada duodécima sesión, que se llevó a cabo la tarde del 13 de diciembre, el primero en hacer uso de la palabra fue el general Francisco J. Múgica, a quien Bojórquez ${ }^{15}$ calificó como: "Líder de las mayorías y conductor de la primera comisión de reformas... la figura más conspicua del Congreso", para iniciar su alocución apuntando: "Estamos en el momento más solemne de la revolución... ningún momento, señores, de los que la revolución ha pasado, ha sido tan grande, tan palpitante, tan solemne como el momento en que el Congreso Constituyente, aquí reunido, trata de discutir el artículo 3o.", y prosiguió: "En aquellas etapas gloriosas no se trataba más que de vencer de una vez por siempre al que tenía el Poder usurpado en sus manos o de acabar con la reacción, y aquí, señores, se trata nada menos que del porvenir de la patria", y argumentó, poco más adelante: "La ciencia pedagógica ha hablado ya mucho sobre la influencia que la enseñanza religiosa, que la enseñanza de las ideas absurdas, ejerce sobre los individuos, para degenerarlos, no sólo en lo moral, sino también en lo físico"; para concluir esta primera parte de su intervención con la siguiente afirmación: "Efectivamente, soy enemigo del clero, porque lo considero el más funesto y el más perverso enemigo de la patria".

A continuación hizo uso de la voz, se supone para rebatir a Múgica, el diputado Luis Manuel Rojas con una perorata que bien podríamos calificar de confusa, profusa y difusa que duró más de una hora, constantemente interpelada por otros diputados, en donde se apuntaba que, en el Proyecto Carranza, la exclusión del clero de la educación se contenía en el artículo 27 y "se formula la perfecta neutralidad del Gobierno en la enseñanza pública, respecto a todas las instituciones o creencias religiosas o filosóficas". Concluyó con una crítica a los miembros de la Comisión de Constitución por separarse de lo sostenido por el primer jefe.

15 Cfr. op. cit., p. 506. 
Este libro forma parte del acervo de la Biblioteca Jurídica Virtual del Instituto de Investigaciones Jurídicas de la UNAM

Posteriormente subió a la tribuna el diputado Alberto Román para apoyar el dictamen de la Comisión con un discurso muy anticlerical que llegó a afirmar: "¿Por qué no tenemos el valor en nuestras leyes, igualmente de afirmar un acto de aniquilamiento para el enemigo" o sea el clero católico.

Luego tomó la palabra el diputado hidalguense Alfonso Cravioto, quien hizo la crítica más lúcida al dictamen que se discutía. Empezó con este adagio: "Si cuerdas faltan para ahorcar tiranos, tripas de fraile tejerán mis manos", que antes ya había pronunciado para expresar, evidentemente, su fe anticlerical; no obstante, calificó el dictamen de la Comisión como "arbitrario, impolítico, imprudente, insostenible, secularmente regresivo y tan preñado de consecuencias funestísimas para nuestras labores constitucionales", es más, señaló: "Que de aceptarse el criterio excesivo de ese dictamen tendremos... que dar al traste con muchas de las preciosas conquistas consagradas ya en la Constitución de 57, que debemos mejorar, pero nunca empeorar. Y concluyó: "Pero el jacobinismo, he ahí también otro enemigo. No cambiemos un error por otro error, ni un fanatismo por otro fanatismo; el error no se combate con el error, sino con la verdad. El fanatismo no se combate con la persecución, sino por medio del convencimiento".

Prosiguió Jesús López Lira, el diputado guanajuatense, para apoyar el dictamen de la Comisión, quien argumentó, básicamente, que el derecho de los niños a ser educados necesariamente pasaba por el que la educación pública o privada, no importaba - fuese ajena a cualquier credo religioso.

Luego vino don José Natividad Macías en una larguísima perorata, donde señaló, en primer lugar, sus afectos personales por los miembros de la Comisión de Constitución, continuó con una extensa - y un poco fuera de caso - exposición histórica, hasta que el diputado Espinosa (el Diario de los Debates, que es el que estamos siguiendo literalmente, no dice cuál de los tres: Juan, Francisco o Luis) señaló que el orador llevaba hablando más de dos horas de diversos asuntos y casi nada del artículo tercero que estaba a discusión. Finalmente, expuso su argumento: "Las costumbres de los pueblos no se cambian de la noche a la mañana; para que un pueblo deje de ser católico, para que el sentimiento que hoy tiene desaparezca, es necesaria una educación", y más adelante: "Y la manera de educarlo no es quitarle la libertad de enseñanza, sino defender la instrucción".

Cuando terminó Macías eran las 9.15 p.m. y, lógicamente, se levantó la sesión. Al día siguiente, jueves 14 de diciembre por la mañana, se continuó la discusión del artículo tercero en la décimo cuarta sesión del Constituyente. 
Este libro forma parte del acervo de la Biblioteca Jurídica Virtual del Instituto de Investigaciones Jurídicas de la UNAM

\section{La cuestión penitenciaria}

El día de Navidad de 1916, en la vigésimo segunda sesión del Constituyente, se presentó el dictamen del artículo 18. El texto de 1857 solamente establecía el principio de que únicamente habría lugar a prisión por delito que mereciera pena corporal, lo cual en la actualidad nos puede parecer una perogrullada, pero ello respondía al principio de derecho romano: $U b i$ culpa non est, non debet ese poena; también señalaba que cuando no hubiera pena corporal se le pondría en libertad bajo fianza y nunca se detendría en prisión por falta de pago de honorarios a sus abogados.

En el Proyecto de don Venustiano, por un lado, lo empeoraba al señalar "o alternativa de pecuniaria y corporal"; pero, por otro, sentaba algunas bases del derecho penitenciario, al establecer que serían diferentes los lugares que servían de prisión preventiva a aquellos donde se purgaría una pena, que serían las colonias penales, que cuando la sanción fuese superior a dos años, dichos lugares de reclusión estarían administrados por el gobierno federal, se situarían fuera de las poblaciones y cada estado pagaría los gastos que generaran sus propios reos. En cuanto a las dos partes finales de la versión del 57, se trasladaron al nuevo artículo 20.

El dictamen de ley, sin dejar de reconocer las ventajas de centralizar el sistema penitenciario, ya que la Federación tenía - y tiene - mayores recursos económicos y científicos, se manifestó en contra, por la afectación al régimen federal que traía consigo ya que hasta ese momento "las penitenciarías establecidas por la Federación han sido tan deficientes como las de los Estados", que se ignorarían las circunstancias locales y que los penales podrían quedar muy alejados de la residencia de los sentenciados, lejos de sus familias y del único lazo que los unía a la sociedad. Y una cosa muy importante: se establecía el régimen penitenciario sobre la base del trabajo como medio de regeneración, pero desechando la propuesta de crear colonias penitenciales.

El primero en hacer uso de la palabra fue David Pastrana Jaimes para señalar algo muy lógico: al tratarse de penas alternativas no debería proceder la prisión preventiva, toda vez que si se hace uso de ella y el juez condena solamente a pena pecuniaria, el infeliz reo ya purgó una pena que no merecía. Colunga hizo una pobre defensa al decir que, al tratarse de una pena alternativa, si el juez ordenaba la prisión preventiva, en cierto sentido se obligaba, comprobado el cuerpo del delito y la responsabilidad del acusado, a imponer una pena privativa de libertad. A continuación hizo uso el diputado José Natividad Macías, quien explicó las ideas postuladas por el primer jefe en su Proyecto. 
Este libro forma parte del acervo de la Biblioteca Jurídica Virtual del Instituto de Investigaciones Jurídicas de la UNAM

En primer lugar, Macías, de manera inoportuna, se refirió a dos artículos ya aprobados, el séptimo y el noveno, acusó a la Comisión de Constitución que, al haber modificado el Proyecto, retrocedió en vez de avanzar en las instituciones humanitarias y republicanas.

Después de señalar que de aceptar lo propuesto por Pastrana acabaría con el sistema de penas alternativas - cárcel, multa-, nuestro biografiado, continuó con una larga alocución en la que habló de la evolución del derecho penal, para señalar las colonias penales como lo más avanzado en sistemas penitenciarios; se manifestó en contra del postulado del trabajo obligatorio, que según él era imposible con cárceles tan reducidas e insalubres como las que había en nuestro país, que según el médico de la penitenciaría de México, doctor Ricardo de la Cueva, nueve de cada diez presos salían locos o tuberculosos de ese centro penitenciario, lo cual era más peligroso para la sociedad que si los delincuentes anduvieran sueltos; por ello mismo, la idea contenida en el Proyecto era establecer las colonias penitenciales - como las Islas Marías - y sin embargo, como era tan bajo el presupuesto de los estados para cárceles era imposible establecer sistemas penitenciarios adecuados, y mucho menos colonias penitenciales, con todos los adelantos científicos modernos en todos los estados, por ello se debería encomendar tal función a la Federación, con la filosofía penitenciarista subyacente en el Proyecto de Carranza, pero siempre para purgar penas de más de dos años, pues menores no tenía sentido.

Acto continuo vino don Hilario Medina y, a través de un largo y erudito discurso, explicó las más recientes teorías penales para aquella época, particularmente se refirió al positivismo criminológico fundado por Cesare Lombroso y seguido por Raffaele Garofalo y Enrico Ferri, lo que aprovechó para echarle en cara a José Natividad el no estar al día en las últimas teorías penales, sólo en la "teoría de la venganza que era la tesis de la escuela clásica"; se manifestó a favor de las colonias penales, pero que no dependieran del gobierno federal, sino de los estatales, en razón del principio federalista.

Siguió el general Jara para expresar su rechazo a las colonias penales, con el ejemplo de Quintana Roo, ${ }^{16}$ que, según relataba, era la síntesis de todos los horrores, motivo de explotación de los reclusos por parte de los que los administraban, se afirmaba que regresarían con un pequeño capital pero la verdad era que regresaban con una enfermedad mortal e incurable; no se explicaba por qué exigir que fuesen centros federales y que los estados pagasen la manutención de los reos, para todo caso, con esos recursos, los

16 En la campaña política de Madero en 1910, varios líderes antirreeleccionistas de Puebla habían sido deportados al entonces inhóspito territorio de Quintana Roo. 
Este libro forma parte del acervo de la Biblioteca Jurídica Virtual del Instituto de Investigaciones Jurídicas de la UNAM

estados mantuviesen sus propias cárceles; se manifestó a favor del trabajo como medio de regeneración, pero trabajo remunerado. Dávalos (al parecer Marcelino) aclaró que Quintana Roo no era una colonia penal, sino "una Siberia a la que el zar de México enviaba al que le estorbaba para mantenerse en el Poder", por lo que no valía de ejemplo como colonia penal.

Prosiguió Colunga, quien explicitó cuál era su postura personal y la de los demás miembros de la Comisión en materia penal. Proclamó su fe lombrosiana y defendió el principio de optimizar recursos económicos con el establecimiento de centros penitenciarios que pudiesen servir a varias entidades federativa. A continuación subió Múgica para hablar en contra de las colonias penales, estimando serían contraproducentes.

Vino después Terrones Benítez, quien se pronunció por la regeneración de los delincuentes a través del trabajo remunerado y la instrucción, además de la semifederalización, como él dijo, de los centros penitenciarios, pues si bien serían administrados por el gobierno nacional, los reclusos dependían todavía de los estados, de otra manera varias entidades federativas no tendrían recursos para crear y sostener dichas penitenciarías e incluso no contarían con un número suficiente de presos para ocuparlas.

Antonio de la Barrera se opuso al sistema de colonias penitenciales, ya que éstas se establecerían en lugares inhóspitos y que los reclusos en vez de volver regenerados, después de dos o tres años, volverían "hechos momia", aseguró que más valía darles un balazo que enviarlos ahí, pues la mayoría de las capitales de los estados ya tenían penitenciarías, lo que hacía falta era reglamentarlas con un régimen adecuado basado en el trabajo remunerado.

Macías subió a la tribuna para responder, de manera muy erudita y razonada, a todas las objeciones que se plantearon, hasta ese momento, a lo propuesto en el proyecto del primer jefe. Al terminar la intervención de Macías se consultó a la asamblea si estaba suficientemente discutido el asunto, manifestándose por la afirmativa se pasó a votar y por tres votos se rechazó el dictamen. El nuevo dictamen se presentó el 27 de diciembre de 1916 (junto con el artículo 16), para ser discutido y aprobado el 3 de enero siguiente por 155 votos contra 37 .

\section{La cuestión laboral}

En primer lugar, debemos recordar cómo, en el Decreto del 29 de enero de 1915, Venustiano Carranza adicionó la Constitución Federal, en su artículo 72, referente a las facultades del Congreso de la Unión, al añadir en la fracción X, la materia del trabajo. Congruente con ello, en su Pro- 
Este libro forma parte del acervo de la Biblioteca Jurídica Virtual del Instituto de Investigaciones Jurídicas de la UNAM

yecto de Constitución presentado ante el Congreso Constituyente el 1o. de diciembre de 1916, en su artículo 73, referente a las facultades del Congreso de la Unión, en la fracción X, reiteraba que el Legislativo federal tenía exclusivamente esa atribución.

No obstante, en el dictamen del artículo 5o. de la primera comisión - que como sabemos se refiere a la libertad de trabajo-, suscrito el 12 de diciembre, se dijo:

Juzgamos, asimismo, que la libertad de trabajo debe tener un límite marcado por el derecho de las generaciones futuras. Si se permitiera al hombre agotarse en el trabajo, seguramente que su progenie resultaría endeble y quizá degenerada y vendría a constituir una carga para la comunidad. Por esta observación proponemos se limiten las horas de trabajo y se establezca un día de descanso forzoso en la semana, sin que sea precisamente el domingo. Por una razón análoga creemos que debe prohibirse a los niños y a las mujeres el trabajo nocturno en las fábricas.

Ha tomado la Comisión estas últimas ideas, de la iniciativa presentada por los diputados Aguilar, Jara y Góngora. Estos ciudadanos proponen también que se establezca la igualdad de salario en igualdad de trabajo; el derecho de indemnizaciones por accidentes del trabajo y por enfermedades causadas directamente por ciertas ocupaciones industriales, así como también que los conflictos entre el capital y el trabajo se resuelvan por comités de Conciliación y Arbitraje. La Comisión no desecha estos puntos de la citada iniciativa; pero no cree que quepan en la sección de las garantías individuales; así es que aplaza su estudio para cuando llegue al de las facultades del Congreso.

En tal virtud, el texto propuesto como cuarto y último párrafo del artículo 5o. constitucional decía:

El contrato de trabajo sólo obligará a prestar el servicio convenido por un período que no exceda de un año, y no podrá extenderse en ningún caso a la renuncia, pérdida o menoscabo de cualquiera de los derechos políticos o civiles. La jornada máxima será de ocho horas. Queda prohibido el trabajo nocturno en las industrias a los niños y a las mujeres. Se establece como obligatorio el descanso hebdomadario.

En la 17a. sesión del 19 de diciembre se volvió a leer ese dictamen, y en esa misma oportunidad, un grupo de diputados presentó por escrito al presidente del Congreso, diputado Luis Manuel Rojas, una moción suspensiva. Después de consultarlo con los miembros de la comisión, el pleno autorizó lo que se pedía. En la 23a. sesión del 26 de diciembre, por la tarde, se presentó un nuevo dictamen de artículo quinto, suscrito el 22 del mismo mes de 
Este libro forma parte del acervo de la Biblioteca Jurídica Virtual del Instituto de Investigaciones Jurídicas de la UNAM

diciembre, en el que no se avanzaba el tema laboral. En esa misma sesión se comenzó a discutir dicho dictamen.

El primero en hacer uso de la voz fue el licenciado Fernando Lizardi con las siguientes célebres palabras:

Este último párrafo desde donde principia diciendo: "la jornada máxima de trabajo obligatorio no excederá de ocho horas", le queda al artículo exactamente como un par de pistolas a un Santo Cristo, y la razón es perfectamente clara: "habíamos dicho que el artículo $4^{a}$ garantizaba la libertad de trabajo y éste garantizaba el derecho de no trabajar; si estas son limitaciones a la libertad de trabajar, era natural que se hubieran colocado más bien en el artículo 4o. que en el 5o., en caso de que se debieran colocar; pero en el artículo 4o. están colocadas, porque se nos dice que todo hombre es libre de abrazar el trabajo lícito que le acomode...

No cabe, pues esta reglamentación aquí. La Comisión estuvo muy cuerda cuando reservó algunas otras de las indicaciones del proyecto presentado por los ciudadanos diputados Aguilar, Jara y Góngora; estuvo muy cuerda reservando esas adiciones para tratarlas en el artículo 72o., pero si tan cuerda estuvo en esos momentos, no me explico el por qué no lo estuvo también reservando esas otras para ponerlas en su lugar.

Continuó el diputado Cayetano Andrade para hablar a favor del dictamen en lo relativo a limitar el trabajo a ocho horas y prohibir el trabajo nocturno a mujeres y niños. Siguió Rubén Martí, quien impugnó el dictamen al señalar que no tenía ni pies ni cabeza. Jara a favor. Más interesante lo señalado por el diputado yucateco Héctor Victoria:

Por consiguiente, el artículo $5^{\mathrm{a}}$ a discusión, en mi concepto, debe trazar las bases fundamentales sobre las que ha de legislarse en materia de trabajo, entre otras, las siguientes: jornada máxima, salario mínimo, descanso semanario, higienización de talleres, fábricas, minas, convenios industriales, creación de tribunales de conciliación, de arbitraje, prohibición del trabajo nocturno a las mujeres y niños, accidentes, seguros, e indemnizaciones, etc. No debe ponerse un plazo tan largo como el que fija la Comisión en el dictamen para la duración de contratos, porque, señores, un año, es mucho.

Siguió el diputado Zavala (el Diario de los Debates no especifica si Dionisio o Pedro) quien pidió se separara la cuestión obrera del resto del artículo 5 o. Vino luego Jorge E. Von Versen, quien expresó:

Yo no quiero que se vote por partes el artículo que presenta la Comisión, yo pido que se rechace y que se reconsidere, que se le ponga las polainas, que se 
Este libro forma parte del acervo de la Biblioteca Jurídica Virtual del Instituto de Investigaciones Jurídicas de la UNAM

le pongan las pistolas, que se le ponga el 30-30 al Cristo, pero que se salve a nuestra clase humilde, a nuestra clase que representa los tres colores de nuestra bandera y nuestro futuro y nuestra grandeza nacional (aplausos - por supuesto-).

Froilán C. Manjarrez precisó más la idea. David Pastrana Jaimes subió a la tribuna para defender una iniciativa de él y del coronel Porfirio del Castillo referente al salario de los trabajadores. Para esto, parece que era muy tarde, se levantó la sesión y se acordó que continuaría el debate al día siguiente, miércoles 27, en la 24a. sesión. Como se comprenderá fue una sesión larga, en la que no se dijo nada nuevo, más bien discursos ramplones de naturaleza demagógica. Se levantó la sesión sin dar el asunto por discutido. Se siguió en la 25a. reunión de la tarde, del jueves 28, en el mismo tenor que la anterior hasta que hizo uso de la palabra el licenciado José Natividad Macías quien aclaró muchas cosas.

En efecto, don José Natividad explicó cómo Carranza, preocupado por las promesas que había hecho de formular "todas las leyes encaminadas a redimir a la clase obrera, de la triste y miserable situación en que se encontraba", lo comisionó a él junto con el licenciado Luis Manuel Rojas, diputado presidente de esa magna asamblea, para que formasen el o los proyectos necesarios "en que se tratase el problema obrero en sus diversas manifestaciones"; así, ambos formularon un proyecto de ley obrera que fue revisado por el licenciado Luis Cabrera y después de hacerle algunas modificaciones, por acuerdo de Carranza, se sometió a la consideración de los obreros para que hicieran las observaciones que estimaran oportunas. Finalmente, el primer jefe no pudo expedir la ley obrera, en los años preconstitucionales, lo cual justificó Macías, por el estado en que se encontraba la República en esos momentos. Para esto, Rojas había tenido que ir en viaje oficial a Guatemala y Macías hizo una gira por Estados Unidos para hacerse una idea de la situación de los trabajadores en ese país y conocer su legislación laboral, junto con la inglesa y la belga, llegó a la conclusión de que la legislación obrera en México debería comprender la ley del trabajo, la ley de accidentes, la ley de seguros y toda aquellas normas relacionadas directamente con el bienestar de los trabajadores.

Por eso, concluyó Macías, que el meter algunos pocos puntos en el artículo 5o. era un error, que el problema obrero era mucho más extenso, bastante complicado; además, consideraba que los detalles de la legislación obrera los tenían que resolver cada estado en particular (no la Federación como había planteado el Constituyente); por ello, reconoció que fue un error el Proyecto que anteriormente elaboró con Rojas, ya que se refería 
Este libro forma parte del acervo de la Biblioteca Jurídica Virtual del Instituto de Investigaciones Jurídicas de la UNAM

únicamente al Distrito y los territorios federales, pues de haberse aprobado seguramente crearía un problema porque, como se recordará, Carranza, a instancias del secretario de gobernación, Zubarán, había reformado la Constitución para darle al Congreso de la Unión la facultad de legislar en dicha materia, por ello, sería un contrasentido que se expidiera esa ley laboral con carácter local. Relató cómo don Venustiano no incorporó la legislación obrera en su Proyecto de Constitución pues consideraba que era materia de una ley secundaria. Respecto a lo proyectado en el artículo 5o. señaló:

Desde luego, señores diputados, les advierto a ustedes que el problema obrero no es el problema obrero tal como los oradores que me han precedido en el uso de la palabra lo han presentado; no es el problema obrero tal como la Comisión lo adapta en el artículo 5o.; hay una confusión grande sobre este punto y se explica perfectamente, no se ha hecho un estudio detenido sobre el particular y naturalmente, las ideas están vagas y precisamente de la vaguedad de las ideas va a venir después la vaguedad en las interpretaciones, cada cual se las adjudicará y tendrán que resolverse estos problemas de una manera verdaderamente inconveniente.

Después de una larga explicación, la conclusión a la que arribó el diputado Macías era tremenda:

Me diréis: ¿Por qué pedís la palabra en contra del proyecto? Porque es rematadamente malo el proyecto en este sentido. Voy a demostrarlo sin ánimo de ofender a nadie. Esos dos o tres artículos que tiene relativos al trabajo, equivalen a que a un moribundo le den una gotita de agua para calmar su sed. Está el proyecto - que había elaborado él junto con Rojas y revisado por Cabrera- a la disposición de ustedes. Yo creo que los que quieran ayudar al señor Rouaix para que formule las bases generales de la legislación del trabajo, para que se haga un artículo que se coloque no sé dónde de la Constitución, pero que no esté en el artículo de las garantías individuales, para obligar a los Estados a que legislen sobre el particular, porque de lo contrario, si se mutila el pensamiento van a destrozarlo y la clase obrera no quedará debidamente protegida. No es, pues, posible hacerlo en estos tres jirones que se le han agregado al artículo, sino que deben ser unas bases generales que no deben comprenderse en unos cuantos renglones.

$\cdots$

La protección debe de ser eficaz, completa, absoluta, y entonces sí podremos decir que la revolución ha salvado a la clase obrera.

Por supuesto, el licenciado Macías, con esta intervención, estableció la clave para que el Constituyente de Querétaro diera las bases para resolver 
Este libro forma parte del acervo de la Biblioteca Jurídica Virtual del Instituto de Investigaciones Jurídicas de la UNAM

la cuestión laboral. Después vinieron algunas otras intervenciones, particularmente una muy larga del general Múgica, quien, en su calidad de presidente de la comisión dictaminadora, trató de justificar su actuar, pero no se cerró a un cambio. Gerzayn Ugarte propuso que la comisión retirara su dictamen, que sólo se dejara la facultad del Congreso de la Unión de legislar en la materia. Froilán C. Manjarrez planteó - por escrito - que se incluyera en la ley fundamental un capítulo exclusivo para abordar los asuntos del trabajo, para ello se formaría una comisión especial de unas cinco personas, no necesariamente diputados (seguro estaba pensando en el secretario del fomento, ingeniero Rouaix, que aunque era constituyente estaba con licencia para desempeñar el cargo de secretario de fomento) para que recogieran todas las iniciativas y formularan un proyecto de tal capítulo. En efecto, Macías postuló al ingeniero Rouaix como miembro de ese grupo de trabajo. Múgica, a nombre de la comisión dictaminadora, expresó su conformidad para retirar el proyecto y lo solicitó, como finalmente lo aprobó la asamblea. ¡Atención!, el Diario de los debates señala sólo eso, no habla de ninguna comisión especial.

Aquí contamos para conocer el origen de nuestro derecho constitucional del trabajo, el libro de Pastor Rouaix, ${ }^{17}$ en el que nos cuenta que, efectivamente, el presidente del Congreso no había hecho ninguna designación de los miembros de esa comisión especial, aunque todas daban por supuesto que dicho grupo de trabajo estaría integrado por el ingeniero Rouaix, el licenciado José Natividad Macías, a quien encabezaba la Dirección del Trabajo de la Secretaría de Fomento, el general y licenciado José Inocente Lugo y al secretario particular de Rouaix, el diputado Rafael L. de los Ríos, los que - ya sabemos - integraron lo que el propio don Pastor denominara "núcleo fundador", mismo que lo veremos posteriormente en acción en la preparación del artículo 27. Como éstos dos últimos miembros del núcleo fundador se alojaban en lo que había sido la casa del obispo de Querétaro - actualmente Palacio Municipal de Santiago de Querétaro, en el jardín Guerrero - las reuniones se llevaban a cabo en lo que había sido la capilla de dicha residencia.

Nos señala el autor del libro que analizamos que los trabajos de dicho grupo fluyeron con agilidad gracias a que no laboraron con los formalismos de una comisión parlamentaria, pues por las tardes había sesiones del Congreso, más bien ajenos a cualquier rigidez, presididas por el propio secretario de fomento, infortunadamente para la historia, sin levantar actas ni minutas, sacando los acuerdos por consenso más que por votación. Dicho

17 Génesis de los artículos 27 y 123 de la Constitución Política de 1917, cit. 
Este libro forma parte del acervo de la Biblioteca Jurídica Virtual del Instituto de Investigaciones Jurídicas de la UNAM

grupo empezó con el análisis de los trabajos relativos de don José Natividad Macías, para formular los postulados que tuvieran el carácter de fundamentales, proyecto inicial que se sometió a la consideración de todos los diputados que libremente concurrían, y, así, en los primeros diez días del mes de enero de 1917, quedó redactado el proyecto de lo que sería el artículo 123 constitucional, junto con un nuevo proyecto de artículo 5o. al que se le retiraron todas las referencias a lo laborar, el servicio obligatorio de los abogados en la judicatura y la prohibición de la vagancia. Se le encargó a Macías formulara la exposición de motivos y el trabajo se concluyó el día 13 del mismo mes de enero.

Los diputados que más participaron en estos trabajos fueron el ingeniero Victorio Góngora, ${ }^{18}$ que según nuestro autor fue el redactor de la primera iniciativa de ampliaciones al artículo 5o. y quien tenía grandes conocimientos en el ramo, por los estudios que había hecho; el general Esteban Baca Calderón, los diputados duranguenses: Silvestre Dorador y Jesús de la Torre (artesanos), el licenciado Alberto Terrones Benítez y Antonio Gutiérrez; los militares José Álvarez, Donato Bravo Izquierdo, Samuel de los Santos, Pedro A. Chapa y Porfirio del Castillo; los obreros Dionisio Zavala y Carlos L. Gracidas y el licenciado Rafael Martínez de Escobar. Además de ellos, la iniciativa fue suscrita por 46 diputados más.

\section{La cuestión agraria}

Congruente con la Ley Agraria del 6 de enero de 1915, el Proyecto del primer jefe proponía una redacción para el artículo 27 constitucional.

El diputado poblano e ingeniero Pastor Rouaix continuó con la narración del testigo excepcional, pues, como señalamos antes, independientemente de haber sido designado oficial mayor encargado del despacho (luego subsecretario y finalmente secretario) de la Secretaría de Fomento, Colonización e Industria ${ }^{19}$ del gobierno provisional de Carranza en Veracruz, durante la expedición de la Ley Agraria del 6 de enero de 1915, ${ }^{20}$ fue el

18 Jorge Adame ha demostrado cómo a través de este diputado llegaron al seno del Congreso Constituyente las ideas de la Doctrina Social Católica. Cffr. "Victorino Góngora: una influencia callada", en La Constitución mexicana de 1917: ideólogos, el núcleo fundador y otros constituyentes, cit., pp. 449-460.

19 Cfr. Madrazo, Jorge, "Pastor Rouaix. 1874-1950", en La Constitución mexicana de 1917: ideólogos, el núcleo fundador y otros constituyentes, cit., p. 370.

20 Aunque él formuló un proyecto, finalmente la que aceptó Carranza fue la propuesta de Luis Cabrera. Siendo gobernador de Durango promulgó una ley agraria para ese estado en 1913. 
Este libro forma parte del acervo de la Biblioteca Jurídica Virtual del Instituto de Investigaciones Jurídicas de la UNAM

diputado constituyente a quien se le debe fundamentalmente el artículo 27, y quien nos ha legado un texto fundamental: Génesis de los artículos 27 y 123 de la Constitución de 1917.21

Comenzó su texto el ingeniero Rouaix con una narración de cómo fue rechazado el texto propuesto en el Proyecto del Primer Jefe "porque sólo contenía innovaciones de interés secundario... sin atacar ninguna de las cuestiones vitales"; afirmaba que desde sus inicios, la Revolución había sido sostenida por el peonaje de las haciendas, impulsado por ideales agrarios; si bien la propuesta de Carranza era importante para contener abusos y garantizar el cumplimiento de las leyes, "no atacaba el problema fundamental de la distribución de la propiedad territorial que debería estar basada en los derechos de la Nación sobre ella y en la conveniencia pública" y que infortunadamente el debate del artículo 27 se posponía indefinidamente, por ello, algunos diputados presentaron iniciativas, incluso, hubo excitativas venidas de fuera. La Comisión de Constitución estaba abrumada por el exceso de trabajo.

Ante los reclamos de los diputados agraristas, la Comisión Nacional Agraria, presidida por el ministro de fomento, envió a Querétaro al afamado abogado especialista en cuestiones agrarias, Andrés Molina Enríquez, autor de la célebre obra Los grandes problemas nacionales, para lo cual el diputado Rouaix le pidió formulara un anteproyecto de artículo 27 que sirviera de base para la discusión. Al respecto, nos dice el propio Rouaix, que al aprovechar el impulso de los diputados redactores del artículo 123, como vimos antes, grupo que él mismo denominó núcleo fundador, encabezó esa ardua tarea auxiliado por los diputados: licenciado José Natividad Macías, Rafael de los Ríos y el general y licenciado José I. Lugo. La primera reunión de ese grupo de trabajo se tuvo el domingo 14 de enero, al día siguiente que se había terminado la iniciativa del artículo 123, igualmente, se utilizó como sala de juntas lo que había sido la capilla de la residencia del obispo de Querétaro. Se comenzó con la lectura de la propuesta de Molina Enríquez, la que causó decepción, pues, independientemente de ser un texto muy docto, era totalmente inaplicable, ${ }^{22}$ por lo cual no se pudo tomar en cuenta y partieron de cero, para ello, don Pastor se puso manos a la obra en compañía de Macías, Lugo y de los Ríos, con el apoyo de Molina. A partir de entonces

21 Cfr. op. cit. en El pensamiento mexicano sobre la Constitución de 1917, Antología, México, Gobierno del estado de Querétaro-INEHRM, 1987, pp. 189-272.

22 Dice el mismo Rouaix: "El Sr. Molina Enríquez fue un talento muy desigual... Sumamente difuso en la exposición de sus ideas en algunas ocasiones, era en otras concreto de preciso, y en este caso su escrito pecó de extensión”. Cffr. op. cit. p. 235. 
Este libro forma parte del acervo de la Biblioteca Jurídica Virtual del Instituto de Investigaciones Jurídicas de la UNAM

se dieron juntas, como había sucedido con la preparación del artículo 123, de manera informal, todos los días, en el mismo local, desde las 15:30 a las 24 horas, en las cuales desfilaron una serie de constituyentes que señaló el mismo Rouaix ${ }^{23}$ concluida la redacción del texto que se iba a proponer a la asamblea y que el propio diputado explicó su contenido en la obra de referencia, se pidió a Molina Enríquez redactara la exposición de motivos. Finalmente, como señalamos antes, el 25 de enero se presentó la iniciativa que contenía la propuesta de dictamen del artículo 27 constitucional, suscrita por Rouaix, Adame, Pastrana, Chapa, José Álvarez, Macías, Porfirio del Castillo, Ibarra, de los Ríos, Terrones, de los Santos, de la Torre, Dorador, Zavala, Enríquez, Gutiérrez, Martínez de Escobar y Martí; mismo que la Comisión de Constitución hizo suyo en el dictamen correspondiente.

En la sexagésima sexta sesión, del lunes 29 de enero por la tarde, se dio lectura al dictamen del artículo 27, sobre la base de la iniciativa de Pastor Rouaix antes mencionada y que a nuestro entender guardaba especial importancia.

\section{MACÍAS Y EL PROYECTO}

Para entender a plenitud los aportes de don José Natividad a nuestra ley fundamental de 1917, aparte de las intervenciones verbales en el Congreso Constituyente de las cuales hemos dado cuenta muy brevemente, es importante destacar las aportaciones que hizo en la redacción del Proyecto y que representaron avances importantes en nuestro derecho constitucional. $\mathrm{Al}$ respecto, queremos destacar los artículos 14, 20, 21 y 107.

Empecemos por el artículo 14. En la Constitución de 1857 dicho numeral era muy sencillo, aparentemente sólo prohibía la retroactividad; sin embargo, el mandato de la aplicación exacta de la ley en las sentencias de los tribunales, contenido en dicho precepto, había provocado tal turbamulta en el desarrollo del juicio de amparo, que ello marcó la historia y el destino de la más importante institución procesal de México. ${ }^{24}$ Como dijo don Emilio Rabasa:25 "la palabra exactamente que, por su mala historia, debe ser desechada del artículo" y los constituyentes le tomaron la palabra, por ello, los redactores del Proyecto de Carranza propusieron esta redacción:

23 Op. cit., p. 239.

24 Cfr. el libro que escribimos con el profesor Faustino José Martínez Martínez, Apuntes para la historia del juicio de amparo, cit., pp. 309-335.

25 Cfr. El artículo 14. Estudio constitucional, prólogo de F. Jorge Gaxiola, 2a. ed., México, Porrúa, 1955, p. 126. 
Este libro forma parte del acervo de la Biblioteca Jurídica Virtual del Instituto de Investigaciones Jurídicas de la UNAM

A ninguna ley se le dará efecto retroactivo en perjuicio de persona alguna.

Nadie podrá ser privado de la vida, de la libertad, o de sus propiedades, posesiones, o derechos, sino mediante juicio seguido ante los tribunales previamente establecidos, en que se cumplan las formalidades esenciales del procedimiento y conforme a las leyes expedidas con anterioridad al hecho.

En los juicios del orden criminal queda prohibido imponer, por simple analogía y aun por mayoría de razón, pena alguna que no esté decretada por una ley exactamente aplicable al delito que se trate.

En los juicios del orden civil, la sentencia definitiva deberá ser conforme a la letra o a la interpretación jurídica de la ley, y a falta de ésta, se fundará en los principios generales del derecho.

Quiere decir que el viejo concepto de legalidad jurisdiccional se transformaba en "formalidades esenciales del procedimiento" que, en términos modernos, por influencia angloamericana, se conoce como el principio del "debido proceso legal", según el pensamiento de Rabasa; la "exactitud" en la aplicación de la ley se dejó para la materia penal, pues la materia civil tenía que ser "conforme a la letra o a la interpretación jurídica de la ley" o los principios generales del derecho, como reza dicho artículo 14 y la fracción IV del 107 constitucionales.

Más adelante, es en el artículo 20 en el que se continúa la enumeración de las garantías procesales en materia penal; sin embargo, mereció artículo aparte del 19, en razón de que se incrementaron notablemente los derechos fundamentales de los acusados que eran, como decía el dictamen de la Comisión, "innovaciones trascendentales que transformarán por completo el sistema de enjuiciamiento penal en toda la República".

El artículo 21 constitucional tradicionalmente ha establecido la llamada garantía jurisdiccional. Recordemos cómo, en la Constitución de 1857, dicho numeral fue como la segunda parte del artículo 14 que, aparte de la prohibición de la irretroactividad de la ley establecía el principio de legalidad jurisdiccional, mientras que el 21 disponía la garantía jurisdiccional: "La aplicación de las penas propiamente tales, es exclusiva de la autoridad judicial" y mencionaba también las faltas administrativas. En el Proyecto de Carranza se hacía un desarrollo mucho más completo de la legalidad judicial en el artículo 14, como vimos antes, por lo tanto, el artículo 21, además de reiterar la garantía jurisdiccional y la facultad de las autoridades gubernativas para sancionar las faltas administrativas, traía una novedad importante: atribuir al ministerio público así como a la policía judicial - que estaría a la disposición de aquel - la función persecutoria de los delitos. Por otro lado, en la carta magna de 1857 se señalaba como límites a las sancio- 
Este libro forma parte del acervo de la Biblioteca Jurídica Virtual del Instituto de Investigaciones Jurídicas de la UNAM

nes administrativas quinientos pesos de multa o hasta un mes de reclusión, en el Proyecto de Carranza se quitaban esas limitantes.

Recordemos que el ministerio público era causahabiente de la fiscalía, o sea, era quien representaba ante los tribunales los intereses de la sociedad (antes, en la época novohispana, los de la Corona); de acuerdo con la tradición española, el fiscal era parte de la judicatura y los jueces llevaban a cabo la investigación de los delitos; en la reforma constitucional del 22 de mayo de 1900 se trasladó tal institución del Poder Judicial al Ejecutivo, en la figura de la Procuraduría General de la República, titular de la función de ministerio público, según la tradición francesa. Al respecto, el artículo segundo del Código de Procedimientos Federales (cuyo título preliminar hacía las veces de ley orgánica del Poder Judicial de la Federación), a partir de la reforma del 3 de octubre de 1900, señalaba: "El Ministerio Público auxiliará en el ejercicio de sus funciones al Poder Judicial de la Federación, para defender ante los tribunales los intereses de la sociedad, en los casos y por los medios que señalan las leyes", sin embargo los jueces seguían llevando la investigación de los delitos, auxiliados por ciertos policías, que por ello se les denominaba "judiciales". Por lo tanto, la propuesta del primer jefe transformaría radicalmente la institución del ministerio público, para continuar en la Procuraduría General de la República y ésta dentro del Poder Ejecutivo, se le asignaba, además, la función persecutoria de los delitos y se creaba la institución de la Policía Judicial que, a pesar del nombre, no se incrustaba en el Poder Judicial sino en el Ejecutivo.

Por último, mencionaremos las aportaciones en lo relativo al juicio de amparo: el 20 de enero se presentó el dictamen de este artículo, junto con otros relativos al Poder Judicial de la Federación; en dicho dictamen, prácticamente, lo que destaca es la creación de un nuevo procedimiento en el amparo: el llamado amparo "directo" o uninstancial que, junto con el otro, al que, lógicamente, se le denominó "indirecto" o biinstancial, constituyó una de las dos formas de tramitar este juicio constitucional. En esa misma oportunidad también se dio lectura a un voto particular de los diputados Heriberto Jara e Hilario Medina sobre este mismo precepto, que no era otra cosa sino suprimir el amparo contra las resoluciones judiciales, retomaron la tesis que se defendió en 1868 y después fue abandonada radicalmente, al proponer, de una forma un tanto extraña, se dejase solamente la fracción primera.

En la 55a. sesión del 22 de enero por la tarde, se comenzaron a discutir tanto el mencionado dictamen como el voto particular; con buen sentido, se puso a discusión primero este último ya que, si se aceptaba, ya no tendría 
Este libro forma parte del acervo de la Biblioteca Jurídica Virtual del Instituto de Investigaciones Jurídicas de la UNAM

sentido pasar al primero; la discusión del dictamen se contrajo a una larga perorata de José Natividad Macías apoyando el dictamen. Se continuó en la 56a. sesión de ese mismo día por la noche en la cual se votaron en conjunto, pero separadamente, los artículos 103 a 107; por lo que hace a este último, el dictamen fue aprobado por una aplastante mayoría de 139 votos, en contra de cuatro, que se supone serían a favor del voto particular (correspondientes, a parte de los dos proponentes del mismo, a los de Meza y Ramírez G.).

Uno no se explica por qué el diputado Hilario Medina Gaona ${ }^{26}$ propuso semejante voto particular que ignoraba casi 50 años de la historia de nuestra máxima institución procesal; de Jara no nos extraña, no conocía el ordenamiento jurídico.

Evidentemente, la redacción de 1917 superaba en mucho al texto de 1857; durante casi 50 años (de 1869, con la segunda ley reglamentaria, hasta 1917) el amparo mexicano se transformó radicalmente a través de una muy rica evolución legislativa, doctrinal y jurisprudencial; podemos decir que el Código Federal de Procedimientos Civiles del 26 de diciembre de 1908, que fue la última legislación reglamentaria de los artículos 101 y 102 constitucionales, anterior a la Revolución mexicana, asume todo ese desarrollo.

El texto constitucional de 1917 tomó la estafeta que había dejado el Código de 1908, en ocasiones lo empeoró, por ejemplo, redujo la suplencia de la queja a la materia penal, cuando que en 1908 era a cualquier tipo de amparo (artículo 759), pero en general, se avanzó positivamente, se mejoró la redacción, pero sobre todo en materia de amparo contra resoluciones judiciales, que, como apuntamos atrás, la creación del amparo directo resultó un avance muy positivo, además de darle al recurso de revisión el carácter potestativo, ya no forzoso, y la cuestión de responsabilidades de las autoridades demandadas. También se estableció que el amparo indirecto en materia penal se pudiese interponer ante el superior del tribunal cuya resolución se impugnase por la vía de amparo, dado el escaso número de juzgados de distrito que en esa época había y las comunicaciones tan deficientes; de igual manera se conservó la jurisdicción auxiliar de los juzgadores locales respecto a los jueces de distrito, que ya existía. ${ }^{27}$

26 Don Hilario era una persona culta, fue ministro y presidente de la Suprema Corte de Justicia varias veces y profesor de derecho constitucional en la Escuela Nacional de Jurisprudencia.

27 Cfr. nuestro trabajo "Algunas reflexiones sobre el amparo judicial en la Constitución de 1917", El juicio de amparo en el centenario de la Constitución mexicana de 1917. Pasado, presente y futuro, México, UNAM, 2017, t. I, pp. 509-530. 
Este libro forma parte del acervo de la Biblioteca Jurídica Virtual del Instituto de Investigaciones Jurídicas de la UNAM

Hasta aquí, esta apretada síntesis de la benemérita labor del licenciado José Natividad Macías en la formación de la Constitución Política de los Estados Unidos Mexicanos, tanto por lo que se refiere al Proyecto que presentara el primer jefe, don Venustiano Carranza, como al debate del mismo en el seno del Congreso Constituyente de Querétaro, por ello, a pesar de los defectos y errores que como ser humano tuvo don José Natividad, reiteramos, fue la figura más importante en el mencionado Congreso Constituyente. 
Este libro forma parte del acervo de la Biblioteca Jurídica Virtual del Instituto de Investigaciones Jurídicas de la UNAM

\title{
EN LOS ALBORES DE LA LEGISLACIÓN Y EL DERECHO URBANO MODERNO Y CONTEMPORÁNEO EN MÉXICO: EL ARTÍGULO 27 CONSTITUGIONAL
}

\author{
Omar Ernesto ROQUe BERNAL*
}

\begin{abstract}
SUMARIO: I. Introducción. II. Los albores de los asentamientos humanos: origen de la planeación y las leyes urbanas. III. Destellos de legislación y derecho urbano en el México colonial, independiente y revolucionario. IV. Bifurcación del artículo 27: entre el origen social y público, y los ajustes para el México contemporáneo. V. Conclusiones. VI. Referencias.
\end{abstract}

\section{INTRODUCGIÓN}

El derecho puede definirse como un cúmulo de normas que rigen la vida social, y se especializa en relación con los elementos que en cada caso dictamina. Por su parte, el urbanismo, como disciplina o práctica de constituir ciudades a partir de la sociedad a la que sirve, genera un complejo y amplio conjunto de relaciones que deben ser reglamentadas por juicios jurídicos. De esta manera el derecho urbano establece las relaciones implicadas en el urbanismo y estipula la forma de hacer la urbe; por tanto, el urbanismo y el derecho urbano son elementos conexos de la misma realidad que trata de estudiar. Por ello, hay dos grandes dimensiones dentro de la categoría llamada urbanismo, por un lado, el propio hecho de la creación de las urbes y, por otro, el derecho a regular el hecho social cuando deriva en conflicto. ${ }^{1}$

* Doctor en historia y etnohistoria por la Escuela Nacional de Antropología e Historia; maestro en Desarrollo Regional por El Colegio de Veracruz. Adscrito a la Licenciatura en Gestión Urbana y Rural de la Universidad de La Ciénega del Estado de Michoacán de Ocampo. Correo electrónico: oeroque@ucienegam.edu.mx.

1 Gómez Rojo, María Encarnación, "Líneas históricas del derecho urbanístico con especial referencia al de España hasta 1936”, Revista de Estudios Histórico-furídicos, núm. 25, 2003, pp. 93-146. 
Este libro forma parte del acervo de la Biblioteca Jurídica Virtual del Instituto de Investigaciones Jurídicas de la UNAM

El surgimiento del fenómeno urbano es tan antiguo como la humanidad misma, considerándose un hito del proceso civilizatorio. El inicio de las ciudades se acompañó de múltiples fenómenos alternos y relacionados; como el surgimiento de la agricultura, el sedentarismo, la estratificación social, la consolidación de los sistemas de pensamiento mítico-religioso, la organización de proto-estados; entre muchas otras estructuras y superestructuras; incluyendo las políticas y leyes que las regían y planificaban.

Para el caso de América se recorrió un camino similar en su historia urbana; truncado de su natural desarrollo por la conquista y colonización europea, permitiendo una amalgama de la visión urbana mesoamericana con la española, para crear un sincretismo urbanístico sui géneris; cuestión aún por demostrar mediante más estudios al respecto. Tal fenómeno se reflejaría en las leyes que rigieron en esta materia a las colonias del imperio español. Para el caso de México, aún hay que demostrar si los criterios de derecho urbano heredados de la Colonia sobrevivieron o se fueron diluyendo en las distintas legislaciones que surgieron de los proyectos conservadores y liberales de la primera etapa del México independiente, así mismo se requiere escrutar sobre los aportes que en materia de derecho urbano dejaron la Reforma y el Porfiriato. Lo que sí se considera un hecho es que la experiencia de México en el aspecto legislativo urbano ha sido muy limitada.

Para la época contemporánea, el fundamento del derecho urbano puede encontrarse en forma implícita en el artículo 27 (Constitución de 1917), por dar cabida a un posible fundamento en materia urbana, señalando que el dominio del suelo corresponde a la nación y que ésta puede asignar distinciones a la propiedad privada; ésta es la primordial característica del derecho urbano en México, que en un principio fue preponderantemente público y social. Esta referencia para la conformación del derecho urbanístico, que inicialmente no regulaba la materia de forma específica ni sistematizada (1917-1975), sino más bien reglamentó los diversos títulos competenciales en materia de población, sanidad de las construcciones y creación de nuevos centros de población, monumentos arqueológicos, medio ambiente, entre otros; pero sin que pudiera considerarse un derecho urbano ordenado o sistematizado, aunque sí dominante, hasta por encima de las visiones teóricourbanistas de aquel momento. Fue hasta 1976, cuando las reformas y adiciones a los artículos 27, 73 y 115, establecieron con claridad el fundamento del derecho urbanístico mexicano por primera vez en la historia. ${ }^{2}$

2 Actualmente hay que agregar los artículos 4o., 26 y 133; así como sus últimas adiciones y reformas a la fecha, sobre todo la de 1992. 
Este libro forma parte del acervo de la Biblioteca Jurídica Virtual del Instituto de Investigaciones Jurídicas de la UNAM

El objetivo de esta propuesta es demostrar mediante un análisis histórico y jurídico cómo el derecho urbano surge como parte del mismo proceso histórico urbanístico, evolucionando en el mismo contexto hasta la época moderna y contemporánea. En el caso mexicano, se impulsó desde lo contenido en el artículo 27 constitucional para desarrollar su actual cuerpo jurídico en materia de urbanismo, y éste a su vez desde antecedentes que provienen del juarismo y la Reforma. Lo anterior permitirá concluir con una reflexión, sobre la forma en que las últimas reformas constitucionales han desvirtuado el espíritu inicial del derecho urbano en México.

\section{LOS ALBORES DE LOS ASENTAMIENTOS HUMANOS: ORIGEN DE LA PLANEACIÓN Y LAS LEYES URBANAS}

Hacia el 4000 a. C., el hombre arcaico había aumentado su capital cultural mediante el acopio de conocimientos, saberes y destrezas prácticas; aplicables a la arquitectura, la agricultura, la metalurgia, la mecánica y a sus creencias mágicas; todas tan importantes como lo es hoy la ciencia y tecnología. Tales conocimientos se propagaron por medio de las migraciones, el comercio y las conquistas. Tal proceso fue la base de un proceso civilizatorio; denominado por Gordon Childe como revolución urbana, producto de una anterior, de naturaleza agrícola. ${ }^{3}$

Los lugares ideales para instaurar los primeros asentamientos urbanos fueron las grandes depresiones o deltas de los ríos, por su abundante agua y suelo fértil que permitió el abastecimiento de alimentos y, con ello, la acentuación demográfica. Pero tales contextos naturales, mejorados aún más por la construcción de infraestructura hidráulica y la aplicación de técnicas de irrigación, carecieron de otras materias primas, imposibilitándoles una autosuficiencia, por lo que tuvieron que desarrollar una manufactura especializada, vías de comercio e importación de productos. Para ello tuvieron que desarrollar una organización social, política y religiosa, que se apoyaba en un sistema económico centralizado. Poco a poco las cuevas, chozas y alquerías se complementaron al lado de grandes monumentos, templos, tumbas, palacios y talleres; incrementándose la riqueza y la densidad poblacional. Las ciudades estaban constituidas de un centro político-religioso, denominada ciudadela, donde se erigieron primero templos y luego palacios. ${ }^{4} \mathrm{La}$

3 Childe, Gordon, Los orígenes de la civilización, México, Fondo de Cultura Económica, 1996, p. 173.

4 Ibidem, p. 188. 
Este libro forma parte del acervo de la Biblioteca Jurídica Virtual del Instituto de Investigaciones Jurídicas de la UNAM

realización de estas obras requirió una enorme fuerza de trabajo de mano especializada y esclava; "los sacerdotes y arquitectos tuvieron que aprender a coordinar y controlar esta enorme fuerza de trabajadores, y a resolver los diversos problemas surgidos de lo mismo". ${ }^{5}$

El Nilo, Tigris y Éufrates, así como el Indo; fueron los primeros paisajes urbanos, que se repetirán en el resto del orbe en tiempos posteriores y con características únicas. En cada región del planeta se trabajó con materias primas similares, utilizando procedimientos básicos y análogos para fabricar herramientas utilizadas para satisfacer necesidades humanas usuales, pero con formas y diseños completamente distintos.

Una identidad fundada en la asociación por lenguaje, creencias, cultura y organización social; instauraron los primeros Estados teocráticos-monárquicos, centralizados y guerreros. Estos entes humanos crearon el orden político necesario para el desarrollo económico del sistema de ciudadesestado. Dicha unificación política trajo consigo un sistema económico primario y a la vez especializado en la manufactura y el comercio. De las castas de sacerdotes surgieron los primeros reyes, guerreros y administradores. La acumulación de las riquezas, producto de las conquistas y el comercio, requirió de una mejora en las destrezas técnicas de administración y planeación. Los trabajadores de esos primeros asentamientos urbanos, recibían paga y alimentos de un depósito y del tesoro controlado y administrado por una fuerza dirigente centralizada.

El contexto anterior impulsó "el desarrollo de la escritura y las matemáticas" ${ }^{6}$ pues se tuvieron que desarrollar tales métodos para llevar registros administrativos y comerciales. Tablillas arcaicas dan testimonio de lo anterior; siendo los ingresos del Estado el tema escrito más antiguo, mas no el único; hay cuentas, contratos y relaciones de signos. ${ }^{7}$ Posterior al 3000 a. C. se comienzan a encontrar inscripciones, hechizos, y fragmentos de códigos legales. ${ }^{8}$ Aunque el propósito original de la escritura era la administración, no la magia ni la liturgia; "su verdadera importancia radica [en su destino] a revolucionar la transmisión del conocimiento humano [pues constituye] el primer paso para elevar a la ciencia por encima de los límites del espacio y del tiempo". ${ }^{9}$ La escritura permitió no sólo el control de la riqueza, sino también la planeación y las leyes en estos primeros centros urbanos.

\footnotetext{
5 Ibidem, pp. 200 y 201.

6 Ibidem, p. 204.

7 Una especie de diccionarios idiomáticos.

8 Ibidem, pp. 219-223.

9 Ibidem, pp. 226 y 227.
} 
Este libro forma parte del acervo de la Biblioteca Jurídica Virtual del Instituto de Investigaciones Jurídicas de la UNAM

El poder político, junto con las leyes, se consideraban de origen divino. Los códigos de leyes escritas son cada vez más comunes, siendo uno de los más antiguos, el de Hammurabí; ${ }^{10}$ conjunto de ordenamientos jurídicos que regulaba diversos aspectos de la vida en sociedad a través de normas penales, civiles y mercantiles. También contenía disposiciones relacionadas con las obligaciones del Estado, como garante "de la seguridad de las personas". ${ }^{11}$ Sus figuras más comunes son la indemnización, el honor y el talión. Tales reglas tuvieron como efecto la unificación de la región bajo el imperio babilónico y del mundo antiguo en general. Varias secciones del código son dedicadas al principio normativo de la propiedad privada, del Estado y lo colectivo. "Se define el derecho sobre las cosas muebles, inmuebles y semovientes. Tropezamos por doquier con tarifas de arrendamiento de muebles, inmuebles"; ${ }^{12}$ necesidad de hacer productivas las tierras y el arrendamiento del mismo. Ejemplo de lo que hoy llamaríamos ley cívica-urbana: "Ley 56: Si un señor dio entrada al agua y permitió que el agua estropease la labor del campo de su vecino pagará diez gur de grano por cada bur" ${ }^{13} \mathrm{El}$ preámbulo, efemérides y cierre del escrito, hacen referencia a que el establecimiento de estas leyes tiene como propósito la justicia y felicidad de los hombres. Igualmente afirma que estas leyes son inmutables, al grado de que hace una invocación a doce divinidades "con el propósito de que maldigan y castiguen al soberano que irrespetuoso a las imprecaciones y conjuros no respete las leyes, las derogue, las cambie, o injurie su imagen o su nombre". ${ }^{14}$

Para el año 2500 a. C. la revolución urbana ya se había consumado en esa región y expandido al resto del mundo; eran característicos calles y callejones, bien alineados acorde a un diseño anticipado, edificios con sistemas de alcantarillado, suntuosas moradas junto a chozas. Lo anterior habla de la presencia de una potestad cívica. ${ }^{15}$ Entre el tercer y segundo milenio antes de nuestra era; en todo esa región del mundo antiguo se establecieron civilizaciones urbanas, con carácter propio, pero con un desarrollo muy parecido a los primeros centros urbanos en Egipto, Mesopotamia y el Indo. Para el 1500 a. C. esta nueva estructura se expandió a toda Europa occidental, y cinco siglos después a la oriental y al Atlántico norte. Pero en ese proceso

10 Ibidem, pp. 191 y 192.

11 González Roacho, Crystal et al., "Obra con legado jurídico: Código de Hammurabi”, Revista Libertades, núm. 2, 2013, pp. 98 y 99; Franco, Gabriel, "Las Leyes de Hammurabi", Revista de Ciencias Sociales, 1962, p. 332.

12 Childe, Gordon, op. cit., p. 99.

13 Idem.

14 Franco, Gabriel, op. cit., pp. 332-335.

15 Childe, Gordon, op. cit., pp. 204 y 205. 
Este libro forma parte del acervo de la Biblioteca Jurídica Virtual del Instituto de Investigaciones Jurídicas de la UNAM

de propagación la cultura original se va degradando, y adoptando formas y expresiones únicas, surgiendo grados de civilización. ${ }^{16}$

En resumen, había una veneración por las tradiciones antiguas, un culto al conocimiento ya existente; ${ }^{17}$ por ello muchas leyes se mantuvieron intactas por mucho tiempo, expandidas por el difusionismo de ideas, gracias a la migración, el comercio y las conquistas. La escritura aceleró un poco ese progreso por la transmisión del conocimiento, ${ }^{18} \mathrm{y}$ tal conocimiento del mundo antiguo, incluyendo buena parte de su cuerpo jurisprudencial, pasó a Grecia, y a su vez a Roma, ${ }^{19}$ importándose los principios del urbanismo romano.

A partir de aquí, en el cierre del periodo antiguo e inicios del medieval, se retoma el escrito de María Encarnación Gómez Rojo, ${ }^{20}$ quien hace una excelente síntesis del desarrollo y el derecho urbanos para este periodo histórico.

En su obra Política, Aristóteles establece como pilares básicos para erigir y planificar la ciudad: la higiene, la defensa, espacios públicos adecuados para la política, la estética urbana, entre otros. Su propuesta será precursora de predilecciones y estilos de desarrollo urbano posteriores; su pensamiento no se limitó a la protección de los monumentos, extendiéndose su rango de acción a la recuperación integral de las urbes, base actual del derecho urbano moderno y contemporáneo; también coincide en el hecho de considerar a la edificación como una expresión de la propiedad como derecho, así mismo las relaciones vecinales que implica no se pueden desligar.

En el caso romano, el poder público correspondía al derecho de construir en aquellas tierras producto de las conquistas. Su normatividad fijaba la repartición de los terrenos conquistados, señalando el trazado de los accesos y la plaza central, delimitando el contorno de la ciudad y fijando a los colonos sus correspondientes terrenos. Las normas urbanísticas fueron englobadas en el derecho romano bajo la idea de controlar la posesión de la tierra. La distancia y altura máxima de los edificios, la conservación, y la reparación de los mismos; son técnicamente las tres órdenes fundamentales o limitaciones legales principales, para ordenar urbanísticamente las ciudades. En síntesis, son las normas urbanísticas romanas principales.

Contrario al interés romano en lo urbanístico, el derecho en el Bajo Imperio y durante el dominio de los pueblos bárbaros, no se interesan mu-

\footnotetext{
16 Ibidem, pp. 216 y 217.

17 Ibidem, p. 231.

18 Ibidem, p. 271.

19 Ibidem, p. 259; Franco, Gabriel, op. cit., pp. 333 у 334.

20 Gómez Rojo, María Encarnación, op. cit.
} 
Este libro forma parte del acervo de la Biblioteca Jurídica Virtual del Instituto de Investigaciones Jurídicas de la UNAM

cho en los aspectos urbanos. En la planificación urbana en la Edad Media tardía reaparece la intervención del Estado en la construcción y edificación, normalizando la ocupación de tierras por medio de cánones reales o capitulares, de forma muy parecida al derecho romano, que estipulaba que los bienes y terrenos sin legítimo dueño se integrarían al fisco y que era el príncipe quien debía concederlos a sus vasallos con fines repobladores. Estas ciudades medievales, tanto las nuevas como las de origen romano, estaban cercadas por grandes muros, y en su interior, circunscritas alrededor de la plaza central, se emplazaban las construcciones más importantes, en torno a las cuales giraba la vida urbana. La mayoría de las poblaciones y centros urbanos fundadas por los príncipes cristianos (finales del siglo XI hasta la primera mitad del XII), estaban pobladas por gente de distintos orígenes, atraídos por privilegios y beneplácitos especiales, predominando en esta época tardía del medievo, la iniciativa monárquica en el proceso de urbanización. En varios textos medievales:

Incluyen disposiciones concretas referentes a la urbanización de los nuevos núcleos de población: superficie de las parcelas, trazado y anchura de las calles, características de la plaza mayor, fortificaciones y en este sentido alrededor de la plaza o zona central, se distribuían la Iglesia o catedral, el mercado, el palacio o ayuntamiento y las casas de los nobles más significados. ${ }^{21}$

Entre los temas más comunes de las normas urbanas de la España medieval se encuentran temas como: fueros y ordenanzas de edificación en general, cimentación de molinos y respeto a los caminos, normas higiénicas conexass con las letrinas, materiales de construcción, evitar los frecuentes incendios, fabricación de canales, edificación de murallas, donaciones del monarca (constitución de un territorio jurídicamente protegido), proyectos de puertos, acciones repobladoras, campos militares, trazado de calles, construcciones públicas, protección de las plazas públicas, baños públicos, hospederías, entre otros.

El pensamiento cristiano influye en el diseño, humildad y opulencia de la edificación de casas y edificios. Igualmente, los prejuicios religiosos fundamentan normas referentes a la proscripción de sinagogas ni mezquitas, únicamente se les permitía repararlas, siempre y cuando no compitieran con las construcciones cristianas-católicas. 
Este libro forma parte del acervo de la Biblioteca Jurídica Virtual del Instituto de Investigaciones Jurídicas de la UNAM

\section{DESTELLOS DE LEGISLAGIÓN Y DERECHO URBANO EN EL MÉXICO COLONIAL, INDEPENDIENTE Y REVOLUCIONARIO}

Es innegable la relevancia del "diseño, función y hegemonía de los más importantes centros urbanos prehispánicos, que sin duda se encontraron bajo el signo de alguna forma de planificación", ${ }^{22}$ así como de una lógica urbana, y, por lo tanto, requieren de un estudio aparte; pero por el corto espacio, y la línea discursiva e importancia de la influencia europea en el proceso y legislación urbana en el México moderno y contemporáneo, se dejará este tema para otra ocasión.

La conquista española determina el inicio de la influencia europea en el trazo y diseño de las principales ciudades latinoamericanas, emergidas gradualmente de asentamientos coloniales nuevos y prehispánicos originales. "Las leyes de Indias, dieron forma y organización efectiva a las ciudades fundadas por los españoles en toda la América conquistada... [se configuran] como un deber del conquistador y una potestad pública, más que como una consecuencia del dominio privado de la asignación de tierras". ${ }^{23}$ $\mathrm{Al}$ respecto, se destacan "como principios y reglas para la urbanización de las nuevas ciudades diversos criterios para la zonificación, la edificación, la orientación, la accesibilidad así como para el desarrollo de actividades agrícolas y comerciales dentro y fuera de la ciudad". ${ }^{24}$

Se considera a las Ordenanzas para Nuevos Descubrimientos y Fundaciones de Felipe II de 1573 como el origen del derecho urbano colonial, en lo general, "indicaban que las calles deberían estar dispuestas en damero con una plaza central en torno a la cual se agrupaban la Iglesia y los edificios reales y civiles... [consideró] la plaza mayor como espacio geométrico base, con una arquitectura civil unificada y al servicio de numerosas necesidades sociales". ${ }^{25}$ Esta ley contiene

una idea del urbanismo avanzada con respecto a su época...[aparecen] claramente diferenciadas y delimitadas [en ellas] las dos dimensiones clásicas del urbanismo, la relativa a los aspectos físicos... [y sociales de cada ciudad]. Estos preceptos, inspirados evidentemente en las concepciones urbanas y de

22 Gutiérrez Chaparro, Juan José, "Planeación urbana en México: un análisis crítico sobre su proceso de evolución”, Urbano, vol. 12, núm. 19, mayo de 2009, pp. 52-63; Universidad del Bío Bío, Concepción, Chile, p. 54.

23 García, 1965 y Margadant, 1987.

24 Idem.

25 Gutiérrez Chaparro, Juan José, op. cit., p. 56. 
Este libro forma parte del acervo de la Biblioteca Jurídica Virtual del Instituto de Investigaciones Jurídicas de la UNAM

diseño del espacio español, influyeron en el diseño y planificación de las ciudades mexicanas al menos hasta el siglo XVIII. ${ }^{26}$

Nuevamente la obra de María Encarnación Gómez Rojo ${ }^{27}$ permite conocer una síntesis del periodo colonial en materia urbanística y su normatividad. "En América, el título jurídico para incorporar las nuevas tierras a la Corona fue el poblamiento, y de ahí el interés de los españoles en fundar ciudades...[para] 1580 se habían fundado 230, esto a pesar de que el [no contar] con licencia de la Corona o de los Adelantados acarreaba la pena de muerte". ${ }^{28}$

A los corregidores, figuras importantes de la política interna, se les precisaban notables recomendaciones en materia urbanística: emplear una parte de las rentas y recursos de los pueblos en la promoción de obras públicas, tanto de construcciones civiles como religiosas, así como la reparación de edificios; diferenciar las obras públicas con licencia real de las que lo carecen; reparación de viviendas viejas o en ruinas, construir o continuar obras públicas iniciadas pero abandonadas por no contar en su momento de la autorización real; no era necesaria la autorización real para seguir con la construcción de edificios públicos; admite el embargo de inmuebles llevados a cabo por razones de beneficio público; se pueden derribar edificios privados que se consideren una amenaza por estar en ruina, instaurar recargos y sanciones en materia de edificación y urbanismo, y están autorizados reducir el plazo de los permisos para realización de obra nueva. ${ }^{29}$

Para el siglo XVIII el establecer ciudades nuevas por iniciativa pública estaba en manos del superintendente, quien debía elegir lugares sanos para emplazar a los habitantes; siendo algunas de sus atribuciones determinar si tales asentamientos estaban:

Bien ventilados y sin aguas estancadas... debía levantar un plan para resolver todas las dudas que pudieran surgir a la vista de la posición material de los terrenos; cada población debía tener entre 15 a 30 casas como máximo... [así como tierra para cultivarla], demarcar los terrenos con señales y mojoneras de piedra para distinguirlo; construcción de una Iglesia en el centro de los lugares que formaran el concejo municipal, y cerca de ella una escuela de primeras letras, construcción de molinos u otros artefactos, una dehesa para animales de labor, las nuevas poblaciones... [deberán estar] sobre los caminos

\footnotetext{
26 Idem.

27 Gómez Rojo, María Encarnación, op. cit.

28 Idem.

29 Idem.
} 
Este libro forma parte del acervo de la Biblioteca Jurídica Virtual del Instituto de Investigaciones Jurídicas de la UNAM

reales o sus inmediaciones para facilidad de las transacciones mercantiles; uso y construcción de cementerios inmediatos a las parroquias y distantes de las casas [de los vecinos]; reparación de castillos y fortalezas; es obligación de los corregidores construir casas de concejo, cárceles donde no hubiera y arcas para custodiar privilegios, escrituras y libros de las leyes del reino; hay prohibición de derribar lo edificado, [y se insta a realizar censos]. ${ }^{30}$

Por lo dicho anteriormente, las ciudades en México, principalmente su capital, han estado influidas urbanísticamente por modelos europeos, primero se reprodujo el estilo español y posteriormente el francés, esto desde la época colonial; misma etapa que definió "una jerarquía de centros urbanos de diferentes tamaños y con distintas funciones, lo cual es posible observar hoy en día". 31

El urbanismo moderno en México se inspiró en Europa, cuya influencia se ubica en el marco de las Reformas Borbónicas en la segunda mitad del siglo XVIII con las propuestas del urbanismo neoclásico, y posteriormente con el urbanismo francés, como la primordial influencia divulgada en el país desde finales del siglo XIX, transformando "la imagen urbana de la ciudad, no sólo por el nuevo estilo arquitectónico que convivía con el colonial, además por el trazo de nuevas y amplias calles bajo la influencia de concepciones urbanísticas que modificaron el perfil urbano arquitectónico a semejanza de las capitales europeas". ${ }^{32}$ Este urbanismo moderno se consolida a finales del siglo XVIII con el "Plano Regulador de México", 33 desarrollado por Ignacio de Castera, esto bajo la propuesta del "pensamiento Ilustrado y del urbanismo neoclásico caracterizado por sus principios de simetría, orden, regularidad y salud pública". ${ }^{34}$

Tras la llegada del urbanismo ilustrado europeo, México cayó en un periodo de estatismo urbano, iniciada por la lucha de independencia, prolongándose a causa de las luchas intestinas por imponer un proyecto de nación entre liberales y conservadores. El derecho urbano quedó delegado a segundo plano durante la primera mitad del siglo XIX, en un contexto

30 Idem.

31 Gutiérrez Chaparro, Juan José, op. cit., p. 54.

32 Ibidem, pp. 56 y 57.

33 "El Plano de Castera constituía el ideal urbano de la Ilustración en México; consideraba a la ciudad como un todo y proponía la ampliación de la traza favoreciendo el orden y control de la ciudad tanto en la parte central como en los barrios periféricos no obstante, hay que reconocer que los proyectos que lo integraban fueron realizados parcialmente aunque años más tarde, algunos se cristalizan; se logra la apertura de algunas calles, la construcción de la acequia exterior y el paulatino alineamiento de las calles". Ibidem, p. 57.

34 McMichael, 2002. 
Este libro forma parte del acervo de la Biblioteca Jurídica Virtual del Instituto de Investigaciones Jurídicas de la UNAM

de monopolización de la propiedad por parte de las elites y la Iglesia, y una banca rota que evita al Estado desarrollar proyectos urbanos, que de paso, carecían de un cuerpo legal base, cuestión que se subsanaría con la promulgación de las leyes de reforma.

El antecedente inmediato de las Leyes de Reforma y su respectiva Constitución (1857) fue la Revolución de Ayutla de 1854, que desconoció al presidente en turno (Antonio López de Santa Anna) y convocó a un Congreso Constituyente para que se promulgara una nueva Constitución de ideología liberal y con una organización política republicana, representativa y popular. Su triunfo llevaría a los liberales a establecer el modelo ideológico y político de la Revolución francesa. Entre 1855 y 1872 se expidieron 174 leyes reformistas. ${ }^{35}$ Entre sus múltiples causas, figuran los problemas económicos y sociales originados por la monopolización de la tierra, siendo que el cúmulo de propiedades las poseía principalmente la Iglesia católica, siendo en su mayoría improductivas.

En 1856 fue expedida la Ley que desamortiza los bienes de la iglesia o Ley Lerdo; a causa de lo que se consideró como uno de los impedimentos para el progreso de la nación, la falta de productividad y libre tránsito comercial de una gran parte de la propiedad en México, plataforma fundamental de la riqueza pública. De inmediato las propiedades alquiladas se adjudicaron a quienes las tuvieran rentando. Las tierras inactivas se rematarían abiertamente; prohibiendo a las sociedades religiosas adquirirlas en el futuro o administrar bienes inmuebles, exceptuando los que eran utilizados llanamente en el uso o servicio de la iglesia.

Estas leyes reformistas fueron anexadas a la nueva Constitución por medio del decreto de 1873, incorporando las Leyes de Reforma a la Constitución de 1857. La Ley Lerdo se anexaría en 1859, con la Ley de Nacionalización de los Bienes Eclesiásticos, que fue más allá, pues la original "había sido hecha con un fin económico, el poner en circulación y hacer productivos los bienes del clero que estaban como «manos muertas»; sin quitarles la propiedad de los mismos. En cambio, la Ley sí les retiró la propiedad, al haberlos declarado bienes propiedad de la nación". ${ }^{36}$ La Constitución de 1857 contenía un segmento orgánico y otro dogmático; a esta última pertenece todo lo referente a los derechos de propiedad.

$\mathrm{Al}$ mismo tiempo que constitucionalmente se daba certeza al papel del Estado en lo referente a la propiedad, base del desarrollo urbano:

35 Carvajal Contreras, Máximo, "Las leyes de reforma. Un tema olvidado en el estudio de las facultades de derecho", Ponencia. XXI Congreso Nacional de ANFADE, San Luis Potosí, septiembre de 2010 (fecha de consulta: 8 de octubre de 2016), p. 4.

36 Ibidem, pp. 5 y 7. 
Este libro forma parte del acervo de la Biblioteca Jurídica Virtual del Instituto de Investigaciones Jurídicas de la UNAM

América Latina se incorpora a la corriente urbanística desarrollada en Europa entre la segunda mitad del siglo XIX y la primera del XX. Las técnicas básicas del moderno derecho urbanístico surgen en el siglo XIX, principiando por la aprobación en Inglaterra de los primeros reglamentos de carácter sanitario (1848). ${ }^{37}$

Normatividad en su momento insuficiente, pero de la que se rescata el método de zonificación, que es el conjunto de técnicas en urbanística predominantes.

[Después de] al menos dos siglos de predominio de los preceptos de las Leyes de Indias y los del urbanismo neoclásico, a partir de la segunda mitad del siglo XIX, durante el Porfiriato es notoria la influencia [de la ideología del urbanismo francés] y la obra de Haussmann en el diseño y planificación de las ciudades en México; siendo la higiene, el tráfico y la estética junto con los valores ideológicos, los fines políticos y policiales y la promoción económica, algunos de los elementos centrales de esta influencia. ${ }^{38}$

Sus reformas fueron ejecutadas primero en París; promoviéndose luego en México con la construcción de avenidas amplias y espacios públicos abiertos que mantenían como referente central un edificio o monumento, creando perspectivas barrocas parecidas a las impulsadas en ciudades europeas.

Los estudios de De Gortari y Hernández (1988), así como McMichael (2002), afirman que el nuevo estilo arquitectónico convivió con el colonial, transformando la imagen urbana de la ciudad porfiriana:

Mientras que la extensión del territorio ocupado, además de verse favorecida de alguna forma por la desamortización, fue estimulada por el trazo de nuevas y amplias calles entre las que destaca el Paseo de la Reforma cuyo trazo y diseño fue muestra palpable de las concepciones urbanísticas de la época. Además de sus glorietas y de numerosas estatuas y monumentos, a lo largo de esta importante vialidad y rodeadas de jardines, se asentaban numerosas edificaciones con estilos arquitectónicos que evocaban al de ciudades de otros países modificándose el perfil urbano arquitectónico de la capital mexicana a semejanza de las capitales europeas. ${ }^{39}$

37 Gómez Rojo, María Encarnación, op. cit.

38 Gutiérrez Chaparro, Juan José, op. cit., pp. 55 y 57.

39 De Gortari y Hernández, 1988 y McMichael, 2002, en Gutiérrez Chaparro, Juan José, op. cit. 
Este libro forma parte del acervo de la Biblioteca Jurídica Virtual del Instituto de Investigaciones Jurídicas de la UNAM

[En este contexto,] cuando en septiembre de 1910 se inauguraba sobre el Paseo de la Reforma la Columna de la Independencia para conmemorar el primer centenario de la Independencia de México, el país asistía al mismo tiempo a uno de los actos que marcaban el fin del Porfiriato. El legado de la política urbanística del régimen por la que se buscó el acondicionamiento de la ciudad bajo la influencia francesa se tradujo en una ciudad llena de contrastes y potenciales conflictos. ${ }^{40}$

Mientras los esbozos ideológicos de esta corriente fueron superados, "la dinámica urbana y poblacional de la ciudad y del país entero asociada con otros tantos factores, provocaron el estallido de la Revolución en ese mismo año". ${ }^{41}$

Al final del siglo XIX y hasta mediados del XX, en el resto del mundo se manifestaron otras propuestas urbanas, como la denominada ciudad jardín perteneciente al inglés Ebenezer Howard que intentó conjugar el ambiente urbano y rural, mediante sus proyectos de áreas habitacionales unifamiliares cercadas por amplias áreas verdes. Después la ciencia urbana:

Se enriquecerá con el denominado regionalismo urbanístico defendido por Lewis Mumford; el funcionalismo de Le Corbusier que se inspira en una ciudad modélica que satisfaga las necesidades básicas del hombre (habitar, trabajar, recrearse, circular), o finalmente la técnica de las nuevas ciudades ["new tows"] surgidas en Inglaterra, después de la II Guerra Mundial, como unidades urbanas completas para descongestionar la gran urbe. El soporte jurídico de esta nueva ordenación urbana será la técnica de la planificación procedente del campo de la economía. En los planes se van a contener aquellas normas indispensables para la urbanización. ${ }^{42}$

\section{BIFURCACIÓN DEL ARTÍCULO 27: ENTRE EL ORIGEN SOCIAL Y PÚBliCO, Y LOS AJUSTES PARA EL MÉXICO CONTEMPORÁNEO}

Después de los acontecimientos de la Revolución en México, la planeación urbana se benefició ante las necesidades de un recuperación nacional, alentando al fomento de diversas iniciativas a partir de la década de los veinte, favoreciendo en la cimentación de una plataforma teórico e institucional como herramienta de la planeación urbana así como su integración progresiva

\footnotetext{
40 Davis, 1999.

41 Gutiérrez Chaparro, Juan José, op. cit., pp. 57 y 58.

42 Gómez Rojo, María Encarnación, op. cit.
} 
Este libro forma parte del acervo de la Biblioteca Jurídica Virtual del Instituto de Investigaciones Jurídicas de la UNAM

como instrumento de intervención urbana. Carlos Contreras fue el principal impulsor y arquitecto de este movimiento en la Ciudad de México. Pero antes de abordar la obra de este connotado arquitecto, y con ella comprender el desarrollo de la planeación urbana en el México contemporáneo, se debe analizar la base jurídica constitucional desde donde se partió, el artículo 27 de la Constitución de 1917, que englobaba muchas de las exigencias de la lucha revolucionaria.

Es interesante observar que el artículo 27 constitucional en ningún momento hace referencia al ámbito urbano, pero al tratar el tópico de la posesión de la tierra y su correlación con el campesino, se vuelven ambos objeto/sujeto activo en relación con los procesos de urbanización en México. La Constitución tiene un carácter normativo que vincula sujetos públicos y privados, definiendo directrices de actuación pública. Es la norma que encabeza el ordenamiento jurídico, institucional y protección de libertades ciudadanas.

En cuanto a los principios constitucionales del urbanismo; el punto de referencia para la actuación pública así como su premisa principal, es la calidad de vida, expresada como ordenamiento del suelo. Algunos de los principios (cláusulas) y valores constitucionales que tienen relación directa con el urbanismo son: el principio de supremacía, de legalidad o estado de derecho, principio de control de la administración pública (de gran importancia para el sistema urbano), la garantía patrimonial, ${ }^{43}$ y sus correspondientes instrumentos por normatividad de cada entidad federativa. Otras cláusulas hacen referencia al sistema federal en cuanto a la jurisdicción territorial, sobre el Estado social y democrático, y por último el medio ambiente adecuado y la calidad de vida. ${ }^{44}$

El tema del federalismo ${ }^{45}$ en la Constitución implica indirectamente al sistema urbano. ${ }^{46} \mathrm{Su}$ primera referencia fue en 1934, con la denominada legislación coordinada en materia de educación, ${ }^{47}$ retomada en 1976, sobre la concurrencia de las entidades jurídicos-públicas territoriales en materia de asentamientos humanos; forma rebuscada para decir urbanismo. La igualdad competencial

43 De gran relevancia, pues se refiere a los límites y ablación de la propiedad del suelo; siendo sus mecanismos constitucionales la expropiación (artículo 27, párrafo 2, constitucional) o por responsabilidad patrimonial (artículo 113, párrafo 2, constitucional).

44 Jiménez Dorantes, Manuel, Constitución y urbanismo, México, UNAM, Instituto de Investigaciones Jurídicas, 2006, pp. 53-90.

45 Relaciones entre la Federación y las entidades federativas, federalismo cooperativo.

46 Jiménez Dorantes, Manuel, op. cit., pp. 58-63.

47 Artículo 3o. y 73, fracción XXV, Constitución Federal de los Estados Unidos Mexicanos. 
Este libro forma parte del acervo de la Biblioteca Jurídica Virtual del Instituto de Investigaciones Jurídicas de la UNAM

territorial entre la Federación y las entidades federativas es otro tema en que el federalismo toca al urbanismo. ${ }^{48}$

Pero la certeza constitucional que ahora tiene el urbanismo trajo consigo desventajas. El sistema federal mexicano tiene disfunciones por la excesiva utilización de técnicas de cooperación y coordinación (leyes básicas, planes y programas conjuntos, convenios, órganos de cooperativos, etcétera) que han complicado la distribución competencial a la hora de delimitar los campos y la acción de las entidades territoriales mexicanos. ${ }^{49}$

El urbanismo está directamente relacionado con el principio de Estado social, en conjunción con la de Estado de derecho; ambos base para la acción pública. El Estado adquiere responsabilidades de orden social, ${ }^{50}$ es su responsabilidad participar en el desarrollo social y económico de la gente a través de la prestación de bienes y servicios o mediante la regulación de algunos otros de interés general, con un conjunto de contenidos fundamentales como educación, vivienda, pensiones de jubilación, enfermedad, desempleo o familia; relaciones laborales, y garantía al medio ambiente. ${ }^{51}$ Pero la discusión teórica de hoy, referente a la imposibilidad de que un Estado social pueda cumplir con todas estas responsabilidades, ha cambiado el enfoque de su definición; ahora más que un proveedor, el Estado se establece como un ente regulador que ordena "la participación privada en actividades públicas, exige niveles de calidad en la gestión de servicios de interés general, garantiza la competencia impidiendo el monopolio, como garantiza al ciudadano la materialización de sus derechos constitucionales". ${ }^{52}$ Pero es notorio que este nuevo planteamiento de Estado social, tampoco ha podido cumplir con estas nuevas atribuciones, y por otro lado, estas nuevas atribuciones no requerirían de las grandes cantidades de recaudación fiscal que se tienen hoy, que son incluso superiores a las del periodo del Estado de bienestar en México. Bajo este supuesto, ¿ise justifica el adelgazamiento del Estado en cuanto a responsabilidades sociales, pero engrosado por ingresos fiscales y públicos? Lo verdaderamente preocupante es:

El progresivo dominio de la ideología del mercado, en el sentido de su elevación de instrumento a fin y valor en sí y por sí mismo y de su aplicación con relativa independencia de su positiva determinación constitucional. Pues esa transformación y aplicación pueden llegar a provocar una verdadera desvir-

\footnotetext{
48 Jiménez Dorantes, Manuel, op. cit., pp. 66-71.

49 Ibidem, pp. 75 y 76.

50 Algunos de ellos son los artículos 3o., 4o. y 27 constitucionales, entre otros.

51 Jiménez Dorantes, Manuel, op. cit., p. 80.

52 Ibidem, pp. 80 y 81.
} 
Este libro forma parte del acervo de la Biblioteca Jurídica Virtual del Instituto de Investigaciones Jurídicas de la UNAM

tuación del sistema constitucional por la vía de su interpretación distorsionada. ${ }^{53}$

Cabe mencionar que el sistema mexicano a partir del diseño constitucional actual, tiene claramente definida la idea del Estado social, no de Estado regulador. ${ }^{54}$ Por otro parte, las condiciones que un tipo de Estado de ese tipo requiere, dificilmente pueden garantizarse por el sistema mexicano actual: relaciones socioeconómicas estables, disminución de la brecha entre ricos y pobres, fortalecimiento de la clase media, aumento del consumo interno, eficiencia en la distribución de los apoyos de los programas sociales, eliminación de la corrupción e impunidad; cuestiones que claramente no puede garantizar el Estado actual. ${ }^{55}$

Otros elementos constitucionales complementarios a los anteriores, y que influyen al urbanismo son: la democracia, medio ambiente, la calidad de vida.

El denominado sistema democrático en donde opera el principio de participación ciudadano en asuntos públicos: "Hay que mencionar que en el sistema jurídico urbanístico, la participación ciudadana es un elemento esencial para la conformación de los instrumentos de planeación (especialmente municipales)". ${ }^{56}$ Tiene la finalidad de coadyuvar (auxiliar, pues no es parte integrante del órgano público) con la administración pública, permitiéndole a los órganos públicos mayores elementos para la toma de decisiones.

La reforma constitucional de 1999, da reconocimiento al medio ambiente adecuado como eje fundamental del desarrollo y bienestar personales; por lo que la previsión constitucional del medio ambiente tiene efectos normativos para la actuación del Estado. El medio ambiente tiene gran relación con el urbanismo y con el ordenamiento territorial; puesto que tiene como objetivo compartido la protección y aumento de la calidad de vida, compartiendo el territorio como dispositivo de referencia y objeto de regulación jurídica. "El medio ambiente como principio constitucional condiciona toda la política en la materia y conecta ésta con otras políticas, todas ellas

53 Parejo Alfonso, Luciano, "El Estado social y administración pública. Algunas reflexiones a propósito de la llamada crisis del primero", Revista Mexicana de Derecho Público, México, núm. 1, 2001; nota 102, pp. 100 y 101; citado en Jiménez Dorantes, Manuel, op. cit., p. 82.

54 Jiménez Dorantes, Manuel, op. cit., p. 82.

55 Ibidem, pp. 83 y 84.

56 Ibidem, p. 87. 
Este libro forma parte del acervo de la Biblioteca Jurídica Virtual del Instituto de Investigaciones Jurídicas de la UNAM

inspiradas en aquella dignidad de la persona y conducente a su preservación y desarrollo". ${ }^{57}$

La reforma de 1992 realizada al artículo 27 constitucional, pretendía "inducir la modernización del campo mexicano y hacerlo más productivo con base en el otorgamiento de certidumbre jurídica a la tenencia de la tierra y en la posibilidad de asociaciones entre todo tipo de productores, lo que a su vez incidiría en una mayor inversión privada y en la capitalización del campo". ${ }^{58}$ Lo anterior permitió al ejido y a la propiedad comunal integrarse al mercado inmobiliario urbano de forma legal por medio de diversos mecanismos de incorporación del suelo de propiedad social, siendo éste su principal efecto, provocando un apogeo del mercado libre en esta materia, sustituyendo la comercialización ilícita por una incorporación sistemática al desarrollo urbano legal. Antes de la reforma, el ejido tenía un carácter "inalienable, imprescriptible e inembargable, negando la posibilidad de que se venda, arriende o hipoteque". ${ }^{59}$ A pesar de lo inminente de la tendencia a la urbanización de estas propiedades sociales, la Ley Agraria reglamentó todo lo relativo a la tenencia del suelo ejidal, prohibiendo su enajenación y su conversión a usos urbanos. El único efecto causado fue el auge de un mercado inmobiliario privado, que no permitía la participación de instituciones públicas de vivienda en el desarrollo urbano, dejando a los gobiernos sólo como facilitadores del mercado libre del suelo; dinámica en la que no participan los sectores populares de la población, por lo que se mantiene la prácticas de urbanización ilegal. ${ }^{60}$

Tras analizar los principios y reformas constitucionales en México en materia de urbanismo, es notorio el hecho que lo que se regula es la propiedad, no al sistema urbano. También sobresale la naturaleza evidentemente social de la regulación urbana en el país, incluso su fin último es la calidad de vida, apoyado en los distintos instrumentos constitucionales que se mencionaron. La esencia o espíritu de la Constitución se mantiene a pesar de la reforma de 1992, pues de hecho, no convirtió de inmediato al sistema de ejido en uno netamente privado, pues la reforma no significó la venta indiscriminada de tierras ejidales, pues el proceso legal de venta aun hoy no

57 Canosa Usera, Raúl, Constitución y medio ambiente, Madrid, Dyckinson, 2004, p. 90, en Jiménez Dorantes, Manuel, op. cit., p. 89.

58 Olivera Lozano, Guillermo, "La reforma al artículo 27 constitucional y la incorporación de las tierras ejidales al mercado legal de suelo urbano en México", Scripta Nova. Revista Electrónica de Geografia y Ciencias Sociales, vol. IX, núm. 194 (33), 2005.

59 Idem.

60 Idem. 
Este libro forma parte del acervo de la Biblioteca Jurídica Virtual del Instituto de Investigaciones Jurídicas de la UNAM

es fácil. ${ }^{61}$ Esta es la base de la legislación y el derecho urbano ${ }^{62}$ en el país, que nos permite comprender esta normatividad especial de mejor forma, así como las características del proceso de planeación urbano en el México contemporáneo.

Bajo criterios de funcionalidad para hacer de los centros urbanos espacios modernos, funcionales, sanos y ordenados, Carlos Contreras propuso alcanzar una nueva forma de organización urbana en México. Se apoyó de una preparación profesional adquirida en los Estados Unidos de América, principal influencia a su pensamiento urbano. Para mediados de la década de los veinte, y a partir de dicha influencia y experiencia adquirida en el extranjero, Carlos Contreras definió a la planeación urbana como el "arte de proyectar, trazar y construir ciudades a partir de entender su forma y patrón de crecimiento y para efectos de conducir su desarrollo en forma armoniosa y ordenada, incorporó la figura del plano regulador como instrumento". ${ }^{63} \mathrm{El}$ cuerpo conceptual y metodológico de la planeación urbana del país se basó en las pautas del urbanismo moderno norteamericano, siendo sus principios la "funcionalidad, orden, estética y salud pública [constituidas] como las nociones [más] aceptadas en este campo del conocimiento, con una clara orientación hacia lo físico-espacial sin dejar de lado las determinantes sociales". ${ }^{64}$ El trabajo de Contreras le dio carácter de científico al urbanismo, así como una gran aceptación de la planeación urbana en México, haciendo evidente el uso generalizado de su carácter funcional-espacialista; por lo anterior, recibió gran impulso a largo del siglo XX con diferentes proyectos dirigidos a la enseñanza del urbanismo y la planeación urbana a nivel superior. ${ }^{65}$

Lo anterior explica cómo la formación profesional de los predecesores de la planeación urbana en México, vienen principalmente del campo de la ingeniería y la arquitectura, influyendo contundentemente en la orienta-

61 Además que la participación en el sector privado del ejido no es nueva, ya que existía la modalidad de permuta, que hasta 1971 permitía adquirir tierra ejidal en una ciudad a cambio de otra, siempre y cuando tuviera características parecidas en otro lugar, sirvió para que desarrolladores privados construyeran complejos turísticos, parques industriales y vivienda no popular. Azuela y Ward, 1994: 170; citado en Olivera Lozano, Guillermo, op. cit.

62 El derecho urbano se define como un conjunto de principios, normas e instituciones que regulan a las ciudades para ordenar, desarrollar y conducir su dinámica. Ruiz Massieu, José Francisco, Derecho urbanístico, México, UNAM, 1981, p. 11; citado en González Roacho, Crystal et al., op. cit., p. 8.

63 Sánchez, 2002 y de Gortari y Hernández, 1988, en Gutiérrez Chaparro, Juan José, op. cit., pp. 58 y 59 .

64 Gutiérrez Chaparro, Juan José, op. cit., p. 58.

65 Ibidem, p. 59. 
Este libro forma parte del acervo de la Biblioteca Jurídica Virtual del Instituto de Investigaciones Jurídicas de la UNAM

ción físico-espacial del enfoque actual dominante en este campo. ${ }^{66}$ Por ello, gradualmente la planeación urbana mexicana se redujo al estudio de los diferentes elementos estructuradores de la ciudad; sin considerar que ésta es un fenómeno complejo, multidimensional y vehementemente social, en donde el análisis de las variables físicas, se complementan con las sociales, dando como resultado una visión integral de la ciudad.

Por otro lado, desde 1940, la planeación urbana se cristalizó en iniciativas como el Plano Regulador del Distrito Federal así como en los ordenamientos legales que lo apuntalaran y apoyaron. Pero el "excesivo carácter regulatorio e institucional [que la planeación urbana] adquiriría durante las décadas siguientes, la debilitaron como instrumento de conducción, perdiendo fuerza como campo de conocimiento y legitimidad como herramienta del gobierno para conducir el desarrollo sano y ordenado de las ciudades". ${ }^{67}$

Las consecuencias negativas de las políticas que orientaron el proceso de industrialización nacional implementadas desde la década de los treinta, truncaron los logros alcanzados por la planeación urbana; relegando los asuntos urbanos en favor de los procesos económicos, debilitándola paulatinamente al no permitirle diseñar alternativas para enfrentar de manera eficiente el consecuente crecimiento de la población.

Industrialización basado en el modelo de sustitución de importaciones fue el principal detonante del México urbano, y sin existir una preocupación específica por regular o impulsar un proyecto urbano nacional... México se convertía en un país urbano con serios problemas para gobernar, administrar, planificar y gestionar la elevada concentración de población y actividades en unos pocos y dispersos puntos del territorio nacional. ${ }^{68}$

El Estado promovió la inversión en la infraestructura que soportaría el desarrollo industrial, pero sin tomar en cuenta que esto provocaría un fenómeno de concentración poblacional, así como pocos recursos para soportarlos en las nuevas áreas urbanas.

Desde la década los cuarenta y cincuenta, ya se habían dado en México procesos de planeación aislados basados en un incipiente derecho urbano, como la Ley sobre Planeación General de la República, los proyectos de cuencas hidrológicas, y las posteriores leyes relacionadas. La Ley General de Asentamientos Humanos de 1976 marca "el inicio de la institucionali-

66 Gutiérrez Chaparro, Juan José, op. cit., p. 59.

67 Ibidem, pp. 59 y 60.

68 Ibidem, pp. 60 y 61. 
Este libro forma parte del acervo de la Biblioteca Jurídica Virtual del Instituto de Investigaciones Jurídicas de la UNAM

zación de la planeación urbana, la que además de afianzar su carácter centralizado y normativo, favoreció el establecimiento de las bases para crear leyes, planes y reglamentos urbanos". ${ }^{69} \mathrm{Al}$ mismo tiempo aparece la Secretaría de Asentamientos Humanos y Obras Públicas (SAHOP) como dirección experta en los temas de suelo y vivienda, ocupada de la planeación, equipamiento y ecología de lo urbano. Entre sus primeras acciones estuvieron, el diseño de la Ley de Planeación así como la realización del primer Plan Nacional de Desarrollo Urbano en 1978 “institucionalizando la acción del Estado en materia de organización del territorio". ${ }^{70}$ A partir de los documentos anteriores, el Estado dictó medidas para el ordenamiento de los asentamientos humanos unificando la legislación y administración urbana en el país. Aunque ya existían ordenamientos estatales de esa naturaleza en todo el país, no tuvieron ni tendrían el mismo impacto que esta nueva ley. Durante este primer periodo la planeación era tradicional, privilegia la zonificación y dispersión de la ciudad sometida a la voluntad política de cada sexenio.

A mediados de la década de los ochenta, el Sistema Nacional de Planeación Democrática y la Ley de Planeación, transitaron el interés del gobierno, de la planeación urbana hacia la cuestión económica.

En los años noventa surgen programas como el de Ciudades Medias y el de 100 Ciudades en los cuales la planeación urbana deja de ser importante, encargándose solamente de regular el crecimiento urbano desde una "perspectiva espacial carente de una visión integral y sin mostrar signos de avance en su concepción". ${ }^{71}$ La transformación de la Secretaría de Desarrollo Urbano y Ecología (Sedue) en Secretaría de Desarrollo Social (Sedesol), marca el fin del periodo de la planeación urbana coordinado a nivel nacional de forma centralizada. Por otra parte, cristalizó a través del Programa de 100 Ciudades, la idea de constituir reservas territoriales para el desarrollo urbano, y retoma "la fase de descentralización de funciones planificadoras a las ciudades, como se había previsto en la legislación de $1983 " .72$ El Programa de Incorporación de Suelo Social al Desarrollo Urbano ${ }^{73}$ era parte de una de las líneas de acción del programa anterior pero actualizado, derivándose a su vez del Plan Nacional de Desarrollo Urbano 1995-2000. ${ }^{74}$

69 Gutiérrez Chaparro, Juan José, op. cit., p. 61.

70 Idem.

71 Idem.

72 Idem.

73 Conocido como PISO, equivalentes a la conformación de reservas territoriales; pero después del año 2000 se consideró insuficiente para el fortalecimiento del sector urbano.

74 Olivera Lozano, Guillermo, op. cit. 
Este libro forma parte del acervo de la Biblioteca Jurídica Virtual del Instituto de Investigaciones Jurídicas de la UNAM

La influencia sostenida de modelos de desarrollo económico y social junto con el intenso proceso de elaboración de planes en todo el país provocó un retroceso sostenido también en el proceso de concepción, desarrollo y consolidación [de la planeación urbana]... promovida más como una herramienta auxiliar de la política de desarrollo económico y social, que como una disciplina integral de análisis y gestión. ${ }^{75}$

$\mathrm{Al}$ inicio del nuevo milenio, la política urbana se concentra en la superación de la pobreza, y se aplican los siguientes criterios:

Programa Hábitat a través de la Secretaría de Desarrollo Social, con el propósito de articular los objetivos de la política social con los de las políticas de desarrollo territorial y urbano, y avanzar hacia la superación de los rezagos y contrastes sociales en las ciudades haciéndose notorio, como en el caso de otros programas similares promovidos años atrás, el vacío de la variable espacial y el carácter integral [que es propio de la planeación urbana]. Se puede afirmar que la Planeación Urbana en México ha estado supeditada a externalidades que la fueron perfilando como un estilo de planeación centrado en criterios técnicos y normativos orientada a cuestiones sociales y económicas y escasamente vinculada con el proceso de toma de decisiones. ${ }^{76}$

La planeación urbana contemporánea en México, desde su inicio, se ha concentrado en generar conocimiento nuevo, empezando desde que el grupo de precursores expertos precedidos por Carlos Contreras, incorporando desde "las primeras décadas del siglo pasado diversos conceptos, modelos, herramientas e instrumentos como fundamento de la planeación urbana mexicana". Se mantiene el uso del "plano regulador como medio de intervención y la zonificación como mecanismo de control del crecimiento"; asignándole a la planeación urbana, un carácter funcional-espacialista convertido en un enredado andamiaje legal-institucional. Los planes tienen a la zonificación y los usos del suelo como sus elementos primordiales, y se han limitado a la fabricación en serie de estos enseres, sin avanzar en el conocimiento de lo urbano al no proponer innovación alguna, desvaneciéndose en los últimos cuarenta años al no permitir una reconceptualización de sí mismo, "es por ello que la planeación urbana vigente ya no opera, modelo evidentemente superado por la realidad". Los postulados centrales iniciales han sido depuestos poco a poco por ideas que se desprenden de una tendencia posmoderna, neoliberal y globalizadora. El carácter rígido y prohi-

\footnotetext{
75 Gutiérrez Chaparro, Juan José, op. cit., p. 61.

76 Idem.
} 
Este libro forma parte del acervo de la Biblioteca Jurídica Virtual del Instituto de Investigaciones Jurídicas de la UNAM

bitivo de la zonificación, propio en los planes en México, ha dado lugar a una forma de planeación urbana infructuosa. "Las acciones se han dirigido casi de manera exclusiva al fortalecimiento legal con la emisión de leyes y la elaboración de planes, más que al fortalecimiento teórico metodológico, a lo que se suma el hecho de que la planeación urbana ha sido un instrumento subordinado a la planeación económica y social". ${ }^{77}$

\section{Gonclusiones}

Para el caso de México, los estudios históricos sobre el principio y desarrollo del derecho urbano y el urbanismo son escasos, dispersos y fragmentados $;^{78}$ lo son mucho más conforme nos acercamos al origen de los mismos, pero resultan más claros al acercarnos a la época contemporánea, en donde los testimonios documentales permiten incluso notar un agotamiento del modelo actual de planeación urbana mexicano. ${ }^{79} \mathrm{Su}$ pensamiento urbano ha estado influenciado por el urbanismo europeo desde el principio, adoptando desde un inicio elementos y prácticas, que con el pasar del tiempo dieron lugar al surgimiento, práctica y avance de la planeación urbana moderna y contemporánea en los centros urbanos.

La construcción del marco teórico-conceptual e instrumental-metodológico actual de la planeación urbana mexicana inicia a partir de la década de los veinte del siglo pasado. Se institucionaliza en los años setenta, pero sin registrarse desde ese momento y hasta hoy acciones destinadas al robustecimiento del urbanismo como disciplina. Debilitados tanto por lo complicado de nuestro sistema urbano, como por el cambio de orientación política en favor de cuestiones económicas y sociales independientes de las urbanas. La generación de conocimiento nuevo en el campo de la planeación urbana se encuentra detenida, resultando "insuficiente para explicar y/o atender los problemas urbanos observados en la ciudad contemporánea". ${ }^{80}$

Los planes e iniciativas urbanas latinoamericanas al empezar el siglo $\mathrm{XX}$, se distinguieron por imitar la experiencia europea, sobro todo francesa, en la que buscaban su estética y forma interna en el contexto del movimiento de la ciudad bella. ${ }^{81}$ Aunque lo más conocido en las ciudades latinoa-

\footnotetext{
77 Ibidem, p. 62.

78 Ibidem, p. 52.

79 Gutiérrez Chaparro, Juan José, op. cit., p. 52.

80 Ibidem, p. 53.

81 Gutiérrez Chaparro, Juan José, op. cit., p. 55.
} 
Este libro forma parte del acervo de la Biblioteca Jurídica Virtual del Instituto de Investigaciones Jurídicas de la UNAM

mericanas fue la noción incompleta de la ciudad jardín de Howard. ${ }^{82}$ Por otro lado, el trabajo de Le Corbusier es el más representativo, bajo la influencia de criterios funcionales y de racionalidad presentes en la formulación de muchos de sus planos reguladores inspirados en la Carta de Atenas. Pero a pesar de que esta perspectiva se fortalecía, la experiencia latinoamericana en materia de planeación urbana era macerada por consecuencias sociales, económicas, ambientales y urbanas observadas en las urbes latinoamericanas producto de una manera de planeación urbana denominada urbanismo sin ciudad o más bien gente, en la que no se tomó en cuenta el potencial ni necesidades humanas, sólo económicas; donde la realidad y las propuestas urbanas no ofrecían soluciones a los múltiples impactos negativos.

La ley que desamortiza los bienes de la iglesia o Ley Lerdo reactivó la economía nacional, al movilizar la propiedad, dando el carácter y valor jurídicos actuales que caracterizan al Estado de derecho en México en la actualidad.

La reforma al artículo 27 constitucional buscó

la incorporación de suelo ejidal al desarrollo urbano legal y ordenado [pero] los nuevos procedimientos [surgidos] no han sido suficientemente exitosos para disminuir la ocupación irregular del suelo, se mantiene una sobreregulación del estado sobre los propietarios de las tierras ejidales y comunales, que es necesario eliminar; y en segundo término, la capacidad de los gobiernos municipales para ordenar y planificar el desarrollo urbano es todavía muy limitada. ${ }^{83}$ La reforma no generalizó la venta de ejidos, pero por desgracia la reforma ha resultado en nuevas formas de ilegalidad basadas en la interpretación dolosa de la ley agraria actual.

Las reformas constitucionales de 2010 han pasado de las "garantías individuales" a los derechos humanos fundamentales que privilegian el bien común. ${ }^{84}$

Los precursores de la planeación urbana en nuestro país, le dieron el reconocimiento y estatus que tiene hoy; pero el excesivo control por medio de una normatividad y planeación supeditada a objetivos económicos la ha debilitado. El progreso científico en este campo ha estado dirigido "básicamente a engrosar el carácter normativo de la planeación urbana, mientras

82 Tras los resultados de los Congresos Internacionales de Arquitectura Moderna (CIAM).

83 Olivera Lozano, Guillermo, op. cit.

84 González Roacho, Crystal et al., op. cit., p. 8. 
Este libro forma parte del acervo de la Biblioteca Jurídica Virtual del Instituto de Investigaciones Jurídicas de la UNAM

que el fenómeno urbano avanza y se aleja de las previsiones" ${ }^{85}$ y el derecho positivo.

Por otro lado, es característico del país la disgregación social, valores nacionales devaluados, territorio y recursos depredados, expuestos al comercio y llevados al límite de sus capacidades amenazados a desaparecer. Quienes por antonomasia se dicen mexicanos, lejanos del compromiso de proteger un patrimonio, dispuestos a vender el suelo, agua, y aire a quien lo compre, sin importar los sueños y vidas enterradas en cada parcela. Los derechos fundamentales son trastocados en todo momento. ${ }^{86}$

El Colegio Nacional de Jurisprudencia Urbanística en 2013 marca en su agenda jurídica ${ }^{87}$ la necesidad de una reforma constitucional en materia de urbanismo con corte ambiental. Se requiere de una reforma urbana ambiental integral; que deje de lado la diferenciación entre ciudad y campo. Ciudad es igual a ciudadano, derecho inalienable del ser humano; de lo anterior parte la discusión entre lo público y lo privado. La ciudad como concepto universal, multidisciplinario e integrador. El derecho a la ciudad es incluyente; sustentable y responsable; espacio de la diversidad, la solidaridad y la convivencia democrática, participativa, viva y creativa.

Hay que pasar a una planeación y gestión estratégica de la ciudad que privilegia a los ciudadanos y orientada en la toma de sesiones consensadas, incluyentes y colectivas, entendida como el derecho a la ciudad, recuperando todas sus propuestas y discusiones. ${ }^{88}$

Este pequeño recorrido histórico muestra cómo el derecho urbano surge como parte del mismo proceso urbano, desde la época antigua hasta la contemporánea. En el caso mexicano, la planeación y derecho urbano se impulsaron a partir del artículo 27 de la Constitución de 1917, con una base social y pública, para desarrollar el actual cuerpo jurídico en materia de urbanismo. Las leyes de reforma demostraron ser una coyuntura importante para comprender ese carácter social y público que caracteriza a la propiedad en México. Por ello, ni la última reforma al artículo 27, ni las reformas

85 Gutiérrez Chaparro, Juan José, op. cit., p. 53.

86 González Roacho, Crystal et al., op. cit., pp. 12 y 13.

87 Ibidem, pp. 6 y 8.

88 Lefebvre, Henri, El derecho a la ciudad, Barcelona, Península, 1969; Carta Europea de Salvaguarda de los Derechos Humanos en la Ciudad (Saint-Denis, Francia, 2000), Carta Mundial del Derecho a la Ciudad (Porto Alegre, Brasil, 2001), Carta de Derechos y Responsabilidades de Montreal (Canadá, 2006), Carta de la Ciudad de México por el Derecho a la Ciudad (México, 2010), Carta-Agenda Mundial de Derechos Humanos en la Ciudad (Florencia, 2011), Carta de Derechos Humanos de Gwangju (Corea del Sur, 2012), entre otras; citado por González Roacho, Crystal et al., op. cit., p. 8. 
Este libro forma parte del acervo de la Biblioteca Jurídica Virtual del Instituto de Investigaciones Jurídicas de la UNAM

estructurales, deberán desvirtuar el espíritu original del derecho urbano en México: público, social y pensado para alcanzar el bienestar humano y una mejor calidad de vida.

\section{REFERENCIAS}

Carvajal Contreras, Máximo, "Las leyes de reforma. Un tema olvidado en el estudio de las facultades de derecho", Ponencia. XXI Congreso Nacional de Anfade. San Luis Potosí, septiembre de 2010, disponible en: http://wrere.anfade.org.mx/docs/ponencias/LASLEYESDEREFORMA.pdf (fecha de consulta: 8 de octubre de 2016).

CHILDE, Gordon, Los orígenes de la civilización, México, Fondo de Cultura Económica, 1996.

Franco, Gabriel, "Las Leyes de Hammurab", Revista de Ciencias Sociales, 1962, pp. 331-356, disponible en: http://rcsdigital.homestead.com/files/Vol_VI _Nm_3_1962/Franco.pdf(fecha de consulta: 12 de agosto de 2015).

Gómez Rojo, María Encarnación, "Líneas históricas del derecho urbanístico con especial referencia al de España hasta 1936", Revista de Estudios Histórico-furídicos, núm. 25, disponible en: https://dx.doi.org/10.4067/ S0716-54552003002500004.

GonzÁlez RoAcho, Crystal et al., "Obra con legado jurídico: Código de Hammurabi", Revista Libertades, núm. 2, 2013, disponible en: http://werere. revistalibertades.com/documents/revistalibertadesnumero2_codigo.pdf (fecha de consulta: 12 de agosto de 2015).

GutiérRez ChaPARro, Juan José, "Planeación urbana en México: un análisis crítico sobre su proceso de evolución", Urbano, vol. 12, núm. 19, mayo de 2009.

Jiménez Dorantes, Manuel, Constitución y Urbanismo, México, UNAM, Instituto de Investigaciones Jurídicas, 2006, disponible en: http://bibliohistorico. juridicas.unam.mx/libros/libro.htm?l=2314 (fecha de consulta: 19 de octubre de 2016).

Moreno Quiroz, Luz María et al. (coords.), Agenda Furídica. Hacia una Reforma Urbana Ambiental del Estado Mexicano, México, Colegio Nacional de Jurisprudencia Urbanística, 2013.

Olivera Lozano, Guillermo, 2005, "La reforma al artículo 27 constitucional y la incorporación de las tierras ejidales al mercado legal de suelo urbano en México", Scripta Nova. Revista Electrónica de Geografia y Ciencias Sociales, vol. IX, núm. 194 (33), 1o. de agosto de 2005. 
Este libro forma parte del acervo de la Biblioteca Jurídica Virtual del Instituto de Investigaciones Jurídicas de la UNAM

\title{
ANÁLISIS DE LA PRESENGIA DEL MUNICIPIO EN EL CONSTITUCIONALISMO MEXICANO
}

\section{Yadira ORNELAS GARCÍA*}

\begin{abstract}
Sumario: I. Introducción. II. Definición de municipio. III. Antecedentes prehispánicos. IV. La colonización de América a través del municipio. V. Cabildos de indios. VI. El cabildo español. VII. Formación del municipio en las Constituciones en México. VIII. Constitución de 1812. IX. La Constitución de Apatzingán. X. El Plan de Iguala. XI. Constitución Federal de 1824. XII. Constitución de 1836. XIII. Constitución de 1857. XIV. El municipio en el Porfiriato. XV. Programa del Partido Liberal Mexicano. XVI. La Constitución de 1917 y el artículo 115 constitucional. XVII. Conclusiones. XVIII. Fuentes de información.
\end{abstract}

\section{INTRODUCCIÓN}

La figura del municipio es sumamente importante como una institución que se encuentra presente desde la adopción del federalismo como forma de Estado, es por ello que resulta interesante analizar las transformaciones que ha sufrido sin olvidar sus antecedentes históricos comenzando en la época prehispánica con los calpullis, para dar paso a la colonización en América a través del municipio, donde vemos que la figura del calpulli se desdibuja, mientras que a mediados del siglo XVI feneció por la fuerza implantada por los conquistadores ocasionando que en el gobierno surgieran nuevas formas de organización, donde vale la pena retomar el sistema político preponderante en la Nueva España en el cual vemos la presencia de los cabildos indígenas y de los españoles con las particularidades de cada uno.

Desprendido del análisis de las distintas Constituciones vigentes en México, observamos que fue hasta la Constitución de 1917 que la figura

* Candidata a maestra con opción terminal en ciencia política de la Universidad Michoacana de San Nicolás de Hidalgo. 
Este libro forma parte del acervo de la Biblioteca Jurídica Virtual del Instituto de Investigaciones Jurídicas de la UNAM

del municipio adquiere una preeminencia importante mediante la elaboración del artículo 115 constitucional por parte del Congreso constituyente de 1916-1917, señalando que dicho artículo no ha sido estático, donde vale destacar las reformas acaecidas en 1983 y 1987 como importantes intentos por lograr una autonomía económica y política de tan importante institución, no siendo éstas las únicas, mismas que se analizarán con la finalidad de ver los avances y retos existentes hasta la actualidad donde existen propuestas incluso de reformar el artículo 115 constitucional e incluir la figura de municipio indígena.

Sin duda la presencia y evolución del municipio como institución ha sido toral en los diferentes momentos del constitucionalismo mexicano siendo piedra angular de la organización política y administrativa en nuestros días.

\section{DEFINICIÓN DE MUNICIPIO}

Es menester entender la definición del municipio y que ésta sea un punto de partida para el trabajo de la presente investigación:

Podemos definir al municipio como la institución primaria sociopolítica por excelencia. En efecto, en el municipio se institucionaliza la convivencia social como cimiento de la estructura sociopolítica de la nación. Por lo tanto como elemento constitutivo entendemos al municipio como un poder autónomo, integrador de un poder soberano y a la vez reconocido por éste. ${ }^{2}$

Municipio es la entidad político-jurídica integrada por una población asentada en un espacio geográfico determinado administrativamente que tiene una unidad de gobierno y se rige por sus propias normas jurídicas de acuerdo con sus propios fines. ${ }^{3}$

\section{ANTECEDENTES PREHISPÁNICOS}

Existe un tema antiquísimo relativo a determinar si en realidad existió un municipio en la época del México prehispánico, Teresita Rendón en su libro Derecho municipal señala que un gran número de estudiosos del tema afirman que el municipio era denominado por los aztecas como calpulli, y que éste cumplía con las actividades equivalentes a las de los municipios de origen europeo. La figura del calpulli se considera como:

2 Ochoa Campos, Moisés, La reforma municipal, México, Porrúa, 1968, p. 485.

3 Rendón Huerta Barrera, Teresita, Derecho municipal, México, Porrúa, 1998, p. 13. 
Este libro forma parte del acervo de la Biblioteca Jurídica Virtual del Instituto de Investigaciones Jurídicas de la UNAM

La organización local que los indígenas mexicanos tenían y que es lo equivalente al municipio de nuestros días, su origen fue de tipo agrario y se trataba de una comunidad en la que los integrantes tenían los mismos dioses, resolvían internamente sus problemas económicos cotidianos y reconocían una autoridad comunal que decidía los problemas fundamentales de orden colectivo. ${ }^{4}$

Se señalan como rasgos que caracterizan a los calpullis los siguientes:

a) Conjunto de linajes o grupos de familias generalmente patrilineales y de amigos y aliados; cada linaje con tierras de cultivo aparte de la de carácter comunal.

b) Entidad residencial localizada, con reglas establecidas respecto a la propiedad y el usufructo de la tierra.

c) Unidad económica que, como persona jurídica tiene derechos sobre la propiedad del suelo y la obligación de cubrir el total de los tributos.

d) Unidad social con sus propias ceremonias, fiestas, símbolos sagrados y organización política que llevan la cohesión de sus miembros.

e) Entidad administrativa con dignatarios propios dedicados principalmente al registro y distribución de tierras y a la supervisión de obras comunales.

f) Subárea de cultura, en cuanto a vestidos, adornos, costumbres actividades, etc.

g) Institución política con representantes del gobierno central y con alguna injerencia en él.

h) Unidad militar, con escuadrones, jefes y símbolos propios. ${ }^{5}$

Asimismo, Teresita Réndon señala que el calpulli estaba sujeto a los jefes aztecas denominados tlatoanis, mismos que: "Ejercían en su provincia la jurisdicción civil y criminal; gobernaban según sus leyes y fueros, y muriendo dejaban el señorío a sus hijos o parientes, si bien se hacía menester la confirmación de los reyes de México, Texcoco o Tlacopán, según su caso". ${ }^{6}$

\section{LA COLONIZACIÓN DE AMÉRICA A TRAVÉS DEL MUNICIPIO}

Reynaldo Robles Martínez en su libro El municipio expresa que el municipio constituyó la fuente de poder que sustituyó la falta del soberano y estableció

4 Torres Estrada, Pedro, La autonomía municipaly su garantía constitucional directa de protección. Estudio comparado de los supuestos español y mexicano, México, UNAM, Instituto de Investigaciones Jurídicas, 2005, p. 122.

5 Rendón Huerta Barrera, Teresita, op. cit., pp. 88 y 89.

6 Idem. 
Este libro forma parte del acervo de la Biblioteca Jurídica Virtual del Instituto de Investigaciones Jurídicas de la UNAM

la conquista de nuestro país, al ser utilizados los ayuntamientos como un instrumento de Cortés, donde una situación interesante la encontramos en el Ayuntamiento de México, mismo que realizaba ordenanzas que se salían de su territorio, inclusive permeaban en Veracruz.

La determinación que tomaba Cortés era que en los casos de resolver algún problema suscitado en cierta Villa, era mandado el alcalde de la Ciudad de México para que lo resolviera. Algunos datos interesantes del ayuntamiento son los siguientes:

En 1519 el Ayuntamiento de Veracruz, primero fundado en la América Continental el 22 de abril de ese año, autorizó la Conquista de México, que realizaron sus milicias comunales encabezadas por Cortés con el grado de Justicia Mayor del cabildo veracruzano.

Los primeros ayuntamientos de la ciudad de México, se compusieron de un alcalde mayor, dos alcaldes comunes y ocho ediles.

La antigua Valladolid, hoy Morelia, fue fundada por el primer Virrey de Nueva España, don Antonio de Mendoza, en 1541 y en 1545 obtuvo el título de ciudad. ${ }^{7}$

En lo relativo a las ciudades y villas españolas realizaban su organización a través de cabildos o ayuntamientos. Cabe mencionar la existencia paralela de cabildos españoles y cabildos indígenas.

Claudia Guarisco en su libro Los indios del valle de México y la construcción de una nueva sociabilidad política 1770-1835 establece que la república de indios era una asociación étnico territorial. Las leyes preservaron su carácter excluyente, al prohibir que cualquier español, mestizo o mulato, participara en ella. Fue concebida por los gobernantes como la unidad mínima de la administración político territorial. A fines del siglo XVIII el gobernador estaba encargado del gobierno de la cabecera y del conjunto de barrios y parcialidades que componían el pueblo. Lo relativo al ámbito fiscal es piedra angular de cualquier Estado, y en el Antiguo Régimen no fue la excepción, lo cual se caracterizó por los reales tributos:

En el Ancien Régime, además la fiscalización constituía una de las mayores barreras que dividían a la población, ya que las contribuciones no eran homogéneas. A lo largo de casi todo el antiguo régimen, los indios de la Nueva España estuvieron sujetos al pago de un impuesto directo, de carácter negativamente privilegiante llamado Reales Tributos. Hacia mediados del siglo XVIII existían dos categorías tributarias: la de "tributo entero" y la de

7 Robles Martínez, Reynaldo, El municipio, México, Porrúa, 1998, pp. 139 y 140. 
Este libro forma parte del acervo de la Biblioteca Jurídica Virtual del Instituto de Investigaciones Jurídicas de la UNAM

"medio tributario." La primera correspondía al indio varón adulto, padre de familia; mientras que en la segunda estaban comprendidos los indios varones adultos solteros (mayores de 18 años). ${ }^{8}$

En relación con la elección de los integrantes de los cabildos indígenas se realizaba de distintas maneras cuya dirección se encontraba a cargo de autoridades españolas (pudiendo ser éstas civiles o eclesiásticas), e incluso por caciques, además de la variedad de funciones:

Los cargos y oficios de los cabildos indígenas eran múltiples. Durante el siglo XVI pocas veces fueron claramente definidos. Siempre se caracterizaron por su tendencia a facilitar la dominación, evangelización y explotación de los maceguales y a la prevención de eventuales conflictos. Sin embargo, nunca fueron suficientemente supervisados por lo que ofrecieron múltiples oportunidades para los abusos de autoridad o enriquecimientos ilícitos. A los alcaldes indígenas se les hizo responsables de recoger los tributos, de fiscalizar los mercados locales, de reglamentar el buen uso y mantenimiento de los edificios públicos y de vigilar el abastecimiento del agua, etc. Los delitos menores y las causas civiles entre indígenas eran juzgados por el gobernador o, más adelante, por los alcaldes y regidores. ${ }^{9}$

Los órganos que se encargaban de conocer los asuntos eran las siguientes instituciones: el Consejo de Indias y Administración de Asuntos Civiles y Penales de los Territorios de América, mismo que actuaba como: a) comité legislativo, $b$ ) organismo conciliatorio, $c$ ) centro administrativo y $d$ ) tribunal supremo. ${ }^{10}$

En cuanto a la organización colonial del municipio hay puntos interesantes que nos menciona Moisés Ochoa Campos en La reforma municipal, ${ }^{11}$ donde grosso modo señala características de la colonia del siglo XVI al XVII encontrando cuatro que son relevantes: 1) el predominio peninsular para controlar los ayuntamientos, lo anterior motivado por la venta de cargos concejiles así como las regidurías perpetuas, mismas que posteriormente serían utilizadas por los criollos pero que en ese momento generaban animadversión que desembocaría en la revelación criolla en 1767 y en el intento de

8 Guarisco Canseco, Claudia, Los indios del valle de México y la construcción de una nueva sociabilidad política 1770-1835, México, El Colegio Mexiquense, 2003, p. 73.

9 Hillerkuss, Thomas, La República en los pueblos de indios de la Nueva Galicia en el siglo XVI, 1995, p. 247, disponible en: http://wrwreiifilologicas.unam.mx/pnovohispano.

10 Vázquez Segura, María de la Luz y Pinto, Neyra, Historia de México, 2a. ed., México, Limusa, 1996, pp. 94 y 95.

11 Cfr. Ochoa, Campos, Moisés, La reforma municipal, México, Porrúa, 1968, pp. 133-135. 
Este libro forma parte del acervo de la Biblioteca Jurídica Virtual del Instituto de Investigaciones Jurídicas de la UNAM

desquite de 1808; 2) disminución del poder municipal al momento de llegar a América, con retraso de ciertos años, el resultado de la derrota comunera acaecida en Villalar en el año de 1521; 3) la presencia simultánea de municipios españoles e indígenas; 4) esta etapa constituye el lapso de mayor función colonizadora, debido a que con las ordenanzas de población no se disminuía la movilidad generativa municipal.

Es clara la idea que señala Moisés Ochoa en El municipio y su evolución constitucional al manifestar que toda la obra de colonización realizada en América, fue efectuada por medio de la institución municipal, siendo la manera en que se implantó el municipio de tipo occidental al edificarse el régimen colonial a lo largo y ancho del Nuevo Mundo. Entre los distintos funcionarios del ayuntamiento:

En lo general, puede decirse que el Ayuntamiento estaba presidido por el Corregidor y constaba de dos alcaldes ordinarios y un número variable de regidores. Tenía, además, un alférez real, procurador general, un alguacil mayor, un síndico y otros cargos dependientes del propio Cabildo, como los diputados de los pobres, los diputados de propios, el obrero mayor, los diputados de fiestas, los diputados de policía, de alhóndiga y pósito, el contador, el mayordomo de propios y rentas, los fieles ejecutores y el vendedor del matadero. ${ }^{12}$

Asimismo, Ochoa Campos refiere que el regidor era el oficio de mayor envergadura existente entre los magistrados que conformaban el municipio, además de poseer el vínculo más íntimo con la población, y facultado en el ámbito legislativo, ejecutivo y en ocasiones judiciales. En las funciones del Cabildo colonial podremos encontrar las siguientes:

Las funciones del Cabildo colonial comprendían:

1.- El cuidado de las obras públicas, puentes y caminos.

2.- La vigilancia de los mercados, ventas y mesones.

3.- El cuidado y disfrute común de pastos y montes.

4.- El corte y plantación de árboles.

5.- El remate de los derechos de vender carne y pan.

6.- La formación de sus ordenanzas que debían ser aprobadas por el virrey.

7.- El repartimiento de vecindades, caballerías y peonerías.

8.- La administración del municipio e inspección de cárceles, hospitales y cementerios.

9.- La atención de los servicios públicos: policía, agua potable, alumbrado y pavimento.

12 Ochoa, Campos, Moisés, El municipio y su evolución constitucional, México, Fomus-Banobras, 1981, p. 136. 
Este libro forma parte del acervo de la Biblioteca Jurídica Virtual del Instituto de Investigaciones Jurídicas de la UNAM

Para cumplir sus funciones, el municipio disponía de dos clases de bienes: los comunes y los propios. ${ }^{13}$

\section{Cabildos de indios}

Reynaldo Robles Martínez señala en El municipio que una manera de obligar a los indios a que vivieran en los respectivos centros poblacionales es que se les otorgaban determinadas protecciones entre las que se mencionan el respeto a los bienes correspondientes a la propiedad comunal, así como la prohibición que imperaba de otorgar solares a españoles en poblaciones indígenas. La organización indígena se encontraba establecida y en funciones, asimismo, era utilizada como medio para obtener el trabajo de los indios. No obstante, quienes habitaban las distintas comunidades desconocían la autoridad impuesta por los españoles. Ante tal circunstancia el rey Felipe III estableció en 1618 lo siguiente:

Que en las poblaciones pequeñas hubiera un alcalde y un regidor, mientras que en los pueblos grandes debían fungir dos alcaldes y cuatro regidores, existían también los escríbanos, quienes registraban todas las actividades de la administración municipal y debían de conservar los documentos referentes a tributos, mapas de propiedades territoriales y acusaciones de indígenas en contra de funcionarios españoles. ${ }^{14}$

En las atribuciones del cabildo indígena se pueden encontrar:

a) En apoyo de la conquista: Recaudación y entrega de los tributos a los españoles; la distribución de mano de obra para construcciones o tareas agrícolas, en beneficio de los españoles; cooperación en el proceso de evangelización.

b) En apoyo de su propia comunidad: Planeación de nuevos caminos, suministro de agua, regular el mercado local, combatir el alcoholismo, administrar justicia en los problemas de sus vecinos.

El cabildo indígena tuvo su apogeo a mediados del siglo XVI, sobre todo en el Valle de México se estableció el pago de los funcionarios del Ayuntamiento. ${ }^{15}$ Reitera Reynaldo Robles que la evolución de la administración española conllevó que se multiplicaran los funcionarios ocasionando con ello que se relegaran a los indígenas dirigentes que se encontraban en

\footnotetext{
13 Ibidem, p. 137.

14 Robles Martínez, Reynaldo, op. cit., p. 70

15 Ibidem, p. 71.
} 
Este libro forma parte del acervo de la Biblioteca Jurídica Virtual del Instituto de Investigaciones Jurídicas de la UNAM

el gobierno municipal, en especial a aquellos que lideraban a los indígenas trastocando los intereses de los colonizadores.

\section{EL CABILDO ESPAÑOL}

De acuerdo con Reynaldo Robles Martínez, en los tiempos coloniales donde se introducía el rey así como el centralismo, el Ayuntamiento siempre preservó la facultad de administración y organización de los vecinos a través de la estructura del cabildo para la administración de justicia así como para la satisfacción de las necesidades de la colectividad. La manera en que se estructuraba el Ayuntamiento fue cambiando con el paso del tiempo, Robles Martínez nos dice que las ordenanzas de gobierno del 11 de diciembre de 1682, mismas que fueron cambiadas por las del 3 de junio de 1720, señalan los términos en que debían llevarse a cabo los cabildos, la forma en que se harán las votaciones, el número de alcaldes, entre otras.

A grandes rasgos Reynaldo Robles señala que el ayuntamiento estaba presidido por el corregidor, se integraba de dos alcaldes ordinarios y un número variable de regidores, tenía además, un alférez real, un procurador general, un alguacil mayor y un síndico, distribuyéndose las comisiones y oficio entre los particulares o personas ajenas designadas por los ayuntamientos.

Como podemos ver, los cabildos españoles tenían bien forjada su estructura y realizaban una serie de funciones de carácter administrativas, legislativas y judiciales.

\section{Formación DeL MUNICIPIO EN LAS CONSTITUGiOneS EN MÉxico}

Reynaldo Robles Martínez en El municipio señala que la normatividad del México independiente podemos dividirla en dos grandes periodos históricos: el anterior a la Constitución de 1917 y el que se inicia con la Constitución revolucionaria, tal y como lo analizaremos a continuación.

\section{CONSTITUGIÓN DE 1812}

La Constitución de 1812 definía a los pueblos como una entidad territorial en las que en caso de haber mil o más habitantes debía establecerse un ayuntamiento, modificando con ello la estructura del gobierno de las provincias, incrustando las diputaciones provinciales y la concepción de los ayuntamientos, entendidos éstos como: "El primer cimiento del gobierno interior de la 
Este libro forma parte del acervo de la Biblioteca Jurídica Virtual del Instituto de Investigaciones Jurídicas de la UNAM

nación, en el que se apoyan y de donde parten todas las funciones gubernativas hasta elevarse a la autoridad suprema". ${ }^{16}$

Con el golpe que la Constitución de Cádiz propinó a la organización de las repúblicas de indios, finiquitaba las funciones político-administrativas de las mismas, puesto que el ayuntamiento como nueva entidad jurídica dejaba fuera a las antiguas repúblicas. ${ }^{17}$

La Constitución gaditana de 1812 contemplaba la figura de los jefes políticos, personajes que ejercían control en el municipio en el siglo XIX hasta el momento de su extinción en la promulgación de la Constitución del 1917. Los artículos que tocaban lo referente al municipio los encontramos en los artículos 309 al 316, 321, incisos tercero y cuarto; 322 al 329, 331 y 335, incisos primero al cuarto y sexto. ${ }^{18} \mathrm{Si}$ formulamos la interrogante referente a la presencia de los indígenas en la Constitución de 1812 nos encontramos con un panorama complicado: suprimidos los ayuntamientos indígenas por la Constitución gaditana, que decretó la igualdad jurídica de todos los vasallos de la Corona, sus miembros se integraron, en varios casos, en los ayuntamientos constitucionales en un par de años. Después de 1815 los ayuntamientos volvieron a funcionar con la antigua organización para desaparecer definitivamente con la independencia de México. ${ }^{19} \mathrm{El}$ municipio queda colocado así dentro de la administración descentralizada, como un caso de descentralización por región. El estado ejerce el control y el Ayuntamiento conserva su autonomía bajo tales limitaciones. ${ }^{20}$

El artículo 309 de la Constitución gaditana señala que habrá ayuntamientos integrados por alcalde, regidores, el procurador y un síndico, quienes serían presididos por un jefe político donde existiese tal figura y en su defecto por el alcalde. Asimismo, de acuerdo con lo estipulado en el artículo 321, los ayuntamientos tendrían bajo su cargo: la policía de salubridad, seguridad de las personas y bienes de los vecinos, el orden público, el cuidado de

16 Castro, Concepción, La revolución liberal y los municipios españoles (1812-1868), Madrid, Alianza Editorial, 1979, p. 62.

17 Franco Mendoza, Moisés, "El gobierno comunal entre los p’urhépecha”, en Paredes Martínez, Carlos y Teran, Marta (coords.), Autoridad y gobierno indígena en Michoacán, Zamora, El Colegio de Michoacán-CIESAS-INAH-UMSNH-Instituto de Investigaciones Históricas, 2003, vol. I, p. 557.

$18 C$ Cr. Constitución Política de la Monarquía Española, disponible en: http//:archivos. juridicas.unam.mx/werwe/bjo/libros/5/2210/7.pdf.

19 Jarquín Ortega, María Teresa, "El municipio en México: actualidad y raíces", en Vega Hernández, Rodolfo, (coord.), Municipio, aspectos políticos, jurídicos y administrativo, Querétaro, Fundación Universitaria de Derecho-Administración y Política FUNDAP, 2002, pp. 140 y 141.

20 Ochoa Campos, Moisés, op. cit., p. 223. 
Este libro forma parte del acervo de la Biblioteca Jurídica Virtual del Instituto de Investigaciones Jurídicas de la UNAM

las escuelas de primeras letras, la beneficencia en el ámbito municipal. Además de las ordenanzas municipales, promoción de la agricultura, entre otras.

Es importante señalar que de acuerdo con el artículo 323 tales cargos efectuados por los ayuntamientos estaban inspeccionados por la diputación provincial, ante quien debían rendir cuentas del recurso obtenido e invertido.

A pesar de que la Constitución de Cádiz de 1812 tuvo vigencia limitada ello no fue escollo para que aportara efectos importantes en sentido positivo como negativo:

Tres meses tan solo permaneció en vigor en México, pero le bastaron para hacer resurgir la institución municipal, dando entrada en ella nuevamente al pueblo.

En síntesis restauró:

El sistema de elección popular directa.

La no reelección de los funcionarios municipales.

Su renovación cada año.

Introdujo innovaciones fundamentales:

La de la integración del Ayuntamiento por un número de regidores en proporción al número de habitantes, "abandonándose, por tanto, la antigua relación entre el número de éstos y la categoría del poblado".

La de declarar el desempeño de los cargos concejiles, como obligación ciudadana.

Pero a la vez, la Constitución de Cádiz sentó precedentes negativos que se recrudecieron en nuestro medio al transcurso de los años:

1.- Con el régimen de centralización al que quedaron sometidos los Ayuntamientos al través de los Jefes Políticos.

2. Con la pérdida de la autonomía municipal en materia fundamental: la de su hacienda. ${ }^{21}$

Sin duda los cambios incrustados no siempre fueron favorables pero al final de cuentas eran parte de la transformación que la institución padecía en ese tiempo.

\section{La Constituaión de APATZingán}

El Decreto Constitucional para la Libertad de la América Mexicana ${ }^{22}$ expedido en Apatzingán el 22 de octubre de 1814, en su artículo 208, señala que

21 Ibidem, p. 226.

22 Constitución de Apatzingán 1814, disponible en: http: wrerr.diputados.gob.mx/biblioteca /bibdig/const_mex/const-apat.pdf. 
Este libro forma parte del acervo de la Biblioteca Jurídica Virtual del Instituto de Investigaciones Jurídicas de la UNAM

en los pueblos, villas y ciudades continuarán respectivamente los gobernadores y repúblicas, los ayuntamientos y demás empleos, mientras no se adopte otro sistema, a reserva de las variaciones que oportunamente introduzca el Congreso, consultando el mayor bien y felicidad de los ciudadanos. Cabe mencionar que el municipio no era señalado en la literalidad del documento.

\section{El Plan De Iguala}

En lo relativo al Plan de Iguala ${ }^{23}$ del 24 de febrero de 1821, estipulaba aún la existencia del régimen municipal tal y como estaba señalado por el artículo 309 de la Constitución de 1812, mismo que estipulaba que el gobierno interior de los pueblos estaría a cargo del Ayuntamiento formado por alcaldes, regidores, un procurador síndico, y presidido por el jefe político o, en su defecto, por el alcalde. Me parece que el Plan de Iguala señala un aspecto relevante cuando Iturbide proponía como forma de gobierno la monarquía constitucional, que se depositaba en Fernando VII y en su defecto en distintos príncipes señalados por él u otro individuo de casa reinante que estime conveniente el Congreso; sin embargo, el Plan de Iguala así como el Tratado de Córdoba no contenían aspectos relevantes relativos al municipio.

\section{Constitución Federal de 1824}

La Constitución Federal de los Estados Unidos Mexicanos promulgada por el Congreso Constituyente el 4 de octubre de 1824, ${ }^{24}$ declaraba la forma de gobierno republicana representativa popular federal de la República mexicana. No obstante, en el tema de nuestro interés relativo al régimen municipal, no aportaba aspectos trascendentales, sino que se limitaba a señalar en su artículo 161, fracción I, que cada uno de los estados estaba obligado a organizar su gobierno y administración interior sin oponerse a esta Constitución ni al Acta Constitutiva.

Como ejemplo, encontramos el caso de Michoacán el cual contemplaba en su Constitución local de 1825 en el artículo 94, título tercero, relativo al gobierno político y económico que en cada departamento habrá en su

23 Plan de Iguala. Centenario de la Constitución Política de los Estados Unidos Mexicanos, disponible en: http://constitucion1917.gob.mx/work/models/Constitucion1917/Resource/263/ 1/images/Independencia18.pdf.

24 Constitución Federal de los Estados Unidos Mexicanos de 1824, disponible en: http://wrere.diputados.gob.mx/biblioteca/bibdig/const_mex/const_1824.pdf. 
Este libro forma parte del acervo de la Biblioteca Jurídica Virtual del Instituto de Investigaciones Jurídicas de la UNAM

gobierno político económico un prefecto con entera dependencia del gobernador del estado, dichos prefectos serán nombrados por el gobierno de acuerdo con el consejo. Mientras que en lo relativo a los ayuntamientos en su artículo 103 la Constitución michoacana indicaba que los ayuntamientos estarán compuestos de alcaldes, regidores y síndicos quienes estarán a cargo del gobierno así como del régimen interior de los pueblos. Además de que para conformar un ayuntamiento se necesitaban como mínimo cuatro mil almas.

Otro dato importante lo encontramos en la fecha del 24 de enero de 1825, cuando el Congreso de Michoacán aprobó una ley para el establecimiento de los ayuntamientos, la ley estaba integrada por 12 artículos. La señalada ley constitucional fijó como requisito para integrar los ayuntamientos "ser ciudadano en ejercicio de sus derechos, mayor de veinte y cinco años o diez y ocho siendo casado y vecino del distrito del ayuntamiento con residencia de un año y mínimo de permanecer en él, teniendo algún capital o industria de que subsistir", además de que se pronosticaba que para el año de 1833 , los alcaldes y síndicos deberían saber leer y escribir y los regidores por lo menos leer. ${ }^{25}$ Con lo anterior podemos deducir que se sigue conservando el régimen municipal que imperaba desde los tiempos de la Colonia, por lo que la Constitución de 1824 no aporto modificaciones novedosas en lo relativo al municipio.

\section{Constitución DE 1836}

En esta Constitución del 20 de diciembre del año de $1836^{26}$ aparece la presencia constitucional de la figura de los ayuntamientos donde es ineludible señalar Las Siete Leyes Constitucionales de la misma:

El sexto Congreso ordinario, convocado conforme a la Constitución de 1824, se encontraba atado a poderes limitados por el texto de aquélla para iniciar el proceso de reforma constitucional, sobre todo por la inalterabilidad declarada de la forma de gobierno que preservaba el federalismo.

Sin embargo, por presión de los centralistas extendió sus facultades, sin fundamento legal, para convertirse en Congreso Constituyente. Emitió así

25 Hernández Díaz, Jaime, "Los ayuntamientos de Michoacán en la vida independiente", en Ortiz Escamilla, Juan y Serrano Ortega, José Antonio (eds.), Ayuntamientos y liberalismo gaditano en México, Zamora, El Colegio de Michoacán-Universidad Veracruzana, 2007, p. 255.

26 Constitución Federal de 1836, disponible en: http://wrere.diputados.gob.mx/biblioteca/ bibdig/const_mex/const_1836.pdf. 
Este libro forma parte del acervo de la Biblioteca Jurídica Virtual del Instituto de Investigaciones Jurídicas de la UNAM

las llamadas Bases para le nueva Constitución que dan fin a la de 1824 y fundamentan la Constitución "dispersa", fragmentada en "Siete Leyes Constitucionales" de $1836 .{ }^{27}$

Siendo un rasgo esencial de dicha Constitución el centralismo inmerso en ella, contrario al modelo federal. Sin duda, su influencia teórica procedía del centralismo francés acorde al modelo de "consulado" aplicado a la República.

Particularmente influyente fue la Constitución napoleónica del año VIII (1799), constitución reconocidamente autoritaria y hecha para establecer el consulado bonapartista, de la que en 1836 se tomó la organización centralizada y el "Senado Conservador" como órgano de control del cumplimiento de la Constitución por los poderes constituidos. ${ }^{28}$

Con lo anterior, es evidente observar que se establece la organización municipal de una manera más íntegra, lo cual se puede constatar en diversos artículos como del 22 al 25 del apartado sexto o relativo a la división del territorio de la república y gobierno interior de sus pueblos.

Artículo 22. Habrá Ayuntamientos en las capitales de Departamento, en los lugares en que los había el año de 1808, en los puertos cuya población llegue a cuatro mil almas, y en los pueblos que tengan ocho mil. En los que no haya esa población, habrá jueces de paz encargados también de la policía, en el número que designen las juntas departamentales de acuerdo con los gobernadores respectivos.

Artículo. 23. Los Ayuntamientos se elegirán popularmente en los términos que arreglará una ley. El número de alcaldes, regidores y síndicos se fijará por las juntas departamentales respectivas, de acuerdo con el gobernador, sin que puedan exceder los primeros de seis, los segundos de doce y los últimos de dos.

Artículo. 24. Para ser individuo del Ayuntamiento se necesita: $1^{\circ}$ Ser ciudadano mexicano en el ejercicio de sus derechos. $2^{\circ}$ Vecino del mismo pueblo. $3^{\circ}$ Mayor de veinticinco años. $4^{\circ}$ Tener un capital (físico o moral) que le produzca por lo menos quinientos pesos anuales.

Artículo. 25. Estará a cargo de los Ayuntamientos la policía de salubridad y comodidad: cuidar de las cárceles, de los hospitales y casas de beneficencia, que

27 Las siete leyes constitucionales de 1836, disponible en: http://wrerr.museodelasconstitu ciones.unam.mx/Exposiciones/page14/page5/page5.html.

28 Federalismo y centralismo. Museo de las Constituciones, disponible en: http://werere. museodelasconstituciones.unam.mx/Exposiciones/page14/page5/page5.html. 
Este libro forma parte del acervo de la Biblioteca Jurídica Virtual del Instituto de Investigaciones Jurídicas de la UNAM

no sean de fundación particular, de las escuelas de primera enseñanza que se paguen de los fondos del común, de la construcción y reparación de puentes, calzadas y caminos y de la recaudación e inversión de los propios y arbitrios: promover el adelantamiento de la agricultura, industria y comercio y auxiliar á los Alcaldes en la conservación de la tranquilidad y el orden público en su vecindario, todo con absoluta sujeción a las leyes y reglamentos.

Mientras que del 26 al 30 de igual manera señala aspectos de índole municipal al expresar las facultades conciliadoras de los alcaldes, de ordenar providencias urgentísimas en asuntos contenciosos, de incluir y practicar diligencias en asuntos criminales y velar, sujetándose a los prefectos por la tranquilidad y el orden. En lo relativo al artículo 31 éste señalaba que una ley secundaria regulará lo correspondiente a los artículos anteriores, mismo que se realizó a través de un Reglamento Provisional para el Gobierno Interior de los Departamentos, ${ }^{29}$ con fecha de expedición el 20 de marzo de 1837.

\section{Constituaión DE 1857}

El 16 de junio de 1857 se presentó en la Cámara el proyecto de Constitución elaborado por Ponciano Arriaga, León Guzmán, Mariano Yáñez, José María del Castillo, José María de Castillo Velasco, José María Mota y Pedro Escudero y Echánove. ${ }^{30}$ La Constitución de 1857 confirma decisiones políticas esenciales de la Constitución de 1824. Se destaca la reforma de las relaciones Estado-Iglesia, y la cimentación de un sistema de defensa de la Constitución.

La estructura de la Constitución de 1857 se compone por ocho títulos con 120 artículos a través de los cuales que protegía rubros como los derechos del hombre; la soberanía nacional; exponía la división de los poderes Ejecutivo, Legislativo y Judicial. En lo referente a los estados se dispone que en lo relativo a su interior recojan el régimen republicano, representativo y popular, con una serie de candados que restrinjan la soberanía estatal y de esta manera se imposibilite que la Federación se disuelva.

Moisés Ochoa Campos ${ }^{31}$ señala que la Constitución reformista no elevó el régimen municipal y únicamente se preocupó por lo relativo al municipio en el Distrito Federal para estipular las distintas maneras de elección de las

29 Dublán y Lozano, Legislación mexicana o colección completa de las disposiciones legislativas, núm. 1839, t. III, disponible en: http://wrerw.biblioweb.tic.unam.mx/dublanylozano/.

30 Constitución de 1857. El surgimiento de una Nación, disponible en: http://wrere.dipu tados.gob.mx/museo/s_surg6.htm.

31 Ochoa Campos, Moisés, op. cit., p. 253. 
Este libro forma parte del acervo de la Biblioteca Jurídica Virtual del Instituto de Investigaciones Jurídicas de la UNAM

autoridades del municipio como vemos a continuación: "Artículo 72, fracción IV.- Para el arreglo interior del Distrito Federal y territorios sobre la base que los ciudadanos elegirán popularmente a las autoridades políticas y municipales, se agregará y judiciales, designándoles las rentas para cubrir sus atenciones locales".

La Constitución de 1857 refleja con claridad la filosofía política del liberalismo mexicano al reconocer los derechos y las libertades públicas de los ciudadanos. La Ley Fundamental limita el ejercicio de los poderes públicos y reconoce la preeminencia del poder del Estado como organización de los ciudadanos sobre cualquier otra corporación. ${ }^{32}$

Por lo visto en el tema municipal no hubo grandes aportaciones, sin embargo, vemos la vigencia actual de ciertas decisiones políticas esenciales de la Constitución de 1857 como lo relativo a la democracia representativa, república, el federalismo, la noción de supremacía constitucional, entre otras cuestiones.

\section{El MUNiCiPIO EN EL PORfIRIATO}

De acuerdo con lo señalado por Carlos Quintana Roldán, el país se vio seriamente sometido durante el periodo dictatorial de Porfirio Díaz de treinta y cuatro años, aprovechándose de la figura de los jefes políticos nacida en la Constitución gaditana de 1812. Lo anterior se puede constatar con la ley de organizaciones municipales de 1903, donde encontramos dos artículos que esbozan las políticas del porfiriato relativa a los municipios: artículo 60.- "Los prefectos políticos serán la primera autoridad política local, en la jurisdicción de sus respectivas municipalidades" y artículo 61.- "Los prefectos serán los jefes de todos los servicios en las municipalidades y estarán subordinados al gobernador del estado". Los jefes políticos actuaban como jefes regionales con gran poder favoreciendo con ello una debilidad en los ayuntamientos, incluso ciertos pensadores identificados como porfiristas como Miguel S. Macedo, detectaron la grave situación de los municipios así como su decaída económica.

Así pues, a las restricciones que los ayuntamientos tenían, de someter a la aprobación de los jefes políticos todos sus actos y decisiones de observancia

32 Trascendencia de la Constitución de 1857. Museo de las Constituciones, disponible en: http://wrwre.museodelasconstituciones.unam.mx/Exposiciones/page14/page8/page8.html. 
Este libro forma parte del acervo de la Biblioteca Jurídica Virtual del Instituto de Investigaciones Jurídicas de la UNAM

general o que se referían a distribución de los fondos, se agregaba la enorme restricción de tener que desempeñar sus funciones, precisamente con los procedimientos y el personal de antemano fijados por la autoridad superior. Lo cual nos obliga a decir que la mezquindad de los poderes confiados a los ayuntamientos, no pudo ser más patente y que, como lo haremos notar en las observaciones finales del presente estudio, jamás el Municipio fue entre nosotros ni un verdadero poder, si siquiera una institución distinta y separada de que en general tuvo a su cargo la administración pública. ${ }^{33}$

Con base en el sometimiento de los municipios, queda justificado uno de los ideales revolucionarios ante la proclama de un municipio libre, ideal que se ve plasmado hasta la Constitución de 1917.

\section{Programa del Partido Liberal Mexicano}

Los hermanos Flores Magón fueron los pioneros en promover los levantamientos ocurridos en Acayucan, ocasionando que se desplegara una persecución contra ellos por parte de la dictadura, obligándolos a salir del país.

El Plan de San Luis Missouri, en realidad llamado Programa y Manifiesto del Partido Liberal Mexicano: dado el 1o. de julio de 1906 por los principales dirigentes de la oposición al gobierno de Díaz, en relación con los municipios, ${ }^{34}$ plantearon lo siguiente:

La supresión de los Jefes Políticos que tan funestos han sido para la República, como útiles al sistema de opresión reinante, es una medida democrática, como lo es también la multiplicación de los Municipios y su robustecimiento. Y en consonancia, en sus puntos de programa establecía:

45. Supresión de los jefes políticos.

46.- Reorganización de los Municipios que han sido suprimidos o robustecimiento del poder municipal. ${ }^{35}$

Lo que se buscaba era contar con libertad en el municipio y dejar de lado el yugo implantado por los jefes políticos.

33 Miguel Macedo citado por Quintana Roldán, Carlos F., Derecho municipal, 2a. ed., México, Porrúa, 1998, p. 71.

34 Silva Herzog, Jesús, Breve historia de la revolución mexicana, México, Fondo de Cultura Económica, 1966, p. 100.

35 Quintana Roldán, Carlos F., Derecho municipal, México, Porrúa, 1998, p. 74. 
Este libro forma parte del acervo de la Biblioteca Jurídica Virtual del Instituto de Investigaciones Jurídicas de la UNAM

\section{La CONSTITUGión DE 1917 y EL ARTÍCUlo 115 CONSTITUCIONAL}

La Constitución Política de los Estados Unidos Mexicanos, que reforma la del 5 de febrero de 1857 fue promulgada el 5 de febrero de 1917, entrando en vigor el 1o. de mayo de $1917^{36}$ ante la necesidad de establecer un orden constitucional capaz de responder por las exigencias requeridas de la Revolución fue que acaeció la instalación del Congreso Constituyente responsable de la promulgación de la Constitución de 1917:

El constitucionalismo fue la corriente triunfante de la Revolución Mexicana. Logró la victoria sobre el villismo y el zapatismo. Venustiano Carranza pudo establecer su gobierno en la ciudad de México e iniciar la pacificación de todas las regiones del país y el establecimiento del orden constitucional. Inició la etapa constructiva de la Revolución, con la Convocatoria del Congreso Constituyente que se celebró en la ciudad de Querétaro entre diciembre de 1916 y enero de 1917. La Constitución promulgada el 5 de febrero de 1917 plasmó las principales demandas sociales, económicas y políticas de la Revolución y estableció un nuevo orden que asumió como su principal función cumplir con el programa de la Revolución y ser el eje articulador del desarrollo de la Nación mexicana en el siglo XX. ${ }^{37}$

Siendo novedosa la contribución que hizo la Constitución de 1917 para incluir en su artículo 115 el modus operandi de la organización y competencias de los municipios. Donde es ineludible la aportación de Carranza al proponer el cimiento del artículo 115 constitucional en la expedición de la Ley de Libertades Municipales, cuyo objetivo reposaba en la reforma del artículo 109 de la Constitución de 1857 y con ello establecer el municipio libre configurándose éste como base de la división territorial así como de la organización política de las entidades federativas, como vemos a continuación:

ARTículo ÚNICO: Se reforma el artículo 109 de la Constitución Federal de los Estados Unidos Mexicanos de 5 de febrero de 1857, en los términos que siguen:

Los Estados adoptarán para su régimen interior la forma de gobierno republicano, representativo, popular, teniendo como base de su división territorial, y de su organización política, el Municipio Libre, administrado por un

36 Constitución Política de los Estados Unidos Mexicanos: Original, disponible en: wrerre. diputados.gob.mx/LeyesBiblio/ref/cpeum/CPEUM_orig_05feb.

37 Congreso Constituyente y Constitución de 1917, disponible en: http://constitucion 1917.gob.mx/es/Constitucion1917/Congreso_Constituyente_y_Constitucion_de_1917. 
Este libro forma parte del acervo de la Biblioteca Jurídica Virtual del Instituto de Investigaciones Jurídicas de la UNAM

Ayuntamiento de elección popular directa y sin que haya autoridades intermedias entre éstos y el gobierno del Estado. ${ }^{38}$

$\mathrm{Al}$ momento que se instaló en Querétaro el Congreso Constituyente, en lo relativo al tema del municipio el debate se enfocó a temas que Carranza no abordó como la Hacienda y las contribuciones; sin embargo, el mérito es mayor que sus imperfecciones al dar apertura a las legislaturas locales para que elaboraran sus propios ordenamientos relativos al ámbito municipal.

Por otro lado, Moisés Ochoa Campos manifiesta que el debate relativo al tema municipal efectuado en Querétaro es una pieza importante para entender las razones que motivaron al legislador a moldear la estructura actual del municipio en México, siendo una cuestión relevante la presentada por la 2a. comisión la cual presentó el siguiente dictamen referente al artículo 115:

Ciudadanos diputados: La diferencia más importante y por tanto la gran novedad respecto de la Constitución de 1857, es la relativa al establecimiento del Municipio Libre como la futura base de la administración política y municipal de los Estados y, por ende, del país. Las diversas iniciativas que ha tenido a la vista la Comisión y su empeño de dejar sentados los principios en que debe descansar la organización municipal, ha inclinado a ésta a proponer las tres reglas que intercala en el artículo 115 y que se refieren a la independencia de los ayuntamientos, a la formación de su hacienda, que también debe ser independiente y al otorgamiento de personalidad jurídica para que puedan contratar, adquirir, defenderse, etc. "Teniendo en cuenta que los municipios salen a la vida después de un largo período de olvido en nuestras instituciones, y que la debilidad de sus primeros años los haga víctimas de ataques de autoridades más poderosas, la Comisión ha estimado que deben ser protegidos por medio de disposiciones constitucionales y garantizarles su hacienda, condición sine qua non de vida y su independencia, condición de su eficacia". ${ }^{39}$

Artículo 115. Los Estados adoptaran, para su régimen interior, la forma de Gobierno republicano, representativo popular, teniendo como base de su división territorial y de su organización política y administrativa el Municipio Libre, conforme a las tres bases siguientes:

38 Ley de Libertades Municipales, citado por Quintana Roldán, Carlos F., El municipio libre producto de la Revolución mexicana, disponible en: http://wrwederecho.unam.mx/investigacion/ publicaciones/librosfac/pdf/pub05/16DrQUINTANA.pdf.

39 Congreso constituyente de los Estados Unidos Mexicanos, Instituto Nacional de Estudios Históricos de las Revoluciones de México, Debates notables, disponible en: http://constitucion 1917.gob.mx/es/Constitucion1917/Congreso_Constituyente_y_Constitucion_de_1917. 
Este libro forma parte del acervo de la Biblioteca Jurídica Virtual del Instituto de Investigaciones Jurídicas de la UNAM

I Cada municipio será administrado por un Ayuntamiento de elección popular directa y no habrá ninguna autoridad intermedia entre éste y el Gobierno del Estado.

II. Los municipios administrarán libremente su hacienda recaudarán, todos los impuestos y contribuirán a los gastos públicos del Estado en la proporción y término que señale la Legislatura local. Los ejecutivos podrán nombrar inspectores para el efecto de percibir la parte que corresponda al Estado y para vigilar la contabilidad de cada municipio. Los conflictos hacendarios entre el municipio y los poderes de un Estado los resolverá la Corte Suprema de Justicia de la Nación, en los términos que establezca la ley.

III. Los municipios estarán investigados de personalidad jurídica para todos los efectos legales. "El Ejecutivo federal y los gobernadores de los Estados tendrán el mando de la fuerza pública en los municipios donde residieren habitual y transitoriamente. "Los gobernadores constitucionales no podrán ser reelectos ni durar en su encargo más de cuatro años. "Son aplicables a los gobernadores substitutos o interinos las prohibiciones del artículo 83. "El número de representantes en las legislaturas de los Estados será proporcional al de habitantes de cada uno; pero, en todo caso, el número de representantes de una Legislatura local no podrá ser menor de quince diputados propietarios.

En los Estados, cada distrito electoral nombrará un diputado propietario y un suplente. "Sólo podrá ser gobernador constitucional de un Estado un ciudadano mexicano por nacimiento". ${ }^{40}$

Teresita Rendón ${ }^{41}$ señala que los principios estipulados en el anterior texto constitucional se contradecían entre sí al momento que las legislaturas estatales debían señalar los ingresos, privando con ello al denominado "municipio libre" en lo relativo a la potestad tributaria. Asimismo, se generaba otro punto de confusión al dotar de competencia a la Suprema Corte de Justicia de la Nación, para que solucionara los conflictos hacendarios suscitados entre el municipio y la entidad federativa, generando polémica y desconcierto.

De este modo Teresita Rendón cita a Tena Ramírez: De este modo la autonomía financiera, y con ella la libertad municipal, han quedado a merced de la legislatura y del ejecutivo, que de acuerdo con su conveniencia política puede aumentar o disminuir los recursos municipales... Atraída su atención por el trascendental problema de la autonomía financiera, la asamblea olvidó en la agonía de la discusión otro aspecto de vital importancia para la libertad del

\footnotetext{
40 Idem.

41 Cfr. Rendón Huerta Barrera, Teresita, op. cit., pp. 100-115.
} 
Este libro forma parte del acervo de la Biblioteca Jurídica Virtual del Instituto de Investigaciones Jurídicas de la UNAM

Municipio: la forma de resolver los conflictos de ésta con las autoridades del Estado.

...pero por desgracia el impensado final a que condujo el cansancio de la asamblea hizo olvidar la defensa del Municipio frente al Estado, a través de un sistema de garantías... De este modo el Municipio libre ingresó a la Constitución con los dos defectos substanciales que acabamos de señalar. ${ }^{42}$

Indudablemente la inclusión constitucional del municipio bajo la propuesta de Venustiano Carranza misma que fue aprobada por los integrantes del Congreso Constituyente fue un gran avance positivo, mismo que posteriormente a través de reformas se buscaba encontrar su perfeccionamiento, en virtud de que el primer paso fundamental estaba dado, su presencia constitucional configuraba la punta de lanza siendo un referente importante en la organización estructural y política del territorio en México, sin embargo no permaneció incólume a reformas; a continuación se muestran algunas de las más importantes:

\section{1.- 1928: para regular el número de diputados de cada estado.}

2.- 1933: consistió en aplicar el principio de no reelección en el gobierno municipal.

3.- 1943: para ampliar a seis años el periodo constitucional de los gobernadores.

4.- 1947: se reconocieron los derechos de la mujer de votar y ser electa, aunque más tarde fue suprimida esta reforma cuando en 1953, el reconocimiento se hizo a nivel nacional, siendo ésta la número 5.

5.- 1976: se adicionaron las fracciones IV y V para otorgar facultades a los municipios con el fin de regular el crecimiento urbano y la planeación en las zonas conurbadas.

6.- 1977: se introduce el principio de representación proporcional en los ayuntamientos de 300,000 habitantes.

7.- 1983: el presidente Miguel de la Madrid, para hacer valer su tesis de campaña como candidato de la descentralización de la vida nacional, con el propósito de fortalecer el régimen municipal, adiciona cinco fracciones más, haciendo de diez fracciones el artículo 115.

8.- 1987: finalmente el 17 de marzo se derogan las últimas dos fracciones, y los principios consagrados en la fracción VIII pasaron a ser las fracciones I y II del artículo 116, quedando el último párrafo en la fracción VIII. ${ }^{43}$

\footnotetext{
42 Ibidem, p. 117.

43 López Sosa, Eduardo, Derecho municipal mexicano, 2a. ed., México, 1999, pp. 80 y 81.
} 
Este libro forma parte del acervo de la Biblioteca Jurídica Virtual del Instituto de Investigaciones Jurídicas de la UNAM

El 23 de diciembre de 1999 se publicó en el Diario Oficial de la Federación una reforma importante al artículo 115 donde sus rasgos principales son los siguientes:

Reconocer al ayuntamiento como ámbito de gobierno del municipio constituido por elección popular y directa, sin que exista entre éste y el estado autoridad intermedia.

Establecer procedimientos para la disolución del ayuntamiento, por parte de las legislaturas y la creación de los consejos municipales constituidos por vecinos cuando así corresponda.

Otorgarle facultades para aprobar, de acuerdo con las leyes que en materia municipal deberán expedir las legislaturas, los bandos de policía y gobierno, los reglamentos, circulares y disposiciones administrativas, entre éstas las que aseguren la participación ciudadana y vecinal.

Precisa la competencia municipal en materia de suministros y servicios, agregando funciones en el tratamiento y disposición de aguas residuales, el equipamiento de calles, parques y jardines.

Sólo están exentos de contribuciones los bienes de dominio público.

Los municipios cumplirán todas las funciones relacionadas con el uso de suelo y su planeación.

Otorgar el mando de la policía preventiva al presidente municipal. ${ }^{44}$

Aparece en el Diario Oficial de la Federación publicada el 14 de agosto de 2001, la cual consistió en una adición de un párrafo de la fracción III del multicitado artículo 115 constitucional, mismo que a la letra dice: "Las comunidades indígenas, dentro del ámbito municipal, podrán coordinarse y asociarse en los términos y para los efectos que prevenga la ley”. Sin duda, en materia indígena se han realizado distintas reformas que favorecen a dicho sector, que si bien no se expresa claramente, el hecho de un reconocimiento de este calado siempre será un avance positivo para los grupos vulnerables en México.

José René Olivos Campos en La gobernabilidad democrática en México ${ }^{45}$ señala que el trayecto de las reformas realizadas en materia municipal, en específico al artículo 115 constitucional, ha comprendido distintos rubros encaminados a ensanchar las atribuciones del municipio, con lo cual se ha

44 Guillén, Tonatiuh y Ziccardi, Alicia, "Parámetros de la reforma municipal en México", en Guillén, Tonatiuh y Ziccardi, Alicia (coords.), Innovación y continuidad del municipio mexicano análisis de la reforma municipal de 13 estados de la república, México, UNAM-Porrúa, 2004, pp. 31 y 32.

45 Cfr. Olivos Campos, José René, La gobernabilidad democrática municipal en México, México, Porrúa, 2006, p. 73. 
Este libro forma parte del acervo de la Biblioteca Jurídica Virtual del Instituto de Investigaciones Jurídicas de la UNAM

institucionalizado una capacidad más amplia para su gobernanza con un atendencia reivindicatoria al federalismo así como el rasgo democrático del Estado mexicano.

\section{CONCLUSIONES}

Para finalizar, debemos entender al municipio como una institución de herencia colonial sui generis de carácter administrativa y política que va más allá de atender cuestiones de gobierno y que su presencia no puede pasar desapercibida en México al mantenerse vigente inclusive cuando no apareció en la Constitución de 1824.

Entendiendo la relevancia de la Constitución de 1917 misma que emergió del movimiento de la Revolución y culminó con la concentración institucional de poder que prevalecía años atrás; sin embargo, es innegable señalar la disminución en la esfera competencial de los municipios en relación con los servicios necesitados por la sociedad que los compone, lo anterior, independientemente de haberse eliminado la figura de los jefes políticos ello no excluyó que otros agentes políticos utilizaran al municipio como medio de control político-social. Con base en lo anterior, hemos podido constatar la distancia que ha separado la enunciación legal de la práctica que acaece en la realidad en nuestro sistema político mexicano.

La figura del municipio así como su reconocimiento constitucional considerándolo con la denominación de municipio libre base de la división territorial así como de la organización política y administrativa de los estados, es uno de tantos rasgos que nos hace entender la vigencia e importancia de la institución por lo cual su estudio y análisis es imprescindible para entender la evolución de las formas de organización social y los retos que faltan por atender en el rubro siendo uno de ellos el tema indígena donde existe la propuesta para transformar el artículo 115 constitucional y moldearlo hacia la nueva realidad que conlleva el reconocimiento expreso de la figura de municipio indígena como una manifestación de autonomía y respeto de los derechos de autogobierno indígenas relativo al ámbito municipal en México, el tema continúa pendiente.

Sin embargo, a pesar de todos sus defectos es indiscutible que el municipio es una institución excepcional al ser la única que ha subsistido a todas las transformaciones, sin que haya una institución de tal calado que se le asemeje. 
Este libro forma parte del acervo de la Biblioteca Jurídica Virtual del Instituto de Investigaciones Jurídicas de la UNAM

\section{FUENTES DE INFORMACIÓN}

Andrade SÁnchez, Eduardo J., Derecho municipal, México, Oxford, 2006.

CASTro, Concepción, La revolución liberaly los municipios españoles (1812-1868), Madrid, Alianza Editorial, 1979.

Covarrubias Dueñas, José de Jesús, La autonomía municipal en México, México, Porrúa, 1998.

Constitución de 1857. El surgimiento de una Nación, disponible en: http:// wrere.diputados.gob.mx/museo/s_surg6.htm.

Constitución de Apatzingán 1814, disponible en: http: wrer.diputados.gob.mx/ biblioteca/bibdig/const_mex/const-apat.pdf.

Constitución Política de la Monarquía Española, disponible en: http//:archi vos.juridicas.unam.mx/wrww/bjv/libros/5/2210/7.pdf.

Constitución Política de los Estados Unidos Mexicanos: Original, disponible en: wrere.diputados.gob.mx/LeyesBiblio/ref/cpeum/CPEUM_orig_05feb.

Constitución Política del Estado de Michoacán de 1825, México, edición facsimilar, Gobierno del Estado de Michoacán de Ocampo, H. Congreso del Estado de Michoacán de Ocampo LXIX Legislatura, 2002.

DUBLÁN y LOZANO, Legislación mmexicana o colección completa de las disposiciones legislativas, núm. 1839, t. III, disponible en: http://wrwrbiblioweb.tic.unam. $m x /$ dublanylozano/.

El Congreso Constituyente y Constitución de 1917, disponible en: http:// constitucion1917.gob.mx/es/Constitucion1917/Congreso_Constituyente_y_Consti tucion_de_1917.

Federalismo y centralismo, Museo de las Constituciones, disponible en: http:// wrew.museodelasconstituciones.unam.mx/Exposiciones/page14/page5/page 5.html.

Guarisco Canseco, Claudia, Los indios del valle de México y la construcción de una nueva sociabilidad política, 1770-1835, México, El Colegio Mexiquense, 2003.

GUILLÉn, Tonatiuh y ZICGARDI Alicia, "Parámetros de la reforma municipal en México", Innovación y continuidad del municipio mexicano análisis de la reforma municipal de 13 estados de la República, México, UNAM-Porrúa, 2004.

Hillerkuss, Thomas, La República en los pueblos de indios de la Nueva Galicia en el siglo XVI, 1995, p. 247, disponible en: http://wrwr.ïfilologicas.unam.mx/ pnovohispano.

JARQUín ORTEGA, María Teresa, "El municipio en México: actualidad y raíces", en VEGA HERnÁNDEZ, Rodolfo (coord.), Municipio, aspectos políticos, 
Este libro forma parte del acervo de la Biblioteca Jurídica Virtual del Instituto de Investigaciones Jurídicas de la UNAM

jurídicos y administrativo, Querétaro, Fundación Universitaria de Derecho, Administración y Política (Fundap), 2002.

Las Siete Leyes Constitucionales de 1836, disponible en: http://wrerr.museode lasconstituciones.unam.mx/Exposiciones/page14/page5/page5.html.

LIRA GONZÁLEZ, Andrés, "Idea y realidad en la formación constitucional del municipio", en BOEHM DE LAMEIRAS, Brigitte (coord.), El municipio en México, Zamora, El Colegio de Michoacán, 1987.

LóPez Sosa, Eduardo, Derecho municipal mexicano, 2a. ed., México, 1999.

MERINO, Mauricio, Gobierno local, poder nacional: la contienda por la formación del Estado Mexicano, México, El Colegio de México, Centro de Estudios internacionales, 1998.

Ochon Campos, Moisés, La reforma municipal, México, Porrúa, 1968.

OchoA Campos, Moisés, El municipio y su evolución constitucional, México, Fomus-Banobras, 1981.

Olivos Campos, José René, La gobernabilidad democrática municipal en México, México, Porrúa, 2006.

Ortiz Escamilla, Juan y Serrano Ortega, José Antonio (eds.), Ayuntamientos y liberalismo gaditano en México, Zamora, El Colegio de Michoacán: Universidad Veracruzana, 2007.

Plan de Iguala. Centenario de la Constitución Política de los Estados Unidos Mexicanos, disponible en: http://constitucion1917.gob.mx/work/models/Cons titucion1917/Resource/263/1/images/Independencia18.pdf.

Quintana Roldán, Carlos F., Derecho municipal, México, Porrúa, 1998.

Rendón Huerta Barrera, Teresita, Derecho municipal, México, Porrúa, 1998.

Robles Martínez, Reynaldo, El municipio, 3a. ed., México, Porrúa, 1998.

Tena Ramírez, Felipe, Leyes fundamentales de México 1808-1999, 22a. ed., México, Porrúa, 1999.

TORRes ESTRADA, Pedro, La autonomía municipal y su garantía constitucional directa de protección. Estudio comparado de los supuestos español y mexicano, México, UNAM, Instituto de Investigaciones Jurídicas, 2005. 
Este libro forma parte del acervo de la Biblioteca Jurídica Virtual del Instituto de Investigaciones Jurídicas de la UNAM

\title{
ZACATECAS 1916: EL AÑO DE LAS ELECGIONES, EL AÑO DEL TIFO, EL AÑO DEL HAMBRE
}

\author{
José ENCISO CONTRERAS*
}

Para Sindy Espinosa Medina y su pancita, con amor

SumARIO: I. Inestabilidad. II. Hambruna e indigencia. III. El tifo tampoco vota. IV. Elecciones municipales. V. Elecciones al Congreso Constituyente. VI. Fuentes.

\section{INESTABILIDAD}

Las principales preocupaciones de Venustiano Carranza ,entre 1915 y 1916, eran la pacificación del país, la solución del conflicto con los Estados Unidos a raíz de la invasión de Francisco Villa al pueblo de Columbus, en Nuevo México y, finalmente, la creación de un marco institucional para el nuevo Estado de la Revolución constitucionalista. La consecución de todas esas cosas, que no eran tarea fácil, se hizo simultáneamente y reclamaron toda la atención del primer jefe, quien se ocupó en una larga gira que comenzó en Veracruz el 11 de octubre de 1915, desde donde partió a Tampico y luego a Torreón para después recorrer buena parte del noroeste del país. Entre sus principales consignas estaba la organización de las elecciones municipales como primer paso para la reconstrucción jurídica y política de México, cuestión que se formalizó mediante convocatoria del 12 de junio del siguiente año.

La guerra revolucionaria y sus funestas consecuencias militares, demográficas y de salud pública para la ciudad de Zacatecas - por excelencia el principal escenario político del estado - trajeron consigo la desarticulación definitiva del espectro de fuerzas políticas heredado de tiempos porfirianos, es decir que, para acabar pronto, representaron la tumba política del porfi-

\footnotetext{
* Poder Judicial del Estado de Zacatecas.
} 
Este libro forma parte del acervo de la Biblioteca Jurídica Virtual del Instituto de Investigaciones Jurídicas de la UNAM

riato en Zacatecas. Después de la derrota del villismo en el Bajío, a fines de julio de 1915 se instalaron en la pequeña urbe de cantera las fuerzas leales a Carranza, inaugurando un periodo que culminaría en octubre de 1916, ${ }^{1}$ justo con las elecciones de diputados al congreso constituyente. Fue el general Benjamín Hill quien ocupó inicialmente la plaza con sus tropas en julio de 1915, y a mediados del mes siguiente sería sustituido por el general Rómulo Figueroa, designado gobernador interino y comandante militar en el estado.

Todo indicaba que bajo las nuevas condiciones se imponía la negociación de los nuevos y viejos grupos de políticos locales con el constitucionalismo de Carranza o con el obregonismo, como parecía sugerirlo la lógica del proceso de reconstrucción institucional. Quienes no captaron este mensaje fueron simplemente ignorados, como ocurrió con el puñado de vivillos conservadores que quiso adueñarse motu proprio del ayuntamiento de la capital y que fueron olímpica y obviamente desconocidos por el gobernador Figueroa. A esas alturas, uno de los más conspicuos activistas del grupo arechiguista - es decir aquellos liberales que se nuclearon durante décadas en torno al general Jesús Aréchiga, el más conspicuo de los gobernadores zacatecanos porfiristas - don Lorenzo T. Villaseñor, fue nombrado en agosto de 1915, o poco antes, como jefe político de Zacatecas, por lo que sabemos con certeza que iba buscando con relativo éxito integrarse con su grupo al nuevo esquema político de la Revolución constitucionalista. ${ }^{2}$ En octubre este prestigiado farmacéutico, masón escocés y profesor del Instituto de Ciencias, ya era integrante de una comisión que se había formado a instancias del gobierno municipal con el fin de organizar la recepción del primer jefe, la que se veía como inminente. Por otro lado, en tanto el secretario de gobierno, el licenciado Gabriel Ruelas, partió a Monterrey para entrevistarse con don Venustiano y concertar la visita, ocupó interinamente su lugar un joven masón escocés de antecedentes maderistas, el profesor Andrés L. Arteaga. ${ }^{3}$ Por cierto, Carranza finalmente no visitaría Zacatecas pero así se dieron las cosas en el ambiente político de la capital.

Conviene comentar que Lorenzo Villaseñor era padre de Adolfo Villaseñor, constituyente por Zacatecas, que asistiría al congreso por muerte de su padre, quien seguramente era el candidato original del constitucionalis-

1 Sánchez Tagle, Héctor, El liberalismo en su laberinto. La Revolución mexicana en Zacatecas, 1910-1917, Zacatecas, Conaculta-Instituto Zacatecano de Cultura Ramón López Velarde, 2015 , p. 339.

2 Ibidem, pp. 352 y 353. Desde ese cargo, como era bastante previsible, se dedicó a aplicar con rigidez las Leyes de Reforma, especialmente en contra de las desdichadas monjas del Colegio Teresiano y de los curas adictos empedernidos a los repiques de campana.

3 Ibidem, p. 345. 
Este libro forma parte del acervo de la Biblioteca Jurídica Virtual del Instituto de Investigaciones Jurídicas de la UNAM

mo. Por su parte, Andrés L. Arteaga asistiría igualmente como diputado al congreso de Querétaro, por el distrito de Tlaltenango, en sustitución del candidato titular Pedro López, a quien le fueron rechazadas sus credenciales.

El de 1916 también fue año de notoria inestabilidad social, económica y militar en el estado. Se reportaba a principios del año que entre las localidades de Calera y Zacatecas había sido cortada la vía por nutridas bandas de rebeldes,$^{4}$ cuestión alarmante por verificarse prácticamente a las goteras de la capital, pese a que aparentemente los enemigos del constitucionalismo no parecían tener una estrategia propiamente dicha, atacaban indistintamente en dispersas regiones del estado, pero su reorganización sería cosa de tiempo. Las acciones del ejército no eran tan diferentes en ese sentido, respondían allí donde se efectuaban ataques y desórdenes de villistas y ex huertistas. Con todo, para algunos observadores las tensiones disminuían en febrero con la captura de Benjamín Argumedo y su lugarteniente en el norte del estado, lo que podría mejorar las condiciones en el territorio entre Zacatecas y Torreón, que había sido escenario de lo que llamaban crímenes y bandolerismo. En realidad no se trataba de otra cosa que de villistas movilizados saboteando vías y puentes, ${ }^{5}$ y ya en abril también operaban con relativo éxito entre Calvillo y Juchipila. ${ }^{6}$ Lo dicho, eran veteranos cuya rearticulación militar era cuestión de tiempo si no se actuaba con eficacia.

Con posterioridad a las batallas de Celaya, en 1915 varios jefes villistas se replegaron en Zacatecas en busca de una reorganización. Un núcleo importante de villistas se concentraba en la región de Jerez, la "manzana de la discordia" que por lo mismo también era hostigada por los carrancistas, de tal forma que el peso militar de ambas facciones era muy parejo. Desde comienzos de 1916 los villistas dominaban Jomulquillo en la zona de Susticacán, que era atacada con artillería por los carrancistas, manteniendo un frágil equilibrio de fuerzas que fue roto en favor de los villistas los que a comienzos de abril recibieron refuerzos de varios puntos cardinales organi-

4 Archivo Histórico del Estado de Aguascalientes, sección Reportes Consulares, caja 4, expediente 69. Aguascalientes, 6 de enero de 1916. Esto lo informaba al secretario de estado de los Estados Unidos, el cónsul estadounidense en el distrito consular que incluía los estados de Zacatecas y Aguascalientes, Gastón Schmutz, agregaba que varios cientos de soldados habían sido asentados en Aguascalientes para ser enviados al sur, donde bandas de rebeldes amenazaban las plazas de León y Guanajuato. (En adelante, este archivo será referenciado con las siglas AHEA, seguido de la sección y el número de expediente, en su caso).

5 AHEA, Reportes Consulares, caja 4, expediente 73. Aguascalientes, 4 de febrero de 1916. Schmutz informaba al secretario de estado que las condiciones políticas del distrito eran aparentemente tranquilas.

6 AHEA, Reportes Consulares, caja 4, expediente 87. Aguascalientes, 13 de abril de 1916. 
Este libro forma parte del acervo de la Biblioteca Jurídica Virtual del Instituto de Investigaciones Jurídicas de la UNAM

zando una acción de armas que puso el alerta máxima a los constitucionalistas. Fortalecidos los rebeldes habían sitiado ${ }^{7}$ y finalmente tomado Jerez, ${ }^{8}$ cuando una fuerza de 350 soldados constitucionalistas bajo el mando del general Silva fue derrotada por una fuerza villista dirigida por Santos Bañuelos y Tomás Domínguez.

Silva resultó herido y su hermano el coronel había perdido la vida, y aunque el cónsul estaduunidense llegó a suponer que los rebeldes también habían tomado la ciudad de Zacatecas, ${ }^{9}$ no hay constancia de que así fuese; sin embargo era algo que parecía inminente porque el sábado 15 de abril las autoridades de la capital se alistaban precipitadamente para evacuar la ciudad, ya tenían sus archivos oficiales a bordo de un tren especial, y los militares su artillería montada en carros plataforma, más que dispuestos a poner tierra de por medio, cuando recibieron órdenes tajantes de que las tropas permanecieran en la plaza y se movilizaran rápidamente hacia el sur del estado a reforzar las fuerzas federales, ${ }^{10} \mathrm{Ni}$ modo, tuvieron que bajarse del tren.

Así las cosas se consideraba que había suficientes tropas en la ciudad de Zacatecas como para defenderla, pero no las necesarias para atacar y dispersar a los alzados en Jerez y sus alrededores, ${ }^{11}$ que estaban bajo el mando de Santos Bañuelos, Tomás Domínguez y Fidel Ávila, y según el cónsul estadounidense en Aguascalientes "no sería una sorpresa saber que el propio Villa encabezara su banda". ${ }^{12}$

La preocupación de los constitucionalistas motivó que las fuerzas del general Martín Triana — zacatecano ex villista, ex cura, a la sazón gobernador militar de Aguascalientes - , también fueron enviadas a territorio del sur de Zacatecas para perseguir rebeldes entre Calvillo y Juchipila. ${ }^{13}$ Había

7 "Manuscrito de Eleuterio Pérez", en Digesto Documental de Zacatecas, Zacatecas, Tribunal Superior de Justicia del Estado de Zacatecas-Universidad Autónoma de Zacatecas, diciembre de 2014, núm. 14, p. 99.

8 AHEA, Reportes Consulares, caja 4, expediente 88. Aguascalientes, 16 de abril de 1916. Schmutz reportaba a Washington que la ciudad de Zacatecas había comenzado a evacuarse por las tropas de Carranza en esa fecha.

9 Loc. cit.

10 AHEA, Reportes Consulares, caja 4, expediente 89. Aguascalientes, 18 de abril de 1916.

11 AHEA, Reportes Consulares, caja 4, expediente 90. Aguascalientes, 20 de abril de 1916.

12 AHEA, Reportes Consulares, caja 4, expediente 92. Aguascalientes, 4 de mayo de 1916.

13 AHEA, Reportes Consulares, caja 4, expediente 89. Aguascalientes, 18 de abril de 1916. 
Este libro forma parte del acervo de la Biblioteca Jurídica Virtual del Instituto de Investigaciones Jurídicas de la UNAM

temor fundado de que se unificaran las bandas que operaban en el sur de Durango, el oeste de Zacatecas, en Aguascalientes y norte de Jalisco y que, una vez combinadas, constituirían formidable fuerza. ${ }^{14}$ Así que actuando en consecuencia, el gobierno envió numerosos refuerzos a la ciudad de Zacatecas amenazada por los rebeldes; a principios de mayo se calculaban en alrededor de tres o cuatro mil efectivos en esa localidad. ${ }^{15} \mathrm{~A}$ finales de abril los villistas fueron expulsados de Jerez por el general Agustín Albarrán, al frente de numeroso ejército, después de lo cual sobrevendría sangrienta represión a la población civil. ${ }^{16}$

Las precarias pero crecientemente organizadas operaciones de las tropas constitucionalistas en los meses posteriores - principalmente entre finales de abril y durante mayo, junio y julio-, fueron haciendo replegarse a las fuerzas villistas. En un reporte al secretario de estado en Washington, el cónsul francés en Aguascalientes, Hillarie Berlie - quien actuaba interinamente en representación del vecinito del norte-, informaba que las condiciones políticas del distrito consular, que incluía a Zacatecas, eran muy tranquilas. ${ }^{17}$

Sin embargo, todavía en agosto, exhaustos grupos rebeldes disgregados por el sur del estado, encabezados por Ramón Flores, hostigaban la cálida zona de Apozol, donde por esos días los vecinos de la comunidad de Achoquen combatieron otro pequeño grupo de ocho individuos encabezado por Apolonio Álvarez, a los que derrotaron y confiscaron un botín compuesto principalmente de armamento. ${ }^{18}$ En Ojocaliente, cuarenta kilómetros al sur de la capital, el coronel constitucionalista R. V. Castro había derrotado a Ignacio Arenas, que estaba acantonado en el rancho El Cocedor, y lo hizo replegarse a territorio potosino. ${ }^{19}$ Todo ese tiempo el gobierno había venido batiendo "bandoleros", que asolaban pueblos en diversas regiones, pese a que muchos rebeldes se habían amnistiado, como ocurrió con Trinidad

14 Loc. cit.

15 AHEA, Reportes Consulares, caja 4, expediente 92. Aguascalientes, 4 de mayo de 1916

16 "Manuscrito de Eleuterio...", pp. 99 y 100. Véase, igualmente, Correa Carrillo, Samuel, 50 años de historia de Ferez, 1900-1950, Jerez, Zacatecas, Publicaciones Gonber, 1997, p. 92. El profesor Correa ha recogido varios testimonios jerezanos al respecto, como el de don Félix Mejía: "Desgraciadamente los carrancistas se convirtieron en azote de los campesinos, con el pretexto de la persecución llegaban a humildes viviendas y hacían un saqueo total, tanta era su osadía, que registraban hasta el último nudo de la costura de los vestidos de las mujeres".

17 AHEA, Reportes Consulares, caja 4, expediente 99, Aguascalientes, 22 julio de 1916.

18 La Voz de Zacatecas, Zacatecas, núm. 65, 11 de agosto de 1916.

19 La Voz de Zacatecas, Zacatecas, núm. 68, 15 de agosto de 1916. 
Este libro forma parte del acervo de la Biblioteca Jurídica Virtual del Instituto de Investigaciones Jurídicas de la UNAM

Cervantes. En agosto Santos Bañuelos, el activo, carismático y aferrado villista, fue alevosamente ultimado en Ciénega Grande, Jalisco, aprovechando que algunos "amigos" lo habían embriagado a propósito en un comelitón. ${ }^{20}$ Lo habían invitado a comer y le llenaron la barriga de plomo. Hecho digno de todo un corrido, sí señor.

Resulta absolutamente comprensible que la prensa de la Capital Bizarra resaltara las acciones militares del constitucionalismo, pero es claro que los villistas llegaron a hostilizar varias regiones del estado con acciones de consideración, ${ }^{21}$ tan es así que el general Rómulo Figueroa, tras dejar el cargo de gobernador fue destinado para combatir a los rebeldes en la región de Sombrerete, cuya zona rural era particularmente inestable a mediados del verano. ${ }^{22}$ Muy regular era la eficacia de las expediciones del ejército en la medida en que no se tenían resultados de manera inmediata, pese a la ferocidad con que llevaron a cabo su tarea. ${ }^{23}$ También es cierto que la mortandad ocasionada por el tifo y la escasez de alimentos, entre otras cosas, pesaban sobre las tropas del gobierno porque al parecer hacían falta efectivos para reforzar las acciones de pacificación; mediante varios anuncios en la prensa se solicitaban altas por parte del coronel J. R. Caloca, para la Brigada Cervantes acantonada en el cuartel de Guadalupe, ${ }^{24}$ cuestión que evidentemente tenía que ver con la drástica despoblación de Zacatecas y su región, asunto del que nos ocuparemos más adelante.

El último semestre de 1916 el gobierno constitucionalista desplegaba actividades prácticamente en todo el país en busca de las fuerzas rezagadas de otras facciones. El país hervía. Los carrancistas estaban combatiendo a

20 Barragán Robles, Luis Alfonso, "Personajes de Monte Escobedo en la Revolución”, Zacatecas en Imagen, Zacatecas, 9 de agosto de 2014.

21 La Voz de Zacatecas, Zacatecas, núm. 108, 4 de octubre de 1916. Una entre muchas pruebas de frecuentes asaltos a los trenes en esta coyuntura es el hecho que un Miguel Rocha, vecino de la Ciudad de México, llevaba tiempo pagando un anuncio en La Voz de Zacatecas, donde decía que gratificaría con la nada despreciable suma de $\$ 500.00$ a quien le hiciera el grandísimo favor de devolverle "dos botes de petróleo" conteniendo documentación que le era muy valiosa; los recipientes se habían perdido en un asalto al tren en Estación Camacho, Zacatecas, en el área de Mazapil.

22 La Voz de Zacatecas, núm. 68. Zacatecas, 15 de agosto de 1916.

23 Don Manuel Saldívar describe parte de su viaje de Zacatecas a Torreón a mediados de 1916: “...por la vía íbamos viendo en muchos de los postes del telégrafo a revolucionarios colgados, ya los cuerpos descompuestos y deshaciéndose. Eran villistas. Al darles alcance los carrancistas los ejecutaban y los colgaban para desmoralizar al resto de las tropas de Villa, que entre más se iban acabando y remontándose hacia la frontera. Véase Saldívar Carrillo, Manuel, Memorias de un agrarista zacatecano, Zacatecas, Tribunal Superior de Justicia del estado de Zacatecas, 2003, p. 68.

24 La Voz de Zacatecas, Zacatecas, núm. 108, 4 de octubre de 1916. 
Este libro forma parte del acervo de la Biblioteca Jurídica Virtual del Instituto de Investigaciones Jurídicas de la UNAM

villistas y zapatistas dispersos en los estados de México, Guanajuato, Puebla, San Luis y Nuevo León, ${ }^{25}$ ya sin mencionar a Durango y Chihuahua, bastiones del villismo, marcadamente este último que se encontraba ocupado en esa época por 10,000 hombres del ejército estadounidense - a consecuencia de la expedición punitiva - y otros tantos efectivos de la federación ${ }^{26}$ para combatir al legendario Centauro del Norte. Como resultado de esta campaña nacional se obtuvo en Torreón la rendición de rebeldes, acaecida el 23 de septiembre, de 13 coroneles, 13 tenientes coroneles, 33 mayores, 61 capitanes primeros, 43 capitanes segundos, 44 tenientes y 221 soldados, ante el general J. Isabel Robles. ${ }^{27}$ Por ese tiempo también llegaba a Zacatecas información de que la plaza de Ciudad del Maíz, en San Luis Potosí, había sido recuperada por la Brigada Cepeda, del ejército constitucionalista. ${ }^{28}$

Insistimos en que el medio rural de Zacatecas se veía permanentemente acosado por los "bandoleros" y éstos perseguidos muy de cerca por los constitucionalistas, cuyo número y capacidad se notaban notoriamente insuficientes, de manera que en varias ocasiones eran los propios vecinos civiles quienes se organizaban en su defensa. Moradores de Apozol habían integrado una columna que derrotó a las fuerzas de Ramón Flores, coronel villista, causándole siete bajas y cogiendo 35 prisioneros incluyendo al líder, el que por aclamación popular fue pasado por las armas en Juchipila, junto con sus oficiales, el 11 de septiembre. El entonces gobernador de Zacatecas, general Carlos Plank, al ser consultado sobre la suerte del resto de los prisioneros, ordenó su inmediata ejecución, eso sí, toda vez que hubieran sido debidamente identificados. ${ }^{29}$

Ya desde agosto fueron fusilados en Ojocaliente el "bandolero" Ignacio Arenas y tres de sus hombres, ${ }^{30} \mathrm{y}$ al mes siguiente, cuando los lugareños se reponían de una soberbia tamaliza popular organizada por la guarnición local, para no cerrar en falso, "después de un juicio sumarísimo hoy a las 4 p. m. fue pasado por las armas en el panteón municipal el bandolero Antonio Diosdado...". ${ }^{31}$ En el norte del estado, el "coronel" Julio Méndez había sido hecho prisionero por fuerzas federales en Sain Alto. ${ }^{32}$

25 La Voz de Zacatecas, Zacatecas, núm. 65, 11 de agosto de 1916.

26 Katz, Friederich, Pancho Villa, México, Era, 2007, t. II, pp. 171 y 175.

27 La Voz de Zacatecas, Zacatecas, núm. 102, 26 de septiembre de 1916.

28 La Voz de Zacatecas, Zacatecas, núm. 108, 4 de octubre de 1916.

29 La Voz de Zacatecas, Zacatecas, núm. 95, 16 de septiembre de 1916.

30 La Voz de Zacatecas, Zacatecas, núm. 73, 21 de agosto de 1916.

31 La Voz de Zacatecas, Zacatecas, núm. 91, 12 de septiembre de 1916.

32 La Voz de Zacatecas, Zacatecas, núm. 84, 3 de septiembre de 1916. 
Este libro forma parte del acervo de la Biblioteca Jurídica Virtual del Instituto de Investigaciones Jurídicas de la UNAM

Las zonas urbanas igualmente fueron escenario de acciones rebeldes; el 25 de septiembre fusilaron a Timoteo Zamora y Santiago Arenas, soldados del cuartel de Guadalupe, del regimiento de ametralladoras. Habían desertado llevándose varias armas y sobornado a otros colegas para integrarse a la gavilla del "bandolero" Ramón Díaz. ${ }^{33}$ Por otro lado, en la capital una mujer fue recluida en la cárcel por pretender pagar con moneda villista a una niña que le ayudara con los bultos de su equipaje. Al verse aprehendida, la señora insultó hasta que llenó al policía y al gobierno por igual. ${ }^{34}$ En tales condiciones el gobierno de Zacatecas optó por crear la policía reservada con la intención de detectar posibles espías actuando a favor del enemigo, misma que fue suprimida a comienzos de octubre, lo que tuvo a bien comunicarse a la población con el fin de prevenir abusos. ${ }^{35}$

La prensa local reprodujo a mediados de diciembre un decreto de Carranza ordenando la ejecución en el acto de ladrones y merodeadores, dado en México el 9 de octubre de 1916,36 la víspera de las elecciones al Congreso Constituyente, y al día siguiente se decretaría la suspensión de garantías para reforzar la lucha contra los rezagados de otras facciones en el territorio nacional. ${ }^{37}$ En este contexto de inestabilidad el gobernador Plank se desplazaba en ocasiones a diferentes puntos del estado con el fin de atender cuestiones tanto militares como administrativas ${ }^{38}$ y políticas que incluyeron seguramente asuntos electorales. Porque para nadie era un secreto que el gobernador determinaba en gran parte la identidad de los candidatos al Constituyente, era una práctica que venía de antiguo, desde tiempos de la Constitución de $1857,{ }^{39}$ si no es que antes. Se miraba con tal naturalidad el hecho de que el constitucionalismo delegara en los gobernadores la tarea de seleccionar en la medida de lo posible a los candidatos, que el propio diputado constituyente general Esteban B. Calderón lo expresaba sin ambages en pleno congreso. Consideró que Pedro López y Fernando Moreno habían sido electos espontáneamente como candidatos y seguramente esco-

33 La Voz de Zacatecas, Zacatecas, núm. 102, 26 de septiembre de 1916.

34 La Voz de Zacatecas, Zacatecas, núm. 65, 11 de agosto de 1916.

35 La Voz de Zacatecas, Zacatecas, núm. 108, 4 de octubre de 1916.

36 Periódico Oficial del Estado de Zacatecas, Zacatecas, núm. 25, 16 de diciembre de 1916.

37 La Voz de Zacatecas, Zacatecas, núm. 115, 12 de octubre de 1916.

38 La Voz de Zacatecas, Zacatecas, núm. 114, 11 de octubre de 1916.

39 En las elecciones para el Congreso Constituyente de 1856-1857 fueron los gobernadores quienes designaron en la práctica a los diputados, ante la relativa debilidad de Ignacio Comonfort, y se entiende igualmente que debido a la fortaleza de los gobiernos, jefes y caciques locales después del movimiento revolucionario de Ayutla. Rabasa, Emilio, La Constitución y la dictadura. Estudio sobre la organización política de México, México, Porrúa, 1982, p. 32. 
Este libro forma parte del acervo de la Biblioteca Jurídica Virtual del Instituto de Investigaciones Jurídicas de la UNAM

gidos por el gobernador de Zacatecas que a la sazón era el general Carlos Plank. ${ }^{40}$

\section{HAMBRUNA E INDIGENCIA}

Aun siendo año electoral el agitado 1916, poco podía esperarse de los zacatecanos en cuanto a participación política, dada la extraordinariamente adversa situación que enfrentaban. Desde hacía muchos años la traían pero que muy de malas en materia de despoblación, porque contra lo que pudiera pensarse no toda la crisis demográfica se debía a la Revolución, pues la tendencia a la despoblación del estado y de su capital venía desde las postrimerías del siglo XIX. No por nada se calcula que entre 1893 y 1907 los decesos por tifo y tifoidea en la capital alcanzaron los 26,642 casos. $^{41}$ En todas las poblaciones la gran mayoría de los pocos vecinos que se quedaron eran pobres de solemnidad y estaban muriendo a ritmo acelerado. Con las enfermedades apareció en esa época terrible escasez de subsistencias que ya era más que aguda en 1916. En "Zacatecas mucha gente murió de hambre, aún entre las familias que tenían dinero", y en regiones como las de Jerez, "la gente se lavaba con lechuguilla y se alimentaba con corazón de nopal, mezote de maguey, mezcal y ratas o conejos, cuando tenía suerte de pescarlos". ${ }^{42}$ Los moradores de la capital y los principales municipios eran ya muy pocos en relación con décadas precedentes, muchos habían muerto o huido a otras partes del país o a los Estados Unidos por causa de la guerra, el hambre y la enfermedad, dejando localidades asoladas, como Zacatecas, Jerez y muchas más. ${ }^{43}$

Desde luego que como consecuencia lógica de los recientes procesos de guerra, sobre todo el de la Batalla de Zacatecas de junio de 1914, sobrevinieron condiciones de vida aún más severas, señaladamente en la capital, pero la minería, agricultura y ganadería, tradicionales pilares de la economía, en todo el estado se encontraban prácticamente paralizadas. Para col-

40 Diario de los Debates del Congreso Constituyente 1916-1917, México, UNAM-Instituto Nacional de Estudios Históricos de las Revoluciones de México, 2014, t. I, p. 319.

41 Enciso Contreras, José, Café y nevería Acrópolis, espacios de modernidad y espacios de tradición (Un paseo por la sociedad, el ocio y la cultura urbana del siglo XX en Zacatecas, Zacatecas, Poder Judicial del Estado de Zacatecas-Café Acrópolis-Instituto Zacatecano de Cultura, 2012, p. 49.

42 Manuel Saldívar Carrillo, op. cit., p. 67.

43 "Manuscrito de Eleuterio...", p. 100. Por "el camino a Guadalajara iban muchas familias pues en Jerez no había nada que comer, mi papá dijo nos vamos pero para el norte, no para el sur; otro «día» vendió los bueyes y nos fuimos solos yo y mi papá. En el Paso «Texas» había contratación para trabajar en la vía...”. 
Este libro forma parte del acervo de la Biblioteca Jurídica Virtual del Instituto de Investigaciones Jurídicas de la UNAM

mo, el año de las elecciones al Congreso Constituyente se arrostraba terrible epidemia de tifo y en menor medida otros padecimientos, junto con devastadora hambruna, así que las capas sociales más desfavorecidas, desempleadas y sin posibilidad alguna para abandonar Zacatecas, se convirtieron en nutrido ejército de indigentes malviviendo, cuando no falleciendo de plano, en la otrora opulenta pequeña urbe de cantera, donde ahora deambulaba una:

Plaga de mendigos que continuamente dan el triste espectáculo de su miseria en las calles de la población, implorando la caridad de los transeúntes, y lo que es peor, diseminando por todos los lugares públicos los gérmenes de todas las enfermedades que se albergan por millones en la andrajosa indumentaria de los mendicantes... ${ }^{44}$

Históricamente la dieta de aquellos miserables se componía casi exclusivamente de maíz y frijoles, ${ }^{45}$ productos que al escasear gravemente desde 1913 y durante todo 1914 y 1915, iban aumentando preocupantemente su precio. Fue entonces cuando no sólo comerciantes sino hasta un ejército de hambrientos y desesperados lugareños hubieron de traer masivamente maíz y frijol de Tlaltenango y el Teul, así como víveres, ropa y medicinas desde Jalisco $^{46}$ o desde donde se podía. A comienzos de 1916 los precios de granos y leguminosas estaban "por los cielos" tanto en Aguascalientes como en Zacatecas: un peso y veinte centavos por litro de frijoles, y un peso por el de maíz, resintiéndose cada día mayor escasez sin que hubiera esperanza de cosechas de ningún tipo para el futuro inmediato, ${ }^{47}$ pues 1915 fue un año de muy escasas y tardías lluvias, y heladas tempranas en la región. ${ }^{48}$

Así que a principios de marzo de 1916 los precios seguían subiendo escandalosamente y sin control, valía de 80 a 100 pesos el hectolitro de maíz y entre 150 y 160 el de frijol, y para colmo se preveía que el abastecimiento de estos productos básicos no sería suficiente para los siguientes treinta días. Prevalecía mucha miseria y hambre en el distrito consular de Zacatecas y

44 La Voz de Zacatecas, Zacatecas, núm. 72, 19 de agosto de 1916.

45 Robinson Wright, Marie, Picturesque Mexico, Philadelphia, J. B. Lippincott Company, 1897, pp. 247 y 248.

46 "Manuscrito de Eleuterio...", pp. 96, 97 y 99. "El camino a Guadalajara se veía como se ven las hormigas que se nombran harrieras. Esto fue todo 1915...".

47 AHEA, Reportes Consulares, caja 4, expediente 73. Aguascalientes, 17 de febrero de 1916

48 "Manuscrito de Eleuterio...", p. 98. "Este año no llovió a tiempo, la primer agua cayó el 10 de agosto y sembramos, pero llegó el hielo temprano y no se dio nada...". Véase también Saldívar Carrillo, Manuel, op. cit, p. 67. 
Este libro forma parte del acervo de la Biblioteca Jurídica Virtual del Instituto de Investigaciones Jurídicas de la UNAM

Aguascalientes sin que se tuviera esperanza de mejoría en el corto plazo, según la opinión del cónsul estadounidense Gaston Schmutz. ${ }^{49}$ Muchos intrépidos arrieros improvisados y profesionales, arriesgando el pellejo seguían dedicándose al acarreo de frijol, maíz y arroz, ahora desde lejanas regiones del sur de Jalisco y norte de Colima. ${ }^{50}$ En 1916 apenas 2\% de las tierras cultivables habían sido sembradas en Aguascalientes y en Zacatecas en proporción aún menor, debido principalmente a las numerosas bandas de rebeldes que operaban en el estado y a la escasez de semilla; ${ }^{51}$ algunos agricultores jerezanos, que lograban traerla de buena calidad procedente de los Estados Unidos, no obtuvieron ese año cosecha alguna, "sólo unas cuantas cañitas se dieron", con todo y las copiosas lluvias de ese año. ${ }^{52}$

Con el objetivo de paliar la alarmante situación en la capital, el gobernador Plank entregó al presidente municipal de Zacatecas, el joven ingeniero Julián Adame Alatorre - futuro diputado constituyente-, "gran suma de dinero" para el establecimiento, en colaboración con la iniciativa privada, de un asilo para desamparados que se ubicaría en la cima del cerro de La Bufa, justo en el sitio que ocupara anteriormente el asilo de niños..$^{53} \mathrm{La}$ medida se complementaría con la instalación de comedores para los pobres y adoptando medidas contra el tifo. Sin embargo, los diezmados recursos del gobierno no eran ni con mucho suficientes para enfrentar una situación de ese calibre, pese a que se ejecutaron acciones urgentes para reunir recursos por la vía fiscal. ${ }^{54}$ "Esos días en Zacatecas fueron muy duros también. La gente se mantenía con puras tunas que unos hombres vendían por allí". ${ }^{55}$

Fue por ello que la Comisión Reguladora del Comercio, organismo privado, sumándose a la iniciativa gubernamental contribuyó al mantenimiento del asilo de mendigos en La Bufa. Agustín Lewells, acaudalado comerciante dirigente de dicha Comisión, recibió el permiso para ello por parte del gobernador. El proyecto tenía sus bemoles pues no era fácil que la famé-

49 AHEA, Reportes Consulares, caja 4, expediente 79. Aguascalientes, 6 de marzo de 1916.

50 "Manuscrito de Eleuterio...”, p. 99. Muchas cargas procedían de Unión de Tula y de Autlán de la Grana.

51 AHEA, Reportes Consulares, caja 4, expediente 102. Aguascalientes, 19 de agosto de 1916.

52 Saldívar Carrillo, Manuel, op. cit., p. 67.

53 La Voz de Zacatecas, Zacatecas, núm. 68, 15 de agosto de 1916.

54 La Voz de Zacatecas, Zacatecas, núm. 99, 22 de septiembre de 1916. Se publicó en esta fecha un decreto del gobernador Carlos Plank en que se establecían sanciones con fuertes multas de entre 500 y 5,000 pesos, a quienes no pagaran sus contribuciones, establecidas sobre las fincas rústicas, o sea las haciendas de campo.

55 Saldívar Carrillo, Manuel, op. cit., pp. 67 y 68. 
Este libro forma parte del acervo de la Biblioteca Jurídica Virtual del Instituto de Investigaciones Jurídicas de la UNAM

lica turba de menesterosos tuviera ánimos ni fuerzas para trepar por la empinada cuesta de la montaña, por lo que la policía municipal se encargaría de recoger a los indigentes en las calles y darles una ayudadita para subirlos al cerro, aunque no quedaba claro si el ingreso al asilo sería voluntario, pero el hecho de que hubiera comida en la cima de la montaña era un aliciente de no poca consideración para trepar el cerro.

Se formó también al efecto un comité de damas para la recaudación de fondos a favor de los pobres y la prensa publicó extensa lista de donadores para su causa, entre otros aparecen en ella la primera dama del estado, doña Carlota G. de Plank, que aportó $\$ 50.00$; su marido $\$ 100.00$ y Andrés L. Arteaga - recordemos que también era futuro Constituyente-, entonces secretario de gobierno, tan solo $\$ 10.00 ;{ }^{56}$ con la intención bastaba.

Según la prensa las causas de la mendicidad eran la escasez de trabajo y los altos precios de los artículos de primera necesidad, ${ }^{57}$ lo que también orillaba a numerosos hambrientos lugareños al robo de artículos básicos, ${ }^{58}$ incluso en los mismísimos expendios de la Comisión Reguladora del Comercio, artículos con los que más tarde se especulaba en el mercado negro. En este tipo de robos ordinariamente estaban involucrados algunos empleados de las propias negociaciones. ${ }^{59}$ En la vecina Aguascalientes las condiciones eran parecidas en ese sentido, rebeldes y ladrones comunes prácticamente mataban por comida, ${ }^{60} \mathrm{y}$ tan sólo en la primera semana de julio murieron 389 personas por inanición. ${ }^{61}$

La situación era ciertamente apremiante; en un periódico chihuahuense se informó que la colonia de zacatecanos avecindados en la ciudad de Chihuahua, organizados en el denominado Comité Zacatecano de Auxilios, había estado recolectando fondos para dar asistencia a sus paisanos de

$56 \quad$ La Voz de Zacatecas, Zacatecas, núm. 95, 16 de septiembre de 1916.

57 La Voz de Zacatecas, Zacatecas, núm. 72, 19 de agosto de 1916.

58 Sir James Cadwell, vicecónsul británico en Zacatecas, esa mañana informaba telefónicamente a su colega estadounidense en Aguascalientes, que las condiciones en Zacatecas eran similares a las de Aguascalientes, con el añadido de los frecuentes robos perpetrados por bandidos y peones. Cfr. AHEA, Reportes Consulares, caja 4, expediente 76. El cónsul Gaston Schmutz al secretario de estado de los Estados Unidos. Aguascalientes, 24 de febrero de 1916.

59 La Voz de Zacatecas, Zacatecas, núm. 103, 27 de septiembre de 1916.

60 AHEA, Reportes Consulares, caja 4, expediente 99. Aguascalientes, 29 de julio de 1916. El cónsul Hillarie Berlier reportaba el dramático asalto de una banda, cuyos miembros asesinaron a un pobre hombre que transportaba tres costales de maíz para sembrar en el rancho de San Gerónimo, propiedad un doctor Rizo.

61 AHEA, Reportes Consulares, caja 4, expediente 96. Aguascalientes, 8 de julio de 1916. 
Este libro forma parte del acervo de la Biblioteca Jurídica Virtual del Instituto de Investigaciones Jurídicas de la UNAM

la capital de Zacatecas, quienes "están sufriendo grandemente por la falta de medios de subsistencia y por la epidemia de tifo que allí mismo se ha desarrollado". ${ }^{62}$ Por otra parte, en noviembre de ese mismo año, Pedro López — viejo masón escocés y más tarde frustrado diputado constituyente-, junto con otros ciudadanos notables, integraba en la Ciudad México la llamada Junta Central Zacatecana de Auxilios, cuya finalidad era el recabar fondos para ayudar a los indigentes zacatecanos y a la población afectada por el tifo. ${ }^{63}$ Pero estos esfuerzos encontraban serios obstáculos para realizar sus fines debido ante todo a que la propia inestabilidad militar hacía muy difícil la llegada de víveres procedentes de otros estados. El 10 de septiembre una "gavilla de bandidos" había asaltado el tren al norte de Jimulco, en las inmediaciones de Torreón, y robado a los pasajeros, perdiéndose varias cargas de maíz y harina destinada para Aguascalientes y Zacatecas. ${ }^{64}$ Las lluvias torrenciales que se presentaron ese mismo año, también llegaban a interrumpir intermitentemente las comunicaciones ferroviarias entre Zacatecas y México durante días o semanas, dificultando la asistencia y el envío de ayuda y el traslado de personas; casi no circulaban convoyes de pasajeros, si acaso y con mucha dificultad algunos cargueros entre Zacatecas y Torreón, ${ }^{65}$ ya fuera por inundaciones o por ataques rebeldes ${ }^{66}$ Hacia el sur la situación del ferrocarril era muy parecida debido a las torrenciales lluvias que habían inhabilitado las vías en Querétaro, Irapuato, Silao y León durante las primeras tres semanas de julio. ${ }^{67}$

62 La Voz de Zacatecas, Zacatecas, núm. 102, 26 de septiembre de 1916, y La Voz de Zacatecas, Zacatecas, núm. 104, 28 de septiembre de 1916.

63 Sánchez Tagle, Héctor, op. cit., pp. 390 y 391.

64 AHEA, Reportes Consulares, caja 5, expediente 4. Aguascalientes, 15 de septiembre de 1916. En el episodio no asesinaron a ningún pasajero pero eso sí, para no cerrar en falso raptaron a tres jovencitas. Se reportaban otros asaltos del tren de México a Piedras Negras, en Empalme, Guanajuato, con un saldo de 34 pasajeros asesinados, incluyendo algunas mujeres.

65 Cuando la familia de Manuel Saldívar, exhausta de hambre y miedo, se vio forzada a abandonar su patria "tuvimos que esperar unos días en Zacatecas para poder tomar un tren para el norte, pues no salían todos los días, y sólo salían trenes de carga". Saldívar Carrillo, Manuel, op. cit., p. 67.

66 AHEA, Reportes Consulares, caja 5, expediente 4. Aguascalientes, 15 de septiembre de 1916.

67 AHEA, Reportes Consulares, caja 4, expediente 99. Aguascalientes, 22 de julio de 1916. 
Este libro forma parte del acervo de la Biblioteca Jurídica Virtual del Instituto de Investigaciones Jurídicas de la UNAM

\section{EL TIFO TAMPOCO VOTA}

El viernes 18 de agosto un tren sanitario proveniente de México arribó a la estación de Zacatecas, transportando un equipo compuesto por seis doctores, 14 enfermeras profesionales, medicamentos y otros elementos para combatir el tifo. ${ }^{68}$ Como ya se adelantaba, la terrible epidemia había comenzado a hacer estragos en la ciudad desde febrero de 1916, pero no fue sino hasta seis meses después que el gobierno federal tomaba esta modesta medida al respecto. Poco después, hacia mediados de octubre, la víspera de las elecciones al Congreso Constituyente, el médico responsable de aquella delegación sanitaria afirmó basado en los libros de registro de enfermos, haberse reducido la incidencia del mal en 51\% a ese tiempo. ${ }^{69}$ Aun tomando como cierto el informe del facultativo no podemos, sin embargo, dejar de mencionar que los datos consignados en la prensa lo contradecían, pues seguían revelando gran mortandad en Zacatecas que afectaba a todos los niveles sociales, y algo similar ocurría en San Luis Potosí donde la epidemia causaba "estragos también entre los ricos". ${ }^{70}$

Por otro lado, el tifo y la viruela igualmente se manifestaron con virulencia en Aguascalientes donde igualmente hubo muchos decesos; hasta el gobernador Gregorio Ozuna caería enfermo a partir del 19 de diciembre. ${ }^{71}$ Los estadounidenses que quedaban en esa ciudad a principios del año apenas eran alrededor de 17, o sea que prácticamente todos habían huido. ${ }^{72}$ $\mathrm{Al}$ igual que en Zacatecas, desde comienzos del año la viruela y el tifo aumentaban sin que hubiera intentos visibles por limpiar la ciudad y sus zonas aledañas. A mediados de febrero se reportaban 18 decesos a causa de viruela y 7 por tifo, aunque eran cifras oficiales, proporcionadas por el juzgado civil de Aguascalientes, y se calculaba que esa cantidad sólo era la mitad de las muertes reales a causa de los dos padecimientos. ${ }^{73}$ Las condiciones sanitarias de los hidrocálidos empeoraban día a día y en una sola semana

68 AHEA, Reportes Consulares, caja 4, expediente 102. Aguascalientes, 19 de agosto de 1916.

69 La Voz de Zacatecas, Zacatecas, núm. 115, 12 de octubre de 1916.

70 La Voz de Zacatecas, Zacatecas, núm. 91, 12 de septiembre de 1916.

71 AHEA, Reportes Consulares, caja 5, expediente 18. Aguascalientes, 23 de diciembre de 1916.

72 AHEA, Reportes Consulares, caja 4, expediente 73. Aguascalientes, 4 de febrero de 1916.

73 AHEA, Reportes Consulares, caja 4, expediente 73. Aguascalientes, 17 de febrero de 1916. 
Este libro forma parte del acervo de la Biblioteca Jurídica Virtual del Instituto de Investigaciones Jurídicas de la UNAM

de marzo dicho juzgado civil había reportado 32 muertes por viruela. ${ }^{74} \mathrm{~A}$ mediados de agosto las condiciones sanitarias seguían siendo bastante malas y sin ser atendidas por las autoridades, las calles estaban sucias y las casas infectadas. $\mathrm{Al}$ cierre del mismo mes se reportaron oficialmente 28 decesos por tifo, sumando un total de 197 por la misma causa, ${ }^{75}$ y las defunciones aumentarían en el mes siguiente ${ }^{76}$ cuando se reportaron oficialmente 29 decesos por tifo. ${ }^{77}$ La tendencia se mantendría durante el mes de las elecciones al constituyente ${ }^{78} \mathrm{y}$ hasta cerrar el año. ${ }^{79}$

En la ciudad de Durango las epidemias de tifo y gripe más severas se agudizarían hasta 1918, causando gran mortandad.80

Los gérmenes causantes del tifo son organismos que poseen pasmosa corología en la que intervienen insectos, principalmente piojos, que actúan como vectores muy eficientes. ${ }^{81}$ Junto con las pulgas constituyeron plaga endémica en México y encontraron condiciones propicias en este y muchos periodos de la historia de Zacatecas. La convivencia entre animales domésticos y humanos en la ciudad y desde luego en las zonas rurales, solamente fue vista tardíamente como un problema grave de salud por los higienistas del siglo XIX, por lo que las estrategias de higiene dejaban mucho que desear en el primer cuarto del XX, lo que ponía a la población a merced de ápteros cuyo ejemplo clásico sería el piojo.

Según textos científicos de la época el clima frío como el de la ciudad de Zacatecas debía inhibir el desarrollo de este tipo de plagas, pero investigaciones los habían llevado a determinar que las costumbres de la población como el poco o nulo aseo personal y mucho abrigo, tendía a provocar el aumento de piojos e inclusive ser causa de una plaga. Esto sin mencionar

74 AHEA, Reportes Consulares, caja 4, expediente 79. Aguascalientes, 6 de marzo de 1916.

75 AHEA, Reportes Consulares, caja 4, expediente 102. Aguascalientes, 19 de agosto de 1916.

76 AHEA, Reportes Consulares, caja 5, expediente 2. Aguascalientes, 2 de septiembre de 1916.

77 AHEA, Reportes Consulares, caja 5, expediente 4. Aguascalientes, 15 de septiembre de 1916.

78 AHEA, Reportes Consulares, caja 5, expediente 9. Aguascalientes, 21 de octubre de 1916.

79 AHEA, Reportes Consulares, caja 5, expediente 18. Aguascalientes, 23 de diciembre de 1916.

80 Lozoya Cigarroa, Manuel, Historia mínima de Durango, Durango, Ediciones Durango, 1995, p. 388.

81 Harant, Herve y Delage, Alix, La epidemiología, México, Fondo de Cultura Económica, 1986 , p. 52 y ss. 
Este libro forma parte del acervo de la Biblioteca Jurídica Virtual del Instituto de Investigaciones Jurídicas de la UNAM

que el ferrocarril y el intenso trasiego de tropas y caballada en tiempos de guerra, contribuyeron a la tremenda diseminación de estos vectores. ${ }^{82}$

La enfermedad se desarrolló de tal manera que miembros de la elite citadina habían sido alcanzados por la infección, como doña Anastacia Aréchiga viuda de Peña, quien murió el 16 de agosto; igual suerte corrió Herón Llamas, de la colonia jerezana en Zacatecas y se reportaron como víctimas del padecimiento, y recluidas en sus respectivos aposentos, a las señoritas Carmen y María Palacios. ${ }^{83}$

También el mes de septiembre fue fatídico. La madrugada del jueves 14 murió de tifo otro reconocido liberal, nada menos que don Lorenzo T. Villaseñor precisamente cuando, como ya hemos visto, estaba muy activo en política, colaborando de lleno con el carrancismo, "dejando un hueco en la intelectualidad zacatecana...". Por la misma razón feneció don Francisco Esparza, hombre liberal de la hacienda de El Carro, que había sido diputado local durante el Porfiriato. La misma suerte corrió J. Refugio Lozano, hijo de don Antonio, propietario del almacén de abarrotes "La Mexicana". Asimismo enfermó Francisco Domínguez, empleado de los juzgados municipales, y el también político ex diputado, Ramón Romero, el padre y su hijo homónimo; el junior había partido ya enfermo para la Ciudad de México donde a poco falleció tras penoso viaje. Enfermaron doña Benita Aréchiga de Iturbe, con domicilio en Interior Alameda, y en la misma circunstancia se encontraba el señor Méndez Calderón, concesionario del cine en el Teatro Calderón. ${ }^{84}$ "Todas las defunciones de que hemos dado cuenta se deben a la epidemia de tifo que día a día siembra luto...". ${ }^{85}$

El de por sí escuálido periodismo local se vio asimismo incluido en la lista de damnificados en la coyuntura. La temible plaga entró a sus oficinas de redacción sin llamar a la puerta, pues se informaba que Francisco Guadiana, jefe de redacción de $\mathrm{La}$ Voz de Zacatecas: "Encuéntrase a las puertas de la muerte luchando contra el tifo"; por su parte Margarita del Río, del de-

82 Martínez Díaz, Hesby, "De insectos y otras alimañas: la higiene pública en la ciudad de Zacatecas durante el porfiriato", en Terán Fuentes, Mariana et al., Al disparo de un cañón. En torno a la Batalla de Zacatecas de 1914: el tiempo, la sociedad, las instituciones, Zacatecas, Instituto Zacatecano de Cultura Ramón López Velarde-Universidad Autónoma de Zacatecas, 2015, p. 242. Los piojos y otros bichos similares encontraron nuevo y portentoso medio para diseminarse por toda la geografía nacional a través del ferrocarril. En la División del Norte, por poner un ejemplo, era proverbial la abundancia de estos insectos que infestaban a la tropa y sus familias. Véase Brondo Witt, Encarnación, La División del Norte (1914) por un testigo presencial, Zacatecas, Tribunal Superior de Justicia del Estado de Zacatecas, 2014, p. 297.

83 La Voz de Zacatecas, Zacatecas, núm. 71, 18 de agosto de 1916.

84 La Voz de Zacatecas, Zacatecas, núm. 115, 12 de octubre de 1916.

85 La Voz de Zacatecas, Zacatecas, núm. 94, 15 de septiembre de 1916. 
Este libro forma parte del acervo de la Biblioteca Jurídica Virtual del Instituto de Investigaciones Jurídicas de la UNAM

partamento de administración del periódico, estaba postrada en cama por la misma causa, y la mecanógrafa Manuela Zapata había caído igualmente enferma con fecha del día anterior. Al "compañero Hurtado", del mismo diario, le había ocurrido una "desgracia", que seguramente era la enfermedad de su señor padre Donaciano Hurtado, ${ }^{86}$ quien moriría por esos días. ${ }^{87}$

En el ocaso del mes patrio habría más defunciones y alivios, así como providenciales anuncios comerciales en la prensa orientados a atacar las causas del tifo: "Único destructor de parásitos. Jabón Anti-Tifo-Formol. Debe usarlo usted con preferencia. Frente a Catedral. Fernando Franco". ${ }^{88}$

Durante el periodo se publicaban en $\mathrm{La}$ Voz de Zacatecas pequeñas orejas, con consejos como: "Báñese usted!", que por lo visto los propios periodistas desoyeron. ${ }^{89}$ A principios de octubre se presentaron más defunciones a causa de la ominosa enfermedad en Zacatecas, entre ellas la de la señorita enfermera Esther Sánchez, que había venido con la delegación sanitaria desde la Ciudad de México y se contagió en el Sanatorio de Tifosos. Otra nota en esta sección denunciaba el desaseo en que permanecían las calles en el centro de la ciudad, así como en Fresnillo. ${ }^{90}$

La despoblación de la capital del estado era evidente, tanto por los que pasaban a mejor vida como por los que huían a otras partes más seguras, como las familias pudientes que habían abandonado la ciudad dos o tres años antes. Sólo tres o cuatro estadounidenses quedaban ya en la ciudad de Zacatecas, donde la comunidad de extranjeros solía ser numerosa en años atrás. ${ }^{91}$ Todo mundo, pobres y ricos, quería huir desesperadamente, siendo los Estados Unidos uno de los destinos preferidos. Las familias menos pobres vendían todo lo que podían, ganado, muebles, hasta tierras de labor y su casa para desaparecer en masa del dantesco escenario zacatecano, tal como lo narra Manuel Saldívar:

Por fin logramos salir un día por la mañana a mediados del mes de agosto de 1916. Para creerlo había que ver cómo iba aquel tren, la gente iba colgada por dondequiera. Todo era un desorden completo. Cada carro parecía un panal de abejas o un tasajo cubierto de moscas. Los carros o furgones tenían unas varillas de fierro grandes por debajo y la gente hasta allí ponía unas ta-

86 La Voz de Zacatecas, Zacatecas, núm. 99, 22 de septiembre de 1916.

87 La Voz de Zacatecas, Zacatecas, núm. 99, 22 de septiembre de 1916.

88 La Voz de Zacatecas, Zacatecas, núm. 104, 28 de septiembre de 1916.

89 La Voz de Zacatecas, Zacatecas, núm. 91, 12 de septiembre de 1916.

90 La Voz de Zacatecas, Zacatecas, núm. 114, 11 de octubre de 1916.

91 AHEA, Reportes Consulares, caja 4, expediente 73. Aguascalientes, 4 de febrero de 1916. 
Este libro forma parte del acervo de la Biblioteca Jurídica Virtual del Instituto de Investigaciones Jurídicas de la UNAM

blas atravesadas y se acomodaba como podía, casi arrastrando y viendo pasar la vía a unos 25 centímetros de altura. A nosotros nos tocó en la azotea. Allí no había nada de dónde agarrarse uno, sólo una varilla que estaba en la orilla del carro. Yo por suerte me cogí de la rueda esa que tienen los carros cargueros enfrente para dirigirlos cuando los desconectan. ${ }^{92}$

Cada quien se marchaba aterrorizado para donde podía, como sir James Cadwell, cónsul inglés en Zacatecas, así como otros extranjeros y demás "prominentes mexicanos" que estaban en el mes de agosto viviendo totalmente aislados del mundo en la Hacienda del Saucillo, en el estado de Aguascalientes, en virtud de las deplorables condiciones sanitarias imperantes en la ciudad de Zacatecas, donde en ese tiempo "se presentan sobre 200 decesos al día". ${ }^{93}$

Había muchas razones que explicaban el fenómeno, como la crisis económica y la guerra, pero la plaga contribuyó de manera más significativa a esta tragedia. El siguiente cuadro nos proporciona una idea aproximada de las dimensiones del desastre.

\section{GuAdro 1}

Población de la ciudad de Zacatecas (1828-1950)

\begin{tabular}{|c|c|c|c|}
\hline Año & Población & $\begin{array}{c}\text { Tasa de crecimiento } \\
(\%)\end{array}$ & Anual (\%) \\
\hline 1828 & 15,891 & - & - \\
\hline $1852 *$ & 25,005 & 57 & -7.7 \\
\hline 1857 & 15,427 & -38.3 & 11.5 \\
\hline 1861 & 22,514 & 46 & -1.8 \\
\hline 1877 & 16,000 & -29 & 10.5 \\
\hline 1892 & 41,271 & 158 & 3.8 \\
\hline $1894 * *$ & 44,353 & 7.5 & -5.0 \\
\hline 1895 & 39,912 & -10.0 & -3.54 \\
\hline 1900 & 32,866 & -17.7 & -2.12 \\
\hline 1910 & 25,900 & -21.2 & \\
\hline
\end{tabular}

92 Saldívar Carrillo, Manuel, op. cit., pp. 67 y 68.

93 AHEA, Reportes Consulares, caja 4, expediente 102. 
Este libro forma parte del acervo de la Biblioteca Jurídica Virtual del Instituto de Investigaciones Jurídicas de la UNAM

GuAdro 1 (continuación)

Población de la ciudad de Zacatecas (1828-1950)

\begin{tabular}{|c|c|c|c|}
\hline Año & Población & $\begin{array}{c}\text { Tasa de crecimiento } \\
(\%)\end{array}$ & Anual (\%) \\
\hline $1918^{* * * *}$ & 12,650 & -51.2 & -6.4 \\
\hline 1921 & 15,462 & -40.3 & -3.7 \\
\hline 1930 & 18,800 & 21.6 & 2.4 \\
\hline 1940 & 21,846 & 16.2 & 1.6 \\
\hline 1950 & 24,254 & 11 & 1.1 \\
\hline
\end{tabular}

* La cifra correspondiente a 1852 proviene de Almonte, Juan Nepomuceno Guía de forasteros y repertorio de conocimientos útiles, edición facsimilar, México, Instituto Mora, 2006, p. 224 bis. ** Velasco, Alfonso Luis, Geografia y estadística del Estado de Zacatecas, México, Oficina Tipográfica de la Secretaría de Fomento, 1894, p. 141. Esta cifra se refiere a la población del municipio, no sólo de la capital.

**** Archivo Histórico Municipal de Zacatecas, Censo municipal. Zacatecas, 1918.

Fuentes: Archivo de José Enciso Contreras, Plan que manifiesta el Censo General del Estado Libre de los Zacatecas, con respecto a su población, industria, agrícola y fabril, número de haciendas de campo, ranchos anexos e independientes de ellas; curas, vicarios, clérigos, regulares y casas de beneficencia, Zacatecas, diciembre de 1828; Ruiz Rubiaurre, Antonio et al., Estadísticas históricas de México, t. I, México, Instituto Nacional de Estadística Geografía e Informática-Instituto Nacional de Antropología e Historia, 1985, p. 32.

El fenómeno sería digno de análisis más detallado pero este trabajo tiene otras preocupaciones. De momento concretémonos a decir que desde tiempos de la Guerra de Reforma la población de la ciudad no se había visto tan reducida, es más, en ningún momento de la época independiente se habían registrado cifras tan negativas como en este periodo que además fue electoral. La población de la Bizarra Capital aún tardaría décadas en recuperarse, ${ }^{94}$ y no fue la única región en verse afectada, pues se calcula que entre 1910 y 1920, fallecieron nada menos que dos millones de mexicanos, ya fuera en los campos de batalla, por las hambrunas o bien víctimas de las enfermedades infecciosas. ${ }^{95}$

94 La tragedia poblacional de la ciudad, así como las epidemias como factor coadyuvante, son analizadas en Enciso Contreras, José, Café y Nevería..., cit., pp. 45 y ss.

95 Kumate, Jesús, "La salud pública en México en el siglo XX. Los protagonistas", en Memoria de El Colegio Nacional, México, 2001, p. 82. 
Este libro forma parte del acervo de la Biblioteca Jurídica Virtual del Instituto de Investigaciones Jurídicas de la UNAM

\section{ELECGIONES MUNICIPALES}

Este era el funesto contexto regional que marcaba las elecciones municipales que a nivel nacional convocara el primer jefe, y constituían el primer paso importante para la rearticulación del país desde el punto de vista institucional, en un proceso que culminaría formalmente con la celebración del Congreso Constituyente de Querétaro.

Como ya hemos visto el horno en Zacatecas no estaba para bollos, las secuelas de la guerra civil, hambrunas y plagas fueron tremendas. Mucho entusiasmo que digamos no encontró la convocatoria a nivel local, pero las cosas tenían que hacerse pese a todo, no obstante que el virtual electorado lo constituyera un exiguo grupo de parias tifosos hambrientos, muchos de ellos arrecholados en el lomo del cerro de La Bufa. Las también famélicas columnas editoriales de $\mathrm{La}$ Voz de Zacatecas, que por cierto andando el tiempo tan sólo aparecería muy esporádicamente, no comprendían cabalmente la situación y acusaban de apatía a los grupos políticos locales ante las elecciones municipales:

Los revolucionarios zacatecanos, y en los que sin ser afectos al gobierno actual, tampoco son sus enemigos, la verdad es que no responden ni con mucho al llamado que la revolución por conducto de su Jefe hace a quienes se precien de ser ciudadanos dignos de una república independiente. ${ }^{96}$

Con todo el desgano del mundo los redactores dedicaban muy de vez en cuando una escueta columna editorial llamando a votar a la ciudadanía. ${ }^{97}$ No existe indicio alguno de que se hubieran organizado campañas electorales en el sentido formal al estilo de los viejos tiempos porfirianos, y a juzgar por los datos de la prensa, como era de esperarse, no se advertía ninguna agitación y los grupos políticos tradicionales, normalmente muy activos en otros tiempos y en este tipo de coyunturas se habían marchado hacía tiempo o materialmente se habían venido consumiendo de tifo en sus casas. Al tradicional capital de experiencia política se lo estaba llevando definitivamente la calaca, por eso no sorprende para nada una editorial de $L a$ Voz de Zacatecas vaticinando el fracaso de las elecciones municipales debido a la apatía mostrada tanto por la ciudadanía como por las agrupaciones políticas locales. ${ }^{98}$ No fue sino hasta sólo cuatro días antes de la cita con las urnas que en una

\footnotetext{
96 La Voz de Zacatecas, Zacatecas, núm. 71, 18 de agosto de 1916.

97 La Voz de Zacatecas, Zacatecas, núm. 72, 19 de agosto de 1916.

98 La Voz de Zacatecas, Zacatecas, núm. 78, 26 de agosto de 1916.
} 
Este libro forma parte del acervo de la Biblioteca Jurídica Virtual del Instituto de Investigaciones Jurídicas de la UNAM

nota minúscula y perdida en las últimas páginas del diario se informaba sin mucho entusiasmo y como que no quiere la cosa, que Antonio Chávez Ramírez - masón ex reyista sobreviviente hasta esa fecha mas no por mucho tiempo al hambre y al tifo - había sido postulado como candidato a presidente municipal de la capital. ${ }^{99} \mathrm{~A}$ escasos tres días antes de las elecciones se anunciaba oficialmente en primera plana de $\mathrm{La} \mathrm{Voz}$ que la candidatura de Chávez Ramírez estaba auspiciada por la Asociación Cívica Popular. ${ }^{100}$

La jornada comicial del 3 de septiembre tuvo una participación ciudadana que fue calificada benignamente por la prensa como "regular". Fueron señaladas varias deficiencias en la organización de los comicios y se anticipaba el triunfo del licenciado Fernando Sansalvador sobre su contrincante Chávez Ramírez. ${ }^{101}$ Sin embargo, tres días más tarde no se conocían aún los resultados de las elecciones, especialmente los de la capital, donde ya eran demasiados los días transcurridos para que las cuentas no cuadraran. A tiempo que pasa la verdad que huye y esa fue la razón por la que "algunas personas" se quejaban de fraude y cochupos a favor de Chávez Ramírez, y de que la ACP, que presidía el mismo Chávez, había expulsado a dos de sus miembros por haber firmado un escrito postulando al ingeniero Julián Adame a la presidencia de Zacatecas. Tal parece que el candidato oficial, Chávez, no gozaba de las simpatías de todos y menos de los periodistas, pero prácticamente no tuvo oposición pues su único "contrincante", el licenciado Sansalvador, afirmó haberse dado cuenta de su postulación por la noche del sábado anterior a las elecciones, y que encima consideraba estar impedido para el efecto por la ley electoral. ${ }^{102}$ Pese a todo, el abogado ganó las elecciones a decir de los redactores del diario.

Desde luego que el gobernador Plank no quiso dejar la cuestión electoral a la deriva y tomó providencias designando dos operadores para las elecciones, a los hermanos Pedro y Manuel Canales, originarios de Río Grande, a fin de que recorrieran los municipios de Ojocaliente, Fresnillo, Sombrerete y Nieves, para cuidar del debido ejercicio de las votaciones y "para que ilustraran al pueblo respecto de sus obligaciones", tarea que éstos obviamente habían aceptado con el fin de "ayudar al constitucionalismo". En el informe que los hermanos Canales presentaron a su regreso se contrastaba su desbordado optimismo en relación con la opinión de $L a$ Voz:

99 La Voz de Zacatecas, Zacatecas, núm. 81, 30 de agosto de 1916.

100 Idem.

101 La Voz de Zacatecas, Zacatecas, núm. 85, 5 de septiembre de 1916.

102 La Voz de Zacatecas, Zacatecas, núm. 88, 8 de septiembre de 1916. 
Este libro forma parte del acervo de la Biblioteca Jurídica Virtual del Instituto de Investigaciones Jurídicas de la UNAM

Los trabajos se vieron coronados por el mayor éxito, habiendo instalado las Juntas de Administración Civil en las partes donde no las había, o bien designando al Presidente municipal y regidores, todo de acuerdo con la voluntad de los vecinos. Que solamente en Fresnillo pudieron notar cierta apatía e indiferencia por las elecciones. ${ }^{103}$

En otros términos que los hermanitos fueron designando a nombre del ejecutivo del estado los integrantes de las juntas de administración que sustituían provisionalmente a los ayuntamientos, como había sucedido en la capital. Agregaron los Canales que las municipalidades con participación más entusiasta habían sido Sombrerete, Río Grande y Nieves, lugar este último donde se presentó cierto retraso en el proceso electoral por estar muy reciente el homicidio del presidente municipal a manos de "unos seis bandoleros". Asimismo dieron cuenta de que en su viaje notaron que se había sembrado "en todas partes... esperándose cosechas magníficas". ${ }^{104}$ Decían incluso que muchos labradores habían preferido comer nopales para sembrar el poco maíz que tenían en su haber. Pese a todos los estragos, el fuerte temporal hacía mantener esperanzas a propios y extraños de buenas cosechas de maíz y frijol, esperanzas que no se cumplieron, como lo hemos visto en el apartado anterior. ${ }^{105}$

El norte del estado según estos informantes estaba pacificado y las familias que se habían ausentado durante las refriegas revolucionarias habían regresado a sus lugares de origen y estaban — ¡cómo no! - muy agradecidas con el gobernador Plank, especialmente en Sombrerete y Río Grande, donde el anterior gobernador, o sea Figueroa, no había sido capaz de imponer la paz. En cambio, Plank había instalado en cada uno de esos lugares una guarnición de 24 soldados y restablecido todos los servicios. ${ }^{106}$

No fue sino hasta el domingo 10 de septiembre que por fin se reunió el Colegio Electoral de Zacatecas para realizar el cómputo de los votos, y según la prensa seguramente se solicitaría la nulidad en las elecciones de la capital porque el licenciado Sansalvador - al parecer el auténtico vencedor de los comicios - no había renunciado en tiempo al cargo público que desempeñaba, "y por ser relativamente escaso el número de votos a favor del señor Chávez Ramírez". ${ }^{107}$ Nuevo prosélito de los liberales locales, el joven

103 La Voz de Zacatecas, Zacatecas, núm. 89, 9 de septiembre de 1916.

104 Idem.

105 AHEA, Reportes Consulares, caja 4, expediente 101. Aguascalientes, 12 de agosto de 1916.

106 La Voz de Zacatecas, Zacatecas, núm. 89, 9 de septiembre de 1916.

107 La Voz de Zacatecas, Zacatecas, núm. 91, 12 de septiembre de 1916. 
Este libro forma parte del acervo de la Biblioteca Jurídica Virtual del Instituto de Investigaciones Jurídicas de la UNAM

profesor Úrsulo A. García, destacado miembro de la ACP, publicó en La Voz de Zacatecas una carta en que defendía la participación de su agrupación y "la legalidad y pureza" de su campaña electoral. Se quejaba de las calumnias recibidas por parte de "políticos de la vieja escuela" y afirmaba que su agrupación había pretendido que las nuevas ideas se abrieran paso en "el ambiente conservador que aún nos envuelve". ${ }^{108}$

También funcionaba en esas fechas un colegio electoral en Fresnillo que estaba por revisar las cédulas de las elecciones, con dos semanas de posterioridad a los comicios ${ }^{109}$, y no fue sino tres semanas después que se informaba que las votaciones municipales de Zacatecas por fin habían sido sancionadas y se publicaron los nombres de titulares y suplentes vencedores de varios ayuntamientos más: Zacatecas, Antonio Chávez Ramírez; Concepción del Oro, Jorge Ortiz; Fresnillo, José Manuel Pro; Guadalupe, Carlos García y como 4o. regidor Pedro Adame; Morelos, Arcadio Gurrola y el síndico 1 o. era Félix Bañuelos, hermano del difunto Santos, asesinado por villista; Villa de Cos, Ezequiel A. Ozuna. ${ }^{110}$ Todavía con más dilación y muy graneados se fueron dando datos relativos a los resultados de elecciones en otros municipios: Pinos, Ignacio Velasco, y Calera, Mateo García.

Hasta ese momento no aparece en cargos edilicios ninguno de los que después serían candidatos al Congreso Constituyente, recordemos que Julián Adame, por ejemplo, era presidente municipal saliente de la capital, ${ }^{111}$ pero tenía un futuro bastante halagüeño. Pausadamente fluían más datos de las elecciones: Mazapil, Juan M. Hernández; Pánuco, Feliciano Cuevas. ${ }^{112}$ Y más de un mes después de la fecha electoral señalada en la convocatoria del primer jefe, en algunas poblaciones de Zacatecas no se habían realizado elecciones municipales, por lo que el gobernador había girado una circular con el fin de organizarlas. ${ }^{113}$

\section{Elecciones al Congreso Gonstituyente}

A finales de agosto de 1916, en pleno apogeo de la plaga, se tuvo conocimiento en la ciudad de las intenciones del primer jefe de convocar a un Congreso Constituyente. La información llegó a Zacatecas de rebote, pues fue tomada

\footnotetext{
108 La Voz de Zacatecas, Zacatecas, núm. 91, 12 de septiembre de 1916.

109 La Voz de Zacatecas, Zacatecas, núm. 97, 20 de septiembre de 1916.

110 La Voz de Zacatecas, Zacatecas, núm. 102, 26 de septiembre de 1916.

111 La Voz de Zacatecas, Zacatecas, núm. 103, 27 de septiembre de 1916.

112 La Voz de Zacatecas, Zacatecas, núm. 104, 28 de septiembre de 1916.

113 La Voz de Zacatecas, Zacatecas, núm. 114, 11 de octubre de 1916.
} 
Este libro forma parte del acervo de la Biblioteca Jurídica Virtual del Instituto de Investigaciones Jurídicas de la UNAM

por la redacción de $L a$ Voz, del periódico El Pueblo, de la Ciudad de México. Se dijo tener noticias de que Carranza haría pública una convocatoria para elecciones al congreso, a celebrarse después de las elecciones municipales.

"El Congreso Constituyente se ocupará en lo absoluto según se ha dicho, en discutir y sancionar, en su caso, todos aquellos decretos y proyectos de ley, así como reformas a la Constitución que el C. Primer Jefe ha dictado desde el principio del movimiento revolucionario". ${ }^{114}$

Ya en la última semana de septiembre, en primera plana formalmente se anunciaba la convocatoria para las elecciones al constituyente, aclarando en una cabeza que:

Instalado el H. Cuerpo, el C. Primer Jefe presentará el proyecto de Constitución Reformada, para que se discuta, apruebe o modifique. Terminados los trabajos el Congreso se disolverá y verificadas las elecciones de los Poderes Federales e instalado el Congreso General, el Sr. Carranza entregará el Poder. ${ }^{115}$

Si la aparente "abulia" de los grupos políticos fue evidente en el proceso electoral municipal, en las elecciones federales la cosa parecía ser peor; en los números de $L a$ Voz inmediatos al anuncio de la convocatoria no se comentaba absolutamente nada sobre el trascendental asunto, si bien hay que tomar en cuenta que la colección del diario que hemos consultado no se conserva completa, pero son pocos los ejemplares faltantes. ${ }^{116}$ Es más que probable que en un ambiente social tan marchito en lo último que se pensara era en convencer a una piojosa, enferma y desfallecida opinión pública de las bondades de un congreso constituyente, había que hacer las elecciones y punto. Es por ello que con pocas excepciones los gobernadores de los estados constitucionalistas desempeñaron papel protagónico en la selección de candidatos y en la organización de los procesos electorales tanto municipales como para el constituyente, incluso llegando a suplantar a la Secretaría de Gobernación, encargada legalmente del asunto. ${ }^{117}$

En Zacatecas la intervención de los gobernadores Carlos Plank y en menor medida Enrique Estrada se explicaría además como sustituto del exangüe impulso de los políticos locales. Por regla general los gobernadores pusieron a quien quisieron en las candidaturas, aunque más bien debería decirse que, por lo menos en Zacatecas, se encargaron directamente

114 La Voz de Zacatecas, Zacatecas, núm. 81, 30 de agosto de 1916.

115 La Voz de Zacatecas, Zacatecas, núm. 99, 22 de septiembre de 1916.

116 La Voz de Zacatecas, Zacatecas, núm. 103, 27 de septiembre de 1916.

117 Palavicini, Félix F., Historia de la Constitución de 1917, t. I, UNAM-INEHRM, 2014, p. 57. 
Este libro forma parte del acervo de la Biblioteca Jurídica Virtual del Instituto de Investigaciones Jurídicas de la UNAM

de las negociaciones pertinentes para armar las fórmulas en un estrecho margen de premura, penuria y emergencia social. A diferencia de Aguascalientes donde el obispo, representante de los grupos católicos conservadores -única fuerza supérstite de la hecatombe revolucionaria- parecía tener la influencia suficiente para designar debajo del agua a los candidatos a gobernador por el supuesto partido liberal, ${ }^{118}$ en Zacatecas el proceso estaba influido por los tradicionales grupos de masones comecuras, aunque bastante mermados, como ya hemos visto. Anotábamos por ejemplo que don Lorenzo T. Villaseñor, el viejo profesor del Instituto de Ciencias, del que había sido su director en 1911, ${ }^{119}$ quiso ocupar el vacío dejado por la muerte o inactividad de los personajes que, a través de las logias habían representado al liberalismo local durante toda una época - como fueron el doctor Tomás Lorck y el licenciado Benito Garza, muertos poco antes-- y en la primavera de 1916, bajo el gobierno del general Planck — que iniciara el 22 de abril de ese año - conducía los esfuerzos de los liberales por mantener creciente cercanía con el constitucionalismo, iniciada a su vez por el general Jesús Aréchiga y Luis J. Salce, a principios de $1914 .{ }^{120}$ El farmacéutico ya había presidido la Junta de Administración Municipal de Zacatecas desde 1915,121 y también coordinó los trabajos de la Junta Colectora de Fondos, con los que se pretendía coadyuvar con el gobernador a fin de ir solventando las necesidades del estado, referentes a los daños causados por el movimiento armado, resolver la escasez de agua potable y combatir la ominosa epidemia. Su labor se vería truncada por el tifo, porque como ya se adelantaba, don Lorenzo moriría a mediados de septiembre de 1916.

Junto con Villaseñor y con el mismo propósito de integrarse al carrancismo, participaron viejos liberales zacatecanos que llegaron a estar en posiciones políticas encontradas durante los quince años previos, como el licenciado Rafael Simoní Castelvi, que ya había sido designado juez municipal

118 AHEA, Reportes Consulares, caja 5, expediente 30. San Antonio, Texas, 26 de octubre de 1916. "Siempre hay el sentimiento de que sucederá algo. La política de este estado está en manos del partido clerical. Estoy enterado de que el presente gobernador del estado, aunque es el candidato oficial de Carranza, realmente fue el candidato del obispo de Aguascalientes".

119 Primer centenario del Instituto de Ciencias. Álbum histórico-gráfico, Zacatecas, Imprenta del Periódico Orientación, 1932.

120 Zalce y Rodríguez, Luis J., Apuntes para la historia de la masonería en México (De mis lecturas y mis recuerdos), tomo segundo, México, Talleres Tipográficos de la Penitenciaría del Distrito Federal, 1950, pp. 52 y 53.

121 Archivo Histórico Municipal de Zacatecas, sección Actas de Cabildo, libro 9, 1915 1916, f. 2. (En adelante este repositorio será referenciado por sus siglas AHMZ, seguido de la sección y expediente, en su caso). 
Este libro forma parte del acervo de la Biblioteca Jurídica Virtual del Instituto de Investigaciones Jurídicas de la UNAM

en 1915 por el gobernador Figueroa, y en septiembre de 1916 fungía síndico del ayuntamiento de Zacatecas. ${ }^{122}$ Pese a su pasado porfirista, para disimularlo sería nominado como candidato suplente a diputado constituyente por el distrito de la capital, obteniendo más votos que el titular, el ingeniero Adolfo Villaseñor.

Como ya vimos, el antiguo reyista del RNM, Antonio Chávez Ramírez, del viejo partido liberal de tiempos porfirianos, se postuló en septiembre de 1916 para presidente municipal de Zacatecas, contando con el apoyo de la ACP, donde descollaba el joven profesor Ursulo A. García, masón de tendencias anarquistas. ${ }^{123}$ Chávez murió en Zacatecas en noviembre de 1916, habiendo ganado en circunstancias poco claras las elecciones municipales, ${ }^{124}$ así como también las del congreso constituyente en las que fue postulado como candidato suplente por el distrito de Ciudad García. La muerte le puso zancadilla. El hubiera no existe, de acuerdo, pero de no haber muerto, probablemente Chávez hubiera ocupado un escaño porque las credenciales del titular Fernando Moreno fueron rechazadas en Querétaro.

Por otro lado, el general Enrique Estrada fue nombrado por Venustiano Carranza gobernador de Zacatecas el 24 de agosto de 1916, por lo que algo, aunque poco, habría tenido que ver en la organización definitiva de las elecciones al congreso. Estrada había combatido bajo las órdenes de Álvaro Obregón en la División del Noroeste, de tal manera que podía identificársele en ese tiempo como adicto a esa corriente, ${ }^{125}$ pues no se explica de otra manera el nombramiento como candidato al constituyente del aguerrido coronel coahuilense Juan Aguirre Escobar, también obregonista de hueso colorado. A su vez, Roque Estrada, hermano de Enrique, también formaba parte del obregonismo desde 1915. ${ }^{126}$

Volviendo a nuestro relato podemos decir que al llamado de la convocatoria electoral acudieron organizándose en nuevos y viejos partidos por todo el país, numerosos grupos políticos de la mayoría de los estados de la federación. La denominación más taquillera para los partidos fue la de "liberal", tal y como se llamaba el que organizara el propio Carranza: el Partido Liberal Constitucionalista. ${ }^{127}$ Aunque es obvio que en cada entidad federativa

122 Sánchez Tagle, Héctor, op. cit., pp. 347 y 350.

123 Ibidem, p. 349.

124 Ibidem, p. 394.

125 Ibidem, p. 393.

126 Ramos Dávila, Roberto, Roque Estrada Reynoso, precursor y actor de la revolución, Zacatecas, Ayuntamiento de Zacatecas-Ayuntamiento de Moyahua de Estrada, s. s. e., pp. 33 y ss.

127 Palavicini, Félix F., op. cit., p. 57. 
Este libro forma parte del acervo de la Biblioteca Jurídica Virtual del Instituto de Investigaciones Jurídicas de la UNAM

imperaron situaciones diferentes, en muchas de ellas la atención puesta en los comicios fue menos que regular. En la prensa de Zacatecas, por ejemplo, sólo apareció inicialmente una muy breve nota en la que se condenaban acremente los asaltos villistas en la capital de Chihuahua ${ }^{128}$ y, en segundo lugar, se ponderaba el decreto de Carranza convocando a las elecciones al constituyente; el autor citaba opiniones de Emilio Rabasa y Francisco Bulnes, así como las alocuciones parlamentarias de Helguero. ${ }^{129} \mathrm{Y}$ no fue sino a finales de septiembre, tres semanas antes de los comicios, que se publicó un solitario manifiesto:

Al pueblo zacatecano. La Agrupación Cívica Popular, teniendo en cuenta la honradez y patriotismo que caracterizan a los GG. Ingeniero Adolfo Villaseñor y Rafael Simoní Castelvi, los propone como candidatos para Diputados propietario y suplente respectivamente, por el PRIMER DISTRITO ELECTORAL, que comprende las Municipalidades de Zacatecas, Vetagrande, Pánuco, Calera y Morelos, siendo la cabecera Zacatecas, en las elecciones al Congreso Constituyente que se efectuarán el 22 del próximo mes de octubre. ${ }^{130}$

En la misma fecha se informaba que igualmente se postularon por parte de la misma agrupación a los ingenieros Julián Adame y Rodolfo Muñoz, por el segundo distrito que abarcaba a Guadalupe, Minillas, San José de la Isla, San Pedro Piedra Gorda, San Francisco de los Adame y Ojocaliente, con cabecera en este último. ${ }^{131}$

Si la apatía caracterizaba el ambiente político local, a nivel nacional las cosas no parecían tan calmas, las expresiones del carrancismo movían sus piezas con miras a las elecciones de octubre, cosa que se constata con el hecho de que, como se supo en la capital del estado, se dio la renuncia de Félix F. Palavicini, como encargado del despacho de la Secretaría de Instrucción Pública y Bellas Artes; en su lugar quedaba como interino Alfonso Cravioto. ${ }^{132}$

En Zacatecas, otros destacados abogados liberales arechiguistas, con antecedente porfirista serían nombrados ese mismo año en puestos de la ad-

128 Villa ocupó parte de la ciudad de Chihuahua el 16 de septiembre de ese año, hecho que ponía sumamente nerviosos a los constitucionalistas. Cfr. Katz, Friederich, Pancho Villa, México, Era, 2007, t. II, pp. 176 y ss. Debe recordarse que la invasión a la población estadounidense de Columbus, en marzo de ese año, desató un conflicto internacional de entre ambos países.

129 La Voz de Zacatecas, Zacatecas, núm. 104, 28 de septiembre de 1916.

130 Idem.

131 Idem.

132 La Voz de Zacatecas, Zacatecas, núm. 108, 4 de octubre de 1916. 
Este libro forma parte del acervo de la Biblioteca Jurídica Virtual del Instituto de Investigaciones Jurídicas de la UNAM

ministración federal, como los licenciados Pedro López y Fernando Moreno, ahora enquistados en la administración nacional de los ferrocarriles del constitucionalismo, a donde serían llamados a su tiempo para participar en las elecciones para diputados al Constituyente de Querétaro. La presencia en las listas de candidatos de estos dos veteranos abogados que vivían ya en la Ciudad de México, muestra cómo el carrancismo estaba integrando en cargos de relativa importancia a los escasos restos de la vieja guardia liberal arechiguista, desde antes de 1916. Neftalí Amador es otro ejemplo de esta relación de la vieja guardia con el primer jefe, quien ya había designado como subsecretario de relaciones al hijo del historiador Elías Amador, también prominente masón escocés y diplomático, quien muriera muy joven el 10 de agosto del año de las elecciones y del tifo. ${ }^{133}$

Diez días antes de los comicios se insertó en $L a$ Voz de Zacatecas una nota editorial obtenida del periódico El Occidental, de Guadalajara, intitulada "El Congreso Constituyente y el Problema Agrario", en la que se criticaba el sistema de propiedad establecido en la Constitución de 1857, calificándolo como insuficiente para resolver los problemas del campo. ${ }^{134} \mathrm{Y}$ más valía tarde que nunca, por fin apareció un anuncio sobre la cuestión electoral, aunque fuera el mero día de las votaciones:

¡A Votar! Hoy es el día en que la Revolución ha convocado al pueblo a elecciones para diputado al Congreso Constituyente, afirma su fruto e inscribe en la Carta Magna de nuestra República las reformas que habrán de adaptar las leyes del país a las condiciones y necesidades del pueblo mexicano. ¡Ciudadanos a votar! ${ }^{135}$

133 La Voz de Zacatecas, Zacatecas, núm. 68, 15 de agosto de 1916. Aparece en este número la nota sobre Neftalí Amador, quien falleció el 10 de agosto de 1916 cuando se desempeñaba como subsecretario de relaciones exteriores. Tras el deceso se le rindieron honores fúnebres encabezados por el primer jefe. "Eminente liberal, hasta alcanzar en la masonería el grado $33^{\circ}$ ". Murió a los 43 años y nació en Villa de Cos, siendo hijo del historiador Elías Amador y de doña María de Jesús Ruiz de Chávez. Egresó como abogado del Instituto de Ciencias de Zacatecas, de donde fue secretario. Radicado en Ciudad Juárez, se incorporó al antirreeleccionismo y fue cercano a Francisco I. Madero. Asistió como delegado a la convención celebrada en el teatro Hidalgo, de la Ciudad de México, en la que el Partido Constitucional Progresista eligió sus candidatos a la presidencia y vicepresidencia de la república en 1910. Permanecía en Ciudad Juárez con su padre durante la Decena Trágica. Se incorporó al grupo de Venustiano Carranza como consultor y sirvió como subsecretario de gobernación al gobierno constitucionalista instalado en Veracruz. Fue agente confidencial del gobierno de México en Washington y murió en Querétaro.

134 La Voz de Zacatecas, Zacatecas, núm. 115, 12 de octubre de 1916.

135 La Voz de Zacatecas, Zacatecas, 22 de octubre de 1916. 
Este libro forma parte del acervo de la Biblioteca Jurídica Virtual del Instituto de Investigaciones Jurídicas de la UNAM

El mismo día de los comicios Julián Adame, pieza fuerte y consentida del constitucionalismo local, no parecía estar muy preocupado por las votaciones, con la tranquilidad de quien se siente asegurado en el cargo actuó, junto con el general Rómulo Figueroa, como testigo en el matrimonio del teniente coronel Alberto Berber con la señorita Domitila Rubalcava. ${ }^{136}$ Y el mismo día de la boda se anunció el restablecimiento del Tribunal Superior de Justicia, que ahora tenía como presidente al licenciado Adolfo Enciso Álvarez y como magistrados a Joaquín Garaycoechea, Rafael Simoní Castelvi, Horacio Rodríguez Real y Rafael Morantes.

Asimismo hubo movimientos en el ejecutivo del estado, mediante los cuales pasaron funcionarios al tribunal de justicia, y Julián Adame, alcalde saliente, fue designado director del ICZ. ${ }^{137}$ Don Julián fue personaje destacado en este periodo por su juventud y por su debut en las lides políticas y administrativas; era recién egresado como ingeniero topógrafo de la Escuela Nacional de Ingenieros y rápidamente se convirtió en el golden boy del carrancismo local, especialmente de los generales Carlos Planck y Rómulo Figueroa; nada más al llegar Planck a la silla, lo nombró presidente municipal de la capital en mayo de 1916, recibiendo la encomienda de reconstruir el Palacio Federal destruido durante la reciente Batalla de Zacatecas, ${ }^{138}$ cosa que por cierto nunca se llevó a cabo, seguramente por el agobio financiero. En febrero de 1916 don Julián estuvo asimismo a cargo de la Comisión Local Agraria, a la que se aplicó con denuedo, como lo demuestra la elaboración de un manual a propósito del reparto, intitulado "Instrucciones de carácter provisional", en el que se orientaba a los presidentes municipales para que coadyuvaran en los trabajos agrarios. ${ }^{139}$ Sin embargo, su actuación más destacada que terminó por afianzarlo como parte necesaria en el equipo político que iría a Querétaro, fue su eficaz desempeño como presidente municipal en la lucha contra el tifo. ${ }^{140}$ Su pariente Pedro fue parte del ayuntamiento de Guadalupe en 1916, ${ }^{141}$ y en octubre, como ya vimos, el ingeniero fue designado director del Instituto de Ciencias en sustitución del

136 La Voz de Zacatecas, Zacatecas, 22 de octubre de 1916. Entre otras personas asistieron doña Luz Elías de Adame, Sofía Valenzuela de Enciso Álvarez, María de Jesús Arellano de Figueroa, Angelita Lorck, Concha y Sofía Enciso Álvarez, y José Campero, director de una agonizante Voz de Zacatecas.

137 La Voz de Zacatecas, Zacatecas, 22 de octubre de 1916.

138 Héctor Sánchez Tagle, op. cit., pp. 347 y 348.

139 Ibidem, p. 360.

140 AHMZ, Ayuntamiento I, ramo Sanidad, caja 1, expediente 20. Zacatecas, 6 de septiembre de 2016.

141 Sánchez Tagle, Héctor, op. cit., p. 350. 
Este libro forma parte del acervo de la Biblioteca Jurídica Virtual del Instituto de Investigaciones Jurídicas de la UNAM

licenciado Adolfo Enciso Álvarez, quien pasó a su vez a ocupar la presidencia del Supremo Tribunal de Justicia del Estado.

Regresando a nuestras elecciones, la evidente pasividad social también era explicable entre otras razones por la lentitud con que el gobierno de Zacatecas hizo llegar a la ciudadanía la información oficial al respecto. La Ley Electoral para la Formación del Congreso Constituyente - dada en la Ciudad de México, el 20 de septiembre de 1916-142 comenzó a publicarse por entregas en Zacatecas el 14 de octubre, es decir, apenas una semana antes de la jornada electoral, la segunda y tercera partes se hicieron públicas un día antes de los comicios y ${ }^{143}$ la tercera salió a la luz pública una semana después de celebrados éstos. ${ }^{144}$ También hubo una edición limitada de la ley que se dio a conocer mediante decreto de Carlos Planck del 30 de septiembre de ese año, por lo que el folleto seguramente fue impreso apresuradamente a principios de octubre en la imprenta de Nazario Espinosa.

Sostiene Gabriel Ferrer que las elecciones celebradas el 22 de octubre de 1916 fueron relativamente ordenadas a nivel nacional, habiéndose postulado en los distintos distritos entre dos y tres candidatos, aunque hubo de cuatro y de cinco aspirantes. ¡En uno de Puebla se registraron 31 propietarios y 44 suplentes! En ningún caso se presentó algún altercado en que llegara la sangre al río. ${ }^{145}$ Contrastan con los de Zacatecas estos datos que revelan el interés y hasta la pasión que se advirtió en numerosos distritos del país, donde por lo menos hubo dos candidatos adversarios, mientras que nos queda la impresión de que los zacatecanos batallaron para ir postulando siquiera un gallo en cada demarcación. Las elecciones sin embargo fueron tranquilas y bastante desairadas. ${ }^{146}$

Como la división electoral se basaba en la de los pasados comicios parlamentarios de 1912, los del constituyente se efectuaron en prácticamente todos los distritos, con excepción en aquellos en los que el estado carrancista

142 Periódico Oficial del Estado de Zacatecas, Zacatecas, núm. 16, 14 de octubre de 1916.

143 Periódico Oficial del Estado de Zacatecas, Zacatecas, núm. 17, 21 de octubre de 1916.

144 Periódico Oficial del Estado de Zacatecas, Zacatecas, núm. 18, 28 de octubre de 1916.

145 Ferrer Mendiola, Gabriel, Historia del Congreso Constituyente de 1916-1917, México, Secretaría de Educación Pública-Instituto Nacional de Estudios Históricos de las Revoluciones de México, 2014, pp. 42 y 43.

146 AHEA, Reportes Consulares, caja 5, expedientes 10 y 11. Aguascalientes, 28 de octubre de 1916. En Aguascalientes las elecciones para el congreso constituyente también se habían verificado sin ningún problema, no obstante que muy poca gente había acudido a votar, y una semana más tarde no se conocían los resultados, mismos que fueron publicados hasta el 31 de octubre, resultando elegidos Aurelio González y Archibaldo Eloy Pedroza, por el primer distrito de Aguascalientes; Daniel Cervantes y Gonzalo E. Ortega por el segundo, todos candidatos por el partido liberal. 
Este libro forma parte del acervo de la Biblioteca Jurídica Virtual del Instituto de Investigaciones Jurídicas de la UNAM

no estaba en condiciones de imponer su autoridad y mantener el orden, Ferrer afirma que solamente en 28 distritos no se llevaron a cabo, entre ellos el 4o. de Zacatecas, ${ }^{147}$ con cabecera en Ciudad García, es decir Jerez, aunque como veremos estos datos son inexactos porque la junta computadora del 4o. distrito informó de los resultados de la jornada que dieron el triunfo en ese distrito al licenciado Fernando Moreno.

Y a propósito de juntas, el mismo desmayo comicial puede observarse del posterior conteo de los votos en los distritos locales. La Junta Computadora del 6o. distrito electoral, con cabecera en Sánchez Román, informó del triunfo de Pedro López como titular, con 2,639 votos, y de Andrés L. Arteaga, su suplente, con 439. ${ }^{148}$ La junta de Ojocaliente comunicó el 29 de octubre haber extendido credenciales como diputados, titular y suplente respectivamente, a los ingenieros Julián Adame y Rodolfo Muñoz; ${ }^{149}$ estas juntas fueron digamos que las más expeditas porque la de la capital, inexplicablemente, fue más lerda, pues informó hasta el 6 de noviembre - es decir con un retraso de dos semanas-, que Adolfo Villaseñor había triunfado con 644 votos y su suplente Simoní Castelvi con 657. ${ }^{150}$

Por su parte, la junta del 3er. distrito, con cabecera en Sombrerete, informaba hasta el 8 de noviembre que el doctor Jairo R. Dyer había triunfado como diputado titular con 1,122 votos, y el doctor Narciso González, ${ }^{151}$ como suplente, con 1,269.152 La junta con más pachorra fue la del 4o. distrito con cabecera en Ciudad García, que informó más de un mes después de las elecciones, el 24 de noviembre, que Fernando Moreno había triunfado

147 Ferrer Mendiola, Gabriel, op. cit., p. 43.

148 Periódico Oficial del Estado de Zacatecas, Zacatecas, núm. 21, 18 de noviembre de 1916. Firmaron por la Junta, Jesús María R. Dávila, J. Guadalupe León y Saturnino Valerio. El informe está fechado en Zacatecas, el 28 de octubre, es decir, una semana después de los comicios.

149 Periódico Oficial del Estado de Zacatecas, Zacatecas, núm. 19, 4 de noviembre de 1916.

150 Periódico Oficial del Estado de Zacatecas, Zacatecas, núm. 21, 18 de noviembre de 1916. Firmaron por la Junta, Miguel Muñoz y Silviano Estrada.

151 El doctor Narciso González había sido maderista desde las primeras campañas antirreleccionistas. Participó como delegado a la Convención Nacional Independiente de los partidos aliados Nacional Antireeleccionista y Nacionalista Democrático, celebrada en el Tívoli del Eliseo, el 15 de abril de 1910, en que se decidió la candidatura presidencial de Francisco I. Madero. Cfr. Estrada, Roque, La revolución y Francisco I. Madero, México, Instituto Nacional de Estudios Históricos de la Revolución Mexicana, 1985, p. 208.

152 Periódico Oficial del Estado de Zacatecas, núm. 23, Zacatecas, 2 de diciembre de 1916. Firmaron Fernando Contreras, Agustín Martínez y Jesús Botello. 
Este libro forma parte del acervo de la Biblioteca Jurídica Virtual del Instituto de Investigaciones Jurídicas de la UNAM

como titular con 1,370 votos y su suplente Antonio Chávez Ramírez con $1,369.153$

\section{Cuadro 2}

RESULTADOS DE LA VOTACIÓN EN ALGUNOS DISTRITOS EN LAS ELECGIONeS AL Gongreso CONSTITUyente DE 1916-17 EN ZaCatecas

\begin{tabular}{|c|c|c|c|c|c|}
\hline \multicolumn{2}{|c|}{ Distrito } & Propietario & Votos & Suplente & Votos \\
\hline 1o. & Zacatecas & $\begin{array}{c}\text { Adolfo } \\
\text { Villaseñor }\end{array}$ & 644 & $\begin{array}{c}\text { Rafael Simoní } \\
\text { Castelvi }\end{array}$ & 657 \\
\hline 3o. & Sombrerete & Jairo R. Dyer & 1,122 & $\begin{array}{c}\text { Narciso } \\
\text { González }\end{array}$ & 1,269 \\
\hline 4o. & Cd. García & $\begin{array}{c}\text { Fernando } \\
\text { Moreno }\end{array}$ & 1,370 & $\begin{array}{c}\text { Antonio } \\
\text { Chávez R. }\end{array}$ & 1,369 \\
\hline 6o. & S. Román & Pedro López & 2,639 & $\begin{array}{c}\text { Andrés L. } \\
\text { Arteaga }\end{array}$ & 439 \\
\hline
\end{tabular}

Fuente: Periódico Oficial del Estado de Zacatecas, núms. 18, 21, 23 y 24, Zacatecas, octubrediciembre de 1916.

Sánchez Tagle sugiere que los resultados de las elecciones no fueron definitivos y que se presentaron negociaciones en ese sentido antes y después de los comicios, así que de los efectivamente elegidos no todos asistieron al constituyente. Afirma que Adolfo Villaseñor, por ejemplo, ocupó la titularidad de la candidatura por el distrito de Zacatecas debido a que el candidato original era su padre - el ingeniero Lorenzo T. Villaseñor-, quien murió poco antes de las elecciones. Adicionalmente un periódico local anunció el 14 de noviembre que el general Enrique Estrada había sido elegido como titular por el partido de Pinos, pero debió haber sido un error. ${ }^{154}$ Es posible que ciertos resultados fueran negociados, aunque por los datos que hemos obtenido y exponemos en el cuadro anterior, esta hipótesis puede no ser valedera en todos los distritos. Queda por averiguar lo sucedido en los de Pinos, Juchipila y Nieves, particularmente en estos últimos, de los que de momento no hemos encontrado información sobre la jornada electoral.

153 Periódico Oficial del Estado de Zacatecas, núm. 24, Zacatecas, 9 de diciembre de 1916. Firmaron Felipe Luna y Pedro Ávila.

154 Sánchez Tagle, Héctor, op. cit., p. 396. 
Este libro forma parte del acervo de la Biblioteca Jurídica Virtual del Instituto de Investigaciones Jurídicas de la UNAM

De cualquier forma, sabemos que formalmente los resultados finales fueron los siguientes:

\section{Guadro 3}

\section{REPRESENTANTES DE ZACATECAS ELECTOS AL CONGRESO CONSTITUYENTE DE QUERÉTARO, 1916-1917}

\begin{tabular}{|l|l|l|l|}
\hline \multicolumn{2}{|l|}{ Distrito } & Propietario & Suplente \\
\hline 1o. & Zacatecas & Adolfo Villaseñor & Rafael Simoní Castelvi \\
\hline 2o. & Ojocaliente & Julián Adame & Rodolfo Muñoz \\
\hline 3o. & Sombrerete & Jairo R. Dyer & Narciso González \\
\hline 4o. & Gd. García & Fernando Moreno* & Antonio Chávez Ramírez \\
\hline 5o. & Pinos & Rosendo A. López & Samuel Castañón \\
\hline 6o. & Sánchez Román & Pedro López & Andrés L. Arteaga \\
\hline 7o. & Juchipila & Antonio Cervantes & Cayetano Estrada \\
\hline 8o. & Nieves & Juan Aguirre Escobar & Jesús Hernández \\
\hline
\end{tabular}

* Este representante no se presentó al congreso, por haber suscrito junto a Pedro López un escrito donde se declaraba impedido. Al parecer en el distrito 4o. de Zacatecas no se realizaron elecciones. Lo hemos ubicado como electo por el distrito 4o. porque así lo indica la lógica de los diarios de los debates.

Fuentes: Ferrer Mendiola, Gabriel, Historia del Congreso Constituyente de 1916-1917, México, Secretaría de Educación Pública-Instituto Nacional de Estudios Históricos de las Revoluciones de México, 2014, p. 43; Sánchez Tagle, Héctor, El liberalismo en su laberinto. La Revolución Mexicana en Zacatecas, 1910-1917, Zacatecas, Conaculta-Instituto Zacatecano de Cultura Ramón López Velarde, 2015, p. 396; Diario de los debates, t. I, pp. 151 y 316; t. II, pp. 1233-1242; Periódico Oficial del Estado de Zacatecas, Zacatecas, núm. 24, 9 de diciembre de 1916.

Estos resultados parecen indicar que por lo menos en lo que atañe a los distritos 1, 4, 5 y 6 , la vieja guardia liberal, lo que iba quedando de ella o el grupo de jóvenes que pretendían ser sus sucesores, logró integrarse al nuevo orden revolucionario, no sin atravesar severas contingencias políticas, sociales y económicas. Como es sabido, no todos estos representantes asistieron a Querétaro, y de los que acudieron, no todos fueron aceptados al habérseles echado en cara su pasado político, pero eso ya es otra historia... 
Este libro forma parte del acervo de la Biblioteca Jurídica Virtual del Instituto de Investigaciones Jurídicas de la UNAM

\section{FUENTES}

Almonte, Juan Nepomuceno, Guía de forasteros y repertorio de conocimientos útiles, edición facsimilar, México, Instituto Mora, 2006.

Archivo de José Enciso Contreras. Plan que manifiesta el Censo General del Estado Libre de los Zacatecas, con respecto a su población, industria, agrícola y fabril, número de haciendas de campo, ranchos anexos e independientes de ellas; curas, vicarios, clérigos, regulares y casas de beneficencia. Zacatecas, diciembre de 1828.

Archivo Histórico del Estado de Aguascalientes, sección Reportes Consulares, Caja 4, expediente 69. 73,76, 79, 87, 88, 89. 90, 96, 92, 99, 101 y 102. Caja 5, expedientes 2, 4, 9, 10, 11, 18 y 30.

Archivo Histórico Municipal de Zacatecas, sección Actas de Cabildo, libro 9, 1915-1916. Y ramo Sanidad, caja 1, expediente 20

BARragán Robles, Luis Alfonso, "Personajes de Monte Escobedo en la Revolución”, Zacatecas en Imagen, Zacatecas, 9 de agosto de 2014.

BRONDO WITT, Encarnación, La División del Norte (1914) por un testigo presencial, Zacatecas, Tribunal Superior de Justicia del Estado de Zacatecas, 2014.

Censo municipal, Zacatecas, 1918.

Correa Carrillo, Samuel, 50 años de historia de Jerez, 1900-1950, Jerez, Zacatecas, Publicaciones Gonber, 1997.

Diario de los Debates del Congreso Constituyente 1916-1917, t. I, México, Instituto Nacional de Estudios Históricos de las Revoluciones de México-UNAM, 2014.

Enciso Contreras, José, Café y nevería Acrópolis, espacios de modernidad y espacios de tradición (Un paseo por la sociedad, el ocio y la cultura urbana del siglo $X X$ en Zacatecas, Zacatecas, Poder Judicial del Estado de Zacatecas-Café Acrópolis-Instituto Zacatecano de Cultura, 2012.

EstradA, Roque, La Revolución y Francisco I. Madero, México, Instituto Nacional de Estudios Históricos de la Revolución Mexicana, 1985.

Ferrer Mendiola, Gabriel, Historia del Congreso Constituyente de 1916-1917, México, Secretaría de Educación Pública-Instituto Nacional de Estudios Históricos de las Revoluciones de México, 2014.

Harant, Herve y Delage, Alix, La epidemiología, México, Fondo de Cultura Económica, 1986.

Katz, Friederich, Pancho Villa, México, Era, 2007, t. II.

Kumate, Jesús, "La salud pública en México en el siglo XX. Los protagonistas", en Memoria de El Colegio Nacional, México, 2001. 
Este libro forma parte del acervo de la Biblioteca Jurídica Virtual del Instituto de Investigaciones Jurídicas de la UNAM

La Voz de Zacatecas, 1916, núms. 65, 68, 71, 72, 73, 78, 81, 84, 85, 88, 89, 91, 94, 95, 97 99, 102, 103, 104, 108, 114 y 115.

Lozoya Cigarroa, Manuel, Historia mínima de Durango, Durango, Ediciones Durango, 1995.

Luis Velasco, Alfonso, Geografia y estadística del Estado de Zacatecas, México, Oficina Tipográfica de la Secretaría de Fomento, 1894.

"Manuscrito de Eleuterio Pérez", en Digesto Documental de Zacatecas, núm. 14, Zacatecas, Tribunal Superior de Justicia del Estado de Zacatecas-Universidad Autónoma de Zacatecas, diciembre de 2014.

MARTÍNEZ DÍAZ, Hesby, "De insectos y otras alimañas: la higiene pública en la ciudad de Zacatecas durante el porfiriato", en TERÁN FUENTES, Mariana et al., Al disparo de un cañón. En torno a la Batalla de Zacatecas de 1914: el tiempo, la sociedad, las instituciones, Zacatecas, Instituto Zacatecano de Cultura Ramón López Velarde-Universidad Autónoma de Zacatecas, 2015.

Palavicini, Félix F., Historia de la Constitución de 1917, UNAM-INEHRM, 2014, t. I.

Primer centenario del Instituto de Ciencias. Álbum histórico-Gráfico, Zacatecas, Imprenta del Periódico Orientación, 1932.

Periódico Oficial del Estado de Zacatecas, 1916, núms. 16, 17, 18, 19, 21, 23, 24, 25.

RABASA, Emilio, La Constitución y la dictadura. Estudio sobre la organización política de México, México, Porrúa, 1982.

RAMOs DÁviLA, Roberto, Roque Estrada Reynoso, precursor y actor de la revolución, Zacatecas, Ayuntamiento de Zacatecas-Ayuntamiento de Moyahua de Estrada, s. s. e.

Robinson Wright, Marie, Picturesque Mexico, Philadelphia, J. B. Lippincott Company, 1897.

Ruiz Rubiaurre, Antonio et al., Estadísticas históricas de México, México, Instituto Nacional de Estadística Geografía e Informática-Instituto Nacional de Antropología e Historia, 1985, t. I.

SALDÍvar Garrillo, Manuel, Memorias de un agrarista zacatecano, Zacatecas, Tribunal Superior de Justicia del estado de Zacatecas, 2003.

SÁnchez TAgLe, Héctor, El liberalismo en su laberinto. La Revolución mexicana en Zacatecas, 1910-1917, Zacatecas, Conaculta-Instituto Zacatecano de Cultura Ramón López Velarde, 2015.

Zalce y RodRÍGUez, Luis J., Apuntes para la historia de la masonería en México (De mis lecturas y mis recuerdos), tomo segundo, México, Talleres Tipográficos de la Penitenciaría del Distrito Federal, 1950. 
Este libro forma parte del acervo de la Biblioteca Jurídica Virtual del Instituto de Investigaciones Jurídicas de la UNAM

\title{
EL JUICIO DE AMPARO GRUZA FRONTERAS. RODOLFO REYES EN ESPAÑA
}

\author{
Eva Elizabeth MARTínEz CHÁvEZ*
}

\begin{abstract}
Sumario: I. Ciencia jurídica, de México para España. II. Fuentes de
\end{abstract} consulta.

La Revolución mexicana trastocó de formas diversas la vida nacional. Fue la causa, por ejemplo, del exilio de juristas que tuvieron alguna participación en el conflicto armado, como fue el caso de Rodolfo Reyes Ochoa. ${ }^{1}$ El hijo del general Bernardo Reyes² salió del país cuando contaba con poco más de

* El Colegio de Michoacán A.C., becaria posdoctoral Conacyt.

1 Sobre la experiencia vital de R. Reyes se puede consultar su propia biografía escrita en tres tomos: De mi vida. Memorias políticas, 1899-1913, Madrid, Biblioteca Nueva, 1929, t. I; De mi vida. Memorias políticas. México 1913-1914, Madrid, Biblioteca Nueva, 1930, t. II, y De mi vida. La bi-revolución española, México, Jus, 1948, t. III.

2 El general Bernardo Doroteo Reyes Ogazón nació el 20 de agosto de 1849, en Guadalajara, Jalisco, y murió el 9 de febrero de 1913 en la Ciudad de México. Se interesó por el estudio del derecho pero no concluyó la carrera; después dirigió sus esfuerzos de manera definitiva hacia el ámbito militar en primera instancia y al político-militar con posterioridad. Inició su carrera militar como soldado raso y después de una brillante trayectoria logró conseguir el grado de general. En Núñez García, Víctor M., "A ambos lados del Atlántico: Hispanismo y exilio en la figura de Rodolfo Reyes Ochoa", en Márquez Macías, Rosario (ed.), Huelva y América. Cien años de Americanismo. Revista "La Rábida" (1911-1933). De corresponsales y colaboradores, Sevilla, UNIA, 2014, p. 151. Entre los logros políticos del general Bernardo Reyes se cuenta el haber sido gobernador del estado de Nuevo León, secretario porfirista de guerra y marina y caudillo político con pretensiones de derrotar al grupo de los científicos en la sucesión presidencial de Díaz. En Garciadiego, Javier, Politica y literatura. Las vidas paralelas de los jóvenes Rodolfo y Alfonso Reyes, México, Centro de Estudios de Historia de México Condumex, 1990, p. 22. Sobre este personaje también pueden consultarse Niemeyer, E. V., El general Bernardo Reyes, Monterrey, Centro de Estudios Humanísticos de la Universidad de Nuevo León, 1966; Arellano, J. G. de, Bernardo Reyes y el movimiento reyista en México, México, INAH, 1982, y Benavides Hinojosa, A., El general Bernardo Reyes. Vida de un liberal porfirista, Monterrey, Ediciones Castillo, 1998. 
Este libro forma parte del acervo de la Biblioteca Jurídica Virtual del Instituto de Investigaciones Jurídicas de la UNAM

treinta años de edad y vivió durante las cuatro décadas siguientes en tierras europeas, principalmente en España, en donde murió en $1954 .^{3}$

La figura de Rodolfo Reyes ha merecido valiosas y reveladoras páginas, ${ }^{4}$ y aunque las pretensiones de este trabajo son modestas, estas letras pretenden mostrar su legado como jurista, su experiencia como exiliado y su participación en el proceso constituyente de las Cortes españolas que elaboraron la Constitución republicana de 1931. También se abordan los motivos que lo llevaron a apoyar al bando franquista durante la Guerra Civil Española, conflicto que fue el origen del exilio de cientos de juristas republicanos que llegaron a tierras mexicanas y dejaron valiosas aportaciones que hasta la fecha siguen dando frutos. En este escenario, el caso de Reyes es un exilio a la inversa, es decir, de México para España; de ciencia jurídica mexicana que cruzó el Atlántico para llegar y quedarse en la Península ibérica.

Antes de hablar de sus años de exilio vamos a abordar su vida en México. Rodolfo Reyes nació en Guadalajara, Jalisco, el 16 de mayo de 1878. Fue el segundo de los doce hijos del matrimonio entre Bernardo Reyes Ogazón y Aurelia Ochoa Zapiain. El 16 de abril de 1902 contrajo matrimonio con Carmen Morales Gasca, con quien procreó cuatro hijos: ${ }^{5}$ Bernardo, Rodolfo, Roberto y Fernando Reyes Morales,${ }^{6}$ los tres primeros nacieron en México y el último en España.

Como resultaba común en aquellos años entre la juventud ilustrada de la Ciudad de México, en 1893 ingresó a la Escuela Nacional Preparatoria; posteriormente se matriculó en la Escuela Nacional de Jurisprudencia (ENJ)

3 La noticia de su fallecimiento apareció en el periódico $A B C$ de Madrid, el 5 de junio de 1954.

4 El último trabajo que conozco sobre este jurista salió de la pluma de Andrés Lira, "Emilio Rabasa y Rodolfo Reyes. Del exilio político a la actualidad constitucional", y se presentó en el seminario Formación política de México. Siglos XVI-XX, de El Colegio de México en 2015. Sobre R. Reyes y las influencias del amparo en México y España véase Ferrer Mac-Gregor, Eduardo, La acción constitucional de amparo en México y España, 4a. ed., México, Porrúa-UNAM, 2007. Recientemente Javier Garciadiego lo menciona en Autores, editoriales, instituciones y libros. Estudios de historia intelectual, México, El Colegio de México, 2015.

5 Durante la Guerra Civil Española sus hijos tomaron posturas diversas ante el enfrentamiento. Mientras Rodolfo, Roberto y Fernando Reyes Morales eran miembros de la Falange española y apoyaron al bando encabezado por el general Francisco Franco, su hermano mayor, Bernardo, se incorporó al servicio diplomático mexicano. Véase Ortuño Martínez, Manuel (ed.), Isidro Fabela y Luis I. Rodríguez, Diplomáticos de Cárdenas. Una trinchera mexicana en la Guerra Civil (1936-1940), Madrid, Trama Editorial, 2007, pp. 124, 141, 146 y 147, y Martínez, José Luis (ed.), Alfonso Reyes/Pedro Henríquez Ureña. Correspondencia 1907-1914, México, Fondo de Cultura Económica, 1986, t. I, p. 302.

6 Núñez García, Víctor M., op. cit., p. 151. Del nacimiento de su hijo español dio noticias el propio R. Reyes en De mi vida. La bi-revolución española, cit., p. 32. 
Este libro forma parte del acervo de la Biblioteca Jurídica Virtual del Instituto de Investigaciones Jurídicas de la UNAM

de 1895 a 1900. Al término de la carrera ganó el premio al mejor alumno de su generación ${ }^{7}$ y se tituló el 8 de enero de $1901 .{ }^{8}$ Antes de graduarse ya había instalado un bufete que resultó exitoso desde un principio, sin duda avalado por las importantes influencias políticas familiares y la calidad profesional del joven abogado. ${ }^{9}$

En esos tiempos todo apuntaba a que sería un gran abogado practicante, además de un reconocido catedrático. ${ }^{10} \mathrm{El} 5$ de abril de 1901 ingresó, como miembro correspondiente, a la Sociedad Mexicana de Geografía y Estadística. Poco después fue nombrado profesor interino de procedimientos penales de la ENJ (marzo de 1902-abril de 1903). Posteriormente, entre abril y mayo de 1903, se opuso con éxito a la cátedra de adjunto de derecho constitucional. "Sus explicaciones incluían un análisis histórico general y de cada uno de los artículos de la Constitución de 1857 y de sus leyes orgánicas". ${ }^{11}$

Su vida dio un giro en 1902, al iniciar su participación en la política nacional al lado de su padre, ${ }^{12}$ al que apoyó en su enfrentamiento contra los científicos por la sucesión en la presidencia de la República. Los primeros contingentes que aportó a la causa de su padre provenían de la Escuela de Jurisprudencia y de otras escuelas universitarias; situación que fue posible por su activismo político y el prestigio que llegó a tener entre los condiscípulos, alumnos y colegas. El gobierno de Díaz se dio cuenta de esto y lo alejó de las aulas. Ese momento llegó cuando Pablo Macedo, considerado un científico cabal, fue nombrado director de la ENJ y le impuso a Rodolfo una licencia no solicitada que se extendió por largo tiempo. El gobierno, a cambio, lo ayudó en otros aspectos, ya fuera en la práctica como abogado o para recibir distinciones, como ingresar a la Academia Mexicana de Le-

7 Garciadiego, Javier, Política y literatura..., cit., pp. 24 y 26.

$8 \mathrm{El}$ sínodo de su examen profesional, que lo aprobó por unanimidad, estuvo compuesto por los profesores Jacinto Pallares, José Algara, Miguel S. Macedo, Víctor M. del Castillo y Antonio Ramos Pedrueza. En Mayagoitia, Alejandro, "El concurso científico y artístico del centenario de la independencia o la historia del derecho como ditirambo", Anuario Mexicano de Historia del Derecho, México, núm. XIII, 2001, p. 89.

9 Instaló el despacho en la Ciudad de México, en la calle San Juan El Real número 16, junto a los licenciados J. Gracia Medrano, Salvador Milanés y Manuel Gutiérrez. En Núñez García, Víctor M., op. cit., p. 157. Poco antes de la Revolución de 1910 se le encontraba en la calle de Esclavo número 2, en la Ciudad de México. En Mayagoitia, Alejandro, op. cit., p. 91.

10 Garciadiego, Javier, Politica y literatura..., cit., pp. 24 y 26.

11 Mayagoitia, Alejandro, op. cit., p. 89.

12 El gusto por la política lo heredó Rodolfo Reyes por vía paterna y por otros ancestros que también se habían dedicado a ella de forma sobresaliente. En Garciadiego, Javier, Cultura y política..., cit., pp. 283-286. 
Este libro forma parte del acervo de la Biblioteca Jurídica Virtual del Instituto de Investigaciones Jurídicas de la UNAM

gislación y Jurisprudencia; pero no accedió a que regresara a la docencia y utilizara las aulas para atacar al régimen. ${ }^{13}$

En la Academia de Legislación y Jurisprudencia también logró sobresalir. Fue el encargado de pronunciar el discurso de bienvenida que esa institución dio a Rafael Altamira en su visita a México. ${ }^{14} \mathrm{El}$ mismo profesor de Oviedo lo menciona en el libro que documentó su viaje a América como el representante de la República de México y miembro de la Academia de Jurisprudencia y Legislación. ${ }^{15}$

Aunque lo alejaron de las aulas no dejó de participar en actividades políticas, sólo que buscó nuevos escenarios y aprovechó cualquier medio para continuar su lucha contra los científicos, a quienes consideraba enemigos irreconciliables de su padre. A mediados de 1908 surgió el reyismo como un movimiento con grandes bases multiclasistas: obreros, clases medias y varias facciones de la burguesía, que pretendían presionar a Díaz para que no gobernara con los científicos como principales colaboradores sino con el general Reyes. Molesto y preocupado por la fuerza creciente de ese movimiento, Díaz envió al general Reyes comisionado a Europa. Cuando éste regresó a México la situación política había cambiado sustancialmente. En un lapso corto de tiempo el maderismo había sustituido al reyismo como principal fuerza de oposición en la sucesión presidencial. ${ }^{16}$

El levantamiento de Madero contra el presidente Díaz fue aprovechado por Rodolfo Reyes para recuperar su cátedra en Jurisprudencia. Cuando su padre fue requerido para que combatiera la rebelión maderista el gobierno buscó la mediación de Rodolfo, el pago por su intervención fue su regreso a la docencia. En este retorno también ayudó la presión de estudiantes de la ENJ que en abril de 1911 pidieron su reincorporación. Otra circunstancia que allanó su regreso fue la sustitución del científico Justo Sierra, en la Secretaría de Instrucción Pública, por Jorge Vera Estañol, joven profesor de Jurisprudencia y político más progresista que los científicos. Con este relevo el antiguo director de Jurisprudencia, Pablo Macedo, dejó de gobernarla. ${ }^{17}$

Finalmente, la rebelión encabezada por Madero logró expulsar del país a Porfirio Díaz y después de convocar a elecciones aquél resultó ganador.

13 Idem.

14 El discurso lo tituló En honor del señor don Rafael Altamira. Discurso de recepción pronunciado por el académico de número licenciado Rodolfo Reyes Ochoa, México, Academia Central Mexicana de Jurisprudencia y Legislación, 1910. Citado en Mayagoitia, Alejandro, op. cit., p. 49.

15 Altamira y Crevea, Rafael, Mi Viaje a América. (Libro de documentos), Oviedo, Universidad de Oviedo, 2007, pp. 192-203.

16 Garciadiego Javier, Política y literatura..., cit., pp. 32-34.

17 Ibidem, pp. 289 y 290. 
Este libro forma parte del acervo de la Biblioteca Jurídica Virtual del Instituto de Investigaciones Jurídicas de la UNAM

Estos cambios no aminoraron las actividades que Rodolfo Reyes emprendió en busca de la presidencia para su padre, lo que los llevó a un fatal enfrentamiento con el nuevo gobierno. ${ }^{18} \mathrm{El}$ resultado fue la muerte del general Reyes en 1913, al intentar tomar el Palacio Nacional. Rodolfo Reyes logró salvar la vida milagrosamente al escapar de la refriega; aunque su participación en el cuartelazo y sus posteriores alianzas políticas sólo le acarrearon censuras y escarnio, pues no faltaron las voces que lo acusaron de ser el responsable de la muerte de su padre. ${ }^{19}$

Durante los días que siguieron a la muerte del general, Rodolfo Reyes pensó en alejarse de "todo"; sin embargo, al concluir el novenario de su padre, participó en la conformación del gobierno que negociaron el sublevado Félix Díaz y Victoriano Huerta, este último presidente de la República por breve tiempo y del que fungiría durante siete meses como secretario de justicia; cargo al que renunció después de que Huerta traicionara el pacto por el que se había comprometido a celebrar elecciones para que Félix Díaz se convirtiera en presidente y al que además expulsó del país. ${ }^{20}$

Después de renunciar como ministro de justicia, Rodolfo se desempeñó de forma efimera como diputado por un distrito de Jalisco. En el Congreso inició una abierta labor antihuertista, y desde un principio logró agrupar a muchos diputados contrarios a Huerta, además de sumar popularidad e influencia, pues a escasas semanas de su incorporación ya encabezaba comisiones; una de ellas fue la de Puntos Constitucionales, que negó a Huerta el permiso para posponer las elecciones de octubre de ese año. ${ }^{21}$

Ante estos hechos, el 10 de octubre de 1913, Huerta disolvió el Congreso y aprehendió a 70 diputados, entre ellos Rodolfo Reyes, quien permaneció en prisión hasta el 9 de febrero de 1914, fecha en que quedó libre como una gracia que el presidente le concedió por el aniversario de la muerte de su padre. Sin embargo, a cambio de su excarcelamiento se le exigió dejar inmediatamente el país, radicarse en Europa y mantenerse alejado de Félix Díaz, quien por entonces se encontraba desterrado en Cuba. El 14 de febrero Rodolfo Reyes zarpó desde Veracruz hacía su exilio, acompañado de su hijo Bernardo y dejando en México a su esposa y a sus otros dos hijos ${ }^{22}$ los que tiempo después se reunieron con él en Europa.

\footnotetext{
18 Ibidem, p. 282.

19 Ibidem, p. 292.

20 Ibidem, pp. 44 y ss.

21 Ibidem, pp. 294, 299 у 300.

22 Ibidem, pp. 44 y ss.
} 
Este libro forma parte del acervo de la Biblioteca Jurídica Virtual del Instituto de Investigaciones Jurídicas de la UNAM

Rodolfo Reyes llegó a París en marzo de 1914, ahí se encontró con su hermano Alfonso, quien había salido del país en 1913. ${ }^{23}$ En Francia le tocó vivir el inicio de la Primera Guerra Mundial, por lo que se trasladó a España ${ }^{24}$ en donde se dedicó a labores profesionales y comerciales..$^{25}$ Después de revalidar su título ${ }^{26}$ consiguió la autorización para trabajar como abogado. ${ }^{27}$ Además, consiguió que ya que había sido profesor por oposición de Derecho Constitucional en la Universidad de México se le revalidara como doctor en derecho y pudiera vestir la toga y las borlas del Foro y de la Universidad de Madrid; ${ }^{28}$ lo que le facilitó vincularse con los ámbitos docentes e intelectuales de los juristas españoles. ${ }^{29}$

Fue un participante regular en las sesiones semanales del Centro de Cultura Hispanoamericana y llegó a ser, hacia 1919, vicepresidente de la Academia Hispanoamericana de Ciencias y Artes; además fue director de la revista La Unión Hispanoamericana desde finales de 1916 hasta mediados de 1922. A sus intereses intelectuales se sumó el interés por la política local española; sin dejar de participar en la política mexicana. A pesar de vivir desterrado, se le llegó a considerar el representante en España de Félix Díaz. Sin embargo, durante los años veinte su participación en la política mexicana fue a la baja. Durante ese tiempo se dio el regreso de muchos desterrados políticos, no así los que se habían acomodado a vivir en el extranjero o los acusados por las muertes de Madero y Pino Suárez, entre ellos Félix Díaz y Rodolfo Reyes. ${ }^{30}$

A diferencia de otros exiliados políticos, Rodolfo Reyes debe ser visto como un doble exiliado. Salió expulsado del país por Victoriano Huerta, "cuyos estilos y modales hacían riesgosa su permanencia en México. Sin

\footnotetext{
23 Ibidem, p. 301.
}

24 Se instaló en Madrid, ciudad en la que transcurrió la mayor parte de su largo exilio. En Víctor M. Núñez García, op. cit., p. 159

25 Garciadiego, Javier, Cultura y política..., cit., pp. 302 y 303.

26 Encuesta realizada a Rodolfo Reyes Ochoa, “¿Qué opina V. de su actual vida políticoliteraria?”, La Rábida. Revista Hispanoamericana, Huelva, segunda época, año XX, núm. 220, 1932, p. 1. También R. Reyes ofrece información sobre la revalidación de su título en De mi vida. La bi-revolución española, cit., p. 42.

27 Mayagoitia, Alejandro, op. cit., p. 91. La Gaceta de Madrid es uno de los repositorios en los que se conservan noticias de la actuación foral de este abogado. Al respecto se puede ver la Real Orden resolviendo instancia presentada por Rodolfo Reyes Ochoa, en nombre y representación de la Sociedad regular colectiva "González Cossio Hermanos". Gaceta de Madrid, núm. 298, 25 de octubre de 1930, pp. 508 y 509.

28 Reyes, Rodolfo, De mi vida. La bi-revolución española, cit., p. 42.

29 Garciadiego, Javier, Cultura y política..., cit., pp. 302 y 303.

30 Ibidem, pp. 302-305. 
Este libro forma parte del acervo de la Biblioteca Jurídica Virtual del Instituto de Investigaciones Jurídicas de la UNAM

embargo, por su violento antimaderismo y por haber sido parte del gobierno huertista, Rodolfo Reyes también fue rechazado por los revolucionarios, al grado que tuvo que permanecer en el exilio cuando éstos derrotaron a Huerta a mediados de 1914".31

$\mathrm{Al}$ vislumbrar lo definitivo de su exilio no todos los miembros de su familia estuvieron de acuerdo en compartir su destino. Su primogénito, Bernardo Reyes Morales, decidió ingresar al servicio diplomático mexicano en el gobierno posrevolucionario, lo que consiguió con la ayuda de su tío Alfonso Reyes. ${ }^{32}$ Ante las aspiraciones de su hijo y para no entorpecer su futuro profesional Rodolfo dejó de lado su postura crítica sobre el gobierno mexicano. ${ }^{33}$

La distancia física, su realismo y las circunstancias familiares fueron alejando y aislando a Rodolfo Reyes de la política mexicana; a lo que deben sumarse las necesidades económicas que tenía que resolver. Comprensiblemente, la nueva situación lo llevó a compenetrarse e interesarse más por el destino de España. Luego de que su hijo Bernardo se hiciera diplomático mexicano, a sus otros tres vástagos les tocó hacerse españoles; ${ }^{34}$ su último hijo nació en España en $1915 .{ }^{35} \mathrm{El}$ mismo jurista exiliado llegó a expresar que "tenía a orgullo considerarse un español más", ${ }^{36}$ que luchó y trabajó con honradez y constancia para sobrevivir. ${ }^{37}$

Fueron años en los que su atención por la política española se intensificó. En el Ateneo de Madrid pasó de la sección Iberoamericana a la de Moral y Política, la que llegó a presidir a finales de 1932. ${ }^{38}$ Eran tiempos de cambios en España, como jurista se interesó por la nueva Constitución y las modificaciones que se daban en la estructura española a partir del triunfo de la

31 Ibidem, p. 301.

32 Colaboró con la legación mexicana en Francia ayudando a los republicanos españoles para su traslado a México. Posteriormente, desempeñó diversos cargos diplomáticos representando al gobierno mexicano. Murió en 1977 en Lisboa, Portugal, como embajador de México. Véase Ortuño Martínez, Manuel (ed.), op. cit., pp. 124, 141, 146 y 147, y Martínez, José Luis (ed.), op. cit., p. 302.

33 Garciadiego, Javier, Cultura y política..., cit., pp. 305 y 306.

34 Ibidem, pp. 307-309.

35 Reyes, Rodolfo, De mi vida. La bi-revolución española, cit., p. 32.

36 Periódico ABC de Madrid, 5 de junio de 1954, p. 20.

37 Garciadiego, Javier, Cultura y política..., cit., pp. 307-309.

38 Era común que ocupara las tribunas de España, donde era muy conocido. A esto ayudó la proyección que logró como abogado, pues en 1932 se anunciaba en una revista que el último Congreso Nacional de Abogados lo había elegido como su vicepresidente; además de pertenecer a todas las Academias afines a sus estudios y dedicación. En Encuesta realizada a Reyes Ochoa, Rodolfo, op. cit., p. 1. 
Este libro forma parte del acervo de la Biblioteca Jurídica Virtual del Instituto de Investigaciones Jurídicas de la UNAM

Segunda República; interés que mostró en sus conferencias y publicaciones. En ese tiempo mantuvo relaciones con varios ideólogos y políticos "de todos los matices" y sus ideas y posturas hacia la política española fueron definidas por varios factores: su credo liberal, su rechazo a los excesos de violencia y radicalismo de la Revolución mexicana, el titubeante curso de la política española, y las posturas de sus hijos "españoles". ${ }^{39}$

Durante la Guerra Civil fue detenido por un grupo anarquista con el peligro de ser pasado por las armas al tenerlo por simpatizante de los "nacionales". Los anarquistas no estaban lejos de la realidad pues en su biografía el propio Rodolfo Reyes dejó constancia de las acciones familiares a favor de los franquistas. ${ }^{40}$ Un motivo más para simpatizar con los "nacionales" fue el saqueo que sufrió su hogar ante la indiferencia de la embajada mexicana. Esta experiencia lo hizo reactivar sus críticas contra el gobierno mexicano, así como rechazar todo lo relacionado con los republicanos españoles. ${ }^{41}$ Víctor M. Núñez también considera que su acercamiento y apoyo al bando nacionalista pudo ser motivado por cuestiones ideológicas o por el posible desengaño ocasionado por el escaso éxito diplomático de la II República a la hora de establecer acercamientos de colaboración y diálogo efectivos con los países latinoamericanos. La relación y buena sintonía con el régimen franquista resultan evidentes "al explorar las actividades propagandísticas en apoyo al bando nacional durante la Guerra Civil que Rodolfo Reyes lleva a cabo desde diversos foros, incluso desde la prensa mexicana". ${ }^{42}$

39 Garciadiego, Javier, Cultura y política..., cit., p. 309.

40 Mencionó que dos de sus hijos: "fueron de los primeros que con, y aún antes de José Antonio [Primo de Rivera] uno de ellos, levantaron bandera en el campo nacional. El abogado Roberto fue de la primera Falange y vistiendo dignamente su toga defendió en la más difícil situación de fines del 35 a julio del 36 a falangistas procesados, formando parte del círculo íntimo del apóstol de esta idea". Posteriormente, Roberto se incorporó como voluntario al Ejército nacional. El hijo menor, Fernando, "sufrió persecuciones y prisiones desde 1934, siendo el primer preso de Falange en Madrid". Fernando también se enroló como voluntario en el Ejército nacional, "en España y Rusia, batiéndose sin cesar en primera línea, siendo herido y obteniendo muchas citaciones y recompensas". Véase en Reyes, Rodolfo, De mi vida. La bi-revolución española, cit., pp. 499 y 500.

41 Garciadiego, Javier, Cultura y politica..., cit., pp. 310 y 311.

42 Fue columnista habitual del periódico de la Ciudad de México El Universal, publicación que hizo campaña propagandística a favor del bando nacional durante la Guerra Civil Española. En la última etapa de su vida tuvo cierta presencia en publicaciones vinculadas a Falange; por ejemplo, "publicó un folleto bajo el título ¡Educar! para el número 35 de ediciones Camisa Azul en el año 1951. La presencia puntual de su pluma en publicaciones femeninas asociadas a Sección Femenina también será un rasgo de esta última etapa”. En Núñez García, Víctor M., op. cit., pp. 166, 167 y 171. 
Este libro forma parte del acervo de la Biblioteca Jurídica Virtual del Instituto de Investigaciones Jurídicas de la UNAM

Así pues, a diferencia de una parte importante de la intelectualidad española que sufrió persecución política y que muchos de ellos tomaron el camino del exilio, ${ }^{43}$ Rodolfo Reyes no sólo salió indemne de este proceso sino que durante los primeros años de la dictadura, mantuvo su ritmo de producción escrita y continuó siendo un habitual conferencista sobre temas hispanistas/americanistas ${ }^{44}$ a lo largo y ancho de la geografía española. También la nómina de personalidades del Movimiento Nacional que asistieron a su entierro resulta un "hecho sintomático de que su posición en la España de los primeros años del franquismo no era ni mucho menos incómoda desde el punto de vista profesional y político". ${ }^{45}$

No obstante que se le identificó con el bando ganador de la guerra, sí resultó perjudicado durante los años de enfrentamientos bélicos. Por ejemplo, el asalto a su casa afectó gravemente su situación económica, al grado de poder decir que de 1940 en adelante vivió la tercera etapa de su vida, "sobre las ruinas de su segunda", ${ }^{46}$ lo que significó una vejez lejos de la bonanza que durante buena parte de su juventud vivió en México.

Aunque no acumuló riquezas en su país de adopción sí logró ser reconocido profesional y socialmente. Fue miembro honorario de la Real Academia de Jurisprudencia española y recibió la Gran Cruz de Isabel La Católica que le otorgó el gobierno español. A su muerte se consideró que "su figura era muy popular y querida en Madrid, donde contaba con numerosos amigos y cuyos medios sociales y literarios frecuentaba". ${ }^{47}$

La nota necrológica de la muerte de Rodolfo Reyes resulta digna de atención pues ofrece un testimonio, vago quizá, de la actividad que este jurista desarrolló y de sus relaciones sociales en España. A su sepelio acudieron importantes personalidades franquistas. En la presidencia oficial figuraban "D. Esteban Bilbao y los ministros de Justicia, Educación Nacional y

$43 \mathrm{Al}$ inicio del conflicto armado en España solicitó la protección de la embajada mexicana en Madrid, lugar en el que permaneció durante algún tiempo al considerar que le ofrecía mayor seguridad que su residencia habitual que había sido saqueada. En Moral Roncal, Antonio Manuel, El asilo diplomático en la Guerra Civil Española, Madrid, Actas Editorial, 2001, p. 103.

44 El periódico $A B C$ de Madrid anunciaba el 17 de febrero de 1949 que en el Ateneo de esa ciudad Rodolfo Reyes ofrecería una charla sobre "Impresiones mejicanas". En Periódico ABC de Madrid, 17 de febrero de 1949, p. 16.

45 Núñez García, Víctor M., op. cit., p. 157. Este autor menciona que también logró consolidar "su posición como catedrático en la Universidad Central de Madrid", por desgracia no menciona la fuente en la que basa esta afirmación ni la facultad en la que Rodolfo Reyes colaboró.

46 Garciadiego, Javier, Cultura y politica..., cit., pp. 310 y 311.

47 Periódico ABC de Madrid, 5 de junio de 1954, p. 20. 
Este libro forma parte del acervo de la Biblioteca Jurídica Virtual del Instituto de Investigaciones Jurídicas de la UNAM

secretario general del Movimiento", además de contarse entre la numerosa concurrencia - sigo citando la nota necrológica-

El vicesecretario general del Movimiento, Sr. Romojaro; el de Secciones, Sr. Pradera; directores generales de Trabajo y Radiodifusión, señores Reguera Sevilla y Suevos, respectivamente; delegado nacional de Sindicatos, Sr. Solís; presidente de la Diputación, marqués de la Valdavia; marqués de Grijalba; señores Bourbón, Acevedo y Palacios (D. Mariano) y gran número de escritores y periodistas. ${ }^{48}$

En la presidencia familiar figuraban "los hijos del finado, D. Bernardo, D. Fernando y don Roberto Reyes, este último, delegado de Justicia y Derecho"49 en Madrid durante la primera fase de la dictadura del general Franco. ${ }^{50}$ Como se puede apreciar, los estudios de derecho y su participación en la Guerra Civil al lado del bando nacional le habían permitido a Roberto Reyes Morales escalar posiciones en la estructura franquista.

La nota necrológica antes citada también dio cuenta de los logros como jurista que se le reconocieron a Rodolfo Reyes, de quien se citan varias publicaciones, entre ellas Derecho constitucional mejicano y La defensa constitucional. ${ }^{51}$ $\mathrm{Al}$ análisis de la producción jurídica de este exiliado en tierras españolas se dedican las siguientes líneas.

\section{CienCiA JURÍDICA, DE MÉXICO PARA ESPAÑA}

Rodolfo Reyes Ochoa mostró diversos intereses a lo largo de su vida; sin embargo, una constante fue su pasión por el derecho, al que se dedicó tanto en su faceta como abogado como en la de autor de valiosos estudios jurídicos. El propio Reyes en 1932 declaró que lo sustantivo de su vida fue siempre la dedicación a los estudios de derecho político y constitucional, "yo soy por esencia eso, Profesor y abogado, Ministro, Diputado, etc. ha sido ocasional nada más". ${ }^{52}$

Su legado como jurista inició en México con el siglo XX. En 1900 apareció su Concepto positivo del derecho, ${ }^{53}$ trabajo leído como acto académico de

48 Idem.

49 Idem.

50 Núñez García, Víctor M., op. cit., p. 150.

51 Periódico ABC de Madrid, 5 de junio de 1954, p. 20.

52 Encuesta realizada a Rodolfo Reyes Ochoa, op. cit., p. 1.

53 Reyes, Rodolfo, Concepto positivo del derecho, Monterrey, Tipografía del Gobierno en Palacio, 1900. 
Este libro forma parte del acervo de la Biblioteca Jurídica Virtual del Instituto de Investigaciones Jurídicas de la UNAM

fin de licenciatura en la Escuela Nacional de Jurisprudencia ${ }^{54}$ y publicado en Monterrey; lo que cobra sentido si recordamos la influencia que tenía su padre en el estado de Nuevo León, del que fue gobernador por largos años..$^{55}$

La misma imprenta del Gobierno en Palacio ubicada en la ciudad de Monterrey le publicó la tesis que presentó en su examen general de abogado, a la que tituló La agricultura y la ley minera. ${ }^{56}$ Fue reimpresa ese mismo año en la Ciudad de México por la Tipografía del Gobierno de don Francisco M. Escobedo; además, apareció en la Revista de Legislación y Jurisprudencia. ${ }^{57}$

Como ya se mencionó, esos años también fueron de una intensa actividad como abogado postulante, lo que se reflejó en diversos escritos producto de los asuntos en los que participó y que fueron publicados en la Ciudad de México. Con frecuencia esas páginas eran reproducidas en la Revista de Legislación y Jurisprudencia. ${ }^{58}$ Por la temática específica de algunas de estas incipientes publicaciones Reyes parece comenzar a especializarse en la representación legal de sociedades industriales y mercantiles, actividad que continuó en su etapa española. ${ }^{59}$

Fue un periodo en el que compaginó su interés por la abogacía y la ciencia jurídica, por tal motivo era frecuente su presencia tanto en actividades académicas como de agrupaciones profesionales. En 1903 pronunció

54 Núñez García, Víctor M., op. cit., p. 169.

55 En 2010 este breve trabajo fue reeditado por Kessinger Publishing.

56 Reyes, Rodolfo, La agricultura y la ley minera, Monterrey, Imprenta del Gobierno en Palacio, 1901.

57 Revista de Legislación y furisprudencia, México, t. XX, 1901, pp. 123-160,

$58 \mathrm{Al}$ respecto véase Licenciado Rodolfo Reyes, por Antonio Granes, alega, en revisión de amparo, contra la sentencia dictada por el inferior del estado de Veracruz, México, Laso, 1901; Con don Luis Fernández Castelló: Apuntes del asunto del Carmen. Alegaciones de la señora Carmen Serna de Gándara ante la Suprema Corte de Fusticia, México, Tipografia de José de Rivero, 1902; Con don Luis Cabrera: Asunto del Carmen. Algunas observaciones sobre los alegatos del licenciado Indalecio Sánchez Gavito, México Tipografía de José de Rivero, 1902; Última palabra en el asunto del Carmen por los licenciados Rodolfo Reyes y Luis Fernández Castelló a nombre de la señora Carmen Serna de Gándara, México, Tipografia de José de Rivero, 1902; Con el licenciado don Francisco G. de Cosío: Hermanos Rafael, Félix y Jacinto Paredes versus intestado de don Manuel Onofre Paredes. Escrito de amparo presentado por los licenciados Rodolfo Reyes y Francisco G. de Cosío, México, Imprenta Central, 1905; El litigio "Espinosa y Cuevas, Hnos." versus "Bruno Rivero y Carmen Caloca de Rivero". Visto en casación, apuntes de alegato en defensa de la Sociedad "Espinosa y Cuevas, Hnos.", México, S. Luis Potosí, Tipografía de la Escuela Industrial Militar, 1911. Citados en Mayagoitia, Alejandro, op. cit., pp. 94 y 95.

59 Véase, por ejemplo, Alegaciones del Lic. Rodolfo Reyes al Recurso de Amparo de la Compañia Industrial de Transportes de Tabasco (1902) y Recurso de Amparo a la Compañia Industrial Fabonera de La Laguna (1914). En Núñez García, Víctor M., op. cit., p. 158. 
Este libro forma parte del acervo de la Biblioteca Jurídica Virtual del Instituto de Investigaciones Jurídicas de la UNAM

un discurso en el acto de apertura del ciclo escolar en la Escuela Nacional de Jurisprudencia; ${ }^{60}$ ese mismo año se presentó a la oposición de la clase de Derecho Constitucional, con el trabajo ${ }_{i}$ Los derechos que la sección primera del título primero de la Constitución Federal proclama como derechos del hombre, corresponden únicamente al individuo fisicamente considerado, o corresponden también a los seres morales formados por la asociación de individuos? ${ }^{61}$ También salieron de su pluma diversos discursos, ${ }^{62}$ memorias para concursos,${ }^{63}$ obras escritas en colaboración con autores extranjeros ${ }^{64}$ y textos sobre derecho constitucional. ${ }^{65}$ En esta etapa sobresale su interés por el juicio de amparo, diversas cuestiones constitucionales y la legislación minera. ${ }^{66}$

Algunos de estos intereses los conserva durante su exilio y otros aparecen o maduran lejos de la tierra que lo vio nacer. Su producción escrita a partir de entonces resulta amplia y variada. Nos encontramos con un Rodolfo Reyes escritor, investigador, ensayista y conferencista inagotable. Los temas de su extensa obra se dirigen hacia tres materias fundamentales: el derecho, la temática hispanista/americanista y la historia. ${ }^{67}$

60 Informe leído por el secretario de la Escuela Nacional de furisprudencia en el acto de apertura de las clases del año escolar de 1903 y discurso pronunciado por el licenciado Rodolfo Reyes, México, Tipografía "El Lápiz del Águila", 1903.

61 Publicada en México, por Francisco Díaz de León en 1903.

62 "Un discurso del licenciado don Rodolfo Reyes y comentarios al mismo", El Tiempo, México, 1904; Legislación sobre carbón de piedra y petróleo. ¿Pueden declararse denunciables los yacimientos de carbón de piedra y depósitos de petróleo existentes en terrenos particulares?, México, Imp. de Escalante, 1907. Discurso de ingreso en la Academia Mexicana de Jurisprudencia y Legislación; La adición al artículo 102 constitucional, México, Imprenta y Librería de Inocencio Arriola, 1908; En honor del señor don Rafael Altamira. Discurso de recepción pronunciado por el académico de número licenciado Rodolfo Reyes, cit.; Discurso inaugural del periodo académico pronunciado por su secretario general y académico de número licenciado Rodolfo Reyes, en la solemne sesión de apertura, México, Academia Central Mexicana de Legislación y Jurisprudencia, 1912.

63 Memoria presentada al concurso abierto por el Nacional Colegio de Abogados: indicación motivada de las reformas que convendría hacer al Código de Procedimientos Federales, en el capitulo destinado al juicio de amparo, México, Imprenta "El Arte Moderno", 1906.

64 Reyes, Rodolfo y Barker, Frederick F., The Mining Lawes of Mexico. Containing a Translation of the Mining Law and Regulations and of the Mining Taxes Law and Regulations with an Introduction, Cross References and Alphabetical Index, México, The American Book and Printing Co., 1910.

65 Reyes, Rodolfo, Contribución al estudio de la evolución del derecho constitucional en México, México, Tipografía de la viuda de F. Díaz de León, Sucesores, 1911.

66 Sobre cuestiones mineras también véase Primer proyecto de ley minera presentado al señor ministro de fomento por los sres. ingenieros Eduardo Martínez Baca y Joaquín Ramos y licenciados Manuel Ortega y Espinosa, Fosé Luis Requena y Rodolfo Reyes (1909) y La agricultura y la ley minera (1911). Citadas en Núñez García, Víctor M., op. cit., p. 158.

67 De entre lo mucho publicado sobre estas líneas temáticas destaca: Posibilidades para una ciudadania hispanoamericana, Santander, Tip. La montaña, 1931; Indigenismo e Hispanidad, 
Este libro forma parte del acervo de la Biblioteca Jurídica Virtual del Instituto de Investigaciones Jurídicas de la UNAM

Como ya se dijo, en España continuó con sus actividades como abogado. Abrió un despacho en la calle Alcalá, número 123, de Madrid, y también llegó a tener despacho en la calle Arenal, número 12, de Bilbao. ${ }^{68}$ Perteneció a los Colegios de Abogados de ambas ciudades. ${ }^{69}$ Durante sus primeros años de exilio trabajó como representante legal de varias sociedades mercantiles vascas especializadas en la importación y la exportación al continente americano; lo que le permitió pasar habituales periodos, junto a su familia, en Bilbao y en la localidad guipuzcoana de Deva; además de visitar regularmente el continente americano, aunque no su país de origen. ${ }^{70}$

Los años como abogado postulante en México enriquecieron la visión que tenía sobre el juicio de amparo contenido en la Constitución mexicana de 1857, pues en el foro se dio cuenta de los aciertos y las fallas que la institución tenía en la letra constitucional. Durante su exilio buscó compartir esta experiencia, lo que hizo a poco de su llegada. Su discurso de ingreso en la Real Academia de Jurisprudencia y Legislación de Madrid, el 8 de febrero de 1916, versó sobre El juicio de amparo de garantías en el derecho constitucional mejicano. ${ }^{71}$ Sus trabajos posteriores dan cuenta del lugar que el juicio de amparo y las cuestiones constitucionales tuvieron en su producción intelectual. Por ejemplo, en 1917 prologó la célebre obra de Emilio Rabasa La organización política de México: la Constitución y la dictadura. ${ }^{72}$

De 1917 es también la nueva carta constitucional mexicana, de cuyos avances y cambios estaba al tanto Rodolfo Reyes, muestra de esto es que al mes siguiente de que dicho documento entrara en vigor abordó su contenido en la sesión del 28 de marzo de 1917 del Centro de Cultura Hispanoamericana. En esa ocasión ofreció un resumen de la nueva carta constitucional y expuso las principales innovaciones que contenía, "llamando sobre todo la atención acerca de las doctrinas avanzadas y peligrosas que sostiene

Madrid, Gráf. Afrodisio Aguado, 1940; El hombre americano y su culto a España, Bilbao, Tip. Hispano Americana, 1944; Los españoles en América, Madrid, Gráficas Barragán, 1946; Cuatro discursos: problemas interhispánicos; problemas constituyentes; el pensamiento político español; mestizaje americano, Madrid, Imp. Pueyo, 1933 y Benito fuárez: ensayo sobre un carácter, Madrid, Ediciones A.B.F., 1935. En Núñez García, Víctor M., op. cit., pp. 169 y 170.

68 Ibidem, pp. 159 y 160.

69 Esta información se encuentra en Reyes, Rodolfo, La defensa constitucional, cit.

70 Núñez García, Víctor M., op. cit., pp. 159 y 160.

71 Reyes, Rodolfo, El juicio de amparo de garantías en el derecho constitucional mejicano, Madrid, Est. Tip. de Jaime Ratés, 1916. Se trata de un folleto de 40 páginas. En Núñez García, Víctor M., op. cit., p. 160. Sobre las diversas actividades que realizó en España también da cuenta Garciadiego, Javier, en Cultura y política, cit., pp. 302-305.

72 Rabasa, Emilio, La organización política de México: la Constitución y la dictadura, prólogo de Rodolfo Reyes, Madrid, Editorial América, 1917. 
Este libro forma parte del acervo de la Biblioteca Jurídica Virtual del Instituto de Investigaciones Jurídicas de la UNAM

respecto de la propiedad y del problema agrario, así como acerca del hecho de que esta Constitución mejicana de 1917 dedique un capítulo especial á los problemas sociales relacionados con el trabajo". ${ }^{73}$

Como estudioso del derecho interesado en los cambios jurídicos que se originaron con el movimiento revolucionario no dejó de ser un crítico de la Constitución, aunque reconocía que muchas de sus ideas tenían un fondo de razón. Se decía más bien partidario de restablecer la Constitución de 1857, pero haciéndole las reformas necesarias con base en la socialización del derecho. ${ }^{74}$

Su exilio español también le permitió realizar algunas acciones a favor de sus colegas mexicanos. Llevó a cabo, por ejemplo, las gestiones necesarias para conseguir que se reorganizara la Academia Mexicana de Jurisprudencia y Legislación; pues ésta había quedado aniquilada con la Revolución de 1910 y la reacción contra Victoriano Huerta. Durante esos años muchos de sus integrantes habían muerto o sufrieron el exilio. "Así, en 1930, con ocasión de un viaje a Madrid del licenciado don Fernando Noriega, éste y Reyes se acercaron a la Academia matritense y obtuvieron que esta benemérita institución nombrara como sus individuos honorarios a un puñado de letrados mexicanos"75 y pasados algunos años el propio Reyes fue nombrado socio de mérito. ${ }^{76}$

Como puede verse, con sus acciones demostró que a pesar de los años y la distancia no dejaba de interesarse por el mundo jurídico mexicano y las transformaciones que en éste se originaron como consecuencia del proceso revolucionario; experiencia que le resultó útil cuando los vientos de cambio político soplaron en España y se vieron reflejados en la legislación. En este escenario, se comprende que en múltiples foros académicos, intelectuales e incluso hispanistas/americanistas su magisterio fuera muy tenido en cuenta a la hora de abordar temas jurídicos de diversa naturaleza. ${ }^{77}$

73 Cultura Hispanoamericana, núm. 53, año VI, 1917, p. 5.

74 Garciadiego, Javier, Cultura y política..., cit., pp. 306 y 307.

75 La Academia Mexicana de Jurisprudencia se instaló en agosto de 1930. El 12 de junio de 1948 Rodolfo Reyes fue nombrado socio de número y, en 1950, en agradecimiento, socio de mérito. En 1951 le otorgó el Premio Peña y Peña, destinado a honrar a los abogados distinguidos no vinculados directamente con la administración de justicia. Finalmente, en octubre de 1954, colocó su retrato en el salón de actos. En Mayagoitia, Alejandro, op. cit., p. 92.

76 El discurso que pronunció con este motivo lleva por título Discurso de recepción del académico de número y de mérito señor licenciado Rodolfo Reyes y contestación del académico de número señor licenciado Manuel Herrera y Lasso, México, Academia Mexicana de Jurisprudencia y Legislación correspondiente de la de España, 1950.

77 Núñez García, Víctor M., op. cit., p. 160. 
Este libro forma parte del acervo de la Biblioteca Jurídica Virtual del Instituto de Investigaciones Jurídicas de la UNAM

Lo anterior debido a la presencia que llegó a tener en numerosos espacios académicos y a su frecuente aparición en las páginas de revistas, así como la labor de divulgación que realizó sobre diversos temas, entre los que sin duda tuvieron un lugar destacado las cuestiones constitucionales y el juicio de amparo. Interés que se intensificó con la llegada de la Segunda República y la elección de las Cortes Constitucionales que a la postre serían las que darían al país la Constitución de $1931 .{ }^{78}$

El mismo Reyes dejó constancia escrita de sus afanes por dar a conocer en España las conquistas jurídicas logradas en México, principalmente las que estaban relacionadas con su experiencia constitucional. Para esto aprovechó todas las ocasiones que le brindó la hospitalidad española y en su obra Ante el momento constituyente español mencionó que materias como el juicio de amparo de garantías, del que se había ocupado en repetidas ocasiones en las Academias españolas, "han logrado ya conocimiento perfecto de parte de algunos eminentes profesores que han de dirigir la nueva conciencia jurídica de España, y confío en que algunas observaciones puedan ser tenidas en cuenta". ${ }^{79}$

Varios estudiosos han puesto de manifiesto la influencia que las reflexiones de Reyes tuvieron en el Constituyente español para la introducción del instrumento procesal que denominaron recurso de amparo de las garantías

78 Son varios los juristas españoles que afirman la influencia mexicana en la acción de amparo de la Constitución Española de 1931, entre los que se encuentran Alcalá-Zamora y Castillo, Niceto, "Significado y funciones del Tribunal de Garantías Constitucionales", en Alcalá-Zamora y Castillo, Niceto, Ensayos de Derecho Procesal (civil, penal y constitucional), Buenos Aires, Revista de Jurisprudencia Argentina, 1944, pp. 525-526; Alcalá-Zamora y Torres, Niceto, Los defectos de la Constitución de 1931, Madrid, Imprenta de R. Espinosa, 1936, pp. 44 y 45; Posada, Adolfo, La nouvelle Constitution spagnole. Le régime constitutionnel en Espagne: evolution, textes, commentaires, París, Recueil Sirey, 1932, p. 218; García Ruiz, José Luis, El recurso de amparo en el derecho español, Madrid, Editorial Nacional, 1980, p. 40; Oliver Araujo, Joan, El recurso de amparo, Palma de Mayorca, Jorvich, 1986, pp. 73 y 74, 87 y 88; Sánchez Agesta, Luis, Sistema político de la Constitución española de 1978, Madrid, Editorial Nacional, 1980, p. 387; Bassols Coma, Martín, La jurisprudencia del Tribunal de Garantías Constitucionales de la II República española, Madrid, Centro de Estudios Constitucionales, 1981, pp. 75 y 76; Jiménez de Asúa, Luis, Proceso histórico de la Constitución de la República española, Madrid, Reus, 1932, p. 75; Esteban, Jorge de, "Prólogo" a la obra de García Ruiz, José Luis, El recurso de amparo en el derecho español, cit., p. 10; Malagón Barceló, Javier, "Influencias del derecho español en Latinoamérica", Anuario de Estudios Americanos, Sevilla, EEHA, núm. XXIV, 1967, p. 1818; Fernández Segado, Francisco, La jurisdicción constitucional en España, Madrid, Dykinson, 1984, p. 123, y Tomás y Valiente, Francisco, Códigos y constituciones (1808-1978), Madrid, Alianza, 1989, pp. 171 y 172. Citados en Ferrer Mac-Gregor, Eduardo, La acción constitucional de amparo en México y España..., cit., pp. 120 y 121.

79 Reyes, Rodolfo, Ante el momento constituyente español, cit., p. 10. 
Este libro forma parte del acervo de la Biblioteca Jurídica Virtual del Instituto de Investigaciones Jurídicas de la UNAM

constitucionales en la carta de 1931.80 Niceto Alcalá-Zamora y Castillo ubica la influencia de Reyes años antes de la carta constitucional, en el proyecto de Tribunales de Amparo Ciudadano, presentado en 1928 por la Asamblea Consultiva. ${ }^{81}$

En este Proyecto ya se descubre la influencia de Rodolfo Reyes a través de artículos y conferencias, mediante los que dio a conocer dicha institución jurídica mexicana, aunque debe tomarse en cuenta que la imagen del juicio de amparo que difundió en España no era la que correspondía a la evolución de la institución, recogida en el artículo 107 de la carta federal del 5 de febrero de 1917, "sino más bien el concepto clásico y primario de la misma". ${ }^{82}$ Esto cobra sentido pues aunque estaba al tanto de los cambios políticos, legislativos y forales que se dieron en México en los años posteriores a su exilio, fue un crítico de la nueva carta constitucional de 1917; además, su experiencia como profesor, jurista y litigante se centró en el contenido de la anterior Constitución, la de 1857, y lo que en ella se estipuló respecto del juicio de amparo.

La influencia del jurista mexicano en el referido Proyecto fue sostenida por uno de sus comentadores, Eduardo Gómez de Vaquero, al citar una carta de Reyes dirigida al director de El Sol sobre la forma en que se había desarrollado el juicio de amparo en la legislación mexicana, "calificada por el jurista mexicano como la más fecunda institución jurídico-política de nuestra América".83

La llegada de la Segunda República fue un acontecimiento que captó de inmediato su atención y resulta comprensible que sus publicaciones y conferencias de esos años las dedicara a la nueva Constitución y a los cambios que se daban en la estructura española. ${ }^{84}$ En 1931 apareció su obra Ante el momento constituyente español. Experiencias y ejemplos americanos, ${ }^{85}$ texto importante para que las Cortes Constituyentes de 1931 conocieran el amparo mexi-

80 Fix-Zamudio, Héctor, Ensayos sobre el derecho de amparo, México, UNAM, Instituto de Investigaciones Jurídicas, 1993, p. 250.

81 Alcalá-Zamora y Castillo, Niceto, "Significado y funciones del Tribunal de Garantías Constitucionales", cit., p. 525.

82 Fix-Zamudio, Héctor, Ensayos sobre el derecho de amparo, cit., pp. 251 y 252.

83 Gómez de Baquero, Eduardo, "El amparo del derecho: jurisdicción o recurso", Revista General de Legislación y Furisprudencia, vol. 77, núm. 153, Madrid, Reus, 1928, p. 114. Citado en Fix-Zamudio Héctor, Ensayos sobre el derecho de amparo, cit., p. 251.

84 Garciadiego, Javier, Cultura y política..., cit., p. 309.

85 Reyes, Rodolfo, Ante el momento constituyente español. Experiencias y ejemplos americanos, Madrid, Compañía Ibero Americana de Publicaciones, 1931. 
Este libro forma parte del acervo de la Biblioteca Jurídica Virtual del Instituto de Investigaciones Jurídicas de la UNAM

cano. ${ }^{86}$ Niceto Alcalá-Zamora y Castillo, en su estudio sobre el Tribunal de Garantías Constitucionales, señaló que el mencionado recurso de amparo no se enlazaba directamente con el derecho medieval aragonés, sino que se inspiraba "hasta en el nombre en el régimen constitucional mejicano". ${ }^{87}$

En Luis Jiménez de Asúa tenemos un testigo de primera mano sobre las vicisitudes que se dieron durante la creación de la carta constitucional de 1931. Este jurista fue nombrado presidente de la comisión parlamentaria que compuso el Proyecto de Constitución de la II República. ${ }^{88} \mathrm{Al}$ reconocer que no era especialista en derecho constitucional quiso rejuvenecer sus conocimientos de derecho público y acudió a los libros más modernos sobre derecho constitucional, además de consultar los textos de las viejas y nuevas Constituciones de Europa y América. ${ }^{89}$

Para Jiménez de Asúa la Constitución mexicana de 1917, la de Rusia de 1918 y la de Alemania de 1919, abrían sus textos "a toda una teoría de derechos y ansias populares que antes no correspondían al puro concepto constitucional de la época individualista". ${ }^{90}$ Pues si se comparan las viejas cartas políticas con las modernas Constituciones de la posguerra - sigue diciendo Jiménez de Asúa-, es fácil percibir en sus textos nuevos artículos que antes no figuraban en las leyes fundamentales del Estado y que muestran que el campo político se ensanchó por los afanes sociales y que el pueblo se cuida más de garantizar sus conquistas.

Estas preocupaciones se revelaban en las leyes fundamentales de posguerra de los tres países mencionados; cada una caracterizada por sus particularidades. Por lo que toca a las garantías establecidas en esas Constitu-

86 Alejandro Mayagoitia, op. cit., p. 92. Sobre este tema también véase Ferrer Mac-Gregor, Eduardo, "La Constitución española de 1931", Revista de Investigaciones Furídicas, México, núm. 23, 1999, pp. 168-173; del mismo autor Ensayos sobre derecho procesal constitucional, México, Porrúa, 2004, y Flores, Alfredo y Machorro Narváez, Paulino, Carta del licenciado Alfredo Flores y oración fúnebre del licenciado Paulino Machorro Narváez en honor del doctor y licenciado Rodolfo Reyes, Academia Mexicana de Jurisprudencia y Legislación, 1954, pp. 10 y 11.

87 Alcalá-Zamora y Castillo, Niceto, "Significado y funciones...", cit., p. 525.

88 Sobre el Anteproyecto de Constitución y la Comisión Jurídica Asesora da noticias Ángel Ossorio y Gallardo en Mis memorias, Madrid, Tebas, 1975, pp. 175 y ss. También Nicolás Pérez Serrano abordó el proceso por el cual se llegó a concretar la Constitución Española de 1931, entre otras cuestiones, trató de la actividad realizada por la Comisión Jurídica Asesora y la Comisión de Constitución, encabezada esta última por Luis Jiménez de Asúa. Esto se puede consultar en Pérez Serrano, Nicolás, La Constitución Española, Madrid, Revista de Derecho Privado, 1932, pp. 22-29.

89 Jiménez de Asúa, Luis, Constitución de la República Española, Madrid, Reus, 1932, pp. IX y X.

90 Ibidem, pp. 47 y 48. 
Este libro forma parte del acervo de la Biblioteca Jurídica Virtual del Instituto de Investigaciones Jurídicas de la UNAM

ciones, se pueden sintetizar en dos ideas: no se concebía ya que los únicos derechos que necesitaban ser protegidos o reconocidos fueran los de la persona individual, sino que con el mismo título se buscaba amparar a las entidades colectivas, lo que permitió que entraran a la Constitución la familia, el sindicato y las asociaciones de toda índole. En segundo lugar, ya no bastaban las meras afirmaciones de principios, que resultaban muchas veces ineficaces en la lucha con el Poder Ejecutivo y aun con el judicial; era necesario algo más, la verdadera garantía, "mediante la regulación concreta y normativa, y el corolario de unos recursos y una jurisdicción ante la cual acudir para promover la queja o exigir el cumplimiento del derecho desconocido por la autoridad". ${ }^{91}$

Con esta finalidad se creó el Tribunal de Garantías Constitucionales ${ }^{92}$ en España, "que es parecido, en parte, al de Austria, pero, sobre todo, es una síntesis del régimen de Norteamérica, del juicio de Amparo de Méjico [sic] y del Tribunal de Conflictos de Francia". ${ }^{93}$ Menciona Jiménez de Asúa que sobre el juicio de amparo mexicano el doctor Rodolfo Reyes ha escrito importantes trabajos, pero resultó de especial relevancia para la Constitución de la República Española el trabajo Ante el momento constituyente español, ${ }^{94}$ en el que comentó en forma minuciosa la regulación jurídica y el funcionamiento del juicio de amparo mexicano. ${ }^{95}$

Después de la entrada en vigor de la Constitución republicana de 1931 Reyes continuó escribiendo sobre la experiencia constituyente en España, relacionándola frecuentemente con la americana. En 1932 apareció su trabajo "España Constituyente y América". ${ }^{96} \mathrm{Al}$ año siguiente se publicó su obra Cuatro discursos, ${ }^{97}$ uno de los cuales dedicó a los que consideró problemas constituyentes.

91 Ibidem, pp. 62-65.

92 Este Tribunal apareció por primera vez en el mecanismo legal español ya que la Comisión entendió que era muy conveniente que no prevalecieran las leyes anticonstitucionales, además de que pudieran ser fácilmente dirimidos "los conflictos del Estado con las Regiones y de éstas entre sí; que se exija responsabilidad criminal a Jueces y Magistrados, Ministros y Presidente de la República; que haya juicio de amparo, y que exista una función jurisdiccional para el examen de las actas de Diputados y Senadores". En Jiménez de Asúa, Luis, Constitución de la República Española, cit., pp. 19 y 20.

93 Ibidem, pp. 75 y 76.

94 Se trata de la obra de Reyes, Rodolfo, Ante el momento constituyente español. Experiencias y ejemplos americanos, cit.

95 Fix-Zamudio, Héctor, Ensayos sobre el derecho de amparo, cit. p. 251.

96 Reyes, Rodolfo, "España Constituyente y América", La Rábida. Revista Colombina Iberoamericana, 2a. época, núm. 206, año XX, 1932.

97 Reyes, Rodolfo, Cuatro discursos..., op. cit. 
Este libro forma parte del acervo de la Biblioteca Jurídica Virtual del Instituto de Investigaciones Jurídicas de la UNAM

En 1934 apareció publicado su trabajo La defensa constitucional en la que realizó un estudio comparativo con las instituciones españolas establecidas tanto en la Constitución de 1931 como en la Ley Reglamentaria del Tribunal de Garantías Constitucionales. ${ }^{98}$ A través de las Cartas prólogo que contiene la obra y que fueron escritas por los juristas Angel Ossorio y Víctor Pradera también se hacen alusiones a los trabajos del tratadista mexicano en el seno de las Cortes Constituyentes, en particular con motivo de la aprobación de la citada Ley Orgánica del Tribunal de Garantías. ${ }^{99}$ En su breve escrito Ossorio rememora la "entusiasmada asiduidad de Reyes [en las Cortes Constituyentes], que no perdía sesión, presenciándola primero en la tribuna, comentándola después en los pasillos y mostrando siempre una afanosa inquietud por el bien de España, por el éxito de España”. ${ }^{100} \mathrm{El}$ mismo Reyes incorpora en esta obra las menciones que se hicieron a sus trabajos en el debate de la Ley Orgánica del Tribunal de Garantías en las Cortes Constituyentes. ${ }^{101}$ En los años que siguieron al triunfo del franquismo Reyes continuó con su producción jurídica aunque el interés por los aspectos constitucionales se deja ver más discreto. ${ }^{102}$

Tenemos, pues, a un jurista mexicano exiliado definitivamente por cuestiones políticas y que muere lejos su patria. Colaborador en revistas, autor de prólogos, artículos periodísticos e interesantes estudios sobre derecho constitucional. Un estudioso del derecho que dejó su país cuando contaba con poco más de treinta años y que en el exilio consolidó los conocimientos que había adquirido en México, los que se vieron enriquecidos con la experiencia que obtuvo en Europa y otros países americanos a los que viajó desde España.

98 La intención que guió el trabajo era explicar el Recurso de Inconstitucionalidad y el Amparo de Garantías "en el actual estado de la legislación española, los más importantes antecedentes, el modo como aquellos se incorporaron al Derecho español, su procedimiento y algunos problemas anexos". En Reyes, Rodolfo, La defensa constitucional, cit., p. 17.

99 Estas Cartas prólogo se pueden consultar en Rodolfo Reyes, La defensa constitucional, cit., pp. 9-16.

100 Ossorio, Ángel, "Cartas prólogo", en Reyes, Rodolfo, La defensa constitucional, cit., p. 10 .

101 Reyes, Rodolfo, La defensa constitucional, op. cit., p. 7.

102 En 1945 publicó un folleto titulado Fisionomía jurídica mexicana, Madrid, Reus; en 1946 escribió el epílogo a la obra de Francisco Villena Sindicación profesionaly legislación social: a través de la historia, la doctrina y los continentes, introducción de Alberto Martin-Artaje, Madrid, Prensa Española; en 1949 apareció el prologó a la obra de Juan Giménez Bayo y Lino RodríguezArias Bustamante, La propiedad intelectual: compilación y comentarios de las disposiciones legales vigentes en España con su jurisprudencia, Madrid, Reus. En 1950 salió al mercado su obra Aspectos jurídicos mexicanos, Madrid, Reus. 
Este libro forma parte del acervo de la Biblioteca Jurídica Virtual del Instituto de Investigaciones Jurídicas de la UNAM

Un Rodolfo Reyes que sobrevivió a varios conflictos bélicos, tanto nacionales como internacionales: la Revolución mexicana, la Primera Guerra Mundial, la Guerra Civil Española y la Segunda Guerra Mundial. Sin duda, su experiencia de vida le permitió madurar tanto como persona como en su faceta intelectual, lo que se reflejó en los intereses profesionales a los que dedicó su existencia. Un Rodolfo Reyes que en 1932 declaró que su ambición en la vida era terminar sus libros, "enseñar a los jóvenes algo útil y dejar a mis hijos, en España y México (pues tengo hijos de ambas nacionalidades), establecidos en patrias ya organizadas y ordenadas bajo las fórmulas que su soberanía dicte a cada una". ${ }^{103}$

\section{FUENTES DE CONSULTA}

Alcalá-Zamora y Castillo, Niceto, "Significado y funciones del Tribunal de Garantías Constitucionales", en Ensayos de derecho procesal. Civil, penal y constitucional, Buenos Aires, Revista de Jurisprudencia Argentina, 1944.

Altamira y Crevea, Rafael, Mi Viaje a América. (Libro de documentos), Oviedo, Universidad de Oviedo, 2007.

Cabrera Acevedo, Lucio, La Suprema Corte de Justicia a principios del siglo XX. 1901-1914, México, SCJN, 1993.

FerRer MAC-Gregor, Eduardo, La acción constitucional de amparo en México y España, 4a. ed., México, Porrúa-UNAM, 2007.

FIX-ZAMUdio, Héctor, Ensayos sobre el Derecho de amparo, México, UNAM, Instituto de Investigaciones Jurídicas, 1993.

Gaceta de Madrid, núm. 298, 25 de octubre de 1930.

GARCIADIEGO, Javier, Autores, editoriales, instituciones y libros. Estudios de historia intelectual, México, El Colegio de México, 2015.

Garciadiego, Javier, Cultura y política en el México posrevolucionario, México, INEHRM, 2006.

Garciadiego, Javier, Politica y literatura. Las vidas paralelas de los jóvenes Rodolfo y Alfonso Reyes, México, Centro de Estudios de Historia de México Condumex, 1990.

JiMÉNeZ DE AsúA, Luis, Constitución de la República Española, Madrid, Reus, 1932.

LIRA, Andrés, "Emilio Rabasa y Rodolfo Reyes. Del exilio político a la actua-

103 Encuesta realizada a Rodolfo Reyes Ochoa, op. cit., p. 2. 
Este libro forma parte del acervo de la Biblioteca Jurídica Virtual del Instituto de Investigaciones Jurídicas de la UNAM

lidad constitucional", manuscrito presentado en el seminario Formación Política de México. Siglos XVI-XX, México, El Colegio de México-CEH, 2015. Martínez, José Luis (ed.), Alfonso Reyes/Pedro Henríquez Ureña. Correspondencia 1907-1914, t. I, México, Fondo de Cultura Económica, 1986.

MaYagoitia, Alejandro, "El concurso científico y artístico del centenario de la independencia o la historia del derecho como ditirambo", Anuario Mexicano de Historia del Derecho, México, núm. XIII, 2001.

Moral Roncal, Antonio Manuel, El asilo diplomático en la Guerra Givil Española, Madrid, Actas Editorial, 2001.

NúÑez García, Víctor M., "A ambos lados del Atlántico: Hispanismo y exilio en la figura de Rodolfo Reyes Ochoa", en MÁrQUez MACÍAs, Rosario (ed.), Huelva y América. Cien años de Americanismo. Revista "La Rábida" (19111933). De corresponsales y colaboradores, Sevilla, UNIA, 2014.

Ortuño Martínez, Manuel (ed.), Isidro Fabela y Luis I. Rodríguez, Diplomáticos de Cárdenas. Una trinchera mexicana en la Guerra Civil (1936-1940), Madrid, Trama Editorial, 2007.

Ossorio y Gallardo, Ángel, Mis memorias, Madrid, Tebas, 1975.

OSSORIO Y GALLARDO, Ángel, "Cartas prólogo", La defensa constitucional. Recursos de inconstitucionalidady amparo, Madrid, Espasa-Calpe, 1934.

Periódico ABC de Madrid, 5 de junio de 1954.

Periódico ABC de Madrid, 17 de febrero de 1949.

Pérez Serrano, Nicolás, La Constitución española, Madrid, Revista de Derecho Privado, 1932.

RABASA, Emilio, La organización política de México: la Constitución y la dictadura, prólogo de Rodolfo Reyes, Madrid, Editorial América, 1917.

Reyes OchOA, Rodolfo, De mi vida. La bi-revolución española, México, Jus, 1948, t. III.

Reyes OCHOA, Rodolfo, "El derecho de asilo en la tragedia española", $L a$ Justicia. Revista Quincenal de Legislación y Jurisprudencia, México, t. IX, núm. $125,1939$.

REYES OcHOA, Rodolfo, La defensa constitucional. Recursos de inconstitucionalidady amparo, Madrid, Espasa-Calpe, 1934.

Reyes OCHOA, Rodolfo, "España Constituyente y América", La Rábida. Revista Colombina Iberoamericana, 2a. época, núm. 216, año XX, 1932.

REyes OchOA, Rodolfo, Encuesta “¿Qué opina V. de su actual vida políticoliteraria?", La Rábida. Revista Hispanoamericana, Huelva, segunda época, año XX, núm. 220, 30 de noviembre de 1932. 
Este libro forma parte del acervo de la Biblioteca Jurídica Virtual del Instituto de Investigaciones Jurídicas de la UNAM

REYES OCHOA, Rodolfo, Ante el momento constituyente español. Experiencias y ejemplos americanos, Madrid, Compañía Ibero Americana de Publicaciones, 1931.

Reyes OchoA, Rodolfo, De mi vida. Memorias políticas. México 1913-1914, Madrid, Biblioteca Nueva, 1930, t. II.

Reyes OchoA, Rodolfo, De mi vida. Memorias políticas, 1899-1913, Madrid, Biblioteca Nueva, 1929, t. I.

REYES OCHOA, Rodolfo, El juicio de amparo de garantías en el derecho constitucional mejicano, Madrid, Est. Tip. de Jaime Ratés, 1916.

Reyes OchoA, Rodolfo, Contribución al estudio de la evolución del derecho constitucional en México, México, Tipografía de la viuda de F. Díaz de León, Sucesores, 1911. 
Este libro forma parte del acervo de la Biblioteca Jurídica Virtual del Instituto de Investigaciones Jurídicas de la UNAM

\title{
LOS DERECHOS SOCIALES EN LA CONSTITUGIÓN DE QUERÉTARO Y EN LA ESPAÑOLA DE LA II REPÚBLICA
}

\author{
Mario BEDERA BRAVO*
} SUMARIO: I. Introducción. II. Contexto histórico y sociopolítico. III. Ges-
tación de los derechos sociales en México y en España. IV. Bibliografía.

\section{INTRODUGCIÓN}

La expresión "derechos sociales" que aparece en el título de este trabajo debe entenderse intercambiable con la de "derechos económicos, sociales y culturales", de mayor predicamento entre los estudiosos de la teoría del Estado y en especial entre quienes cultivan la parcela de los derechos humanos. Su constitucionalización significó probablemente "la conquista más importante

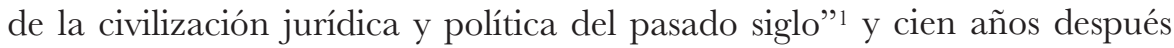
de verse reflejados por vez primera en la carta magna de Querétaro, cobran especial relieve en nuestros días en un momento desocializador, de retroceso generalizado de las políticas de bienestar.

En todo caso, con dicho término se trata de señalar un momento posterior del proceso de reconocimiento de los derechos humanos superada la fase de los derechos civiles y de los políticos. ${ }^{2}$ Estos tienen como principal

* Universidad de Valladolid (España).

1 Ferrajoli, Luigi, "Prólogo", en Abramovich, Víctor y Courtis, Christian, Los derechos sociales como derechos exigibles, Madrid, Trotta, 2015, p. 9.

2 No es este el lugar de debatir si los llamados derechos civiles y políticos deben entenderse como pertenecientes a una misma generación de derechos fundamentales. Aunque aquí se traten de forma conjunta por razones de economía expositiva, en nuestra opinión los derechos políticos se encuentran histórica y teleológicamente más próximos a los derechos sociales que a los civiles; o como señala Peces-Barba, "suponen una segunda generación, al menos inicialmente, más impulsada por quienes propugnaban los derechos sociales en el siglo XIX, que por quienes lo hicieron con los individuales y civiles en el siglo XVIII", véase Peces-Barba Martínez, Gregorio, "Los derechos económicos, sociales y culturales: su génesis 
Este libro forma parte del acervo de la Biblioteca Jurídica Virtual del Instituto de Investigaciones Jurídicas de la UNAM

paradigma la libertad y exigen la no injerencia de los poderes públicos en la esfera privada que deben limitarse, de forma pasiva, a vigilar su cumplimiento.

Por el contrario, el reconocimiento de los derechos sociales parte de la quiebra del principio de la libertad por la presión de las exigencias de la igualdad. ${ }^{3} \mathrm{Su}$ origen debe situarse en "la desigual distribución de la riqueza y de la propiedad que impide que muchas personas puedan satisfacer por sí mismas sus necesidades básicas". ${ }^{4}$ Lo relevante será la diferencia que existe entre individuos de una misma sociedad y, por consiguiente, la necesidad de partir de una discriminación de hecho que ponga en manos de los desfavorecidos los instrumentos necesarios para que puedan competir y convivir con quienes no necesitan de ayuda alguna.

El reconocimiento constitucional de los derechos sociales en el primer tercio del siglo XX exigirá pues una intervención activa de los poderes públicos; ya no estaremos ante obligaciones negativas o de abstención como en el caso de los derechos de primera y segunda generación; ${ }^{5}$ ahora será necesario impulsar acciones positivas. De este modo, los derechos sociales se convierten en derechos de crédito frente a la sociedad y el Estado y reconocen a los sujetos la posibilidad de exigir determinadas protecciones sociales.

Pues bien, la Constitución de Querétaro cuyo centenario origina este trabajo, fue la primera en reconocer estos derechos de tercera generación

y su concepto", Derechos y Libertades: Revista del Instituto Bartolomé de las Casas, núm. 6, 1998, pp. 15-34, en especial p. 19. Este planteamiento conduce a reconocer a los derechos sociales como derechos de tercera generación.

3 Castro Cid, Benito de, Los derechos económicos, sociales y culturales. Análisis a la luz de la teoría de los derechos humanos, León, Universidad de León, 1993, p. 28. En la misma línea y citado por el anterior, Díaz, Elías, "Ideología y derecho: para una crítica de la cultura jurídica de la sociedad burguesa”, Anales de la Cátedra Francisco Suárez, núm. 17, 1977, pp. 43-68, esp. p. 48 al realizar la crítica del iusnaturalismo.

Esta afirmación no equivale a identificar a los derechos económicos, sociales y culturales como los derechos de la igualdad y mucho menos enfrentar derechos de la libertad y derechos de la igualdad, véase Rodríguez Palop, María Eugenia, La nueva generación de derechos humanos. Origen y justificación, Madrid, Dykinson, 2010, pp. 82-84.

4 Peces-Barba Martínez, Gregorio, op. cit., p. 31.

5 Conviene señalar que la expresión "generación" de derechos humanos se utiliza aquí únicamente por su utilidad para explicar el idéntico nacimiento y evolución de algunos de ellos así como también las características que comparten cada grupo o generación, sin olvidar la posibilidad que brinda la perspectiva histórica de plantear el posible nacimiento de nuevos derechos que respondan a nuevas necesidades y no porque la historia otorgue justificación alguna a ningún derecho, véase Rodríguez Palop, María Eugenia, Claves para entender los nuevos derechos humanos, Madrid, Catarata, 2011, pp. 40 y 41 y La nueva generación de derechos humanos, cit., pp. 89-92 a quien seguimos. 
Este libro forma parte del acervo de la Biblioteca Jurídica Virtual del Instituto de Investigaciones Jurídicas de la UNAM

pero además, generalizó el interés por los mismos y sirvió de catalizador para que los derechos sociales se incorporaran a los nuevos textos constitucionales de todo el mundo en un claro intento por conciliar los viejos principios liberales con las exigencias derivadas del nuevo orden social. ${ }^{6}$ Nuevo orden social que supuso importantes modificaciones en el modelo organizativo del Estado mexicano y que convierte a la Constitución de 1917 en la pionera del Estado social de derecho, ${ }^{7}$ haciendo que algunas de las políticas sociales producto de la Revolución se identifiquen, como afirma el profesor Soberanes, con los perfiles definidores del Estado del bienestar que verá la luz tras la Segunda Guerra Mundial. ${ }^{8}$

Con anterioridad, el interés por estos temas había crecido en paralelo a la llamada "cuestión social" producto del nuevo orden económico impuesto con la Revolución Industrial. La necesidad de respuesta por parte de los poderes públicos para reparar o al menos mitigar las desigualdades sociales nacidas del proceso de industrialización y de la anomia legal que le daba

6 Para entender esta conciliación puede resultar de interés señalar que, incluso en la etapa de auge de los derechos clásicamente liberales, la tradición constitucionalista latinoamericana siempre ha sido mucho más proclive a la intervención del Estado sin que por ello se haya considerado tal actitud como una amenaza a la libertad, antes al contrario, se entendía como "un elemento fundamental para el cumplimiento de derechos y deberes", véase Paolo G. , "La perspectiva histórica del aporte latinoamericano al concepto de los Derechos Económicos, Sociales y Culturales", en Ely Yamin, Alicia (coord.), Los derechos económicos, sociales y culturales en América Latina. Del invento a la herramienta, México, Plaza y Valdés, 2006, p. 48.

7 Aunque se trate de un lugar común en la doctrina hacer corresponder la primera generación de derechos humanos (derechos civiles y políticos) con el Estado liberal de Derecho y la segunda (derechos sociales, económicos y culturales) con el Estado social, véase entre otros posibles Pérez Luño, Antonio-Enrique, La tercera generación de derechos humanos, Pamplona, Aranzadi, 2006, p. 28, en puridad, hay derechos sociales cuyo reconocimiento se produce en el marco del Estado liberal (Preámbulo de la Constitución francesa del 24 de junio de 1793 que contiene las referencias al derecho a la educación, la asistencia social o al trabajo, incorporadas de la Declaración de Derechos del Hombre y del Ciudadano), por más que su valor jurídico sea inexistente hasta que mucho más tarde se asuma la naturaleza normativa de la Constitución. Véase Matia Portilla, Francisco Javier, "Droits sociaux et droits fondamentaux", en Bon Pierre (dir.), Trente ans d'application de la Constitution espagnole, París, Dalloz, 2009, pp. 43-71.

8 Soberanes Fernández, José Luis, "Los derechos económicos y culturales en México", en Zapatero, Virgilio y Garrido, Ma. Isabel (eds.), Los derechos sociales como una exigencia de la justicia, Madrid, Universidad de Alcalá-Defensor del Pueblo, 2009, p. 64, reconociendo así su mayor influencia histórica pues aunque las expresiones Estado social y Estado de bienestar se consideren a menudo equivalentes, el primero responde al modelo inicial planteado por el liberalismo y el Estado de bienestar al propugnado por la socialdemocracia sobre todo tras la Segunda Guerra Mundial, véase esta última diferencia en Sotelo, Ignacio, El Estado social: Antecedentes, origen, desarrollo y declive, Madrid, Trotta, 2010, esp. pp. 230-232 y 267-268. 
Este libro forma parte del acervo de la Biblioteca Jurídica Virtual del Instituto de Investigaciones Jurídicas de la UNAM

cobertura, dio lugar a un amplio debate teórico a mediados del siglo XIX ${ }^{9}$ y a la adopción de las primeras reformas sociales en los Estados europeos más industrializados. Estos debates tendrán su acabada plasmación constitucional en el denominado constitucionalismo social del periodo de entreguerras, sin que esta afirmación haga olvidar lo que algún autor ha denominado "la prehistoria del constitucionalismo social", refiriéndose a las realizaciones del constitucionalismo revolucionario francés, desde la Declaración de Derechos del Hombre y del Ciudadano de 1789, donde tímidamente aparece una referencia a lo público dentro del ámbito de los derechos individuales, hasta las Constituciones de 1791 y 1793 que recogen en su articulado el tratamiento social de la propiedad, la instrucción pública o los socorros mutuos. ${ }^{10}$

Mayor importancia merece como precedente la Constitución de la II República francesa de 1848; producto de la llamada Primavera de los Pueblos, la oleada de revoluciones liberales que recorrieron Europa en esa fecha y que sumaron por vez primera la voz del incipiente movimiento obrero, recoge en su texto la regulación de las relaciones entre patronos y obreros y un interesante artículo 13 que la aproxima a los textos del periodo de entreguerras. Mirkine-Guetzévitch, advertía en 1931 que si "las Declaraciones de 1789 y 1793 encerraban ya, al lado de los derechos negativos, obligaciones positivas del Estado en lo relativo a la instrucción pública y a la asistencia social, la Constitución de 1848 fue aún más lejos y estableció el principio de la protección del trabajo". ${ }^{11}$ De hecho, algún destacado constitucionalista mexicano no duda en señalar que "si se atiende únicamente al contenido de la Constitución, la francesa de 1848, resultado asimismo de una revolución (como la mexicana), fue la primera que incluyó las relaciones obrero-patronales... (y) por ende... derechos sociales de gran calado". ${ }^{12}$ Sin embargo, su

9 Véase Carmona Cuenca, Encarnación, El Estado social de derecho en la Constitución, Madrid, Consejo Económico y Social, 2000, pp. 31-39, donde se abordan las dos formas de tratar la cuestión social en el siglo XIX: La seguida por el marxismo y el socialismo revolucionario, y la que apuesta por el reformismo social de la mano del socialismo moderado (Lasalle, Kautsky...) y del pensamiento social-conservador (von Stein, Wegener...) que para la autora constituyen "el verdadero antecedente del actual concepto de Estado social".

10 Pérez Ayala, Andoni, "Los orígenes del constitucionalismo social. Una aproximación desde una perspectiva histórico-comparativa”, en García Herrera, Miguel Ángel (dir.), El constitucionalismo en la crisis del estado social, Bilbao, Universidad del País Vasco, 1997, pp. 336 y ss.

11 Mirkine-Guetzévitch, Boris, Modernas tendencias del derecho constitucional, Madrid, Reus, 2011 (trad. en 1933 por Sabino Álvarez-Gendín de Les nouvelles tendances du droit constitutionnel, Paris, Marcel Giard, 1931), p. 134.

12 Valadés, Diego, "La función constitucional de la estabilidad social", en Cienfuegos 
Este libro forma parte del acervo de la Biblioteca Jurídica Virtual del Instituto de Investigaciones Jurídicas de la UNAM

efímera vida, pues fue derogada apenas tres años después de promulgarse, su nula influencia en otros sistemas constitucionales y la falta de efectividad para la que había nacido, la relegaron, en mi opinión, a un simple ensayo dentro de la historia del constitucionalismo social que inauguraría la Constitución mexicana de 1917. ${ }^{13}$

\section{CONTEXTO HISTÓRICO Y SOCIOPOLÍTICO}

Aunque cada Constitución es hija de su tiempo, la Constitución de Querétaro y la Española de la II República tienen similitudes históricas, políticas y sociales que conviene resaltar para entender mejor las causas y el contexto en que aparecerán regulados en ellas los derechos sociales.

Querétaro es el resultado de un sincopado proceso revolucionario de siete años, tras seis lustros de gobierno dictatorial de Porfirio Díaz, y de una grave situación económica y social que afecta a la mayoría de la población cuyos anhelos de revertir la injusta estructura de la propiedad de la tierra, en un país predominantemente agrario, quedaría pronto reflejada en el Plan de San Luis Potosí de 1910 y en el Plan de Ayala de un año después.

Por su parte, la Constitución de la II República española señala el arranque de un proceso que si no puede denominarse revolucionario en el sentido mexicano, supone una profunda transformación de las estructuras políticas anteriores. La España de la Restauración aun cuando fuera un régimen representativo, al contrario que el Porfirismo, compartió con él la ausencia de democracia. ${ }^{14}$ A su vez, la postración socioeconómica, la injusta distribución de la riqueza y el importante contingente de campesinos sin tierra, al que en el caso español habrá que añadir el creciente descontento obrero, perfilan en los últimos años del reinado de Alfonso XIII un escenario similar al mexicano, abocado a la catarsis política.

Por otra parte, la Constitución mexicana de 1917 y la española de 1931 se inscriben histórica e ideológicamente en un contexto de superación del liberalismo clásico. Frente a la exaltación del individualismo y a sus deriva-

\footnotetext{
Salgado, David y Macías Vázquez, María Carmen (eds.), Estudios en homenaje a Marcia Muñoz de Alba Medrano: estudios de derecho público y política, México, UNAM, 2006, p. 392.

13 En el mismo sentido, Pérez Ayala, Andoni, "Los orígenes del constitucionalismo social", cit., p. 341, y el mismo Valadés, Diego, "La función constitucional", cit., p. 392.

14 Barrio Alonso, Ángeles, “¿Constitucionalización de derechos o institucionalización de su ejercicio?: la cuestión de los derechos sindicales en España y México (1910-1930)”, en Cano, Aurora et al. (eds.), Cultura liberal, México y España 1860-1930, Santander, Universidad de Cantabria, 2010, p. 505.
} 
Este libro forma parte del acervo de la Biblioteca Jurídica Virtual del Instituto de Investigaciones Jurídicas de la UNAM

das de libertad, seguridad y propiedad con que se legitimaba el orden social del primer liberalismo, aparecerá a finales del siglo XIX un "nuevo liberalismo" como corriente de pensamiento que desplegará su acción reformista tanto por Europa como por América.

El nuevo liberalismo se va a caracterizar por una modificación en la forma de entender la primitiva ecuación individuo-sociedad, en el sentido de asegurar la libertad del primero pero a través de una política de asistencia social. Esta renovación social del liberalismo ${ }^{15}$ implicará la intervención del Estado pero dicho intervencionismo no será homogéneo ni se reflejará con igual intensidad en todos los países.

En México se utilizará la vía directa que proporciona la Revolución. En 1910 Francisco I. Madero inicia un movimiento revolucionario que en sus siete años de duración se irá tiñendo de componentes sociales hasta que cristalice en la Constitución de 1917.

La nueva carta magna dibuja "un proyecto nacional de construcción de un Estado moderno, próximo al modelo interventor y árbitro del nuevo liberalismo europeo" 16 que abordará con generosidad la principal reclamación del sector radical que acaba triunfando en el constituyente: la reforma de la propiedad agraria, ${ }^{17}$ y que aprovechará para avanzar en la solución de la cuestión obrera fijando las reglas que garanticen a futuro la paz social. Ambos temas capitales, recogidos en los artículos 27 y 123, esbozaban constitucionalmente un Estado protector que aunaba el primitivo objetivo carrancista de estructurar políticamente al país, con el obregonista de dotarlo de la suficiente consistencia social, "que asegure al individuo un mínimo decoroso de existencia". 18

En España, por el contrario, el proceso será distinto y mucho más lento. El reformismo social aparecerá como producto de la frustración de expectativas y el desencanto hacia los principios defendidos por el liberalismo clásico. Será pues la crisis del modelo individualista tradicional lo que provoque que las diferentes familias del liberalismo español abracen las reformas y

15 Langewiesche, Dieter, "Liberalismo y burguesía en Europa”, en Fradera, Josep Ma. y Millán, Jesús (eds.), Las burguesías europeas del siglo XIX. Sociedad civil, política y cultura, Valencia, Biblioteca Nueva-Universitat de València, 2000, p. 199.

16 Barrio Alonso, Ángeles, “¿Constitucionalización de derechos o institucionalización de su ejercicio?", cit., p. 497.

17 Wolf, Eric R., Las luchas campesinas del siglo XX, México, Siglo Veintiuno, 1979, pp. 13-76 para México.

18 Carpizo, Jorge y Madrazo, Jorge, "El sistema constitucional mexicano”, en García de Belaunde, D. et al. (eds.), Los sistemas constitucionales iberoamericanos, Madrid, Dykinson, 1992, p. 566. 
Este libro forma parte del acervo de la Biblioteca Jurídica Virtual del Instituto de Investigaciones Jurídicas de la UNAM

con ello apuesten por la intervención del Estado; intervención y reformismo "que no formaban parte previamente del programa de ninguna de las corrientes liberales", ${ }^{19}$ muy al contrario de lo acontecido en México cuando en 1906 Ricardo Flores Magón presentó el "Programa del Partido Liberal y Manifiesto a la Nación" donde, reconociéndose la libertad individual, se la condiciona a la intervención del Estado para garantizar así la protección social. ${ }^{20}$

Cuando iniciado el siglo XX se constate también la frustración de las nuevas iniciativas y se empiece a pensar que la causa del problema social no reside en las imperfecciones del régimen de libre concurrencia sino en el régimen mismo, socialistas y republicanos habían tomado ya la bandera de un nuevo reformismo social que debería conducir a un nuevo derecho, mientras los partidos liberales perdían el tren de la modernidad. La tardía crisis del liberalismo clásico español producto del retraso en la implantación de los principios liberales, unida al escaso arrastre electoral inicial de los partidos de nuevo cuño hizo que ese nuevo reformismo no tuviera un anclaje constitucional y se viera superado por los planteamientos democráticos y socializantes de la Constitución republicana de 1931.

\section{GESTACIÓN DE LOS DERECHOS SOCIALES EN MÉXICO Y EN ESPAÑA ${ }^{21}$}

Desde la óptica de la historia del derecho constitucional, los textos de Querétaro y de la II República se inscriben en el llamado constitucionalismo de entreguerras cuya principal característica fue la acogida de los derechos sociales. Esta idea estuvo muy presente en ambos países, antes incluso de iniciarse los procesos constituyentes propiamente dichos.

19 Cabrera, Miguel Ángel, El reformismo social en España (1870-1900). En torno a los orígenes del Estado del Bienestar, Valencia, Universitat de València, 2014, p. 37.

20 El Programa enumera algunas de las líneas de fuerza que acabarán reflejadas en la Constitución de Querétaro como la obligación de los patronos de "dar alojamiento higiénico a los trabajadores"; "pagar indemnización por accidentes del trabajo"; o "hacer productivas todas las (tierras) que posean", véase La Revolución mexicana. Crónicas, documentos, planes y testimonios, estudio introductorio, selección y notas de Javier Garciadiego, México, UNAM, 2010, p. 57-67.

21 Aunque la expresión derechos sociales pueda incluir los referidos a la familia, la educación, etcétera, en este artículo nos ceñimos al estudio del trabajo y los derechos laborales junto a la propiedad y la reforma agraria por ser los más significativos que debatió el constituyente de Querétaro cuyo centenario conmemoramos. 
Este libro forma parte del acervo de la Biblioteca Jurídica Virtual del Instituto de Investigaciones Jurídicas de la UNAM

En México, porque forma parte de la propia esencia revolucionaria y así será recordado en momentos solemnes como el discurso de Carranza en Hermosillo en septiembre de 1913:

Pero sepa el pueblo de México que terminada la lucha armada a que convoca el plan de Guadalupe tendrá que principiar formidable y majestuosa la lucha social... (y) las nuevas ideas sociales tendrán que imponerse en nuestras masas... Tendremos que removerlo todo. Crear una nueva Constitución... Nos faltan leyes que favorezcan al campesino y al obrero, pero éstas serán promulgadas por ellos mismos, puesto que ellos serán los que triunfen en esta lucha reivindicadora y social. ${ }^{22}$

También en las adiciones al Plan de Guadalupe en diciembre de 1914, por las que se establece el compromiso de expedir, durante la lucha, las leyes agrarias, laborales y fiscales que satisfagan las necesidades económicas, sociales y políticas del país.

En el caso español, aún excluido el componente revolucionario, los acontecimientos se desarrollan de forma similar. El 15 de abril, al día siguiente de proclamada la II República, el gobierno publica un Estatuto Provisional, una especie de Constitución para el tiempo de interinidad, ${ }^{23}$ donde declara su voluntad de "...ensanchar (los derechos de los ciudadanos), adoptando garantías de amparo para aquellos derechos y reconociendo como uno de los principios de la moderna dogmática jurídica el de la personalidad sindical y corporativa, base del nuevo derecho social". ${ }^{24}$ Pero además, en los siguientes meses y antes de su plasmación constitucional, desde el Ministerio de Trabajo se impulsan varias leyes sobre laboreo forzoso de las tierras, contrato de trabajo, seguro de enfermedad, etcétera, que ponen de relieve el compromiso del nuevo gobierno con el derecho social anunciado en el Estatuto Provisional.

De nuevo, en el arranque mismo de ambos procesos constituyentes y, más en concreto, en los discursos de presentación de los proyectos constitucionales ante los respectivos parlamentos, se vuelve a insistir en la idea de dar respuesta a las demandas sociales de la población.

En México, cuando el ciudadano primer jefe entrega al Congreso de la Unión el Proyecto de Constitución, el 1o. de diciembre de 1916, declara

22 Ibidem, doc. 36, pp. 193-198.

23 Clavero, Bartolomé, Manual de historia constitucional de España, Madrid, Alianza, 1989, p. 173.

24 Artículo 4o. del Decreto del Gobierno Provisional de la República, Gaceta de Madrid, núm. 105, 15 de abril de 1931, p. 195. 
Este libro forma parte del acervo de la Biblioteca Jurídica Virtual del Instituto de Investigaciones Jurídicas de la UNAM

que con las reformas que se presenta espera "que las instituciones políticas del país responderán satisfactoriamente a las necesidades sociales (del pueblo)". ${ }^{25}$

En España, Jiménez de Asúa presenta el 27 de agosto de 1931 el Proyecto de Constitución redactado por la comisión constitucional de la que él es presidente y señala:

El título III... más que una parte dogmática, puede afirmarse que se trata de una parte substantiva, porque han de ser llevados ahí todos aquellos derechos, aspiraciones y proyectos que los pueblos ansían... Fijémonos... en la Constitución mejicana de 1917... (que) engrandece el territorio de los derechos del hombre de una manera extraordinaria, y van a parar ahí, no sólo los derechos individuales, sino los derechos de las entidades colectivas: Sindicatos, familia, etc. ${ }^{26}$

\section{Trabajo y derechos laborales}

El carácter predominantemente agrario de la economía mexicana había provocado que durante el proceso revolucionario no hubiera reclamaciones laborales significativas de modo que la cuestión obrera estuvo oscurecida ante el problema de la propiedad de la tierra, verdadera urgencia nacional y fundamento último de la Revolución. Este mismo escenario se trasladó al artículo 5o. del proyecto de Carranza que regulaba la libertad de trabajo casi en los mismos términos que la carta federal de 1857, regulación que resultó claramente insuficiente para el sector radical de la asamblea que postulaba una amplia consignación de los derechos de los trabajadores en el texto constitucional. Aunque Carranza siempre estuvo más preocupado por la organización del poder y su correspondiente plasmación constitucional, una vez conseguido su objetivo principal de dotar al país de una presidencia fuerte, tuvo la habilidad política de atender las demandas de los constituyentes puestas de manifiesto en el acalorado debate de las navidades de 1916. ${ }^{27}$ Fueron sus hombres de confianza quienes en los primeros diez días

25 Diario de los Debates del Congreso Constituyente, núm. 12, 1o. de diciembre de 1916, p. 343.

26 Diario de Sesiones, Cortes constituyentes, núm. 28, 27 de agosto de 1931, pp. 643, 645 y 646 .

27 Admitida la necesidad de recoger en el texto los derechos obreros, la discusión se planteó sobre la extensión que debían tener los mismos para no convertir a la Constitución en una norma reglamentaria. El carrancista Lizardi alegaba que "este último párrafo...: La jornada máxima de trabajo obligatorio no excederá de ocho horas, le queda al artículo exactamente como un par de pistolas a un santo Cristo" (Diario de los Debates, núm. 36, 26 de di- 
Este libro forma parte del acervo de la Biblioteca Jurídica Virtual del Instituto de Investigaciones Jurídicas de la UNAM

de 1917 llevaron a cabo lo que posiblemente pase por ser el sucedáneo de comisión más heterodoxo y eficaz de la historia del constitucionalismo, ${ }^{28}$ que concluyó con la aprobación por unanimidad del Título VI y que justifica las palabras del maestro Carpizo: "Una de las etapas más bellas en la lucha por la libertad, la igualdad y la dignidad humana en México, se desarrolló en los días que nuestro Constituyente discutió los antecedentes del art. $123 " .29$

Con el nombre, "Del Trabajo y la Previsión social", el citado título dice regular las bases sobre las que deben expedirse las leyes laborales pero en realidad reguló casi todos los aspectos de la vida laboral del trabajador: desde la jornada laboral a los criterios salariales, pasando por los derechos de sindicación y huelga. Tuvo también el acierto de incluir el germen de algunas instituciones muy avanzadas para su tiempo como la obligación patronal de alojar al trabajador, el servicio de colocación, las bases de la Seguridad Social o la participación en las utilidades de las empresas. ${ }^{30}$

El contenido de este artículo y su prolija redacción le dota de un elemento de originalidad, irrepetible en el constitucionalismo comparado, que

ciembre de 2016, p. 850). Los radicales respondían con el discurso del diputado Manjarrez, quien tras afirmar que "esta revolución no es una revolución política, sino una revolución social”, añadía, "¿quién nos garantizará que el nuevo Congreso habrá de estar integrado por revolucionarios? ...si es preciso pedirle a la comisión que nos presente un proyecto en que se comprenda todo un título... yo estaré con ustedes porque con ello habremos cumplido nuestra misión de revolucionarios", (Diario de los Debates, cit., pp. 861 y 862). Finalmente, Cravioto, renovador y autoproclamado carrancista, aceptaba que "para venir a procurar el mayor bien de nuestro pueblo" se pudieran intercalar "ciertas cosas reglamentarias en nuestro derecho constitucional" y tras aceptar que todas las cuestiones obreras se reunieran en un artículo especial, pronunció unas palabras que resultaron premonitorias, “...artículo especial que sería el más glorioso de todos nuestros trabajos aquí; pues, así como Francia, después de su revolución, ha tenido el alto honor de consagrar en la primera de sus cartas magnas los inmortales derechos del hombre, así la Revolución mexicana tendrá el orgullo legítimo de mostrar al mundo que es la primera en consignar en una Constitución los sagrados derechos de los obreros" (Diario de los Debates, cit., p. 897).

28 Véase Carpizo, Jorge, La Constitución mexicana de 1917, México, UNAM, 1982, p. 99, donde relata que la presidencia no nombró una Comisión especial encargada de redactar el título específico sobre el trabajo, sino que tácitamente se entendió que Pastor Rouaix dirigía la "comisión" acompañado por José Natividad Macías, a los que se sumaron por invitación otros técnicos ministeriales no constituyentes. Las reuniones o "juntas", en las que no se levantó acta alguna ni había presidencia formal, se celebraron en el antiguo palacio episcopal y acudían a ellas los diputados que tenían algo que decir al respecto.

29 Ibidem, p. 93.

30 Fix-Zamudio, Héctor, "La Constitución y el Estado social de Derecho", en El constitucionalismo en las postrimerías del siglo XX. La Constitución mexicana 70 años después, México, UNAM, 1988, t. V, p. 83. 
Este libro forma parte del acervo de la Biblioteca Jurídica Virtual del Instituto de Investigaciones Jurídicas de la UNAM

ya entonces provocó la admiración de expertos publicistas como el socialista español Luis Araquistáin quien recordaba que el artículo 123, "entre otras providencias notables por lo justas y humanitarias, establece la jornada máxima de ocho horas y la obligación de someter las diferencias entre capital y trabajo a los laudos de una Junta de conciliación" y que sólo por esta razón debería ser imitado por España. ${ }^{31}$

No será ésta la única referencia de las reformas laborales mexicanas que llegaron a España. A diferencia de Querétaro y Weimar, el constituyente republicano dispone de modelos filtrados diariamente por la prensa socialista y liberal-izquierdista que siguió puntualmente los acontecimientos desde el inicio de la Revolución. ${ }^{32}$ Periódicos reformistas como El Sol pero también anarquistas como Tierra y Libertad, de izquierdas como El Socialista o revistas como la republicana España, publicaban de forma regular artículos donde exaltaban las reformas laborales que constitucionalizaban aspiraciones míticas del proletariado internacional mientras en España seguía en vigor la Constitución de 1876, típico ejemplo del liberalismo clásico y, por tanto, ajeno al reconocimiento de los derechos sociales.

Las crónicas de la época reflejaron también los efectos del artículo 123 de la Constitución de Querétaro en el mundo laboral mexicano posterior a 1917. Si en el momento de su promulgación se convirtió en una de las claves de la estabilidad social mexicana y hubo coincidencia en afirmar que amplió los derechos de los obreros ante los patronos, también la hubo en manifestar que no ocurrió otro tanto con el movimiento sindical desde el momento en que empezó a depender del poder político. Esta asimilación es cierto que favoreció en muchas ocasiones a los trabajadores, pero no lo es menos que éstos se vieron impelidos a ajustar sus reivindicaciones a los objetivos gubernamentales, ${ }^{33} \mathrm{o}$ en palabras del profesor Valadés, se produjo

31 Araquistáin, Luis, La revolución mejicana. Sus orígenes. Sus hombres. Su obra, Madrid, Renacimiento, 1929, p. 229. Buen conocedor de la política mexicana y estudioso de su revolución, su obra tuvo gran resonancia en España. Araquistáin fue diputado en la legislatura constituyente, formó parte de la comisión constitucional que elaboró la carta magna de la II República y ocupó la subsecretaría del Ministerio de Trabajo con Largo Caballero.

32 Delgado Larios, Almudena, La revolución mexicana en la España de Alfonso XIII (19101931), Salamanca, Junta de Castilla y León, 1993.

33 Delgado Larios, Almudena, "Una revolución regeneracionista: la reforma laboral y educativa mexicana en la prensa española (1910-1931)", Revista Complutense de Historia de América, núm. 17, 1991, p. 219-257, esp. p. 256. Con mayor especificidad puede consultarse la obra clásica de Barry Carr, El movimiento obrero y la política en México, 1910-1929, 2 vols., trad. de R. Gómez Ciriza, México, Secretaría de Educación Pública, 1976, y también Leff Zimmerman, Gloria, "Los pactos obreros y la institución presidencial en México (1915-1938)", Estudios sociológicos, vol. IX, núm. 27, 1991, pp. 527-540. 
Este libro forma parte del acervo de la Biblioteca Jurídica Virtual del Instituto de Investigaciones Jurídicas de la UNAM

la paradoja de que las políticas encaminadas a la tutela de los derechos de los trabajadores fueron acompañadas por una sensible merma de la libertad sindical. ${ }^{34}$

En España, por razones obvias, la aureola de seducción que había generado la Revolución mexicana en numerosos intelectuales extranjeros, se sentía más cercana y para muchos españoles, México y su Constitución señalaban el camino a seguir en materia de reconocimiento de derechos sociales. El propio Araquistáin, defendiendo la identificación entre sindicatos y gobierno, justificaba inicialmente el carácter restrictivo de la legislación mexicana en materia de huelga arguyendo que de esta manera se moderaba a los elementos más irreflexivos. ${ }^{35}$ Sin embargo, como ha estudiado la profesora Ángeles Barrio, ${ }^{36}$ cuando finalmente el constituyente español acometa la tarea de redacción del apartado relativo a los derechos obreros y sindicales, los sindicatos de clase ya no exhibirán el artículo 123 de Querétaro como el modelo a imitar. La seducción por la Revolución seguía estando presente pero no ocurría lo mismo ni con Carranza ni con el movimiento obrero mexicano a los que, sobre todo la poderosa CNT, no consideraba auténticamente revolucionarios. Quizás este extremo, unido a la alta calidad técnica de la Carta de Weimar que tuvo al insigne jurista Hugo Preuss como principal redactor, y a la diferente técnica normativa utilizada en las Constituciones europeas de entreguerras, fueran posibles motivos por los que la Constitución de Weimar, especialmente su artículo 165, sirviera finalmente de guía a los artículos 46 y 47 de la Constitución de la II República Española.

La cuestión social se pondrá de relieve desde la discusión del artículo 1o. de la Constitución republicana donde se define a España como una "República democrática de trabajadores de toda clase", expresión ilustrativa de la orientación social del nuevo régimen político que se inauguraba. ${ }^{37}$

34 Valadés, Diego, "La función constitucional", cit., p. 406.

35 “...estas formas de conciliación entre el capital y el trabajo no son gratas a los obreros más radicales, a los del todo o nada; pero representan un enorme avance en las relaciones de los obreros y patronos mejicanos", véase Araquistáin, Luis, La revolución mejïcana, cit., p. 235.

36 Barrio Alonso, Ángeles, “¿Constitucionalización de derechos o institucionalización de su ejercicio?”, cit., pp. 507-513.

37 Tal redacción no estuvo exenta de polémica. Inicialmente se propuso la expresión, más aséptica, de "República democrática" que fue modificada en el debate parlamentario por el de "República de trabajadores" lo que concitó el vivo rechazo de una parte de la Cámara y de personalidades que, como Ortega y Gasset, advertían de su semejanza con términos contenidos en El Manifiesto del Partido Comunista. La expresión final, con el añadido "de toda clase", fue fruto de una transacción propuesta por el propio presidente de la Repú- 
Este libro forma parte del acervo de la Biblioteca Jurídica Virtual del Instituto de Investigaciones Jurídicas de la UNAM

El tratamiento expreso del trabajo se contiene en el artículo 46 donde al tiempo que se le considera una obligación social, se le dota, en palabras de Pérez Serrano, "de un vasto y generoso programa de política social, que recoge todos los aspectos importantes de la protección del obrero". ${ }^{38}$ La enumeración de supuestos abarca todo el conjunto de la vida laboral del obrero, como corresponde a una "República de trabajadores", 39 aunque está lejos de la exhaustiva enumeración del texto de Querétaro pues deja para desarrollo posterior cuestiones como el seguro de enfermedad y accidentes, la protección a la maternidad, las vacaciones anuales, etcétera. Las referencias a la legislación protectora del obrero del artículo 46 se completan con la inclusión de otras categorías específicas de trabajadores en el artículo 47 como son los campesinos y los pescadores, sólo justificable por el peso de los sectores agrícola y pesquero. ${ }^{40}$

Como se ha señalado con anterioridad, la Constitución Española de 1931 es deudora en temas laborales de la de Weimar y en especial de su completo artículo 165 cuyo autor intelectual fue Hugo Sinzheimer, el padre del derecho del trabajo alemán, para quien la labor del constituyente consistió en crear una "Constitución social específica, al lado de la Constitución política". ${ }^{41}$

\section{Propiedad, expropiación y reformas agrarias}

En el maravilloso mural pintado por Diego Rivera en el Palacio Nacional de Ciudad de México dedicado a la epopeya del pueblo mexicano, se destacan los artículos 27 y 123 como los más significativos de la Constitución de Querétaro. Sin embargo, siendo esto cierto, los estudiosos de la Constitución mexicana coinciden en priorizar la importancia de los derechos laborales porque estos se plasman de forma novedosa mientras que los

blica, Alcalá-Zamora, que rebajó la tensión pero no la eliminó como quedó demostrado en la igualada votación final.

38 Pérez Serrano, Nicolás, La Constitución española (9 diciembre 1931). Antecedentes. Texto. Comentarios, Madrid, Editorial Revista de Derecho Privado, 1932, p. 201. A su condición de catedrático de Derecho político, Pérez Serrano unía la de letrado en las Cortes Constituyentes lo que le sitúa como observador privilegiado del proceso.

39 Cabe significar que, al igual que en Weimar y a diferencia de Querétaro, la Constitución de la II República no recoge explícitamente el derecho de huelga.

40 Pérez Ayala, Andoni, "Los orígenes del constitucionalismo social”, cit., p. 346.

41 Herrera, Carlos Miguel, "Teoría constitucional de lo social”, en Valadés, Diego et al. (coords.), Ideas e instituciones constitucionales en el siglo XX, México, Siglo Veintiuno, 2011, p. 261. 
Este libro forma parte del acervo de la Biblioteca Jurídica Virtual del Instituto de Investigaciones Jurídicas de la UNAM

relativos a la propiedad agraria ya venían siendo parcialmente atendidos a lo largo del siglo XIX.

En efecto, desde los tiempos de la colonia, uno de los principales problemas de México era la injusta distribución de la tierra. A mediados de siglo los reformistas liberales llevaron a cabo una decidida política de reforma legal de la propiedad agraria que, sin embargo, se deslizó hacia la fragmentación de la propiedad más que al reparto efectivo de la tierra, y hacia la desamortización de los bienes de la Iglesia pero también de las comunidades indígenas y de los ayuntamientos con los que se constituirán las haciendas rurales mexicanas. ${ }^{42}$ Esta normativa, en especial la Ley de Desamortización de fincas rústicas y urbanas propiedad de corporaciones civiles y eclesiásticas de junio de 1856, que el liberalismo decimonónico creyó definitiva, nunca logró los objetivos perseguidos ${ }^{43}$ porque al ser confirmada en el artículo 27 de la Constitución de 1857 obligó a la parcelación y titulación individual de ejidos y terrenos comunales entre los vecinos, lo que ocasionó un nuevo triunfo de los latifundistas que acabaron comprando sus parcelas al faltarles los recursos para poder trabajarlas. ${ }^{44}$ Los vecinos, sin medios de subsistencia, se vieron condenados en muchos casos a la condición de peones acasillados $^{45}$ en las haciendas levantadas sobre los antiguos terrenos ejidales.

Urgía pues que la Revolución tomara medidas desde el primer momento para realizar una verdadera reforma agraria, y así se hizo en el Plan de San Luis Potosí (octubre de 1910) ${ }^{46}$ y al año siguiente cuando Zapata lanzó

42 Véase Guevas Murillo, Óscar, "La política de desamortización de bienes en Zacatecas durante las reformas liberales (1856-1876)", Revista mexicana de Historia del Derecho, 32, 2015, pp. 95-143, esp. p. 103 y 114.

43 La crítica puede encontrase tempranamente en dos de los precursores del agrarismo mexicano: Molina Enriquez, Andrés, Los grandes problemas nacionales, México, A. Carranza e Hijos, 1909, y en Orozco, Wistano Luis, Legislación y jurisprudencia sobre terrenos baldios, 2 vols., México, El Tiempo, 1895 y La organización de la República. Tratado primero: Los ejidos de los pueblos. Exposición jurídica, Guadalajara, Impr. José Cabrera, 1914; véase su influencia en Cuevas Murillo, Óscar, "La reforma liberal en materia de propiedad según Wistano Luis Orozco y Andrés Molina Enríquez", Anuario Mexicano de Historia del Derecho, núm. 20, 2008, pp. 97-128.

44 Rouaix, Pastor, Génesis de los artículos 27 y 123 de la Constitución politica de 1917, México, Instituto Nacional de Estudios Históricos de las Revoluciones de México, 2016, p. 196.

45 Ulloa, Berta, Historia de la Revolución mexicana 1914-1917, núm. 6, La Constitución de 1917, México, El Colegio de México, 1988, p. 343.

46 Artículo 3o.: “...Abusando de la ley de terrenos baldíos, numerosos pequeños propietarios, en su mayoría indígenas, han sido despojados de sus terrenos... (por lo que) se les exigirá a los que los adquirieron de un modo tan inmoral... que los restituyan a sus primitivos propietarios...", véase La Revolución mexicana, cit., 101. 
Este libro forma parte del acervo de la Biblioteca Jurídica Virtual del Instituto de Investigaciones Jurídicas de la UNAM

el Plan de Ayala (noviembre de 1911), ${ }^{47}$ momento cumbre donde se confirma la naturaleza agraria de la Revolución mexicana ${ }^{48}$ a la vez que la Junta Zapatista de Morelos desconoce como presidente y jefe de la Revolución a Madero. Las tensiones entre los dos grupos revolucionarios tuvieron siempre el telón de fondo de la propiedad de la tierra y su restitución a los campesinos; por ello, cuando Carranza proclama el Plan de Guadalupe (marzo de 1913) con el que repudia al gobierno de Huerta e intenta acercar posiciones con los sureños de Zapata, estos le hacen saber que la condición sine qua non para cualquier negociación pasa por la sumisión del primer jefe del Ejército Constitucionalista y de sus generales al Plan de Ayala. ${ }^{49}$

Tras el fracaso de concordia en la Convención de Aguascalientes (octubre-noviembre de 1914), Carranza dio a conocer las adiciones al Plan de Guadalupe (diciembre de 1914) con la intención de legitimarse ante los campesinos y restar apoyos a Zapata y Villa. Su artículo 2o. contenía la promesa de promulgar "leyes agrarias que favorezcan la formación de la pequeña propiedad, disolviendo los latifundios y restituyendo a los pueblos las tierras de que fueron injustamente privados". ${ }^{50}$ La promesa se hará realidad el 6 de

47 Que el Plan de San Luis señala el camino a seguir queda claro en el artículo 4o. del Plan de Ayala: "La Junta revolucionaria del Estado de Morelos, manifiesta a la Nación, bajo formal protesta: Que hace suyo el Plan de San Luis de Potosí, con las adiciones que a continuación se expresan...", véase Menegus Bornemann, Margarita (ed.), El agrarismo de la Revolución mexicana, Madrid, Agencia Española de Cooperación Internacional, 1990, p. 34.

48 Recuérdese que lo que empezó como una revuelta política se transformó en revolución social y la clave de ésta residió en el campo. "Mientras el maderismo fue predominantemente urbano, la revolución fue rural", véase Knight, Alan, La Revolución mexicana. Del Porfiriato al nuevo régimen constitucional, Vol. I, Porfiristas, liberales y campesinos, México, Grijalbo, 1996, p. 109.

49 Informe del licenciado Luis Cabrera y del general Antonio I. Villarreal a don Venustiano Carranza, primer jefe del Ejército Constitucionalista (4 de septiembre de 1914), en La Revolución mexicana, cit., pp. 245-257, donde relatan su visita al cuartel general del ejército zapatista en Cuernavaca el 27 de agosto por encargo de Carranza. Allí se les comunica que "la Revolución de Guadalupe no es más que un incidente en el movimiento nacional, que debe considerarse supeditado a la de Ayala". Se les explica también que "en el estado de Morelos la cuestión agraria ya está resuelta... las usurpaciones ya están reivindicadas (y) las tierras repartidas", y además, se les hace saber que interpretan "como actitud sospechosa la de que el jefe del Ejército Constitucionalista no haya querido nunca hacer una declaración de sus principios políticos y agrarios...".

50 Resulta llamativo observar la evolución política de Carranza, producto de su indudable genio político. Tan solo seis meses antes (8 de julio de 1914), el primer jefe constitucionalista se había negado a aceptar, por excesivamente radicales, los acuerdos a los que habían llegado sus representantes con los del general Francisco Villa en la ciudad de Torreón. Sin embargo, el programa de reformas de las adiciones al Plan de Guadalupe será más ambicioso que el Pacto de Torreón con el propósito de disipar las dudas que sobre su intención de 
Este libro forma parte del acervo de la Biblioteca Jurídica Virtual del Instituto de Investigaciones Jurídicas de la UNAM

enero de 1915 cuando Carranza expide la Ley Agraria con la que arrebata a los zapatistas la bandera del agrarismo. ${ }^{51}$

La trascendencia de este texto es capital ya que, de una parte, introduce los dos procedimientos para la redistribución de la propiedad agraria: la restitución y la dotación, ${ }^{52}$ declarando nulas las enajenaciones de tierras, aguas y montes en contravención a lo dispuesto en la ley del 25 de junio de 1856, y de otra, porque no sólo justifica el movimiento revolucionario sino que postula la tesis de que "todos los individuos, por el hecho de existir, tienen derecho a que la sociedad les proporcione los medios de subsistencia". ${ }^{53}$ La importancia cardinal de la Ley Agraria de 1915 hizo que fuera doblemente inmortalizada: por Diego Rivera en su mural, donde aparece sostenida por su redactor, Luis Cabrera, y por los constituyentes de 1917 que acabaron otorgándole rango constitucional en el artículo 27.

La significación social de la cuestión agraria, base de la revolución rural, auguraba un tratamiento acorde en el proyecto constitucional que presentó Carranza, sin embargo las expectativas se vieron defraudadas y si la resistencia al redactado original del artículo 123 fue importante, al del 27 fue aún superior.

Aunque el problema agrario era más urgente que el laboral, esa misma importancia, unida al rechazo del texto inicial y al volumen de trabajo de las comisiones, hizo que la discusión se fuera retrasando hasta casi agotar la fecha del 31 de enero señalada como límite de los trabajos del constituyente. ${ }^{54}$

Finalmente, los propios diputados agraristas urgieron a que se adoptara la misma solución tomada en su día respecto del artículo 123: encargar los trabajos a una junta especial que actuara con gran flexibilidad y poner al frente de ella al mismo diputado, Pastor Rouaix, que con tanto éxito había dirigido la anterior. Así se acordó y a pesar de un primer intento frustrado y en un tiempo récord, la iniciativa liderada por el diputado poblano se presentó el 24 de enero guiada como él mismo manifestó, "por un principio básico, sólido e inalterable: que sobre los derechos individuales a la propie-

reforma agraria pudiera tener el campesinado, a la vez que tomaba la iniciativa estratégica frente a villistas y zapatistas que confirmaría poco después con la ley agraria. Véase, en este sentido, Gilly, Adolfo, La revolución interrumpida, México, Era, 2007, p. 200.

51 Véase Ramírez, María de Jesús, "La política agraria en México: de la ley de desamortización de 1856 al reparto de tierras ejidales", disponible en: http://wrere.economia.unam.mx/cla dhe/registro/ponencias/473_abstract, para entender la pugna entre constitucionalistas y zapatistas.

52 Fix-Zamudio, Héctor, "La Constitución y el Estado social de derecho", cit., p. 89.

53 Silva Herzog, Jesús, Trayectoria ideológica de la Revolución mexicana, 1910-1917, México, Cuadernos americanos, 1963, p. 99.

54 Rouaix, Pastor, Génesis de los artículos 27 y 123, cit., p. 180. 
Este libro forma parte del acervo de la Biblioteca Jurídica Virtual del Instituto de Investigaciones Jurídicas de la UNAM

dad, estuvieran los derechos superiores de la sociedad, representada por el Estado, para regular su repartición, su uso y su conservación". ${ }^{55}$ Pasó a la comisión dictaminadora y su dictamen favorable empezó a discutirse el 29 de enero para aprobarse definitivamente a las tres y media de la madrugada del día 31, el último posible.

El discurso del diputado Bojórquez resumía claramente lo que representaba el problema de la propiedad de la tierra que se estaba dilucidando: "Digo que la cuestión agraria es el problema capital de la revolución, porque en la conciencia de todos los revolucionarios está que si no se resuelve debidamente este asunto, continuará la guerra". ${ }^{56}$

El texto final consagra los derechos sociales de los campesinos en lo que el profesor Pérez Ayala ha denominado "constitucionalismo social agrario" 57 y asigna a la propiedad una nueva función social rompiendo con la concepción clásica del derecho romano (ius utendi et abutendi) al atribuir originariamente a la nación la propiedad de las tierras y aguas y la facultad de transmitir a los particulares el dominio de ellas que constituye la propiedad privada. ${ }^{58}$ Pero a la vez, acomete la restitución de tierras a los campesinos y la posibilidad de fraccionar y expropiar latifundios para dotar de tierras a los que carezcan de ellas.

En definitiva y a diferencia del artículo 123 que tuvo que crearse ex novo, la cuestión agraria, tal como afirmó el maestro Fix-Zamudio, ${ }^{59}$ tenía ya una base jurídica sobre la que construir el edificio del artículo 27, como así se hizo. Todos los extremos de la Ley Agraria del 6 de enero de 1915: las dotaciones y restituciones de tierras, así como el disfrute de tierras, bosques y aguas, encontraron entonces acomodo constitucional.

Desde el punto de vista del reformismo liberal, con los artículos 27 y 123 la obra de Querétaro inauguraba la obligación exigible al Estado de intervenir directa y activamente en la vida económica para proteger los derechos de obreros y campesinos. Si la carta magna de 1857 fue obra de

55 Ibidem, p. 192.

56 Diario de los Debates, núm. 80, 31 de enero de 1917, p. 1887.

57 Pérez Ayala, Andoni, "Los orígenes del constitucionalismo social", cit., p. 344.

58 Rouaix, Pastor, Génesis de los artículos 27 y 123, cit., p. 193. Rouaix es aquí deudor de las ideas de Wistano Luis Orozco sobre el dominio eminente que corresponde sólo a la República y que no puede ceder a ninguna otra instancia, ni siquiera a los Estados (al contrario de lo que se hizo con la Ley de Colonización del 8 de agosto de 1824). Este argumento del dominio dividido, deslizado desde la recepción romano-canónica hasta el derecho mexicano, estará presente también en la obra de Molina Enríquez y a través de él pasará al artículo 27 de la mano de Pastor Rouaix.

59 Fix-Zamudio, Héctor, "La Constitución y el Estado social de derecho", cit., p. 89. 
Este libro forma parte del acervo de la Biblioteca Jurídica Virtual del Instituto de Investigaciones Jurídicas de la UNAM

unos constituyentes que tuvieron que afrontar con gran dignidad la conflictividad social que envolvió sus deliberaciones ${ }^{60}$ para consignar en su texto los principios del liberalismo clásico, los constituyentes queretanos serán convocados por Venustiano Carranza para modificar ${ }^{61}$ aquellos parámetros clásicos e introducir la obligación del Estado de intervenir activamente en la vida económica para proteger los derechos de obreros y campesinos. Esta rectificación, que los debates del constituyente llevaron al límite tanto en cuestiones laborales como agrarias, imprimió al Estado mexicano un sello inequívoco de Estado interventor reformista y promotor de la justicia social que algún autor llega a considerar precursor del Estado social y democrático de derecho. ${ }^{62}$

En España, si algún aspecto de la Revolución mexicana tuvo especial eco fue el de la reforma agraria. Como ya se ha señalado, la épica en torno a sus protagonistas se extendió por toda Europa y caló especialmente en aquellos países que atravesaban una situación política y social que pudiera parecer asimilable, como ocurrió en el caso español.

En la España de la Restauración, la cuestión agraria era una de las materias recurrentes y la escalada de violencia que provocaban los enfrentamientos empezaba a dejar entrever el potencial revolucionario que anidaba en los campos. Consignas como "la tierra es para el que la trabaja", de claras resonancias zapatistas, se escuchaban habitualmente en las concentraciones del campo andaluz donde la imagen del latifundista absentista y las masas de jornaleros que trabajan la tierra ajena en situación de hambre y miseria recuerda los motivos agrarios que prendieron la mecha de la Revolución mexicana. La oleada de huelgas campesinas entre 1918 y 1920, conocida como el "Trienio bolchevique", ${ }^{63}$ provocó que la opinión pública

60 Zertuche Muñoz, Fernando, "El Congreso constituyente de 1856-1857: el decenio de su entorno", en Valadés Diego y Carbonell, Miguel (coords.), El proceso constituyente mexicano. A 150 años de la Constitución de 1857 y 90 de la Constitución de 1917, México, UNAM, 2007, p. 864.

61 Conviene recordar que la idea inicial de Carranza era modificar la Constitución de 1857, por más que el debate constituyente posterior acabara generando una nueva Constitución que, no obstante, sigue formalmente denominándose "Constitución Política de los Estados Unidos Mexicanos que reforma la de 5 de febrero de 1857", véase Diario Oficial, núm. 30, 5 de febrero de 1917, p. 1.

62 Noriega Cantú Alfonso, "El nacimiento de los derechos sociales", en El constitucionalismo en las postrimerías del siglo XX. La Constitución mexicana 70 años después, México, UNAM, 1988, t. V, pp. 206 y 207.

63 El término procede de Juan Díaz del Moral, Historia de las agitaciones campesinas andaluzas: Córdoba. (Antecedentes para una reforma agraria), Madrid, 1928, aunque su expresión exacta fuera "Trienio bolchevista". La visión del estallido de un movimiento revolucionario en el campo andaluz entre los años 1918-1920 que se transmitió a través de su obra, tuvo gran eco 
Este libro forma parte del acervo de la Biblioteca Jurídica Virtual del Instituto de Investigaciones Jurídicas de la UNAM

volviera la mirada hacia México que pocos años antes había puesto los medios para resolver, al menos jurídicamente y en su carta magna, los problemas sociales del campo y además lo había hecho con un cambio radical de modelo político.

En la España bipolar de finales de la Restauración, para los partidarios de un cambio de régimen político y socioeconómico, el triunfo de la Revolución mexicana, que sobre todo se consideraba campesina, fue un momento de gran esperanza; liberales progresistas, republicanos, socialistas y anarquistas denunciaban en la prensa afin la situación de penuria que reinaba en el campo español y la necesidad de actuar como se estaba haciendo en México. El propio diario anarquista, Tierra y Libertad, iniciaba en mayo de 1911 una suscripción pública para recaudar fondos en favor de la Revolución mexicana, confiando en el posible efecto contagioso de la misma en España. Mientras, los sectores más conservadores trataban de silenciar el éxito del movimiento revolucionario mexicano y utilizaban su prensa leal para trasladar una imagen de anarquía generalizada, cargando las tintas en el indigno despojo que sufrían los hacendados españoles en México a los que se privaba ilegítimamente de sus tierras. ${ }^{64}$

En este contexto se producía el advenimiento ${ }^{65}$ de la II República y ya desde el propio Estatuto Provisional del 15 de abril, el nuevo gobierno proclamaba su compromiso con los campesinos a la vez que anticipaba la fórmula social de intervención del Estado en la economía agraria del país, alejándose por tanto del modelo tradicional del liberalismo clásico. ${ }^{66}$ Los principios esbozados en esta primera legislación de urgencia, se consolidarán y ampliarán en el capítulo II del título III de la nueva Constitución,

historiográfico pero ha sido matizada en numerosos trabajos posteriores por otra que otorga al movimiento huelguístico de esos años un carácter reformista, no revolucionario, orientado a la consecución de mejoras para los trabajadores del campo; véase, por todos, González, Ángeles, "La construcción de un mito. El Trienio bolchevique en Andalucía", Revista de Historia contemporánea, núm. 9-10, fasc. 1, 1999-2000, pp. 163-206.

64 Delgado Larios, Almudena, La Revolución mexicana en la España de Alfonso XIII, cit., pp. 117-130.

65 Recuerda Santos Juliá que tras las elecciones municipales del domingo 12 de abril la "República habría de caer... como fruta madura, tanto, que a su llegada se llamó advenimiento", véase Juliá, Santos, La Constitución de 1931, Madrid, Iustel, 2009, p. 28.

66 Artículo 5o.: “...este Gobierno, sensible al abandono absoluto en que ha vivido la inmensa masa campesina española, al desinterés de que ha sido objeto la economía agraria del país, y a la incongruencia del derecho que la ordena con los principios que inspiran y deben inspirar las legislaciones actuales adopta como norma de su actuación el reconocimiento de que el derecho agrario debe responder a la función social de la tierra”, Gaceta de Madrid, núm. 105, 15 de abril de 1931, p. 195. 
Este libro forma parte del acervo de la Biblioteca Jurídica Virtual del Instituto de Investigaciones Jurídicas de la UNAM

dedicado a "la familia, la economía y la cultura", y específicamente en su artículo 44 que regulaba la propiedad y la forma en que el Estado podía intervenir limitándola.

$\mathrm{Al}$ igual que en otras cuestiones tratadas en la parte dogmática, el constituyente republicano se posiciona, también en ésta, con las nuevas tendencias del constitucionalismo social de entreguerras (sobre todo Querétaro y Weimar) y rompe con una larga historia constitucional apegada al artículo 17 de la Declaración de los Derechos del Hombre y del Ciudadano, que defiende la propiedad como un derecho inviolable y sagrado. ${ }^{67}$

Así las cosas, desde el primer momento en que la Comisión constitucional defendió su dictamen, quedó claro que la pugna principal se iba a centrar entre quienes sin defender radicalmente la concepción individualista de propiedad se encontraban próximos a ella y quienes respetando la propiedad privada proponían su limitación e incluso su socialización, y el elemento que iba a servir de medida entre ambas posiciones sería el distinto tratamiento que se diera a la expropiación. ${ }^{68}$ Los socialistas plantearon la posibilidad de efectuar expropiaciones sin indemnización y consiguieron dejar esa puerta abierta en el artículo 44 aunque en aras del consenso se optó por utilizar una fórmula similar a la aprobada en la Constitución de Weimar: se regulaba la expropiación forzosa con indemnización, "a menos que disponga otra cosa una ley aprobada por los votos de la mayoría absoluta de las Cortes". ${ }^{69}$ A cambio, el precepto prohibía expresamente la pena de confiscación de bienes; era el tributo pagado por el Estado intervencionista a la teoría del liberalismo individualista. La versión que finalmente se impuso limitaba severamente la propiedad privada pero sin caer en radicalismos, al renunciar los socialistas a sus objetivos máximos y al entender la derecha católica que el carácter absoluto del derecho de propiedad se atemperaba al

67 Para seguir la permanencia de la visión individualista liberal en todas las constituciones anteriores a la de 1931, sin el menor atisbo de contaminación social, véase Corral Dueñas, Francisco, "La agricultura en las Constituciones españolas", Revista Crítica de Derecho inmobiliario, núm. 79, 2003, pp. 391-436.

68 En esta cuestión se observa de nuevo la ruptura con la tradición constitucional anterior ya que hasta el texto de 1931 la expropiación se enunciaba siempre en forma negativa, como la excepción al principio de inviolabilidad de la propiedad privada, mientras que la nueva Constitución "da curso a la idea de expropiación como instrumento de acción positiva”, García de Enterría, Eduardo, Los principios de la nueva Ley de expropiación forzosa, Cizur Menor (Navarra), Thomson-Civitas, 2006, p. 34.

69 Mientras en el artículo 153 de la Constitución de Weimar se señalaba que: "No puede procederse a ninguna expropiación sino por utilidad pública y con sujeción a la ley. Se realizará mediante indemnización adecuada, a menos que una ley del Reich disponga otra cosa”, en el caso español se blinda tal posibilidad exigiéndose además una mayoría cualificada. 
Este libro forma parte del acervo de la Biblioteca Jurídica Virtual del Instituto de Investigaciones Jurídicas de la UNAM

filtrarlo con la nueva doctrina social de la Iglesia. ${ }^{70} \mathrm{El}$ modo de resolver la cuestión de la expropiación, no sólo señalaba el grado de compromiso de la República con una concepción más social del derecho de propiedad sino que, como señala García de Enterría, "esta materia pasa a ser inevitablemente uno de los elementos definidores más característicos de la organización fundamental de una comunidad, es decir, de una Constitución". ${ }^{71}$

La trascendencia del debate parlamentario seguirá viva cuando, sin el acaloramiento de la porfía parlamentaria, algunos protagonistas directos den a la imprenta sus impresiones y comentarios sobre el mismo: Royo Villanova, diputado por Valladolid y encuadrado como independiente en las filas de la minoría agrarista, es decir, la derecha monárquica que se había quedado sin rey, defendía que el artículo 44, "contenía principios jurídicos y audacias sociales... (como) la novedad grave, de admitir la posibilidad de que se expropie sin indemnización si así lo acuerda la mayoría absoluta de las Cortes". ${ }^{72}$ Por su parte, el socialista Jiménez de Asúa, presidente de la Comisión de Constitución, escribía en 1932: "En materia de propiedad se recortó un poco el sentido socializante de nuestro dictamen porque para expropiar sin indemnización se requiere la mayoría absoluta de las Cortes", y más adelante, "largo y accidentado fue el debate. Nadie, sin embargo, ni los sectores más moderados... ni aquellos de personal significación conservadora... defendieron el clásico concepto individualista de la propiedad"..$^{73}$ Niceto Alcalá-Zamora, primer presidente de la II República, sostenía en 1936 justo antes de salir al exilio que el artículo 44 "es una amenaza que se cierne sobre la propiedad. No tiene un criterio firme, definido..., sino que deja la suerte de la misma a la incertidumbre numérica, caprichosa y voluble de un quórum determinado... (y) suma los inconvenientes del criterio individualista y del socialismo". ${ }^{74}$ Por último, la voz ponderada de Nicolás Pérez Serrano, el catedrático de Derecho político y letrado de Cortes que asistió a los diputados constituyentes, resumía perfectamente lo que fueron

70 Palmer Valero, Ramón, Los problemas socioeconómicos de la Constitución de 1931, Madrid, Centro de Estudios Políticos y Constitucionales, 1997, pp. 110-126.

71 García de Enterría, Eduardo, Los principios de la nueva Ley de expropiación forzosa, cit., pp. 30 y 31.

72 Royo Villanova, Antonio, La Constitución Española de 9 de diciembre de 1931, con glosas jurídicas y apostillas políticas, Valladolid, Imp. Castellana, 1934, p. 144.

73 Jiménez de Asúa, Luis, Proceso histórico de la Constitución de la República española, Madrid, Reus, 1932, pp. 100, 101 y 294.

74 Alcalá-Zamora, Niceto, Los defectos de la Constitución de 1931, seguido de tres años de experiencia constitucional, Madrid, Civitas, 1981, p. 128 (edición moderna de Los defectos de la Constitución de 1931, Madrid, R. Espinosa, 1936). 
Este libro forma parte del acervo de la Biblioteca Jurídica Virtual del Instituto de Investigaciones Jurídicas de la UNAM

los debates en materia de propiedad, empezando por confirmar las afirmaciones de Jiménez de Asúa:

Bueno será notar que nadie defendió el criterio individualista a ultranza... En esta pugna de opiniones se impuso la tonalidad media, avanzada y no agresiva, de las fuerzas templadas... Recuérdase sin poderlo evitar, el tono general de algunas constituciones modernas (la alemana en sus arts. 153 y 156, y la mexicana en el art. 27). Pero la marcha del mundo no permite ya independencias individualistas que serían jurídicamente heréticas, y que irían contra principios de justicia y contra imperativos de buena ordenación económica. ${ }^{75}$

En efecto, aunque la regulación de la propiedad fue objeto de extensos y acerados debates, se aprobó casi por unanimidad porque el tiempo del modelo individualista había pasado, estaba en crisis. El código político que se promulgaba en 1931 suponía una revisión económica pero también política del liberalismo y permitía limitar y restringir la propiedad por exigencias del bien común. La fórmula ecléctica y socializante del artículo 44 se adaptaba así, al igual que el resto de artículos del Capítulo II del Título III, a las nuevas funciones del Estado y alumbraba la aparición del constitucionalismo social en España.

\section{BiBLIOGRAFÍA}

Alcalá-Zamora, Niceto, Los defectos de la Constitución de 1931, Madrid, imp. R. Espinosa, 1936 (reed. en 1981, Civitas, junto al ensayo Tres años de experiencia constitucional).

ARAQUistáin, Luis, La Revolución mejicana. Sus orígenes. Sus hombres. Su obra, Madrid, Renacimiento, 1929.

BARrio Alonso, Ángeles, “¿Constitucionalización de derechos o institucionalización de su ejercicio?: La cuestión de los derechos sindicales en España y México (1910-1930)", en CANO, Aurora et al. (eds.), Cultura liberal, México y España 1860-1930, Santander, Universidad de Cantabria, 2010.

CABRERA, Miguel Ángel, El reformismo social en España (1870-1900). En torno a los orígenes del Estado del Bienestar, Valencia, Universitat de València, 2014.

Carmona Cuenca, Encarnación, El Estado social de derecho en la Constitución, Madrid, Consejo Económico y Social, 2000.

Carozza, Paolo G., "La perspectiva histórica del aporte latinoamericano

75 Pérez Serrano, Nicolás, La Constitución española, cit., pp. 193 y 194. 
Este libro forma parte del acervo de la Biblioteca Jurídica Virtual del Instituto de Investigaciones Jurídicas de la UNAM

al concepto de los derechos económicos, sociales y culturales", en ELY YAMIN, Alicia (coord.), Los derechos económicos, sociales y culturales en América Latina. Del invento a la herramienta, México, Plaza y Valdés, 2006.

CARPIZO, Jorge, La Constitución mexicana de 1917, México, UNAM, 1982.

CARPIZO, Jorge y MADRAZO, Jorge, "El sistema constitucional mexicano", en GARCía DE BELAUNDE, D. (eds.), Los sistemas constitucionales iberoamericanos, Madrid, Dykinson, 1992.

CARR, Barry, El movimiento obrero y la política en México, 1910-1929, 2 vols., trad. de R. Gómez Ciriza, México, Secretaría de Educación Pública, 1976.

Castro CiD, Benito de, Los derechos económicos, sociales y culturales. Análisis a la luz de la teoría de los derechos humanos, León, Universidad de León, 1993.

Clavero, Bartolomé, Manual de historia constitucional de España, Madrid, Alianza, 1989.

Corral DueÑas, Francisco, "La agricultura en las Constituciones españolas", Revista Crítica de Derecho Inmobiliario, núm. 79, 2003.

Cuevas Murillo, Oscar, "La política de desamortización de bienes en Zacatecas durante las reformas liberales (1856-1876)", Revista Mexicana de Historia del Derecho, núm. 32, 2015.

Cuevas Murillo, Oscar, "La reforma liberal en materia de propiedad según Wistano Luis Orozco y Andrés Molina Enríquez", Anuario Mexicano de Historia del Derecho, núm. 20, 2008.

Delgado LARIOS, Almudena, "Una revolución regeneracionista: la reforma laboral y educativa mexicana en la prensa española (1910-1931)", $R e^{-}$ vista Complutense de Historia de América, núm. 171991.

Delgado LaRios, Almudena, La revolución mexicana en la España de Alfonso XIII (1910-1931), Salamanca, Junta de Castilla y León, 1993.

DíAz, Elías, "Ideología y derecho: Para una crítica de la cultura jurídica de la sociedad burguesa", Anales de la Cátedra Francisco Suárez, núm. 17, 1977.

DÍAZ DEL MORAL, Juan, Historia de las agitaciones campesinas andaluzas: Córdoba. (Antecedentes para una reforma agraria), Madrid, 1928.

EsPing-ANDERsen, Gösta, The Three Worlds of Welfare Capitalism, Cambridge, Princeton University, 1990.

Ferrajoli, Luigi, "Prólogo", en Abramovich, Víctor y Courtis, Christian, Los derechos sociales como derechos exigibles, Madrid, Trotta, 2015.

FiX-ZAmudiO, Héctor, "La Constitución y el Estado social de Derecho", en El constitucionalismo en las postrimerías del siglo XX. La Constitución mexicana 70 años después, México, UNAM, 1988, t. V. 
Este libro forma parte del acervo de la Biblioteca Jurídica Virtual del Instituto de Investigaciones Jurídicas de la UNAM

GARCÍA DE ENTERRÍA, Eduardo, Los principios de la nueva Ley de expropiación forzosa, Cizur Menor (Navarra), Thomson-Civitas, 2006.

Garaiadiego, Javier, La Revolución mexicana. Crónicas, documentos, planes y testimonios, México, UNAM, 2010.

GILLY, Adolfo, La revolución interrumpida, México, Era, 2007.

GonzÁlez, Angeles, "La construcción de un mito. El Trienio bolchevique en Andalucía”, Revista de Historia Contemporánea, 9-10, fasc. 1, 1999-2000.

Herrera, Carlos Miguel, "Teoría constitucional de lo social", en VALADÉS, Diego et al. (coords.), Ideas e instituciones constitucionales en el siglo XX, México, Siglo Veintiuno, 2011.

JimÉneZ DE ASÚA, Luis, Proceso histórico de la Constitución de la República Española, Madrid, Reus, 1932.

Juliá, Santos, La Constitución de 1931, Madrid, Iustel, 2009.

KNIGHT, Alan, La Revolución mexicana. Del Porfiriato al nuevo régimen constitucional, Vol. I, Porfiristas, liberales y campesinos, México, Grijalbo, 1996.

LANGEWIESCHE, Dieter, "Liberalismo y burguesía en Europa", en FRADERA Josep Ma. y MiLlán, Jesús (eds.), Las burguesías europeas del siglo XIX. Sociedad civil, política y cultura, Valencia, Biblioteca Nueva-Universitat de València, 2000.

LEFF ZIMMERMAN, Gloria, "Los pactos obreros y la institución presidencial en México (1915-1938)", Estudios sociológicos, IX, 27, 1991.

Matia Portilla, Francisco Javier, "Droits sociaux et droits fondamentaux", en Bon, Pierre (dir.), Trente ans d'application de la Constitution espagnole, París, Dalloz, 2009.

Menegus Bornemann, Margarita, El agrarismo de la Revolución mexicana, Madrid, Agencia española de Cooperación Internacional, 1990.

Mirkine-Guetzévitch, Boris, Modernas tendencias del Derecho Constitucional, Madrid, Reus, 2011 (trad. de 1933 por Sabino Álvarez-Gendín de Les nouvelles tendances du droit constitutionnel, París, Marcel Giard, 1931).

Molina EnRIQUEZ, Andrés, Los grandes problemas nacionales, México, A. Carranza e Hijos, 1909.

Noriega Cantú, Alfonso, "El nacimiento de los derechos sociales", en El constitucionalismo en las postrimerías del siglo XX. La Constitución mexicana 70 años después, t. V, México, UNAM, 1988.

Orozco, Wistano Luis, Legislación y jurisprudencia sobre terrenos baldios, 2 vols., México, El Tiempo, 1895.

Orozco, Wistano Luis, La organización de la República. Tratado primero: Los ejidos de los pueblos. Exposición jurídica, Guadalajara, Impr. José Cabrera, 1914. 
Este libro forma parte del acervo de la Biblioteca Jurídica Virtual del Instituto de Investigaciones Jurídicas de la UNAM

Palmer Valero, Ramón, Los problemas socioeconómicos de la Constitución de 1931, Madrid, Centro de Estudios Políticos y Constitucionales, 1997.

Peges-BARba Martínez, Gregorio, "Los derechos económicos, sociales y culturales: su génesis y su concepto", Derechos y libertades: Revista del Instituto Bartolomé de las Casas, 6, 1998.

PÉrez Ayala, Andoni, "Los orígenes del Constitucionalismo Social. Una aproximación desde una perspectiva histórico-comparativa", en GARCíA HERRERA, Miguel Ángel (dir.), El constitucionalismo en la crisis del estado social, Bilbao, Universidad del País Vasco, 1997.

PÉREz LuÑo, Antonio-Enrique, La tercera generación de derechos humanos, Pamplona, Aranzadi, 2006.

PÉrez SerRano, Nicolás, La Constitución española (9 diciembre 1931). Antecedentes. Texto. Comentarios, Madrid, Revista de Derecho privado, 1932.

RAMírez, María de Jesús, "La política agraria en México: de la ley de desamortización de 1856 al reparto de tierras ejidales", disponible en: http:// wrerce.economia.unam.mx/cladhe/registro/ponencias/473_abstract.

RoDRíguez PALOP, María Eugenia, La nueva generación de derechos humanos. Origen y justificación, Madrid, Dykinson, 2010.

RodríGuez PALOP, María Eugenia, Claves para entender los nuevos derechos humanos, Madrid, Catarata, 2011.

ROUAIX, Pastor, Génesis de los artículos 27 y 123 de la Constitución politica de 1917, México, Instituto Nacional de Estudios históricos de las revoluciones de México, 2016.

Royo Villanova, Antonio, La Constitución Española de 9 de diciembre de 1931, glosas jurídicas y apostillas políticas, Valladolid, Imp. Castellana, 1934.

Silva Herzog, Jesús, Trayectoria ideológica de la Revolución mexicana, 1910-1917, México, Cuadernos americanos, 1963.

SOBERANES FERnánDeZ, José Luis, "Los derechos económicos y culturales en México", en Los derechos sociales como una exigencia de la justicia", en ZAPATERO, Virgilio y GARRIDO, Ma. Isabel (eds.), Cuadernos de la cátedra de democracia y derechos humanos, 1, Madrid, Universidad de Alcalá-Defensor del Pueblo, 2009.

Sotelo, Ignacio, El Estado social: Antecedentes, origen, desarrollo y declive, Madrid, Trotta, 2010.

UlloA, Berta, Historia de la Revolución mexicana 1914-1917, núm. 6, La Constitución de 1917, México, El Colegio de México, 1988.

VALADÉS, Diego, "La función constitucional de la estabilidad social", en Cienfuegos Salgado, David y Macías Vázouez, María Carmen 
Este libro forma parte del acervo de la Biblioteca Jurídica Virtual del Instituto de Investigaciones Jurídicas de la UNAM

(eds.), Estudios en Homenaje a Marcia Muñoz de Alba Medrano: estudios de derecho público y política, México, UNAM, 2006.

WOLF, Eric R., Las luchas campesinas del siglo XX, México, Siglo XXI, 1979.

Zertuche MuÑoz, Fernando, "El Congreso constituyente de 1856-1857:

El decenio de su entorno", en VALADÉS, Diego y CARbOnell, Miguel (coords.), El proceso constituyente mexicano. A 150 años de la Constitución de 1857 y 90 de la Constitución de 1917, México, UNAM, 2007. 
Este libro forma parte del acervo de la Biblioteca Jurídica Virtual del Instituto de Investigaciones Jurídicas de la UNAM

\title{
LA REVOLUGIÓN MEXICANA Y LA GONSTITUGIÓN DE 1917. UNA VISIÓN DESDE CUBA
}

\author{
Santiago Antonio BAHAMOnde RodRÍGUEZ
}

\begin{abstract}
SUMARIO: I. La influencia del derecho novohispano en la legislación colonial. II. Condicionantes comunes que facilitaron la influencia de la Revolución mexicana en el derecho cubano. III. La Revolución mexicana en el ideario político y jurídico cubano. IV. Influencia del derecho de la Revolución mexicana en el derecho cubano. V. Conclusiones.
\end{abstract}

Pocos acontecimientos han marcado tanto la historia del siglo XX como la Revolución mexicana. Las transformaciones ocurridas en el orden económico, político y social a raíz de este proceso incidieron en el desarrollo del pensamiento político y jurídico latinoamericano de la centuria.

Cuba no quedó al margen de este fenómeno. La Revolución mexicana sirvió de inspiración a toda la generación de dirigentes políticos cubanos que hicieron la revolución frustrada de 1933. Los ideales de justicia social, reforma agraria, igualdad y derechos laborales permearon profundamente el ideario de la intelectualidad cubana de los años veinte. A ello hay que añadir el ejemplo de ejercicio de la soberanía y de la autodeterminación, frente a la agresión extranjera, o la nacionalización de recursos naturales básicos, que actúo como acicate para los pensadores y dirigentes políticos cubanos.

En este orden de cosas, la Constitución mexicana de 1917 marcó un hito en la historia del constitucionalismo moderno, al ser la primera en reconocer los derechos de segunda generación, es decir, los económicos, sociales y culturales. No es extraño que la misma haya servido de inspiración a diversos textos alrededor del orbe, entre los que se encuentra la cubana de 1940. Su presencia resultó visible en los debates de la Convención Constituyente y en los programas de los partidos políticos de la época.

* Profesor de historia general del estado y del derecho y de historia del Estado y del derecho en Cuba de la Facultad de Derecho de la Universidad de La Habana. 
Este libro forma parte del acervo de la Biblioteca Jurídica Virtual del Instituto de Investigaciones Jurídicas de la UNAM

Lamentablemente, este proceso no ha sido bien analizado en nuestra doctrina, encontrándose entre nuestros autores algunas referencias aisladas. ${ }^{1}$ Hoy por hoy, muchos de los logros de la Constitución de 1940, parecen resultados de un esfuerzo autóctono, cuando en realidad, sobre todo en el tema referido a los derechos, mucha referencia hay que buscar en la carta magna mexicana de 1917, y, en sentido general, del derecho de la revolución mexicana. ${ }^{2}$

Es por ello que, en este pequeño estudio en homenaje al centenario de la Constitución de 1917, procuraremos ofrecer algunas claves de la influencia del derecho mexicano, emanado de la Revolución, en las transformaciones del derecho en Cuba con anterioridad a 1959. Con ello procuraremos el estudio de las principales líneas teóricas de influencia, y la visión que de las mismas se plantearon en los círculos intelectuales y jurídicos cubanos. Esperamos que de obtener los resultados esperados, podamos contribuir al mejor conocimiento de la historia del derecho cubano, en especial de las influencias externas que han incidido en su conformación y desarrollo. Igualmente pretendemos contribuir a un mejor conocimiento de este particular capítulo de la historia de las relaciones entre Cuba y México, que no por estar geográficamente cercanos resulta de los más conocidos.

1 Como ejemplo podemos consultar la obra de Tejera, Diego Vicente, Estado actual de la legislación cubana e influencia que en ella ejercen la de otros países, Madrid, Reus, 1926

2 Desde la historia de Cuba han trabajado este tema: Gutiérrez, Gustavo, "La Convención constituyente y la Convención de 1940", en Guerra, Ramiro et al., Historia de la Nación Cubana, t. IX, La Habana, Editorial Historia de la Nación Cubana, 1952; Le Riverend, Julio, Historia de Cuba, t. 5, La Habana, Editorial Pueblo y Educación, Instituto Cubano del Libro, 1973; Le Riverend, Julio, La República, La Habana, Editorial de Ciencias Sociales, 1973; Instituto de Historia de Cuba, La República neocolonial: formación y crisis 1899 a 1940, La Habana, Editorial de Ciencias Sociales, 2004; Rodríguez, Rolando, República de corcho, 2 ts., La Habana, Editorial de Ciencias Sociales, 2010; Rodríguez, Rolando. República de rigurosamente vigilada, 2 ts., La Habana, Editorial de Ciencias Sociales, 2011; Rodríguez, Rolando, Rebelión en la República, 3 ts., La Habana, Editorial de Ciencias Sociales, 2012; López Civeira, Francisca et al., Historia de Cuba: Estado nacional, dependencia y Revolución, La Habana, Editorial Pueblo y Educación, 2013. Desde la historia jurídica puede consultarse a: Álvarez Tabío, Fernando, Teoría general de la Constitución cubana, La Habana, Jesús Montero, 1946; Infiesta, Ramón, Historia constitucional de Cuba, La Habana, Cultural, 1951; Lazcano y Masón, Andrés, Las Constituciones de Cuba. Madrid, Cultura Hispánica, 1952; Hernández Corujo, Enrique, Historia constitucional de Cuba, 2 ts., La Habana, Editora de Libros y Folletos, 1960; Carreras, Julio, Historia del Estado y el derecho en Cuba, La Habana, Ministerio de Educación Superior, 1981; Fuente, J. de la, Análisis constitucional desde Fimaguayú hasta el 40, La Habana, Ed. Ciencias Sociales, 1989; Fernández Bulté, Julio, Historia del Estado y el Derecho en Cuba, La Habana, Editorial Félix Varela, 2005; Bernal Gómez, Beatriz, Constituciones iberoamericanas. Cuba, México, UNAM, Instituto de Investigaciones Jurídicas, 2008; Pavó Acosta, Rolando, "Legado de la Revolución mexicana en la reforma agraria cubana de 1959", Política y Cultura, núm. 33, 2010. 
Este libro forma parte del acervo de la Biblioteca Jurídica Virtual del Instituto de Investigaciones Jurídicas de la UNAM

Para abordar esta temática trabajaremos analizando en primer lugar la influencia histórica de México en el derecho cubano. Acto seguido entraremos en el estudio de las similitudes económicas, sociales y políticas que favorecerán la influencia del ideario de la Revolución mexicana en el derecho cubano. Por último, analizaremos la presencia de la misma en el ideario político y la normativa cubana durante la primera mitad del siglo veinte.

Nos detendremos en nuestro estudio en los primeros años de la década de 1960. Ciertamente, la influencia mexicana en nuestro derecho es perceptible en la legislación de los primeros años de la Revolución, especialmente en la primera Ley de Reforma Agraria, ${ }^{3}$ como tendremos ocasión de apreciar. No obstante, la influencia del derecho y la doctrina jurídica de los países del antiguo campo socialista, que terminó por desplazar cualquier otro ascendiente en el derecho cubano. Igualmente, el proceso de transformación que sufrió la normativa jurídica cubana en esta etapa llevó a la progresiva desaparición de aquellas regulaciones inspiradas en el modelo revolucionario mexicano.

Antes de abordar de lleno este tema resulta necesario realizar dos precisiones. La primera de ellas está necesariamente relacionada con el marco temporal. El influjo de la revolución mexicana no fue en Cuba un episodio de un solo momento, sino que tuvo etapas características y bien diferenciadas. Es así que podemos advertir tres períodos fundamentales que marcaron hitos en su devenir en tierras antillanas.

El primero de ellos trascurrió desde el propio inicio de la Revolución hasta el año 1940. Durante esta etapa su impacto en los programas políti$\cos$, la doctrina jurídica y la legislación es directo y visible. Igualmente aquí pueden acotarse dos fases bien delimitadas. La inicial, que transcurrió de 1917 a 1933, donde la recepción resulta visible en la ciencia y en el discurso político, pero muy escasa en el orden legislativo. El segundo momento, de 1933 a 1940, esta marcado por la explosión de la legislación social cubana, con un significativo paralelismo en cuanto a los temas tratados con la mexicana. El cierre de estos 23 años sería la Constitución de 1940, que marcó el auge del influjo de la Revolución mexicana en la legislación caribeña.

A partir de aquí, se inició un segundo ciclo, que se prolongó hasta 1959, donde los postulados mexicanos pasan a un segundo plano frente a la carta magna de 1940. No es que se desconozcan sus aportes, es que se convierten en apoyo y legitimación de lo recogido en la Convención de 1940.

3 Pavó Acosta, Rolando, "Legado de la Revolución mexicana en la reforma agraria cubana de 1959", Política y Cultura, México, núm. 33, 2010, pp. 35-58, disponible en: http:// wrere.redalyc.org/articulo.oa?id=26712504003 (fecha de consulta: 1o. de abril de 2016). 
Este libro forma parte del acervo de la Biblioteca Jurídica Virtual del Instituto de Investigaciones Jurídicas de la UNAM

Un tercer ciclo se inicia en 1959. En el mismo, hay un pasajero interés por la obra revolucionaria mexicana, centrado esencialmente en el proceso de reforma agraria. No obstante, el mismo desaparece rápidamente ante la progresiva alineación de Cuba con el campo socialista, lo que conllevó a una creciente influencia del derecho de la Europa del Este, especialmente la Unión Soviética, lo que trajo aparejada la virtual desaparición de toda otra influencia doctrinal.

Un segundo aspecto es el referente a qué temas tuvieron mayor eco y cómo fueron asimilados a nivel local. En este punto hay que señalar que los que mayor interés despertaron fueron los vinculados con familia e igualdad, los derechos sociales, la reforma agraria, la intervención del Estado en la economía, y la limitación del mandato presidencial. Esto no quiere decir que fueran los únicos, sino que en torno a ellos se produjeron los mayores debates y se obtuvieron los principales resultados legislativos. Es por ello que concentraremos nuestra exposición en estos aspectos.

Un segundo punto es el referente a cómo se recibieron las propuestas mexicanas en el ámbito cubano. En este caso no podemos hablar de un fenómeno de copia. La tendencia fue a tratar de adaptarlas a las condiciones de la realidad cubana, lo cual no resulta difícil de comprender, dadas las diferencias existentes entre ambos países a las que hemos hecho referencia anteriormente.

\section{LA INFLUENGIA DEL DERECHO NOVOHISPANO EN LA LEGISLAGIÓN COLONIAL}

El influjo de México en el derecho cubano puede remontarse a la época de la Conquista y colonización española. Ambos países recibieron el mismo derecho fruto del proceso de conquista y colonización española. En este sentido, las Leyes de Indias, actuaban como paraguas bajo el que se abrigaron jurídicamente ambos países hasta el siglo XIX.

Durante esta etapa, la presencia mexicana en el derecho vigente en Cuba resulta extremadamente limitada. En principio, la mayoría de los asuntos eran decididos en la corte madrileña, de donde emanaban las normas y la jurisprudencia. No obstante, hay tres importantes vías, por las cuales podía producirse una cierta penetración de la influencia mexicana en Cuba.

En primer lugar, en determinados pleitos los habitantes de esta isla debían acudir ante órganos jurisdiccionales asentados en suelo azteca. ${ }^{4}$ Ello

4 Esencialmente en jurisdicción apelada. Véase al respecto nuestro artículo Breves notas para una evolución histórica del derecho procesal en Cuba de próxima aparición. 
Este libro forma parte del acervo de la Biblioteca Jurídica Virtual del Instituto de Investigaciones Jurídicas de la UNAM

significó, la aplicación a litigios cubanos, no sólo de las normas vigentes castellanas o de Derecho de Indias, sino también las prácticas y regulaciones particulares vigentes en estos tribunales. Es interesante señalar que para algunos autores esto constituyó un subsistema dentro del derecho de Indias, ${ }^{5}$ criterio que aquí seguimos.

En segundo lugar, la propia autoridad de los virreyes de la Nueva España, los cuales, en determinadas materias podían legislar para resolver temas en Cuba. ${ }^{6}$

Un tercer tema donde existía este influjo, quizás el más importante, radicó en la esfera de la enseñanza del derecho. Hasta $1728,{ }^{7}$ los futuros juristas cubanos debían formarse en el extranjero, siendo los dos centros más adecuados, por su cercanía geográfica, las universidades de Santo Domingo y México. Sin dudas, la capital virreinal resultaba más atrayente para un joven con ciertas posibilidades económicas que la principal ciudad de La Española.

De hecho, este flujo constante de cubanos para cursar estudios en México, no se interrumpió con la fundación de la Real y Pontificia Universidad de San Jerónimo de La Habana en 1728. De hecho, los aspirantes al ejercicio del derecho, tenían en este punto un incentivo adicional, ya que, por Real Cédula, les estaba prohibido ejercer la profesión, al no haber obtenido la habilitación correspondiente por parte de la Audiencia. Este órgano no radicaba en la isla, viéndose obligados los egresados para tomar el curso práctico de jurisprudencia elegir otra vez entre trasladarse a México o Santo Domingo para obtenerlo. De esta forma, los juristas de la isla recibían durante su proceso de formación, no sólo las normas del derecho romano, del castellano o del canónico, sino también de las prácticas y costumbres vigentes en el foro mexicano. Esta conexión se mantendrá hasta el traslado a Cuba de la Audiencia de Santo Domingo, y la creación de la Academia Práctica de Jurisprudencia.

Lamentablemente, el estudio de estos tres aspectos no ha sido tratado, que sepamos, por la doctrina cubana. Sin dudas, cualquier investigador interesado en el mismo encontraría una rica fuente de información, que ayudará a comprender mejor la evolución del derecho cubano, y la interacción del mismo con el de otros países.

5 González, María del Refugio, Historia del derecho mexicano, México, UNAM, 1983, p. 39.

6 En determinados momentos Cuba quedó subordinada a la autoridad del virreinato de la Nueva España, en especial en temas económicos.

7 Armas, Ramón de et al., Historia de la Universidad de La Habana, La Habana, Editorial de Ciencias Sociales, 1983, t. 1. 
Este libro forma parte del acervo de la Biblioteca Jurídica Virtual del Instituto de Investigaciones Jurídicas de la UNAM

Los vínculos coloniales con México quedaron rotos con el proceso independentista ocurrido en la América hispana a comienzos del siglo XIX. No obstante, ambos participaron en la efimera experiencia constitucionalista española de $1812 .{ }^{8}$

La independencia mexicana significó la ruptura de los vínculos jurídicos y un distanciamiento en lo referente a la evolución del derecho. Los destinos del mismo en Cuba, a lo largo de la centuria, quedarían indisolublemente unidos a los de España. Esto explica la relativamente tardía recepción de la codificación en tierras antillanas, ${ }^{9}$ y condicionaría significativamente el futuro jurídico de la isla hasta nuestros días.

No obstante, en ambos países siguieron procesos similares en cuanto a la evolución del derecho a lo largo del siglo XIX. En primer lugar, en ambas tierras encontró arraigo la doctrina liberal, que ensalzaba como base de la convivencia entre los hombres el individualismo, el reconocimiento de los derechos naturales del hombre y la libertad como bien supremo. Ciertamente la condición colonial de Cuba impuso un significativo desfase en este proceso con respecto a México. Así, si desde el proceso de la reforma en $1867,{ }^{10}$ puede considerarse al mismo arraigado en el ámbito azteca, en caso cubano habrá que esperar a la carta magna de $1901^{11}$ para que adquiera naturaleza definitiva.

Como consecuencia de este influjo liberal, se llevó a cabo el proceso de desamortización de los bienes de la Iglesia católica, que en lugar de transformar las estructuras agrarias heredadas de la Colonia, contribuyó a su deformación, con significativas consecuencias en el orden económico, social y político, como tendremos ocasión de ver más adelante.

8 Puede consultarse: Matilla Correa, Andry y Massó Garrote, Marcos Francisco (coords.), De Cádiz (1812) a La Habana (2012). Escritos con motivo del Bicentenario de la Constitución española de 1812, La Habana, Ediciones ONBC, Universidad de Castilla-La Mancha, Universidad de La Habana, Unión Nacional de Juristas de Cuba, 2011.

9 Carreras Collado, Julio Ángel, Historia del Estado y del derecho en Cuba, La Habana, Editorial Pueblo y Educación, 1980; Fernández Bulté, Julio, Historia del Estado y del derecho en Cuba, La Habana, Editorial Félix Varela, 2005

10 Véase al respecto: Mardagant, Guillermo F., Introducción a la historia del derecho mexicano, México, UNAM, 1971, pp. 169 y ss.; González, María del Refugio, Historia del derecho mexicano, México, UNAM, 1983, pp. 76-94, y Rabasa, Emilio, Historia de las Constituciones mexicanas, México, UNAM, 2004, pp. 57-74.

11 Infiesta, Ramón, Historia constitucional de Cuba, La Habana, Cultural S.A., 1951; Hernández Corujo, Enrique, Historia constitucional de Cuba, 2 ts., La Habana, Editora de Libros y Folletos, 1960; Carreras Collado, Julio Ángel, Historia del Estado y del Derecho en Cuba, La Habana, Editorial Pueblo y Educación, 1980; Fernández Bulté, Julio, Historia del Estado y del derecho en Cuba, La Habana, Editorial Félix Varela, 2005. 
Este libro forma parte del acervo de la Biblioteca Jurídica Virtual del Instituto de Investigaciones Jurídicas de la UNAM

En tercer lugar, se produjo una paulatina modernización del derecho vigente, con la paulatina introducción de códigos, inspirados en la obra napoleónica. Aquí, volvemos a advertir el desfase en su implantación a ambos lados del Golfo de México. El proceso en tierras continentales comenzó a dar frutos en 1870, ${ }^{12}$ mientras que en ámbito insular hubo que esperar a 1889.13 Otra vez, la influencia española incidió en el relativo retraso del Derecho cubano.

Como hemos podido apreciar, desde los albores de la época colonial México y Cuba recibieron una base legislativa común durante la etapa colonial, y mantuvieron caminos paralelos a lo largo del siglo XIX. Igualmente el derecho mexicano influyó en el desarrollo del derecho en Cuba y en la formación de juristas cubanos hasta el momento de la Independencia.

\section{CONDICIONANTES GOMUNES QUE FACILITARON LA INFLUENCIA DE LA REVOLUGIÓN MEXICANA EN EL DEREGHO GUBANO}

El advenimiento de Cuba como Estado independiente el 20 de mayo de 1902, permitió que se reanudaran los vínculos jurídicos entre ambos países, rotos en la segunda década del siglo XIX, como resultado del proceso independentista en la Nueva España. No obstante, ambos países habían compartido procesos históricos comunes en cuanto a la evolución del derecho a lo largo de la centuria.

Sin embargo, este no era el único punto de coincidencia. Existían una serie de problemas económicos, sociales y políticos, que favorecían la recepción del discurso revolucionario mexicano, aún salvando las obvias diferencias en cuanto a extensión territorial, población y recursos naturales.

Desde el punto de vista económico, ambos eran países donde la mayoría de la población dependía de la agricultura para su sostenimiento. ${ }^{14} \mathrm{La}$ tierra se encontraba desigualmente distribuida, con una significativa concentración en muy pocas manos, mientras que la mayoría de la población

12 Véase al respecto Cruz Barney, Oscar, La codificación en México: una aproximación, México, UNAM, 2004.

13 Carreras Collado, Julio Ángel, Historia del Estado y del derecho en Cuba, La Habana, Editorial Pueblo y Educación, 1980; Fernández Bulté, Julio, Historia del Estado y del Derecho en Cuba, La Habana, Editorial Félix Varela, 2005

14 Para el caso mexicano véase: Mardagant, Guillermo, Introducción a la historia del derecho mexicano, México, UNAM, 1971 y Silva Herzog, Jesús, Breve historia de la Revolución mexicana, 2a. ed., México, Fondo de Cultura Económica, 1995. Para Cuba: Friedlaender, Harold, Historia económica de Cuba, 2 ts., La Habana, Ed. Ciencias Sociales, 1971; LeRiverend, Julio, Historia económica de Cuba, 4a. ed., La Habana, Instituto Cubano del Libro, 1974. 
Este libro forma parte del acervo de la Biblioteca Jurídica Virtual del Instituto de Investigaciones Jurídicas de la UNAM

rural carecía totalmente de ella, o la explotaba en condiciones precarias, lo que generó un fuerte malestar social en las zonas rurales. ${ }^{15}$

Un segundo factor económico a considerar estaba vinculado a la presencia extranjera en la economía. En México su presencia se hacía sentir en sectores como los ferrocarriles, las minas, el petróleo y la explotación de la tierra. En el ámbito cubano su incidencia en el campo resultaba especialmente visible, sobre todo en la industria azucarera, el principal rubro de la economía doméstica. ${ }^{16}$

Igualmente, en ambos países existía un incipiente desarrollo industrial, controlado fundamentalmente por empresas de capital extranjero, vinculadas a los sectores punteros de la economía, como el petróleo y la industria azucarera, así como al sector de los servicios, como los ferrocarriles.

Estas asimetrías económicas se traducían en significativas desigualdades sociales.

En primer lugar, en ambos países existía una población mestiza, pese a lo cual, la discriminación racial era un fenómeno habitual, a pesar de la declarada igualdad ante la ley establecida en los textos constitucionales. ${ }^{17}$ Igualmente subsistía la discriminación por razón de sexo, en este caso institucionalizada en la legislación y en los códigos civiles. ${ }^{18}$

En segundo lugar, las grandes masas de población campesina vivían en pésimas condiciones, en muchos casos sin acceso a servicios básicos y sometidos a una situación de dependencia de los grandes propietarios rurales que los explotaban a su antojo, con el apoyo de las autoridades. ${ }^{19}$

En tercer lugar, en las ciudades emergía un incipiente movimiento obrero, cuyas condiciones laborales variaban enormemente, y que comenzaba a presentar sus demandas en torno a ciertos temas básicos. ${ }^{20}$

15 Véase la bibliografía recomendada en la nota anterior.

16 Véase la bibliografía recomendada en la nota 14.

17 En el caso cubano el artículo 11 de la Constitución de 1901 expuso: "Todos los cubanos son iguales ante la ley. La República no reconoce fueros, ni privilegios personales". Lazcano y Masón, Andrés, Las Constituciones de Cuba, Madrid, Cultura Hispánica, 1952

18 En el caso cubano el artículo 38: "Todos los cubanos, varones, mayores de veintiún años, tienen derecho de sufragio". Lazcano y Masón, Andrés, Las Constituciones de Cuba, Madrid, Editorial Cultura Hispánica, 1952. Por su parte, el Código Civil español de 1889 vigente entonces en Cuba la colocaba bajo la potestad del marido.

19 Para el caso mexicano véase: Mardagant, Guillermo, Introducción a la historia del derecho mexicano, cit., y Silva Herzog, Jesús, Breve historia de la revolución mexicana, cit. Para Cuba: Friedlaender, Harold, Historia económica de Cuba, cit.; LeRiverend, Julio, Historia económica de Cuba, cit.

20 Véase la bibliografía recomendada en la nota anterior y Le Riverend, Julio, $L a R e^{-}$ pública, La Habana, Editorial de Ciencias Sociales, 1973; Carreras, Julio, Historia del Estado y el Derecho en Cuba, cit.; Instituto de Historia de Cuba, La República neocolonial: formación y 
Este libro forma parte del acervo de la Biblioteca Jurídica Virtual del Instituto de Investigaciones Jurídicas de la UNAM

En el orden político en ambos países predominaba a comienzos de siglo la ideología liberal, claramente reflejada en las Constituciones de la época. En el caso mexicano este era el resultado directo del programa de la reforma de mediados del siglo XIX. ${ }^{21}$ Como plantea un autor mexicano: "El esquema de la Constitución comprendía, en forma sumaria, todos los elementos del constitucionalismo liberal avanzado del siglo XIX" ${ }^{22}$ En el caso cubano, la carta magna de 1901 basó sus principios en una adopción tardía del liberalismo decimonónico. ${ }^{23}$ En este sentido, señaló Enrique Hernández Corujo: "En el orden formal el constitucionalismo seguía, más o menos, los principios invariables del Estado liberal, individualista y de limitación al poder". ${ }^{24}$ Entendido el mismo como apuntó en su momento Orestes Ferrara: "El principio liberal del siglo XIX, latu sensu adaptado por la Constitución cubana de 1901, es distinto de cualquier otro practicado en el pasado. La palabra libertad... se refiere a la suma de derechos individuales, considerándolos al margen del Estado, y hasta contra el Estado". ${ }^{25}$ En palabras de Gustavo Gutiérrez:

No es de extrañar, por consiguiente que la Constitución de 1901 se concibiese a la luz de las dos grandes directrices del pensamiento constitucional de la época, la declaración de los derechos individuales, y la organización del Estado y del gobierno bajo el signo clásico de la separación de poderes al estilo de Montesquieu sin comprender los enunciados de los derechos sociales ni

crisis 1899 a 1940, La Habana, Editorial de Ciencias Sociales, 2004; Fernández Bulté, Julio, Historia del Estado y el derecho en Cuba, La Habana, Editorial Félix Varela, 2005; Rodríguez, Rolando, República de corcho, cit.; Rodríguez, Rolando, República de rigurosamente vigilada, 2 ts., La Habana, Editorial de Ciencias Sociales, 2011; Rodríguez, Rolando, Rebelión en la República, 3 ts, La Habana, Editorial de Ciencias Sociales, 2012; López Civeira, Francisca et al., Historia de Cuba: Estado nacional, dependencia y Revolución, La Habana, Editorial Pueblo y Educación, 2013.

21 Mardagant, Guillermo, Introducción a la historia del derecho mexicano, cit.; González, María del Refugio, Historia del derecho mexicano, México, UNAM, 1983; varios autores, Un siglo de derecho civil mexicano. Memorias del II Coloquio Nacional de Derecho Civil, México, UNAM, 1985; Rabasa, Emilio, Historia de las Constituciones mexicanas, México, UNAM, 2004; Cruz Barney, Oscar, La codificación en México: 1821 a 1917. Una aproximación, México, UNAM, 2004.

22 Rabasa, Emilio, Historia de las Constituciones mexicanas, México, UNAM, 2004, p. 72.

23 Para autores como Carreras, Julio y Fernández Bulté, Julio, "La Constitución de 1901 nació vieja”. Véase Infiesta, Ramón, Historia constitucional de Cuba, La Habana, Cultural S.A., 1951; Hernández Corujo, Enrique, Historia constitucional de Cuba, 2 ts., La Habana, Editora de Libros y folletos, 1960; Carreras Collado, Julio Ángel, Historia del Estado y del Derecho en Cuba, La Habana, Editorial Pueblo y Educación, 1980. Fernández Bulté, Julio, Historia del Estado y del Derecho en Cuba, La Habana, Editorial Félix Varela, 2005.

24 Hernández Corujo, Enrique, Los fundamentos históricos y filosóficos de la Constitución de 1901, La Habana, Editorial Lex, 1953, p. 9.

25 Ferrara, Orestes, Las ideas jurídico sociales, en las constituciones cubanas, Madrid, 1946, p. 19. 
Este libro forma parte del acervo de la Biblioteca Jurídica Virtual del Instituto de Investigaciones Jurídicas de la UNAM

del régimen económico nacional, que a pesar de llevar más de medio siglo de exposición en la palestra de las luchas doctrinarles, todavía no había logrado clavar el pendón de sus avances en ninguna constitución... ${ }^{26}$

En segundo lugar, en ambos países se estableció formalmente un modelo republicano presidencialista inspirado en la Constitución norteamericana de 1787. En el caso mexicano el fenómeno no era nuevo, pues arrancaba de la Constitución de 1824. ${ }^{27}$ Las razones para ello podían ser varias, no obstante hay que concordar con Emilio Rabasa que:

A mi juicio, lo importante no es determinar si fueron ideas originales las que aparecieron en los primeros documentos del México independiente, ya que tantos siglos de coloniaje y la somera ilustración que había permitido la metrópoli, impidieron el generar ideas o instituciones originales. Lo fundamental fue cómo aquellos primeros constituyentes lograron trasplantar a su medio lo más adelantado del pensamiento liberal del siglo XVIII y lo mejor de las doctrinas constitucionales de su época. ${ }^{28}$

Por su parte, la Constitución de 1857, sin dudas con el triste recordatorio de las dictaduras de la primera mitad del siglo, trató de colocar al ejecutivo bajo el control del legislativo, siendo este, en opinión de Guillermo Margadant, uno de sus puntos criticables. ${ }^{29}$ Pese a ello el presidencialismo estaba sólidamente asentado en la doctrina jurídica y el ideario popular mexicano, de tal forma que, pese a sus visibles defectos y a lo establecido en la norma no pudo ser desalojado del sitial que ocupaba. ${ }^{30}$ De hecho, bajo la dictadura de Porfirio Díaz, se volvió inaplicable. ${ }^{31}$ En el caso cubano, el

26 Gutiérrez, Gustavo, Constitución de la República de Cuba. Sus antecedentes históricos, su espiritu y estudio crítico sobre sus más fundamentales principios, La Habana, Editorial Lex, 1941, p. 29.

27 Rabasa, Emilio, Historia de las Constituciones mexicanas, cit., p. 9.

28 Ibidem, p. 10.

29 Margadant, Guillermo, Introducción a la historia del derecho mexicano, cit., p. 171.

30 Ya en 1867 el gobierno de Juárez había solicitado que se concediera más poder al ejecutivo. Refugio González, María del, Historia del Derecho Mexicano, cit., pp. 78-80; Margadant, Guillermo, Introducción a la historia del derecho mexicano, cit., p. 171 y lo relativo al porfirismo; Torre Villar, Ernesto y García Laguardia, Jorge, Desarrollo histórico del constitucionalismo latinoamericano, México, UNAM, 1976, pp. 183 y 184. No obstante, el debate en este tópico sigue abierto como lo demuestra el estudio de Mijangos y González, Pablo, El nuevo pasado jurídico mexicano, Madrid,Universidad Carlos III, 2011, pp. 37-41.

31 En ello coinciden la mayoría de los autores consultados. Véase al respecto: Margadant, Guillermo, Introducción a la Historia del Derecho mexicano, cit.; Torre Villar, Ernesto y García LaGuardia, Jorge, Desarrollo histórico del constitucionalismo latinoamericano, cit.; González, María del Refugio, Historia del derecho mexicano, cit.; Rabasa, Emilio, Historia de las constituciones mexicanas, cit. 
Este libro forma parte del acervo de la Biblioteca Jurídica Virtual del Instituto de Investigaciones Jurídicas de la UNAM

modelo presidencialista fue asumido sin discusión por la Convención Constituyente de $1901 .{ }^{32}$

Paralelamente, todo este andamiaje institucional se encontraba severamente lastrado por la práctica política vigente en ambos países caracterizada por el caudillismo, los fraudes y las revueltas electorales, la supresión de facto o de iure de los derechos reconocidos, la corrupción, y otros males. En el caso mexicano el Porfiriato ${ }^{33}$ supuso la implantación de un autoritarismo, que si bien estabilizó al país, supuso la ruptura y crisis del modelo democrático de 1857. En Cuba, los problemas resultaron muy similares, con varios períodos de dictaduras militares que suprimieron el orden constitucional y el ejercicio de los derechos fundamentales. ${ }^{34}$

Como podemos apreciar, a lo largo del siglo XX, Cuba y México enfrentaron, en distintos momentos, dificultades similares en el orden económico, político y social. No resulta extraño, que los cubanos miraran con especial interés lo que ocurría en tierras aztecas, y sacáramos lecciones para aplicarlas a la realidad nacional.

\section{LA REVOLUGIÓN MEXICANA EN EL IDEARIO POLÍTICO Y JURÍDICO GUBANO}

En el caso cubano, el ideario de la Revolución mexicana comenzó en la década de los veinte como un movimiento de reforma y renovación nacional, para convertirse en la década del treinta en un verdadero movimiento revolucionario. El reformismo tuvo sus raíces en la necesidad de hacer frente a los anteriormente aludidos males de la República.

32 Véase al respecto: Infiesta, Ramón, Historia constitucional de Cuba, cit.; Hernández Corujo, Enrique, Historia constitucional de Cuba, cit.; Carreras Collado, Julio Ángel, Historia del Estado y del Derecho en Cuba, cit.; Fernández Bulté, Julio, Historia del Estado y del Derecho en Cuba. cit.

33 Para más información se puede consultar: Margadant, Guillermo, Introducción a la historia del derecho mexicano, cit.; Torre Villar, Ernesto y García LaGuardia, Jorge, Desarrollo histórico del constitucionalismo latinoamericano, cit.; González, María del Refugio, Historia del Derecho Mexicano, cit.; Silva Herzog, Jesús, Breve historia de la Revolución mexicana, cit.; Rabasa, Emilio, Historia de las Constituciones mexicanas, cit.

34 Especialmente los periodos de tiempo transcurridos de 1928 a 1940 y 1952 a 1959. Para más información véase Le Riverend, Julio, La República, cit.; Carreras, Julio, Historia del Estado y el Derecho en Cuba, cit.; Instituto de Historia de Cuba, La República neocolonial: formación y crisis 1899 a 1940, cit.; Fernández Bulté, Julio, Historia del Estado y el Derecho en Cuba, cit.; Rodríguez, Rolando, República de corcho, cit.; Rodríguez, Rolando, República de rigurosamente vigilada, cit.; Rodríguez, Rolando, Rebelión en la República, cit.; López Civeira, Francisca et al., Historia de Cuba: Estado nacional, dependencia y Revolución, cit. 
Este libro forma parte del acervo de la Biblioteca Jurídica Virtual del Instituto de Investigaciones Jurídicas de la UNAM

El primer documento de esta oleada reformista fue el Programa del Movimiento de Veteranos y Patriotas, elaborado en 1923. ${ }^{35}$ El mismo contenía medidas de regeneración nacional entre las que se encontraban tímidas propuestas de reforma agraria y medidas de beneficio social. ${ }^{36}$

Un documento más significativo fue el Manifiesto Programa de la Junta de Renovación Nacional de 1923. ${ }^{37}$ El mismo incluyó algunas propuestas reformistas como la protección a la agricultura ${ }^{38}$ y la incorporación de la mujer a la vida social. ${ }^{39}$ Con respecto a la situación de la clase obrera sus autores expresaron: "El mejoramiento de las condiciones de vida obrera ha sido desdeñado y el cumplimiento de las normas protectoras del trabajo suelen ser una ilusión...". 40

Ciertamente, ambos programas de reformas se caracterizaron por un incipiente planteamiento de los problemas social y agrario, lo que revela un incipiente influjo del pensamiento de la Revolución mexicana en Cuba.

Para la década de 1930 comparecieron nuevos actores políticos, que dieron comienzo a un proceso revolucionario, contra la dictadura del general Gerardo Machado. ${ }^{41}$ El mismo llevó a una radicalización de los programas políticos, que comenzaron a reflejar rápidamente el ideario de la Revolución mexicana.

Así el programa del Directorio Estudiantil Universitario, ${ }^{42}$ esbozó un tímido planteamiento de reformas en beneficio de los obreros agrícolas. ${ }^{43}$

Más radical resultó el programa del Ala Izquierda Estudiantil. ${ }^{44} \mathrm{El} \mathrm{mis-}$ mo incluyó en su apartado quinto una propuesta de igualdad civil y política

35 Pichardo, Hortensia. Documentos para la historia de Cuba, cit., t. 2.

36 Idem.

37 Ibidem, t. 3, pp. 140 y ss.

38 Ibidem, pp. 141 y 142.

39 Ibidem, p. 142.

40 Ibidem, p. 147.

41 Roig de Leuchsering, Emilio, Curso de Introducción a La Historia de Cuba, La Habana, Municipio de La Habana, 1937; Le Riverend, Julio, La República, La Habana, Editorial de Ciencias Sociales, 1973; Instituto de Historia de Cuba, La República neocolonial: formación y crisis 1899 a 1940, La Habana, Editorial de Ciencias Sociales, 2004; Rodríguez, Rolando, República de corcho, 2 ts., La Habana, Editorial de Ciencias Sociales, 2010; Rodríguez, Rolando, República de rigurosamente vigilada, 2 ts., La Habana, Editorial de Ciencias Sociales, 2011; Rodríguez, Rolando, Rebelión en la República, 3 ts., La Habana, Editorial de Ciencias Sociales, 2012; López Civeira, Francisca et al., Historia de Cuba, Estado nacional, dependencia y Revolución, La Habana, Editorial Pueblo y Educación, 2013.

42 Pichardo, Hortensia, Documentos para la Historia de Cuba, La Habana, Editorial de Ciencias Sociales, 1973, t. 3.

43 Ibidem, pp. 481 y 482.

44 Idem. 
Este libro forma parte del acervo de la Biblioteca Jurídica Virtual del Instituto de Investigaciones Jurídicas de la UNAM

de la mujer reconocida en la nueva Constitución. ${ }^{45}$ Igualmente en su apartado decimotercero incluyó algunas medidas de beneficio para la clase obrera: jornada máxima de trabajo, salario mínimo, seguro contra el paro, sistema eficaz de seguro de accidentes, retiro obrero. ${ }^{46}$ Estas medidas recuerdan, sin dudas, al programa del Partido Liberal Mexicano de 1906.

Pocos meses después vería la luz la controvertida organización conocida por $\mathrm{ABC}^{.47} \mathrm{Su}$ manifiesto programa ${ }^{48}$ introdujo un largo listado de propuestas de reformas, varias de contenido social. Entre ellas encontramos la propuesta de un proyecto de fomento de la colonización interior, ${ }^{49}$ nacionalización de los servicios públicos que tienden al monopolio, ${ }^{50}$ creación del homestead o patrimonio familiar inembargable ${ }^{51}$ y rescate de la propiedad minera no explotada. ${ }^{52}$ Igualmente incluyó una propuesta de reforma agraria basada en dos puntos fundamentales. El primero de ellos sugería: "Implantación de medidas que propendan a la desaparición gradual de los latifundios, tales como el impuesto progresivo sobre la tierra". ${ }^{53} \mathrm{El}$ segundo proponía: "Limitación en cuanto a la adquisición del dominio de la tierra por compañías extranjeras y adopción de medidas que tiendan a la nacionalización de la misma". ${ }^{54}$ Por último recogía postulados de legislación social: "Promulgación de una legislación social avanzada de protección al obrero, seguro contra la inhabilitación, vejez, desempleo y muerte; jornada de ocho horas, descanso período, regulación del trabajo de mujeres, niños y adultos". 55

45 Ibidem, p. 486.

46 Idem.

47 Organización política clandestina, con una estructura celular, caracterizada por su uso de la violencia y su discurso nacionalista.

48 Pichardo, Hortensia, Documentos para la Historia de Cuba, cit., t. 3.

49 Apartado A del Manifiesto Programa del ABC en Pichardo, Hortensia, op. cit., t. 3, p. 517.

50 Apartado H del Manifiesto Programa del ABC en Pichardo, Hortensia op. cit., t. 3, p. 518.

51 Apartado E del Manifiesto Programa del ABG en Pichardo, Hortensia, op. cit., t. 3, p. 518.

52 Apartado G del Manifiesto Programa del ABC en Pichardo, Hortensia, op. cit., t. 3, p. 518.

53 Apartado B del Manifiesto Programa del ABG en Pichardo, Hortensia, op. cit., t. 3, p. 517.

54 Apartado C del Manifiesto Programa del ABC en Pichardo, Hortensia, op. cit., t. 3, p. 517.

55 Apartado Ñ del Manifiesto Programa del ABC en Pichardo, Hortensia, op. cit., t. 3, p. 518. 
Este libro forma parte del acervo de la Biblioteca Jurídica Virtual del Instituto de Investigaciones Jurídicas de la UNAM

Como puede apreciarse la visión de los problemas sociales, inspirada en la Revolución mexicana es evidente.

Otro programa fue el presentado en agosto de 1933 por Antonio Guiteras. ${ }^{56} \mathrm{El}$ mismo incluyó algunas propuestas de contenido social. El mismo proponía el establecimiento de una legislación obrera con seguros contra accidentes, enfermedades o desempleo. ${ }^{57}$ Además exigía el establecimiento de un salario mínimo dentro de una jornada máxima de trabajo regulada por las leyes. ${ }^{58}$ Igualmente recomendaba la nacionalización de los servicios públicos como ferrocarriles, gas, agua, alumbrado, transporte, entre otros..$^{59}$ Por último, proponía un programa de reforma agraria, basado en la entrega de las tierras del estado en calidad de usufructo y con la obligación de hacerlas producir. ${ }^{60}$ Además recomendaba la adopción de leyes contra el latifundio ${ }^{61}$ e imponer a los particulares la obligación de cultivar la tierra para no perder su propiedad. ${ }^{62}$

De hecho, la cuestión agraria formaba parte del discurso político de la época en Cuba. Así, el propio Guiteras, como secretario de gobernación del Gobierno Provisional expresó en septiembre de 1933:

La función social de la tierra figurará en el estatuto primero del actual gobierno, contra el latifundio, contra los elementos que ocuparon las tierras y las hacen improductivas. La propiedad será respetada, pero tendrá que haber una mejor distribución de la tierra para el cultivo de la misma entre el campesino pobre. Se reglamentaría el cultivo forzoso de la tierra, no podrán permanecer improductivas las tierras. ${ }^{63}$

Esta visión de los problemas cubanos apareció reflejada en el programa de la organización revolucionaria Joven Cuba. ${ }^{64}$ El mismo, recuerda en su forma al programa de Pascual Orozco en México. Su contenido es muy detallado, abarcando todos los aspectos de la vida económica, social

56 Apartado B del Manifiesto Programa del ABC en Pichardo, Hortensia, op. cit., t. 3, p. 518.

57 Idem.

58 Idem.

59 Idem.

60 Idem.

61 Idem.

62 Idem.

63 Guiteras Holmes, Antonio, Pensamiento revolucionario cubano, La Habana, Editorial de Ciencias Sociales, 1971, t. I, p. 384.

64 Programa de La Joven Cuba en Pichardo, Hortensia, Documentos para la Historia de Cuba, cit., t. 4, pp. 513-523. 
Este libro forma parte del acervo de la Biblioteca Jurídica Virtual del Instituto de Investigaciones Jurídicas de la UNAM

y política cubana. Así en el acápite dedicado a la reforma social se planteó la completa igualdad civil, económica y política de la mujer. ${ }^{65}$ Igualmente, caso probablemente único en la política cubana de la época se aplicaría una política anticlerical, basada en la investigación de sus propiedades, la expropiación de aquellas habidas indebidamente y reglamentación restrictiva de la profesión clerical, ${ }^{66}$ que recuerda mucho los postulados de la reforma al Plan de Guadalupe.

En el apartado referente a las reformas económicas, financieras y fiscales, se plantea que: "Bajo el principio de que la propiedad no es un derecho absoluto, sino una función social, se imprimirá una orientación francamente nacional a la economía, y se aprovecharán todas las oportunidades que permitan realizar la socialización de los medios de producción". ${ }^{67}$ En consecuencia se aplicaría un amplio programa de reforma agraria ${ }^{68}$ y nacionalización de los recursos del subsuelo. ${ }^{69}$

Con respecto a la reforma agraria, la misma se basaría en establecer un límite máximo de tierras a las propiedades particulares, expropiación de las tierras que no estén cultivadas, prohibición a las compañías extranjeras de adquirir nuevas propiedades, y revisión de los procesos de deslinde de haciendas comuneras realizados después de 1902. ${ }^{70}$ Se crearía además un Instituto Agrario, para reglamentar la ejecución de las leyes agrarias. ${ }^{71}$

A estas medidas se añadía en materia industrial la nacionalización de los servicios públicos. ${ }^{72}$

65 Reforma Social, apartado A en Programa de La Joven Cuba Pichardo, Hortensia, Documentos para la historia de Cuba, cit., t. 4, p. 519.

66 Reforma Social, apartados J y M en Programa de La Joven Cuba, Pichardo, Hortensia, Documentos para la historia de Cuba, cit., t. 4, p. 519.

67 Reforma Económica, Financiera y Fiscal en Programa de La Joven Cuba en Pacto de México entre el Partido Revolucionario Cubano y La Joven Cuba en Pichardo, Hortensia. Documentos para la historia de Cuba, cit., t. 4, p. 520.

68 Reforma Económica, Financiera y Fiscal, apartado C en Programa de La Joven Cuba en Pacto de México entre el Partido Revolucionario Cubano y La Joven Cuba en Pichardo, Hortensia. Documentos para la historia de Cuba, cit., t. 4, pp. 519 y 520.

69 Reforma Económica, Financiera y Fiscal, apartados D a J en Programa de La Joven Cuba en Pacto de México entre el Partido Revolucionario Cubano y La Joven Cuba en Pichardo, Hortensia, Documentos para la historia de Cuba, cit., t. 4, p. 520.

70 Reforma Económica, Financiera y Fiscal, apartado D en Programa de La Joven Cuba en Pacto de México entre el Partido Revolucionario Cubano y La Joven Cuba en Pichardo, Hortensia, Documentos para la historia de Cuba, cit., t. 4, p. 520.

71 Reforma Económica, Financiera y Fiscal, apartados E en Programa de La Joven Cuba en Pacto de México entre el Partido Revolucionario Cubano y La Joven Cuba en Pichardo, Hortensia, Documentos para la historia de Cuba, cit., t. 4, p. 520.

72 Reforma Económica, Financiera y Fiscal, Industria, apartado A en Programa de La 
Este libro forma parte del acervo de la Biblioteca Jurídica Virtual del Instituto de Investigaciones Jurídicas de la UNAM

Por último, incluía un programa de reformas sociales basada en el reconocimiento de los derechos del trabajo y la creación de un Código de Trabajo, que regule la jornada máxima de trabajo, el salario mínimo, las indemnizaciones por accidentes, enfermedades y descanso y el seguro social. ${ }^{73}$

Por su parte, en su programa político, el recién fundado Partido Revolucionario Cubano, ${ }^{74}$ expuso una línea caracterizada por las reformas económicas y sociales. En lo referente a la economía definían la propiedad como una función social limitada por el interés general. ${ }^{75}$ Igualmente se declaraban propiedad pública las minas ${ }^{76}$ y se autorizaba el control del Estado sobre la gestión de los servicios públicos. ${ }^{77}$

Con respecto a la reforma agraria se declaraba: "El Estado podrá fijar por medio de una ley, si lo estima necesario a la utilidad pública, la cantidad de tierras que podrá poseer un individuo o corporación". ${ }^{78}$ Las tierras de esta forma rescatadas serían asignadas a campesinos agrupados en cooperativas. ${ }^{79}$

Como complemento se incluyó una avanzada propuesta de legislación social. ${ }^{80}$

Más adelantada la década encontraremos otros programas políticos como el denominado Pacto de México. ${ }^{81}$ El mismo sólo incluyó en su acápite quinto la protección del trabajo y sus organizaciones de defensa. ${ }^{82}$

Joven Cuba en Pacto de México entre el Partido Revolucionario Cubano y La Joven Cuba en Pichardo, Hortensia, Documentos para la historia de Cuba, cit., t. 4, p. 520.

73 Reforma Económica, Financiera y Fiscal, Trabajo, apartados B y F en Programa de

La Joven Cuba en Pacto de México entre el Partido Revolucionario Cubano y La Joven Cuba en Pichardo, Hortensia, Documentos para la historia de Cuba, cit., t. 4, pp. 522 y 523.

74 Programa Constitucional del Partido Revolucionario Cubano, Auténtico Pichardo, Hortensia, Documentos para la historia de Cuba, cit., t. 4, pp. 290-317.

75 Programa Constitucional del Partido Revolucionario Cubano, Auténtico Pichardo,

Hortensia, Documentos para la historia de Cuba. cit., t. 4, p. 301.

76 Idem.

77 Programa Constitucional del Partido Revolucionario Cubano, Auténtico Pichardo, Hortensia. Documentos para la historia de Cuba, cit., t. 4, p. 302.

78 Programa Constitucional del Partido Revolucionario Cubano, Auténtico Pichardo, Hortensia. Documentos para la historia de Cuba, cit., t. 4, p. 301.

79 Programa Constitucional del Partido Revolucionario Cubano, Auténtico Pichardo, Hortensia, Documentos para la historia de Cuba, cit., t. 4, p. 302.

80 Programa Constitucional del Partido Revolucionario Cubano, Auténtico Pichardo, Hortensia, Documentos para la historia de Cuba, cit., t. 4, pp. 303-305.

81 Pacto de México entre el Partido Revolucionario Cubano y La Joven Cuba en Pichardo, Hortensia, Documentos para la historia de Cuba, cit., t. 4, pp. 24-32.

82 Pacto de México entre el Partido Revolucionario Cubano y La Joven Cuba en Pichardo, Hortensia, Documentos para la historia de Cuba. cit., t. 4, p. 24. 
Este libro forma parte del acervo de la Biblioteca Jurídica Virtual del Instituto de Investigaciones Jurídicas de la UNAM

Ya de cara a las elecciones para la convención constituyente de 1940, los diferentes paridos presentaron bases constitucionales, inspiradas en el ideario de la Revolución mexicana. Esto resulta visible en los planteamientos del Partido Acción Republicana ${ }^{83}$ y del Partido Demócrata. ${ }^{84}$

El primero postuló los derechos laborales en sus apartados 10 y 11,85 siguiendo una línea similar a lo que hemos expuesto anteriormente. Por su parte, el punto 13 declaró: "Se reconoce la propiedad privada con un sentido de función social y de utilidad colectiva. El reparto y la explotación de la tierra serán vigilados por el Estado para evitar el latifundio...". ${ }^{86}$

Un elemento adicional a tener en cuenta es el progresivo impacto en la doctrina jurídica. Si en los años veinte apenas encontramos obras destinadas al estudio de estos temas, pronto veremos su eclosión durante las décadas del treinta y del cuarenta, y comenzamos a encontrar estudios dedicados al tema de los derechos sociales, la reforma agraria, entre otros temas.

Así, encontramos los primeros planteamientos en este sentido aparecen en la obra del profesor Enrique Hernández Corujo, Las transformaciones del derecho constitucional cubano desde el 12 de agosto de $1933 .{ }^{87}$ En la misma, al analizarse las modificaciones sufridas por el Derecho Constitucional cubano desde la caída del gobierno de Machado, incluyó en sus obras algunas referencias a la legislación social de la etapa, aunque sin analizarla.

Sin embargo, una de las obras más significativas de la etapa sobre estos temas es la de Juan Clemente Zamora, Nuevas orientaciones en materia constitucional, ${ }^{88}$ publicada en 1939. En la misma se hizo un análisis minucioso de los problemas que debía abordar el, entonces, nuevo constitucionalismo. Aquí aparecen referencias directas a la Constitución mexicana en varias

83 Puntos esenciales del Programa Constitucional de Acción Republicana en Pichardo, Hortensia, Documentos para la historia de Cuba, cit., t. 4, pp. 269-276.

84 Programa de Doctrinas del Partido Demócrata en Pichardo, Hortensia, Documentos para la historia de Cuba, cit., t. 4, pp. 276-285.

85 Apartados 10 y 11 Puntos esenciales del Programa Constitucional de Acción Republicana en Pichardo, Hortensia. Documentos para la historia de Cuba. cit., t. 4, p. 271.

86 Apartados 13 Puntos esenciales del Programa Constitucional de Acción Republicana en Pichardo, Hortensia. Documentos para la historia de Cuba. cit., t. 4, p. 271.

87 Hernández Corujo, Enrique, "Las transformaciones del derecho constitucional cubano desde el 12 de agosto de 1933", Revista Cubana de Derecho, año XII, núm. 4, octubrediciembre de 1935.

88 Zamora, Juan Clemente, Nuevas orientaciones en materia constitucional, conferencia dictada en el club Atenas de La Habana el 13 de febrero de 1939, La Habana, Instituto Nacional de Prevención y Reformas Sociales-Atalaya, 1939. 
Este libro forma parte del acervo de la Biblioteca Jurídica Virtual del Instituto de Investigaciones Jurídicas de la UNAM

partes de la obra. ${ }^{89}$ Igualmente se argumentó a favor de reconocer determinados derechos sociales. Así, con respecto al trabajo plantea:

Es evidente que en todo momento, - y sobre todo en épocas de crisis y de desempleo-, el hermoso principio de la libertad contractual, que coloca en igualdad aparente de condiciones a un obrero famélico y angustiado par la destitución y la miseria en que se encuentran el y los suyos, frente a un patrono que impone las condiciones de trabajo mas intolerables e injustas; pero que puede brindarle aunque no sea mas que una mísera pitanza, resulta una ficción sin contenido real. La necesidad imperiosa de alimentarse y de vivir obliga al obrero, temeroso de ser desplazado o sustituido por otro aún mas necesitado que el, a pactar las condiciones que le impongan. La libertad de contratación resulta así una burla inicua..$^{90}$

\section{En consecuencia:}

El Estado no puede cumplir ciertamente sus fines sociales permaneciendo sordo e indiferente ante esa realidad. La intervención del Estado para rescatar la dignidad, del hombre que vende su fuerza o su capacidad para el trabajo, ya sean esta capacidad y esta fuerza materiales o intelectuales, es absolutamente esencial. ${ }^{91}$

Frente a la propiedad considera que:

La Constitución Mexicana: aun cuando en forma más radical, puesto que atribuye al Estado el derecho original de propiedad, expresando que es la Nación la que trasmite el dominio a los particulares para constituir la propiedad privada y agregando, en su articulo 27: "La Nación tendrá en todo tiempo el derecho de imponer a la propiedad privada las modalidades que: dicte el interés público. ${ }^{92}$

\section{En consonancia con lo anterior recomienda para Cuba que:}

Si se procediera a una reforma constitucional inmediata, la nueva Constitución debería reconocer el derecho a la propiedad privada; pero reservándose el; Estado el derecho de expropiación, previa indemnización, de toda clase de riquezas o bienes; fijándose constitucionalmente también la necesidad de que

89 Ibidem, pp. 17, 20 у 23.

$90 \quad$ Ibidem, p. 17.

91 Ibidem, p. 18.

92 Ibidem, p. 15. 
Este libro forma parte del acervo de la Biblioteca Jurídica Virtual del Instituto de Investigaciones Jurídicas de la UNAM

todos los impuestos directos sobre el capital y las herencias tengan un carácter gradualmente progresivo. ${ }^{93}$

Similar de cauta es su postura ante el tema agrario, aunque aquí aboga por el control estatal directo sobre algunos grandes latifundios. ${ }^{94}$

Igualmente, comenzaron a aparecer obras doctrinales sobre legislación obrera como la de Rodolfo Méndez Peñate. ${ }^{95}$

Con la redacción de la Constitución de 1940, la influencia del constitucionalismo y la legislación mexicana pasó a ser indirecta, aunque se seguía reconociendo ésta como referente obligado. En este sentido la encontramos en las obras de Derecho constitucional de Juan Clemente Zamora ${ }^{96}$ y Ramón Infiesta. ${ }^{97}$

Igualmente a esta etapa corresponde el Manual de derecho agrario y proyecto de código de reforma agraria de Manuel Dorta Duque, ${ }^{98}$ y la Legislación obrera de Aureliano Sánchez Arango. ${ }^{99}$

\section{INFLUENGIA DEL DEREGHO DE LA REVOLUCIÓN MEXICANA EN EL DERECHO GUBANO}

La obra legislativa de la Revolución mexicana, consagrada en la Constitución mexicana de 1917, tuvo un significativo impacto en Cuba. En primer lugar, no hay que olvidar que esta Constitución, al igual que la de 1940, estuvo destinada a consagrar los resultados jurídicos de la Revolución, institucionalizando el proceso. ${ }^{100}$ Es por ello, que fue la primera en el mundo en contemplar un amplio catálogo de derechos sociales. ${ }^{101}$ Como ha dicho al

93 Ibidem, p. 16.

94 Ibidem, pp. 21-24.

95 Méndez Peñate, Rodolfo, Legislación obrera, La Habana, Departamento de Publicaciones de la Facultad de Derecho de la Universidad de La Habana, 1947. La primera edición de esta obra vio la luz en 1939.

96 Zamora, Juan Clemente, Manual de Derecho Constitucional, 2 ts., La Habana, Departamento de Publicaciones de la Facultad de Derecho, 1941.

97 Infiesta, Ramón, Derecho constitucional, 2a. ed., La Habana, s.e., 1954.

98 Dorta Duque, Manuel, Manual de derecho agrario y proyecto de Código de Reforma Agraria, La Habana, s.e., 1941.

99 Sánchez Arango, Aureliano, Legislación obrera, La Habana, Editorial Selecta, 1953.

100 Mardagant, Guillermo, Introducción a la historia del derecho mexicano, cit.; González, María del Refugio, Historia del derecho mexicano, cit.; varios autores, Un siglo de derecho civil mexicano, cit., y Rabasa, Emilio, Historia de las Constituciones mexicanas, cit.

101 Véase la bibliografía recomendada en la nota anterior. 
Este libro forma parte del acervo de la Biblioteca Jurídica Virtual del Instituto de Investigaciones Jurídicas de la UNAM

respecto un autor: "La nota más característica de nuestra ley fundamental consiste en que fue la primera en incorporar normas de contenido social" ${ }^{102}$ En palabras de uno de los asistentes a la Convención de 1917:

Así, como Francia, después de su revolución, ha tenido el alto honor de consagrar en la primera de sus cartas magnas los inmortales derechos del hombre, así la Revolución Mexicana tendrá el orgullo legítimo de mostrar al mundo que es la primera en consignar en una constitución los sagrados derechos de los obreros. ${ }^{103}$

A ello se sumó la concepción del problema agrario:

En el artículo 27 se incluyeron las disposiciones sobre el problema de la tierra. Se preceptuó, primordialmente, entre otros aspectos; que la propiedad de las tierras y aguas comprendidas dentro de los límites del territorio nacional corresponde originalmente a la nación, la que puede constituir la propiedad privada imponiéndole las modalidades que dicte el interés público; se estableció la dotación de tierras y aguas a los pueblos, rancherías o comunidades que carecieran de ellas; se precisaron los elementos de los cuales la nación es propietaria y sobre los cuales ejerce dominio directo; se reglamentó el fraccionamiento de las grandes propiedades y cómo debía efectuarse, y se autorizó la expropiación por causa de utilidad pública. ${ }^{104}$

A ello hay que añadir una copiosa legislación ordinaria cuyo impacto se extiende hasta la década de los treinta. Entre ellas cabe destacar la Ley sobre Relaciones Familiares, que es reputada como el primer ordenamiento jurídico que se ocupó en el mundo de este tema. ${ }^{105}$

Igualmente habría que reconocer su propuesta de reforma agraria y su amplia legislación obrera. ${ }^{106}$

Cuba tenía entonces algunos antecedentes en materia de legislación social que se remontan a la Constitución de 1901. Aunque esta fue un texto esencialmente liberal, incluyó en su articulado uno de los que posterior-

102 Carpizo, Jorge y Madrazo, Jorge, Derecho constitucional, México, UNAM, 1991, p. 11.

103 Citado por ibidem, p. 12.

104 Idem.

105 Barroso Figueroa, Jorge, "La Revolución mexicana de 1910 y el derecho civil", en La Revolución mexicana a cien años de su inicio. Pensamiento social y jurídico, México, Comisión Organizadora de festejos del Bicentenario de la Independencia y Centenario de la Revolución mexicana, 2010, p. 76.

106 Artículos 27 y 123 de la Constitución Política de los Estados Unidos Mexicanos que reforma la de 5 de febrero de 1857. Diario Oficial, del 5 de febrero de 1917, núm. 20, t. V. 
Este libro forma parte del acervo de la Biblioteca Jurídica Virtual del Instituto de Investigaciones Jurídicas de la UNAM

mente serían considerados derechos sociales. Efectivamente, el artículo 31 de la misma estableció que:

La enseñanza primaria es obligatoria, y así ésta como la de artes y oficios serán gratuitas. Ambas estarán a cargo del Estado, mientras no puedan sostenerlas respectivamente, por carecer de recursos suficientes, los Municipios y las Provincias. La segunda enseñanza y la superior estarán a cargo del Estado. No obstante, toda persona podrá aprender o enseñar libremente cualquier ciencia, arte, o profesión y fundar y sostener establecimientos de educación y enseñanza; pero corresponde al Estado la determinación de las profesiones en que exija títulos especiales, la de las condiciones para su ejercicio o la de los requisitos necesarios para obtener los títulos, y la expedición de los mismos, de conformidad con lo que establezcan las leyes. ${ }^{107}$

Originalmente, su redacción era la habitual en los textos del siglo XIX, reconociendo la libertad de enseñanza, pero sin hacerla obligatoria. A propuesta del convencional Leopoldo Berriel, se desechó la formula original, siendo sustituida por la antes reseñada. ${ }^{108}$ Con ella Cuba fue más allá en este aspecto, que el constitucionalismo precedente, al establecer la obligatoriedad y gratuidad de la educación. Con ello, la Constitución de 1901 incluyó en su articulado lo que en buena técnica sería un derecho colectivo o de segunda generación. Con ello, sin dudas, se convertía en una de las más avanzadas de su tiempo y sentó un significativo precedente para su ulterior desenvolvimiento en el texto constitucional de 1940. Lamentablemente, el mismo no pasó mas allá de las buenas intenciones de sus proponentes.

Durante los años finales de la segunda década del siglo XX, comenzaron a aparecer algunas normativas jurídicas, derivadas de un cierto influjo de la Revolución mexicana. Entre ellas encontramos la Ley Arteaga de 1917, ${ }^{109}$ que prohibió el pago a los trabajadores con vales o fichas, que recordaba a la supresión de las tiendas de raya en 1915. La misma estableció sanciones de multa o de prisión para los patronos que no pagaran a sus empleados en moneda de curso oficial.

107 Artículo 31 de la Constitución de 1901, en Lazcano y Masón, Andrés, Las Constituciones de Cuba, Madrid, Cultura Hispánica, 1952.

108 Bravo Correoso, Antonio, Cómo se hizo la Constitución de 1901, La Habana, Imprenta y Papelería Rambla, Bouza y Cía, pp. 37 y 38.

109 Pichardo, Hortensia, Documentos para la historia de Cuba, cit., t. 2. 
Este libro forma parte del acervo de la Biblioteca Jurídica Virtual del Instituto de Investigaciones Jurídicas de la UNAM

Otra normativa emanada de la influencia de la Revolución mexicana fue la Ley de Divorcio de 1917, ${ }^{110}$ que estableció formalmente esta institución en nuestro derecho.

No obstante, a la altura de 1928, un destacado publicista cubano, Diego Vicente Tejera, al estudiar la influencia del derecho foráneo en predios cubanos, sólo lo aprecia en el recurso de amparo en la posesión, creado durante la primera ocupación norteamericana, como una versión reducida del amparo constitucional mexicano. En este sentido, el autor reconoce que:

Se recordó que en la república mexicana existía una ley cuyos efectos liberales y democráticos habían sido admirables, que se llamaba amparo, por la cual, tanto en lo penal como en lo civil, se protegía al ciudadano que arbitrariamente había sido lesionado en sus derechos, por alguna decisión judicial o de la administración pública, restableciéndose las cosas al ser y estado en que se encontraban antes que la decisión oficial hubiera causado el efecto dañino. ${ }^{11}$

Lamentablemente, el mismo sólo era aplicable a los bienes, con lo que se perdió la posibilidad de introducir una institución de indudable utilidad. ${ }^{112}$

Dicho sea de paso, hay que reconocer que, en materia de control constitucional, el amparo mexicano casi no ha incidido en nuestro derecho, en el cual este mecanismo de defensa constitucional y protección de los derechos ha transitado por otros derroteros. ${ }^{113}$

La reforma constitucional de 1928, al tratarse el tema de la duración del mandato presidencial y la prohibición expresa de la reelección, recibió un influjo directo de la carta magna mexicana de 1917. En esta última, como remedio contra la reelección indefinida, que legitimaba a dictaduras como la de Porfirio Díaz se estableció, en su artículo 83 que: "El Presidente entrará a ejercer su encargo el 1o. de diciembre y durará en él seis años. El ciudadano que haya desempeñado el cargo de Presidente de la República, electo popularmente, o con el carácter de interino, provisional o substituto, en ningún caso y por ningún motivo podrá volver a desempeñar ese puesto". ${ }^{114}$

110 Llaca y Argudín, Francisco, Legislación sobre divorcio, La Habana, Imprenta Rambla, Bouza y Cía, 1931.

111 Vicente Tejera, Diego, Estado actual de la legislación cubana e influencia que en ella ejercen la de otros países, Madrid, Reus, 1926, p. 83.

112 Idem.

113 Benítez de Cárdenas, Rogelio, Reformas en nuestra legislación. Compilación de disposiciones emitidas durante el gobierno interventor americano en Cuba, La Habana, Imprenta Anchsa del Norte, 1903.

114 Artículo 83 de la Constitución política de los Estados Unidos mexicanos que reforma la de 5 de febrero de 1857. En Diario Oficial, núm. 20, t. V, 5 de febrero de 1917, p. 155. 
Este libro forma parte del acervo de la Biblioteca Jurídica Virtual del Instituto de Investigaciones Jurídicas de la UNAM

En el caso cubano, después de un largo proceso de debate político, que se remontaba a 1906, se abordó la reforma constitucional como un mecanismo para evitar las continuas disputas electorales y evitar la perpetuación de los mandatarios en el poder. El resultado fue el artículo 66 que dispuso: "El Presidente de la República será elegido por sufragio de segundo grado, en un solo día y conforme al procedimiento que establezca la ley. El cargo durará seis años y nadie podrá desempeñar las funciones de Presidente en dos períodos consecutivos" ${ }^{115}$ Ciertamente su redacción resulta un pálido reflejo del texto mexicano, y una broma cruel a la luz de los acontecimientos posteriores, ${ }^{116}$ pero, en alguna medida refleja el ideario de no reelección, y sirvió de base ulterior a la Constitución de 1940.

A partir de 1933 la influencia de la legislación de la Revolución mexicana en nuestro derecho se incrementó, siendo esta la época de auge de la legislación obrera.

En este sentido podemos encontrar la creación de la Secretaría de Trabajo, ${ }^{117}$ como ente rector de las actividades laborales en Cuba, la ley de nacionalización del trabajo, ${ }^{118}$ el establecimiento de la jornada de ocho horas, ${ }^{119}$ la legalización de las organizaciones sindicales, ${ }^{120}$ el reconocimiento

115 Artículo 66 de la Reforma Constitucional de 1928, en Lazcano y Masón, Andrés, Las Constituciones de Cuba. Madrid, Editorial Cultura Hispánica, 1952.

116 Una disposición transitoria de la reforma constitucional de 1928, permitió al presidente en funciones presentarse como candidato a los comicios de ese año, estableciendo, de facto, un régimen dictatorial hasta 1933. Véase al respecto Disposición Transitoria Primera de la Reforma Constitucional de 1928 en Lazcano y Masón, Andrés, Las Constituciones de Cuba, Madrid, Editorial Cultura Hispánica, 1952.

117 Decreto 2355 del 25 de octubre de 1933, por el cual se determinó la competencia de la Secretaria de Trabajo, en Pichardo, Hortensia, Documentos para la Historia de Cuba, cit., t. 4, pp. 89-92.

118 Decreto 2583 del 8 de noviembre de 1933. Ley provisional de nacionalización del trabajo. En Pichardo, Hortensia, Documentos para la Historia de Cuba, cit., t. 4, pp. 99-101.

119 Decreto 2513 del 19 de octubre de 1933. Reglamento para la ejecución del Decreto 1693 de 1933 sobre la jornada laboral de ocho horas, en Pichardo, Hortensia, Documentos para la Historia de Cuba cit., t. 4, pp. 84-89.

120 Decreto 2605. Reglamento sobre la organización sindical, en Pichardo, Hortensia, Documentos para la historia de Cuba, cit., t. 4, pp. 92-98. 
Este libro forma parte del acervo de la Biblioteca Jurídica Virtual del Instituto de Investigaciones Jurídicas de la UNAM

del derecho a huelga, ${ }^{121}$ la regulación del salario mínimo, ${ }^{122}$ protección a la maternidad, ${ }^{123}$ descanso retribuido, ${ }^{124}$ entre otras. Esta amplia legislación obrera puso a Cuba, junto con México, entre los países de avanzada en cuanto al derecho laboral. Una parte significativa de la misma se incorporó a la carta magna cubana de 1940.

Otro aspecto significativo de la legislación de esta etapa fueron los esfuerzos por nacionalizar o intervenir el funcionamiento de algunos servicios básicos. Entre las medidas de este tipo encontramos la rebaja de las tarifas de electricidad y gas, ${ }^{125}$ la intervención de centrales azucareros cuyos propietarios aplicaron un lock out patronal ${ }^{126}$ y la intervención de la Compañía Cubana de Electricidad. ${ }^{127}$ Lamentablemente, estas medidas precursoras de una posible nacionalización de los recursos naturales terminaron frustradas por un golpe militar.

Los derechos sociales entraron de manera definitiva en el constitucionalismo cubano con las reformas, aprobadas por el Congreso, a la Ley Constitucional de 1935. ${ }^{128}$ La misma añadió una nueva sección al título IV dedicada a reconocerlos. Como fundamento doctrinal se planteó en el artículo 37 que: "El régimen de la vida cubana se basará en los principios de la justicia

121 Artículos XV al XIX del Decreto 2605. Reglamento sobre la organización sindical. En Pichardo, Hortensial Documentos para la Historia de Cuba, cit., t. 4, pp. 95 y 96, y Decreto Ley 3 del 12 de febrero de 1934 regulando el derecho a huelga, en Pichardo, Hortensial Documentos para la Historia de Cuba, cit., t. 4, pp. 321-324. Considerado este último por Rodolfo Méndez Peñate como muy restrictivo, por agravar los requisitos de la anterior legislación y por las sanciones penales que estableció: Por ello, pudiéramos decir que es una disposición legal proyectada con fines más bien de represión que de regulación del derecho de huelga. Méndez Peñate, Rodolfo, Legislación obrera, La Habana, Departamento de Publicaciones de la Facultad de Derecho de la Universidad de La Habana, 1947, p. 33.

122 Decreto 117 de 9 de enero de 1934, en Pichardo, Hortensia, Documentos para la Historia de Cuba, cit., t. 4, pp. 181-184.

123 Decreto Ley 781 de 28 de diciembre de 1934, en Pichardo, Hortensia, Documentos para la Historia de Cuba, cit., t. 4, pp. 527-531.

124 Decreto Ley 40 de 20 de marzo de 1935, en Pichardo, Hortensia, Documentos para la Historia de Cuba, cit., t. 4, pp. 601-604.

125 Decreto 2974 de 6 de diciembre de 1933, en Pichardo, Hortensia, Documentos para la Historia de Cuba, cit., t. 4, pp. 153-158. En el mismo se alega su condición de servicio público para justificar la intervención estatal.

126 Decreto 96 de 6 de enero de 1934, en Pichardo, Hortensia, Documentos para la Historia de Cuba, cit., t. 4, p. 190.

127 Decreto 172 de 14 de enero de 1934, en Pichardo, Hortensia, Documentos para la Historia de Cuba, cit., t. 4, pp. 188-190.

128 Reforma integral de la Ley Constitucional de 1935 de 16 de diciembre de 1936, en Lazcano y Masón, Andrés, Las Constituciones de Cuba, Madrid, Editorial Cultura Hispánica, 1952. 
Este libro forma parte del acervo de la Biblioteca Jurídica Virtual del Instituto de Investigaciones Jurídicas de la UNAM

social, y asegurará los beneficios de la vida familiar, de la cultura y de la armonía entre el trabajo y el capital a todos los habitantes de la República, a fin que disfruten de una existencia digna". ${ }^{129}$ A continuación se desglosa un catálogo de derechos, que es reconocido como el antecedente directo de la Constitución de 1940. Aquí aparece de manera clara la influencia de la Constitución mexicana de 1917 en artículos como el $38^{130}$ que dio rango constitucional al divorcio, y el $39^{131}$ que estableció el patrimonio mínimo inembargable. Su presencia se advierte igualmente en los artículos dedicados a la legislación obrera, como el 44, ${ }^{132}$ que estableció el salario mínimo, el $45^{133}$ que recogió lo referente al seguro social, el $46^{134}$ que estableció la jornada máxima de ocho horas, el $47{ }^{135}$ que reguló el tema de la sindicalización y el derecho a huelga y el $48^{136}$ con lo referente a la nacionalización del trabajo. De hecho, su estilo de redacción, con párrafos largos, donde se vinculan diferentes normas jurídicas, recuerda mucho al título sexto de la carta magna mexicana. ${ }^{137}$

Con respecto a la propiedad el texto cubano introdujo normas atenuadas con respecto al artículo $27^{138}$ de la Constitución mexicana. Por principio se declaró que:

129 Artículo 37 de la Reforma integral de la Ley Constitucional de 1935 del 16 de diciembre de 1936, en Lazcano y Masón, Andrés, Las Constituciones de Cuba, cit.

130 Artículo 38 de la Reforma integral de la Ley Constitucional de 1935 del 16 de diciembre de 1936, en Lazcano y Masón, Andrés, Las Constituciones de Cuba, cit. Este mismo artículo equiparó los derechos y deberes de ambos cónyuges y eliminó la distinción entre hijos legítimos e ilegítimos.

131 Artículo 39 de la Reforma integral de la Ley Constitucional de 1935 del 16 de diciembre de 1936, en Lazcano y Masón, Andrés, Las Constituciones de Cuba, cit.

132 Artículo 44 de la Reforma integral de la Ley Constitucional de 1935 del 16 de diciembre de 1936, en Lazcano y Masón, Andrés, Las Constituciones de Cuba, cit.

133 Artículo 45 de la Reforma integral de la Ley Constitucional de 1935 del 16 de diciembre de 1936, en Lazcano y Masón, Andrés, Las Constituciones de Cuba, cit.

134 Artículo 46 de la Reforma integral de la Ley Constitucional de 1935 del 16 de diciembre de 1936, en Lazcano y Masón, Andrés, Las Constituciones de Cuba, cit.

135 Artículo 47 de la Reforma integral de la Ley Constitucional de 1935 del 16 de diciembre de 1936, en Lazcano y Masón, Andrés, Las Constituciones de Cuba, cit.

136 Artículo 48 de la Reforma integral de la Ley Constitucional de 1935 del 16 de diciembre de 1936, en Lazcano y Masón, Andrés, Las Constituciones de Cuba, cit.

137 Título Sexto: Del trabajo y la prevención social de la Constitución política de los Estados Unidos mexicanos que reforma la de 5 de febrero de 1857, en Diario Oficial, núm. 20, t. V, 5 de febrero de 1917 , pp. 158 y 159.

138 Artículo 27 de la Constitución Política de los Estados Unidos Mexicanos que reforma la de 5 de febrero de 1857, en Diario Oficial, núm. 20, t. V, 5 de febrero de 1917, pp. 150 y 151. 
Este libro forma parte del acervo de la Biblioteca Jurídica Virtual del Instituto de Investigaciones Jurídicas de la UNAM

El Estado reconoce la propiedad privada pero su uso y explotación ha de realizarse de manera que propenda al bienestar del pueblo cubano. La propiedad de la tierra, del subsuelo, de los bosques, de las aguas, de los ferrocarriles y demás vías de comunicación y transporte y de las empresas de servicios públicos será explotada de manera que fomente el bienestar social. ${ }^{139}$

A ello hay que añadir el reconocimiento de la expropiación forzosa por razón de utilidad pública, ${ }^{140}$ y el complejo artículo 58, ${ }^{141}$ que autorizaba al Estado a regular la tenencia de tierras, aunque no se ataca directamente al latifundio.

La Constitución de 1940, mantuvo casi intacto el catálogo de derechos de la norma de 1936. ${ }^{142}$ No obstante, se introdujeron algunas modificaciones con respecto a la legislación anterior. Así, por ejemplo, el artículo 43, al tratar las relaciones familiares añadió: "La mujer casada disfruta de la plenitud de la capacidad civil, sin que necesite de licencia o autorización marital para regir sus bienes, ejercer libremente el comercio, la industria, profesión, oficio o arte y disponer del producto de su trabajo". ${ }^{143}$ Igualmente se incluyó la prohibición de despido, sin las debidas formalidades legales, ${ }^{144}$ la creación de cooperativas ${ }^{145}$ y mutualidades, como complementos a la anterior legislación obrera. ${ }^{146}$

Sin embargo, donde mejor se advierte en influjo mexicano es en lo referente a la economía. Aquí se incluyó el artículo 88 que dispuso: "El subsuelo pertenece al Estado, que podrá hacer concesiones para su explotación, conforme a lo que establezca la Ley. La propiedad minera concedida y no explotada dentro del término que fije la Ley, será declarada nula y reintegrada

139 Artículo 51 de la Reforma integral de la Ley Constitucional de 1935 de 16 de diciembre de 1936, en Lazcano y Masón, Andrés, Las Constituciones de Cuba, cit.

140 Artículo 54 de la Reforma integral de la Ley Constitucional de 1935 de 16 de diciembre de 1936, en Lazcano y Masón, Andrés, Las Constituciones de Cuba, cit.

141 Artículo 58 de la Reforma integral de la Ley Constitucional de 1935 de 16 de diciembre de 1936, en Lazcano y Masón, Andrés, Las Constituciones de Cuba, cit.

142 Véase los títulos V y VI que comprenden los artículos 43 a 96 de la Constitución cubana de 1940, en Lazcano y Masón, Andrés, Las Constituciones de Cuba, cit.

143 Artículo 43 de la Constitución Cubana de 1940, en Lazcano y Masón, Andrés, Las Constituciones de Cuba, cit.

144 Artículo 77 de la Constitución Cubana de 1940, en Lazcano y Masón, Andrés, Las Constituciones de Cuba, cit.

145 Artículo 75 de la Constitución Cubana de 1940, en Lazcano y Masón, Andrés, Las Constituciones de Cuba, cit.

146 Artículo 81 de la Constitución Cubana de 1940, en Lazcano y Masón, Andrés, Las Constituciones de Cuba, cit. 
Este libro forma parte del acervo de la Biblioteca Jurídica Virtual del Instituto de Investigaciones Jurídicas de la UNAM

al Estado". ${ }^{147}$ Igualmente inspirado en el ejemplo mexicano es el artículo 90, que abrió la tan ansiada posibilidad de una reforma agraria:

Se proscribe el latifundio y a los efectos de su desaparición, la Ley señalará el máximo de extensión de la propiedad que cada persona o entidad pueda poseer para casa tipo de explotación a que la tierra se dedique y tomando en cuenta las respectivas peculiaridades. La Ley limitará restrictivamente la adquisición y posesión de la tierra por personas y compañías extranjeras, y adoptará medidas que tiendan a revertir la tierra al cubano. ${ }^{148}$

Si se observa, una de sus principales diferencias con la Constitución de 1917, es que las atribuciones conferidas por este último a los estados, resultan aquí competencia del poder central.

Con posterioridad a la Constitución de 1940 comenzó a declinar la influencia de la Revolución mexicana en nuestro derecho. Como apuntábamos anteriormente, la carta magna de 1940 se convirtió en el referente jurídico doctrinal para los juristas cubanos.

Durante un breve momento, después del triunfo revolucionario de 1959, se rescató el impacto directo de la legislación de la Revolución mexicana en nuestro derecho. Ello es especialmente visible en la Ley de Reforma Agraria del 17 de mayo de 1959.149 Esta es la opinión defendida por Rolando Pavó Acosta, en un interesante análisis comparado de las mismas. ${ }^{150}$ Este momento resultó efímero. La radicalización del proceso revolucionario, conllevó a que se comenzara a mirar con mayor insistencia al modelo de socialismo real europeo, quedando progresivamente arrinconada la tradición de beber de las fuentes de la Revolución mexicana para modernizar nuestro derecho.

\section{Gonclusiones}

Es innegable que, desde el siglo XVI existen fuertes lazos jurídicos entre Cuba y México, hilvanados a través del vínculo colonial.

147 Artículo 88 de la Constitución cubana de 1940, en Lazcano y Masón, Andrés, Las Constituciones de Cuba, cit.

148 Artículo 90 de la Constitución cubana de 1940, en Lazcano y Masón, Andrés, Las Constituciones de Cuba, cit.

149 Ley de 17 de mayo de 1959, Ley de Reforma Agraria, en I Forum Nacional de Reforma Agraria, La Habana, s. e., 1960, pp. 613 y ss.

150 Véase Pavó Acosta, Rolando, "Legado de la Revolución mexicana en la reforma agraria cubana de 1959", Politica y Cultura, núm. 33, 2010, pp. 35-58, disponible en http:// wrere.redalyc.org/articulo.oa?id=26712504003 (fecha de consulta: 1o. de abril de 2016). 
Este libro forma parte del acervo de la Biblioteca Jurídica Virtual del Instituto de Investigaciones Jurídicas de la UNAM

En segundo lugar, aunque, con obvias diferencias temporales, ambos países siguieron hasta la mitad del siglo XX una paralela evolución del derecho.

En tercero, en ambos se presentaron problemas económicos, políticos y sociales comunes, cuyas soluciones podían ser adaptadas a las circunstancias propias de cada uno.

En cuarto, como resultado de lo anterior, los políticos y juristas cubanos comenzaron a utilizar al derecho emanado de la Revolución mexicana como referente, a la hora de proponer soluciones a los problemas cubanos.

En quinto, dichas propuestas se tradujeron en normas jurídicas, que entraron en vigor fundamentalmente durante la primera mitad de la centuria. En ellas es posible apreciar claramente, los paralelismos con la Constitución mexicana de 1917 y la legislación ordinaria del periodo revolucionario, y la Constitución de 1940. 
1916 rumbo a la Constitución de 1917, editado por el Instituto de Investigaciones Jurídicas de la UNAM, se terminó de imprimir el 14 de noviembre de 2018 en los talleres de Arte Gráfico y Sonoro, Agys Alevin, S. C., Retorno de Amores 14-102, colonia Del Valle, delegación Benito Juárez, 03100 Ciudad de México, tel. 5523 1151. Se utilizó tipo Baskerville de 9, 10 y 11 puntos. En esta edición se empleó papel cream book de 70 × 95 de 60 gramos para los interiores y cartulina couché de 250 gramos para los forros. Consta de 200 ejemplares (impresión digital) 


\section{7 fue muy importante para nuestra historia}

constitucional, ya que fue el del centenario de nuestra Constitución Política, promulgada en la ciudad de Querétaro el 5 de febrero de 1917 por el primer jefe del Ejército Constitucionalista encargado del Poder Ejecutivo Federal, don Venustiano Carranza.

Muchas instituciones públicas y privadas quisieron conmemorar esta efeméride con reuniones académicas, pero sobre todo con publicación de trabajos de investigación y de divulgación, individuales y colectivos, como el contenido en este volumen, promovido conjuntamente por dos dependencias de la Universidad Nacional Autónoma de México: el Instituto de Investigaciones Jurídicas y la Unidad Académica de Estudios Regionales de la Coordinación de Humanidades (Jiquilpan, Michoacán).

Con este libro se busca homenajear a nuestra ley suprema, además de participar en la reflexión académica en torno a la misma, en el cual han participado profesores no sólo de universidades nacionales, sino también de otros países como Cuba y España. 